\title{
THE EFFECT OF AUTOMATED SPEED CAMERAS ON FATAL TRAFFIC COLLISIONS IN THE STATE OF KUWAIT
}

\author{
A thesis submitted to \\ the Faculty of Graduate and Postdoctoral Affairs \\ in Partial Fulfillment of the requirements for the degree \\ Masters of Applied Science
}

by

Amal Abdulsalam

Department of Civil and Environmental Engineering

Carleton University

Ottawa-Carleton Institute of Civil and Environmental Engineering

May 2012

(C2012 Amal Abdulsalam 
Library and Archives

Canada

Published Heritage

Branch

395 Wellington Street

Ottawa ON K1A ON4

Canada
Bibliothèque et

Archives Canada

Direction du

Patrimoine de l'édition

395 , rue Wellington

Ottawa ON K1A ON4

Canada
Your file Votre référence

ISBN: 978-0-494-91586-8

Our file Notre référence

ISBN: $978-0-494-91586-8$
NOTICE:

The author has granted a nonexclusive license allowing Library and Archives Canada to reproduce, publish, archive, preserve, conserve, communicate to the public by telecommunication or on the Internet, loan, distrbute and sell theses worldwide, for commercial or noncommercial purposes, in microform, paper, electronic and/or any other formats.

The author retains copyright ownership and moral rights in this thesis. Neither the thesis nor substantial extracts from it may be printed or otherwise reproduced without the author's permission.
AVIS:

L'auteur a accordé une licence non exclusive permettant à la Bibliothèque et Archives Canada de reproduire, publier, archiver, sauvegarder, conserver, transmettre au public par télécommunication ou par l'Internet, prêter, distribuer et vendre des thèses partout dans le monde, à des fins commerciales ou autres, sur support microforme, papier, électronique et/ou autres formats.

L'auteur conserve la propriété du droit d'auteur et des droits moraux qui protege cette thèse. $\mathrm{Ni}$ la thèse ni des extraits substantiels de celle-ci ne doivent être imprimés ou autrement reproduits sans son autorisation.
In compliance with the Canadian Privacy Act some supporting forms may have been removed from this thesis.

While these forms may be included in the document page count, their removal does not represent any loss of content from the thesis.
Conformément à la loi canadienne sur la protection de la vie privée, quelques formulaires secondaires ont été enlevés de cette thèse.

Bien que ces formulaires aient inclus dans la pagination, il n'y aura aucun contenu manquant. 


\begin{abstract}
Improvements to highway safety are a high priority for highway authorities due to the social and economic costs of traffic collisions. Therefore, the main objective of this thesis was to examine the effect of automated speed cameras (ASCs) as measured in fatal traffic collision frequencies using data from Kuwait. This thesis also established traffic safety benchmarks for Kuwait to improve the practice of analyzing safety trends and identifying locations with high fatal collisions. A database of fatal collisions was created, and qualitative spatial analysis was performed using GIS software. Collision prediction models were developed and the results of the statistical analysis showed that there is a statistically significant relationship between fatal traffic collisions and ASCs in one of three influence ranges studied. The model showed an increase in fatal collision frequency with the presence of ASC, which might suggest among other possible explanations, that the ASCs in Kuwait have been correctly installed at locations with high collision frequencies.
\end{abstract}




\section{Acknowledgements}

I would like to thank my supervisors, Professors Yasser Hassan and A.O. Abd El Halim, for their support, advice and guidance.

Special thanks to the General Traffic Department, at the Ministry of Interior in Kuwait, for their valuable cooperation and for allowing me access to their data. 


\section{Table of Contents}

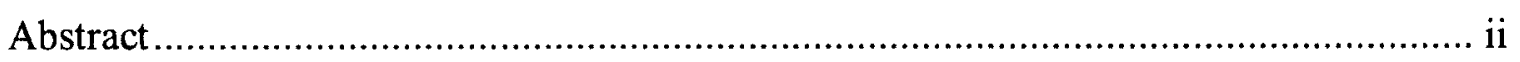

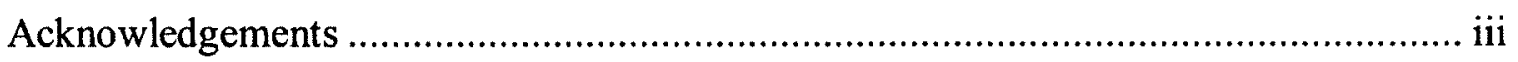

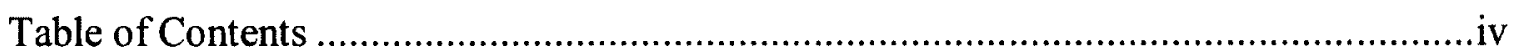

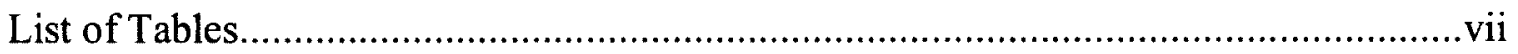

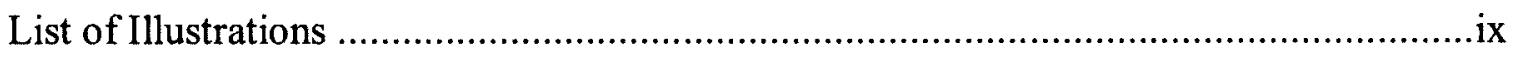

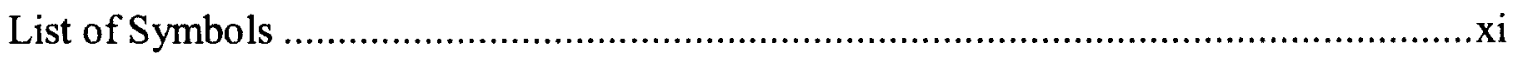

List of Appendices............................................................................................. xiii

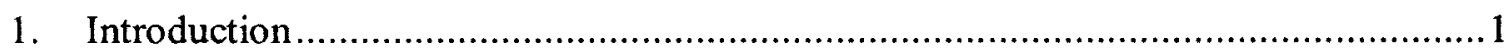

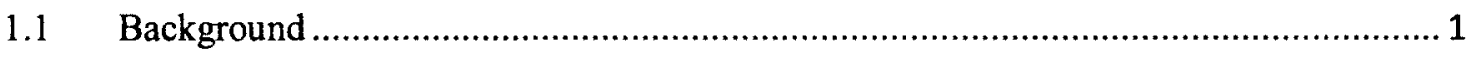

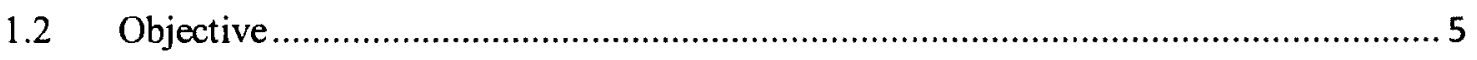

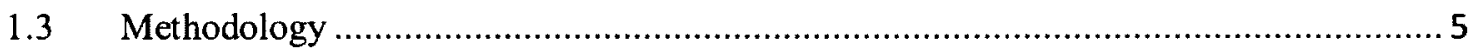

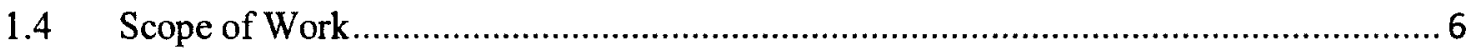

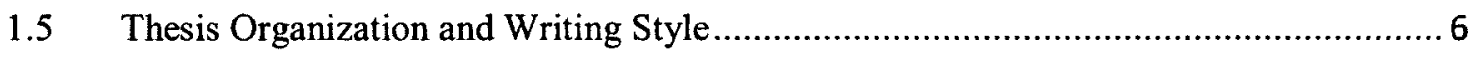

1.6 Thesis Challenges and Contributions ................................................................. 7

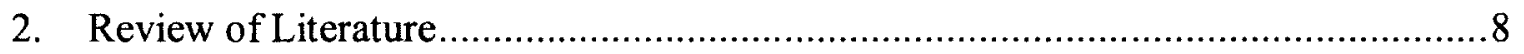

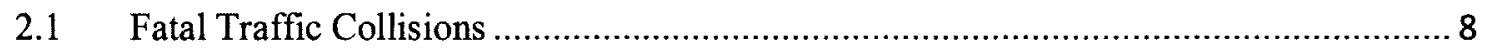

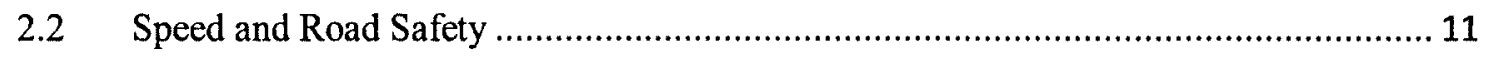

2.3 Automated Traffic Enforcement and Road Safety …….......................................... 15 


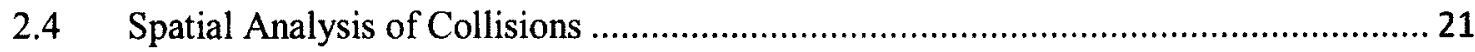

2.4.1 Use of GIS Systems for Collision Reporting ................................................. 22

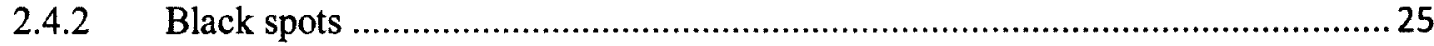

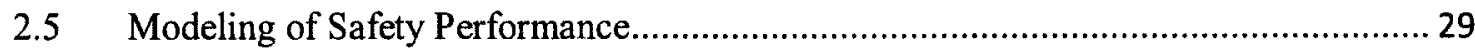

3. Kuwait Demographics and Road Characteristics.......................................... 32

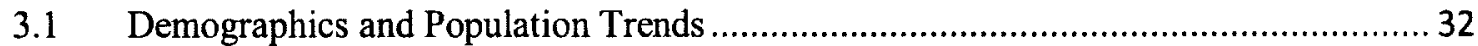

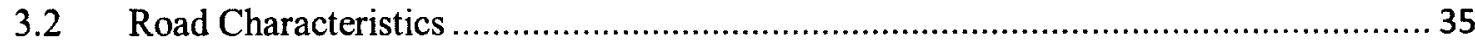

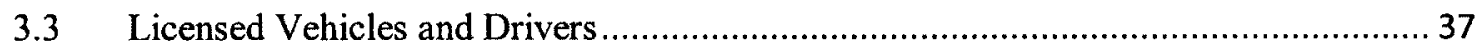

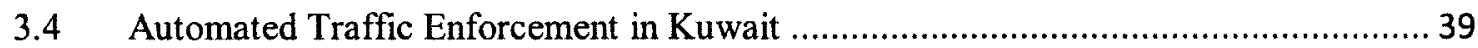

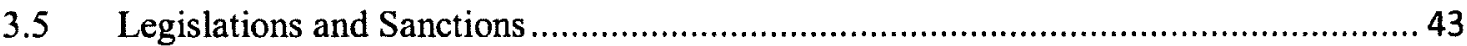

4. Methodology and Data Preparation............................................................ 45

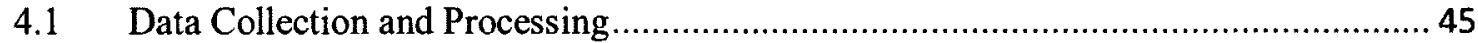

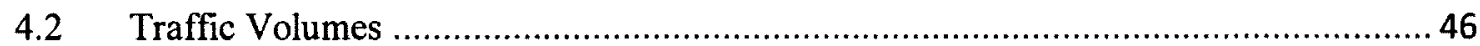

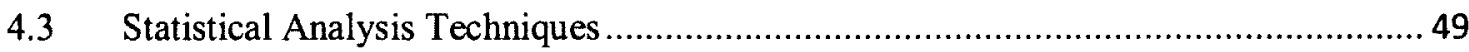

5. Descriptive Analysis of Violation and Collision Statistics...............................55

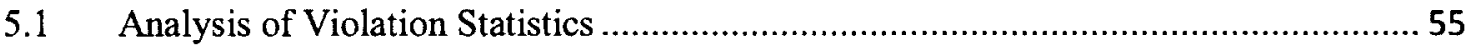

5.2 Analysis of Fatal Traffic Collision Statistics ................................................. 58

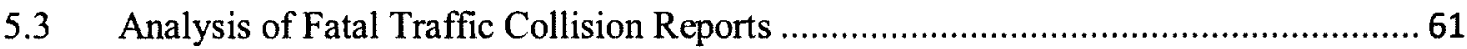

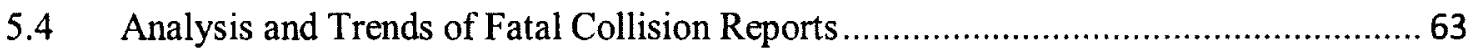

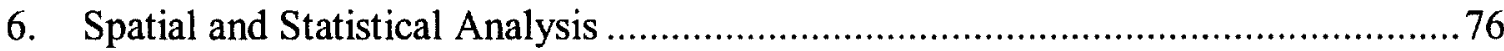

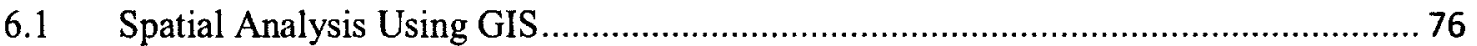




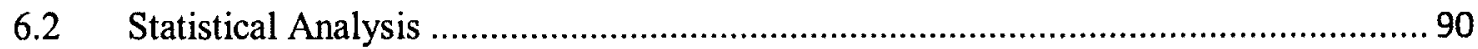

6.2.1 Statistical Models for the 500 m Radius Influence Area .................................96

6.2.2 Statistical Models for the $1000 \mathrm{~m}$ Radius Influence Area.................................98

6.2.3 Statistical Models for the $2000 \mathrm{~m}$ Radius Influence Area................................ 100

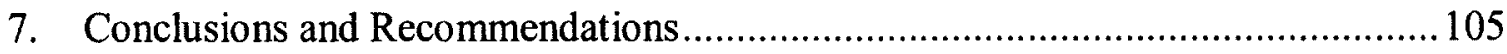

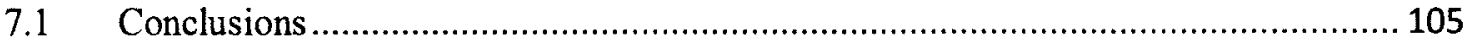

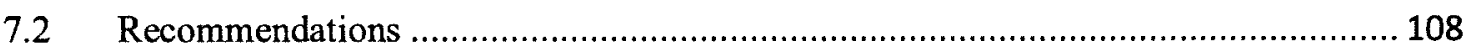

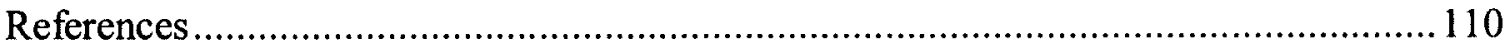




\section{List of Tables}

Table 2.1 - Leading Causes of Death Worldwide, Years 2004 and Predicted 2030 ................... 10

Table 2.2 - Leading Causes of Death by Age, World Data, 2004 ......................................... 11

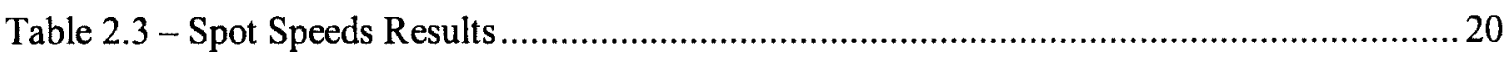

Table 2.4 - Overview of Definitions of Black Spots in Selected European Countries................ 28

Table 3.1 - Kuwait's Traffic Laws (Article 33 of Law 52 of 2001) ........................................4 44

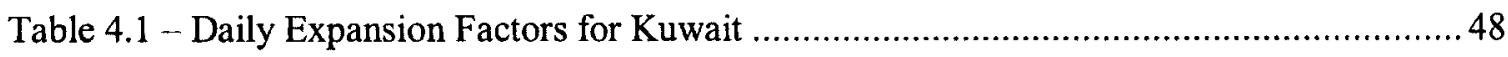

Table 4.2 - Monthly Expansion Factors for Kuwait ............................................................. 49

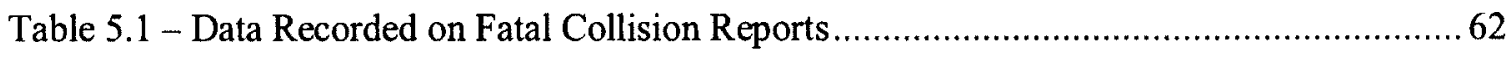

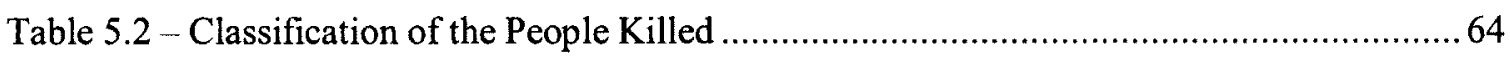

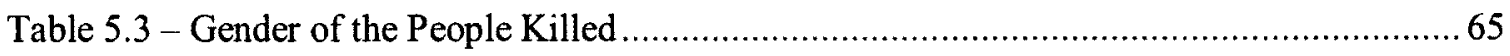

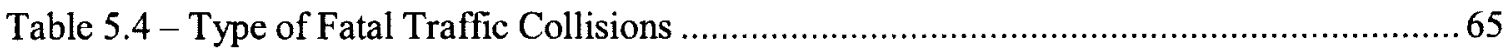

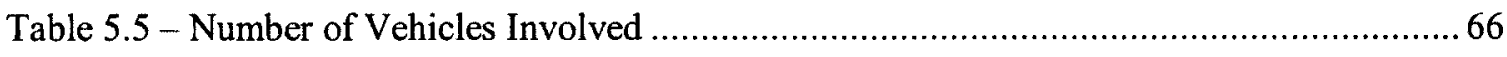

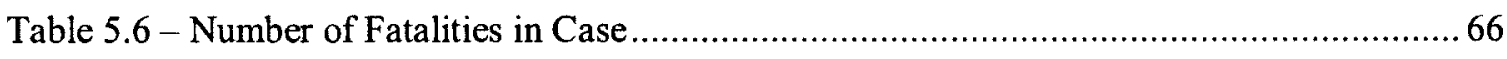

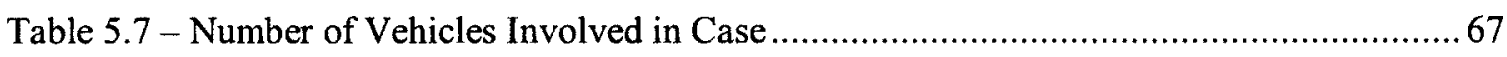

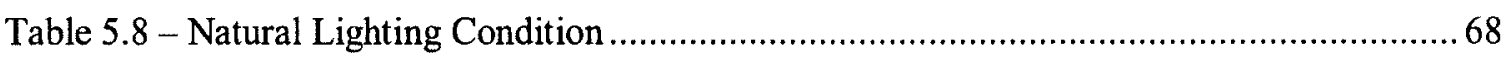

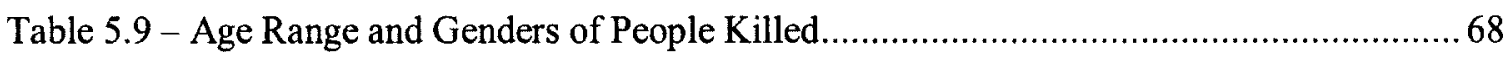

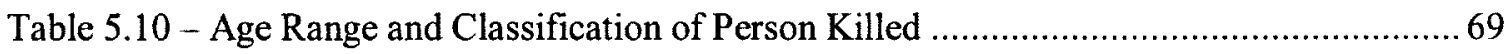

Table 5.11 - Vehicle Type and Classification of Person Killed........................................... 70

Table 5.12 - Vehicle Type and Type of Fatal Collision ............................................... 71

Table 5.13 - Time of Day and Day of Week.............................................................. 72

Table 5.14 - Nationality of People Killed...................................................................... 72

Table 5.15 - Month of the Year where Fatal Collision Occurred........................................ 74

Table 6.1 - Number of Fatal Traffic Collisions within and outside Governorates ................... 77 
Table 6.2 - High Fatal Traffic Collision Frequency Zones (500 m Radius Influence Area) .......84

Table 6.3 - High Fatal Traffic Collision Frequency Zones (1000 m Radius Influence Area) ...... 86

Table 6.4 - High Fatal Traffic Collision Frequency Zones (2000 m Radius Influence Area) ..... 88

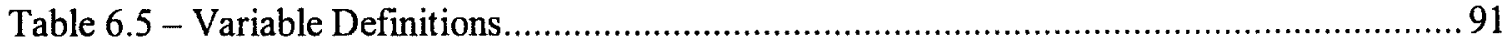

Table 6.6 - Variable Parameters for 500 m Radius Influence Area ..................................... 92

Table 6.7 - Variable Parameters for 1000 m Radius Influence Area..................................... 92

Table 6.8 - Variable Parameters for 2000 m Radius Influence Area......................................93

Table 6.9 - Phase 1 of the Collision Prediction Models Developed..........................................94

Table 6.10 - Phase 2 of the Collision Prediction Models Developed........................................ 95

Table 6.11 - Phase 1 - Significant Traffic Exposure Variables (500 m Radius Influence Area) .. 97

Table 6.12 - Phase 2 - Significant Dummy Variables (500 m Radius Influence Area) ..............98

Table 6.13 - Phase 1 - Significant Traffic Exposure Variables (1000 m Radius Influence Area) 99

Table 6.14 - Phase 2 - Significant Dummy Variables (1000 m Radius Influence Area) .......... 100

Table 6.15 - Phase 1 - Significant Traffic Exposure Variables (2000 m Radius Influence Area)

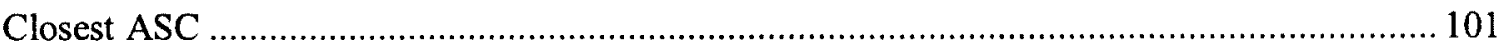

Table 6.16 - Phase 2 - Significant Dummy Variables (2000 m Radius Influence Area) Closest

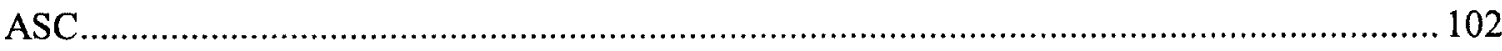

Table 6.17 - Phase 1 - Significant Traffic Exposure Variables (2000 m Radius Influence Area)

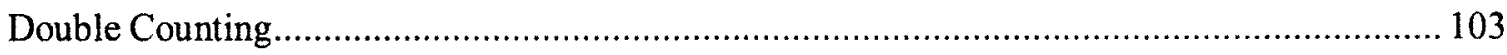

Table 6.18 - Phase 2 - Significant Dummy Variables (2000 m Radius Influence Area) Double

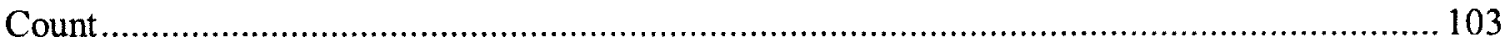




\section{List of Illustrations}

Figure 1.1 - Traffic Fatality Rates (per 100,000 inhabitants) .......................................... 3

Figure 2.1 - Population, Road Traffic Deaths, and Registered Vehicles, by Income Group ......... 9

Figure 2.2 - Speed Change According to Distance from ASE Station - Korea ........................ 19

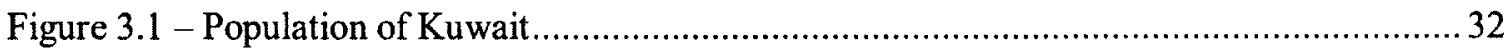

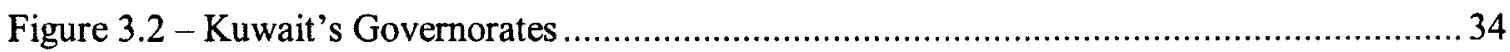

Figure 3.3 - Population Breakdown Within the Six Governorates of Kuwait (2007) ................. 34

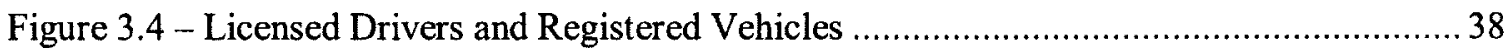

Figure 3.5 - Percentage Increase of Traffic Indicators during 2000-2008 in Kuwait ................. 39

Figure 3.6 - Number of Licensed Drivers vs. Speeding Violations in Kuwait ..........................40

Figure 3.7 - Number of Traffic Enforcement Cameras in Kuwait ..................................... 41

Figure 3.8 - Locations of Speed Cameras in Kuwait....................................................... 42

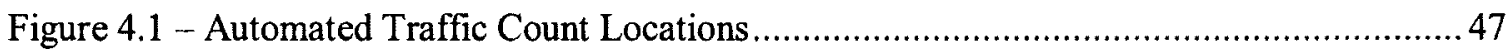

Figure 5.1 - Annual Traffic Violations vs. Licensed Drivers ........................................... 56

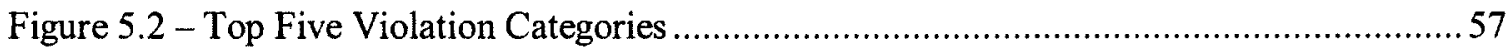

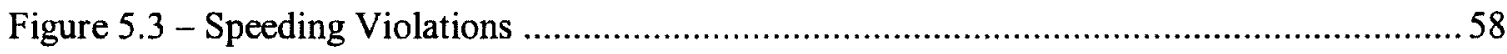

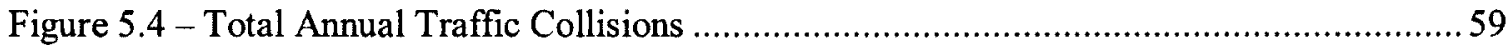

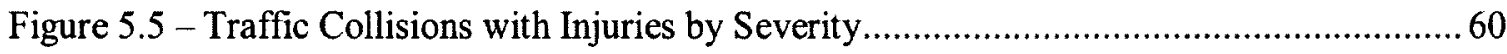

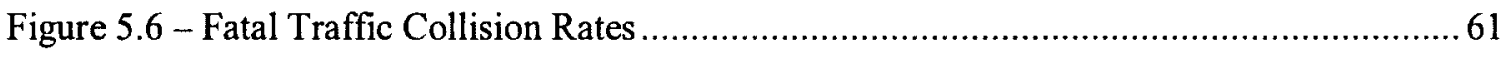

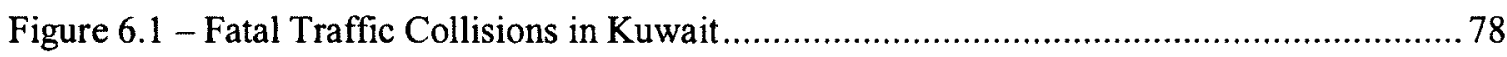

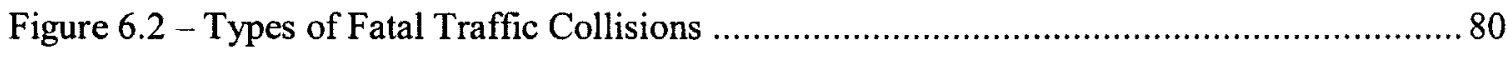

Figure 6.3 - $500 \mathrm{~m}$ Radius Influence Area - 3+ Fatal Collision Zones ................................ 83

Figure 6.4 - 1000 m Radius Influence Area - 3+ Fatal Collision Zones ................................ 85

Figure 6.5 - 2000 m Radius Influence Area - 5+ Fatal Collision Zones ................................. 87 
Figure 6.6 - Frequency Distribution of Fatal Collisions for $500 \mathrm{~m}$ Radius Influence Area......... 89

Figure 6.7 - Frequency Distribution of Fatal Collisions for $1000 \mathrm{~m}$ Radius Influence Area........ 89

Figure 6.8 - Frequency Distribution of Fatal Collisions for $2000 \mathrm{~m}$ Radius Influence Area....... 90 


\section{List of Symbols}

$\alpha=$ Over-dispersion parameter

$\beta_{i}=$ Coefficients quantifying the relationship between $X$ and $\lambda$

$\lambda=$ Expected number of collisions on a roadway segment

$\omega=$ Intercept

$L_{i}=$ A dummy (dummy) variable

$\theta_{i}=$ Coefficient quantifying the relationship between $L$ and $\lambda$

$A D T=$ Average daily traffic

$A A D T=$ Average annual daily traffic

$A S C=$ Automated speed camera

$A S E=$ Automated speed enforcement

$D^{m}=$ Scaled deviance

$D E F=$ Daily expansion factor

$E\left(y_{i}\right)=$ Expected collision frequency at location i;

$e$ Crash $=$ Electronic crash

Expo $=$ Single exposure term $($ million vehicle $-\mathrm{km})$

$G E N M O D=$ General linear model

$G I S=$ Geographical information system

$K=$ Over-dispersion parameter

$K_{\max }=$ Maximum over-dispersion parameter

$k=$ Scaled deviance or chi-square dispersion measure

$K W D=$ Kuwaiti Dinars

$L_{f}=\log -$ likelihood achieved if the model gave a perfect fit 
$L_{m}=$ Log-likelihood of the model under study

$L R=$ Local road

$M E F=$ Monthly expansion factor

$M O I=$ Ministry of Interior

$M O V E=$ Mobile officers' virtual environment

$n=$ Number of observations

$p=$ Number of coefficients considered in model

$P R N=$ Primary road network

$R^{2}=$ Coefficient of determination

$R_{k}{ }^{2}=$ Goodness of fit measure

$S R=$ Secondary road

$S R N=$ Special road network

TraCS $=$ Traffic and Criminal Software

$T R L=$ Transport Research Laboratory

$\operatorname{Var}\left(y_{i}\right)=$ variance of observed collision occurring at location $\mathrm{i}$

$W H O=$ World Health Organization

$X_{i}=$ Variables influencing $\lambda$ (e.g., roadway and roadside geometry, etc.)

$Y=$ Expected three-year mean collision frequency 


\section{List of Appendices}

Appendix A - Fatal Traffic Collisions Database

119

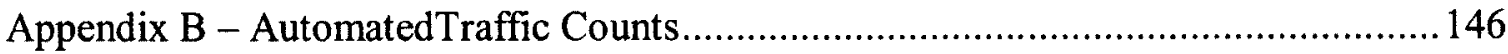

Appendix C - SAS Input \& Output - 500 m Radius Influence Area..............................179

Appendix D - SAS Input \& Output - 1000 m Radius Influence Area

Appendix E - SAS Input \& Output - 2000 m Radius Influence Area ...........................234 


\section{Introduction}

\subsection{Background}

Road transportation has brought considerable benefits to society by facilitating the movement of people and goods. However, continuous population growth coupled with economic development has resulted in increasing demands for road transportation. Consequently, the result is a severe worldwide traffic safety problem in terms of increased traffic collisions, leading to significant burden on public health and adverse impacts on the global economic and social development.

The main danger to road users is the likelihood of a traffic collision. Such dangers can be reduced by individual road users operating cautiously and defensively, by building roads with competent traffic engineering practices and by the application of rational traffic control methods. Even though traffic collisions are unpredictable and rare events, they occur on a daily basis all over the world. There are several outcomes that may occur due to a traffic collision, which are: property damage, minor injury, major injury, and/or fatality.

A report published by the World Health Organization (WHO), which uses vital registration (death certificate) data, estimated that around 1.2 million people die each year on the world's roads due to traffic collisions, and between 20 and 50 million suffer nonfatal injuries (WHO 2011). There is no restriction on where the death happens (e.g. at the collision scene, hospital, home, etc.) as long as the underlying cause of death was due to a 
traffic collision (Bhalla 2009). The definition of what constitutes a road traffic fatality based on how soon after the collision the death occurs varies from one country to another.

The current recommended definition of a road traffic fatality for harmonization of surveillance purposes is "any person killed immediately or dying within 30 days as a result of a road traffic injury accident" (European Communities 2003). The choice of 30 days was based on research which showed that most persons who die as a result of a crash succumb to their injuries within 30 days of sustaining them and that, while extension of this 30-day period resulted in a marginal increase in numbers, it required a disproportionately large increase in surveillance efforts (Jacobs, Aeron-Thomas and Astrop 2000).

Traffic collisions are most severe in developing countries, where simple prevention measures could reduce the number of deaths. In Kuwait, around 400 people lose their lives to traffic collisions every year. Based on Kuwait's population of around $2,500,000$ inhabitants, this yields a death rate of 16 fatalities per 100,000 inhabitants. This is a high fatality rate compared to other developed and developing countries. Deaths per 100,000 inhabitants is a common statistic used to make comparisons between nations, mainly because these two variables tend to be widely and relatively well-recorded by most countries (Baguley 2001). Otherwise, it is very difficult to make comparisons in relative road safety between countries due a number of factors such as the reliability of collision data, differences in ways data are recorded, differences in definitions (e.g. over what constitutes a fatal collision: death within 30 days of the collision is not standard worldwide). 
Figure 1.1 was created using traffic fatality statistics gathered by the WHO from different developed and developing nations, including data from Kuwait (WHO 2007). As shown in the figure, Kuwait has a lower traffic fatality rate than most of the countries in its region. However, it has a higher rate than the developed countries which implies that there are opportunities for considerable improvements in safety practices.

Research shows that the traffic situation tends to be worsening in developing countries as these countries' vehicle fleets are increasing, and efforts to improve safety are not keeping pace (Baguley 2001). However, methods applied in many of the developed countries have demonstrated that it is possible to slow down the trend of growth in collision frequency. Achieving this requires dedicated safety workers to carry out regular, in-depth analyses of patterns of accidents and to then target many of these with various remedial actions that are likely to yield the most effective results.

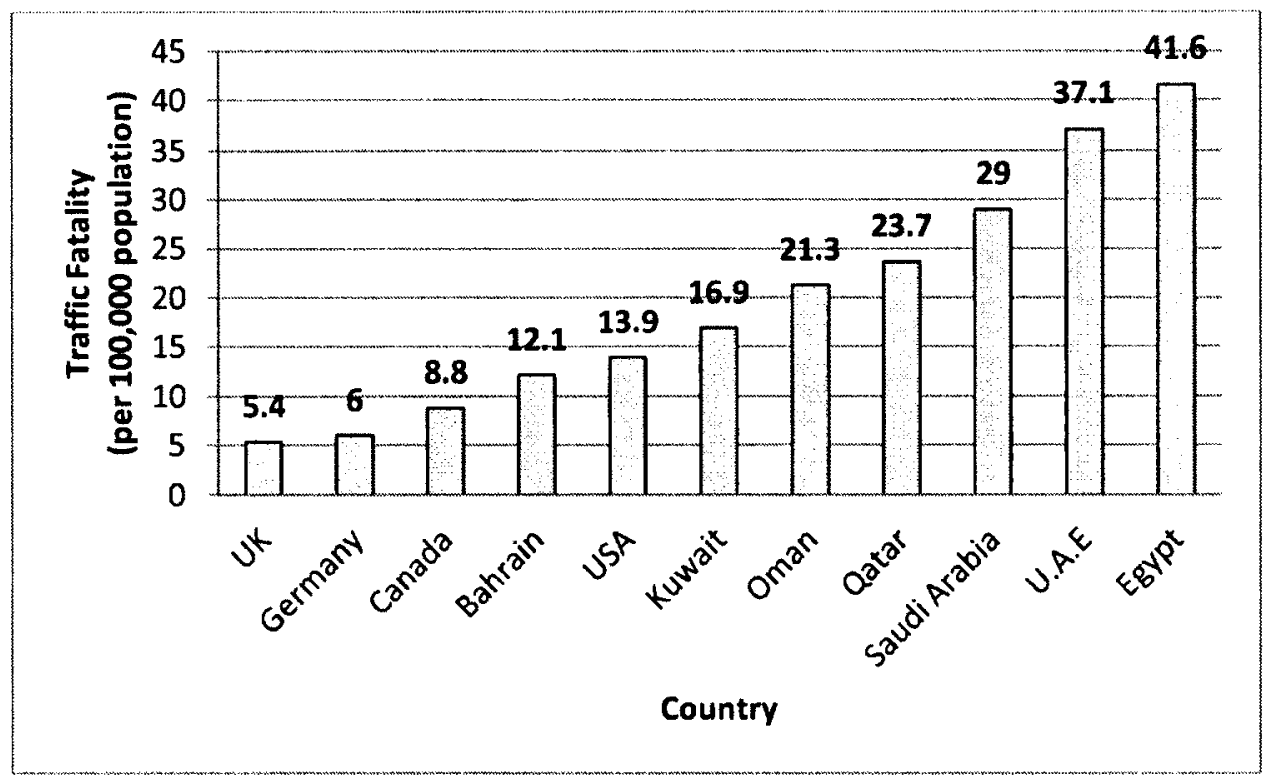

Figure 1.1 - Traffic Fatality Rates (per 100,000 inhabitants)

Source: Data from (WHO 2007) 
The establishment of a reliable road accident database and analysis system is of paramount importance when it comes to road safety, and it must be made accessible to all disciplines that are able to contribute to collision reduction (e.g. the Police, highway engineers, vehicle engineers, etc). It is likely that an unreliable or inaccessible database will lead to inefficient management of road safety.

Building and maintaining a digital database of traffic collisions can help identify hazardous locations along the roadway, which is an essential step in order to draw proper plans for improving safety, reducing the number of traffic collisions and resulting causalities. In order to perform such step, is it important to collect complete sets of data related to traffic collisions.

Creating a collision database can be used at three different levels. First, at the national level it can be used to help the government decide on safety policy (e.g. compulsory seat belt wearing or motorcycle helmet wearing, etc.). Second, at a regional level it can be researched to help regional authorities make appropriate decisions (e.g. on local police campaigns, child safety education, etc.). Third, at the local level the database can be used by local engineers to determine where the main problems are on the network they are responsible for and to identifying hazardous locations along the roads (Baguley 2001). Understanding and identifying the factors contributing to the safety issues lead to developing countermeasures for mitigating the safety problems. Evaluating the effectiveness of these remedial measures is necessary to ensure continued and increased safety on the roads.

One of the advanced remedial measures used on the roads around the world are automated speed cameras (ASCs). The ASCs were introduced in Kuwait in 1994 as a 
pilot project, and later as a full project in 2000 . The project was initiated as an effort to reduce the high volume of speeding violations and the severe traffic collisions, which are due to excessive speeding in most cases. However, there are no current standard procedures that can identify hazardous locations on the roads in Kuwait or set guidelines to assess the safety countermeasures implemented. Road authorities in Kuwait need to establish road safety improvement programs which aim at minimizing the suffering and losses due to traffic collisions.

\subsection{Objective}

The main objective of this thesis is to quantify the effect of ASCs as measured in the frequency of fatal traffic collisions for three sizes of influence areas using traffic statistics from the State of Kuwait. Associated with achieving this objective, several fatal traffic collision prediction models were developed for the State of Kuwait using statistical analysis.

\subsection{Methodology}

In order to achieve the main objective, several other sub-objectives were set. The sequence of achieving the sub-objectives corresponds to the methodology followed in this research, which is as follows: (1) create a detailed, digital database of the police fatal traffic collision reports collected from the Ministry of Interior (MOI) of Kuwait; (2) study the conditions governing the phenomenon of fatal traffic collisions in Kuwait and determine its main trends; and (3) spatially identify and analyze the locations with fatal traffic collisions along the road network in Kuwait using Geographical Information System (GIS) software. Chapter 4 discusses the methodology used in more detail. 


\subsection{Scope of Work}

The research work presented in this thesis focuses only on fatal collisions, where the fatality took place at the time of the collision, using the police fatal collision reports provided by the MOI of Kuwait. Collisions involving property damage and injuries are not investigated in this thesis due to lack of data. Furthermore, the research effort of the thesis was limited to the consideration of ASCs installed on continuous road sections away from the influence of intersections.

The police fatal collision reports, obtained from the General Traffic Department at the MOI of Kuwait, cover data for a three year period from January 2008 to December 2010. Older reports were not readily available. Traffic violation data, obtained from the Traffic Planning and Research Department at the MOI of Kuwait, which was used in analyzing safety trends cover the duration from January 2000 to December 2010. There are no properly kept records of violations or collision data before the year 2000 .

\subsection{Thesis Organization and Writing Style}

This thesis consists of seven chapters. Chapter 1 introduces the thesis and its objectives and scope. Chapter 2 presents a detailed literature review of studies that have been conducted on road safety, relationships between vehicle speed and safety, and the use of automated traffic enforcement tools. Chapter 3 presents Kuwait's demographic statistics, road characteristics and automated traffic enforcement tools. Chapter 4 covers the methodology and data preparation. Chapter 5 covers the qualitative analysis of traffic violation and collision statistics, with the main focus on the fatal collisions and their trends. Chapter 6 covers qualitative spatial analysis using GIS software and the statistical 
analysis of prediction models using regression analysis. Chapter 7 draws conclusions from this thesis and provides recommendations for future research directions.

This thesis was written using Carleton University thesis guidelines and the Chicago citation methods. Also, the words "collision", "accident" and "crash" are used synonymously.

\subsection{Thesis Challenges and Contributions}

There is currently no proper system for data exchange between the traffic police, the MOI, hospitals and ambulance services in Kuwait. Therefore, considering the data availability, this thesis was limited to fatal traffic collisions reports where the fatalities occurred during the time of the collision. The data was obtained from the traffic police since they are the first to document these incidents. The fatal collision reports gathered are not a complete set of all traffic collision fatalities that occurred. Some reports were not retrievable from the head of the Collision Investigations Department at the MOI of Kuwait due to misplacement.

The fatal collision locations are all documented by the police patrol that responded to the collision, and all information related to the incident was handwritten on paper. Police patrol tends to prioritize human safety and traffic management above paperwork at the scene, therefore, documented errors and missing fields in the reports retrieved were recurrent. One of the key deficiencies of the current police report form is the lack of a proper method for identifying the location on a particular roadway at which the collision occurred. As part of the spatial analysis conducted in this thesis, $\mathrm{X}-\mathrm{Y}$ coordinates were pinpointed for each fatal traffic collision based on the description of location provided in the reports. 
The data collection process was very time consuming due to lack of coordination between the departments which are intertwined. There were discrepancies between some of the data, such as the violations statistics which were obtained from two different departments, both at the MOI.

Despite these challenges, several research contributions were achieved through this thesis. A digital database was created consisting of the fatal traffic collision reports obtained from the MOI in Kuwait. No such database existed in Kuwait prior to this research. Also, coordinates were assigned to the descriptive locations of the fatal traffic collisions, which allowed geographical plotting of these fatal collisions in GIS software. This allowed for spatial assessment of the effect of ASCs on fatal traffic collisions using GIS software for the first time in Kuwait. Collision prediction models were also successfully developed using the database created which also assess the effect of ASCs on the fatal traffic collisions in Kuwait. 


\section{Review of Literature}

A comprehensive literature review was carried out to study research work performed in the field of traffic collisions related to the objectives of this thesis. The studies reviewed in this chapter covered issues such as causes of traffic collisions, the relationship between speed and road safety, automated traffic enforcement tools, spatial analysis studies, and collision prediction modeling techniques. The primary sources of literature reviewed were World Health Organization reports, Institute of Transportation Engineers publications, conference proceedings of the Transportation Research Board, and Kuwait University research reports.

\subsection{Fatal Traffic Collisions}

Road safety involves identifying the interactions between the road user, the vehicle and the road infrastructure. The term road safety is an indication of how safe individual users are on some particular road, or on the roads belonging to some region. A safe traffic system is one that accommodates and compensates for human vulnerability and fallibility (WHO 2009). The aim of traffic safety work is to avoid injuries in traffic collisions, especially serious injuries and fatalities. The first way is of course to avoid the injury collision and the second way is to reduce the consequences to persons involved in the collision when it occurs.

Traffic collisions are a major cause of severe injuries in most countries, as well as accounting for the highest absolute cause of road traffic deaths (Baguley 2001). This can 
be due to the fact that motor vehicles and the human population of highly motorised countries are on increase each year.

A WHO (2004) report states that while road traffic death rates in many highincome countries have stabilized or declined in recent decades, the data suggest that in most regions of the world the global epidemic of traffic injuries is still increasing. Furthermore, on average in the industrialized countries, and also in many developing countries, one hospital bed in ten is occupied by a traffic collision victim.

Figure 2.1 presents a breakdown of global population, traffic fatalities, and registered vehicles by income group. The figure shows that even though the high-income countries have the highest number of registered vehicles, they account for the lowest road traffic deaths, which can be due to increased safety practices.
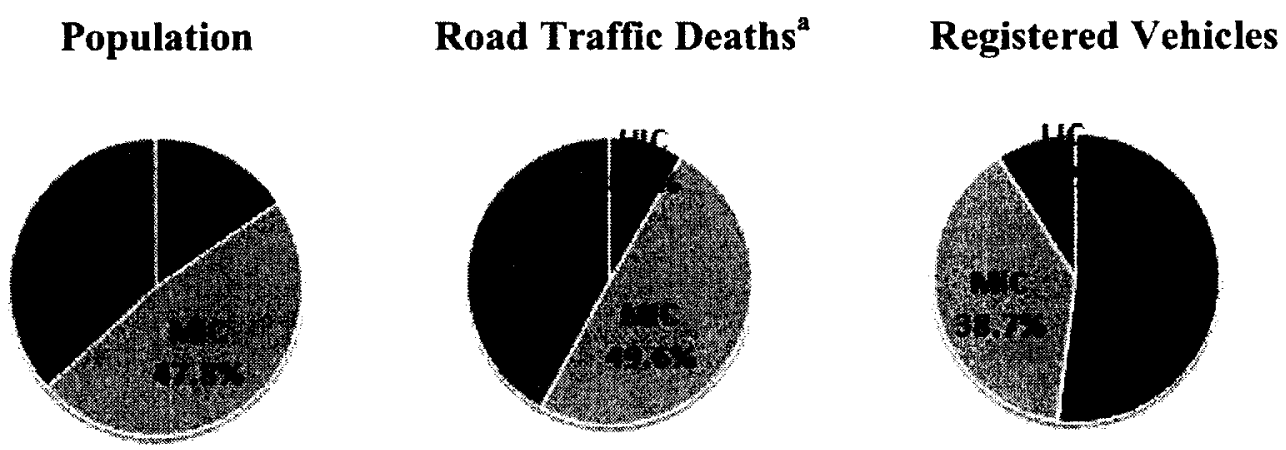

${ }^{\mathrm{a}}=30$-day definition, modeled data.

HIC $=$ high-income countries, $\mathrm{MIC}=$ middle-income countries, $\mathrm{LIC}=$ low-income countries

Figure 2.1 - Population, Road Traffic Deaths, and Registered Vehicles, by Income Group

Source: Adapted from Figure 3 from (WHO 2009) 
It has been estimated by the WHO that, unless an immediate action is taken, traffic collisions will rise to the fifth leading cause of death by 2030 , resulting in an estimated 2.4 million fatalities per year (WHO 2009). Table 2.1 presents the top 10 leading causes of death for the year 2004 and as predicted for 2030, as identified by the WHO. These predictions are primarily due to the increased motor vehicle ownership and use associated with economic growth in low and middle-income countries within the past few years (WHO 2008).

Road traffic injuries have been one of the top three consistent causes of death for people aged between 5 and 44, as shown in Table 2.2. The category of road traffic injuries, listed in the table, encompasses all road users such as drivers, passengers, cyclists, and pedestrians. Data sources show that about three-quarters of road traffic deaths are among men and that the highest impact is in the economically active age ranges (WHO 2009).

Table 2.1 - Leading Causes of Death Worldwide, Years 2004 and Predicted 2030

\begin{tabular}{|c|c|c|c|}
\hline \multicolumn{2}{|r|}{ Total 2004} & \multicolumn{2}{|r|}{ Total 2030} \\
\hline Rank & Leading Cause & Rank & Leading Cause \\
\hline 1 & Ischaemic heart disease & 1 & Ischaemic heart disease \\
\hline 2 & Cerebrovasculor disease & 2 & Cerebrovasculor disease \\
\hline 3 & Lower respiratory infections & 3 & $\begin{array}{l}\text { Chronic obstructive pulmonary } \\
\text { disease }\end{array}$ \\
\hline 4 & $\begin{array}{l}\text { Chronic obstructive pulmonary } \\
\text { disease }\end{array}$ & 4 & Lower respiratory infections \\
\hline 5 & Diarrhoeal diseases & 5 & Road traffic injuries \\
\hline 6 & HIV/AIDS & 6 & Trachea, bronchus, lung cancers \\
\hline 7 & Tuberculosis & 7 & Diabetes mellitus \\
\hline 8 & Trachea, bronchus, lung cancers & 8 & Hypertensive heart disease \\
\hline 9 & Road traffic injuries & 9 & Stomach cancer \\
\hline 10 & $\begin{array}{l}\text { Prematurity and low birth } \\
\text { weight }\end{array}$ & 10 & HIV/AIDS \\
\hline
\end{tabular}

Source: Adapted from (WHO 2008) 
Table 2.2 - Leading Causes of Death by Age, World Data, 2004

\begin{tabular}{|c|c|c|c|c|c|c|}
\hline Rank & $0-4$ Yrs & 5-14 Yrs & 15-29 Yrs & $30-44$ Yrs & 45-69 Yrs & $70+$ Yrs \\
\hline 1 & $\begin{array}{c}\text { Prenatal } \\
\text { causes }\end{array}$ & $\begin{array}{l}\text { Lower } \\
\text { respiratory } \\
\text { infections }\end{array}$ & $\begin{array}{c}\text { Road } \\
\text { Traffic } \\
\text { Injuries }\end{array}$ & HIV/AIDS & $\begin{array}{c}\text { Ischemic } \\
\text { heart disease }\end{array}$ & $\begin{array}{c}\text { Ischemic } \\
\text { heart disease }\end{array}$ \\
\hline 2 & $\begin{array}{l}\text { Lower } \\
\text { respiratory } \\
\text { infections }\end{array}$ & $\begin{array}{c}\text { Road } \\
\text { Traffic } \\
\text { Injuries }\end{array}$ & HIV/AIDS & Tuberculosis & $\begin{array}{c}\text { Cerebro- } \\
\text { vascular } \\
\text { disease }\end{array}$ & $\begin{array}{l}\text { Cerebro- } \\
\text { vascular } \\
\text { disease }\end{array}$ \\
\hline 3 & $\begin{array}{c}\text { Diarrheal } \\
\text { diseases }\end{array}$ & Malaria & Tuberculosis & $\begin{array}{c}\text { Road } \\
\text { Traffic } \\
\text { Injuries }\end{array}$ & HIV/AIDS & $\begin{array}{l}\text { Chronic } \\
\text { obstructive } \\
\text { pulmonary } \\
\text { disease }\end{array}$ \\
\hline 4 & Malaria & Drowning & Violence & $\begin{array}{c}\text { Ischemic } \\
\text { heart disease }\end{array}$ & Tuberculosis & $\begin{array}{l}\text { Lower } \\
\text { respiratory } \\
\text { infections } \\
\end{array}$ \\
\hline 5 & Measles & Meningitis & $\begin{array}{l}\text { Self- } \\
\text { inflicted } \\
\text { injuries }\end{array}$ & $\begin{array}{l}\text { Self- } \\
\text { inflicted } \\
\text { injuries }\end{array}$ & $\begin{array}{l}\text { Chronic } \\
\text { obstructive } \\
\text { pulmonary } \\
\text { disease }\end{array}$ & $\begin{array}{c}\text { Trachea, } \\
\text { bronchus, } \\
\text { lung cancer }\end{array}$ \\
\hline 6 & $\begin{array}{c}\text { Congenital } \\
\text { anomalies }\end{array}$ & $\begin{array}{c}\text { Diarrheal } \\
\text { diseases }\end{array}$ & $\begin{array}{l}\text { Lower } \\
\text { respiratory } \\
\text { infections } \\
\end{array}$ & Violence & $\begin{array}{c}\text { Trachea, } \\
\text { bronchus, } \\
\text { lung cancer }\end{array}$ & $\begin{array}{l}\text { Diabetes } \\
\text { mellitus }\end{array}$ \\
\hline 7 & HIV/AIDS & HIV/AIDS & Drowning & $\begin{array}{l}\text { Lower } \\
\text { respiratory } \\
\text { infections }\end{array}$ & $\begin{array}{c}\text { Cirrhosis of } \\
\text { the lover }\end{array}$ & $\begin{array}{l}\text { Hypertensive } \\
\text { heart disease }\end{array}$ \\
\hline 8 & $\begin{array}{c}\text { Whopping } \\
\text { cough }\end{array}$ & Tuberculosis & Fires & $\begin{array}{c}\text { Cerebro- } \\
\text { vascular } \\
\text { disease } \\
\end{array}$ & $\begin{array}{c}\text { Road } \\
\text { Traffic } \\
\text { Injuries } \\
\end{array}$ & $\begin{array}{c}\text { Stomach } \\
\text { cancer }\end{array}$ \\
\hline 9 & Meningitis & $\begin{array}{c}\text { Protein- } \\
\text { energy } \\
\text { malnutrition }\end{array}$ & $\begin{array}{l}\text { War and } \\
\text { conflict }\end{array}$ & $\begin{array}{c}\text { Cirrhosis of } \\
\text { the lover }\end{array}$ & $\begin{array}{l}\text { Lower } \\
\text { respiratory } \\
\text { infections }\end{array}$ & $\begin{array}{l}\text { Colon and } \\
\text { rectum } \\
\text { cancers }\end{array}$ \\
\hline 10 & Tetanus & Fires & $\begin{array}{c}\text { Maternal } \\
\text { hemorrhage }\end{array}$ & Poisonings & $\begin{array}{l}\text { Diabetes } \\
\text { mellitus }\end{array}$ & $\begin{array}{l}\text { Nephritis } \\
\text { and } \\
\text { nephrosis }\end{array}$ \\
\hline
\end{tabular}

Source: Adapted from (WHO 2009)

\subsection{Speed and Road Safety}

Highways and motor vehicles are designed and built for safe operation at the speeds traveled by most motorists (FHWA 2000). The speed drivers choose to travel at is influenced by many factors, which can be road and vehicle related, traffic and 
environment related, and/or driver related. The speed at which people travel, in turn, affects road safety.

Speed influences both collision risk and collision consequence. Traffic collision risks increase mainly when speeding drivers approach road junctions, run red lights, tailgate, weave in and out of traffic, fail to yield right of way, and while overtaking - as road users underestimate the speed, and overestimate the distance, of an approaching vehicle. The consequences of excessive speed include increased potential for loss of vehicle control, reduced effectiveness of passenger safety equipment, greater stopping distances, increased distance traveled during driver reaction time, and an increase in the degree of collision severity (FHWA 1997).

It has been mentioned in the literature that the speed of motor vehicle is a welldocumented risk factor which contributes to as much as one-third of fatal accidents (Frith, Strachan and Patterson 2006). Collision statistics from Canada reveal that $27 \%$ of fatalities and $19 \%$ of serious injuries involve speeding (Transport Canada 2011). In Europe, speed has been found to be a major contributory factor in around $10 \%$ of all accidents and in around $30 \%$ of the fatal accidents (Transportation Research Board 1998).

Some research indicates that there is a significant relationship between mean speed and collision risk. A wide range of before and after studies conducted in a number of countries examined the change in road safety before and after a speed limit change. A conclusion was drawn in a report, by the Organization for Economic Cooperation and Development in Europe, stating that a $1 \%$ reduction in speed results in reducing the likelihood of a fatal collision by $5 \%$ (OECD 2008). Therefore, a downward shift in the 
distribution of driving speeds for all drivers would be beneficial not just for those speeding on highways.

Also, based on work by Nilsson (2004) conducted in Sweden, a change in average speed of $1 \mathrm{~km} / \mathrm{h}$ would result in a change in accident numbers ranging between $2 \%$ for a $120 \mathrm{~km} / \mathrm{h}$ road and $4 \%$ for a $50 \mathrm{~km} / \mathrm{h}$ road. This result has been confirmed by many before and after studies of different speed reduction measures. This relationship is used by other Scandinavian countries and by Australian and Dutch safety engineers.

A similar relationship is assumed in Britain, based on empirical studies, where changes in accident numbers associated with a $1 \mathrm{~km} / \mathrm{h}$ change in speed have been shown to vary between $1 \%$ and $4 \%$ for urban roads and $2.5 \%$ and $5.5 \%$ for rural roads, with the lower value reflecting good quality roads and the higher value poorer quality roads (Taylor, Lynam and Baruya 2000).

A summary of studies carried out by the WHO show that the higher the impact speed, the greater the likelihood of serious and fatal injury (WHO 2004). Some of their main results are listed below:

- Excess and inappropriate speed contributes to around $30 \%$ of fatal crashes in high-income countries.

- For car occupants, the severity of crash injury depends on the change of speed during the impact. As the speed increases from about $20 \mathrm{~km} / \mathrm{h}$ to $100 \mathrm{~km} / \mathrm{h}$, the probability of fatal injuries increases from close to zero to almost $100 \%$.

- For car occupants in a crash with an impact speed of $80 \mathrm{~km} / \mathrm{h}$, the likelihood of death is 20 times what it would have been at an impact speed of $30 \mathrm{~km} / \mathrm{h}$. 
- Pedestrians have a $90 \%$ chance of surviving car crashes at $30 \mathrm{~km} / \mathrm{h}$ or below, but less than a $50 \%$ chance of surviving impacts at $45 \mathrm{~km} / \mathrm{h}$ or above.

- The probability of a pedestrian being killed rises by a factor of eight as the impact speed of the car increases from $30 \mathrm{~km} / \mathrm{h}$ to $50 \mathrm{~km} / \mathrm{h}$.

Despite the research already mentioned about the relationship between speed and safety, it remains a subject of much debate. Ezra Hauer, a well-known professor emeritus in the department of Civil Engineering at the University of Toronto who has researched road safety for years, conducted numerous reviews about speed and road safety. He also noted the gaps in knowledge and described where opinions differ and why. He stated that "despite decades of speed measurement and monitoring, the evolution of speed over time is poorly documented, and the understanding of what drives the evolution is largely missing. It is known that speeds evolve over time, but not why; it is known that there is some spillover of the change from one road to another, but its size or extent cannot be predicted" (Hauer 2009).

Hauer (2009) stated that there are strong beliefs supported by weak evidence as to whether or not collision involvement depends on speed. To many it seems obvious that the faster one drives the more likely one is to crash. This is why the dependence of the stopping distance on speed plays such an important role in geometric design. Others believe that the likelihood of a collision has more to do with deviation from mean speed..

Hauer (2009) argues that there can be no reasonable doubt that if speed increases while other conditions (vehicles, roads, medical services) remain unchanged, the accidents that occur will tend to be more severe. However, the prevalent and strongly held belief that the greater the speed, the higher is the probability that accidents will 
occur is, at present, not well supported by research. Even so, given a change in mean speed, one can predict the consequences in injuries and fatalities. The outcome of a collision severity depends not on speed but on the change in speed, which, in turn, depends on many factors, not only the speed of the crashing vehicle. The link between the effects of vehicle design, advertising, speed limits, infrastructure standards, etc. and the speed on the road is less clear.

There is no single solution to the problem of speeding. What is needed is a combination of better road design, enforced speed limits, traffic enforcement tools and driver education.

\subsection{Automated Traffic Enforcement and Road Safety}

Traffic officials seek ways to increase compliance with traffic rules and regulations especially at locations where there are high and repeated number of violations. Sometimes engineering countermeasures can be used, such as adjusting road geometry or changing signal phasing or timing at signalized intersections. However, the problem is often driver decision making, and therefore enforcement becomes necessary.

One method of enforcement is for police officers to cite the violators they observe. This requires police officers to spend their time on the streets and results in an occasional enforcement presence. It also requires police officers' time away from other duties. Automated traffic enforcement tools were introduced to provide more comprehensive enforcement without diverting police officers from other duties (Bochner and Walden 2010). An automated traffic enforcement system is defined as a mechanical recording device that is triggered automatically by a traffic violation, so that information 
about the violating vehicle is recorded, making possible the subsequent identification of the vehicle for the purpose of sanctioning the owner or driver (Sagberg 2000).

Another advantage of using automated traffic enforcement is that it provides continuous coverage and produces a record of the violations that can be reviewed in case of question. They are typically used where collisions or violations are most frequent.

When discussing the automated traffic enforcement technologies, there are technologies for detecting violations and other technologies for identifying the vehicle. Some technologies are common for detecting several violations, whereas others are particularly tailored to the detection of specific kinds of violations. The basic technologies that have been used for detecting speed violations are (Sagberg 2000):

- radar

- laser

- inductive loops in pavement

- pneumatic tubes across road

- piezoelectric cables

- infrared detectors, and other optical sensors

- video image processing

- electronic detection based on in-car electronic tags

A traffic safety criterion must be used to determine where automated traffic technology will be used. These criteria include, but are not limited to, high-risk, highcollision and high pedestrian volume locations. Below are some factors that must exist before automated traffic enforcement technology is used at a specific site (Preamble 2009). 
- Road segments where the safety of citizens or police officers would be at risk or ineffective through conventional enforcement methods.

- Road segments with an identifiable, documented history of property damage, injury and/or fatal collisions.

- Road segments with an identifiable, documented history of speeding problems.

- Road segments with an identifiable, documented history of offences where motorists are ignoring or breaking traffic laws on an ongoing basis.

- Road segments near schools and play-ground zones or areas, post secondary institutions, other areas with high pedestrian volumes.

- High-speed, multi-lane roadways.

Cameras have been used as speed enforcement tools in several countries worldwide. Several studies have reported reduction in number of collisions and injuries due to the implementation of automated traffic enforcement programs. Below is a summary of experiences with various automated enforcement technologies in different countries.

A decline of $20 \%$ in the number of injury collisions and a decline of $12 \%$ in property damage are reported from speed camera implementation is Saskatchewan, Canada (Liu and Popoff 1997). Research in the province of British Columbia, Canada has also demonstrated that speed camera method has been very effective. A drop in speeding vehicles at camera sites from $66 \%$ in 1996 to less than $40 \%$ after implementing the scheme was reported (Insurance Institute for Highway Safety 1999).

Introduction of speed cameras in West London over a 6-year period led to threefold reduction in deaths from 68 to 20 and a reduction in serious injuries by over a 
quarter from 813 to 596 (Lyons 1998). Evaluation of data 5 years before and 3 years after the introduction of cameras in Bristol, UK found a statistically significant association of before-after reduction in collisions and killed and seriously injured (KSI) index at camera sites (Pilkington 2002). Digital camera-based speed enforcement systems have led to a reduction in traffic collisions and injuries by $52 \%$ in Nottingham, UK (Dalbert 2001).

In 1999-2000, two mobile speed cameras were introduced in Canberra, Australia and the results were very promising. In a period of six months, there has been a $26 \%$ reduction in vehicle speeds. In Australia, the speed camera is now considered a valuable and valid deterrent to speeding (Anderson 2000).

In the city of Brasilia, Brazil, the average vehicle speed was $90 \mathrm{~km} / \mathrm{h}$ and there were 3 to 4 traffic deaths each day. The government installed 330 electronic speedcontrolling devices, performed engineering work in critical locations and created traffic division with 500 officers. Local media also participated in the campaign. Private companies participated in the installation of electronic speed controlling devices. This private-government partnership towards traffic safety has resulted in significant traffic speed reduction with a significant decrease in traffic mortalities. This model has been successfully copied in numerous other Brazilian cities (Affonso 2000).

A study was conducted in Korea to evaluate the effects of automated speed enforcement (ASE) systems on traffic flow characteristics and collisions. Speed data was collected at seven locations along a highway to evaluate speed change according to the distance from an ASE station. The results are shown in Figure 2.2. Although minor speed reduction was observed from $3.0 \mathrm{~km}$ as vehicles approached an ASE station, significant 


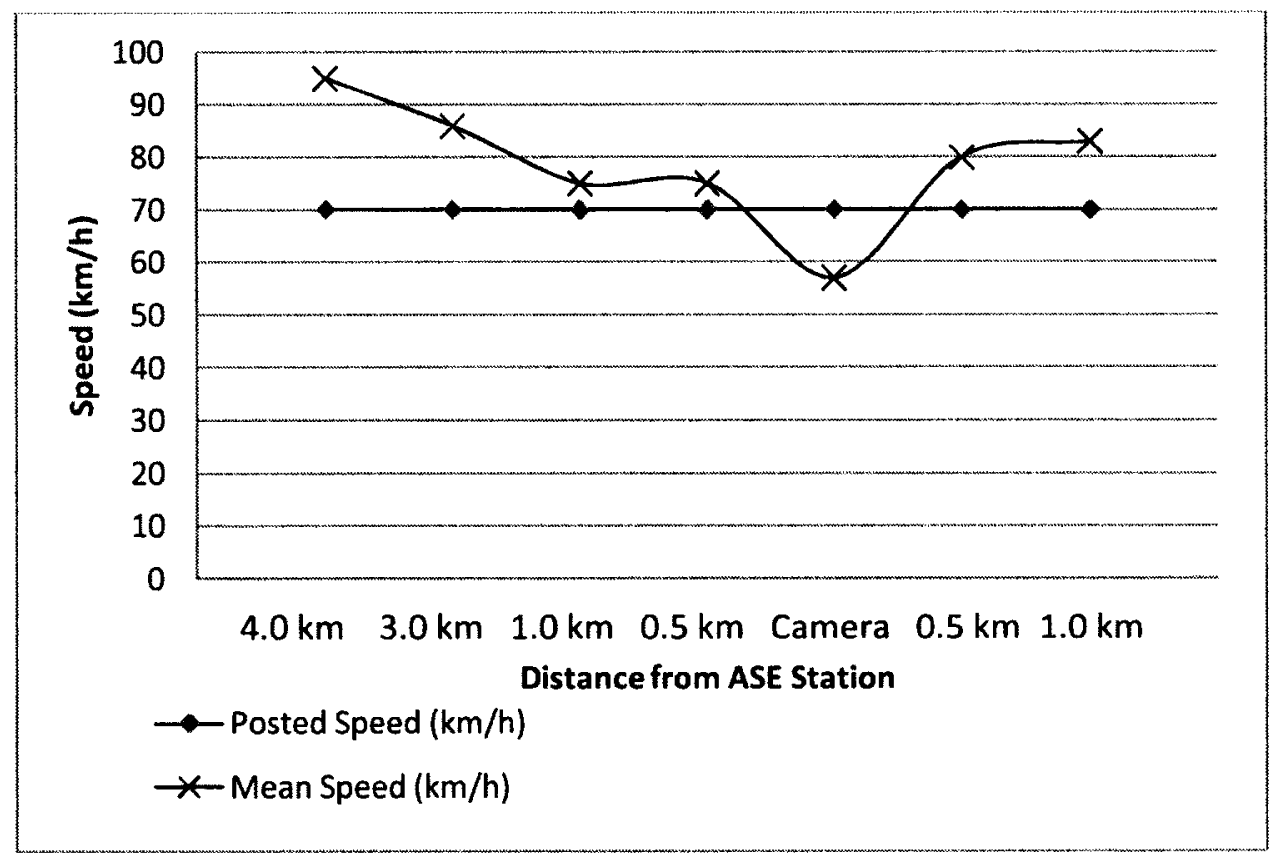

\section{Figure 2.2 - Speed Change According to Distance from ASE Station - Korea}

Source: Adapted from Figure 1 (Ha, Kang and Park 2003)

(C) 2003 Institute of Transportation Engineers, 1627 Eye Street, NW, Suite 600, Washington, DC 20006 USA, www.ite.org. Used by permission.

speed reduction was observed only $1.0 \mathrm{~km}$ before an ASE station where warning signs were posted (Ha, Kang and Park 2003). The results showed that drivers tend to reduce their speed when approaching the ASE systems. However, it has been shown that drivers accelerate back to their original speeds upon passing the ASE stations.

A similar spot speed study was conducted in Kuwait in 2003, by Kuwait University researchers, to measure speed differences at ASC locations and $500 \mathrm{~m}$ before four of the main roads in Kuwait. The exact locations of the ASCs chosen for the study were not identified in the paper. The results of spot speed survey "at" and $500 \mathrm{~m}$ "before" ASC locations are presented in Table 2.3. Measurements were repeated three times within one month (between April-May 2003). In each measurement about 100 randomly selected cars were targeted to obtain the speeds (Aljassar, Al-Anzi and Ali 2004). 
Table 2.3 - Spot Speeds Results

\begin{tabular}{|l|c|c|c|c|c|c|c|c|c|c|c|c|c|}
\hline \multirow{2}{*}{ Street } & \multicolumn{2}{|c|}{ Mean } & \multicolumn{2}{|c|}{ SD( \pm} & \multicolumn{2}{|c|}{ Median } & \multicolumn{2}{c|}{ Mode } & \multicolumn{2}{c|}{$\begin{array}{c}\text { 85th } \\
\text { Percentile }\end{array}$} & \multicolumn{2}{|c|}{$\begin{array}{c}\text { 97th } \\
\text { Percentile }\end{array}$} & $\begin{array}{c}\text { Posted } \\
\text { Speed } \\
\text { Limit }\end{array}$ \\
\cline { 2 - 15 } & $\mathbf{1}$ & $\mathbf{2}$ & $\mathbf{1}$ & $\mathbf{2}$ & $\mathbf{1}$ & $\mathbf{2}$ & $\mathbf{1}$ & $\mathbf{2}$ & $\mathbf{1}$ & $\mathbf{2}$ & $\mathbf{1}$ & $\mathbf{2}$ & \\
\hline Gulf Road & 74 & 83 & 13 & 16 & 75 & 85 & 82 & 95 & 86 & 96 & 94 & 113 & 80 \\
\hline $\begin{array}{l}\text { Fahaheel } \\
\text { Road }\end{array}$ & 99 & 111 & 10 & 12 & 100 & 109 & 100 & 112 & 107 & 124 & 115 & 135 & 100 \\
\hline $\begin{array}{l}\text { 4th Ring } \\
\text { Road }\end{array}$ & 60 & 82 & 13 & 16 & 61 & 82 & 66 & 88 & 74 & 98 & 79 & 113 & 80 \\
\hline $\begin{array}{l}\text { 2nd Ring } \\
\text { Road }\end{array}$ & 56 & 69 & 17 & 11 & 56 & 71 & 64 & 67 & 75 & 79 & 83 & 84 & 80 \\
\hline
\end{tabular}

1: Values "at" camera location

2: Values "before" camera location

Source: Adapted from (Aljassar, Al-Anzi and Ali 2004)

At all locations, the mean, median, the modal speed and the $85^{\text {th }}$ percentile speeds were found to be below or near the speed limit at the ASC location with the exception of the $97^{\text {th }}$ percentile speed limit. There is a clear evidence of differential speed behavior "at" and "before" the camera site. All the speed descriptive values increase for the measurements of "before" locations. The mode, $85^{\text {th }}$ and $97^{\text {th }}$ percentile, all were found to be above the speed limit except in the $2^{\text {nd }}$ Ring Road site.

Analysis of the speed data showed that traffic speeds were consistently higher in sections before the automatic camera at the camera site. The data reveals that many drivers being aware of cameras reduce their speed "at" the camera sites so as to avoid a violation being recorded by the camera.

It has to be noted that the introduction of speed cameras may be accompanied by other road safety initiatives such as traffic calming and education campaigns, against speeding for example. Temporal changes such as improvements in car safety, changes in traffic volume, and changes in driver behaviour can also influence the frequency of road traffic collisions. Speed cameras are generally introduced at sites identified on the basis 
of high frequencies of speed related collisions. However, as a rise in traffic collisions could be due to chance, any subsequent reduction could merely be indicative of random variation. All these factors could result in underestimating or overestimating of the effectiveness of cameras, and most studies only controlled for a few of these factors, if any (Pilkington 2004).

\subsection{Spatial Analysis of Collisions}

Recognizing the traffic safety problem and the importance of reducing the frequency and severity of road collisions, detailed spatial analysis should be carried out to determine where the hazardous sections are located along the roadway. A hazardous location can be defined as any section or spot that exhibits a higher collision potential (Lovegrove and Sayed 2008). Targeting problem locations and developing plans to reduce collisions are vital and have proven to be very successful (Sayed and de Leur 2003).

The use of GIS software is one of the tools to better represent and analyze multiyear collision data on maps. One of the most important benefits of GIS is its ability to graphically represent a large amount of data on a single map. This type of representation is very helpful in understanding multiple data types and values at a glance according to the location. GIS can be instrumental in improving the interpretation and representation of collision data. GIS and collision data can be delineated into categories according to fundamental issues such as: graphical representation of collision data, collision patterns, collision types, collision rates, and traffic safety (Graettinger, Lindly and Mistry 2005). 


\subsubsection{Use of GIS Systems for Collision Reporting}

Geographic Information Systems offer a promising new technology for locating, viewing and analyzing collision data. Using a spatial referencing system, other databases can also be linked to the collisions database using the same location coordinates. The province of New Brunswick has implemented GIS, while Nova Scotia and other provinces are investigating the implementation of these systems (CCMTA 2006).

The New York State Police have been using GIS based system for over a decade now in the US. They have taken the lead in a program called Traffic and Criminal Software (TraCS) and currently, there are over 400 officials using TraCS and transmitting data electronically (New York State Police 2012). TraCS is an automated data collection system that includes electronic ticket and accident forms, arrest and incident forms, commercial vehicle inspection forms, and the use of GPS devices and GIS maps. A diagram tool allows officers to create clear, accurate depictions of accident scenes. Templates of problematic intersections or roadways can be saved for repeated use. TraCS includes a location tool with state maps for pinpointing exact accident locations. These maps contain $\mathrm{X}-\mathrm{Y}-\mathrm{Z}$ coordinates and other location identifying features.

It has been reported that using the TraCS system benefits highway safety by greatly improving the accuracy of accident and ticket data that police collect. It also significantly decreases the amount of time it takes an officer to write a traffic ticket or collect accident report information. The less time officers and motorists spend parked along busy roads, the less chance of accident, injury or traffic disruption. TraCS has also proved to help in accelerating the flow of accident and ticket data to highway safety 
managers, allowing agencies to deploy their limited resources to high risk accident areas based on the most current and accurate data. Also government efficiency is enhanced using this system by reducing duplicative data entry by police, DMV and the courts, which will save time and minimize errors. Each year, TraCS transmits over 2,000,000 traffic citations and 200,000 crash reports (New York State Police 2012).

Another electronic crash reporting and transmission system, called electronic crash (eCrash), is used in the United States by several states including Alabama, Kentucky and Maryland (KLEN News 2003). The eCrash system uses the Mobile Officers' Virtual Environment (MOVE), which enables license scanning and GPS in addition to other functions for collecting and entering the data elements that describe motor vehicle collisions. The eCrash system is a major innovation in that it enables the entry of this important data as close to the crash scene as possible, thus assuring completeness, consistency and fewer interpretation errors. It also saves money and resources in reducing all duplicative efforts (e.g. officer's entering data on hard copy forms only to have these data re-entered into the computer). The electronic submission eliminates the need to mail in paper crash forms since the data is virtually instantaneous and readily available for processing (The University of Alabama 2009).

In Britain, GIS systems are used by the Transport Research Laboratory (TRL) in their Microcomputer Accident Analysis Program (MAAP), and by local authorities and regional police forces as an accident investigation tool (Asian Development Bank 2007). A report by Baguley documented how TRL's MAAP package arose from need when safety specialists visiting developing countries during the 1970's often found that 
collision data were very poor and not computerised. Back at that time, microcomputers were fast developing and becoming more powerful. They were robust and together with user-friendly software that tended to be written for them, meant that users needed little or no training in computing. Thus, were seen as the ideal tool for database management and analyses in the Third World (Baguley 2001).

TRL began a project with the Egyptian Government in 1981 initially to study safety on the arterial roads out from Cairo. The Egyptian Police knew that there were many collisions along these roads but were unsure about the actual number of collisions and their precise locations and types. Much effort was initially spent in developing a suitable and easy-to-complete collision report form. The software was then written to be as general as possible so that during much of the 1980 's the system could be adapted for use in other countries, and is still in use today (Baguley 2001).

In Brazil, the quality of the information on road accidents has been widely criticized due to the discrepancies in the number of traffic collision death statistics published by the National Highway Department and Ministry of Health. Therefore, an initiative has been taken by authorities in presenting a system for handling road accident statistics, based on geographically plotted information to be made available on-line to the police, highway operators and other interested parties. This system was developed with the aim of making road accident data more useful and bringing the disclosure of such information into line with national and international standards (Junior and Nassi 2008).

Malaysia is also working on developing a comprehensive GIS system to cover collision management and analysis, smart automated service for collision locations, 
collision and service diagnosis, reducing the number of collisions, increasing the level of road safety and fast delivery services such as insurance companies and emergency services (Mahmud 2008).

The next section discusses the methods used to label locations identified as having high frequency of collisions, which are also known as black spots.

\subsubsection{Black spots}

The term "black spot" is used by engineers and researchers to describe a location that has a higher number of collisions than other similar locations as a result of local risk factors, and this has been one of the standard safety engineering methodologies for over 30 years (Meuleners 2008, Elvik 2007). The identification, analysis and treatment of black spots are widely regarded as an effective approach to traffic collision prevention (Meuleners 2008). Potentially hazardous locations are selected on the basis of road safety analysis.

No standard definition exists when it comes to black spots, or hazardous road sections. However, from a theoretical point of view, black spots and hazardous road sections should be defined as any location that has a higher expected number of accidents, within a specific time period (typically 1 to 3 years), than other similar locations as a result of local risk factors (FHWA 2011). Black spots should be identified by reference to a clearly defined population of roadway elements as for example curves, bridges or four-leg junctions, while hazardous road sections should be identified by reference to 2-10 kilometres homogeneous road sections (Sorensen 2005). This makes it 
possible to estimate the general expected number of accidents by use of an accident model.

In the USA and Canada there is no fixed method for black spot analysis or network screening and ranking of high collision locations (Imran 2012). Selection of criteria or methodology depends upon the size of the jurisdiction and availability of the required data. In Alberta, a combination of critical collision rate and collision severity is used to rank high collision locations (black spots). They do not use any specific number of collisions that will declare a location as a black spot. Depending on the funding, they pick top ranking locations for safety review and improvement. Some agencies use certain number of similar collisions in five years as a criterion to identify locations for treatment.

The Manual of Transportation Engineering Studies, published by the Institute of Transportation Engineers in 1994, explains one methodology used to identify the high collision locations in the Unites States. That methodology states that a high collision location is defined as those locations that have a 3-year weighted accident crash rate greater than the mean rate for all locations, plus a constant times the standard deviation for all locations. At the $90 \%$ confidence level, that constant is 1.282 (Kirkham Michael Consulting Engineers 2000).

In the UK 'black spots' are locations where four or more fatal or serious road collisions have occurred over the previous three years (Van Hooijdonk 2009). A comparative analysis of methods for identifying road accident black spots has been conducted for other European countries. The various definitions of road collision black 
spots and the techniques used for identifying them differ along the following dimensions (Elvik 2007):

- Whether they make a reference to a population of sites (roadway segments, or intersections, or just any location) or not.

- Whether black spots are identified by means of a sliding window or by reference to a set of given locations.

- Whether they make a reference to the normal level of safety or not (normal level of safety are generally made by comparing the number of accidents at sites identified as black spots to the number of accidents predicted for similar sites).

- Whether they are based on the recorded number of accidents or prediction of the expected number of accidents.

- Whether accident severity is considered or not.

- The length of the identification period used.

Table 2.4 provides an overview of the definitions presented above. It is seen that none of the definitions listed are identical in all respects. The most appropriate level of spatial aggregation for road collisions is the road section, but in most studies its length is not justified and not controlled. No clear indication exists of what the best length of a dangerous road segment should be, nor whether a fixed length or variable length is to be defined. The problem relates especially to road sections. If these road sections are divided into not overlapping segments with a length of for example 0.5 kilometres there is a risk that the division will not correspond to the accident pattern. Local accident peaks might be divided between two segments and thus not identified as a black spot. 
Table 2.4 - Overview of Definitions of Black Spots in Selected European Countries

\begin{tabular}{|c|c|c|c|c|c|c|}
\hline Country & $\begin{array}{l}\text { Reference to } \\
\text { population } \\
\text { of sites }\end{array}$ & $\begin{array}{l}\text { Sliding } \\
\text { window } \\
\text { applied }\end{array}$ & $\begin{array}{c}\text { Reference } \\
\text { to normal } \\
\text { level of } \\
\text { safety }\end{array}$ & $\begin{array}{c}\text { Recorded or } \\
\text { expected } \\
\text { number of } \\
\text { accidents }\end{array}$ & $\begin{array}{l}\text { Accident } \\
\text { severity } \\
\text { considred }\end{array}$ & $\begin{array}{l}\text { Length } \\
\text { of } \\
\text { identific- } \\
\text { ation } \\
\text { period }\end{array}$ \\
\hline Austria & No & $\begin{array}{l}\text { Yes, } \\
250 \mathrm{~m}\end{array}$ & $\begin{array}{c}\text { Yes, by } \\
\text { means of } \\
\text { critical } \\
\text { values for } \\
\text { accident } \\
\text { rate }\end{array}$ & $\begin{array}{c}\text { Recorded, } \\
\text { minimum } \\
\text { critical value } \\
3 \text { - function } \\
\text { of traffic } \\
\text { volume } \\
\end{array}$ & No & 3 years \\
\hline Denmark & $\begin{array}{l}\text { Yes, detailed } \\
\text { categorisation } \\
\text { of roadway } \\
\text { elements }\end{array}$ & $\begin{array}{l}\text { Yes, for } \\
\text { road } \\
\text { sections - } \\
\text { variable } \\
\text { length }\end{array}$ & $\begin{array}{l}\text { Yes, by } \\
\text { means of } \\
\text { accident } \\
\text { prediction } \\
\text { models }\end{array}$ & $\begin{array}{c}\text { Recorded, } \\
\text { based on } \\
\text { statistical test } \\
\text { - minimum } 4 \\
\text { accidents }\end{array}$ & No & 5 years \\
\hline Germany & No & $\begin{array}{c}\text { No, } \\
\text { accident } \\
\text { maps } \\
\text { inspected }\end{array}$ & No & $\begin{array}{l}\text { Recorded, } \\
\text { minimum } 4\end{array}$ & $\begin{array}{c}\text { Yes, by } \\
\text { different } \\
\text { critical } \\
\text { values }\end{array}$ & $\begin{array}{l}1 \text { year (all } \\
\text { accidents) } \\
\text { or } 3 \text { years } \\
\text { (injury } \\
\text { accidents) }\end{array}$ \\
\hline Hungary & No & $\begin{array}{c}\text { Yes, } \\
100 \mathrm{~m} \text { or } \\
1000 \mathrm{~m}\end{array}$ & No & $\begin{array}{l}\text { Recorded, } \\
\text { minimum } 4\end{array}$ & No & 3 years \\
\hline Norway & $\begin{array}{l}\text { Not when } \\
\text { identifying } \\
\text { black spots }\end{array}$ & $\begin{array}{c}\text { Yes, } \\
100 \mathrm{~m} \\
\text { (spot) or } \\
1000 \mathrm{~m} \\
\text { (section) }\end{array}$ & $\begin{array}{l}\text { Yes, by } \\
\text { means of } \\
\text { normal } \\
\text { accident } \\
\text { rates for } \\
\text { roadway } \\
\text { elements }\end{array}$ & $\begin{array}{c}\text { Recorded } \\
\text { higher than } \\
\text { the normal by } \\
\text { statistical test, } \\
\text { minimum } \\
\text { values } 4 \\
\text { (spot) or } 10 \\
\text { (section) }\end{array}$ & $\begin{array}{l}\text { Yes, by } \\
\text { estimating } \\
\text { accident } \\
\text { costs and } \\
\text { potential } \\
\text { savings }\end{array}$ & 5 years \\
\hline Portugal & $\begin{array}{l}\text { Yes, for one } \\
\text { definition; no } \\
\text { for the other }\end{array}$ & $\begin{array}{l}\text { Yes, for } \\
\text { one } \\
\text { definition; } \\
\text { no for the } \\
\text { other }\end{array}$ & $\begin{array}{l}\text { Yes, for } \\
\text { one } \\
\text { definition; } \\
\text { no for the } \\
\text { other }\end{array}$ & $\begin{array}{l}\text { Recorded in } \\
\text { one definiton } \\
\text { (minimum 5), } \\
\text { expected in } \\
\text { the other }\end{array}$ & $\begin{array}{c}\text { Yes in one } \\
\text { definition } \\
\text { (by } \\
\text { severity } \\
\text { weighting), } \\
\text { no in other }\end{array}$ & $\begin{array}{l}1 \text { year or } \\
5 \text { years }\end{array}$ \\
\hline Switzerland & $\begin{array}{l}\text { Yes, open } \\
\text { roads and } \\
\text { junctions }\end{array}$ & $\begin{array}{l}\text { No. fixed } \\
\text { sections } \\
\text { of } \\
\text { variable } \\
\text { length } \\
\end{array}$ & Yes & $\begin{array}{l}\text { Recorded, a } \\
\text { set of critical } \\
\text { values }\end{array}$ & $\begin{array}{c}\text { Yes, by } \\
\text { differnet } \\
\text { critical } \\
\text { values }\end{array}$ & 2 years \\
\hline
\end{tabular}

Source: Adapted from Table 3 (Elvik 2007) 


\subsection{Modeling of Safety Performance}

Officials are required to evaluate the expected safety performance of a network especially after a specific improvement (e.g. the installation of automated traffic enforcement tools) to compare its net benefit to other improvement options as well as to justify its implementation at subsequent locations. When current or future safety performance estimates for a roadway are needed, they are developed by one of four main approaches: expert judgments made by experienced engineers, averages from historical collision data, results of before-after studies, and predictions from statistical models based on regression analysis (FHWA 2011).

Expert judgment, developed from many years of experience in the highway safety field, can have an important role in making reliable safety estimates (FHWA 2011). However, experts need a frame of reference based on historical accident data, statistical models, or before-and-after study results to make useful, quantitative judgments.

Historical accident data are an important indicator of the safety performance of a roadway, but they suffer from the weakness of being highly variable (FHWA 2011). Given this high variability, it is difficult to estimate the long-term expected collision rate using a relatively short-duration sample of 1 to 3 years of collision data. If a location has experienced no collisions in the past several years, it is certainly not correct to think that it will never experience an accident, yet the available data for that site alone provide an insufficient basis for estimating its long-term expected safety performance.

The most common method for evaluating the effectiveness of safety treatment is the observational before-and-after study. A before-and-after study is used when it is 
desired to study the safety implications of a certain improvement or operational change, where many attributes of a facility remain unchanged. Before-and-after studies compare two statistical estimates, an estimate of the expected number of accidents after the countermeasure improvement program is implemented and the number of accidents that would have been expected if the treatment had not been implemented (Hauer and Persaud 1988).

A before-and-after study using a comparison group attempts to account for changes, other than the treatment, that may affect safety between the before-and-after periods. The minimum length of the before-and-after period considered in any beforeand-after analysis should be at least 3 years (Mikulik and Holló 2007). However, most before-and-after studies reported in the literature have design flaws such that the study design cannot account for the effects of regression to the mean. Therefore, the potential user of the before-and-after study results cannot be certain whether they represent the true effectiveness of the potential improvement in reducing accidents or an overoptimistic forecast that is biased by regression to the mean (FHWA 2011).

When data is not available to conduct a before-and-after study, statistical techniques are used to develop collision prediction models for roadways and intersections. The accident prediction models relate the annual accident experience of a road segment to its characteristics. Such models are developed by obtaining/creating a database of accident and roadway characteristics (e.g., traffic volumes, geometric design features, and traffic control features), selecting an appropriate functional form for the 
model, and using regression analysis to estimate the values of the coefficients or parameters in that model (FHWA 2011).

Traffic collisions are non-negative and discrete in nature, therefore, modeling these count data requires using discrete distribution instead of a continuous one. The Poisson distribution has been used to model the count data for a long time. It has an important constraint that the mean and variance are equal. However, many processes in real life are over-dispersed (variances are greater than means) and violate the underlying assumption of Poisson distribution. In that case the negative binomial (NB) distribution is a more flexible extension of the Poisson distribution and allows for over-dispersion.

A key drawback of regression models is that they are based on statistical correlations between roadway characteristics and accidents that do not necessarily represent cause-and-effect relationships (FHWA 2011). Furthermore, if the independent variables in the model are strongly correlated to one another, it is difficult to separate their individual effects. In addition, if a variable in the model is strongly correlated to an important variable that happens not to be included in the available database, the coefficient of the variable in the model may represent the effect of the unavailable variable rather than its own effect. Thus, the value of the coefficient of a particular geometric feature may be a good estimate of the actual effect of that feature on safety, or it may be merely an artifact of, or a surrogate for, its correlation to other variables (FHWA 2011). 


\section{Kuwait Demographics and Road Characteristics}

This chapter provides information as well as statistics about the road and traffic characteristics and conditions in Kuwait. In Section 3.1, the demographics and population trends are introduced. Next, Section 3.2 presents the road hierarchy and characteristics followed by Sections 3.3 discussing statistics regarding licensed vehicles and drivers. In Sections 3.4 and 3.5 the presence of automated traffic enforcement, the legislations and sanctions are covered.

\subsection{Demographics and Population Trends}

The State of Kuwait is an independent Arab country bordered by Saudi Arabia to the south, and Iraq to the north and west. It has a population of over 3.5 million inhabitants, and an area of 17,818 square kilometres. From the statistical data collected from the assistant manager of the traffic planning and research department at the MOI,

Figure 3.1 was created to show the total population of Kuwait, the number of Kuwaiti

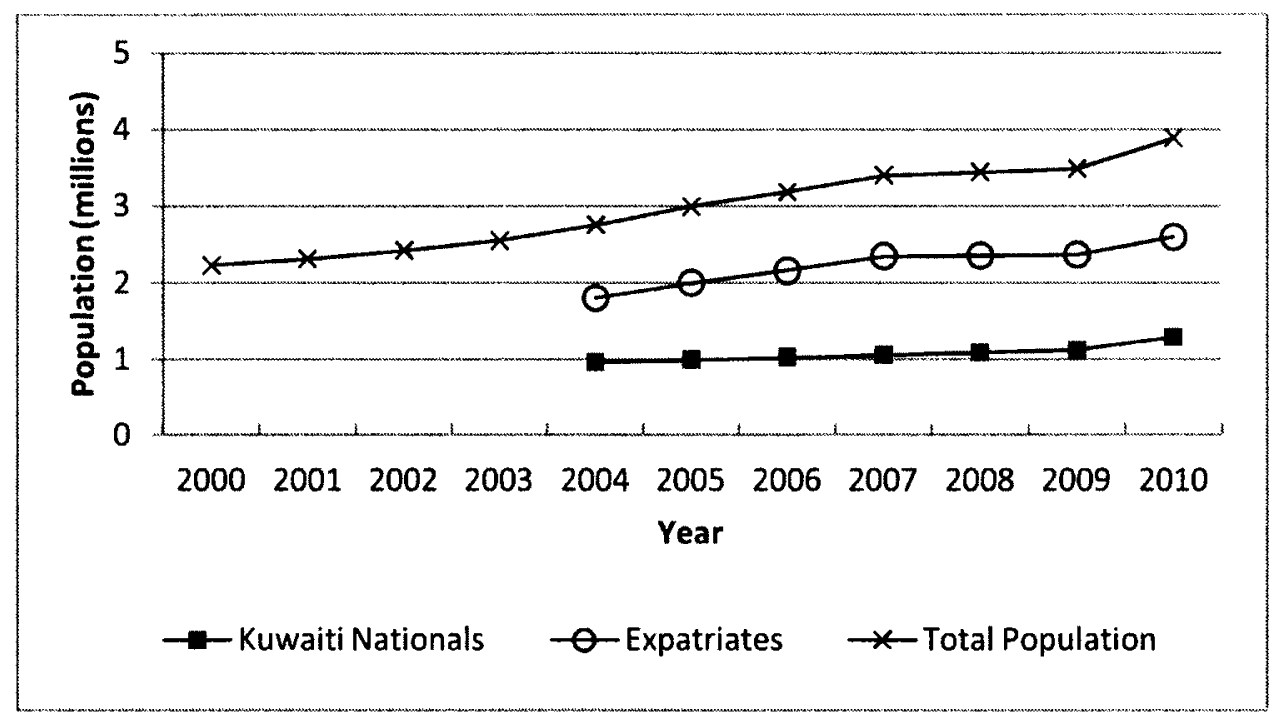

Figure 3.1 - Population of Kuwait

Data Source: MOI \& Public Authority for Civil Information, Kuwait 
nationals and the number of expatriates for the years 2000 to 2010 .

According to the Public Authority for Civil Information in Kuwait (PACI), population trends have been consistent throughout the years in Kuwait, specifically the dominance of the expatriate population that accounts for around $68 \%$ of the total population (KAMCO 2010). The largest age demographic according to its footprint is the 20-39 age group, which represents almost half the total population followed by the group of under 15 years representing $27 \%$, both statistics are indicators of a young population which leads to a greater need for mobility and country growth (KAMCO 2010).

Over $95 \%$ of the population lives in the major governorates, in $8 \%$ of the total area of the country (UNDP 2009). The six governorates of Kuwait are: AlAsima, Hawalli, AlAhmadi, AlJahra, AlFarwaniya and Mubarak AlKabeer, as shown in Figure 3.2, which was created using ArcGIS software. Statistics from the PACI were used, from 2007 , to create Figure 3.3 showing the population breakdown within the six governorates. The population breakdown can be referred to when assessing the collision frequencies per number of inhabitants.

As for Kuwait's overall population, $60-65 \%$ are Arabs (including Kuwaiti and non-Kuwaiti Arabs), $30-35 \%$ are Asian, and $5-10 \%$ are signified as "others". The foreign population mainly consists of Indians, Egyptians, Bangladeshi, Pakistani, Filipino and Sri Lankan residents. Other foreigners consist of European, North American and Northeast Asian communities. In 2009, more than 580,000 Indian nationals lived in Kuwait making them the largest expatriate community (Wikipedia 2011). 


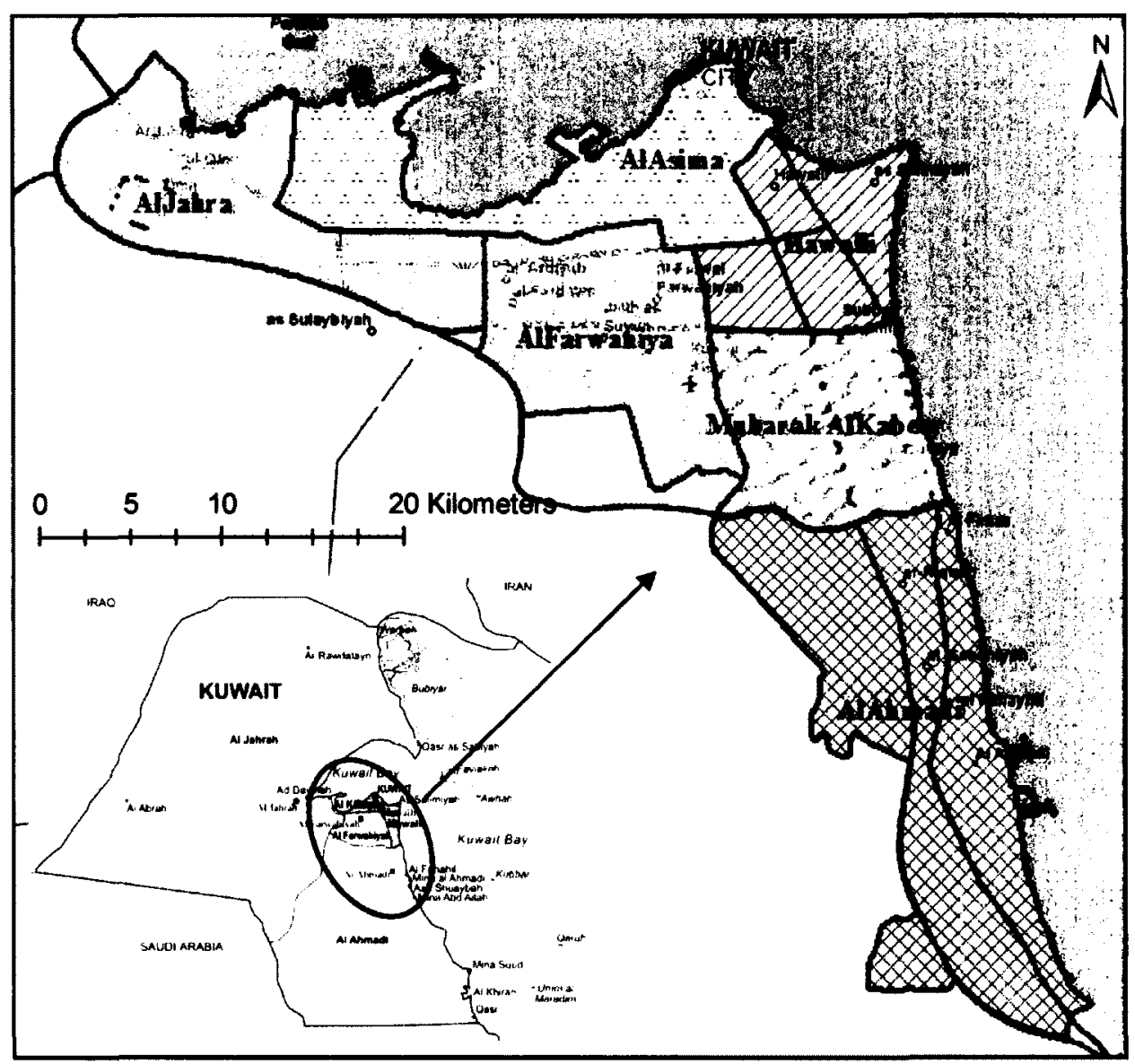

Figure 3.2 - Kuwait's Governorates

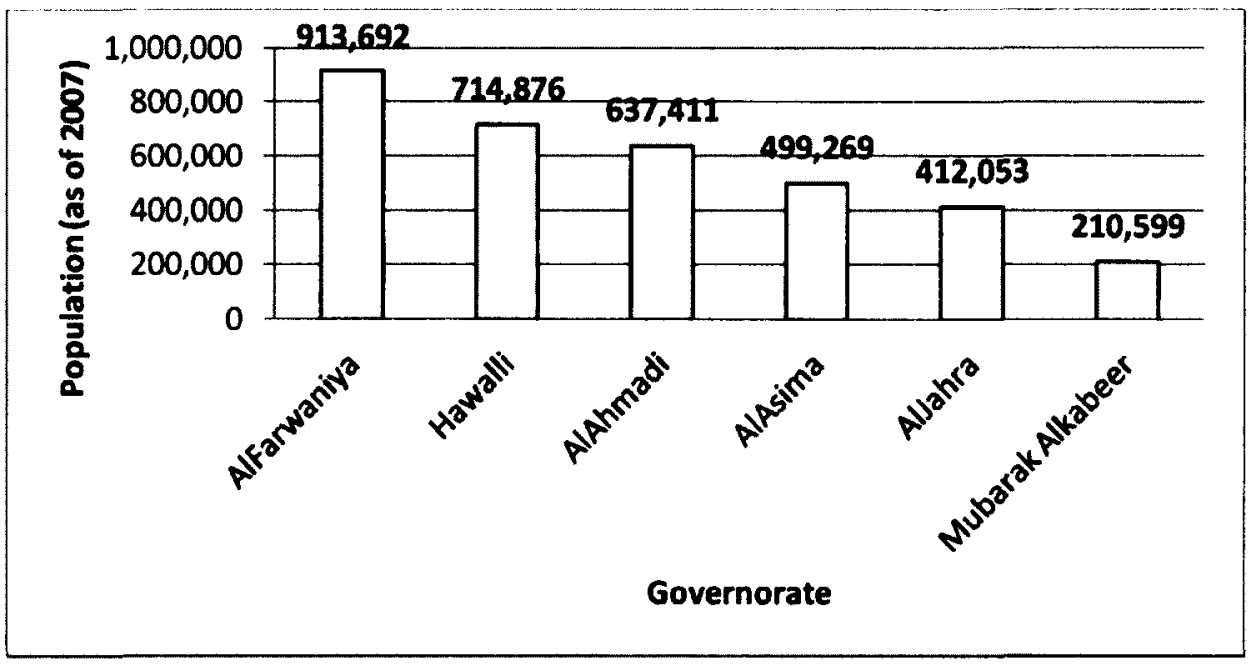

Figure 3.3 - Population Breakdown Within the Six Governorates of Kuwait (2007) 
One of the population difficulties encountered in Kuwait involves stateless people who claim residency for Kuwait (will get referred to as Non-Kuwaiti in this report). The majority of these people migrated from Iraq and Saudi Arabia after the economic boom of Kuwait. Since the rise of Kuwait's standard of living, many have flocked to the country. Most stateless people are Arabs, and count up to 100,000 people (Wikipedia 2011). Some are slowly naturalized through different legislative processes, which are ultimately increasing the Arab population of Kuwaiti people.

The downtown area of Kuwait, which is contained in AlAsima governorate, and its suburbs contain most of the Kuwaiti population, especially along the shore of the Arabian Gulf. The expatriates population concentration is in Hawalli Governorate (around AlSalmiya area) and also in AlFarwaniya Governorate (around Jileeb Alshuyoukh).

\subsection{Road Characteristics}

Kuwait has an extensive, modern and well-maintained network of highways. As of 2004 , roadways extended $5,749 \mathrm{~km}$, of which $4,887 \mathrm{~km}$ are paved and $862 \mathrm{~km}$ are unpaved (Wikipedia 2011).

The road network in Kuwait is classified into five categories: Special Road Network (SRN) Ring, SRN Radial, Primary Road Network (PRN), Secondary Roads (SR), and Local Roads (LR). The five distinct roadway types were identified for the purpose of developing functional, class-specific expansion factors. Below is a description of the five categories as presented in (Aljassar, et al. 1998): 
Special Road Network (ring and radial) includes motorways and expressways that are major through-routes for traffic with grade-separated junctions and full acceleration and deceleration lanes. They are similar in characteristics to expressways and freeways in North America. The estimated average annual daily traffic (AADT) is 130,000 for the SRN Ring and 123,000 and for SRN Radial. Roads in this category have at least one hard shoulder per carriageway and do not have $u$-turn facilities. The accessibility to SRN is restricted to motor vehicles only. Speed limit on such roads is $120 \mathrm{~km} / \mathrm{h}$. Traffic directions are divided by raised concrete barriers. SRN roads are mainly ring roads or radial roads. A total length of about $900 \mathrm{~km}$ or $16.3 \%$ of the total road network consists of SRN.

Primary Road Network includes through traffic routes that are usually of a lower design standard than SRN routes. They are similar in characteristics to arterials in North America. The estimated average AADT is 50,000. Roads under this category have atgrade junctions. Speed limit on these roads is $80 \mathrm{~km} / \mathrm{h}$. Traffic directions are divided by paved or landscaped islands. A total length of about $1654 \mathrm{~km}$ or $30 \%$ of the total road network consists of PRN.

Secondary Roads are used to distribute local traffic through a district and perhaps to serve a place of importance within a local community. They are similar to collector roads in North America. The estimated average AADT is 40,000 . Such roads usually have $\mathrm{u}$-turn facilities. Speed limit on these roads is $60 \mathrm{~km} / \mathrm{h}$ and medians generally divide traffic directions. Secondary roads usually run between blocks in a district to collect 
traffic from local roads and distribute them on SRN or PRN roads. About $1113 \mathrm{~km}$ or $20.2 \%$ of the total road network consists of SR.

Local Roads include those, which provide access to individual commercial or local residential units. The estimated average AADT is 2,500 . They run within blocks in a district and distribute traffic on secondary roads. Speed limit on local roads is $45 \mathrm{~km} / \mathrm{h}$, and they are not divided by medians. A total length of about $1845 \mathrm{~km}$ or $33.5 \%$ of the total road network consists of $L R$.

\subsection{Licensed Vehicles and Drivers}

The current tremendous growth in motor vehicle's use, heavy vehicle operations, the population, and the economy, has led to a sharp increase in the demand for road space and transport services. All key roads and ports have reached, or will reach soon, their design capacities. Roads are essential as the movements of people and goods are to the economic and social aspects of community life, they also present people and their surroundings with the problems of congestion, road collisions and environmental impacts, which impose a huge impact on the socioeconomic development (UNDP 2009).

In Kuwait, around $85 \%$ of the people travel by private vehicles. Public transport bus services are provided by both private and state-owned corporations. The government plans to build around $700 \mathrm{~km}$ of new high standard roads during the next five years and to construct US\$11 billion rail network which will include a city metro to encourage public transportation and to relief the vehicle traffic on the roads (UNDP 2009). 
A local publication issued by the MOI of Kuwait indicated that the highest numbers of vehicles were registered in AlAsima, Hawalli and AlFarwaniya, and that there was a general increase in licensed private cars compared to construction and public transport vehicles (MOI 2007). To compare the number of licensed drivers with the number of registered vehicles in Kuwait, Figure 3.4 was created using statistics collected from the MOI. The increase in number of registered motor vehicles seems to be increasing at a proportional rate with the number of licensed drivers.

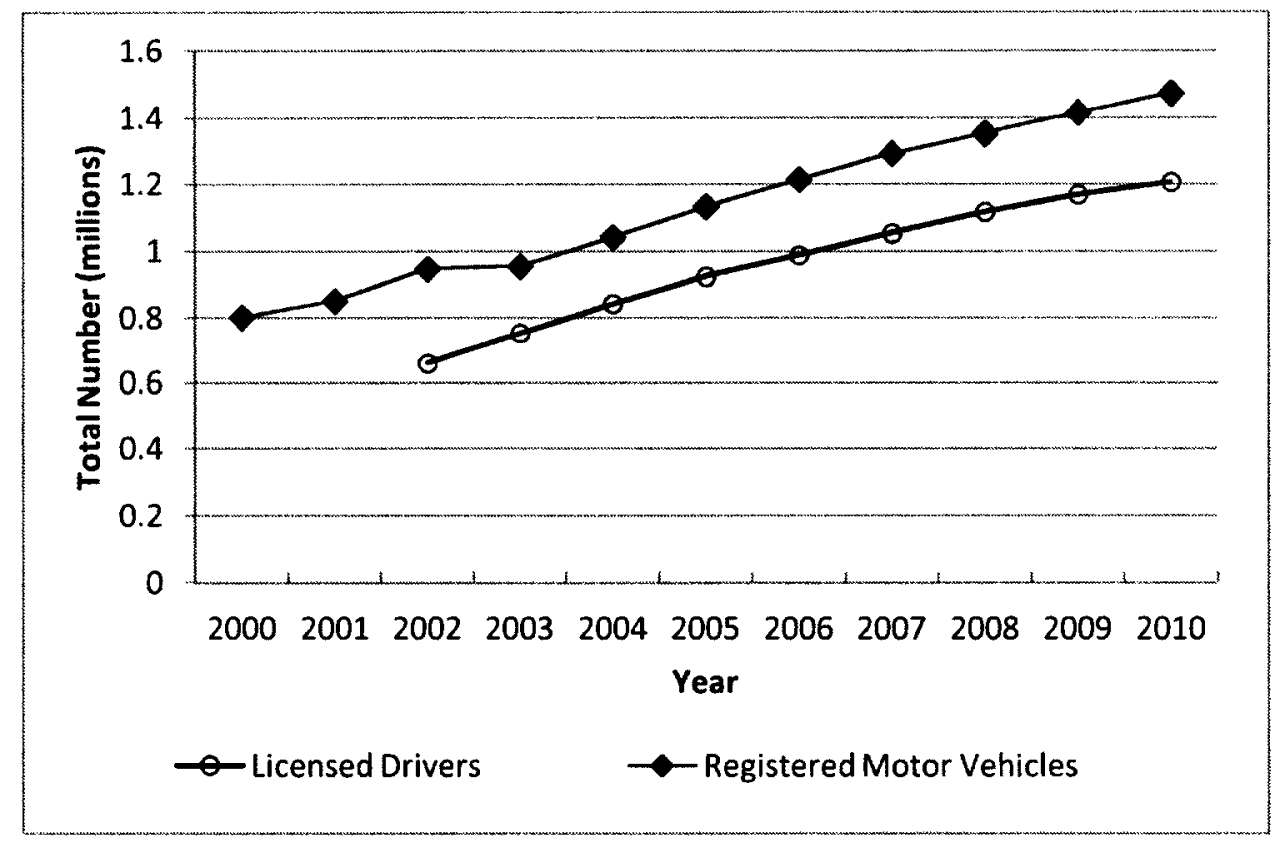

Figure 3.4 - Licensed Drivers and Registered Vehicles

Given Kuwait's rapid economic growth, low price of old vehicles, and easy access to loans to finance new vehicle purchases, the vehicle fleet is expected to continue to grow in the coming years. Figure 3.5, which was developed by the United Nations Development Programme report for the National Traffic \& Transport Sector Strategy for Kuwait (UNDP 2009), shows the percentage increase in traffic indicators between the years 2000 to 2008 in Kuwait. The abrupt increase of the number of licensed drivers can 
be an indicator as to why there were increases in traffic collisions, traffic fatalities and road offences.

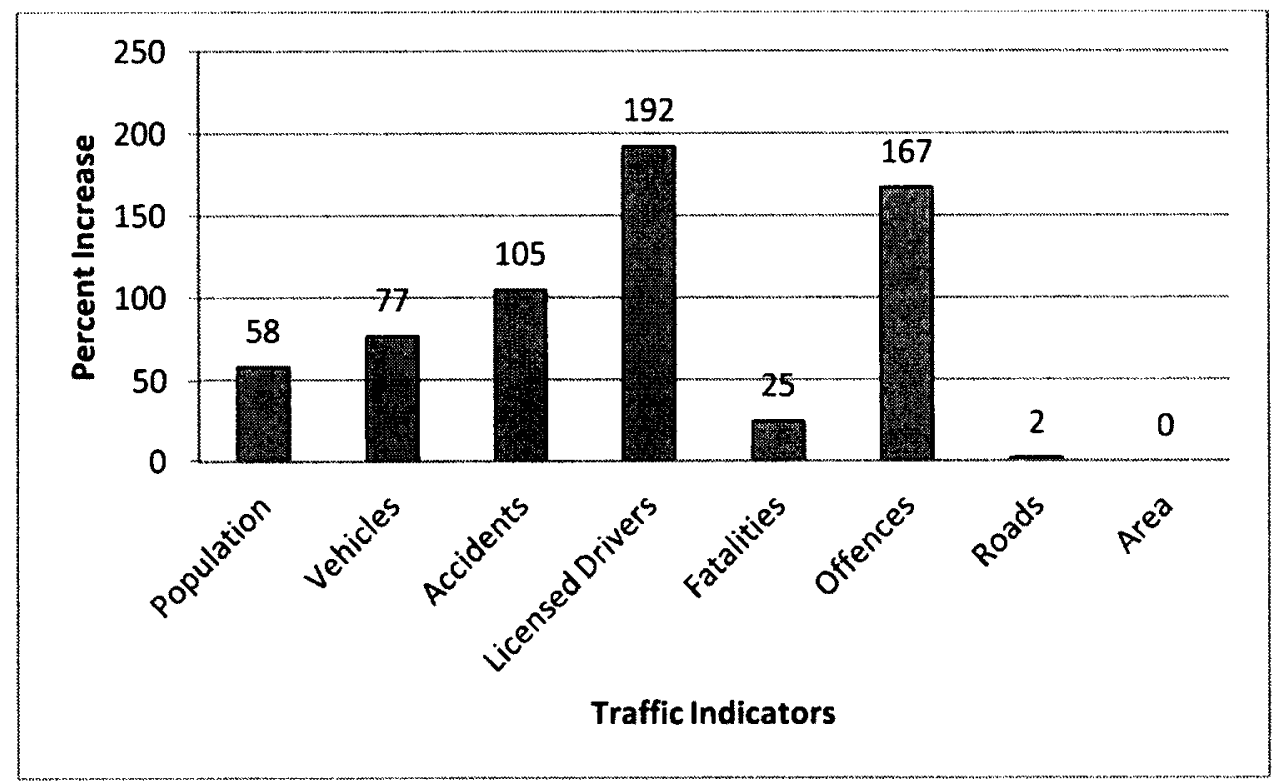

Figure 3.5 - Percentage Increase of Traffic Indicators during 2000-2008 in Kuwait Source: Adapted from (UNDP 2009)

\subsection{Automated Traffic Enforcement in Kuwait}

Recent traffic safety records point to an increase in both the number of violations and the occurrence of road collisions. The number of speeding violations is on an abrupt rise compared to the steady increase of the number of licensed drivers in Kuwait. Figure 3.6 was created using statistics collected from MOI to show the level of increase in both speeding violations and number of licensed drivers.

In 1994, the General Traffic Department of the MOI installed ASCs to monitor traffic speed at a number of roadway locations in Kuwait. A total of six cameras were installed. Three cameras were installed at traffic lights, to monitor red-light running and 


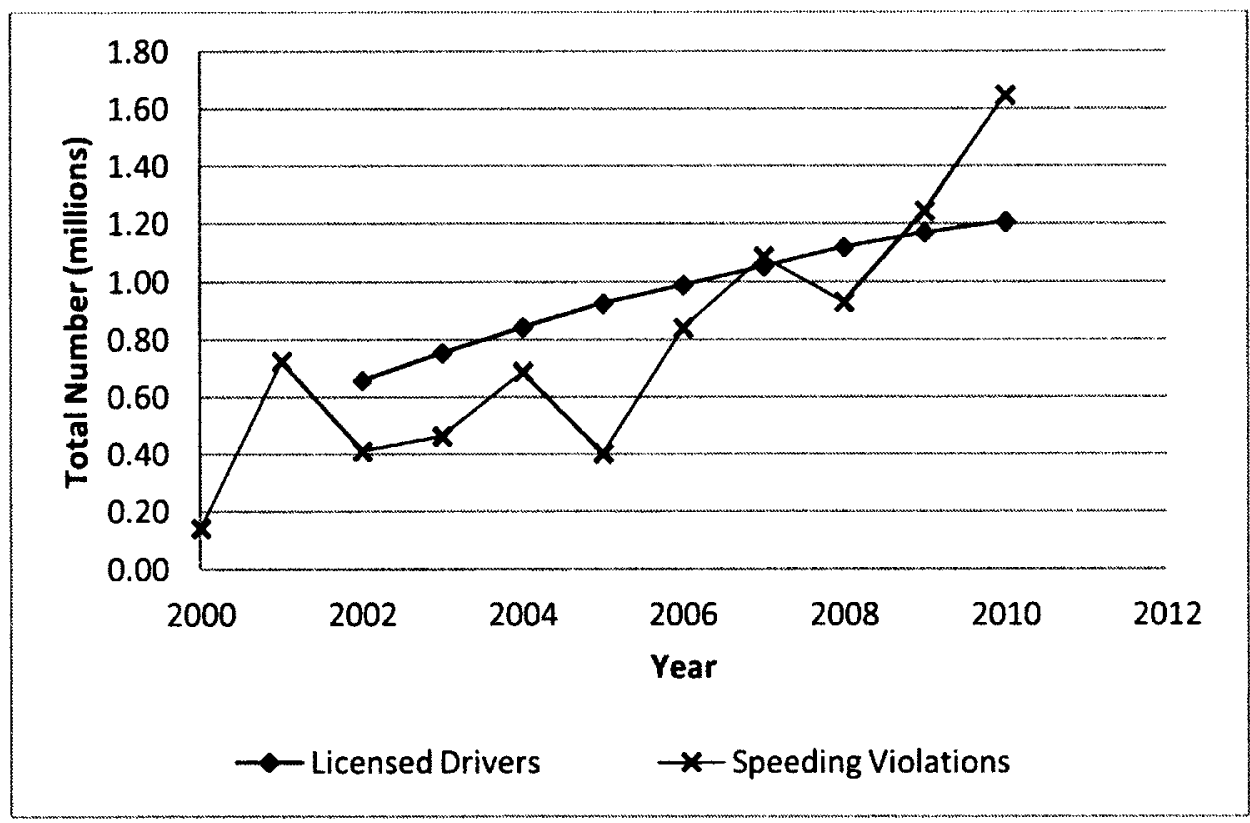

Figure 3.6 - Number of Licensed Drivers vs. Speeding Violations in Kuwait

speed, and the other three were speed cameras on road segments (Aljassar, Al-Anzi and Ali 2004).

Later, a new project started in 2000 by The First Joint Group, through a tender with the MOI, to supply them with traffic signals and speed cameras. The objective of introducing such enforcement tools in Kuwait was to control the lack of traffic discipline among violating drivers, reduce collisions causing injuries and minimize fatalities. The First Joint Group is considered the only company in Kuwait in the field of supplying installing, operating and maintaining speed cameras, traffic signals and mobile cameras. The First Joint Group is the exclusive agent of Robot-Germany, a company specialized in the manufacturing of these types of cameras (Alroudhan Group 2008).

In 2000 , the number of automated traffic enforcement cameras was increased from the original six that were installed in 1994, at the request of the MOI, which carried 
out a planned introduction of speed cameras in a phased manner. Figure 3.7 shows a timeline which was created using data collected from Traffic Enforcement Maintenance and Operations department at the MOI for the total number of automated traffic enforcement cameras that were installed each year.

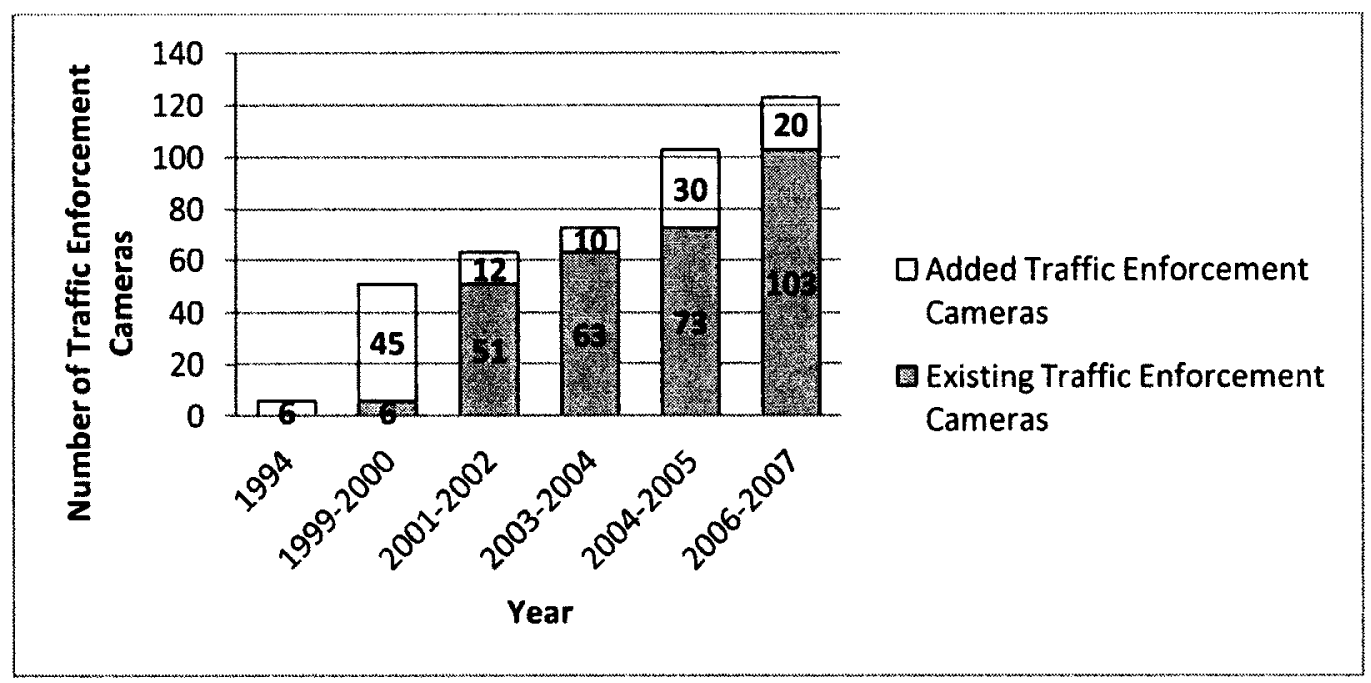

\section{Figure 3.7 - Number of Traffic Enforcement Cameras in Kuwait}

As of today, Kuwait has 123 automated traffic enforcement cameras installed on major roads and traffic signalized intersections, of which 51 are speed cameras. A map was created to show the locations of these 51 ASCs across the country which are shown in Figure 3.8. The Kuwaiti government has spent over $\$ 450$ million USD on these cameras (Wikipedia 2011).

In Kuwait, drivers are informed of the ASC stations by road signs posted 1.0 kilometre before each automated speed enforcement station. If speed enforcement does not include the use of warning signs, vehicle speeds near an automated speed enforcement station area decrease abruptly, and can create hazardous conditions. 


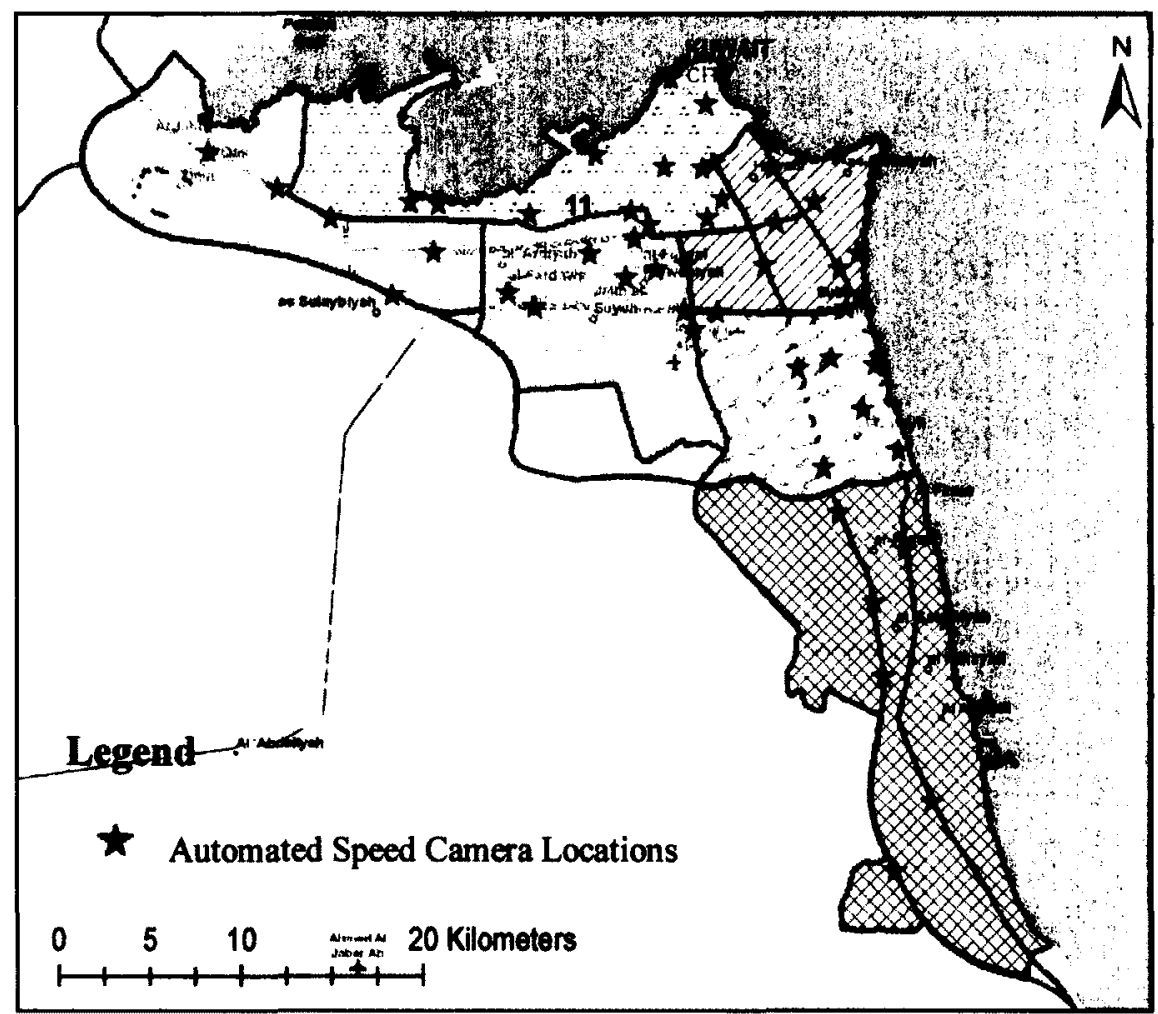

Figure 3.8 - Locations of Speed Cameras in Kuwait

Most of the current ASCs in Kuwait use "wet film", while the newer cameras being installed have digital photo technology. The change from analogue "wet film" to digital technology has revolutionized speed cameras, particularly their maintenance and the back-office processing required to issue penalty notices. Photo documentation is performed using the digital SmartCamera, which has a resolution of up to 11 megapixels (Alroudhan Group 2008). It is therefore possible to monitor one to three traffic lanes. Depending on the type of network used, images from digital cameras can be uploaded in seconds to a remote office over a network link, while optical character recognition software can automate the "reading" of vehicle plate information. However, violations always get checked by an official to validate the correctness of the automated recognition software before issuing the violation (Alroudhan Group 2008). 


\subsection{Legislations and Sanctions}

The responsibility for the investigation of road violations and collisions lies presently with the General Directorate of Investigation (GDI) of the MOI. The GDI has a primary responsibility for investigation and reporting of all activities which are legally defined as crime-related as well as traffic collisions. In addition, the GDI is responsible for reporting on traffic collision disputes which cannot be settled by the individual persons involved. On the other hand, the General Directorate for Traffic (GDT) at the MOI are in charge of the day-to-day functions of traffic management, road safety, traffic enforcement and other tasks involved related to the orderly flow of traffic in Kuwait.

Fines and penalties within the traffic law aim to repel people from breaking these laws and to punish the violators, to ultimately save their properties and their lives. The two techniques of issuing fines in Kuwait are:

1. Direct Fine: which is given in person by a police official in the presence of the violator, where the violator's signature or refusal to sign the fine is required, after recording all the fundamental data of the violation. This will then be taken to court for further investigation.

2. Indirect Fine: the violator is not present when the fine is recorded, usually refers to violations caught by automated traffic enforcement tools.

To back up the automated traffic enforcement program, MOI has implemented a new "Traffic Law 52 of 2001" effective November 2001. Article 33 of the new law includes penalties for red-light running and speed violations. The new rules along with their old counterparts are presented in Table 3.1. The conciliation is the sanction amount 
that needs to get paid if the payment was made within two months from the date of the offense. Otherwise, the set fine of 100 Kuwaiti Dinars (KWD) is to be paid for excessive speeding if more than two months pass the date of the offense.

Table 3.1 - Kuwait's Traffic Laws (Article 33 of Law 52 of 2001)

\begin{tabular}{|l|c|c|c|c|}
\hline \multirow{2}{*}{ Offense } & \multicolumn{3}{|c|}{ New Law } & Old Law \\
\cline { 2 - 5 } & $\begin{array}{l}\text { Conciliation } \\
\left(\mathrm{KWD}^{*}\right)\end{array}$ & Imprisonment & $\begin{array}{l}\text { Fine } \\
(\mathrm{KWD})\end{array}$ & $\begin{array}{c}\text { (Fine } \\
\text { KWD) }\end{array}$ \\
\hline Exceed speeding by $<20 \mathrm{kph}$ & 20 & 3 Months & 100 & 15 \\
\hline Exceed speeding by $21-30 \mathrm{kph}$ & 30 & 3 Months & 100 & 15 \\
\hline Exceed speeding by $31-40 \mathrm{kph}$ & 40 & 3 Months & 100 & 15 \\
\hline Exceed speeding by $41-50 \mathrm{kph}$ & 50 & 3 Months & 100 & 15 \\
\hline
\end{tabular}

*KWD: Kuwaiti Dinars (1.000KWD $=3.606 \mathrm{CAD}$ as of January 30,2012)

Source: Traffic planning and research department at the MOI

This chapter presented information about the demographics, the road characteristics, the road users, the automated traffic enforcement, and the legislations and sanctions in Kuwait. This information can help in understanding the traffic situation in Kuwait. 


\section{Methodology and Data Preparation}

This chapter provides a detailed description of the database developed in this thesis for the qualitative spatial analysis and the statistical model development. Section 4.1 presents the data collection technique and processing, in addition to the sources from which data were obtained. Section 4.2 provides the traffic volume data collection. Subsequently, Sections 4.3 discusses the statistical analysis techniques and the one that will be used as part of the analysis in this thesis.

\subsection{Data Collection and Processing}

Due to lack of data and follow-up after fatal collisions, regarding the wellness of the people involved in collisions, only reports of collisions where fatality took place at the time of the collision were collected and considered for this thesis. Fatal traffic collision data in Kuwait are currently not available in a database; therefore, this thesis relied on the original data collected from the police reports. The head of the Traffic Collisions' Investigation department at the MOI indicated that some of the fatal traffic collision reports were missing, and that the missing reports are considered random. Therefore, the locations of these fatal traffic collisions are assumed to be randomly distributed over the study area, and they should not sway the analysis or disturb the results.

In Kuwait, like most other countries, traffic police are the key source of information related to road safety, traffic enforcement and some traffic operation data. The first step in the production of the country database was the compilation of the fatal traffic collision reports from the MOI. In order to smoothen out random fluctuations, as 
well as providing sufficient evidence of any temporal trend in collision, three years worth of data were collected, which is within the time generally recommended in collision analysis studies (Hauer, Harwood, et al. 2000). A comprehensive database was created in Microsoft Excel encompassing all the records from the collected police reports. This database can be found in Appendix A.

Since the exact coordinates of the fatal traffic collision locations were not available in the reports, Google Earth was used in this thesis as the location identification system. Google Earth provides the visual capability through satellite images of roads, buildings, and roadway features which aided in locating the coordinates of the collisions. With the free mapping software already available from Google Earth, a virtual pin was dropped on each collision location, and the coordinates were obtained. The coordinates obtained from Google Earth were then exported to ArcGIS software in order to plot them on the map of Kuwait to be able to conduct the spatial analysis and the statistical analysis.

The GIS spatial data, including the map and roads of Kuwait, was obtained from Kuwait Municipality (KM), and the attribute data were processed from the fatal traffic collision reports. Various spatial analyses were performed on the fatal traffic collision data with respect to collision date, collision type, which governorate's jurisdiction the fatal traffic collisions falls under, and the specific collision location.

\subsection{Traffic Volumes}

Continuous traffic counts using automated counters provide a good estimate of total vehicular traffic at a point in the roadway network. In Kuwait, automated traffic 
counts are collected from embedded induction loops in the asphalt pavement. ADR 3000 automatic data recorders are used by the Ministry of Interior at 17 automated count locations (Aljassar, Al-Anzi and Ali 2004). The locations of the automated traffic counters are shown in Figure 4.1. These counters provide optimum functionality as permanent instrument. In its basic configuration as a counter/classifier, it can monitor up to four lanes of traffic with a combination of loops and piezos (Aljassar, Ali and Al-Saleh 2005).

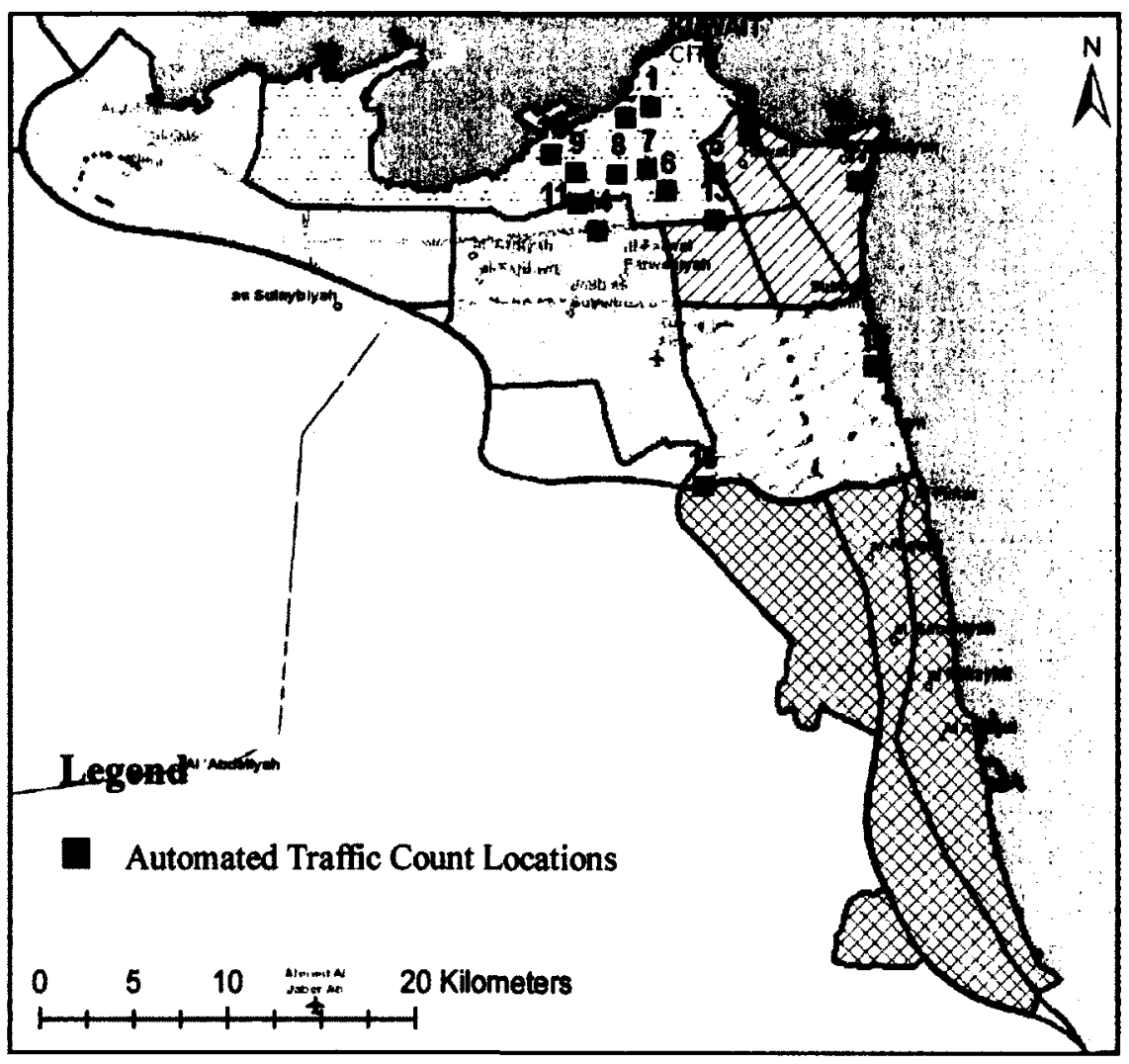

Figure 4.1 - Automated Traffic Count Locations

Short term traffic count data from 16 of the sites were obtained from the MOI for a 14 day period (Dec. 1st - 14th 2010). The traffic count data can be found in Appendix B. The AADT can be estimated from a few hours of count on a location. The traffic count 
data are used to estimate the AADT using the daily expansion factors (DEF) and the monthly expansion factors (MEF). First, the 24-hour volume for the particular day, on which the volume is counted, is multiplied by the DEF and averaged for a week to get an adjusted ADT for the week of that particular month. This ADT is then multiplied by the MEF for the month to get the AADT. Hence a count of few hours on any day can result in obtaining sufficient estimates of AADT, provided that reliable expansion factors are used.

Road-specific expansion factors for Kuwait were developed by the Kuwait University Research Administration (Aljassar, Ali and AlSaleh 2006) and are used by researchers and officials to estimate AADT from short-term counts. The DEF and the MEF are listed in Table 4.1 and Table 4.2 respectively. Since the data obtained were from the month of December, only the December expansion factors will be used from the table to estimate the AADT for modeling purposes.

Table 4.1 - Daily Expansion Factors for Kuwait

\begin{tabular}{|c|c|c|c|c|c|}
\cline { 2 - 6 } \multicolumn{1}{c|}{} & \multicolumn{5}{c|}{ Road Type } \\
\hline Day & $\begin{array}{c}\text { SRN } \\
\text { (Ring) }\end{array}$ & $\begin{array}{c}\text { SRN } \\
\text { (Radial) }\end{array}$ & PRN & SR & LR \\
\hline Saturday & 6.7396 & 6.5183 & 6.5 & 6.6988 & 6.5211 \\
\hline Sunday & 6.7253 & 6.3816 & 6.2522 & 6.5546 & 6.2569 \\
\hline Monday & 6.5792 & 6.4097 & 6.2961 & 6.5755 & 6.4002 \\
\hline Tuesday & 6.5386 & 6.3714 & 6.2438 & 6.609 & 6.3487 \\
\hline Wednesday & 6.518 & 6.4358 & 6.2545 & 6.5082 & 6.2954 \\
\hline Thursday & 7.3824 & 7.9355 & 8.1879 & 7.3745 & 8.3736 \\
\hline Friday & 9.2804 & 10.7443 & 11.3513 & 9.5813 & 10.5485 \\
\hline
\end{tabular}

Source: Adapted from Table 3 (Aljassar, Ali and AlSaleh 2006) 
Table 4.2 - Monthly Expansion Factors for Kuwait

\begin{tabular}{|c|c|c|c|c|c|}
\cline { 2 - 6 } \multicolumn{1}{c|}{} & \multicolumn{5}{c|}{ Road Type } \\
\hline & $\begin{array}{c}\text { SRN } \\
\text { Month }\end{array}$ & $\begin{array}{l}\text { SRN } \\
\text { (Radial) }\end{array}$ & PRN & SR & LR \\
\hline January & 1.0266 & 0.9407 & 1.0034 & 1.0283 & 1.1402 \\
\hline February & 1.0834 & 1.1783 & 1.0396 & 1.0709 & 1.1053 \\
\hline March & 0.9724 & 0.9471 & 0.8987 & 0.9273 & 0.8675 \\
\hline April & 0.9386 & 0.9525 & 0.9147 & 0.9549 & 0.8923 \\
\hline May & 0.9557 & 0.9349 & 0.9367 & 0.9602 & 0.9479 \\
\hline June & 0.9893 & 0.9758 & 0.961 & 0.9961 & 1.0519 \\
\hline July & 1.0528 & 1.0739 & 1.1168 & 1.0694 & 1.3028 \\
\hline August & 1.0915 & 1.1754 & 1.1968 & 1.159 & 1.449 \\
\hline September & 1.0654 & 1.0925 & 1.095 & 1.0238 & 1.0044 \\
\hline October & 0.9828 & 0.9338 & 0.9914 & 0.9541 & 0.8229 \\
\hline November & 0.9805 & 0.9732 & 1.0336 & 0.9725 & 0.9154 \\
\hline December & $\mathbf{0 . 9 7 0 6}$ & $\mathbf{0 . 9 5 1 7}$ & $\mathbf{0 . 9 4 8 1}$ & $\mathbf{0 . 9 7 9 4}$ & $\mathbf{0 . 8 4 8 7}$ \\
\hline
\end{tabular}

Source: Adapted from Table 4 (Aljassar, Ali and AlSaleh 2006)

\subsection{Statistical Analysis Techniques}

Examining the effect of speed cameras on safety performance is usually better carried out using a well designed before-and-after study. However, collision data for the period before automated speed cameras were installed is not available in Kuwait. Therefore, a before-and-after study could not be performed in this thesis. Therefore, regression techniques were used to develop collision prediction models for roadway sections to assess the effect of ASCs on the frequency of fatal traffic collision.

The use of collision prediction models allows for an improvement in the accuracy of safety measurement, and can facilitate the establishment of acceptable safety performance benchmarks and thresholds (Sayed and de Leur 2008). The collision prediction models will relate the three-year collision frequency to traffic exposure parameters. Such models will be developed using the fatal traffic collision database 
created in this thesis and traffic exposure parameters (e.g., traffic volumes, length of roadway, and traffic control features). Selection of the appropriate functional form for the model and using regression analysis to estimate the values of the coefficients is further discussed in Chapter 6.

Traditionally, collision statistical models were developed using multiple linear regression techniques. However, since collision frequencies are non-negative, nonnormally distributed and have error terms with unequal variance, these conditions violate the statistical assumptions of the multiple linear regression. Linear regression models follow a continuous probability distribution (the normal distribution), and thus are not considered appropriate for the modeling of discrete, rare and positive data such as collisions. The symmetrical shape of the normal distribution conflicts with the distribution of collision frequency, which tends to be positively skewed. Violation of the assumptions can invalidate the hypothesis tests concerning the significance of the parameters (Jovanis and Chang 1986). In addition, the multiple linear regression model might predict a negative number of collisions that cannot occur in reality.

Due to the problems associated with the multiple linear regression models, researchers use Poisson and negative binomial regression analyses which are theoretically better suited to accident data based on small counts (i.e., zero or nearly zero accidents at many sites) (Hauer, Harwood, et al. 2000). The positively skewed Poisson distribution has been shown to be acceptable in modeling collisions since it is particularly suited for modeling rare, discrete, and non-negative events. However, Poisson regression requires the variance of the data to be equal to the mean. When the mean and the variance of the 
data are not approximately equal, the model coefficients are biased (Peng 2004). Collision data over a series of sites often exhibit a large variance and a small mean. Therefore, the assumptions needed for the Poisson distribution are not met.

Collision data is usually over-dispersed, with a variance-to-mean value greater than 1. For this reason, the negative binomial distribution, also known as the PoissonGamma distribution, has become the most commonly used probabilistic distribution of collisions at a series of sites (Yunlong 2006). At this point, it should also be noted that to apply either the Poisson or negative binomial distributions, the only assumptions needed are that the events must occur randomly and independently of one another.

The negative binomial distribution is considered an extension of the Poisson distribution, since it is similar to it in every aspect except for the assumption that the mean is equal to the variance. The negative binomial distribution adds an extra term to the variance that accommodates over-dispersion, and is therefore more appropriate for modeling collision data with extra variation.

Determining whether the Poisson or negative binomial technique is more appropriate can be achieved by examining several statistics. The goodness of fit of the model is assessed using two statistical measures. The first measure is to test whether the Pearson Chi-squared $\left(\chi^{2}\right)$ statistic is significant at a given confidence level. This statistic is a random variable that approximately follows the $\chi^{2}$ distribution with degrees of freedom equal to the number of observations $(n)$ minus the number of parameters $(p)$ for a valid Poisson model. If the value of the $\chi^{2}$ statistic is in excess of $n-p$, this suggests over-dispersion, in other words, when the $\chi^{2}$ statistic divided by the degrees of freedom is 
considerably larger than one, over-dispersion is indicated. This value is referred to here as the dispersion parameter $(k)$. It should be noted that cases where the dispersion parameter is less than one, referred to as under-dispersion, have also been reported in collision models, but are far less likely to occur. When the dispersion is close to one, Poisson and negative binomial models will provide approximately identical results. Generally, values of $k$ between 0.8 and 1.2 are acceptable. The $\chi^{2}$ statistic and its associated dispersion parameter $(k)$ are expressed in Equations (4.1) and (4.2). The equations are adapted from a Federal Highway Administration report (FHWA 1998).

$$
\chi^{2}=\sum_{i=1}^{n} \frac{\left[y_{i}-E\left(Y_{i}\right)\right]^{2}}{\operatorname{Var}\left(Y_{i}\right)}
$$

where:

$$
\begin{aligned}
& y_{i}=\text { observed collision frequency at } i \\
& E\left(Y_{i}\right)=\text { predicted collision frequency at } i \text { as obtained from the model; } \\
& \operatorname{Var}\left(Y_{i}\right)=\text { variance of the collision frequency for } i . \\
& \qquad k=\frac{\chi^{2}}{n-p}
\end{aligned}
$$

The second measure for testing goodness of fit is the scaled deviance $\left(D^{m}\right)$, which represents model discrepancy as twice the difference between the maximum loglikelihood achievable and the log-likelihood achieved by the model developed, refer to Equation (4.3), below adapted from (FHWA 1998).

$$
D^{m}=2\left(L_{f}-L_{m}\right)
$$

where:

$L_{f}=$ the $\log$-likelihood achieved if the model gave a perfect fit; and $L_{m}=$ the $\log$-likelihood of the model under study. 
Over-dispersion is indicated when the value of $k$ in the equation below is greatly in excess of one:

$$
k=\frac{D^{m}}{n-p}
$$

The Statistical Analysis System (SAS) version 9.2 was used in this thesis to estimate the model's parameters. The generalized linear model (GENMOD) procedure is used to estimate the model coefficients and the dispersion parameter, $p$-values, scaled deviance and Pearson $\chi^{2}$ statistics. This procedure uses the maximum likelihood method based on the negative binomial error structure and 'log' link function. Both the $\chi^{2}$ and scaled deviance measures are provided as SAS goodness of fit output. The $p$-value is the probability that the estimated coefficient would have the value shown or any value farther from zero when the true coefficient is zero. A $p$-value of less than $5 \%$ is usually considered ample confirmation that the true coefficient is non-zero and that the estimated coefficient is statistically significant.

As in all stochastic modeling exercises, numerous candidate models were estimated. Criteria used to maintain variables in the models satisfied two conditions: the $p$-value of the variable's estimated coefficient was smaller than or equal to 0.05 , corresponding to a $5 \%$ level of significance; and the sign and magnitude of the modeled effect agree with theoretical expectations of the collision process.

After the selection of an appropriate regression technique, which was discussed earlier in this section, a suitable model form is now selected. For this thesis, the negative binomial regression model was assumed to take the general form presented in Equation 4.5 adapted from (Donnell, Venkataraman and Porter 2009): 


$$
\lambda=\exp \left(\omega+X_{i} \beta_{i}+L_{i} \theta_{i}\right)
$$

where:

$\lambda=$ expected number of collisions in a time period on a roadway segment;

$\omega=$ intercept;

$X_{i}=$ variables influencing $\lambda$ (e.g., roadway and roadside geometry, etc.)

$\beta_{i}=$ coefficients quantifying the relationship between $X$ and $\lambda$;

$L_{i}=$ a dummy (dummy) variable;

$\theta_{i}=$ coefficient quantifying the relationship between $L$ and $\lambda$.

The dependent variable considered in the model is the frequency of fatal traffic collisions. The independent variables are traffic exposure parameters, including the traffic volumes and length of roadway segments. The regression coefficients (i.e. $\beta_{i}$ and $\theta_{i}$ ) were estimated using the method of maximum likelihood. The variables in $X$ as well as $L$ were assumed to be independent (i.e., its values vary independently of other variables during a specified time period). However, the likelihood that speed cameras would be installed on a roadway segment (i.e., $L=1$ ) may depend on variables including traffic volumes, geometrics, presence of a traffic signal and collision experience (Donnell, Venkataraman and Porter 2009).

In summary, as part of the data collection and preparation for this thesis, a fatal collision database was created. Locations of the fatal traffic collisions were identified and quantified for spatial analysis. Also, the AADT was estimated for the roadways in order to develop collision prediction models using the negative binomial regression technique. 


\section{Descriptive Analysis of Violation and Collision Statistics}

This chapter presents results of the analysis of the traffic violations, traffic collisions, traffic fatalities and descriptive statistics of traffic collision reports that result in the loss of human life. This kind of statistics and analyses can help in understanding the situation and also help in identifying the factors contributing to the safety issues. Collaborated data from different MOI departments are used to assess the trends and fluctuations overtime. The presented results can be beneficial to aid in future research geared towards formulating mitigations and countermeasures to decrease violations and collisions. Section 5.1 presents the analysis of violation statistics. Analysis of the fatal collision statistics are discussed in Section 5.2. In Section 5.3 an overview of the traffic collision police reports will be presented. Section 5.4 will present analysis of the different trends from the traffic collision police reports.

\subsection{Analysis of Violation Statistics}

Using the data collected from the MOI, Figure 5.1 was created presenting the number of traffic violations and the number of licensed drivers from 2000 to 2010 . It is apparent that the increase in violations is much higher, and not in proportion, to the number of drivers. The numbers of violations were more than three times higher in 2010 compared to those reported in 2000 . One of the reasons of the increase is due to the introduction of automated traffic enforcement technology throughout these years, which has helped capture a bigger number of violators. The decrease in violations in 2006 was due to changes in the traffic laws and fines in 2005 , where fines became more stringent. In 2008 the violations took a dip with the slowdown in economic activity as a 
consequence of the financial crisis. The soaring oil prices might have had an effect on the number of recreational drivers on the roads.

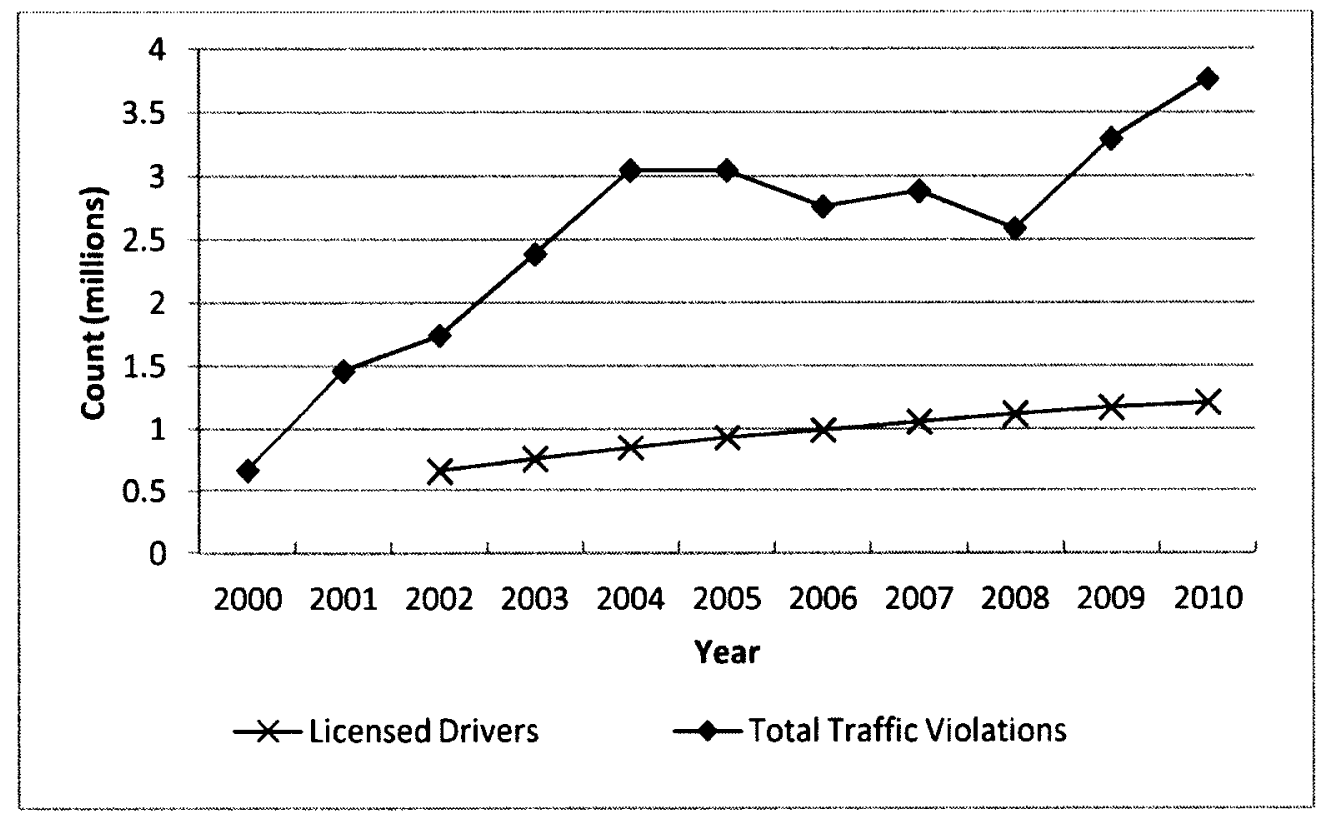

Figure 5.1 - Annual Traffic Violations vs. Licensed Drivers

The violations statistics provided by MOI identifying the top five traffic violations were graphed using the data collected for 2000 to 2010 , as shown in Figure 5.2. The data shown in the figure suggests that the top five violations are all behavioural, which indicates the lack of traffic and road obedience by many drivers, despite awareness campaigns by the MOI. Out of the top five violations, speeding and red-light running have a direct effect on traffic collisions.

Since speeding violations were always the first or second highest number of violations for the 10 year period investigated, it has been decided to pay more attention to this variable in the analysis. The statistics for direct versus indirect speed violations were plotted in Figure 5.3, indicating that the number of direct violations has been increasing 


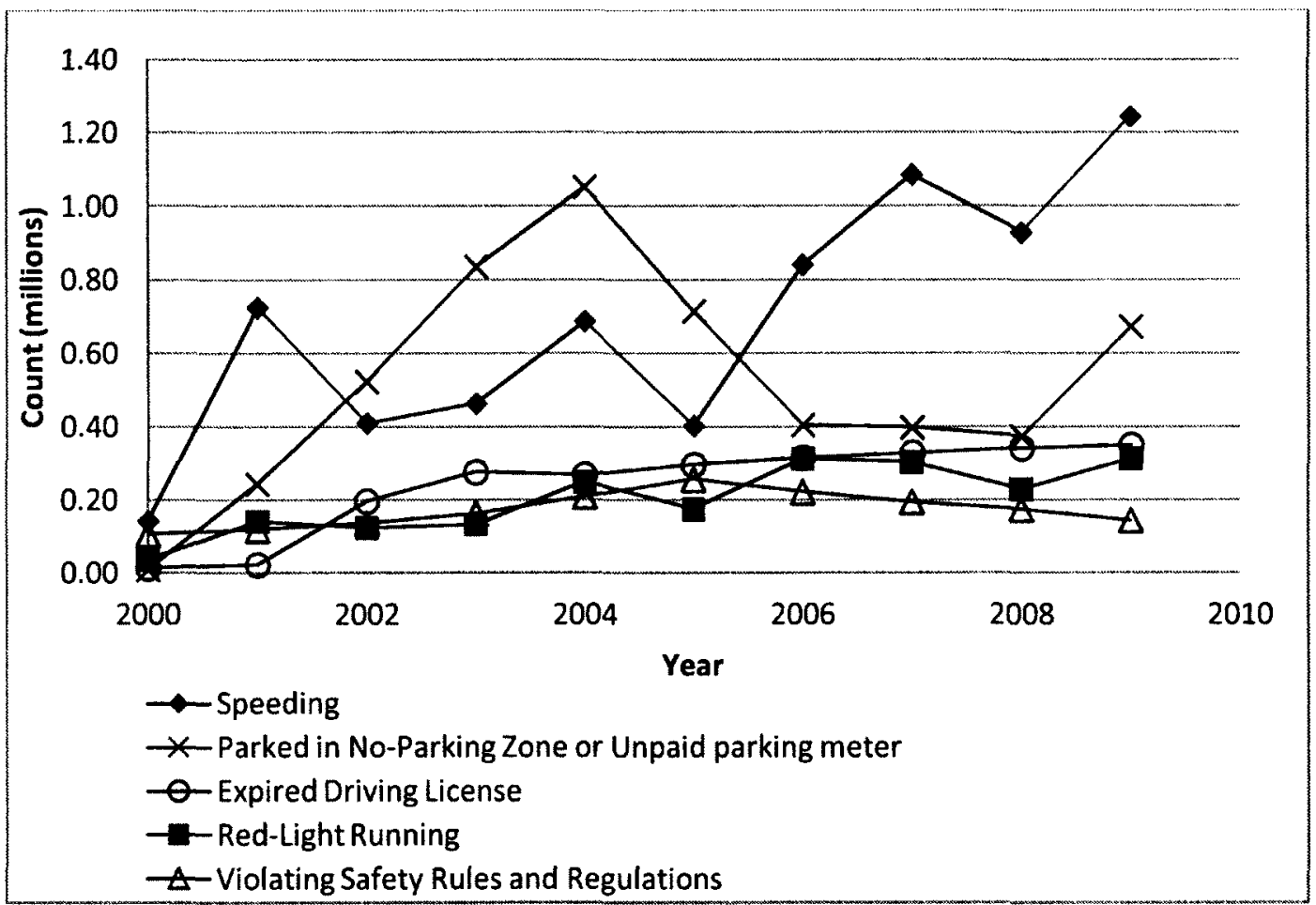

Figure 5.2 - Top Five Violation Categories

at a steady rate whereas the number of indirect violations has shown a significant increase especially between 2008 and 2010. This high rise in indirect violations is due to the increasing number of automated traffic enforcement cameras each year. Reckless driving is a major problem in Kuwait, which is reflected in the graph because the addition of automated speed enforcement should lead to a reduction in the number of violations due to people slowing down; however the statistics from Kuwait show otherwise. 


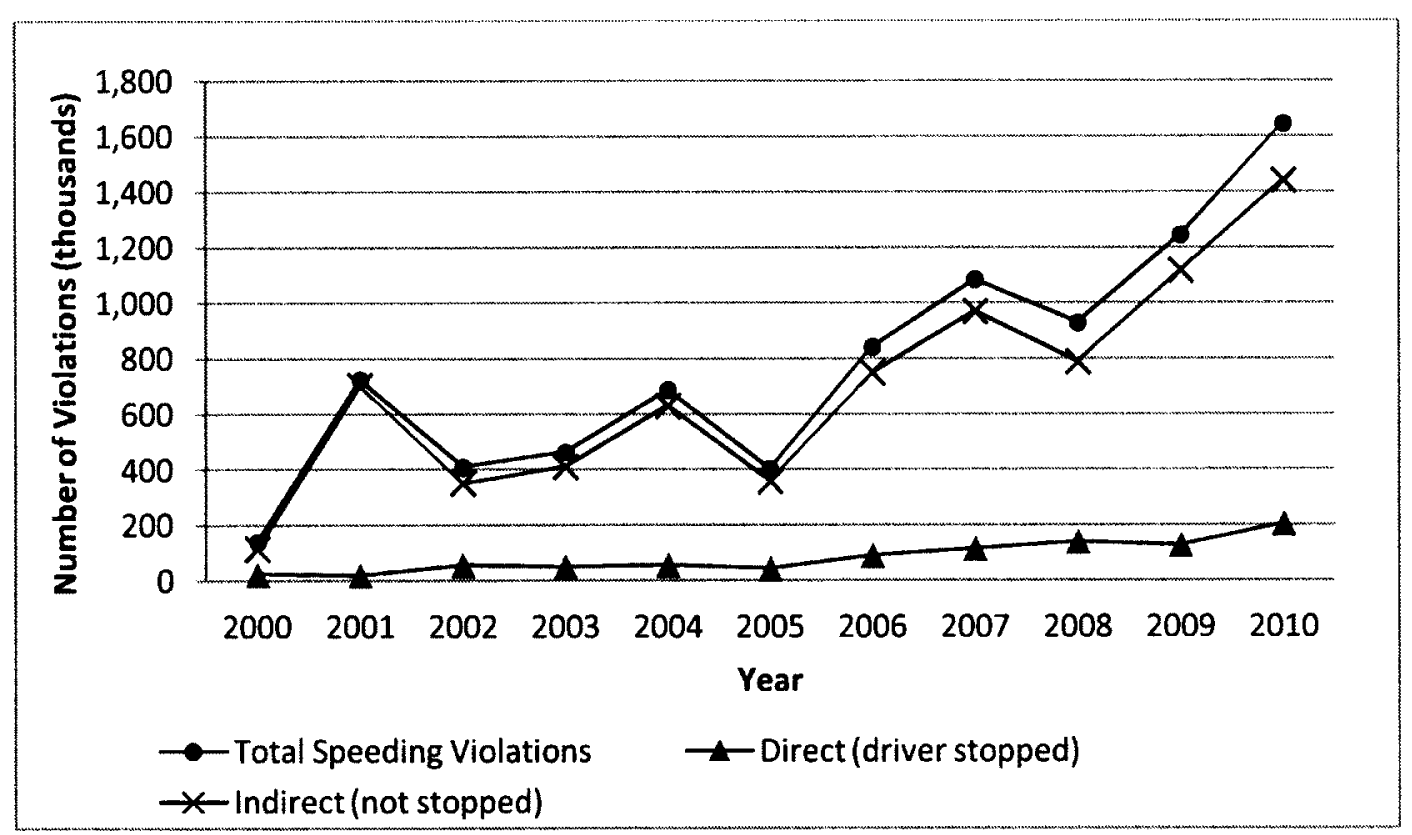

\section{Figure 5.3 - Speeding Violations}

This section discussed the general trend in the overall traffic violation statistics between 2000 and 2010 and statistics regarding the speeding violations. Speeding can lead to serious consequences beyond violations, which can be a collision or even a fatality. The next section discusses the trend in traffic collisions, focusing on the fatal collisions.

\subsection{Analysis of Fatal Traffic Collision Statistics}

The total numbers of traffic collisions are presented in Figure 5.4 for the years 2000 to 2010 . The general trend in traffic collisions was on the rise from 2000 to 2005 . Then from 2006 to 2010 the numbers have been slightly fluctuating up and down. The general trend in fluctuation follows that of the number of violations which was discussed earlier in Section 5.1. 


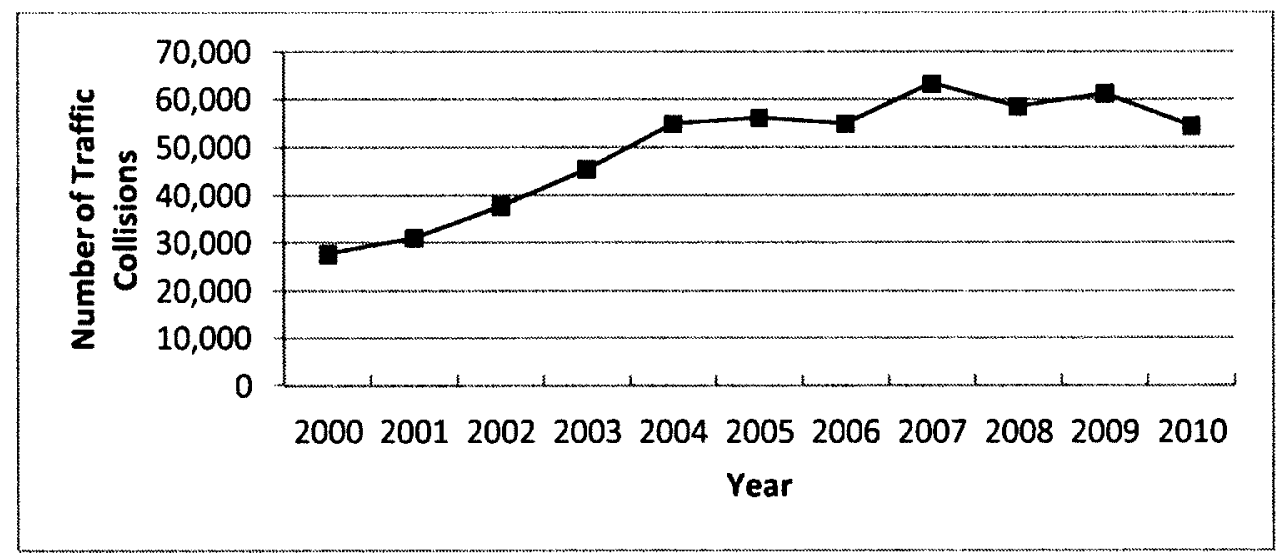

\section{Figure 5.4 - Total Annual Traffic Collisions}

Even though Kuwait is experiencing an increasing growth in traffic each year and an escalating number of vehicles on the road each year, many efforts are being made by the MOI in improving traffic safety each year. It is argued that the number of annual traffic collisions could have been less if a comprehensive collision recording and analysis system was present.

The number of collisions with minor injuries, major injuries, and fatalities are plotted in Figure 5.5. According to the MOI of Kuwait, a fatal traffic collision is a person who dies within 30 days of a traffic collision, the death being the result of the collision. Data for property damage collisions was not available, due to lack of records for this category. 


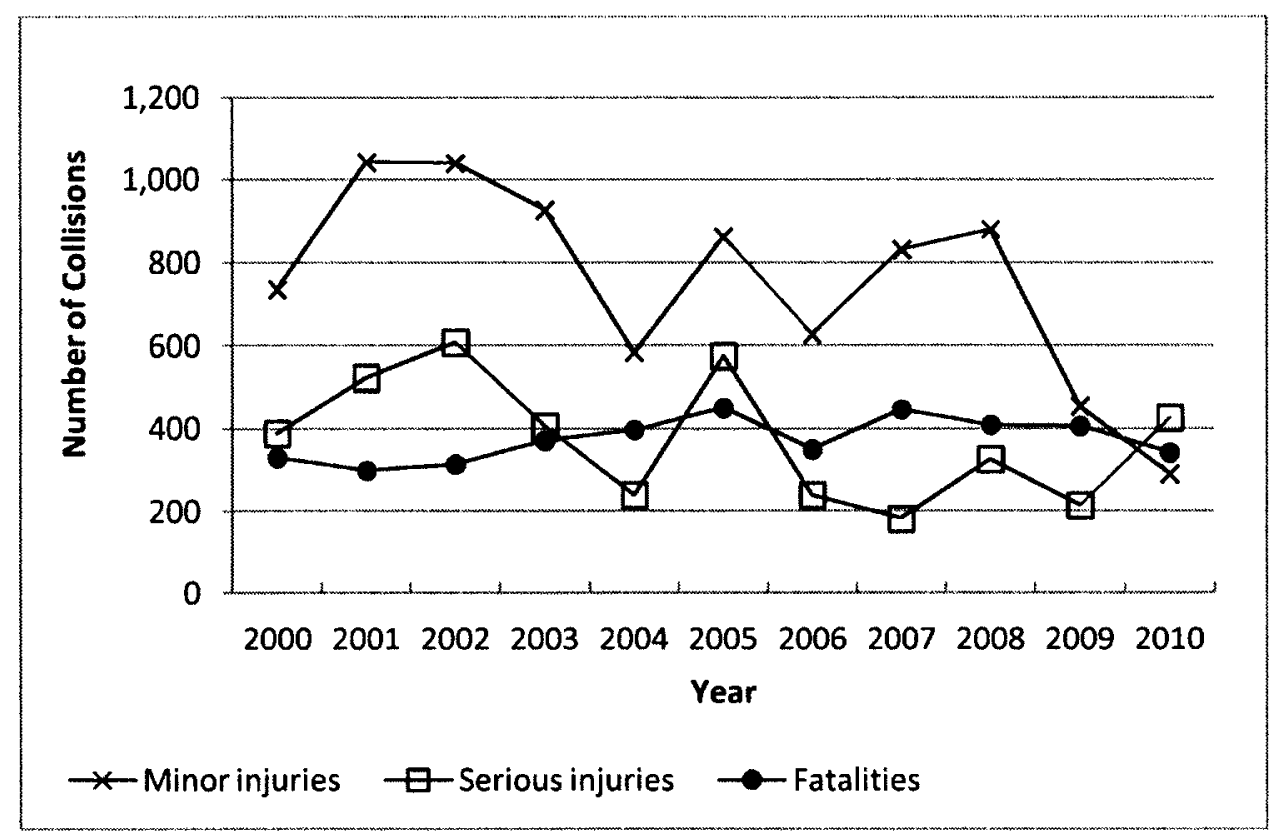

Figure 5.5 - Traffic Collisions with Injuries by Severity

For a better assessment of the annual fatalities data, Figure 5.6 was created presenting the annual traffic fatalities as rates per 100,000 inhabitants, per 100,000 licensed drivers and per 100,000 registered vehicles. The graph shows all rates have decreased over the past five years. It is not certain as to why there seems to be a noticeable decline in the number of fatalities between 2005 and 2010. Future discussions with the MOI need to be conducted in order to identify and determine the specific reasons, if known, for the decline in number of annual traffic fatalities.

This section discussed the general trend in traffic collisions between 2000 and 2010 and statistics regarding the fatal collisions. The next section discusses the fatal collision reports documented by the police. 


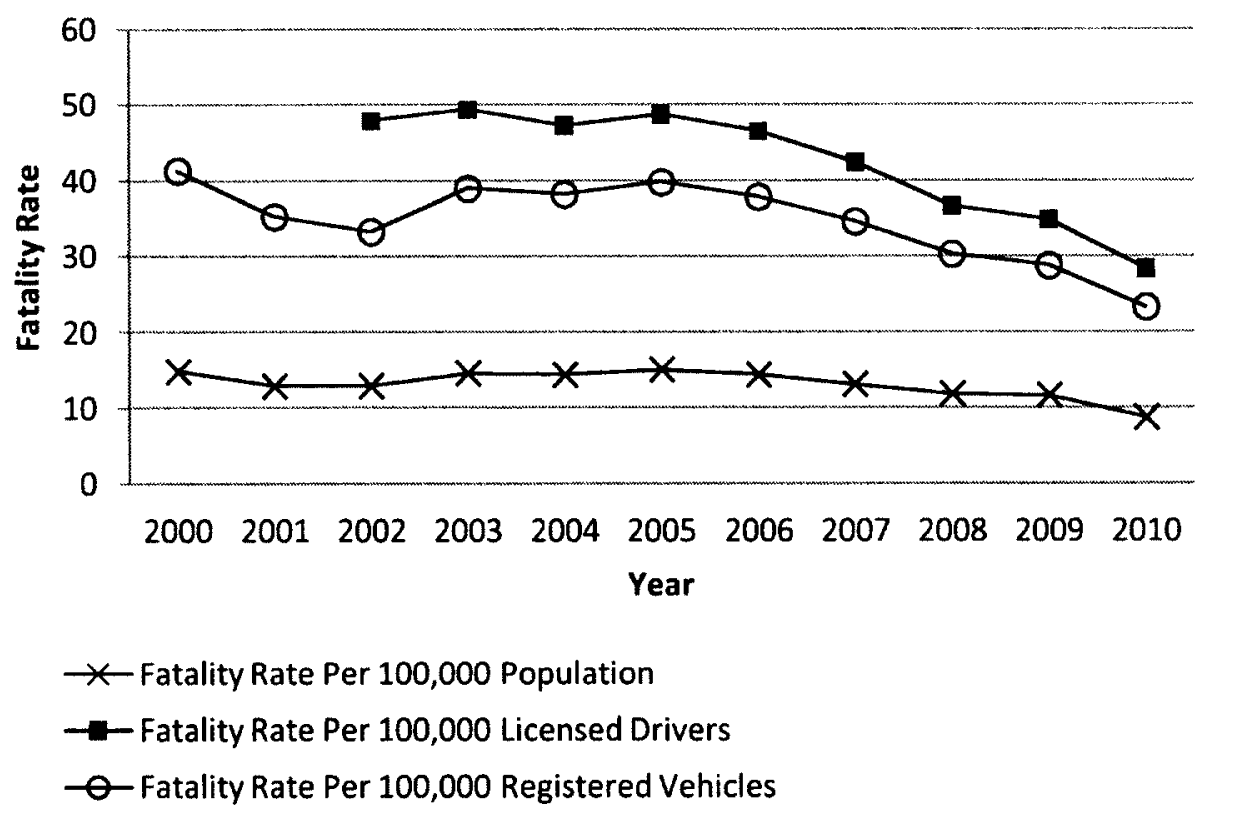

Figure 5.6 - Fatal Traffic Collision Rates

\subsection{Analysis of Fatal Traffic Collision Reports}

Forms used by the police patrol in the Kuwait to record data pertaining to road fatal collisions offer an insight into the nature of the fatal traffic collisions. The description completed for each collision captures the essential features of the collision, including a brief commentary of what happened along with a sketch, details of the vehicles involved, which vehicles collided, and the vehicle occupant(s) or pedestrian(s) that suffered the fatal injuries. Table 5.1 lists the information that the police record on the scene as part of the fatal collision report.

The current fatal collision investigation reports in Kuwait are paper reports filled out by police on the scene; these are manually coded by a case number based on the responding police station. One of the key deficiencies of the investigation form used is the lack of a uniform method for identifying the location on a particular roadway at which 
Table 5.1 - Data Recorded on Fatal Collision Reports

\begin{tabular}{|c|c|}
\hline $\begin{array}{c}\text { Type of } \\
\text { Information }\end{array}$ & Description \\
\hline \multirow{6}{*}{ General } & o Case number \\
\hline & o Police station responding to incident \\
\hline & D Date and time \\
\hline & o Main road \\
\hline & O Direction of travel \\
\hline & - Brief description and sketch of collision scene \\
\hline \multirow{2}{*}{ Vehicle } & o Make and model \\
\hline & O License plate number \\
\hline \multirow{5}{*}{ Deceased } & o Name \\
\hline & o Gender \\
\hline & $\circ$ Age \\
\hline & o Ethnicity \\
\hline & $\begin{array}{l}\text { Seat in vehicle (driver vs. passenger) } \\
\text { pedestrian }\end{array}$ \\
\hline
\end{tabular}

the accident occurred. There is no practical and uniform traffic data collection and forecasting system in Kuwait, and there is no system for data exchange and interface between the traffic police, road and transport agencies, hospitals, and fire and ambulance services. Also, there is no electronic database that combines all the data from fatal collisions in order to perform safety analysis and studies. Therefore, the official statistical figures are not appropriate for in-depth analysis, comparison and efficient strategy development.

In addition, reports filled out manually take weeks, sometimes months, to be reviewed by traffic investigators depending on the backlog of paper reports and the complexity of the collisions. Safety professionals are relying on verbal data from police patrol and investigators regarding the overview of the collisions, which limits any queries 
that can be run on the data annually for those who need it to assess safety countermeasures.

When the location of a collision using paper reports is determined by police, who rightly prioritize human safety and traffic management above paperwork at the scene, errors and inaccurate reporting are inevitable. The current way of recording the location of fatal traffic collisions in Kuwait is the police approximating the location based on road names and landmarks. The location of collisions should be recorded as $\mathrm{X}-\mathrm{Y}$ coordinates using a GPS device to provide accuracy of the location.

This section discussed the data documented by the police when a fatal traffic collision occurs. The next section presents the analysis of results and trends resulting from the collected police fatal traffic reports from 2008 to 2010 .

\subsection{Analysis and Trends of Fatal Collision Reports}

The tables in this section present the analytical results of the fatal traffic collision reports. Trends for fatal collisions are presented from 2008 to 2010 in Table 5.2 to Error! Reference source not found.. The created tables present quantitative characteristics of the fatal traffic collisions, including when and how often they occurred, the type of collision, types of vehicles, and statistics about the drivers, passengers and pedestrians killed.

It should be noted that year-to-year differences may be the result of the sampling process, and not the result of an actual trend. The variability or sampling errors associated with the estimates must be considered when making any year-to-year comparisons. Also, although there were a few reports with missing dates of occurrence (unknown), it was 
verbally confirmed by the head of the Collision Investigations Department at the MOI that these reports did occur within the time period studied in this thesis. Therefore, these reports will be included as part of the analysis. There were a total of 299 reports, representing 299 cases, which were collected and quantified for the three year period. Within these 299 cases, a total of 350 individuals were killed at the time of the traffic collisions.

The majority of persons killed in the fatal traffic collisions were drivers at 58.6 percent, followed by passengers at 26.3 percent, pedestrians at 13.7 percent, and unknown classification at 1.4 percent. Table 5.2 shows the relationship between the description of the deceased person (driver, passenger, or pedestrian) and the year of the fatal traffic collision. The drivers represent the highest ratio of those killed in accidents, which can be explained by various reasons among them the fact that vehicles must have a driver as a minimum.

Table 5.2 - Classification of the People Killed

\begin{tabular}{|l|l|l|l|l|l|}
\hline \multirow{2}{*}{ Year } & \multicolumn{4}{l}{ PERSON TYPE } \\
\cline { 2 - 6 } & Driver & Passenger & Pedestrian & Unknown & Grand Total \\
\hline 2008 & 106 & 34 & 21 & N/A & 161 \\
\hline 2009 & 56 & 37 & 15 & N/A & 108 \\
\hline 2010 & 40 & 21 & 12 & 5 & 78 \\
\hline Unknown & 3 & N/A & N/A & N/A & 3 \\
\hline Grand Total & $\mathbf{2 0 5}$ & $\mathbf{9 2}$ & $\mathbf{4 8}$ & $\mathbf{5}$ & $\mathbf{3 5 0}$ \\
\hline Percentage & $\mathbf{5 8 . 6 \%}$ & $\mathbf{2 6 . 3} \%$ & $\mathbf{1 3 . 7} \%$ & $\mathbf{1 . 4 \%}$ & $\mathbf{1 0 0 \%}$ \\
\hline
\end{tabular}

Table 5.3 provides data of those killed in traffic collisions by gender. As shown in the table, males account for 87.7 percent of the vehicle occupants deceased in the fatal traffic collisions compared with only 9.7 percent females. The remaining 2.6 percent the 
gender was not documented for the deceased, and as a result, the persons were marked as unknown. The ratio of killed males compared to females is very high which can be due to the fact that in general females are more cautious drivers, and most of the foreign workers that come to Kuwait and drive are males.

Table 5.3 - Gender of the People Killed

\begin{tabular}{|l|l|l|l|l|}
\hline \multirow{2}{*}{ Year } & \multicolumn{4}{l}{ GENDER } \\
\cline { 2 - 5 } & Female & Male & Unknown & Grand Total \\
\hline 2008 & 20 & 137 & 4 & 161 \\
\hline 2009 & 10 & 94 & 4 & 108 \\
\hline 2010 & 4 & 73 & 1 & 78 \\
\hline Unknown & N/A & 3 & N/A & 3 \\
\hline Grand Total & $\mathbf{3 4}$ & $\mathbf{3 0 7}$ & $\mathbf{9}$ & $\mathbf{3 5 0}$ \\
\hline Percentage & $\mathbf{9 . 7} \%$ & $\mathbf{8 7 . 7 \%}$ & $\mathbf{2 . 6 \%}$ & $\mathbf{1 0 0 \%}$ \\
\hline
\end{tabular}

Table 5.4 presents a breakdown of the type of fatal collision for each year. Four main categories of fatal traffic collisions were identified in the reports which are: collision with another vehicle, collision with a roadside object, vehicle rollover, and a pedestrian run-over. The most frequent type of fatal collision was vehicle with another vehicle, accounting for around 37.5 percent of the total cases.

Table 5.4 - Type of Fatal Traffic Collisions

\begin{tabular}{|l|l|l|l|l|l|}
\hline \multirow{2}{*}{ Year } & \multicolumn{5}{|l}{ TYPE OF FATAL COLLISION } \\
\cline { 2 - 6 } & $\begin{array}{l}\text { Collision } \\
\text { w/Other } \\
\text { Vehicle(s) }\end{array}$ & $\begin{array}{l}\text { Collision } \\
\text { w/Road } \\
\text { Object }\end{array}$ & $\begin{array}{l}\text { Vehicle } \\
\text { Rollover }\end{array}$ & $\begin{array}{l}\text { Pedestrian } \\
\text { Run-over }\end{array}$ & $\begin{array}{l}\text { Grand } \\
\text { Total }\end{array}$ \\
\hline 2008 & 57 & 16 & 45 & 23 & 141 \\
\hline 2009 & 27 & 18 & 23 & 18 & 86 \\
\hline 2010 & 27 & 16 & 14 & 12 & 69 \\
\hline Unknown & 1 & N/A & 2 & N/A & 3 \\
\hline Grand Total & $\mathbf{1 1 2}$ & $\mathbf{5 0}$ & $\mathbf{8 4}$ & $\mathbf{5 3}$ & $\mathbf{2 9 9}$ \\
\hline Percentage & $\mathbf{3 7 . 5 \%}$ & $\mathbf{1 6 . 7 \%}$ & $\mathbf{2 8 . 1 \%}$ & $\mathbf{1 7 . 7 \%}$ & $\mathbf{1 0 0 \%}$ \\
\hline
\end{tabular}


Table 5.5 shows the breakdown of the number of vehicles involved in each type of collision. When considering the number of vehicles involved, the single vehicle collisions involved had a higher percentage than collision involving two vehicles, 58 percent and 37 percent respectively.

Table 5.5 - Number of Vehicles Involved

\begin{tabular}{|l|l|l|l|l|l|}
\hline \multirow{2}{*}{$\begin{array}{l}\text { No. } \\
\text { Vehicles }\end{array}$} & \multicolumn{2}{|l|}{ TYPE OF FATAL COLLISION } \\
\cline { 2 - 6 } & $\begin{array}{l}\text { Collision } \\
\text { w/Other } \\
\text { Vehicle(s) }\end{array}$ & $\begin{array}{l}\text { Collision } \\
\text { w/Road } \\
\text { Object }\end{array}$ & $\begin{array}{l}\text { Vehicle } \\
\text { Rollover }\end{array}$ & $\begin{array}{l}\text { Pedestrian } \\
\text { Run-over }\end{array}$ & $\begin{array}{l}\text { Grand } \\
\text { Total }\end{array}$ \\
\hline Single & & 40 & 80 & 52 & 172 \\
\hline Two & 91 & 11 & 4 & 1 & 107 \\
\hline Three & 16 & N/A & N/A & N/A & 16 \\
\hline Four & 3 & N/A & N/A & N/A & 3 \\
\hline Five & 1 & N/A & N/A & N/A & 1 \\
\hline $\begin{array}{l}\text { Grand } \\
\text { Total }\end{array}$ & $\mathbf{1 1 1}$ & $\mathbf{5 1}$ & $\mathbf{8 4}$ & $\mathbf{5 3}$ & $\mathbf{2 9 9}$ \\
\hline Percentage & $\mathbf{3 7 . 1 \%}$ & $\mathbf{1 7 . 1 \%}$ & $\mathbf{2 8 . 1 \%}$ & $\mathbf{1 7 . 7 \%}$ & $\mathbf{1 0 0 \%}$ \\
\hline
\end{tabular}

Table 5.6 presents the number of people killed in each case. Ninety percent of the cases accounted for one fatality, 6.7 percent had two fatalities, and 2.3 percent had three fatalities or more. In single fatality cases the killed person is not necessarily the driver, since the number of passengers of each vehicle involved is not recorded in the reports.

Table 5.6 - Number of Fatalities in Case

\begin{tabular}{|l|l|l|l|l|l|l|}
\hline \multirow{2}{*}{ Year } & \multicolumn{6}{|l|}{ NUMBER OF FATALITIES IN CASE } \\
\cline { 2 - 7 } & $\mathbf{1}$ & $\mathbf{2}$ & $\mathbf{3}$ & $\mathbf{4}$ & $\mathbf{5}$ & Grand Total \\
\hline 2008 & 127 & 10 & 2 & 2 & - & 141 \\
\hline 2009 & 75 & 5 & 1 & 5 & - & 86 \\
\hline 2010 & 63 & 5 & N/A & N/A & 1 & 69 \\
\hline Unknown & 3 & N/A & N/A & N/A & N/A & 3 \\
\hline Grand Total & $\mathbf{2 6 8}$ & $\mathbf{2 0}$ & $\mathbf{3}$ & $\mathbf{7}$ & $\mathbf{1}$ & $\mathbf{2 9 9}$ \\
\hline Percentage & $\mathbf{8 9 . 6} \%$ & $\mathbf{6 . 7} \%$ & $\mathbf{1 . 0} \%$ & $\mathbf{2 . 3} \%$ & $\mathbf{0 . 3} \%$ & $\mathbf{1 0 0 \%}$ \\
\hline
\end{tabular}


Table 5.7 presents the number of vehicles involved in each case analyzed. Fiftyeight percent of the fatalities involved single vehicle collisions. Single vehicle collisions occur usually when a vehicle runs off the road and is tripped by a curb, tree, concrete barrier, light pole or other road objects. Single vehicle collisions are usually caused by driver behavior, such as speeding or inattention.

Table 5.7 - Number of Vehicles Involved in Case

\begin{tabular}{|l|l|l|l|l|l|l|}
\hline \multirow{2}{*}{ Year } & \multicolumn{6}{|c|}{ NUMBE R OF VEHCILES INVOLVED IN CASE } \\
\cline { 2 - 7 } & Single & Two & Three & Four & Five & Grand Total \\
\hline 2008 & 84 & 45 & 10 & 2 & N/A & 141 \\
\hline 2009 & 47 & 38 & 1 & N/A & N/A & 86 \\
\hline 2010 & 38 & 24 & 5 & 1 & 1 & 69 \\
\hline Unknown & 3 & N/A & N/A & N/A & N/A & 3 \\
\hline Grand Total & $\mathbf{1 7 2}$ & $\mathbf{1 0 7}$ & $\mathbf{1 6}$ & $\mathbf{3}$ & $\mathbf{1}$ & $\mathbf{2 9 9}$ \\
\hline Percentage & $\mathbf{5 7 . 5 \%}$ & $\mathbf{3 5 . 8} \%$ & $\mathbf{5 . 4 \%}$ & $\mathbf{1 . 0} \%$ & $\mathbf{0 . 3 \%}$ & $\mathbf{1 0 0 \%}$ \\
\hline
\end{tabular}

Table 5.8 presents the natural lighting condition each case took place in. All roads in Kuwait are well lit, and the road lighting is maintained on a regular basis. Nevertheless, thirty-four percent of the fatal collisions occurred at night, between the hours of 6:00pm and 2:59am. This time frame does not have any rush hour traffic and the roads are usually calmer at night. In many cases, this leads to excessive speeding and irresponsible driving behavior by young male drivers who enjoy staying outside driving around during the late hours of the night.

Table 5.9 presents data about the age and gender of the people killed on the road. Persons 25 to 34 years old had the highest fatality count, and persons 5 to 9 years old had 
the lowest fatality count. For every age group, the frequency of fatalities was significantly lower for females than for males.

Table 5.8 - Natural Lighting Condition

\begin{tabular}{|c|c|c|c|c|c|c|c|}
\hline \multirow[b]{2}{*}{ Year } & \multicolumn{7}{|c|}{ NATURAL LIGHTING CONDITION } \\
\hline & Dawn & Morning & Afternoon & Twilight & Night & Unknown & $\begin{array}{l}\text { Grand } \\
\text { Total }\end{array}$ \\
\hline 2008 & 2 & 30 & 23 & 18 & 52 & 16 & 141 \\
\hline 2009 & 20 & 11 & 23 & 7 & 21 & 4 & 86 \\
\hline 2010 & 4 & 8 & 17 & 5 & 30 & 5 & 69 \\
\hline Unknown & $\mathrm{N} / \mathrm{A}$ & $\mathrm{N} / \mathrm{A}$ & $\mathrm{N} / \mathrm{A}$ & N/A & N/A & 3 & 3 \\
\hline $\begin{array}{l}\text { Grand } \\
\text { Total }\end{array}$ & 26 & 49 & 63 & 30 & 103 & 28 & 299 \\
\hline Percentage & $8.7 \%$ & $16.4 \%$ & $21.1 \%$ & $10.0 \%$ & $34.4 \%$ & $9.4 \%$ & $100 \%$ \\
\hline
\end{tabular}

Table 5.9 - Age Range and Genders of People Killed

\begin{tabular}{|c|c|c|c|c|}
\hline \multirow[b]{2}{*}{ Age } & \multicolumn{4}{|c|}{ GENDER } \\
\hline & Female & Male & Unknown & Grand Total \\
\hline$<5$ yrs & 3 & 4 & N/A & 7 \\
\hline $5-9$ yrs & N/A & 5 & N/A & 5 \\
\hline $10-15$ yrs & 1 & 9 & N/A & 10 \\
\hline $16-20 \mathrm{yrs}$ & 6 & 33 & N/A & 39 \\
\hline $21-24$ yrs & 2 & 23 & N/A & 25 \\
\hline $25-34$ yrs & 5 & 80 & $\mathrm{~N} / \mathrm{A}$ & 85 \\
\hline $35-44$ yrs & 7 & 62 & $\mathrm{~N} / \mathrm{A}$ & 69 \\
\hline $45-54$ yrs & 4 & 36 & $\mathrm{~N} / \mathrm{A}$ & 40 \\
\hline $55-64$ yrs & 1 & 20 & N/A & 21 \\
\hline$\geq 65$ & N/A & 16 & N/A & 16 \\
\hline Unknown & 5 & 19 & 9 & 33 \\
\hline Grand Total & 34 & 307 & 9 & 350 \\
\hline Percentage & $9.7 \%$ & $87.7 \%$ & $2.6 \%$ & $100 \%$ \\
\hline
\end{tabular}

Table 5.10 presents the age range of the people killed in the traffic collisions. Considering that the legal driving age in Kuwait is 18 , it would have been expected that the younger age groups of drivers, 16 to 20 or 21 to 24 , would have the highest rates of 
fatalities due to lack driving experience. However, the highest rate of fatalities is within the age group of 25 to 34 year old drivers followed by the 35 to 44 year old drivers, 16 percent and 10 percent respectively. This might be due to several factors that can include the number of car owners within this age group is more, most of the foreigners coming to Kuwait fall within this age group as workers, and more freedom of going out and staying out late at night for the older age groups.

Table 5.10 - Age Range and Classification of Person Killed

\begin{tabular}{|l|l|l|l|l|l|}
\hline \multirow{2}{*}{ Age } & \multicolumn{4}{|l}{ PERSON TYPE } & \multicolumn{4}{l|}{} \\
\cline { 2 - 6 } & Driver & Passenger & Pedestrian & Unknown & Grand Total \\
\hline$<5$ yrs & N/A & 3 & 4 & N/A & 7 \\
\hline $5-9$ yrs & N/A & 4 & 1 & N/A & 5 \\
\hline $10-15$ yrs & 1 & 3 & 6 & N/A & 10 \\
\hline $16-20$ yrs & 19 & 13 & 4 & 3 & 39 \\
\hline $21-24$ yrs & 19 & 5 & 1 & N/A & 25 \\
\hline $25-34$ yrs & 55 & 22 & 6 & 2 & 85 \\
\hline $35-44$ yrs & 36 & 24 & 9 & N/A & 69 \\
\hline $45-54$ yrs & 28 & 5 & 7 & N/A & 40 \\
\hline $55-64$ yrs & 15 & 4 & 2 & N/A & 21 \\
\hline$\geq 65$ & 14 & N/A & 2 & N/A & 16 \\
\hline Unknown & 18 & 9 & 6 & N/A & 33 \\
\hline Grand Total & $\mathbf{2 0 5}$ & $\mathbf{9 2}$ & $\mathbf{4 8}$ & $\mathbf{5}$ & $\mathbf{3 5 0}$ \\
\hline Percentage & $\mathbf{5 8 . 6 \%}$ & $\mathbf{2 6 . 3} \%$ & $\mathbf{1 3 . 7} \%$ & $\mathbf{1 . 4 \%}$ & $\mathbf{1 0 0} \%$ \\
\hline
\end{tabular}

Table 5.11 presents the type of vehicle involved in the traffic collision and the classification of the person killed. The results shows that 38 percent of the people deceased were riding in vehicles of type salon, four doors. SUV's were the second highest type of vehicles that people involved in the collisions were riding, accounting for 32 percent. 
Table 5.11 - Vehicle Type and Classification of Person Killed

\begin{tabular}{|l|l|l|l|l|l|}
\hline \multirow{2}{*}{ Vehicle Type } & \multicolumn{3}{|l}{ PERSON TYPE } \\
\cline { 2 - 6 } & Driver & Passenger & Pedestrian & Unknown & Grand Total \\
\hline Bus & 4 & 13 & 1 & N/A & 18 \\
\hline $\begin{array}{l}\text { HGV/Construction } \\
\text { Vehicle }\end{array}$ & 14 & 3 & 5 & N/A & 22 \\
\hline Motorcycle & 8 & N/A & N/A & N/A & 8 \\
\hline Pick-up Truck & 26 & 13 & 1 & N/A & 40 \\
\hline Salon & 80 & 30 & 18 & 5 & 133 \\
\hline Sports Vehicle & 3 & 1 & 5 & N/A & 9 \\
\hline SUV & 64 & 32 & 15 & N/A & 111 \\
\hline Unknown & 6 & N/A & 3 & N/A & 9 \\
\hline Grand Total & $\mathbf{2 0 5}$ & $\mathbf{9 2}$ & $\mathbf{4 8}$ & $\mathbf{5}$ & $\mathbf{3 5 0}$ \\
\hline Percentage & $\mathbf{5 8 . 6} \%$ & $\mathbf{2 6 . 3} \%$ & $\mathbf{1 3 . 7} \%$ & $\mathbf{1 . 4} \%$ & $\mathbf{1 0 0} \%$ \\
\hline
\end{tabular}

Table 5.12 presents the type of fatal collision and the vehicle type involved in the collision. For three of the four types of fatal collisions listed (collision with other vehicle, collision with road object and pedestrian run-over) most of the vehicles involved were salon type. The only category where the number of SUVs were almost double the salon vehicles were in the vehicle rollover type collisions. This can be due to the fact that many drivers chose to use SUV's to drive long stretches of road (e.g. to and from Saudi Arabia), where rollovers can take place due to speeding and exhaustion as some of the main causes. Spatial analysis will be discussed in the next chapter and it will shed more light on the locations of these four categories of collisions confirming that most of the rollover collisions took place outside the residential areas, where there is less traffic. 
Table 5.12 - Vehicle Type and Type of Fatal Collision

\begin{tabular}{|l|l|l|l|l|l|}
\hline \multirow{2}{*}{ Vehicle Type } & \multicolumn{5}{|l|}{ TYPE OF FATAL COLLISION } \\
\cline { 2 - 6 } & $\begin{array}{l}\text { Collision } \\
\text { w/Other } \\
\text { Vehicle(s) }\end{array}$ & $\begin{array}{l}\text { Collision } \\
\text { w/Road } \\
\text { Object }\end{array}$ & $\begin{array}{l}\text { Vehicle } \\
\text { Rollover }\end{array}$ & $\begin{array}{l}\text { Pedestrian } \\
\text { Run-over }\end{array}$ & $\begin{array}{l}\text { Grand } \\
\text { Total }\end{array}$ \\
\hline Bus & 2 & 1 & 4 & 2 & 9 \\
\hline $\begin{array}{l}\text { HGV/Construction } \\
\text { Vehicle }\end{array}$ & 10 & 2 & 3 & 5 & 20 \\
\hline Motorcycle & 4 & 2 & 1 & 1 & 8 \\
\hline Pick-up Truck & 18 & N/A & 17 & 1 & 36 \\
\hline Salon & 47 & 27 & 19 & 21 & 114 \\
\hline Sports Vehicle & 1 & 2 & 1 & 4 & 8 \\
\hline SUV & 26 & 15 & 38 & 16 & 95 \\
\hline Unknown & 3 & 2 & 1 & 3 & 9 \\
\hline Grand Total & $\mathbf{1 1 1}$ & $\mathbf{5 1}$ & $\mathbf{8 4}$ & $\mathbf{5 3}$ & $\mathbf{2 9 9}$ \\
\hline Percentage & $\mathbf{3 7 . 1 \%}$ & $\mathbf{1 7 . 1 \%}$ & $\mathbf{2 8 . 1 \%}$ & $\mathbf{1 7 . 7 \%}$ & $\mathbf{1 0 0 \%}$ \\
\hline & & & & & \\
\hline
\end{tabular}

Table 5.13 presents the time frame and the day of the week of the fatal collisions. The overall deadliest 3-hour period turns out to be between 6 p.m. to $8: 59$ p.m., and Sundays accounted for the majority of the cases, 17 percent of the total cases. However, the numbers were all very close as to which day of the week the fatal collisions took place. The weekend in Kuwait is on Friday and Saturday. Surprisingly, Thursdays had the lowest number of cases, even though it would have been thought it would have the highest considering that it is the first night of the weekend, where people would be out and stay out longer.

Table 5.14 presents a breakdown of the nationalities of the people killed during each of the three years analyzed. Even though the population in Kuwait is made up of more expatriates than national Kuwaitis, Kuwaitis still fell under the highest count of 
Table 5.13 - Time of Day and Day of Week

\begin{tabular}{|c|c|c|c|c|c|c|c|c|c|}
\hline \multirow[b]{2}{*}{ Time of Day } & \multicolumn{9}{|c|}{ DAY OF WEEK } \\
\hline & Sunday & Monday & Tuesday & Wednesday & Thursday & Friday & Saturday & Unknown & $\begin{array}{l}\text { Grand } \\
\text { Total }\end{array}$ \\
\hline Midnight to $2: 59$ a.m. & 5 & 1 & 4 & 5 & 1 & 6 & 2 & $\mathrm{~N} / \mathrm{A}$ & 24 \\
\hline 3 a.m. to 5:59 a.m. & 2 & 5 & 8 & 3 & 3 & 3 & 4 & N/A & 28 \\
\hline 6 a.m. to $8: 59$ a.m. & 2 & 5 & 2 & 3 & 2 & - & 3 & N/A & 17 \\
\hline 9 a.m. to $11: 59$ a.m. & 5 & 5 & 4 & 4 & 6 & 2 & 5 & N/A & 31 \\
\hline Noon to $2: 59$ p.m. & 7 & 8 & 8 & 9 & 1 & 3 & 3 & $\mathrm{~N} / \mathrm{A}$ & 39 \\
\hline 3 p.m. to $5: 59$ p.m. & 12 & 3 & 9 & 2 & 3 & 3 & 6 & N/A & 38 \\
\hline 6 p.m. to $8: 59$ p.m. & 8 & 13 & 6 & 4 & 6 & 8 & 7 & N/A & 52 \\
\hline 9 p.m. to $11: 59$ p.m. & 6 & 8 & 7 & 5 & 5 & 5 & 5 & N/A & 41 \\
\hline Unknown & 5 & N/A & 1 & 5 & 2 & 7 & 6 & 3 & 29 \\
\hline Grand Total & 52 & 48 & 49 & 40 & 29 & 37 & 41 & 3 & 299 \\
\hline Percentage & $17.4 \%$ & $16.1 \%$ & $16.4 \%$ & $13.4 \%$ & $9.7 \%$ & $12.4 \%$ & $13.7 \%$ & $1.0 \%$ & $100 \%$ \\
\hline
\end{tabular}

Table 5.14 - Nationality of People Killed

\begin{tabular}{|l|l|l|l|l|l|l|l|l|l|}
\hline \multirow{2}{*}{ Year } & \multicolumn{9}{l}{ NATIONALITY OF DECEASED } \\
\cline { 2 - 10 } & Kuwaiti & Egyptian & Indian & Pakistani & Bangladesh & Saudi Arabian & Other* & Unknown & Grand Total \\
\hline 2008 & $\mathbf{6 2}$ & 27 & 14 & 13 & 10 & 3 & 24 & $\mathbf{8}$ & 161 \\
\hline 2009 & $\mathbf{3 8}$ & $\mathbf{1 8}$ & 10 & 5 & 6 & $\mathbf{8}$ & 16 & 7 & 108 \\
\hline 2010 & 35 & 9 & 10 & 4 & 2 & 3 & 13 & 2 & 78 \\
\hline Unknown & 1 & 1 & N/A & N/A & N/A & N/A & 1 & N/A & 3 \\
\hline Grand Total & $\mathbf{1 3 6}$ & $\mathbf{5 5}$ & $\mathbf{3 4}$ & $\mathbf{2 2}$ & $\mathbf{1 8}$ & $\mathbf{1 4}$ & $\mathbf{5 4}$ & $\mathbf{1 7}$ & $\mathbf{3 5 0}$ \\
\hline Percentage & $\mathbf{3 8 . 9} \%$ & $\mathbf{1 5 . 7 \%}$ & $\mathbf{9 . 7} \%$ & $\mathbf{6 . 3} \%$ & $\mathbf{5 . 1} \%$ & $\mathbf{4 . 0} \%$ & $\mathbf{1 5 . 4} \%$ & $\mathbf{4 . 9 \%}$ & $\mathbf{1 0 0 \%}$ \\
\hline
\end{tabular}

*Others include - America, Syria, Ethiopia, Nepal, Oman, Bahrain, Iran, Iraq, Lebanon, Afghanistan, Philippines, Palestine, Srilanka, Non-Kuwaiti 
fatalities when looking at the different nationalities involved in these fatal collisions. Usually foreigners are more cautious drivers and abide to the rules.

Error! Reference source not found. presents the month of the year which the fatal collisions took place in. In Kuwait, the middle of the school year holiday is in JanuaryFebruary, which is comparable to the Christmas holiday in the western countries. January accounted for the most fatality rates compared to the other months.

The analysis of the data presented in this section resulted in several important observations which are summarized below:

- The majority of persons killed in the fatal traffic collisions were drivers at $59 \%$, followed by passengers at $26 \%$, pedestrians at $14 \%$, and unknown $1 \%$.

- Males account for $88 \%$ of the vehicle occupants deceased in the fatal traffic collisions when looking at the gender. Females accounted for $10 \%$, and unknowns were $2 \%$.

- Four main categories of fatal traffic collisions were identified in the reports which are: collision with another vehicle, collision with a roadside object, vehicle rollover, and a pedestrian run-over. The most frequent type of fatal collision was vehicle with another vehicle, accounting for around 38 percent of the total cases. However when considering the number of vehicles involved, the single vehicle cases had a higher percentage than two vehicles involved, 58 percent and 37 percent respectively. 
Table 5.15 - Month of the Year where Fatal Collision Occurred

\begin{tabular}{|c|c|c|c|c|c|c|c|c|c|c|c|c|c|c|}
\hline \multirow[b]{2}{*}{ Year } & \multicolumn{14}{|c|}{ MONTH } \\
\hline & Jan. & Feb. & Mar. & Apr. & May & Jun. & Jul. & Aug. & Sept. & Oct. & Nov. & Dec. & Unknown & Grand Total \\
\hline 2008 & 25 & 15 & 10 & 16 & 9 & 9 & 8 & 14 & 12 & 5 & 7 & 11 & N/A & 141 \\
\hline 2009 & 14 & 6 & 5 & 7 & 3 & 6 & 9 & 6 & 4 & 10 & 11 & 5 & N/A & 86 \\
\hline 2010 & 7 & 13 & 10 & 5 & 1 & 4 & 11 & 5 & 2 & 3 & 2 & 6 & N/A & 69 \\
\hline Unknown & N/A & N/A & $\mathrm{N} / \mathrm{A}$ & $\mathrm{N} / \mathrm{A}$ & $\mathrm{N} / \mathrm{A}$ & $\mathrm{N} / \mathrm{A}$ & N/A & N/A & $\mathrm{N} / \mathrm{A}$ & N/A & $\mathrm{N} / \mathrm{A}$ & $\mathrm{N} / \mathrm{A}$ & 3 & 3 \\
\hline $\begin{array}{l}\text { Grand } \\
\text { Total } \\
\end{array}$ & 46 & 34 & 25 & 28 & 13 & 19 & 28 & 25 & 18 & 18 & 20 & 22 & 3 & 299 \\
\hline Percentage & $15.4 \%$ & $11.4 \%$ & $8.4 \%$ & $9.4 \%$ & $4.3 \%$ & $6.4 \%$ & $9.4 \%$ & $8.4 \%$ & $6.0 \%$ & $6.0 \%$ & $6.7 \%$ & $7.4 \%$ & $1.0 \%$ & $100 \%$ \\
\hline
\end{tabular}


- Ninety percent of the cases accounted for one fatality, seven percent had two fatalities, and three percent had three fatalities or more. Fifty-eight percent of the fatalities involved single vehicle collisions.

- Persons 25 to 34 years old had the highest fatality count, and persons 5 to 9 years old had the lowest fatality count.

- The highest rate of fatalities was within the age group of 25 to 34 year old drivers followed by the 35 to 44 year old drivers, 16 percent and 10 percent respectively.

- Thirty-eight percent of the people deceased were riding in vehicles of type salon, four doors. SUV's were the second highest type of vehicles that people involved in the collisions were riding, accounting for 32 percent.

- The overall deadliest 3-hour period turned out to be between 6 p.m. to 8:59 p.m., and Sundays accounted for the majority of the cases between the other days of the week at 17 percent of the total. 


\section{Spatial and Statistical Analysis}

This chapter presents the main results of the spatial and statistical analyses to examine the effect of ASCs on fatal traffic collisions. In Section 6.1, spatial analysis is conducted as a visual identification of the locations with high fatal collision frequencies and their proximity to ASCs. Section 6.2 presents the modelling process where binomial regression models are examined, compared and the most suitable approach for incorporating exposure are determined.

\subsection{Spatial Analysis Using GIS}

It is important to analyze collision locations and patterns visually to identify what possible traffic and/or road factors might make a road section more collision prone. Geographical Information System (GIS) is a tool designed for the acquisition, storage, manipulation, analysis and display of geographic data. This system allows linking an attribute database to the base map which may contain relevant data such as traffic flow, speed limit, divided or undivided status, and road classification.

GIS allows the user to manipulate and visually display numerous types of data for easy comprehension. One of the most important benefits of GIS is its ability to graphically present a large amount of data on a single map. In the context of traffic safety, GIS can be used to analyze various types of data in combination with collision data to identify patterns of collisions with respect to time, demographic composition, etc. This type of presentation is very helpful in understanding multiple data types and values at a glance according to the location. 
As mentioned earlier, the numbers of fatal traffic collisions were quantified from the original police traffic reports for the years 2008 to 2010 . The results of this step are shown in Table 6.1. As shown in the table, the number of fatal traffic collisions dropped from 141 in 2008 to only 69 in 2010 , which is about $50 \%$ reduction in total reported fatal collisions. However, as mentioned in Section 4.1, these year-to-year differences in this study may be the result of the sampling process and not necessarily due to the result of an actual trend or explainable cause. Sixty-six percent of the fatal traffic collisions recorded occurred within the residential areas, the six Governorates. This was expected since most of the vehicle movement occurs within this area of the country.

Table 6.1 - Number of Fatal Traffic Collisions within and outside Governorates

\begin{tabular}{|l|l|l|l|}
\hline Year & $\begin{array}{l}\text { Within } \\
\text { Governorates }\end{array}$ & $\begin{array}{l}\text { Outside } \\
\text { Governorates }\end{array}$ & Total \\
\hline 2008 & 92 & 49 & 141 \\
\hline 2009 & 58 & 28 & 86 \\
\hline 2010 & 46 & 23 & 69 \\
\hline Unknown & N/A & 3 & 3 \\
\hline Grand Total & $\mathbf{1 9 6}$ & $\mathbf{1 0 3}$ & $\mathbf{2 9 9}$ \\
\hline Percentage & $\mathbf{6 5 . 6 \%}$ & $\mathbf{3 4 . 4 \%}$ & $\mathbf{1 0 0 \%}$ \\
\hline
\end{tabular}

The fatal traffic collisions were plotted in GIS for the three years, according to the year they occurred, and are presented in Figure 6.1. As seen in the figure, the distribution of the collisions seems to be similar across the country each year, with the majority of fatal collisions occurring within the urban area, the Governorates. Most of the fatal traffic collisions outside the Governorates occurred on Alabdaly Road, Alsalmi Road, and Kind Fahad Expressway which are the three main highways leading to farms, beach-houses, Saudi Arabia, and Iraq. 

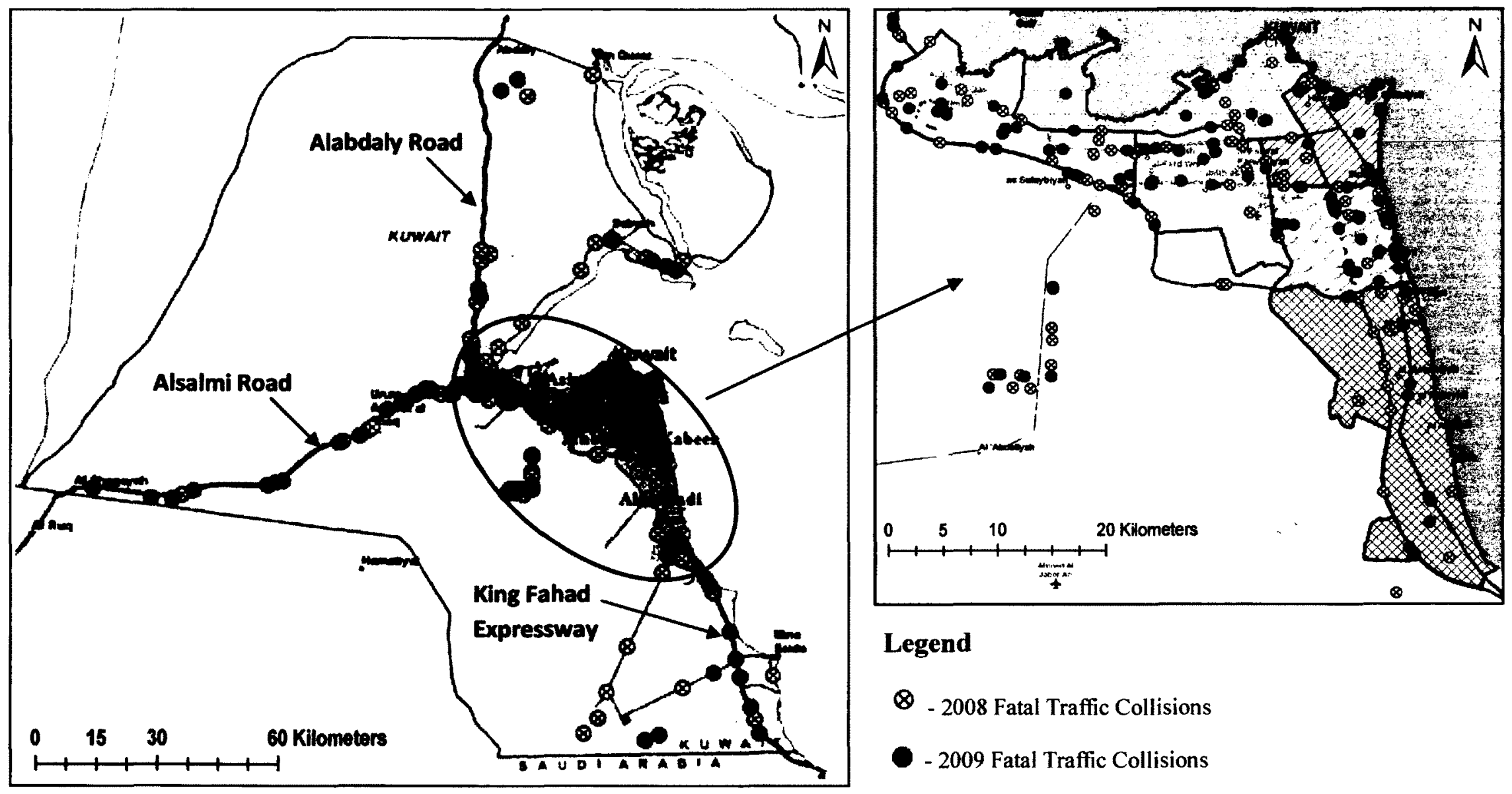

Legend

$\otimes$ - 2008 Fatal Traffic Collisions

- 2009 Fatal Traffic Collisions

Figure 6.1 - Fatal Traffic Collisions in Kuwait

-2010 Fatal Traffic Collisions 
Next, the fatal traffic collisions were plotted according to their type, as shown in Figure 6.2. The distribution across the country shows that the majority of the rollover collisions occurred outside the Governorates, where the remaining three types of collisions were mainly within the urban area.

Since most of the fatal traffic collisions occurred within the Governorates, and all ASCs are located within the Governorates, the main focus of the next set of analysis will be limited to this region of the country. As part of the spatial analysis, the 'buffering' tool was employed in the GIS software, which is a technique that draws a ring boundary around selected objects. This technique was used to create road sections around all the SRN roads, PRN roads, and the SRs in Kuwait. A 500 m radius, a 1000 m radius and a $2000 \mathrm{~m}$ radius buffer zones (influence areas) were created around all road sections including ones with ASCs, thus creating three datasets. Three different influence areas were investigated to assess the effect of ASCs on fatal traffic collisions at different radii. Road sections with ASCs had the center point of the buffer ring being the ASC coordinate location. 


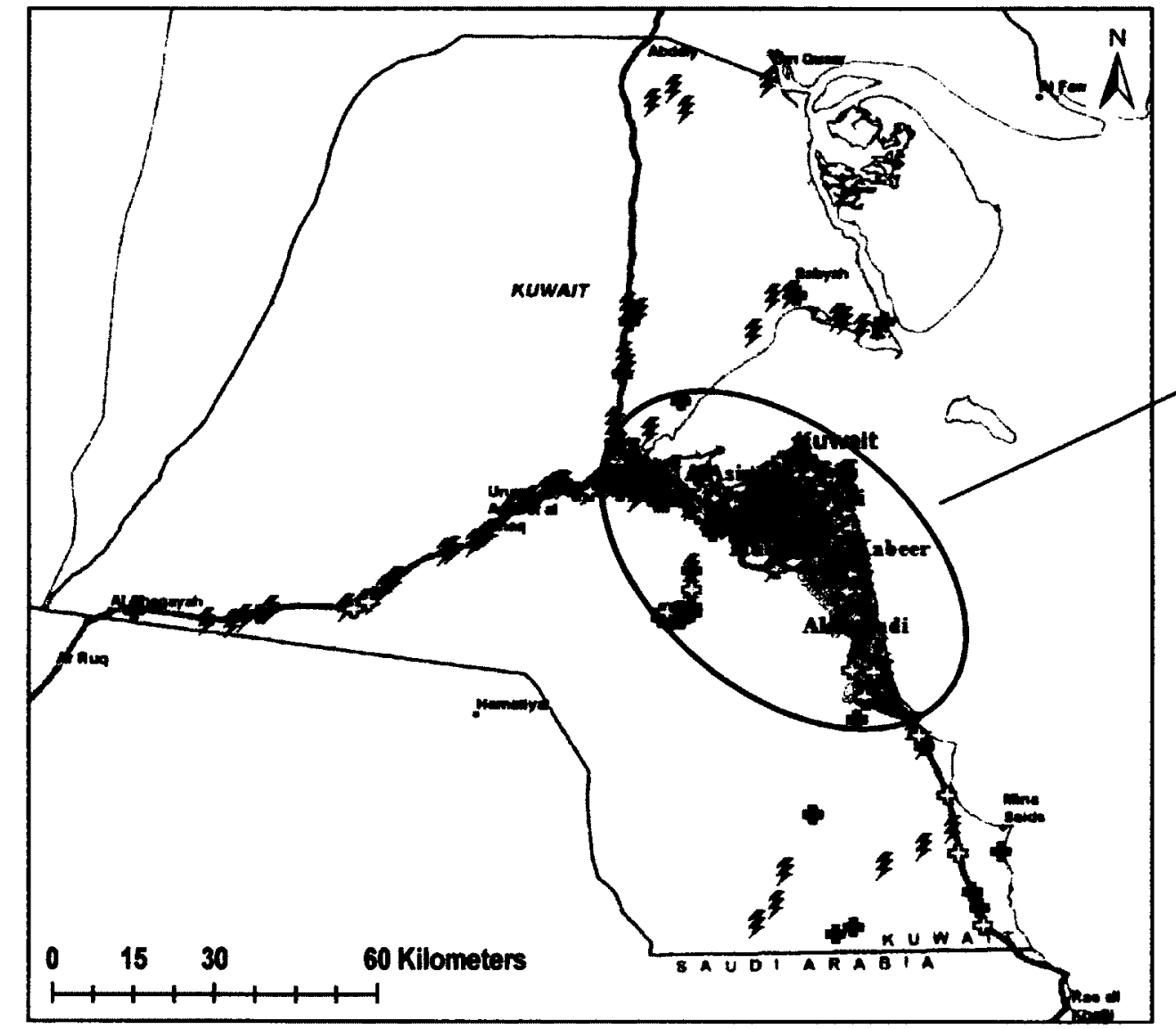

Figure 6.2 - Types of Fatal Traffic Collisions

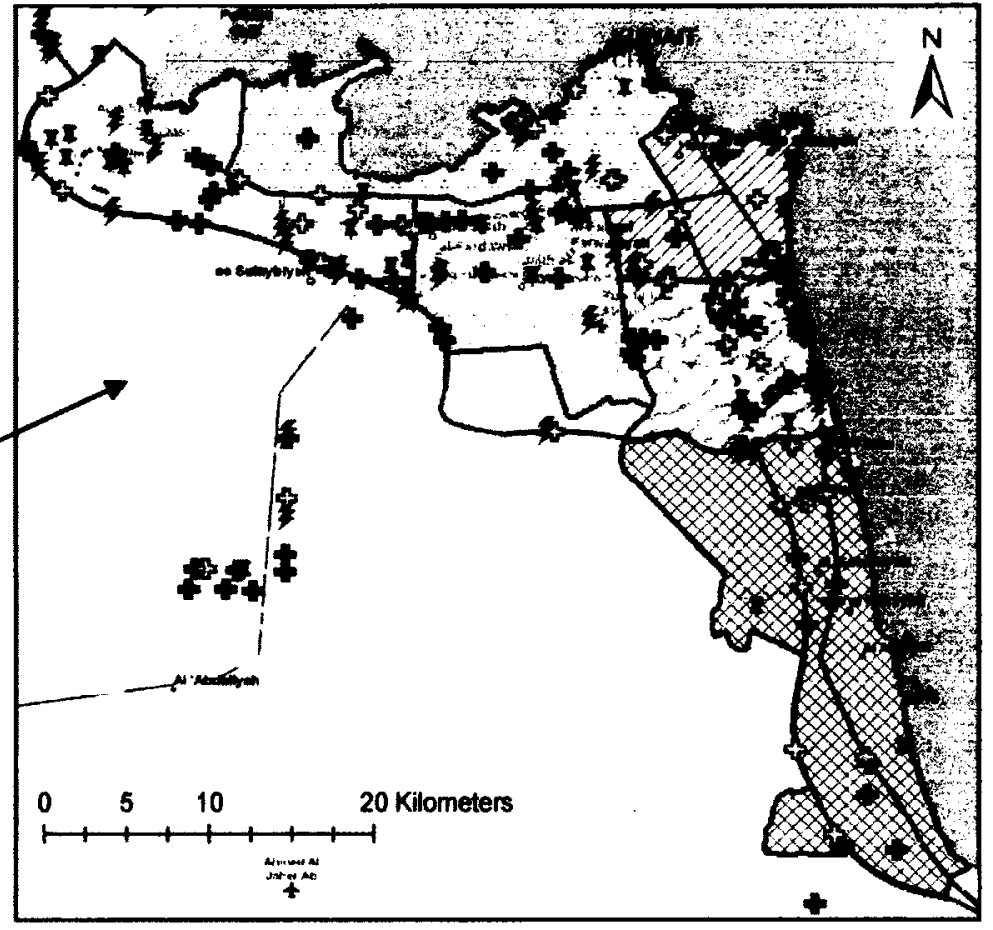

Legend

- Collision w/ Other vehicle

\$. Collision w/roadside object

I - Pedestrian run over collision

F - Vehicle rollover collision 
The number of collisions to make a location titled a high collision location is variable, as discussed earlier in Section 2.4. Locations having between three and five incidents are considered critical in most European countries. (Elvik 2007). The Manual of Transportation Engineering Studies method of calculating the high collision locations will be used in this thesis for the three influence areas. That methodology states that a high collision location is defined as those locations that have a 3-year weighted accident crash rate greater than the mean rate for all locations, plus a constant times the standard deviation for all locations. At the $90 \%$ confidence level, that constant is 1.282 based on the Poisson distribution (Kirkham Michael Consulting Engineers 2000).

Using this methodology, the mean of the fatal collisions for all locations within the $500 \mathrm{~m}$ radius was 0.276 fatal collisions, and the standard deviation was calculated to be 0.646 . With these values, the corresponding value that determines a high collision location is 1.10 . Therefore, a zone with two collisions or more was considered a black spot. However, to ensure that there is a collision pattern, zones with three or more collisions will be looked at.

For the $1000 \mathrm{~m}$ radius influence area, the mean for all locations was 1.02 fatal collisions, and the standard deviation was calculated to be 1.17 . With these values, the corresponding value that determines high collision locations is 2.5 . Therefore, a zone with three collisions or more was considered a black spot.

For the $2000 \mathrm{~m}$ radius influence area, the mean for all locations was 2.10 fatal collisions, and the standard deviation was calculated to be 1.83 . With these values, the 
corresponding collision rate that determines high collision locations is 4.94 . Therefore, a zone with five collisions or more was considered a black spot.

Figure 6.3 and Figure 6.4 present the $500 \mathrm{~m}$ radius and $1000 \mathrm{~m}$ radius influence areas, identified with the rings. Zones with red rings are the ones that had three or more fatal traffic collisions during the three years period from 2008 to 2010 , while black rings represent areas with less than three fatal collisions. Similarly, Figure 6.5 presents the $2000 \mathrm{~m}$ radius influence areas zones in which five collisions or more were identified by a red ring. The numbers of fatal traffic collisions within each of the red rings, which were identified in Figure 6.3 to Figure 6.5 are listed in Table 6.2 to Table 6.4 , respectively. In these three tables, 'Buffer ID' starting with the letter ' $R$ ' refers to an ASC zone and ones starting with ' $\mathrm{N}$ ' are zones with no ASC.

In the $500 \mathrm{~m}$ radius influence area, 13 zones had three or more fatal traffic collisions. Out of the 13, two zones were ASC zones and the remaining 11 were not. The maximum number of collisions within one zone was four. In the $1000 \mathrm{~m}$ radius influence area, 18 zones had three or more fatal traffic collisions. Out of the 18 , seven zones were ASC zones and the remaining eleven were not. The maximum number of collisions within one zone was six. In the $2000 \mathrm{~m}$ radius influence area, ten zones had five or more fatal traffic collisions. Out of the ten, seven zones were ASC zones and the remaining three were not. The maximum number of collisions within one zone was eight.

These figures and tables identify the hazardous locations with high frequencies of fatal traffic collisions, the black spots. Future research needs to be conducted in order to determine what possible roadway, traffic, or environmental factors might have caused 
these high frequencies of fatal traffic collisions in these specified critical zones in order to implement appropriate safety measures.

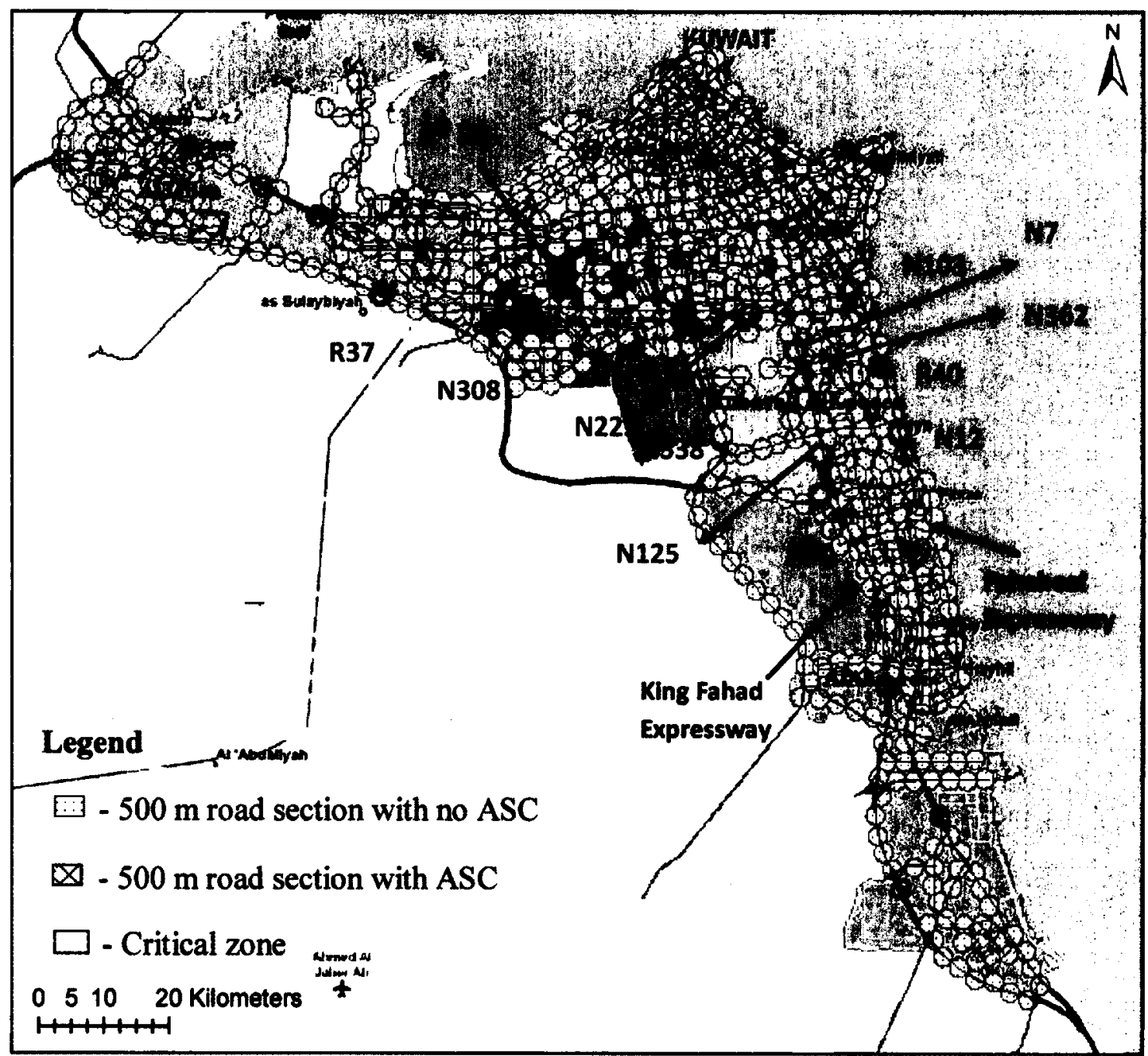

Figure 6.3 - 500 m Radius Influence Area - 3+ Fatal Collision Zones

Analysis from the $500 \mathrm{~m}$ radius influence area indicated that the majority of the zones identified as high fatal collision locations are along King Fahad Expressway and Fahaheel Expressway, seven out of the eleven. The results show that only two of the zones identified as high fatal collision locations were zones with ASCs. There seemed to be no apparent pattern or trend when analyzing the results in the table. Also, when 
calculating the average number of fatal traffic collisions within an ASC zone and the average number of fatal traffic collisions in zones with no ASC, the results turned out to be four fatal collisions in both cases. Therefore, no firm conclusions can be made from the results obtained. In order to better assess the effect of ASCs on the fatal collisions, collision data must be collected and before-and-after studies need to get conducted.

Table 6.2 - High Fatal Traffic Collision Frequency Zones (500 m Radius Influence Area)

\begin{tabular}{|c|c|c|c|c|}
\hline Buffer ID & $\begin{array}{c}\text { Number of } \\
\text { Fatal } \\
\text { Collisions } \\
\text { Inside } \\
\text { Buffer } \\
\text { Zone } \\
\end{array}$ & Location & $\begin{array}{l}\text { Road } \\
\text { Type }\end{array}$ & AADT \\
\hline $\begin{array}{l}\text { R } 37 \\
\text { (Cam) }\end{array}$ & 4 & $\begin{array}{l}\text { 6th RR infront } \\
\text { of Sulaibiya }\end{array}$ & SRN Ring & 121,325 \\
\hline N7 & 4 & $\begin{array}{l}\text { King Fahad } \\
\text { Exwy }\end{array}$ & $\begin{array}{l}\text { SRN } \\
\text { Radial }\end{array}$ & 110,500 \\
\hline N90 & 4 & 7th RR & PRN & 110,000 \\
\hline N103 & 4 & $\begin{array}{l}\text { Fahaheel } \\
\text { Exwy }\end{array}$ & $\begin{array}{l}\text { SRN } \\
\text { Radial }\end{array}$ & 100,000 \\
\hline N125 & 4 & $\begin{array}{l}\text { King Fahad } \\
\text { Exwy }\end{array}$ & $\begin{array}{l}\text { SRN } \\
\text { Radial }\end{array}$ & 109,000 \\
\hline N225 & 4 & 6th RR & SRN Ring & 123,500 \\
\hline $\begin{array}{l}\text { R } 40 \\
\text { (Cam) }\end{array}$ & 3 & $\begin{array}{l}\text { Fahaheel } \\
\text { Exwy infront } \\
\text { of Qurain }\end{array}$ & $\begin{array}{l}\text { SRN } \\
\text { Radial }\end{array}$ & 110,023 \\
\hline $\mathrm{N} 12$ & 3 & $\begin{array}{l}\text { Fahaheel } \\
\text { Exwy }\end{array}$ & $\begin{array}{l}\text { SRN } \\
\text { Radial } \\
\end{array}$ & 115,000 \\
\hline N308 & 3 & 6th RR & SRN Ring & 125,500 \\
\hline N338 & 3 & $\begin{array}{l}\text { King Faisal } \\
\text { Exwy near } \\
\text { airport }\end{array}$ & PRN & 51,700 \\
\hline N362 & 3 & $\begin{array}{l}\text { King Fahad } \\
\text { Exwy }\end{array}$ & $\begin{array}{l}\text { SRN } \\
\text { Radial }\end{array}$ & 110,000 \\
\hline
\end{tabular}




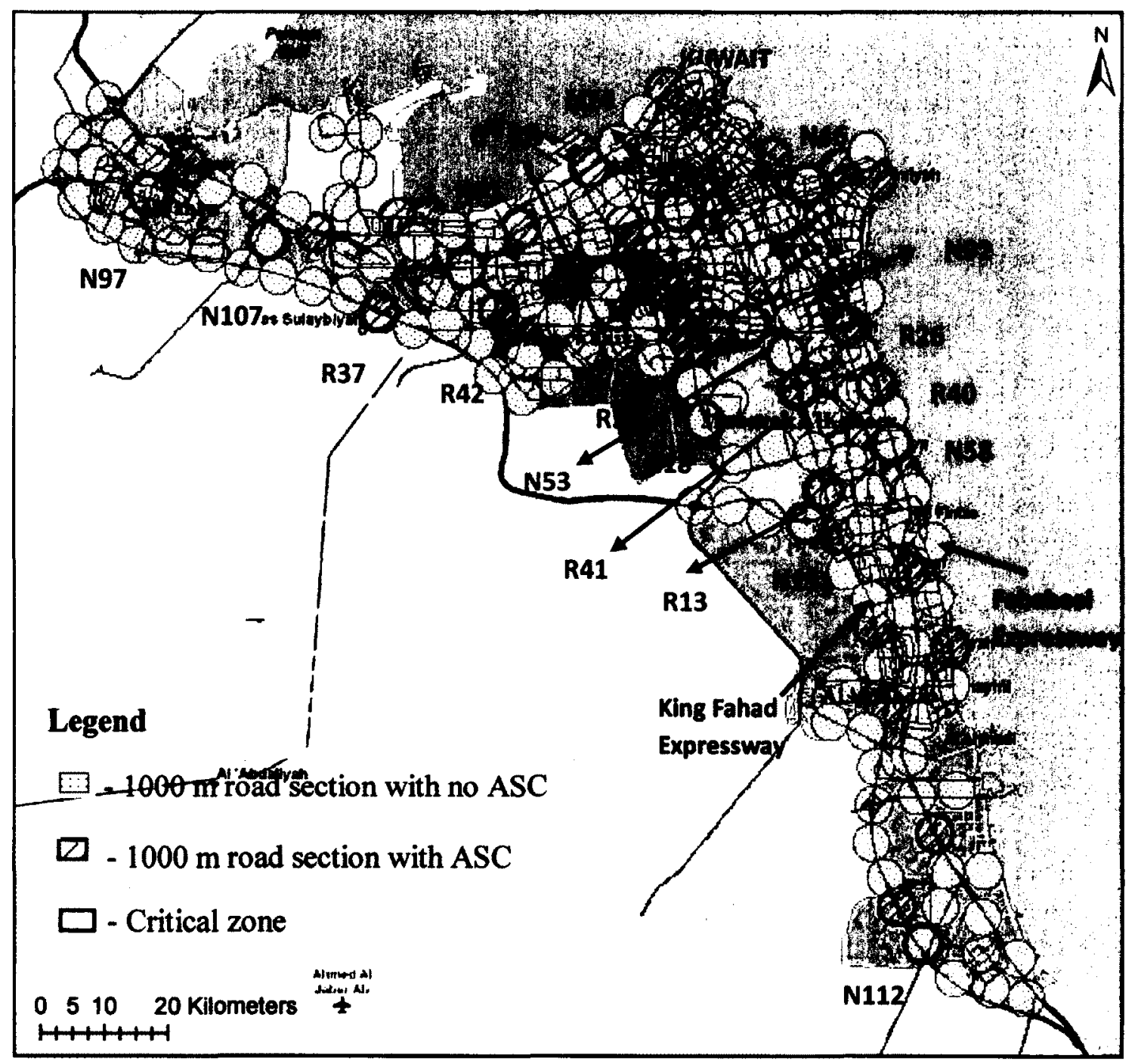

Figure 6.4 - 1000 m Radius Influence Area - 3+ Fatal Collision Zones

Analysis from the $1000 \mathrm{~m}$ radius influence area indicated that seven out of the zones identified as high fatal collision locations were zones with ASCs. The high collision location zones were scattered and no apparent trend is visible other than the majority of the high collision zones were on SRN roads, which is expected since they are the freeways. Similar to the previous set of results, when calculating the average number of fatal traffic collisions within an ASC zone and the average number of fatal traffic collisions in zones with no ASC, the results turned out to be four fatal collisions in both 
cases. No apparent trend or pattern was spotted from the results. Therefore, no firm conclusions can be made from the results obtained.

Table 6.3 - High Fatal Traffic Collision Frequency Zones (1000 m Radius Influence Area)

\begin{tabular}{|c|c|c|c|c|}
\hline Buffer ID & $\begin{array}{c}\text { Number of Fatal } \\
\text { Collisions Inside } \\
\text { Buffer Zone } \\
\end{array}$ & Location & $\begin{array}{l}\text { Road } \\
\text { Type }\end{array}$ & AADT \\
\hline R 37 (Cam) & 6 & $\begin{array}{l}\text { 6th RR infront of } \\
\text { Sulaibiya }\end{array}$ & $\begin{array}{l}\text { SRN } \\
\text { Ring }\end{array}$ & 121,325 \\
\hline N53 & 5 & King Fahad Mwy & $\begin{array}{l}\text { SRN } \\
\text { Radial }\end{array}$ & 114,204 \\
\hline R 13 (Cam) & 4 & $\begin{array}{l}\text { King Fahad Exwy infront } \\
\text { Mubarak Alkabeer }\end{array}$ & $\begin{array}{l}\text { SRN } \\
\text { Radial }\end{array}$ & 121,673 \\
\hline R 40 (Cam) & 4 & $\begin{array}{l}\text { Fahaheel Exwy infront of } \\
\text { Qurain }\end{array}$ & $\begin{array}{l}\text { SRN } \\
\text { Radial }\end{array}$ & 110,023 \\
\hline R 41 (Cam) & 4 & $\begin{array}{l}\text { King Fahad Exwy infront } \\
\text { Qurain }\end{array}$ & $\begin{array}{l}\text { SRN } \\
\text { Radial }\end{array}$ & 122,721 \\
\hline R 51 (Cam) & 4 & $\begin{array}{l}\text { 6th RR bt. King } \\
\text { Faisal/King Fahad }\end{array}$ & $\begin{array}{l}\text { SRN } \\
\text { Ring }\end{array}$ & 124,207 \\
\hline N24 & 4 & Qortuba Street & SR & 114,665 \\
\hline N46 & 4 & Arabian Gulf Road & PRN & 56,886 \\
\hline N58 & 4 & $\begin{array}{l}\text { Abdulaziz Bin } \\
\text { Abdulrahman Al Saud } \\
\text { Ewy }\end{array}$ & $\begin{array}{l}\text { SRN } \\
\text { Radial }\end{array}$ & 107,542 \\
\hline N92 & 4 & 6th Ring & $\begin{array}{l}\text { SRN } \\
\text { Ring }\end{array}$ & 101,913 \\
\hline N131 & 4 & 7th Ring & $\begin{array}{l}\text { SRN } \\
\text { Ring }\end{array}$ & 64,060 \\
\hline R 26 (Cam) & 3 & $\begin{array}{l}\text { 6th RR infront Equestrian } \\
\text { club }\end{array}$ & $\begin{array}{l}\text { SRN } \\
\text { Ring }\end{array}$ & 112,722 \\
\hline R 42 (Cam) & 3 & $\begin{array}{l}\text { 6th RR bt. Saad } \\
\text { AlAbdulla }\end{array}$ & $\begin{array}{l}\text { SRN } \\
\text { Ring }\end{array}$ & 56,354 \\
\hline N18 & 3 & Magwa Road & SR & 21,547 \\
\hline N71 & 3 & 5th Ring & $\begin{array}{l}\text { SRN } \\
\text { Ring }\end{array}$ & 119,869 \\
\hline N97 & 3 & Al-Najashe Street & SR & 32,320 \\
\hline N107 & 3 & Incinerator Road & SR & 44,073 \\
\hline $\mathrm{N} 112$ & 3 & King Fahad Mwy & $\begin{array}{l}\text { SRN } \\
\text { Radial }\end{array}$ & 113,728 \\
\hline
\end{tabular}




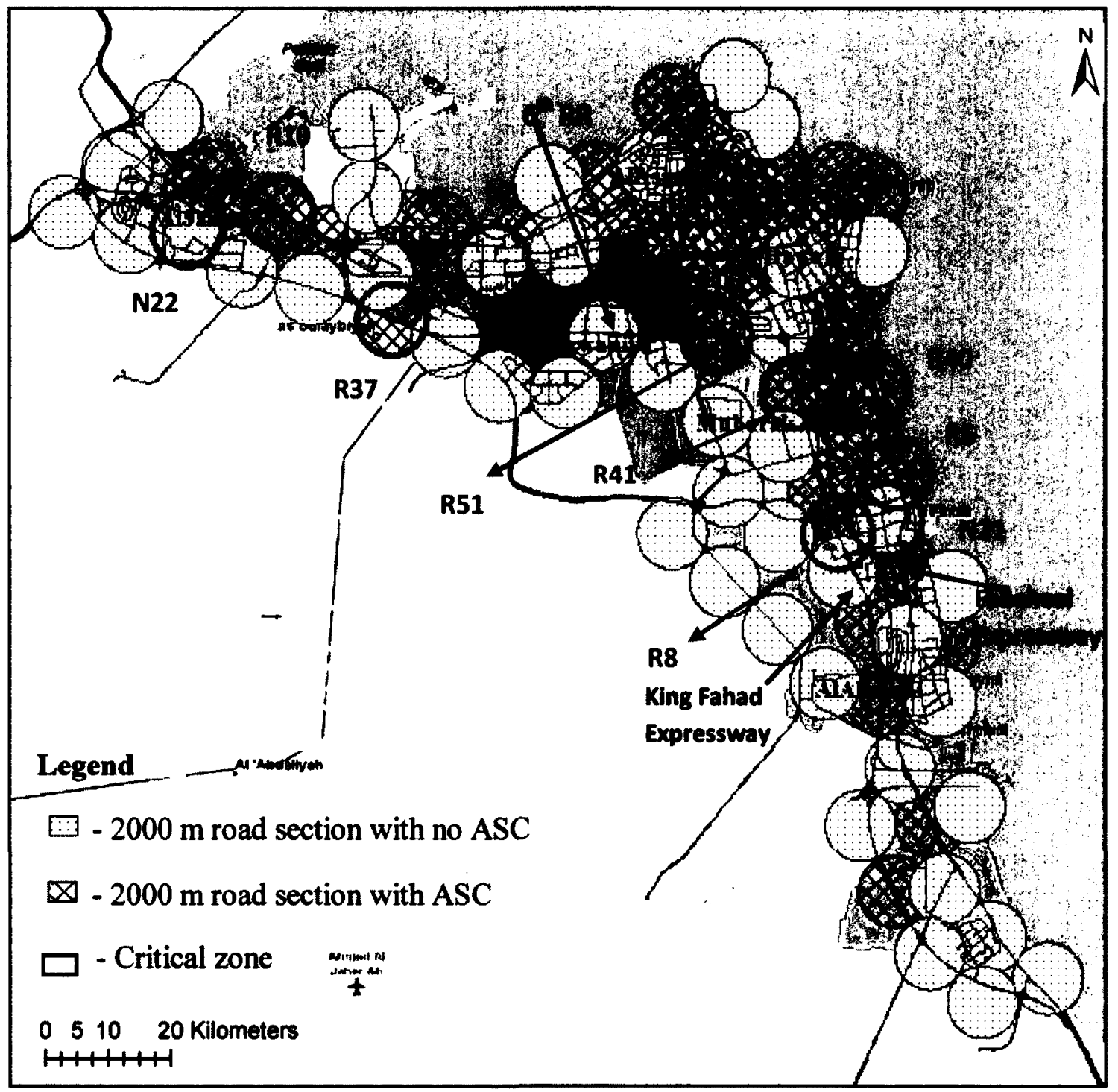

Figure 6.5 - 2000 m Radius Influence Area - 5+ Fatal Collision Zones

Analysis from the $2000 \mathrm{~m}$ radius influence area indicated that the majority of the zones identified as a high fatal collision locations were zones with ASCs. When calculating the average number of fatal traffic collisions within an ASC zone the result was six fatal collisions, and the average number of fatal traffic collisions in zones with no ASC was five fatal collisions. It seems like the zones with ASCs have a higher number of fatal collisions in this influence area. However, no definite conclusions can be made, and 
in order to better assess the effect of ASCs on the fatal collisions, collision data must be collected and before-and-after studies need to get conducted.

Table 6.4 - High Fatal Traffic Collision Frequency Zones (2000 m Radius Influence Area)

\begin{tabular}{|l|c|l|l|l|}
\hline Buffer ID & $\begin{array}{c}\text { Number of } \\
\text { Fatal } \\
\text { Collisions } \\
\text { Inside } \\
\text { Buffer } \\
\text { Zone }\end{array}$ & \multicolumn{1}{|c|}{ Location } & $\begin{array}{c}\text { Road } \\
\text { Type }\end{array}$ & AADT \\
\hline R 41 (Cam) & 8 & $\begin{array}{l}\text { King Fahad Exwy } \\
\text { infront Qurain }\end{array}$ & $\begin{array}{l}\text { SRN } \\
\text { Radial }\end{array}$ & 122,721 \\
\hline R 37 (Cam) & 7 & $\begin{array}{l}\text { 6th RR bt. infront } \\
\text { Sulaibiya }\end{array}$ & $\begin{array}{l}\text { SRN } \\
\text { Ring }\end{array}$ & 121,325 \\
\hline R 51 (Cam) & 7 & $\begin{array}{l}\text { 6th RR bt. King } \\
\text { Faisal/King Fahad }\end{array}$ & $\begin{array}{l}\text { SRN } \\
\text { Ring }\end{array}$ & 124,207 \\
\hline R 10 (Cam) & 5 & $\begin{array}{l}\text { Jahra Rd after } \\
\text { Amghara Bridge }\end{array}$ & PRN & 61,627 \\
\hline R 40 (Cam) & 5 & $\begin{array}{l}\text { Fahaheel Exwy } \\
\text { infront Qurain }\end{array}$ & $\begin{array}{l}\text { SRN } \\
\text { Radial }\end{array}$ & 110,023 \\
\hline R 6 (Cam) & 5 & $\begin{array}{l}\text { Fahaheel Exwy bt. } \\
\text { 6th RR/South } \\
\text { Sabhan }\end{array}$ & $\begin{array}{l}\text { SRN } \\
\text { Radial }\end{array}$ & 107,542 \\
\hline R 8 (Cam) & 5 & $\begin{array}{l}\text { King Fahad Exwy } \\
\text { Dhahar \& Hadiya }\end{array}$ & $\begin{array}{l}\text { SRN } \\
\text { Radial }\end{array}$ & 121,818 \\
\hline N8 & 5 & $\begin{array}{l}\text { Abdulaziz Bin } \\
\text { Abdulrahman Al } \\
\text { Saud Ewy }\end{array}$ & $\begin{array}{l}\text { SRN } \\
\text { Radial } \\
\text { Ning }\end{array}$ & 106,500 \\
\hline N22 & 5 & Al-Najashe Street & LR & 60,000 \\
\hline
\end{tabular}

The frequency distributions of the fatal traffic collisions were plotted for the three datasets and are presented in Figure 6.6 to Figure 6.8. The histograms are simply a means of presenting descriptive information about fatal accident frequencies and fatality distributions. There were 628 road sections for the $500 \mathrm{~m}$ radius influence area, 187 road 
sections for the $1000 \mathrm{~m}$ radius influence area and 96 road sections for the $2000 \mathrm{~m}$ radius influence area.

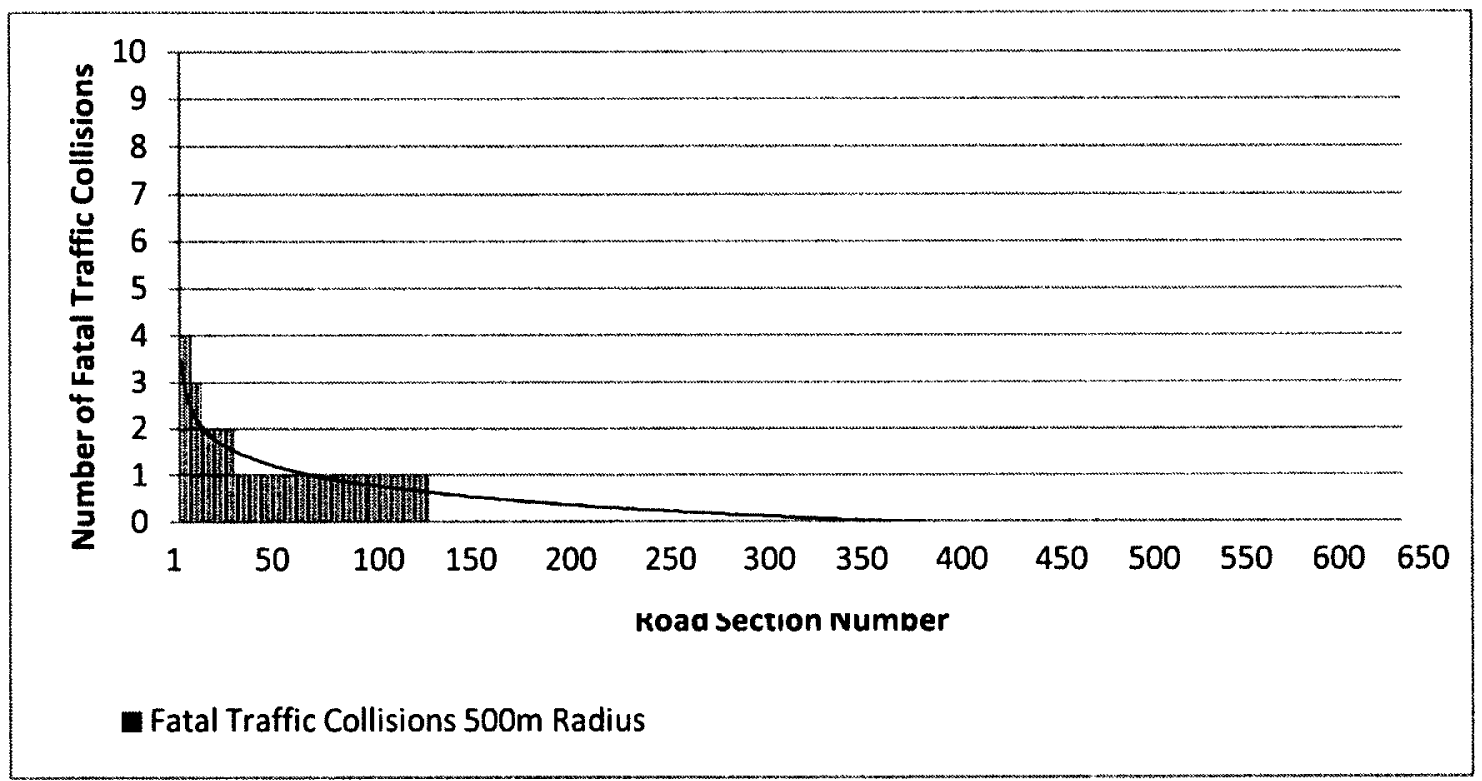

Figure 6.6 - Frequency Distribution of Fatal Collisions for 500 m Radius Influence Area

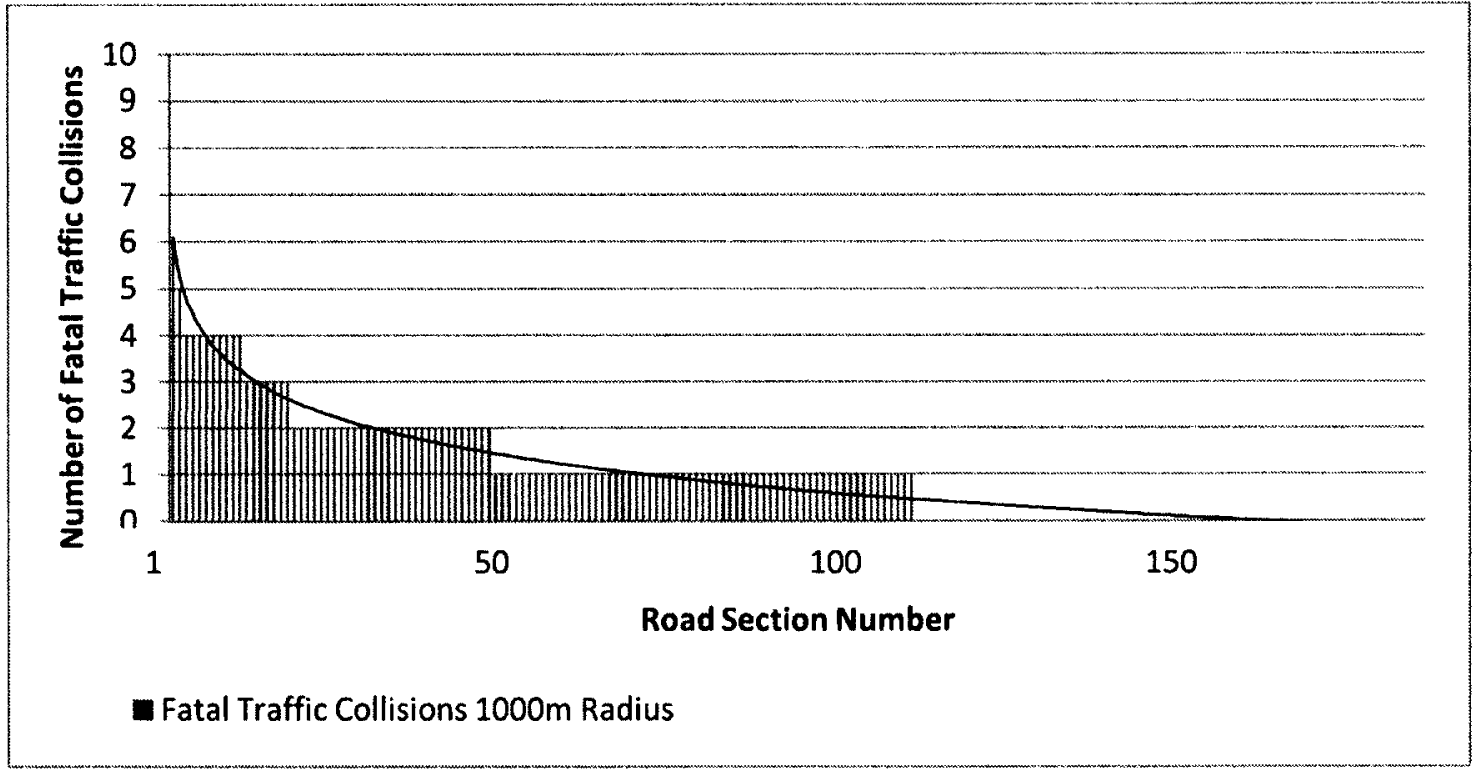

Figure 6.7 - Frequency Distribution of Fatal Collisions for $1000 \mathrm{~m}$ Radius Influence Area 


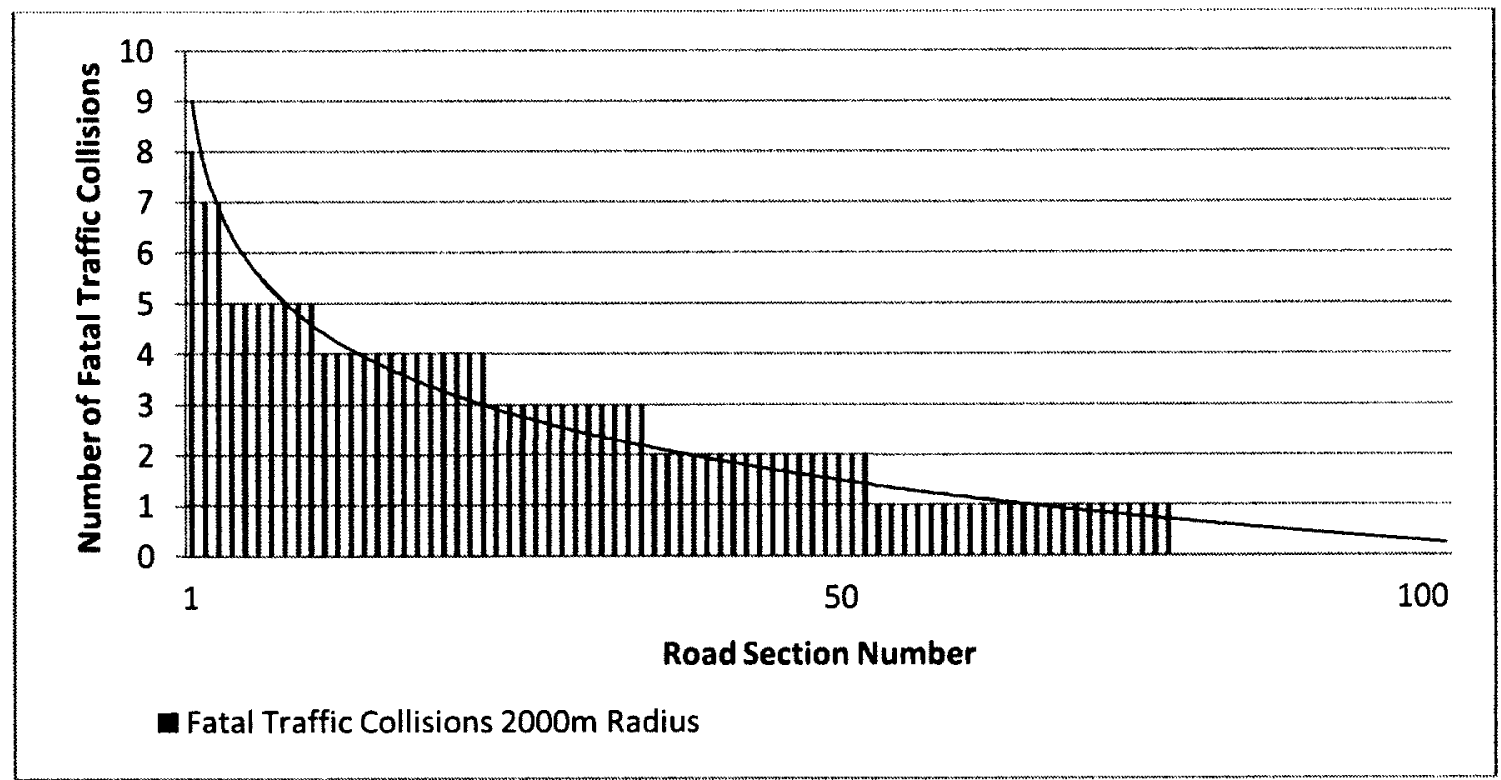

Figure 6.8 - Frequency Distribution of Fatal Collisions for 2000 m Radius Influence Area

The statistics presented in this section were quantitative, for the purpose of providing a better representation of the frequency of the fatal traffic collisions and the critical locations along the road network. The next section will focus on the regression technique used to create collision prediction models.

\subsection{Statistical Analysis}

A common way to define the safety of a system (usually measured by expected number of collisions) is the product of the probability of having a collision (also called collision risk) for a unit of exposure and the observed level of exposure (Xiao, Ivan and Ravishanker 2004). Collision prediction models have been developed to explain uncertainty in the occurrence of collisions. A report by Shope and Bingham (2008) explained that exposure can be represented at a global level using population size, total vehicle kilometres driven, or average kilometres driven per capita. Exposure can also be measured at the level of the individual as person-kilometres driven, time spent driving, or 
a combination of the two. Measures of individual exposure, however, are very expensive and difficult to obtain. As a result, population level exposure measures are more commonly used. The purpose of the exposure is to estimate the probability for a collision occurring. In practical applications, exposure can vary according to the mode or context being analyzed, and in this study traffic exposure was examined.

The traffic exposure and dummy variables used in this thesis are defined in Table 6.5 , and they represent the independent variables in the models. The traffic exposure variables are combinations and variations of the AADT, which was discussed in Section 4.2, and the length of the road sections, which were created in GIS. Also, a single exposure term combining the AADT and length was developed. The natural logarithms of these independent variables were also considered. A typical use of a logarithmic transformation variable is to pull outlying data from a positively skewed distribution closer to the bulk of the data in a quest to have the variable be normally distributed. In regression analysis the logs of variables are routinely taken, not necessarily for achieving a normal distribution of the predictors and/or the dependent variable but for interpretability (UCLA Academic Technology Services 2007).

Table 6.5 - Variable Definitions

\begin{tabular}{|l|l|}
\hline Variable & Definition \\
\hline$A A D T$ & Average annual daily traffic \\
\hline $\ln (A A D T)$ & Natural log of $A A D T$ \\
\hline Length & Length of roads in kilometres \\
\hline $\ln ($ Length $)$ & Natural log of Length \\
\hline Expo & Exposure $(A A D T \mathrm{x}$ Length $)$ \\
\hline $\ln ($ Expo $)$ & Natural log of Exposure \\
\hline Cam & Presence of Automated Speed Camera $(1=$ yes, $0=$ no) \\
\hline HighFlow & Traffic volume $>100,000$ vehicles per day $(1=$ yes, $0=$ no $)$ \\
\hline SRN & Special Road Network Ring \& Radial (road type $)(1=$ yes, $0=$ no) \\
\hline
\end{tabular}


In addition to the traffic exposure variables, dummy variables were introduced to code categorical variables, such as the presence of ASCs. The dependent variable was the number of fatal traffic collisions, obtained from the police reports. The variables' parameters have been quantified for the three influence areas (datasets) used and their results are listed in Table 6.6 to Table 6.8 .

Table 6.6 - Variable Parameters for 500 m Radius Influence Area

\begin{tabular}{|l|r|r|r|r|}
\hline Variable & \multicolumn{1}{|c|}{ Mean } & Std Dev & Minimum & Maximum \\
\hline \hline Accidents & 0.2755 & 0.6456 & 0 & 4 \\
\hline AADT & 64530 & 34439 & 3628 & 128683 \\
\hline $\operatorname{In}($ AADT $)$ & 10.9306 & 0.5421 & 8.1965 & 11.7651 \\
\hline Length & 2.1540 & 0.3503 & 0.9282 & 3.0296 \\
\hline In $($ Length $)$ & 0.7523 & 0.1812 & -0.0745 & 1.1084 \\
\hline Expo & 139218 & 78684 & 9059 & 354773 \\
\hline $\operatorname{In}($ Expo $)$ & 11.6829 & 0.5745 & 9.1115 & 12.7792 \\
\hline Cam & 0.0812 & 0.2734 & 0 & 1 \\
\hline HighFlow & 0.3355 & 0.4725 & 0 & 1 \\
\hline SRN & 0.3041 & 0.4604 & 0 & 1 \\
\hline
\end{tabular}

Table 6.7 - Variable Parameters for 1000 m Radius Influence Area

\begin{tabular}{|l|r|r|r|r|}
\hline Variable & Mean & Std Dev & Minimum & Maximum \\
\hline Accidents & 1.0214 & 1.1730 & 0 & 6 \\
\hline AADT & 75568 & 33336 & 3628 & 122005 \\
\hline $\ln ($ AADT $)$ & 11.1036 & 0.5615 & 8.1965 & 11.7118 \\
\hline Length & 3.4842 & 1.1240 & 0.3287 & 5.6393 \\
\hline $\ln ($ Length $)$ & 1.1787 & 0.4120 & -1.1125 & 1.7298 \\
\hline Expo & 263016 & 148504 & 15882 & 640150 \\
\hline $\ln ($ Expo $)$ & 12.2823 & 0.6948 & 9.6729 & 13.3695 \\
\hline Cam & 0.2727 & 0.4466 & 0 & 1 \\
\hline HighFlow & 0.4492 & 0.4987 & 0 & 1 \\
\hline SRN & 0.5455 & 0.4993 & 0 & 1 \\
\hline
\end{tabular}


Table 6.8 - Variable Parameters for 2000 m Radius Influence Area

\begin{tabular}{|l|r|r|r|r|}
\hline Variable & \multicolumn{1}{|c|}{ Mean } & Std Dev & Minimum & Maximum \\
\hline \hline Accidents & 2.1042 & 1.8323 & 0 & 8 \\
\hline AADT & 80866 & 32164 & 3628 & 122005 \\
\hline $\ln ($ AADT $)$ & 11.1793 & 0.5812 & 8.1965 & 11.7118 \\
\hline Length & 7.0424 & 1.2671 & 2.6926 & 9.3075 \\
\hline $\ln ($ Length $)$ & 1.9314 & 0.2188 & 0.9905 & 2.2308 \\
\hline Expo & 578102 & 249793 & 21461 & 1018787 \\
\hline $\ln ($ Expo $)$ & 13.1107 & 0.6821 & 9.9740 & 13.8341 \\
\hline Cam & 0.5313 & 0.5016 & 0 & 1 \\
\hline HighFlow & 0.4894 & 0.5026 & 0 & 1 \\
\hline SRN & 0.6146 & 0.4892 & 0 & 1 \\
\hline
\end{tabular}

A total of 12 general models were developed and investigated for each of the three datasets. The general model forms for the different combinations of variables are expressed mathematically in Equations 6.1 to 6.12. They follow the general model presented in Equation (4.6), which was discussed earlier in Section 4.4. A total of 60 trials were generated for all three influence areas to develop a predictive model assessing the effect of ASCs as measured in terms of frequency of fatal traffic collisions. The trials will be discussed later in this section.

The way the models were developed was by a two phase approach. Phase 1 consisted of examining the corelation between the traffic exposure variables to the fatal traffic collisions, as shown in Table 6.9. Six models (Equations 6.1 to 6.6) were attempted with a maximum of two independent variables included in the models. The traffic exposure variables introduced in the equations were used in two different forms, mathematical and in algorithm. It should be noted that the results of Phase 1 were the basis of developing Phase 2 . 
Table 6.9 - Phase 1 of the Collision Prediction Models Developed

\begin{tabular}{|l|c|c|c|c|c|c|}
\hline \multicolumn{7}{|c|}{ PHASE 1 } \\
\hline $\begin{array}{l}\text { Traffic } \\
\text { Exposure } \\
\text { Variables }\end{array}$ & Model 1 & Model 2 & Model 3 & Model 4 & Model 5 & Model 6 \\
\hline AADT & $\mathbf{x}$ & & $\mathbf{x}$ & & & \\
\hline $\ln ($ AADT $)$ & & $\mathbf{x}$ & & $\mathbf{x}$ & & \\
\hline Length & & & $\mathbf{x}$ & & & \\
\hline $\ln ($ Length) & & & & $\mathbf{x}$ & & \\
\hline Expo & & & & & $\mathbf{x}$ & \\
\hline $\ln ($ Expo $)$ & & & & & & $\mathbf{x}$ \\
\hline
\end{tabular}

Model $1(A A D T)$ :

$$
\lambda=\exp \left(\omega+A A D T * \beta_{1}\right)
$$

Model $2(\ln (A A D T))$ :

$$
\lambda=\exp \left(\omega+\ln (A A D T) * \beta_{1}\right)
$$

Model 3 (AADT, Length):

$$
\lambda=\exp \left(\omega+A A D T * \beta_{1}+\text { Length } * \beta_{2}\right)
$$

Model $4(\ln (A A D T), \ln ($ Length $))$ :

$$
\lambda=\exp \left(\omega+\ln (A A D T) * \beta_{1}+\ln (\text { Length }) * \beta_{2}\right)
$$

Model 5 (Expo):

$$
\lambda=\exp \left(\omega+\operatorname{Expo} * \beta_{1}\right)
$$

Model $6(\ln ($ Expo $))$ :

$$
\lambda=\exp \left(\omega+\ln (\text { Expo }) * \beta_{1}\right)
$$

In Phase 2, the significant traffic exposure variable(s) identified in Phase 1 were combined with the dummy variables to test the corelation between the presence of ASCs to the statistically significant traffic exposure variables, as shown in Table 6.10. Six 
models (Equation 6.7 to 6.12 ) were attempted with a maximum of four independant variables included in the models.

Table 6.10 - Phase 2 of the Collision Prediction Models Developed

\begin{tabular}{|l|c|c|c|c|c|c|}
\hline \multicolumn{7}{|c|}{ PHASE 2 } \\
\hline $\begin{array}{l}\text { Binary } \\
\text { Variables }\end{array}$ & Model 7 & Model 8 & Model 9 & Model 10 & Model 11 & Model 12 \\
\hline $\begin{array}{l}\text { Significant } \\
\text { Traffic } \\
\begin{array}{l}\text { Exposure } \\
\text { Variable (s) }\end{array}\end{array}$ & $\mathbf{x}$ & $\mathbf{x}$ & $\mathbf{x}$ & $\mathbf{x}$ & $\mathbf{x}$ & $\mathbf{x}$ \\
\hline Cam & $\mathbf{x}$ & & & $\mathbf{x}$ & $\mathbf{x}$ & $\mathbf{x}$ \\
\hline SRN & & $\mathbf{x}$ & & $\mathbf{x}$ & & $\mathbf{x}$ \\
\hline HighFlow & & & $\mathbf{x}$ & & $\mathbf{x}$ & $\mathbf{x}$ \\
\hline
\end{tabular}

Model 7 ((Significant Exposure Variable), Cam):

$$
\lambda=\exp \left(\omega+s * \beta_{1}+\operatorname{Cam} * \theta_{1}\right)
$$

Model 8 ((Significant Exposure Variable), SRN):

$$
\lambda=\exp \left(\omega+s * \beta_{1}+S R N * \theta_{1}\right)
$$

Model 9 ((Significant Exposure Variable), HighFlow):

$$
\lambda=\exp \left(\omega+s * \beta_{1}+\text { HighFlow } * \theta_{1}\right)
$$

Model 10 ((Significant Exposure Variable), Cam, SRN):

$$
\lambda=\exp \left(\omega+s * \beta_{1}+\operatorname{Cam} * \theta_{1}+\operatorname{SRN} * \theta_{2}\right)
$$

Model 11 ((Significant Exposure Variable), Cam, HighFlow):

$$
\lambda=\exp \left(\omega+s * \beta_{1}+\text { Cam } * \theta_{1}+\text { HighFlow } * \theta_{2}\right)
$$

Model 12 ((Significant Exposure Variable), Cam, SRN, HighFlow):

$$
\lambda=\exp \left(\omega+s * \beta_{1}+\operatorname{Cam} * \theta_{1}+S R N * \theta_{2}+\text { HighFlow } * \theta_{3}\right)
$$


As per the methodological process discussed earlier in Section 4.3, collision frequency models were estimated using negative binomial regression. The level of model dispersion was assessed based on the values of the scaled deviance and $\chi^{2}$ statistics divided by the model degrees of freedom, both parameters are referred to as the dispersion parameters. These values were provided in the SAS output as part of the criteria for assessing model goodness of fit. In general, values that deviate greatly from 0.8 to 1.2 indicate an unacceptable level of model dispersion and goodness of fit. The next three subsections discuss the statistically significant variables identified with their results.

\subsubsection{Statistical Models for the $500 \mathrm{~m}$ Radius Influence Area}

As part of Phase 1 of the analysis, which was determining the significant traffic exposure variable(s), four out of the six models were statistically significant at the $5 \%$ level of significance. The significant models were Model 1, Model 2, Model 5 and Model 6 incorporating the following traffic exposure variables respectively, $A A D T$, the untransformed exposure variable (Expo) and the natural logarithm of the single exposure term $(\ln (\operatorname{Expo}))$. Refer to Table 6.11 for a summary of statistics of the significant results.

A "Test" value was obtained from the standard table of percentiles of the $\chi^{2}$ distribution, based on $\chi^{2}(0.95 ; 626)$, and was applied for assessing the goodness of fit of all models developed for this influence area. The model's scaled deviance and the $\chi^{2}$ values indicated an acceptable model goodness of fit for all models, as the results were below the maximum allowable value of 685.32, except Model 6 with $\ln ($ Expo $)$ which had a $\chi^{2}$ exceeding the acceptable limit. 
Table 6.11 - Phase 1 - Significant Traffic Exposure Variables (500 m Radius Influence Area)

\begin{tabular}{|c|c|c|c|c|c|c|c|}
\hline $\begin{array}{c}\text { Model } \\
\#\end{array}$ & Variable & Estimate & $\begin{array}{c}p- \\
\text { value } \\
\left(\operatorname{Pr}>\chi^{2}\right)\end{array}$ & $\begin{array}{c}\text { Scaled } \\
\text { Deviance } \\
\text { Values }\end{array}$ & $\begin{array}{c}\chi^{2} \\
\text { Values }\end{array}$ & $\begin{array}{c}\text { Scaled } \\
\text { Deviance } \\
\text { Dispersion } \\
\text { Parameters }\end{array}$ & $\begin{array}{c}\chi^{2} \\
\text { Dispersion } \\
\text { Parameters }\end{array}$ \\
\hline \multirow{2}{*}{1} & Intercept & -2.2954 & $<.0001$ & \multirow{2}{*}{389.8228} & \multirow{2}{*}{659.2443} & \multirow{2}{*}{0.6227} & \multirow{2}{*}{1.0531} \\
\hline & $A A D T$ & $1.4 * 10^{-05}$ & $<.0001$ & & & & \\
\hline & & & & & & & \\
\hline \multirow{2}{*}{5} & Intercept & -2.2369 & $<.0001$ & \multirow{2}{*}{389.0495} & \multirow{2}{*}{662.0012} & \multirow{2}{*}{0.6215} & \multirow{2}{*}{1.0575} \\
\hline & Expo & $6.0 * 10^{-06}$ & $<.0001$ & & & & \\
\hline & & & & & & & \\
\hline \multirow{2}{*}{6} & Intercept & -11.1170 & $<.0001$ & \multirow{2}{*}{392.1677} & \multirow{2}{*}{696.0432} & \multirow{2}{*}{0.6265} & \multirow{2}{*}{1.1119} \\
\hline & $\ln ($ Expo $)$ & 0.8313 & $<.0001$ & & & & \\
\hline
\end{tabular}

Therefore, the results show that Model 5, incorporating the traffic exposure term Expo, provides more meaningful results than Model 1 with only $A A D T$ since it incorporates both the AADT and road section length parameters. This model was found to be statistically significant at the $5 \%$ level of significance, with an estimated $p$-value of $<0.0001$. The dispersion parameters of this model based on the scaled deviance and $\chi^{2}$ parameters respectively are 0.6215 and 1.0575 respectively. Following the Model 5 (6.5) general form, yields the following statistical model:

$$
\lambda=\exp \left(-2.2369+\text { Expo } * 6 * 10^{-06}\right)
$$

As part of Phase 2 of the analysis, modeling the natural logarithm of the single exposure term Expo was combined with the dummy variables, and the results indicated that none of the models were significant at the $5 \%$ level of significance. So, the other two statistically significant traffic exposure variables, mentioned in Table 6.11, were combined with the dummy variables as well to test their significance with the presence of 
ASCs. However, none of the exposure variables produced a statistically significant model either, as shown in Table 6.12. The complete set of SAS inputs and outputs of all the models generated can be found in Appendix C.

Table 6.12 - Phase 2 - Significant Dummy Variables (500 m Radius Influence Area)

\begin{tabular}{|c|c|c|c|c|c|c|c|}
\hline Model \# & Variable & Estimate & $\begin{array}{c}p- \\
\text { value } \\
\left(\operatorname{Pr}>\chi^{2}\right)\end{array}$ & $\begin{array}{c}\text { Scaled } \\
\text { Deviance } \\
\text { Values }\end{array}$ & $\begin{array}{c}\chi^{2} \\
\text { Values }\end{array}$ & $\begin{array}{c}\text { Scaled } \\
\text { Deviance } \\
\text { Dispersion } \\
\text { Parameters }\end{array}$ & $\begin{array}{c}\chi^{2} \\
\text { Dispersion } \\
\text { Parameters }\end{array}$ \\
\hline \multirow{3}{*}{7} & Intercept & -2.2986 & $<.0001$ & \multirow{3}{*}{389.2269} & \multirow{3}{*}{658.8677} & \multirow{3}{*}{0.6228} & \multirow{3}{*}{1.0542} \\
\hline & $A A D T$ & $1.3 * 10^{-05}$ & $<.0001$ & & & & \\
\hline & Cam & 0.4038 & 0.1462 & & & & \\
\hline
\end{tabular}

\begin{tabular}{|l|l|r|r|r|r|r|r|}
\hline \multirow{3}{*}{7} & Intercept & -2.2408 & $<.0001$ & & & & \\
\cline { 2 - 4 } & Expo & $5.7 * 10^{-06}$ & $<.0001$ & 388.0173 & 659.2366 & 0.6208 & \multirow{2}{*}{1.0548} \\
\cline { 2 - 4 } & Cam & 0.3930 & 0.1595 & & & & \\
\hline
\end{tabular}

\begin{tabular}{|l|l|r|r|r|r|r|r|}
\hline \multirow{3}{*}{7} & Intercept & -10.6879 & $<.0001$ & & & & \\
\cline { 2 - 4 } & $\ln ($ Expo $)$ & 0.7913 & $<.0001$ & 390.9059 & 683.4176 & 0.6254 & 1.0935 \\
\cline { 2 - 4 } & Cam & 0.3982 & 0.1533 & & & & \\
\hline
\end{tabular}

The lack of a significant relation between the fatal traffic collisions and the presence of ASCs may be due to the size of the influence area and the relatively low number of fatal collisions in most areas. Therefore, a larger influence area will be investigated in the next subsections.

\subsubsection{Statistical Models for the $1000 \mathrm{~m}$ Radius Influence Area}

As part of Phase 1 of investigating the statistically significant collision prediction models, the $A A D T$ variable from Model 1 was the only statistically significant traffic exposure variable at the $5 \%$ level of significance, with a $p$-value of 0.0239 . A summary 
of results of this model is presented in Table 6.13. The complete set of SAS inputs and outputs of all the models generated can be found in Appendix D.

The dispersion parameters of this model based on scaled deviance and $\chi^{2}$ respectively are 1.0926 and 0.9901 , which are considered acceptable. Also, the models' scaled deviances and $\chi^{2}$ values indicate an acceptable model goodness of fit, as their results were all below their maximum allowable value of 217.73 . This maximum value was obtained from the standard table of percentiles of the $\chi^{2}$ distribution, based on $\chi^{2}$ $(0.95 ; 185)$. This follows Model $1(6.1)$ general form, resulting in the following model:

$$
\lambda=\exp \left(-0.4263+A A D T *\left(5.7 * 10^{-06}\right)\right)
$$

Table 6.13 - Phase 1 - Significant Traffic Exposure Variables (1000 m Radius Influence Area)

\begin{tabular}{|c|l|c|c|c|c|c|c|}
\hline $\begin{array}{c}\text { Model } \\
\#\end{array}$ & Variable & Estimate & $\begin{array}{c}p \text {-value } \\
\left(\text { Pr }>\chi^{2}\right)\end{array}$ & $\begin{array}{c}\text { Scaled } \\
\text { Deviance } \\
\text { Value }\end{array}$ & $\chi^{2}$ Value & $\begin{array}{c}\text { Scaled } \\
\text { Deviance } \\
\text { Dispersion } \\
\text { Parameter }\end{array}$ & $\begin{array}{c}\chi^{2} \\
\text { Dispersion } \\
\text { Parameter }\end{array}$ \\
\hline \multirow{2}{*}{1} & Intercept & -0.4263 & 0.0511 & 202.1401 & 183.1668 & 1.0926 & 0.9901 \\
\cline { 2 - 8 } & AADT & $5.7^{*} 10^{-06}$ & 0.0239 & & & &
\end{tabular}

As part of phase two, the variable $A A D T$ was modeled with the dummy variable indicating the presence of ASCs (Model 7). As shown in Table 6.14, the AADT variable was statistically significant at the $5 \%$ level of significance in the model, with a $p$-value of 0.0412 . However the presence of ASCs ( $\mathrm{Cam})$ was not significant model, with a $p$-value of 0.4415 . 
Table 6.14 - Phase 2 - Significant Dummy Variables (1000 m Radius Influence Area)

\begin{tabular}{|c|c|c|c|c|c|c|c|}
\hline Model \# & Variable & Estimate & $\begin{array}{c}p- \\
\text { value } \\
\left(\operatorname{Pr}>\chi^{2}\right)\end{array}$ & $\begin{array}{c}\text { Scaled } \\
\text { Deviance } \\
\text { Values }\end{array}$ & $\underset{\text { Values }}{\chi^{2}}$ & $\begin{array}{c}\text { Scaled } \\
\text { Deviance } \\
\text { Dispersion } \\
\text { Parameters }\end{array}$ & $\begin{array}{c}\chi^{2} \\
\text { Dispersion } \\
\text { Parameters }\end{array}$ \\
\hline \multirow{3}{*}{7} & Intercept & -0.43386 & 0.0469 & \multirow{3}{*}{202.2916} & \multirow{3}{*}{182.5912} & \multirow{3}{*}{1.0994} & \multirow{3}{*}{0.9923} \\
\hline & $A A D T$ & $5 * 10^{-06}$ & 0.0412 & & & & \\
\hline & Cam & 0.14038 & 0.4415 & & & & \\
\hline
\end{tabular}

\subsubsection{Statistical Models for the $2000 \mathrm{~m}$ Radius Influence Area}

Since the radius of this influence area is large, some buffer zones around the ASCs overlapped, with some fatal collisions lying within intersecting regions. Therefore, two approaches were taken as to how the collisions were counted. The first approach was to associate each fatal collision in an intersecting region to the closest ASC location to avoid double counting collisions. The second approach was counting the total number of collisions within each buffer, allowing for double-counting of these fatal collisions. Results for both approaches will be presented in this section.

As part of Phase 1 of the analysis for the first approach of associating the fatal collisions within the intersecting buffer zones to the nearest ASC zone, Models 1,5 and 6 with $A A D T$, the untransformed exposure variable (Expo) and the natural logarithm of the single exposure term $(\ln ($ Expo $))$ were statistically significant at the $5 \%$ level of significance, as shown in Table 6.15. The complete set of SAS inputs and outputs of all the models generated can be found in Appendix E. 
Table 6.15 - Phase 1 - Significant Traffic Exposure Variables (2000 m Radius Influence Area) Closest ASC

\begin{tabular}{|c|c|c|c|c|c|c|c|}
\hline $\begin{array}{c}\text { Model } \\
\#\end{array}$ & Variable & Estimate & $\begin{array}{c}p- \\
\text { value } \\
\left(\operatorname{Pr}>\chi^{2}\right)\end{array}$ & $\begin{array}{c}\text { Scaled } \\
\text { Deviance } \\
\text { Values }\end{array}$ & $\underset{\text { values }}{\chi^{2}}$ & $\begin{array}{c}\text { Scaled } \\
\text { Deviance } \\
\text { Dispersion } \\
\text { Parameters }\end{array}$ & $\begin{array}{c}\chi^{2} \\
\text { Dispersion } \\
\text { Parameters }\end{array}$ \\
\hline \multirow{2}{*}{1} & Intercept & 0.0956 & 0.7121 & \multirow{2}{*}{112.8092} & \multirow{2}{*}{95.2019} & \multirow{2}{*}{1.2001} & \multirow{2}{*}{1.0128} \\
\hline & $A A D T$ & $2.8 * 10^{-06}$ & 0.0069 & & & & \\
\hline & & & & & & & \\
\hline \multirow{2}{*}{5} & Intercept & 0.1117 & 0.6425 & \multirow{2}{*}{112.8404} & \multirow{2}{*}{95.6964} & \multirow{2}{*}{1.2004} & \multirow{2}{*}{1.0180} \\
\hline & Expo & $1.2 * 10^{-06}$ & 0.0041 & & & & \\
\hline & & & & & & & \\
\hline \multirow{2}{*}{6} & Intercept & -3.1734 & 0.0981 & \multirow{2}{*}{112.9882} & \multirow{2}{*}{96.9294} & \multirow{2}{*}{1.202} & \multirow{2}{*}{1.0312} \\
\hline & $\ln ($ Expo $)$ & 0.2973 & 0.0406 & & & & \\
\hline
\end{tabular}

However, it was found that the use of the single exposure term (Expo) provided better results, since it was statistically significant and it incorporates both $A A D T$ and Length variables. Model 5 was statistically significant at the $5 \%$ level of significance, with a $p$-value of 0.0041 . The dispersion parameters of this model based on scaled deviance and $\chi^{2}$ respectively are 1.2004 and 1.0180. This follows Model 5 (Equation 6.5) general form, resulting in the following model:

$$
\lambda=\exp \left(-0.1117+\operatorname{Expo} *\left(1.2 * 10^{-06}\right)\right)
$$

The model scaled deviance and $\chi^{2}$ values w13sindicate an acceptable model goodness of fit, as these statistics are both below their maximum allowable value of 117.63. This maximum value was obtained from the standard table of percentiles of the $\chi^{2}$ distribution, based on $\chi^{2}(0.95 ; 94)$.

As part of Phase 2 of the analysis, the results indicated that the traffic exposure variable Expo was statistically significant at the 5\% level of significance when combined with Cam, as shown in Table 6.16. 
Table 6.16 - Phase 2 - Significant Dummy Variables (2000 m Radius Influence Area) Closest ASC

\begin{tabular}{|c|l|c|c|c|c|c|c|}
\hline Model \# & Variable & Estimate & $\begin{array}{c}p- \\
\text { value } \\
\left(\mathbf{P r}>\chi^{2}\right)\end{array}$ & $\begin{array}{c}\text { Scaled } \\
\text { Deviance } \\
\text { Values }\end{array}$ & $\begin{array}{c}\chi^{2} \\
\text { Values }\end{array}$ & $\begin{array}{c}\text { Scaled } \\
\text { Deviance } \\
\text { Dispersion } \\
\text { Parameters }\end{array}$ & $\begin{array}{c}\chi^{2} \\
\text { Dispersion } \\
\text { Parameters }\end{array}$ \\
\hline \multirow{3}{*}{7} & Intercept & -0.0957 & 0.7013 & & & & \\
\cline { 2 - 4 } & Expo & $9 * 10^{-07}$ & 0.0115 & 112.98 & 99.5317 & 1.2148 & 1.0702 \\
\cline { 2 - 4 } & Cam & 0.4841 & 0.0056 & & & & \\
\hline
\end{tabular}

Model 7 incorporating the Expo traffic exposure variable resulted in a $p$-value of 0.0115. The dispersion parameters of this model based on scaled deviance and $\chi^{2}$ respectively are 1.2148 and 1.0702 . The Cam variable was statistically significant at the $5 \%$ level of significance in this model with a $p$-value of 0.0056 . Following the Model 7 (Equation 6.7) general form, resulting in the following equation:

$$
\lambda=\exp \left(-0.0957+\text { Expo } *\left(9 * 10^{-07}\right)+\text { Cam } * 0.4841\right)
$$

The results for the second approach of counting the total number of fatal collisions within each buffer, allowing double-counting of some fatal collisions, were similar to those of the first approach. In Phase 1, Models 1, 5 and 6 were statistically significant at the $5 \%$ level of significance, as shown in Table 6.17 . The use of the single exposure term (Expo) in Model 5provided better results, since it was statistically significant and it incorporates both $A A D T$ and Length variables. Model 5 was statistically significant at the $5 \%$ level of significance, with a $p$-value of 0.0005 . The dispersion parameters of this model based on scaled deviance and $\chi^{2}$ respectively are 1.1991 and 0.9776. This follows Model 5 (Equation 6.5) general form, resulting in the following model:

$$
\lambda=\exp \left(0.1861+\operatorname{Expo} *\left(1.2 * 10^{-06}\right)\right)
$$


Table 6.17 - Phase 1 - Significant Traffic Exposure Variables (2000 m Radius Influence Area) Double Counting

\begin{tabular}{|c|c|c|c|c|c|c|c|}
\hline $\begin{array}{c}\text { Model } \\
\#\end{array}$ & Variable & Estimate & $\begin{array}{c}p- \\
\text { value } \\
\left(\operatorname{Pr}>\chi^{2}\right)\end{array}$ & \begin{tabular}{|c} 
Scaled \\
Deviance \\
Values
\end{tabular} & $\begin{array}{c}\chi^{2} \\
\text { Values }\end{array}$ & $\begin{array}{c}\text { Scaled } \\
\text { Deviance } \\
\text { Dispersion } \\
\text { Parameter }\end{array}$ & $\begin{array}{c}\chi^{2} \\
\text { Dispersion } \\
\text { Parameter }\end{array}$ \\
\hline \multirow{2}{*}{1} & Intercept & 0.1288 & 0.6156 & \multirow{2}{*}{113.3924} & \multirow{2}{*}{93.2995} & \multirow{2}{*}{1.2063} & \multirow{2}{*}{0.9925} \\
\hline & $A A D T$ & $2.8 * 10^{-06}$ & 0.0005 & & & & \\
\hline \multirow{3}{*}{5} & & & & \multirow{3}{*}{112.7171} & \multirow{3}{*}{91.8937} & \multirow{3}{*}{1.1991} & \multirow{3}{*}{0.9776} \\
\hline & Intercept & 0.1861 & 0.4422 & & & & \\
\hline & Expo & $1.2 * 10^{-06}$ & 0.0005 & & & & \\
\hline \multirow[b]{2}{*}{6} & Intercept & -4.3198 & 0.0272 & \multirow{2}{*}{113.4594} & \multirow{2}{*}{96.3871} & \multirow{2}{*}{1.207} & \multirow[b]{2}{*}{1.0257} \\
\hline & $\ln ($ Expo $)$ & 0.4004 & 0.0068 & & & & \\
\hline
\end{tabular}

As part of Phase 2 of the analysis, the results also indicated that the traffic exposure variable Expo was statistically significant at the 5\% level of significance when combined with Cam, as it was in the first approach, as shown in Table 6.18. This follows the Model 5 (Equation 6.5) general form, resulting in the following model:

$$
\lambda=\exp \left(-0.1767+\text { Expo } *\left(1 * 10^{-06}\right)+\text { Cam } * 0.7893\right)
$$

Table 6.18 - Phase 2 - Significant Dummy Variables (2000 m Radius Influence Area) Double Count

\begin{tabular}{|c|c|c|c|c|c|c|c|}
\hline $\begin{array}{l}\text { Model } \\
\#\end{array}$ & Variable & Estimate & $\begin{array}{c}\text { p- } \\
\text { value } \\
(\operatorname{Pr}>\chi 2)\end{array}$ & $\begin{array}{c}\text { Scaled } \\
\text { Deviance } \\
\text { Values }\end{array}$ & $\begin{array}{c}x^{2} \\
\text { Values }\end{array}$ & $\begin{array}{c}\text { Scaled } \\
\text { Deviance } \\
\text { Dispersion } \\
\text { Parameters }\end{array}$ & $\begin{array}{c}\chi^{2} \\
\text { Dispersion } \\
\text { Parameters }\end{array}$ \\
\hline \multirow{3}{*}{7} & Intercept & -0.1767 & 0.4637 & \multirow{3}{*}{113.9294} & \multirow{3}{*}{100.7172} & \multirow{3}{*}{1.225} & \multirow{3}{*}{1.083} \\
\hline & Expo & $1 * 10^{-06}$ & 0.002 & & & & \\
\hline & $\mathrm{Cam}$ & 0.7893 & $<.0001$ & & & & \\
\hline
\end{tabular}


The positive estimate of the variable Cam in both approaches suggests that the presence of ASCs is associated with higher collision frequency in that area. Although this can indicate that the presence of ASCs has a negative impact on safety, the result can also be due to the fact the installation of the ASCs throughout the years has been at locations with observed high collision frequencies. The fact that the collisions keep occurring around the ASC zones from year to year at a constant rate, instead of getting reduced, can be due to lack of before-and-after studies for collision frequencies in these areas. These types of studies can identify possible factors causing the collisions besides speeding, where other mitigations and countermeasures can be taken to reduce the number and severity of collisions.

In summary, this chapter presented the frequencies of fatal traffic collisions for the three influence areas identified and discussed the results of the high collision locations using GIS software. Also, collision prediction models were developed and tested for their significance to assess the effect of ASCs on the fatal traffic collisions. 


\section{Conclusions and Recommendations}

This chapter presents a summary of the main results and findings. In Section 7.1, the main conclusions of the thesis are presented and discussed, followed by Section 7.2 which covers recommendations for future research.

\subsection{Conclusions}

The main objective of this thesis was to quantify the effect of ASCs as measured in frequency of fatal traffic collisions using traffic statistics from the state of Kuwait. In order to achieve this main objective, several other objectives were identified and discussed in Chapter 1. The following paragraphs provide the main conclusions of the objectives achieved in this thesis.

A comprehensive literature review for the problem of collisions in general and in particular in Kuwait was carried out and discussed. There is a lack of traffic and road obedience by many drivers in Kuwait, despite awareness campaigns by the MOI. Many efforts have been made by the MOI of Kuwait to improve the traffic safety each year; however, recent traffic safety records point to an increase in both the number of violations and the occurrence of road collisions. In Kuwait there are no current standard procedures that neither identify hazardous locations on the roads nor set guidelines to assess safety countermeasures implemented. It was concluded that road authorities in Kuwait need to establish road safety improvement programs which aim at minimizing the suffering and losses due to road collisions.

A detailed comprehensive, digital database was created using the raw data from the police fatal collision reports, collected from the MOI of Kuwait, covering the period 
from January 2008 to December 2010. The importance of collecting and maintaining a collision database is that it represents the ultimate measure of how effective the remedial action has been in terms of reduced collisions. It should be mentioned that there were some limitations in creating the database. The fatal collision reports that were gathered did not consist of a complete set of reports; some reports were not retrievable from MOI due to misplacement on their part. It was assumed that the missing fatal traffic collision reports were random and that their locations are randomly distributed over the study area. It should also be noted that year-to-year differences in counts may be the result of the sampling process and not the result of actual trends.

The conditions governing the phenomenon of fatal traffic collisions in Kuwait and main trends were studied and several observations were identified and discussed. Next, the locations of the fatal traffic collisions along the road network in Kuwait were identified by assigning $\mathrm{X}$ and $\mathrm{Y}$ coordinates based on the written locations provided by the police. A collision density map was created using GIS software and qualitative spatial analysis was performed. The results of the spatial analysis identified the hazardous locations within three different sizes of influence areas, and the results showed that the presence of ASCs did not seem to have a direct effect on the number of collisions when compared to locations with no ASCs present. The high collision location zones were scattered for the most part and no apparent trend was visible other than the majority of the high collision zones were on SRN roads, which was expected since they are the freeways. However, no firm conclusions could be made from the results obtained.

Collision prediction models were developed using statistical analyses that assess the effect of ASCs as measured in frequency of fatal traffic collisions. Examining the 
effect of ASCs on safety performance is usually better carried out using a well designed before-and-after study. However, fatal traffic collision data for the period before automated speed cameras were installed in Kuwait was not available. Therefore, a before-and-after study could not be performed in this thesis. Alternatively, regression techniques were applied to develop collision prediction models which relate the fatal traffic collision frequency to the presence of ASCs and traffic exposure variables. The collision prediction models were developed based on negative binomial regression, using the SAS 9.2 statistical analysis software, to estimate the model coefficients through the method of maximum likelihood. A total of 12 collision prediction models were developed, and a total of 60 trials were tested for the three datasets created. These models were used to quantify the effect of ASCs on fatal traffic collision frequency and the major findings are summarized below:

- For the $500 \mathrm{~m}$ radius and the $1000 \mathrm{~m}$ radius influence areas, the traffic exposure variables Expo and $A A D T$ turned out to be statistically significant variables. However, when combined with the Cam variable, which represents the presence of ASCs, none of the models turned out to be significant. Therefore, there was no correlation between the presence of ASCs and the fatal traffic collisions in these influence areas.

- For the $2000 \mathrm{~m}$ radius influence area, that $A A D T$ was a statistically significant traffic exposure variable in the presence of ASCs. However, the results from the model provided a counterintuitive direction for the traffic exposure variable's relationship to the presence of ACSs. The positive estimate of the variable Cam suggests that the presence of ASCs is associated with higher collision frequency 
in those zones. Although this can indicate that the presence of ASCs has a negative impact on safety, the result can also be due to the fact the installation of the ASCs throughout the years has been at locations with observed high collision frequencies. The fact that the collisions keep occurring around the ASC zones from year to year at a constant rate, instead of getting reduced, can be due to lack of proper studies and follow up to these areas to identify possible factors causing the collisions besides speeding, where other mitigations and countermeasures can be taken to reduce the number and severity of collisions.

\subsection{Recommendations}

The main recommendations resulting from this thesis are summarized as follows:

- It is recommended to conduct a thorough before-and-after study for a comprehensive evaluation of the effect of automated speed enforcement on fatal traffic collisions. Another approach to estimating fatalities due to traffic collisions during the data collection phase is by analyzing sources other than police reports, including death registers and hospital records. These estimates should then be compared with policebased figures to test the validity of official government statistics. This leads to the recommendation of improving data linkages between police, transport, and health services to improve data quality.

- A simple, user-friendly collision reporting system should be developed for police and authorized civilians to improve data uniformity and accessibility. The system can be enhanced to provide features like adding multimedia capabilities, such as the ability to store digital photographs on scene of the traffic collisions. Also, using GIS 
mapping to locate collisions would enable traffic officials to visually identify trends and patterns more easily. When assessing critical zones based on high fatal traffic collision frequencies, a range of influence areas should be studied in future research.

- It is recommended to have automated traffic count stations distributed widely along the road network, on all road types, in order to capture accurate traffic flow counts. The AADT was the main roadway variable used in the statistical analysis of this thesis due to data availability. However, road geometry and environmental factors are also important to analyze fatal traffic collisions; such as the number of lanes, the median width, speed limits. Therefore, these types of variables should be included in future research when available.

- The use of automated traffic technology must be justified and reasonable, based on a site selection criteria and procedure. It is recommended to have ongoing evaluations to measure the effectiveness of automated traffic enforcement technology on lowering speeds, reducing collisions and most of all reducing traffic fatalities. 


\section{References}

Affonso, N.S. "Traffic Taming In Brasilia - A Revolution In Attitudes, Brazil." The Institute Of Sustainable Mobility. 2000. www.ruaviva.org.br.

Aljassar, A., A. Al-Kulaib, E. Metwalli, and K. Helali. "Performance of Roads in Kuwait." Ist International Conference on Performance of Roads, Bridges and Airport Pavements in Hot Climates. Dubai, 1998.

Aljassar, Ahmad, Mamdouh Al-Anzi, and Mohammed Ali. "An Investigation on the Effect of Traffic Cameras on Road Safety in Kuwait." Kuwait, 2004.

Aljassar, Ahmad, Mohammed Ali, and Omar AlSaleh. "Expansion Factors to Determine AADT from Short-Term Traffic Counts in Kuwait." Third Gulf Conference on Roads. Kuwait, 2006.

Aljassar, Ahmad, Mohammed Ali, and Omar Al-Saleh. Traffic Analysis on Kuwait Road Network. Kuwait: Kuwait University, 2005.

Alroudhan Group. Traffic safety systems. Humoud Al-Roudhan Group. 2008. http://alroudhangroup.org/fristjointgroup.php.

Anderson, Robin. Introducing Speed Cameras In The ACT-How To Win Friends And Influence People. Canberra: ACT Urban Services, 2000.

Asian Development Bank. Accident Database Design and Practice. Manila: Asian Development Bank, 2007.

Baguley, Chris. The importance of a road accident data system and its utilisation. United Kingdom: Transport Research Laboratory, 2001. 
Bhalla, Kavi. Global Burden of Road Injuries. International Journal of Injury Control and Safety Promotion. 2009. http://roadinjuries.globalburdenofinjuries.org/methods.

Bochner, Brian, and Troy Walden. Effectiveness of Red Light Cameras. Texas Transportation Institute White Paper, 2010.

CCMTA. Rural Road Safety in Canada: Traffic Collision Trends \& Recommended Strategies. Ottawa: Canadian Counsil of Motor Transport Administrators, 2006.

Dalbert, Tom. "Speed Cameras Slash Road Deaths: New Digital Technology is Having a Significant Deterrent Effect." ITS International 7, no. 3 (2001): 58.

Donnell, Eric, Shankar Venkataraman, and Richard Porter. Analysis of Safety Effects for the Presence of Roadway Lighting. University Park, PA: The Pennsylvania State University, 2009.

Elvik, Rune. State-of-the-art Approaches ro raod accident black spot management and safety analysis of road networks. Oslo: Norwegian Centre for Transport Research, 2007.

European Communities. Glossary of transport statistics, 3rd ed. United Nations, Luxembourg: Office for Official Publications of the European Communities, 2003.

FHWA. Accident Models for Two-Lane Rural Roads: Segment and Intersections. Washington, D.C.: United States Department of Transportation - Federal Highway Administration, 1998.

FHWA. Prediction of the Expected Safety Performance of Rural Two-Lane Highways. 2011. http://www.fhwa.dot.gov/publications/research/safety/99207/01.cfm.

FHWA. Speed Management Work Plan. Washington, D.C.: United States Department of Transportation - Federal Highway Administration, 1997. 
FHWA. Speeding and Highway Safety. 2000.

http://safety.fhwa.dot.gov/speedmgt/policy/spdppolicybro.cfm.

Finch, D., P. Kompfner, C. Lockwood, and G. Maycock. Speed, Speed Limits and Accidents. Crowthorne: Transport Research Laboratory, 1994.

Frith, B., G. Strachan, and T. Patterson. Road Safety Implications of Excessive and Inappropriate Vehicle Speed. Australasian Road Safety Handbook, 2006.

Graettinger, A., J. Lindly, and G. Mistry. Display and Analysis of Crash Data. Huntsville: University Transportation Center for Alabama, 2005.

Ha, Tae-Jun, Jeong-Gyu Kang, and Je-Jin Park. "The Effects of Automated Speed Enforcement Systems on Traffic-Flow Characteristics and Accidents in Korea." Institute of Transportation Engineers, 2003: 28-31.

Hauer, E. "Speed and Safety." Transportation Research Record: Journal of the Transportation Research Board (Transportation Research Board of the National Academies), no. 2103 (2009): 10-17.

Hauer, E., and B.N. Persaud. "How to Estimate the Safety of Rail-Highway Grade Crossings." Transportation Research Record: Journal of the Transportation Research Board (Transportation Research Board of the National Academies), 1988: 131-140.

Hauer, E., D. Harwood, F. Council, W. Hughes, and A. Vogt. Prediction of the Expected Safety Performance of Rural Two-Lane Highways. FHWA-RD-99-207, McLean: US DOT Federal Highway Administration, 2000.

Imran, Muhammad, interview by Private Email Conversation. Blackspot diagram preparation guidelines Alberta, (March 30, 2012). 
Insurance Institute for Highway Safety. "Who Cares about a Camera if you are not Speeding." 34, no. 6 (1999): 1-3.

ITE. Before-and-After Study Technical Brief. Institute of Transportation Engineers Transportation Safety Council, 2009.

Jacobs, G., A. Aeron-Thomas, and A. Astrop. Estimating Global Road Fatalities. Crowthome: Transport Research Laboratory, 2000.

Jovanis, P., and H. Chang. "Modeling the relationship of accidents to miles traveled." Transportation Research Record: Journal of the Transportation Research Board (Transportation Research Board of the National Academies) 1068 (1986).

Junior, Rudel, and Carlos Nassi. System of Geographically Plotted Information on Road Accidents. Sao Paulo: Federal University of Mato Grosso do Sul, 2008.

KAMCO. "Influencing Factors in the Real Estate Market in Kuwait." KAMCO Research . Issued by the Investment Research Department at KIPCO Asset Management Company (KAMCO). 2010. www.menafn.com/updates/research_center/Kuwait/.../kamcol00510ee.pdf.

Kentucky, University of. Negative Binomial; Testing For Overdispersion in Poisson regression. July 8, 2008. http://www.uky.edu/ComputingCenter/SSTARS/www/documentation/P_NB_3.htm.

Kirkham Michael Consulting Engineers. South Dakota Interstate Corridor Study. Pierre: South Dakota Department of Transportation, 2000.

KLEN News. Kentucky Law Enforcement News. Richmond: Kentucky Justice Cabinet, 2003. 
Liu, Guo Xin, and Al Popoff. "State-Wide Travel Speed and Traffic Safety in Saskatchewan." Transportation Research Record: Journal of the Transportation Research Board (Transportation Research Board of the National Academies) 1595 (1997): 8-13.

Lovegrove, G., and T. Sayed. "Macrolevel Collision Prediction Models to Enhance Traditional Reactive Road Safety Improvement Programs." Transportation Research Record: Journal of the Transportation Research Board (Transportation Research Board of the National Academies), 2008: 65-73.

Lyons, Ronan. Road Traffic Accidents. 1998. http://hebw.cf.ac.uk/injury/chapter3.html.

Mahmud, Ahmad Rodzi. "Intelligent GIS-Based Road Accident Analysis and Real-Time Monitoring Automated System using WiMAX/GPRS." International Journal of Engineering 2, no. 1 (2008): 1-7.

Meuleners, Lynn. Effectiveness of the Black Spot Programs in Western Australia. Australia: Elsevier, 2008.

Mikulík, Josef, and Péter Holló. Road Accident Investigation Guidelines for Road Engineers. World Road Association PIARC Technical Committee, 2007.

MOI. "Prospective view of traffic - Traffic study." (Ministry of Interior), no. 9 (2007): 18-21.

New York State Police. TraCS - Traffic and Criminal Software. 2012. http://www.tracs.troopers.ny.gov/.

Nilsson, G. Traffic safety dimensions and the power model to describe the effect of speed on safety. Bulletin 221, Lund: Lund Institute of Technology, 2004.

OECD. Speed Management. Paris, France. : Organization for Economic Cooperation and Development , 2008. 
Peng, Haolei. Effects of Two-Lane Left-Turn Lane on Roadway Safety. M.S.Thesis, Department of Civil Engineering, University of South Florida, 2004.

Pilkington, Paul. Do Speed Cameras Reduce Collisions and Related Casualties? No. 46, Bristol, UK: The Bristol Cyclist, 2002.

Pilkington, Paul. Effectiveness of speed cameras in preventing road traffic collisions and related casualties: systematic review. Bristol: University of the West of England, 2004.

Preamble, A. Automated Traffc Enforcement Technology Guidelines. Alberta Solicitor General and Public Security, 2009.

Sagberg, Fridulv. "Automatic Enforcement Technologies and Systems." Technical Research Centre of Finland (VTT), 2000.

Sayed, Tarek, and Paul de Leur. "A framework to proactively consider road safety within the road planning process." (Canadian Journal of Civil Engineering) 30:(4) 711-719, no. 10.1139/103-034 (2003).

Sayed, Tarek, and Paul de Leur. Collision Prediction Models For British Columbia. British Columbia: Engineering Branch BC Ministry of Transportation \& Infrastructure, 2008.

Shope, Jean, and Raymond Bingham. "Teen Driving - Motor-Vehicle Crashes and Factors That Contribute." American Journal of Preventive Medicine (Elsevier Inc.), 2008: 261 -271.

Sorensen, Michael. Black Spot Management and Safety Analysis of Road Networks - Best Practice Guidelines and Implementation Steps. Riserest, 2005.

TARC. Development of Accident Prediction Model. Thailand Accident Research Center (TARC), 2009. 
Taylor, M., D. Lynam, and A. Baruya. The effect of drivers' speed on the frequency of accidents. TRL Report TRL421, Crowthorne: Transport Research Laboratory, 2000.

The University of Alabama. eCrash - Electronic Traffic Crash Reporting. Tuscaloosa: Center for Advanced Public Safety, 2009.

Tian, Zhun. Investigating Speed-Accident Relationship at Urban Signalized Intersections Using Accident Prediction Models. Vancouver: The University of British Columbia, 2011.

Transport Canada. Road Safety in Canada. Ottawa: Road Safety and Motor Vehicle Regulation \& Public Health Agency of Canada, 2011.

Transportation Research Board. Managing speed; review of current practice for setting and enforcing speed limits. Washington, DC: National Academy Press, 1998.

UCLA Academic Technology Services. Regression Models with Count Data - Statistical Consulting Group. April 2007. http://128.97.141.26/stat/stata/seminars/count_presentation/count.htm.

UCLA Academic Technology Services. SAS FAQ. 2007. http://www.ats.ucla.edu/stat/sas/faq/sas_interpret_log.htm.

UNDP. National Traffic \& Transport Sector Strategy for Kuwait 2009-2019 - UNDP \& General Directorate of Traffic Project 2009-2013. Kuwait: United Nations Development Programme - State of Kuwait, 2009.

Van Hooijdonk, Andreas. Information on GPS navigation and other GPS applications. 2009. http://www.gps-practice-and-fun.com/radar-detectors.html.

WHO. Eastern Mediterranean status report on road safety. Office for the Eastern Mediterranean: World Health Organization, 2010. 
WHO. "Global Burden of Disease 2004." World Health Organization. World Health Organization. 2004.

http://www.who.int/healthinfo/global_burden_disease/GBD_report_2004update_full.pdf.

WHO. Global Status Report on Road Safety: Time for Action. Geneva: World Health

Organization, 2009.

WHO. "Number of road traffic deaths." Global Health Observatory (GHO). World Health Organization. 2011.

http://www.who.int/gho/road_safety/mortality/traffic_deaths_number/en/index.html.

WHO. World Health Organization - Global Health Observatory Data Repository. World Health Organization, 2007.

WHO. "World Health Statistics." World Health Organization. 2008. http://www.who.int/whosis/whostat/2008/en/index.html.

WHO. World Report on Road Traffic Injury Prevention. Geneva: World Health Organization, The World Bank, 2004.

Wikipedia. "Demographics of Kuwait." Wikimedia Foundation, Inc., March 23, 2011.

Wikipedia. "Kuwait." Wikimedia Foundation, Inc., May 9, 2011.

Wikipedia. "Transport in Kuwait." Wikimedia Foundation, Inc., September 2, 2011.

Xiao, Qin, John N. Ivan, and Nalini Ravishanker. "Selecting exposure measures in crash rate prediction for two-lane highway segments." Accident Analysis and Prevention, 2004: $183-191$. 
Yunlong, Zhang. "Estimating the Dispersion Parameter of the Negative Binomial Distribution for Analyzing Crash Data Using a Bootstrapped Maximum Likelihood Method." Texas A\&M University. 2006.

https://ceprofs.civil.tamu.edu/dlord/papers/zhang_et_al._bmle.pdf. 
Appendix A

Fatal Traffic Collisions Database 


\begin{tabular}{|c|c|c|c|c|c|c|c|c|c|c|c|c|c|c|}
\hline Case * & MOI case " & $\begin{array}{l}\text { Police } \\
\text { Station }\end{array}$ & Type & Type Brand & $\begin{array}{l}\text { Vehicle } \\
\text { Model }\end{array}$ & $\begin{array}{l}\text { No. of } \\
\text { Veciles } \\
\text { Involved }\end{array}$ & $\begin{array}{l}\text { Day of } \\
\text { Week }\end{array}$ & Date & Time & $\begin{array}{l}\text { Time of } \\
\text { Day }\end{array}$ & Main Road & Towards & In front of & $\begin{array}{l}\text { Seat in } \\
\text { vehicle }\end{array}$ \\
\hline 1 & $\frac{428 / 2009}{679 / 2009}$ & \begin{tabular}{|l} 
AlRouda \\
Sharg
\end{tabular} & \begin{tabular}{|l|} 
Rollover \\
Run-over
\end{tabular} & $\frac{\text { Missubishi }}{\text { Mini Cospe }}$ & Suv & Single & Manday & $03 / 30 / 09$ & $10: 30 \mathrm{AM}$ & $\frac{\text { Morning }}{\frac{\text { Twillight }}{\text { nat }}}$ & $\frac{\text { Rivadh Expr }}{\text { Toulf had }}$ & Kuwait Gry & AlAdailiya & \begin{tabular}{|l} 
Driver \\
Passenger
\end{tabular} \\
\hline$\frac{2}{3}$ & $\frac{1 / 99 / 2009}{477 / 2009}$ & $\frac{\mid 5 \text { harg }}{\text { A|Adan }}$ & $\frac{\mid \text { Ron-over }}{\text { Collision w }}$ & Thinca & \begin{tabular}{|l} 
Saion \\
Bus
\end{tabular} & $\frac{\mid \text { Single }}{\text { Twoo }}$ & \begin{tabular}{|l} 
Eriday \\
Sunday
\end{tabular} & $\frac{0405 / 17 / 09}{0.03 / 09}$ & $\frac{66: 30 \mathrm{PM}}{7 \mathrm{7} 30 \mathrm{PM}}$ & $\frac{\text { Whlight }}{\text { Night }}$ & \begin{tabular}{|l|} 
Gulf Road \\
King AbdulA
\end{tabular} & 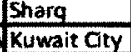 & 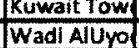 & $\frac{\text { Passenger }}{\text { Passenger }}$ \\
\hline 4 & $589 / 2009$ & \begin{tabular}{|l} 
jileeb \\
Alshiyookk
\end{tabular} & $\begin{array}{l}\text { Collision } \\
\text { w/Other } \\
\text { vehicle(s) }\end{array}$ & Mercedes & Salon & Itwo & Friday & $05 / 01 / 09$ & $2: 00 \mathrm{PM}$ & Afternoon & $\begin{array}{l}\text { Alfarwaniy } \\
\text { a Hospital } \\
\text { Bridge }\end{array}$ & 6th RR & $\begin{array}{l}\text { Alfarwaniy } \\
\text { a Hospital }\end{array}$ & Doriver \\
\hline 5 & $443 / 2009$ & Trima & Run-over & Toyota & SUV & Single & Wednesday & $04 / 29 / 09$ & $1: 35 \mathrm{PM}$ & Afternoon & South Jahra & Area & House 46 & Pedestrian \\
\hline 6 & $435 / 2009$ & Trima & Rollover & Ford & Salon & Single & Tuesday & $04 / 28 / 09$ & 5:00 AM & Dawn & & Allahra & Xilo 60 & Driver \\
\hline 7 & $99 / 2009$ & Sabah Ainas & Run-aver & Toyota & SUV & Single & Monday & $104 / 27 / 09$ & 12:15 PM & Afternoon & ah AINag & & & Pedestrian \\
\hline 8 & $623 / 2009$ & Taima & Run-over & Toyote & SUV & Single & Thursday & $104 / 23 / 09$ & 5:00 PM & Twilight & Allahra Alu & & House : 54 & Pedestrian \\
\hline 9 & $157 / 2009$ & Alwaha & $\begin{array}{l}\text { Collision } \\
\text { w/other } \\
\text { Vehicle(s) }\end{array}$ & Toyota & Salon & Two & Monday & $104 / 20 / 09$ & 8:00 PM & Night & Alsalmi & Alsalmi & \begin{tabular}{|l} 
Wahat \\
AlGhanim
\end{tabular} & briver \\
\hline 10 & $383 / 2009$ & Trima & Run-over & Bus & Salon & Single & Tuesday & $04 / 14 / 09$ & $1: 30 \mathrm{PM}$ & Afternoon & Trima Area & Parking lot & Alkhansa Sc & Pedestrian \\
\hline 11 & $332 / 2009$ & Alfarwaniva & Run-over & BMW & Salon & Single & Wednesday & $03 / 04 / 09$ & $1: 00 \mathrm{AM}$ & Morning & Airport Roa & Airport & Alfarwaniyad & Pedestrian \\
\hline 12 & $324 / 2009$ & 5 abah Alsal & Run-over & Bus & Bus & Single & Tuesday & $03 / 10 / 09$ & $12: 45$ PM & Afternoon & $77 \mathrm{thR}$ & Allahra & Signal post & Passenger \\
\hline 13 & $217 / 2009$ & $\begin{array}{l}\text { Mubarak } \\
\text { AlKabeer }\end{array}$ & $\begin{array}{l}\text { Collition } \\
\text { w/Other } \\
\text { Vehicle(s) }\end{array}$ & Nissan & SuV & Three & Tuesday & $03 / 10 / 09$ & $O P M$ & Afternoon & King Fahad & Kuwait City & \begin{tabular}{|l|} 
Mubarak \\
Alkabeet \& \\
Qurain Exit
\end{tabular} & Driver \\
\hline & & & & Nissan & suV & & & & & & & & & ssenger \\
\hline$\frac{14}{15}$ & $252 / 2009$ & Taima & over & Mercedes & Bus & |Jingle & Tuesday & $\frac{03 / 10 / 09}{1021 / 100}$ & $100 \mathrm{AM}$ & Dawn & Vaseem & Ainaseem & ANseem ri & ver \\
\hline 16 & $20 / 2009$ & Alzoor & \begin{tabular}{|l} 
Collision \\
w/Other \\
vehicle(s)
\end{tabular} & Lexus & Salon & Two & Wednesday & $102 / 25 / 09$ & 12:30 PM & Afternoon & $\begin{array}{l}\text { King Fahad } \\
\text { Kheeran }\end{array}$ & |Road 295 & & Driver \\
\hline 17 & $95 / 2009$ & Traima & $\begin{array}{l}\text { Collision } \\
\text { w/Other } \\
\text { Vehicle(s) }\end{array}$ & Leep & SUV & Jwo & Saturday & $01 / 24 / 09$ & 4:00 PM & Afternoon & & $\begin{array}{l}\text { Markaz } \\
\text { Aissalmi }\end{array}$ & $\mid$\begin{tabular}{|l|l}
$\mid \begin{array}{l}\text { Luwa' } \\
\text { Alshhaheed }\end{array}$ \\
\end{tabular} & |Driver \\
\hline 18 & $183 / 2009$ & Taima & $\begin{array}{l}\text { Collision } \\
\text { w/Other } \\
\text { vehicle(s) }\end{array}$ & & Unknown & Two & Thursday & $02 / 19 / 08$ & 6:30 PM & Twilight & \begin{tabular}{|l} 
BRTA \\
AINaeem \\
\& RA \\
Ainaseem \\
\end{tabular} & Allahra & Traima & Driver \\
\hline 19 & $228 / 200$ & Kaifan & $\begin{array}{l}\text { Collision } \\
\text { w/Other } \\
\text { Vehicle(s) }\end{array}$ & & Saton & Two & Thursday & $102 / 12 / 09$ & $D O A M$ & Morning & 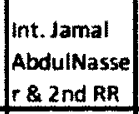 & Aluahra & Aalshwaikh & \\
\hline & & & & \begin{tabular}{|c|} 
Milsubishi \\
Mitsubishi
\end{tabular} & $\sqrt{5 a}$ & & & & & & & & & Passenger \\
\hline 20 & $141 / 2009$ & Sabah Alsa & Rollover & Nissan & Pick-up True & dTwo & Saturday & $101 / 3$ & $\bar{M}$ & & thit $7 \mathrm{thRR}$ & Alohahar & Sabhan Cem & Passenger \\
\hline 21 & $125 / 2009$ & Aladan & Run-over & Nissan & Salon & Single & Truesday & & & Afternoon & Aalta'awun a & Aissalmiya & AlMissela & Pedestrian \\
\hline 22 & $175 / 2009$ & Kalfan & Rollover & Alifí Rom & Sports & S Single & Saturday & $01 / 31 / 09$ & $100 \mathrm{AM}$ & awn & lamal $A b d u$ & & & Driver \\
\hline
\end{tabular}




\begin{tabular}{|c|c|c|c|c|c|c|}
\hline Gender & Nationality & $\begin{array}{l}\text { Year of } \\
\text { Birth }\end{array}$ & Age (no) & \begin{tabular}{|l} 
Number of \\
Fatallies \\
in Case
\end{tabular} & $\begin{array}{l}\text { Collision X } \\
\text { coordinate }\end{array}$ & $\begin{array}{l}\text { Collision Y } \\
\text { coordinate }\end{array}$ \\
\hline Male & Kuwaiti & 1991 & 18 & 1 & 47.973308 & 29.325350 \\
\hline Male & Egyptian & 1998 & $\sqrt{11}$ & 1 & 48.002136 & 29.389017 \\
\hline Male & Egyptian & 1975 & 34 & 5 & 48.105546 & 29.205802 \\
\hline Male & Exyptian & 1956 & 53 & 1 & 47.907839 & 29.269267 \\
\hline Female & Kuwaiti & 2007 & 2 & 1 & 47.685936 & 29.330394 \\
\hline Male & Kuwaiti & 1986 & 23 & $\sqrt{1}$ & 47.182884 & 29.125052 \\
\hline Female & Unknown & 2006 & 3 & $\frac{1}{1}$ & 47.882100 & 29.269539 \\
\hline Male & Kuwaiti & 2003 & $\frac{1}{6}$ & 1 & 47.654839 & 29.329672 \\
\hline |Male & Kuwait! & 1986 & 23 & $I_{1}$ & 47617761 & 29335185 \\
\hline Female & Kuwaiti & 1999 & 100 & $\frac{1}{1}$ & 47.690267 & 29.324767 \\
\hline Male & Unknown & Unknown & Unknown & + & 47.969114 & 29.273178 \\
\hline Maie & Egyptian & 1958 & 51 & $\frac{1}{1}$ & 47.865130 & 29.251964 \\
\hline Female & Kuwaiti & 1977 & 32 & 2 & 48.062775 & 29.196278 \\
\hline Male & Kuwbaiti & 2003 & 6 & & & \\
\hline Male & Egyptian & 1983 & 26 & 1 & 47.069778 & 29.318531 \\
\hline Male & $\begin{array}{l}\text { Kuwaiti } \\
\end{array}$ & 2947 & $\frac{62}{62}$ & \pm & 47.657609 & 29.543865 \\
\hline Female & Kuwaiti & 1992 & 17 & 1 & 48.319486 & 28.633142 \\
\hline Male & Kuwaiti & 1973 & 36 & 1 & 47.615257 & 29.334082 \\
\hline Maie & lother & 1960 & 49 & 1 & 47.68514 & 29.333875 \\
\hline Male & Egyptian & 1975 & 34 & 3 & 47.950108 & \\
\hline Male & Egyptian & 1971 & 38 & & & \\
\hline Male & Egyptian & 1987 & $\frac{122}{22}$ & & & \\
\hline Male & Kuwaiti & 1991 & 18 & & 48.060106 & 29.173447 \\
\hline Male & Tother & 1958 & 51 & & 48.087383 & 29.270814 \\
\hline Male & Kuwait & 1973 & 36 & & 47.92 & \\
\hline
\end{tabular}




\begin{tabular}{|c|c|c|c|c|c|c|c|c|c|c|c|c|c|c|}
\hline 23 & $13 / 2009$ & AlAndalos & \begin{tabular}{|l|} 
Collision \\
w/Other \\
vehicle(s)
\end{tabular} & Suriki & suv & Two & Friday & $01 / 15 / 09$ & $1: 00$ PM & Afternoon & Sth RR & Allaha & AlAndalos & Driver \\
\hline 24 & $61 / 2009$ & Taima & $\begin{array}{l}\text { Collision } \\
\text { w/Other } \\
\text { Vehicle(s) }\end{array}$ & Ford & $\begin{array}{l}\text { Pick-up } \\
\text { Truck }\end{array}$ & Two & Friday & $01 / 23 / 09$ & 3:30 PM & Afternoon & 4th RR & Kuwait City & Gas Station & Passenger \\
\hline 25 & $98 / 2009$ & Alsulaibiya & Collision w/ & Mini Coope & Salon & Single & Friday & $01 / 30 / 09$ & $1: 15 \mathrm{AM}$ & Night & Behind & Sabah AINa: & Gas Station & Driver \\
\hline 26 & $38 / 2009$ & Alsabahiya & $\begin{array}{l}\text { Collision } \\
\text { w/Other } \\
\text { Vehiclets) }\end{array}$ & $\begin{array}{l}\text { Bus } \\
\text { (Nissan) }\end{array}$ & $\begin{array}{l}\text { Pick-up } \\
\text { Truck }\end{array}$ & I wo & Monday & $01 / 19 / 09$ & 7:30 PM & Night & $\begin{array}{l}\text { Fahaheel } \\
\text { Exy on Top } \\
\text { of fahaheel } \\
\text { Bridge }\end{array}$ & $\mid \begin{array}{l}\text { AlNuwaisee } \\
\mathrm{b}\end{array}$ & $\begin{array}{l}\text { Fahaheei } \\
\text { Club }\end{array}$ & Driver \\
\hline 27 & $23 / 2009$ & Sabah Alsal & Run-over & Tahoe & SUV & Single & Wednesday & $101 / 07 / 09$ & $1: 00 \mathrm{AM}$ & Night & King Fahad & AlAhmadi & Alqurain & Pedestrian \\
\hline 28 & $78 / 2009$ & AlArdhiya & Run-over & Ford & Unknown & Single & Monday & $01 / 19 / 09$ & $8: 00 \mathrm{PM}$ & Night & West of Ard & AIRiggie & AlArdhiya & Pedestrian \\
\hline 29 & $33 / 2009$ & AlArdhiya & $\begin{array}{l}\text { Collision } \\
\text { w/Other } \\
\text { Vehiclefs\} }\end{array}$ & Nissan & Salon & Two & Saturday & $01 / 17 / 09$ & 6:00 PM & I wilight & $\begin{array}{l}\text { imtidad } \\
\text { Muhamad } \\
\text { bil gassem }\end{array}$ & 1 & - & Passenger \\
\hline 30 & $53 / 2009$ & Alsulaibiya & Run-over & Mercedes & HGV/Constr & Single & Thursday & $01 / 15 / 09$ & $3: 30 \mathrm{PM}$ & Afternoon & In side (alma & $E$ & Gate 13 & Pedestrian \\
\hline 31 & $60 / 2009$ & Aladan & Collision w/ & Chevrolet & Salon & Single & Sunday & $01 / 18 / 09$ & 3:30 PM & Dawn & Seperator b & king fahad & Man6agat a & Passenger \\
\hline 32 & $38 / 2009$ & AlAdan & $\begin{array}{l}\text { Collision } \\
\text { w/Other } \\
\text { Vehicle(s) }\end{array}$ & Toyota & Salon & Two & Thursday & $01 / 08 / 09$ & 12:10 PM & Afternoon & \begin{tabular}{|l} 
Kign \\
Abdulaziz \\
alsaud
\end{tabular} & Kuwait Oty & Almissela & Driver \\
\hline 33 & $74 / 2009$ & & $\begin{array}{l}\text { Collision } \\
\text { w/other } \\
\text { Vehicle(s) }\end{array}$ & Mitsubishi & sur & Ino & Sunday & $01 / 11 / 09$ & $7: 00 \mathrm{PM}$ & Night & 4th RR & Suwaikh & $\begin{array}{l}\text { maidan } \\
\text { hawali } \\
\text { (right) } \\
\text { salmiva } \\
\text { (left) }\end{array}$ & Lriver \\
\hline & & & & Mitsubishi & suv & & & & & & & & & Passenger \\
\hline 34 & $1350 / 2009$ & Traima & {$\left[\begin{array}{l}\text { Collision } \\
\text { w/Other } \\
\text { vehiclets }\end{array}\right.$} & Toyota & Salon & Two & Tuesday & $12 / 22 / 09$ & $5: 30 \mathrm{AM}$ & Dawn & Alsalmi & $\begin{array}{l}\text { manfath } \\
\text { alsalmi }\end{array}$ & signal post & Driver \\
\hline & & & & Toyota & Salon & & & & & & & & & Passenger \\
\hline & & & & Toyota & Salon & & & & & & & & & Passenger \\
\hline & & & & Toyota & Salon & & & & & & & & & Passenger \\
\hline 35 & $541 / 2009$ & Alsulaibiya & Collision wf & ford & Salon & Single & Saturday & $07 / 18 / 09$ & $7: 00 \mathrm{PM}$ & Night & Kabd & Kabd & Gas Station & Driver \\
\hline 36 & $146 / 2009$ & Alsulaibiya & $\begin{array}{l}\text { Collision } \\
\text { w/other } \\
\text { Vehicle(s) }\end{array}$ & Toyota & Salon & Two & Sunday & $02 / 22 / 09$ & 7:00 AM & Morning & Kabd & $\begin{array}{l}\text { luwakheer } \\
\text { Kabd }\end{array}$ & $\begin{array}{l}\text { Media } \\
\text { fence }\end{array}$ & Doriver \\
\hline 37 & $1702 / 2000$ & AlAhmad| & $\begin{array}{l}\text { Collision } \\
\text { w/Other } \\
\text { Vehicle(s) }\end{array}$ & Mercedes & Unknown & Two & Tuesday & $11 / 10 / 09$ & 5:45 AM & loawn & Kabd & $\begin{array}{l}\text { Sabah } \\
\text { AlNasser }\end{array}$ & & loriver \\
\hline 38 & $578 / 2009$ & Alsulaiblya & Collision w/ & Toyota & suv & Single & Wednesday & $08 / 05 / 09$ & $5: 00 \mathrm{AM}$ & Dawn & kabd & kabd & Gas Station & Driver \\
\hline 39 & $1317 / 2009$ & Allahra & Rollover & GMC SOnON & Pick-up Tru & Single & Saturday & $12 / 19 / 09$ & $12: 15 \mathrm{PM}$ & Afternoon & Alsalmi & Allahra & Kilo 85 & Driver \\
\hline 40 & $1377 / 2009$ & AlAdan & Collision w/ & Hundai & Salon & Two & Tuessday & $12 / 22 / 09$ & $9: 30 \mathrm{PM}$ & Night & King AbdulA & Alfahaheel & Right of AlA & Driver \\
\hline & & & & Hundai & Salon & & & & & & & & & Passenger \\
\hline 41 & $735 / 2009$ & M. Abdulla & Rollover & Toyota & Salon & Single & Monday & $11 / 16 / 09$ & $9: 30 \mathrm{AM}$ & Morning & fir 3y to fahe & & shalainat & Driver \\
\hline & & & & Toyota & Salon & & & & & & & & & Passenger \\
\hline
\end{tabular}




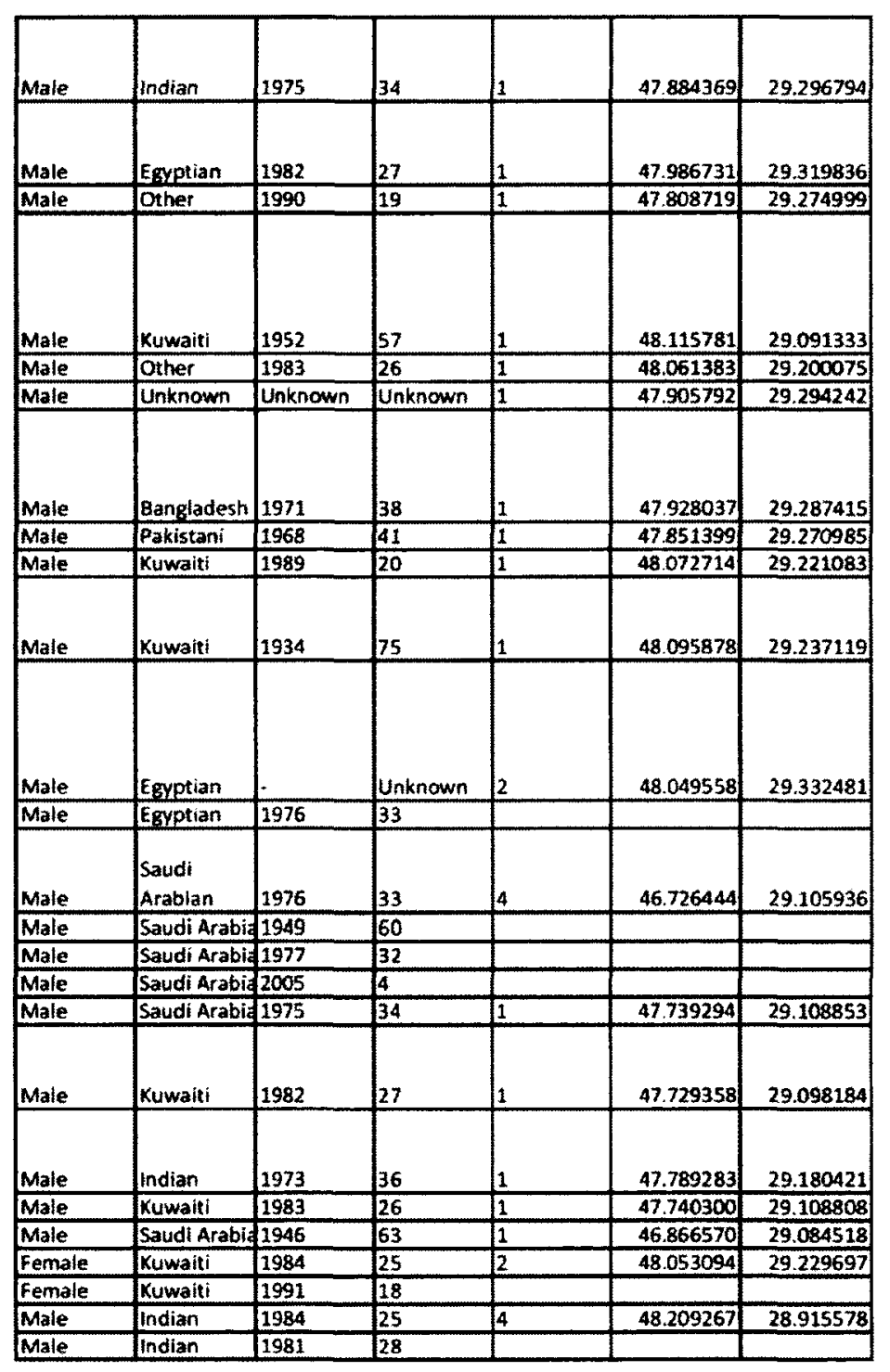




\begin{tabular}{|c|c|c|c|c|c|c|c|c|c|c|c|c|c|c|}
\hline & & & & Toyota & TSalon & & & & & & & & & JPassenger \\
\hline & & & & Toyota & Salon & & & & & & & & & Passenger \\
\hline 42 & $1112 / 2009$ & Allahra & Rollover & Suburban & SUV & Single & Tuesday & $12 / 01 / 09$ & $10: 30 \mathrm{AM}$ & Morning & \multicolumn{2}{|c|}{ Alabdily inner } & albaghly far & Driver \\
\hline 43 & $1106 / 2009$ & Aljahra & Collision w & Toyota & Salon & Single & Thursday & $11 / 26 / 09$ & $4: 00 \mathrm{AM}$ & Dawn & AlMutlaa' & Aljahra & Signal Post & Driver \\
\hline 44 & $1108 / 2009$ & Alizahra & Rollover & Nissan & Suv & Single & Saturday & $11 / 28 / 09$ & $5: 00 \mathrm{PM}$ & Twilight & Subiya dese & road & & Passenger \\
\hline 45 & $1075 / 2009$ & Mubarak AII & Run-over & Missan & Salon & Single & Thursday & $11 / 20 / 09$ & 11:00PM & Night & AlQoos st & Alsubahiya & Mubarak AI & Pedestrian \\
\hline 46 & $1206 / 2009$ & Taima & Run-over & scooper & HGV/Constr & Single & Saturday & $11 / 14 / 09$ & $5: 00 \mathrm{AM}$ & Dawn & deset lot $\mathrm{Ar}$ & & dikan & Pedestrian \\
\hline 47 & $1593 / 2009$ & Sabah Alsal & Collision w & Jeep & suv & Single & Tuesday & $11 / 10 / 09$ & $2.35 \mathrm{PM}$ & Afternoon & King lahad & Alahmadi & AlAskari Ho & Driver \\
\hline 48 & $1533 / 2009$ & Sabah AISal & Collision w/ & Toyota & Salon & Two & Wednesday & $10 / 28 / 09$ & $12: 45 \mathrm{PM}$ & Afternoon & King Abdul & Alfahaheel & Sabah Alsale & Passenger \\
\hline 49 & & & Collision w/ & Jeep & suv & Two & Tuesday & $10 / 27 / 09$ & $1: 15 \mathrm{PM}$ & Afternoon & King Fahad & Kuwait Gity & Aladan Gas & Driver \\
\hline 50 & $636 / 2009$ & M. Abdulla & $\begin{array}{l}\text { Collision } \\
\text { w/Other } \\
\text { vehicle(s) }\end{array}$ & & Salon & Itwo & Saturday & $10 / 03 / 09$ & $6: 00 \mathrm{AM}$ & Morning & $\begin{array}{l}\text { M. } \\
\text { Abdullah } \\
\text { Bridge }\end{array}$ & bridge & $\begin{array}{l}\text { King Fahad } \\
\text { exwy }\end{array}$ & Driver \\
\hline 51 & $435 / 2009$ & AlRigga & Collision wl & Pigeut & Saton & Single & Friday & $10 / 02 / 09$ & Unknown & Unknown & Fahaheel Ex & AlNuwaised & Rigga Area & Driver \\
\hline 52 & $645 / 2009$ & M. Abdulla & Collision w & Foyota & Unknown & Two & Wednesday & $10 / 07 / 09$ & $1.00 \mathrm{PM}$ & Afternoon & Fahaheel Ex & Kuwait City & Mina Abdul & Driver \\
\hline 53 & $1769 / 2009$ & Aisulaibiya & Collision w & Chevrolet & suv & Single & Monday & $10 / 19 / 09$ & $2: 30 \mathrm{PM}$ & Afternoon & 5 Sth $R R$ & Kuwait City & Special Forc & Driver \\
\hline 54 & $357 / 2009$ & Airport & $\begin{array}{l}\text { Collision } \\
\text { w/Other } \\
\text { Vehicle(s) }\end{array}$ & Bus & Bus & Twoo & Monday & $10 / 19 / 09$ & 5:20 AM & Dawn & Sabhan & Alahmadi & $\begin{array}{l}\text { Saad } \\
\text { Alabdulia } \\
\text { Airport } \\
\text { fence }\end{array}$ & Driver \\
\hline & & & & Bus & Bus & & & & & & & & & Passenger \\
\hline & & & & Bus & Bus & & & & & & & & & Passenger \\
\hline & & & & Bus & Bus & & & & & & & & & Passenger \\
\hline 55 & $1075 / 2009$ & Taima & Rollover & Toyota & suv & Two & Tuesday & $10 / 13 / 09$ & $6: 00 \mathrm{AM}$ & Morning & Alsalmi & aljahra & Light pole & Driver \\
\hline 56 & $937 / 2009$ & Mubarak Al & Rollover & GMC & Pick-up Truc & dTwo & Friday & $10 / 09 / 09$ & $5: 15 \mathrm{AM}$ & Dawn & King Abdult & Alfahaheel & Fintas Bridg & Passenger \\
\hline 57 & $971 / 2009$ & 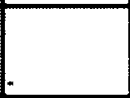 & $\begin{array}{l}\text { Collision } \\
\text { w/Other } \\
\text { Vehicle(s) }\end{array}$ & Toyota & Salon & Two & Wednesday & $09 / 16 / 09$ & 9:00 PM & Night & AlSaimi & Alsaimi & $\begin{array}{l}\text { Abdullah } \\
\text { Alsalem }\end{array}$ & Passenger \\
\hline 58 & $917 / 2009$ & Allahra & Run-over & Suzuki & suv & Single & Wednesday & $109 / 23 / 09$ & $4: 15 \mathrm{AM}$ & Dawn & Alsubira & Aljahra & Alsubiya & Driver \\
\hline 59 & $861 / 2009$ & Mubarak AII & Rollover & Toyota & Salon & Single & Tuesday & $09 / 15 / 09$ & $5: 00 \mathrm{PM}$ & Twillight & King Abdut & Alfahaheel & mubarak alt & Driver \\
\hline 60 & $1444 / 2009$ & Bayan & Collision w/ & Mitsubishi & saion & Two & Tuesday & $09 / 01 / 09$ & $7: 30 \mathrm{PM}$ & Night & Alfahaheel & Alahmadi & Mishrel & Passenger \\
\hline 61 & $850 / 2009$ & Allahra & Rollover & Mercedes & HGV/Constr & Single & Sunday & $08 / 30 / 09$ & $8: 00 \mathrm{PM}$ & Night & Alsubiya & Alsubiya & Subiya Elect & Doriver \\
\hline 62 & $805 / 2009$ & $\begin{array}{l}\text { Mubarak } \\
\text { AlKabeer }\end{array}$ & $\begin{array}{l}\text { Collision } \\
\text { w/Other } \\
\text { Venicle(s) }\end{array}$ & Toyota & suv & Two & Monday & $08 / 31 / 09$ & $8: 30 \mathrm{PM}$ & Night & $208 \mathrm{Ro}$ & Alfahaheel & $\begin{array}{l}\text { verote } \\
\text { bridge } \\
\text { qisoor } \\
\text { alqurain } \\
\text { with king } \\
\text { Abdulaziz } \\
\text { (dwg) }\end{array}$ & Deiver \\
\hline 63 & $2892 / 2009$ & Salmiya & Collision w/ & Nissan & Unknown & Two & Wednesday & $08 / 12 / 09$ & $7: 00 \mathrm{PM}$ & Night & Baghdad St & Beach & LaBaghette & Deiver \\
\hline 64 & $1175 / 2009$ & $\begin{array}{l}\text { Sabah } \\
\text { Alsalem }\end{array}$ & $\begin{array}{l}\text { Collision } \\
\text { w/Other } \\
\text { Vehicle(s) }\end{array}$ & Chevrolet & suv & Two & Friday & $8 / 14 / 2009$ & s:30 AM & Dawn & $\begin{array}{l}\text { 6th RR } \\
\text { Alsaimi Int. }\end{array}$ & $\begin{array}{l}\text { Alta'awun } \\
\text { rd }\end{array}$ & 1 & Passenger \\
\hline 65 & $1856 / 2009$ & Khaitan & Rollover & Mitsubishi & suv & Two & Sunday & $07 / 12 / 09$ & Unknown & Unknown & King Faisal & Airport & Khaitan & Driver \\
\hline 66 & $767 / 2009$ & Allahra & Rollover & Mitsubishi & SUN & Single & Thursday & $107 / 30 / 09$ & $7: 30 \mathrm{PM}$ & Afternoon & & Alabdily & Deser & Doriver \\
\hline & & & & Mitsubishi & Suv & & & & & & & & & Passenger \\
\hline & & & & Mitsubishi & Suv & & & & & & & & & Passenger \\
\hline & & & & Mitsubishi & suv & & & & & & & & & Passenger \\
\hline
\end{tabular}




\begin{tabular}{|c|c|c|c|c|c|c|}
\hline Male & Pakistani & T1972 & 37 & & & \\
\hline Male & Indian & 1974 & 35 & & & \\
\hline Male & Kuwail! & 1995 & $\frac{14}{14}$ & ti & 47.710447 & 29.973569 \\
\hline Male & Kuwaiti & 1992 & 18 & $\pi$ & 47.643954 & 29.364741 \\
\hline Male & Other & 2004 & 5 & $\sqrt{1}$ & 48.081092 & 29.604781 \\
\hline Male & Kuwaiti & 1992 & 17 & $\frac{1}{1}$ & 48.089864 & 29.185975 \\
\hline Male & Bangladesh & 1971 & 38 & 1 & 47.755191 & 29.313937 \\
\hline Male & Kuwaiti & 1987 & $\sqrt{22}$ & $\sqrt{1}$ & 48.048539 & 29.243750 \\
\hline Male & Indian & 1979 & 30 & 1 & 48.047067 & 29.248914 \\
\hline Male & Kuwaiti & 1990 & 19 & $\frac{1}{1}$ & 48.052994 & 29.229486 \\
\hline Male & Other & 1974 & 35 & 1 & 48.121772 & 28.958511 \\
\hline Male & Kuwaiti & 1966 & 43 & $\sqrt{1}$ & 48.112228 & 29.149606 \\
\hline Male & Kuwaiti & 1985 & 24 & $\sqrt{1}$ & 48.135314 & 29,006881 \\
\hline Male & Other & 1962 & $\sqrt{47}$ & 1 & 47.857875 & 29.294803 \\
\hline unknown & Junknown & unknown & Junknown & 4 & 47.995811 & 29.226247 \\
\hline unknown & Unknown & unknown & unknown & & & \\
\hline unknown & Unknown & funknown & unknown & & & \\
\hline unknown & Unknown & unknown & unknown & & & \\
\hline Male & Saudíl Arabic & 1943 & 66 & 1 & 47.589205 & 29.312775 \\
\hline Male & Kuwaiti & 1993 & 116 & 1 & 48.113531 & 29.176883 \\
\hline Female & $\begin{array}{l}\text { Saudi } \\
\text { Arabian }\end{array}$ & 1988 & 21 & 1 & 47.538667 & 29.324311 \\
\hline Male & Egyptian & 1936 & 73 & 1 & 48.140383 & 29.582064 \\
\hline Male & Kuwaiti & 1985 & 124 & $\sqrt{1}$ & 48.108211 & 29.196014 \\
\hline Male & indian & 1987 & 22 & $\pi$ & 48.079347 & 29.277292 \\
\hline Male & Tother & 1972 & 37 & $\frac{1}{1}$ & 48.114242 & 29.590533 \\
\hline Male & Kuwaiti & 1982 & 27 & 1 & 48.089075 & 29.208739 \\
\hline Male & Kuwaiti & 1991 & 18 & 1 & 48.056717 & 29.336836 \\
\hline Female & Kuwaiti & 1979 & 30 & 1 & 47.630458 & 29.337978 \\
\hline Male & Egyptian & 1964 & 45 & $\frac{1}{12}$ & 47.985817 & 29.280244 \\
\hline Male & Other & 1968 & 41 & $\frac{1}{4}$ & 47.609112 & 29.330340 \\
\hline Male & Other & 1953 & 56 & & & \\
\hline Male & Jother & 1953 & 56 & & & \\
\hline Male & Oother & 1981 & 28 & & & \\
\hline
\end{tabular}




\begin{tabular}{|c|c|c|c|c|c|c|c|c|c|c|c|c|c|c|}
\hline 67 & $130 / 2009$ & Phase 1 & Collision w/ & Mitsubishi & TSaton & Single & Tuesday & $07 / 28 / 09$ & 5:00 AM & Jown & Sth RR & Allahra & Phase 1 & Passenger \\
\hline 68 & $854 / 2009$ & Traima & Rollover & Toyota & Bus & Single & Wednesday & $08 / 12 / 09$ & $1: 00 \mathrm{AM}$ & Dawn & Alsalmi & Alsalmi & Light pole & Passenger \\
\hline 69 & $1623 / 2009$ & Maida Haw: & Run-over & Chevrolet & Unknown & Single & Tuesday & $07 / 21 / 09$ & Unknown & Juknown & Gulf Road & Alsalmiya & Sha'ab Palad & Pedestrian \\
\hline 70 & $818 / 2009$ & Aladan & Rollover & Chevrolet & Salon & Single & Sunday & $07 / 20 / 09$ & $1: 45$ AM & Jawn & King AbduiA & Atahmadi & Missela are: & Driver \\
\hline 71 & $1035 / 2009$ & $\begin{array}{l}\text { Sabah } \\
\text { Alsalem }\end{array}$ & $\begin{array}{l}\text { Collision } \\
\text { w/Other } \\
\text { Vehicle(s) }\end{array}$ & Nissan & salon & Two & Tuesday & $07 / 14 / 09$ & 12:30 PM & Afternoon & \begin{tabular}{|l} 
Int. Sabhan \\
Brigde \\
inner
\end{tabular} & fnarth & $\begin{array}{l}\text { Southern } \\
\text { Sabhan } \\
\text { Bridge }\end{array}$ & Driver \\
\hline 72 & $625 / 2009$ & $\begin{array}{l}\text { Mubarak } \\
\text { Alkabeer }\end{array}$ & $\begin{array}{l}\text { Collision } \\
\text { w/Other } \\
\text { Vehicle(s) }\end{array}$ & BMw & Salon & Two & Wednesday & $07 / 08 / 09$ & Unknown & Unknown & $\begin{array}{l}\text { Betweeri } \\
\text { Qurain \& } \\
\text { Mubarak } \\
\text { Alkabeer } \\
\text { int } 11\end{array}$ & & & Doriver \\
\hline 73 & $317 / 2009$ & Alwaha & Rollover & Honda & Motorcycle & Single & Monday & $07 / 06 / 09$ & $8: 30 \mathrm{PM}$ & Night & Algser & fire st bridg & lahra fire st: & Driver \\
\hline 74 & $37 / 2009$ & Alwafra & \begin{tabular}{|l} 
Collision \\
w/Other \\
Vehicle(s)
\end{tabular} & Nissan & $\begin{array}{l}\text { Pick-up } \\
\text { Truck }\end{array}$ & Two & Friday & $05 / 29 / 09$ & $10: 30 \mathrm{PM}$ & Night & \begin{tabular}{|l|} 
Alwafra \\
internal
\end{tabular} & $+1=0.01 .0$ & 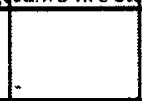 & Driver \\
\hline 75 & $448 / 2009$ & M. Abdulla & $\begin{array}{l}\text { Collision } \\
\text { w/Other } \\
\text { Vehicle(s) }\end{array}$ & Toyota & $\begin{array}{l}\text { Pick-up } \\
\text { Truck }\end{array}$ & Itwo & Tuesday & $06 / 23 / 09$ & 4:15 PM & Afternoon & $\begin{array}{l}\text { Wafra \& } \\
\text { Mina } \\
\text { Abdulla }\end{array}$ & South & Kilo 1 & Driver \\
\hline 76 & $850 / 2009$ & AlAtmadi & $\begin{array}{l}\text { Collision } \\
\text { w/Other } \\
\text { vehicle(s) }\end{array}$ & Nissan & $\begin{array}{l}\text { Pick-up } \\
\text { Truck }\end{array}$ & Two & Wednesday & $106 / 03 / 09$ & 7:00 AM & Morning & $\begin{array}{l}\text { Base after } \\
\text { kabd RA }\end{array}$ & North & & Doriver \\
\hline & & & & Nissan & Pick-up True & & & & & & & & & Passenger \\
\hline 77 & $839 / 2009$ & Jileeb AIShiy & Run-over & Cheurolet & SUV & Single & Tuesday & $06 / 30 / 09$ & 2:15 AM & Dawn & Eth RR & Almissela & ilieeb alshiy & Pedestrian \\
\hline 78 & $611 / 2009$ & Aljahra & Rollover & Nissan & Bus & Single & Friday & $06 / 12 / 09$ & $7: 30 \mathrm{PM}$ & Night & Alabdili & Almitaa' & Desert area & Driver \\
\hline & & & & Nissan & Bus & & & & & & & & & Passenger \\
\hline & & & & Nissan & Bus & & & & & & & & & Passenger \\
\hline & & & & Nissan & Bus & & & & & & & & & Passenger \\
\hline 79 & $362 / 2009$ & AlRabya & Run-over & BMW & Salon & Single & Saturday & $106 / 13 / 09$ & $6: 30 \mathrm{PM}$ & Twilight & 6 thRR & Allahra & Ishdadiya & Pedestrian \\
\hline 80 & $417 / 2009$ & Alsulaibiya & Rollover & Ford & suv & Single & Tuesday & $06 / 02 / 09$ & 3:00 PM & Afternoon & Aldoha & & F & Driver \\
\hline & & & & Ford & SUV & & & & & & & & & Passenger \\
\hline 81 & $1184 / 2009$ & $\begin{array}{l}\text { Mubarak } \\
\text { AlKabeer }\end{array}$ & $\begin{array}{l}\text { Collision } \\
\text { w/Other } \\
\text { Vehicle(s) }\end{array}$ & Chevrolet & suv & Two & Saturday & $12 / 26 / 09$ & 5:00 AM & Dawn & Ghoos St & South & Micdonalds & Driver \\
\hline 82 & $115 / 2009$ & Alzoor & Collision w/ & Mitsubishi & Salon & Single & Monday & $11 / 30 / 09$ & $11: 00 \mathrm{PM}$ & Night & King Fahad & Kuwait City & Mcdonalds & Driver \\
\hline 83 & $768 / 2009$ & M.Abdulla & Rollover & & Unknown & Single & Sunday & $111 / 01 / 09$ & 5:00 AM & Dawn & 460 & west & Sabah Alahr & IDriver \\
\hline 84 & $1563 / 2009$ & AlAhmadi & Collision w/ & Lexus & suv & Two & Friday & $10 / 16 / 09$ & $12: 20 \mathrm{AM}$ & Night & kabd & Sabah AINa & AIHijen RA & Driver \\
\hline 85 & $520 / 2010$ & Alrigga & Run-over & Nissan & Salon & Single & Monday & $11 / 30 / 09$ & $10: 00 \mathrm{AM}$ & Morning & Fahaheel ex & XilNuwaisee & Alugaila & Pedestrian \\
\hline 86 & $1119 / 2009$ & Allahra & Rollover & Maxda & Pick-up Trut & Single & Saturday & $111 / 28 / 09$ & 9:00 AM & Marning & Internal $A b c$ & farms & & Driver \\
\hline 87 & $16 / 2010$ & \begin{tabular}{|l} 
Sabah \\
Alsalem
\end{tabular} & $\begin{array}{l}\text { Collision } \\
\text { w/Other } \\
\text { vehicle(s) }\end{array}$ & Motorcycie & Motorcycle & Two & Sunday & $01 / 04 / 10$ & 4:45 PM & Afternoon & $\begin{array}{l}\text { Northern } \\
\text { Sabhan }\end{array}$ & Alsharg & \begin{tabular}{|l|} 
Sharikat \\
aljazeera \\
aluminum
\end{tabular} & Driver \\
\hline 88 & $48 / 2010$ & Allahra & Rollover & Toyota & Salon & Single & Tuesday & $01 / 19 / 10$ & $9: 30 \mathrm{PM}$ & Night & Alartal Al3a & $1 \times x \times$ al3awaz & desert & Passenger \\
\hline & & & & Toyota & Salon & & & & & & & & & Passenger \\
\hline 89 & $52 / 2010$ & Allahra & Rollover & Truck & Pick-up True & Single & Saturday & $01 / 23 / 10$ & Unknown & Unknown & Alabdili & Alabdili & Kilo 20 & Passenger \\
\hline
\end{tabular}




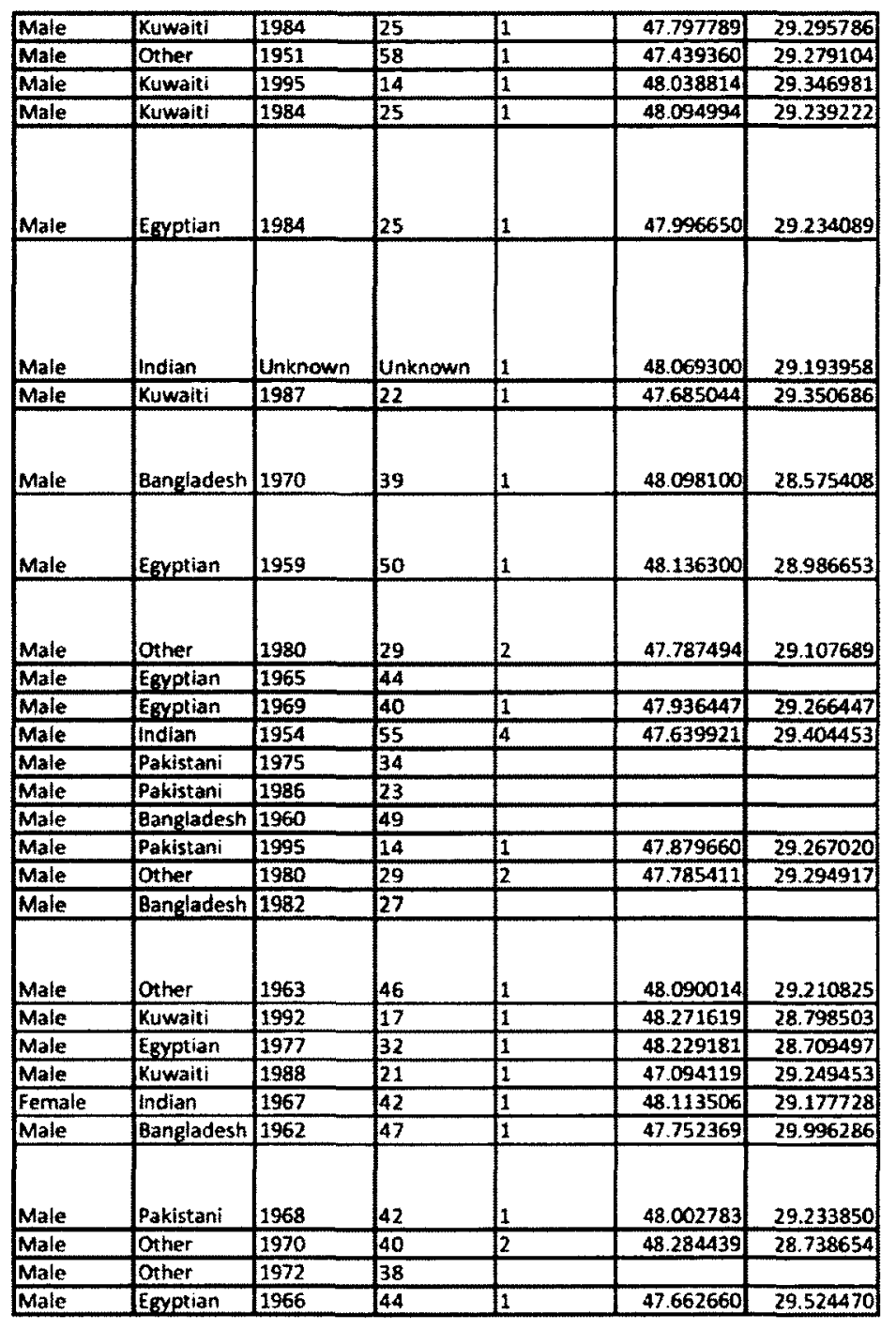




\begin{tabular}{|c|c|c|c|c|c|c|c|c|c|c|c|c|c|c|}
\hline 90 & $74 / 2010$ & Traima & $\begin{array}{l}\text { Collision } \\
\text { w/other } \\
\text { Vehicle(s) }\end{array}$ & Chevrolet & suv & Two & Monday & $01 / 25 / 20$ & $8: 00 \mathrm{AM}$ & Morning & $\begin{array}{l}\text { Aljahra } \\
\text { Main rd }\end{array}$ & Kuwait City & MPW & Driver \\
\hline 91 & $85 / 2010$ & \begin{tabular}{|l} 
Alsulaibekh \\
at
\end{tabular} & $\begin{array}{l}\text { Collision } \\
\text { w/Other } \\
\text { vehicie(s) }\end{array}$ & Cheurolet & Salon & Five & Mondar & $01 / 25 / 10$ & I1:45 PM & Night & $\begin{array}{l}\text { wa9lat } \\
\text { alDoha }\end{array}$ & $\begin{array}{l}\text { Emtertainm } \\
\text { ent city }\end{array}$ & & Driver \\
\hline & & & & Chevrolet & Salon & & & & & & & & & Unknown \\
\hline & & & & \begin{tabular}{|l} 
Chevrolet \\
tcherolet
\end{tabular} & \begin{tabular}{|l} 
Salon \\
Salom
\end{tabular} & & & & & & & & & \begin{tabular}{|l} 
Unknown \\
Unknown
\end{tabular} \\
\hline & & & & Cheurolet & Salon & & & & & & & & & known \\
\hline 92 & $168 / 2010$ & Sabah Aisal & Collision w/ & Toyota & Salon & Single & turday & $01 / 30 / 10$ & $55 \mathrm{AM}$ & Morning & King fahad & wait City & Sabah a & \\
\hline 93 & $111 / 2010$ & Allahra & Rollover & Toyota & SUV & Single & Monday & $02 / 08 / 10$ & $2: 30 \mathrm{PM}$ & Afternoon & Alrigga & Alrigga & Kilo ? & Driver \\
\hline 94 & $202 / 2010$ & $\begin{array}{l}\text { Sabah } \\
\text { Alsalem }\end{array}$ & $\mid \begin{array}{l}\text { Collision } \\
\text { w/Other } \\
\text { Vehicle(s) }\end{array}$ & Nissan & suv & Three & Saturday & $02 / 06 / 10$ & 8:15 PM & Night & King fahad & Alahmadi & $\begin{array}{l}\text { Sabah } \\
\text { alsalem }\end{array}$ & Passenger \\
\hline 95 & $106 / 2010$ & & \begin{tabular}{|l} 
Collision \\
w/Other \\
Vehicle(s)
\end{tabular} & Ford & Salon & Tiwo & |Wednesday & $02 / 10 / 10$ & 9:00 AM & Morning & A Alsalmi & Alssalmí & Kilo 91 & Passenger \\
\hline 96 & $232 / 2010$ & Alsalhiya & Collision w/ & Motorcycle & Motorcycle & Single & Friday & $02 / 26 / 10$ & $1.00 \mathrm{AM}$ & Dawn & Gulf Road & Mulama3al & Majiles alwiz & Epriver \\
\hline 97 & $102 / 2010$ & Alwaha & Collision w/ & Missan & Salon & Single & Monday & $02 / 22 / 10$ & I1:00 PM & Night & GthRR & desert & aljahra & Oriver \\
\hline 98 & $155 / 2010$ & Trima & Rollover & Toyota & suv & Single & Wednesday & $02 / 24 / 10$ & $4.00 \mathrm{PM}$ & Afternoon & Alsalmi & Alsalmi & kilo 80 & Driver \\
\hline 99 & $259 / 2010$ & Traima & Rollover & ford & suv & Single & Monday & $03 / 01 / 10$ & $3.00 \mathrm{AM}$ & Night & Alsalmi & Aljahra & kilo 40 & Passenger \\
\hline 100 & $463 / 2010$ & Alsalhiya & Run-over & Mercedes & Salon & Single & Monday & $03 / 01 / 10$ & $7.30 \mathrm{PM}$ & Night & Lamai Abdu & Kuwait GiY & shwaikh al9 & Pedestrian \\
\hline 101 & $654 / 2010$ & Alsalmiya & Run-over & Ford & Sports Vehic & Ssingle & Tuesday & $02 / 03 / 10$ & $9: 50 \mathrm{PM}$ & Night & Gulf Road & Bide; $R A$ & Trikka chicke & Pedestrian \\
\hline 102 & $201 / 2010$ & $\begin{array}{l}\text { Sabah } \\
\text { Alsalem }\end{array}$ & $\begin{array}{l}\text { Collision } \\
\text { w/Other } \\
\text { vehicle(s) }\end{array}$ & Matorcycie & Motorcycle & Two & Sunday & /28/10 & $10: 30 \mathrm{PM}$ & Night & $\begin{array}{l}\text { Int south } \\
\text { missela \& } \\
\text { king faisal } \\
\text { id }\end{array}$ & Imissela & issela & iver \\
\hline 103 & $199 / 2010$ & Aliahra & Rollover & Chevrolet & Salon & Single & onday & $08 / 03 / 10$ & 5:30 AM & Dawn & Jahrard & Kuwait City & mathakhat & Driver \\
\hline 104 & $58 / 2010$ & Phase 1 & Collision w/ & Mitsubishi & Salon & Single & Saturday & $03 / 13 / 10$ & $9: 00 \mathrm{AM}$ & Morning & 4 th RR & Kuwait Ciy & phase 1 $10 \mathrm{aa}$ & Driver \\
\hline 105 & $216 / 2010$ & Alahmadi & $\begin{array}{l}\text { Collision } \\
\text { w/Other } \\
\text { vehicle(s) }\end{array}$ & Volvo & $\begin{array}{l}\text { Piek-up } \\
\text { Truck }\end{array}$ & Two & Truesday & $02 / 09 / 10$ & $9000 \mathrm{PM}$ & Night & Deth RA & Dhahar & $\begin{array}{l}\text { Abdullah } \\
\text { Mbarak }\end{array}$ & Doriver \\
\hline 106 & $16 / 2010$ & Alwafra & $\begin{array}{l}\text { Collision } \\
\text { w/orther } \\
\text { vehicless }\end{array}$ & BBMW & $\begin{array}{l}\begin{array}{l}\text { Pick-up } \\
\text { Truck }\end{array} \\
\text { The }\end{array}$ & Two & Friday & $02 / 05 / 10$ & $11: 00 \mathrm{AM}$ & Morning & Walfa coop & & wafra coop & Driver \\
\hline 107 & $89 / 2010$ & m. Abdulla & Collision w/ & Nissan & Salon & Single & Friday & $01 / 29 / 10$ & $11: 30 \mathrm{PM}$ & Night & King fahad & south & Wwafra bridg & Ooriver \\
\hline 108 & $907 / 2010$ & Alsalmiya & \begin{tabular}{|l} 
Collision \\
w/Other \\
Vehicle(s)
\end{tabular} & Motorcycle & suv & Two & Tuesday & $123 / 10$ & $2: 30$ AM & Night & JGulf Road & $\mid \begin{array}{l}\text { kuwait } \\
\text { towers }\end{array}$ & |plaza hotel & Doriver \\
\hline 109 & $539 / 2010$ & Hawalli & Run-over & Porsche & Sports Vehit & Two & Monday & $03 / 22 / 10$ & $11: 45 \mathrm{PM}$ & Night & Gulf Road & salmiya & sha'ab palar & Pedestrian \\
\hline 110 & $177 / 2010$ & AlRabya & Run-over & \begin{tabular}{|l} 
Porsche \\
Toyota
\end{tabular} & Sports vehic & cle & Sunday & $03 / 21 / 10$ & 5:00 PM & Twilight & & & Gas station & Pedestrian \\
\hline 111 & $213 / 2010$ & Alsulaibiya & $\begin{array}{l}\text { Collision } \\
\text { w/Other } \\
\text { vehicle(s) }\end{array}$ & Nissan & Salon & Two & Monday & $03 / 15 / 10$ & $2: 00$ AM & Night & Gth RR & Aljiahra & gas station & Doriver \\
\hline
\end{tabular}




\begin{tabular}{|c|c|c|c|c|c|c|}
\hline Male & Indian & 1970 & 40 & 1 & 47.733394 & 29.331378 \\
\hline Male & Kuwaiti & 1991 & 19 & 5 & 47.801181 & 29.341983 \\
\hline Male & Kuwaiti & 1990 & 20 & & & \\
\hline Male & Kuwaiti & 1992 & 18 & & & \\
\hline Male & Kuwaiti & 1982 & 28 & & & \\
\hline Male & Kuwaiti & 1993 & 17 & & & \\
\hline Male & Kuwaiti & 1978 & 32 & & 48.046631 & 29.251286 \\
\hline Male & Pakistani & 1959 & 51 & $i$ & 47.529897 & 29.323962 \\
\hline Mate & Xuwaiti & 1991 & 19 & 1 & 48.047478 & 29.247944 \\
\hline Male & Kuwaiti & 2002 & 8 & 1 & 47.801181 & 29.341983 \\
\hline Male & Kuwaiti & Unknown & Unknown & $\frac{1}{1}$ & 47.961919 & 29.369031 \\
\hline Male & Kuwaiti & 1960 & 50 & - & 47.652511 & 29.313486 \\
\hline Male & Kuwaiti & 1969 & 41 & & 46.914402 & 29.083537 \\
\hline Male & Egyptian & 1964 & $\frac{2}{46}$ & & 47.371400 & 29.223897 \\
\hline Male & Egyptian & 1981 & 29 & & 47.932267 & 29.343903 \\
\hline Female & other & Unknown & Unknown & 1 & 48.090958 & 29.329061 \\
\hline Male & Kuwaiti & 1960 & 50 & 1 & 48.103039 & 29.212561 \\
\hline Male & Kuwaiti & 1988 & 22 & 1 & 47.071547 & 29.362583 \\
\hline Male & Egyptian & Unknown & Unknown & 1 & 47.808756 & 29.311297 \\
\hline Male & Egyptian & 1956 & 54 & 1 & 47.883736 & 29.233236 \\
\hline Maie & Kuwaiti & 1971 & 39 & 1 & 48.063258 & 28.563508 \\
\hline Male & Kuwaiti & 1964 & 46 & 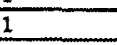 & 48.117106 & 28.965600 \\
\hline Male & Kuwaiti & 1983 & 27 & 1 & 48.008611 & 29.371653 \\
\hline Male & Pakistani & 1994 & 16 & 2 & 48.039067 & 29.346825 \\
\hline Male & Eangladesh & 1995 & 15 & & & \\
\hline Male & other & 1974 & 36 & I & 47.939283 & 29.293225 \\
\hline Male & Kuwaiti & 1970 & 40 & 1 & 47.809925 & 29.274606 \\
\hline
\end{tabular}




\begin{tabular}{|c|c|c|c|c|c|c|c|c|c|c|c|c|c|c|}
\hline 112 & $312 / 2010$ & AlAdan & $\begin{array}{l}\text { Collision } \\
\text { w/Other } \\
\text { Vehicle(s) }\end{array}$ & Mercedes & Salon & Three & Saturday & $03 / 27 / 10$ & 5:00 PM & Twilight & King fahad & kuwait city & $\begin{array}{l}\text { before } \\
\text { sabah } \\
\text { alsalem } \\
\text { bridge }\end{array}$ & Driver \\
\hline & & & & Mercedes & salon & & & & & & & & & Passenger \\
\hline 113 & $389 / 2010$ & Hawalli & Collision w/ & Mitsubishi & suv & Single & Tuesday & $02 / 23 / 10$ & $3: 15 \mathrm{PM}$ & Afternoon & Beirut St & Algadsiya & sadeg RA & Driver \\
\hline 114 & $240 / 2010$ & AlRabya & Rollover & GMC & Pick-up Trud & J Single & Friday & $04 / 12 / 10$ & 4:00 AM & Down & Sth RR & Alsalmiya & Alrabya & Passenger \\
\hline 115 & $303 / 2010$ & Alzoor & Collision w & Toyota & salon & Single & Fridey & $04 / 19 / 10$ & $12: 10 \mathrm{AM}$ & Night & King fahad & Alnuwaiseet & Alrabya & Passenger \\
\hline 116 & $174 / 2010$ & m. Abdulla & $\begin{array}{l}\text { Collision } \\
\text { w/Other } \\
\text { Vehicle(s) }\end{array}$ & Toyota & Salon & Three & Tuesday & $02 / 23 / 10$ & $1.00 \mathrm{AM}$ & Night & $\begin{array}{l}\text { Fahaheel } \\
\text { exy }\end{array}$ & kuwait city & $\begin{array}{l}\text { M. } \\
\text { Abdullah } \\
\text { gas station }\end{array}$ & Driver \\
\hline 117 & $193 / 2010$ & m. Abdulla & Collision w & Audii & Salon & Single & Monday & $03 / 01 / 10$ & $3: 40 \mathrm{AM}$ & Night & King fahad & Alnuwaisee & desert lot & Unknown \\
\hline 118 & $406 / 2010$ & Alahmadi & $\begin{array}{l}\text { Collision } \\
\text { w/Other } \\
\text { Vehicle(s) }\end{array}$ & Jruck & \begin{tabular}{|l|} 
HoV/Const \\
ruction \\
vehicle
\end{tabular} & Two & Saturday & $03 / 20 / 10$ & 7:00 PM & Night & 7th RR & |Aldhahar & Alshuwaikh & Driver \\
\hline 119 & $146 / 2010$ & Alsabahiye & $\begin{array}{l}\text { Coilision } \\
\text { w/Other } \\
\text { Vehicle(s) }\end{array}$ & Ford & Salon & Two & Thursday & $04 / 01 / 10$ & $8: 00 \mathrm{PM}$ & Night & $\begin{array}{l}\text { Fahaheel } \\
\text { exy }\end{array}$ & $\begin{array}{l}\text { Alnuwaisee } \\
b\end{array}$ & Alsabahiya & Driver \\
\hline 120 & $335 / 2010$ & Taima & Collision wf & Mitsubishl & suv & Single & Wednesday & $04 / 21 / 10$ & $1: 00 \mathrm{AM}$ & Night & Alsaimi & Aljahra & Jahra Stable & Driver \\
\hline & & & & Mitsubishi & suv & & & & & & & & & Passenger \\
\hline 121 & $322 / 2010$ & Alsulaibiya & Rollover & Infinity & suv & Single & Truesday & $04 / 27 / 10$ & $4: 30 \mathrm{AM}$ & Night & 6thRR & Almissela & Sulaibiya tar & Oriver \\
\hline 122 & $390 / 2010$ & MubarakAl & Collision w & GMMC & suv & Two & Friday & $05 / 07 / 10$ & 11:50PM & Night & King Abdula & tahaheel & left of villa $n$ & Driver \\
\hline 123 & $2229 / 2010$ & $\begin{array}{l}\text { Industrial } \\
\text { Shwaikh }\end{array}$ & $\begin{array}{l}\text { Collision } \\
\text { w/Other } \\
\text { Vehicle(s) }\end{array}$ & Toyota & Salon & Four & Sunday & los/29/10 & $3: 00 \mathrm{PM}$ & Afternoon & $\begin{array}{l}\text { Ajgahra - } \\
\text { Aljahedh } \\
\text { intersectio } \\
\text { n }\end{array}$ & Aljahra & $\begin{array}{l}\text { Sharee'ah } \\
\text { college }\end{array}$ & Passenger \\
\hline 124 & $1262 / 2010$ & Sabah Alsal & Collision w/ & Nissan & suv & Single & Sunday & $08 / 29 / 10$ & $9: 00 \mathrm{AM}$ & Morning & 6 th $\mathrm{rr}$ & Almissela & Diwaniyats & Driver \\
\hline 125 & $555 / 2010$ & Alsalam & Collision w & IGMC & suv & trwo & Friday & $09 / 10 / 10$ & Unknown & Unknown & King fahad & Alahmadi & Alsalam Are & Driver \\
\hline 126 & $1369 / 2010$ & $\begin{array}{l}\text { Sabah } \\
\text { Alsalem }\end{array}$ & \begin{tabular}{|l|} 
Collision \\
w/Other \\
Vehicleds)
\end{tabular} & $\begin{array}{l}\text { Volks } \\
\text { Wagon }\end{array}$ & Salon & Itwo & Juesday & $09 / 21 / 10$ & 4:15 PM & Afternoon & $\begin{array}{l}\text { Sabhan } \\
\text { northern - } \\
\text { pepsi st }\end{array}$ & least & fire station & Driver \\
\hline 127 & $3100 / 2010$ & Alsalmiya & Run-over & Range Rove & SUV & Single & Friday & $10 / 01 / 10$ & $7: 30 \mathrm{PM}$ & Night & Gulf Road & towers & scientific ce & Pedestrian \\
\hline 128 & $1191 / 2010$ & Aladan & Run-over & Chevrolet & suv & Single & Tuesday & $10 / 19 / 10$ & 3:00 PM & Afternoon & Alghoos st. & Alsubahiya & Aladan finfr & Pedestrian \\
\hline 129 & $984 / 2010$ & Aljahra & \begin{tabular}{|l|} 
Collision \\
w/Other \\
Vehicle(s)
\end{tabular} & Toyota & Salon & Jwo & Thursday & $12 / 09 / 10$ & 6:15 PM & Twilight & Alabdili & Aljahra & Kilo 5 & Driver \\
\hline 130 & $1103 / 2010$ & Taima & Rollover & KIA & suv & Single & Monday & $111 / 08 / 10$ & $12: 00 \mathrm{PM}$ & Afternoon & Alsalmi & mantath als. & kilo 45 & Driver \\
\hline 131 & $792 / 2010$ & Alsulaibiya & $\begin{array}{l}\text { Collision } \\
\text { w/Other } \\
\text { Vehiciets) }\end{array}$ & Truck & $\begin{array}{l}\text { HGV/Const } \\
\text { ruction } \\
\text { Vehicle }\end{array}$ & Two & Monday & $10 / 25 / 10$ & $2: 30 \mathrm{PM}$ & Afternoon & 6 thir & Aljahra & $\begin{array}{l}\text { wa9lat } \\
\text { aldoha }\end{array}$ & Passenger \\
\hline 132 & $772 / 2010$ & Taima & $\begin{array}{l}\text { Collision } \\
\text { w/Other } \\
\text { Vehicle(s) }\end{array}$ & Nissan & Salon & Two & Friday & $08 / 20 / 10$ & 8:00 PM & Night & lamghara & sikrab & sikrab cars & Passenger \\
\hline 133 & $1167 / 2010$ & Traima & $\begin{array}{l}\text { Collision } \\
\text { w/Other } \\
\text { Vehicle(s) }\end{array}$ & GMC & suv & |Two & Tuesday & $11 / 23 / 10$ & $2: 15 \mathrm{PM}$ & Afternoon & 6th ir & Aljahra & $\begin{array}{l}\text { dha7ya } \\
\text { exit jahra }\end{array}$ & | Driver \\
\hline 134 & $887 / 2010$ & AlRabya & Collision w & Road Object & Salon & Single & Unknown & Unknown & Unknown & Unknown & Unknowm & Unknown & Unknown & Driver \\
\hline
\end{tabular}




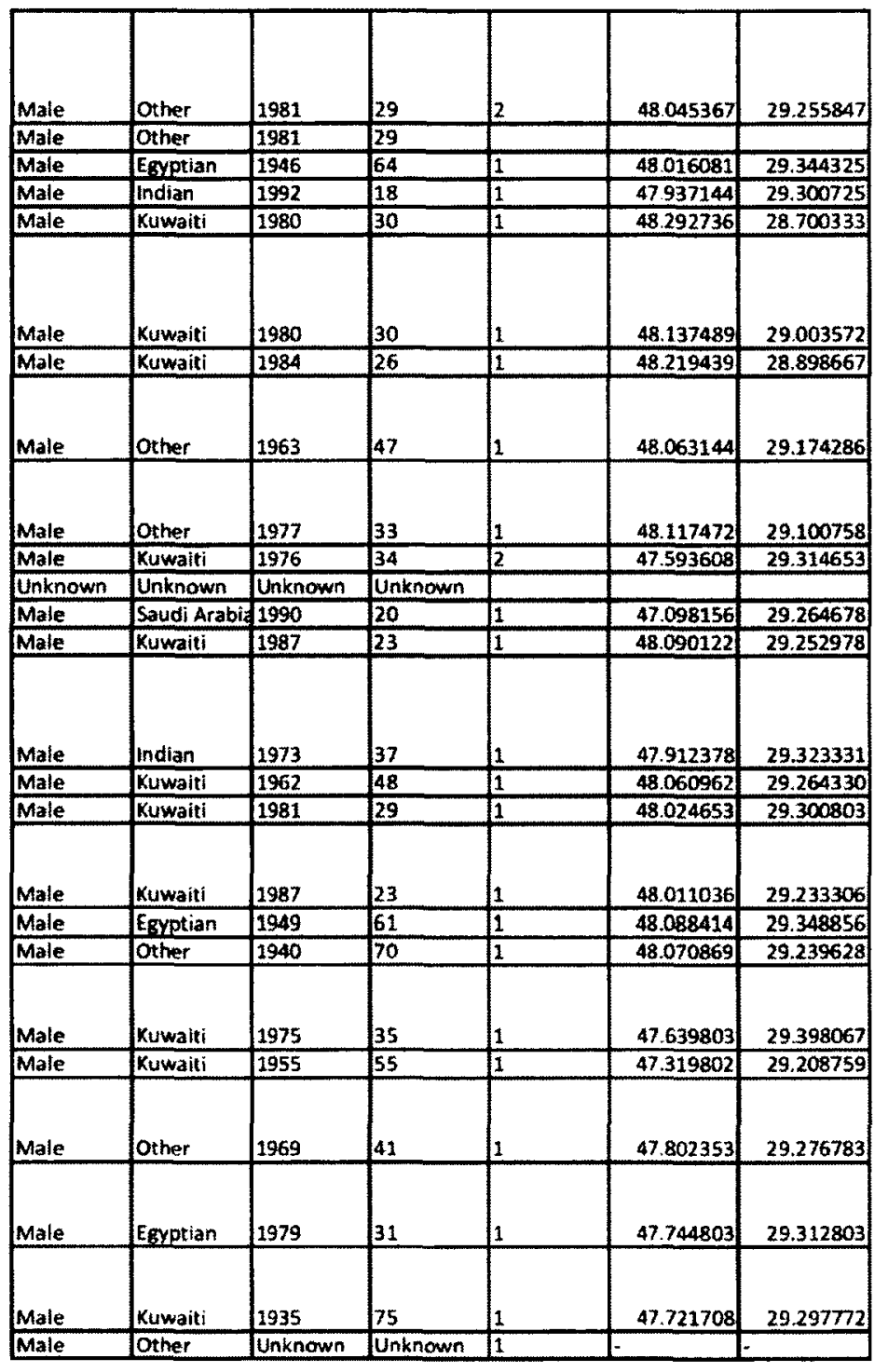




\begin{tabular}{|c|c|c|c|c|c|c|c|c|c|c|c|c|c|c|}
\hline 135 & $800 / 2010$ & Traima & $\begin{array}{l}\text { Collision } \\
\text { w/Other } \\
\text { Vehicle(s) }\end{array}$ & Nissan & Bus & Two & Monday & $08 / 30 / 10$ & 8.00 PM & Night & $\begin{array}{l}\text { amghara } \\
\text { wood }\end{array}$ & $\begin{array}{l}\text { silkrab } \\
\text { wood }\end{array}$ & $\begin{array}{l}\text { sharika } \\
\text { alkuwaitiva }\end{array}$ & Passenger \\
\hline 136 & $38 / 2010$ & Alsulabibiya & $\begin{array}{l}\text { Collision } \\
\text { w/Other } \\
\text { vehicle(s) }\end{array}$ & Nissan & $\begin{array}{l}\text { Pick-up } \\
\text { Truck }\end{array}$ & Itwo & Wednesd & $12 / 08 / 10$ & 1::30 AM & & kabd & liwakneer & $\begin{array}{l}\text { banzeen } \\
\text { kabd }\end{array}$ & briver \\
\hline 137 & $945 / 2010$ & Alsulabibiya & Rollower & Toyota & salon & Single & Friday & $12 / 10 / 10$ & Unknown & Junknown & sulabibiy an & & sakan wizar & toriver \\
\hline 138 & $1011 / 2010$ & Ailahra & $\begin{array}{l}\text { Collision } \\
\text { w/Other } \\
\text { vehiclels }\end{array}$ & Nissan & \begin{tabular}{|l} 
Pick-up \\
Truck
\end{tabular} & Jwo & Eriday & $12 / 17 / 10$ & 8:30 PM & Night & Alsubiyz & kuwait & light pole & Passenger \\
\hline 139 & $1823 / 2010$ & Salwa & Collision w & Cherrolet & Sports Vehi & SSingle & sunday & $12 / 27 / 10$ & $1.20 \mathrm{PM}$ & Afternoon & Imasjed al ad & salwa & Irumaithiya & Passenger \\
\hline 140 & $8 / 2010$ & m. Abdulla & Collision w/ & Range Rove & suv & Single & Friday & $12 / 17 / 10$ & 4.00 PM & Afternoon & king fahad & Alnuwaisseet & nnuwaiseeb & Driver \\
\hline$\frac{141}{142}$ & $\frac{148 / 2008}{334 / 2008}$ & $\begin{array}{l}\text { Mubarak } \\
\text { Alkabeer } \\
\text { Mubarak A }\end{array}$ & $\begin{array}{l}\text { Collision } \\
\text { w/Sther } \\
\text { Vehicletss) } \\
\text { TCollision w/ }\end{array}$ & Toyota & $\frac{\text { suv }}{\text { Salon }}$ & $\frac{\text { Two }}{\text { Two }}$ & $\begin{array}{l}\text { Monday } \\
\text { Saturday }\end{array}$ & $\frac{02 / 25 / 08}{04 / 26 / 08}$ & \begin{tabular}{|l} 
1:30 PM \\
$12: 45$ PM
\end{tabular} & $\frac{\text { Afternoon }}{\text { Affternoon }}$ & \begin{tabular}{|l|} 
King Fahad \\
King Abdula
\end{tabular} & \begin{tabular}{|l|} 
Kuwait city \\
Kuwait city
\end{tabular} & 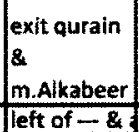 & $\begin{array}{l}\text { Passenger } \\
\text { Doriver }\end{array}$ \\
\hline 143 & $683 / 2008$ & Aladan & Run-over & Jeep & suv & Single & Wednesday & $106 / 18 / 08$ & $1: 30 \mathrm{PM}$ & Afternoon & tar $3 y$ from & Kuwait CIIY & Wady al uyg & Pedestrian \\
\hline 144 & $703 / 2008$ & Aladan & $\begin{array}{l}\text { Collision } \\
\text { w/Other } \\
\text { vehicle(s) }\end{array}$ & Honda & Salon & Four & Sunday & $106 / 22 / 08$ & 7:30 PM & vight & \begin{tabular}{|l|}
$\begin{array}{l}n+b \\
\text { sabah } \\
\text { alsalem \& } \\
\text { adan }\end{array}$ \\
\end{tabular} & north & & Driver \\
\hline 145 & $816 / 2008$ & $\begin{array}{l}\text { Mubarak } \\
\text { Alkabeer }\end{array}$ & $\begin{array}{l}\text { Collision } \\
\text { w/Other } \\
\text { Vehicle(s) }\end{array}$ & subish: & Salon & IThree & Wednesd & 10 & M & fternoon & $\begin{array}{l}\text { Abdulaziz } \\
\text { expuyy }\end{array}$ & Kuwwait City & \begin{tabular}{|l} 
Sabah \\
Alsalem \\
club
\end{tabular} & Driver \\
\hline$\frac{146}{147}$ & $710 / 2008$ & AlAdan & Rollover & Ford & suv & Single & Wednesday & $06 / 26 / 08$ & 1:40AM & Night & Abdulaziz ex & Kuwait Gity & Wady al uyd & Doriver \\
\hline 147 & $428 / 2008$ & Mubarak A & Trollover & KIA & suv & Single & Monday & $05 / 26 / 08$ & 8:10PM & Night & king fahad & kuwait city & after 7 rr bri & Passenger \\
\hline 148 & 1034/2008 & $\begin{array}{l}\text { Sabah } \\
\text { Aisalem }\end{array}$ & $\begin{array}{l}\text { Collision } \\
\text { w/Other } \\
\text { Vehicle(s) }\end{array}$ & Toyota & Salon & ITwo & onday & $107 / 22 / 08$ & OAM & Aorning & $\begin{array}{l}\text { sabah } \\
\text { alsalem } \\
\text { shuzara } \\
\text { alnaba6 }\end{array}$ & $\begin{array}{l}\text { diwan } \\
\text { shuzara } \\
\text { inaba6 }\end{array}$ & $\begin{array}{l}\text { makhazen } \\
\text { gab7an }\end{array}$ & Doriver \\
\hline 149 & $567 / 2008$ & Sabah Alsal & Rollover & Cheurolet & Salon & Single & ay & $04 / 25 / 08$ & $5.55 \mathrm{pM}$ & Twillght & fithrr & Almissela & Sabhan & Driver \\
\hline 150 & $238 / 2008$ & Aladan & Rollover & Cheurolet & Salon & Single & $\frac{1}{\text { day }}$ & $03 / 09 / 08$ & 11:00 PM & Night & King abdula & Kuwait city & before saba & Driver \\
\hline 151 & 4 & AIAdan & Rin-over & Buick & Salon & Single & $\overline{\text { Friday }}$ & $67 / 18 / 08$ & 11.45 AM & Morning & Cairo St & Kuwwit Ory & & Driver \\
\hline 152 & $2928 / 2008$ & Alsalmiya & Run-over & BMW & Salon & Single & Sunday & $07 / 06 / 08$ & $8: 45 \mathrm{PM}$ & Night & Gulf Raad & Kuwait Gity & scientifice & \\
\hline & & & & BMW & Salon & & & & & & & & & Pedestrian \\
\hline 153 & 008 & $\begin{array}{l}\text { Mubarak } \\
\text { Alkabeer }\end{array}$ & $\begin{array}{l}\text { Collision } \\
\text { w/Other } \\
\text { vehicle(s) }\end{array}$ & Nissan & suv & Two & day & 88 & $M$ & hit & \begin{tabular}{|l} 
King \\
Abdulaziz \\
bin \\
abdulrah al \\
saod
\end{tabular} & fahaheel & Qurain & Passenger \\
\hline 154 & $2014 / 2008$ & Hawalli & $\frac{R u}{R u}$ & GMC & suv & Single & Saturday & $04 / 05 / 08$ & $8.25 \mathrm{PM}$ & Night & Gulf Road & Albide' & Sultan Cente & Pedestrian \\
\hline 155 & $964 / 2008$ & Bayan & $\begin{array}{l}\text { Collision } \\
\text { w/Other } \\
\text { vehicle(s) }\end{array}$ & Ford & Salon & Three & lesday & 108 & $3.00 \mathrm{PM}$ & on & $\begin{array}{l}\text { Bt Alsalam } \\
\text { \&. Miteen }\end{array}$ & & & Driver \\
\hline 156 & $1503 / 2008$ & Alsalmiya & Run-over & Mitsubishi & Salon & \begin{tabular}{|l} 
Single \\
\end{tabular} & Wednesday & $05 / 21 / 08$ & $\frac{1}{1.00 \mathrm{PM}}$ & $\begin{array}{l}\text { Afternoon } \\
\text { nol }\end{array}$ & 4ther & Ssalmiya & salmiya & Pedestrian \\
\hline 157 & $2948 / 2008$ & Alsaimiya & Run-over & Mitsubishi & Salon & Single & Wednesday & $05 / 20 / 08$ & $12: 30 \mathrm{PM}$ & Afternoon & athor & & & \\
\hline 158 & ]581/2008 & J Bay: & Rollo & Jeen & J sut & Single & & & G:10 PM & & Tinternal AII & & & Driver \\
\hline
\end{tabular}




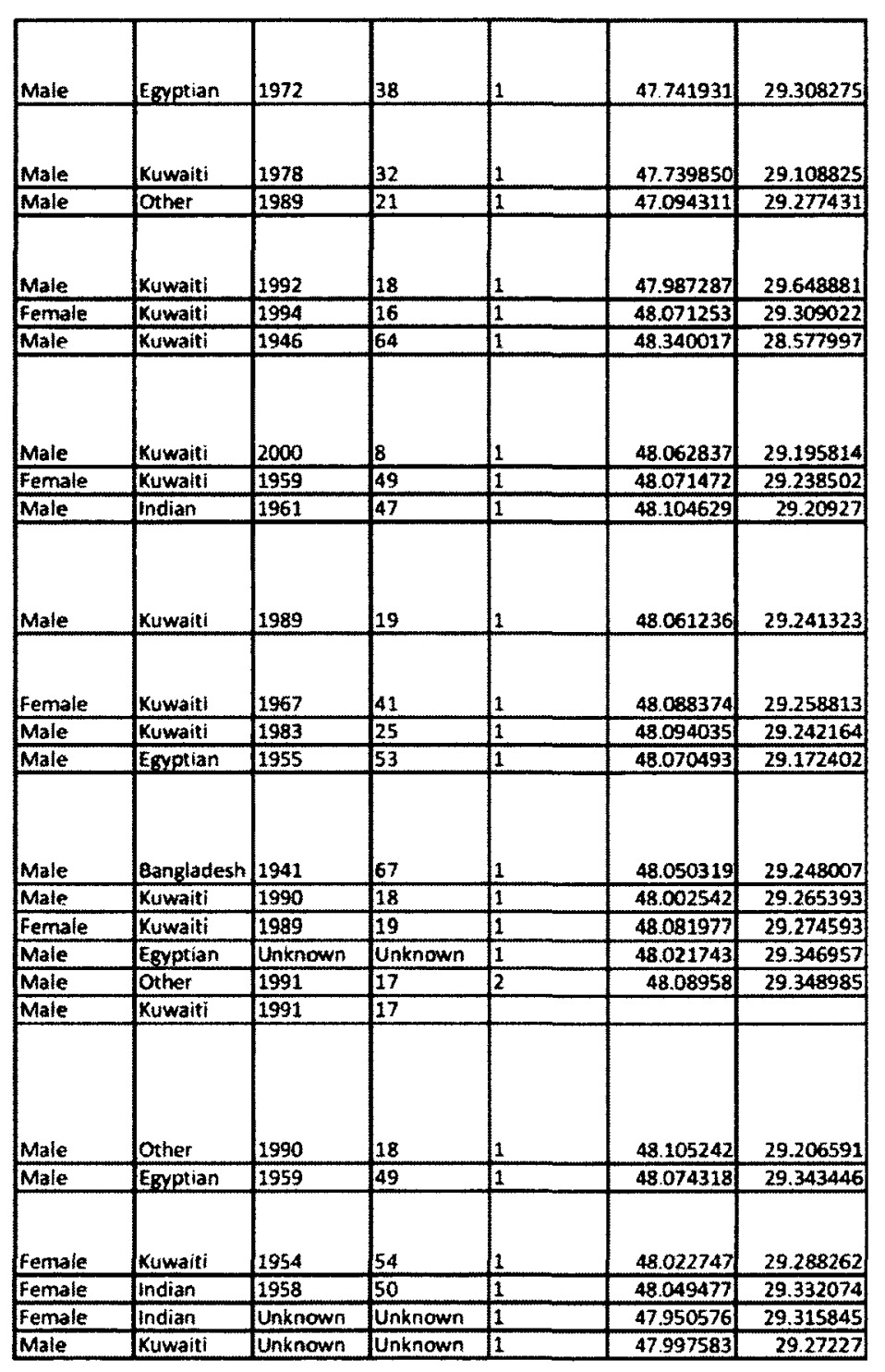




\begin{tabular}{|c|c|c|c|c|c|c|c|c|c|c|c|c|c|c|}
\hline 159 & $1646 / 2007$ & Hawalli & $\begin{array}{l}\text { Collision } \\
\text { w/Other } \\
\text { Vehicle(s) }\end{array}$ & Mitsubishi & $\begin{array}{l}\text { Pick-up } \\
\text { Truck }\end{array}$ & Iwo & Saturday & $03 / 22 / 08$ & $6: 00 \mathrm{AM}$ & Morning & king & kuwait & $\begin{array}{l}\text { bt shi3ib } \\
\text { albahry } \\
\text { (right) and } \\
\text { she3eb }\end{array}$ & Driver \\
\hline 160 & $536 / 2008$ & Bayan & Run-over & Chevrolet & Bus & Single & Sunday & $03 / 09 / 08$ & $8.00 \mathrm{PM}$ & Night & to king faisa & kuwait cify & south surra & Pedestrian \\
\hline 161 & $32 / 2008$ & Alsurra & Collision w/ & Toyota & Salon & Single & Sunday & $01 / 06 / 08$ & Unknown & Unknown & 4th ir & salmiya & qurtuba & Driver \\
\hline 162 & $410 / 2008$ & Aidasma & Run-over & Toyota & Saion & Single & Friday & $03 / 14 / 08$ & $6: 30 \mathrm{PM}$ & Twilight & Gulf Road & alsalmiya & & Pedestrian \\
\hline 163 & $348 / 2008$ & Alsulaibeek & Run-over & Mitsubishi & 5alon & Single & Saturday & $05 / 17 / 08$ & $21: 20 \mathrm{PM}$ & Night & ahra rd & jahra & sulaibeekha & Pedestrian \\
\hline 164 & $831 / 2008$ & Aldasma & Run-over & Jeep & suv & Single & Sunday & $05 / 25 / 08$ & $5: 20 \mathrm{PM}$ & Twilight & Alsoor St & $=$ & Almahlaba f & Pedestrian \\
\hline 165 & $151 / 2008$ & Aljahra & Run-over & Toyota & SUV & Single & Saturday & $02102 / 08$ & Unknown & Unknown & Desert area & E & E. & Pedestrian \\
\hline 166 & $117 / 2008$ & Aljahra & $\begin{array}{l}\text { Collision } \\
\text { w/Other } \\
\text { Vehicle(s) }\end{array}$ & Troyota & suv & Jwo & Wednesday & $102 / 27 / 08$ & Unknown & Unknown & Alabdily & Iraq & desert area & Driver \\
\hline 167 & 99/2008 & Alsulaibiya & $\begin{array}{l}\text { Collision } \\
\text { w/Other } \\
\text { Vehicle(s) }\end{array}$ & Nissan & Salon & Jwo & Saturday & $102 / 02 / 08$ & Junknown & Unknown & 5 th rr & saimiya & & Driver \\
\hline 168 & $251 / 2008$ & Allahra & Rollover & GMC & suv & Single & Sunday & $02 / 24 / 08$ & Unknown & Unknown & Alsubira & Aljahra & desert area & Oriver \\
\hline & & & & GMC & SUV & & & & & & & & & Passenger \\
\hline 169 & $249 / 2008$ & Aljahra & \begin{tabular}{|l|} 
Collision \\
w/Other \\
Vehicle(s)
\end{tabular} & Mercedes & $\begin{array}{l}\text { HGV/Const } \\
\text { ruction } \\
\text { Vehicle } \\
\end{array}$ & Irwo & Saturday & $01 / 23 / 08$ & 15:20 PM & Twilight & 7th RR & kand rd & lósert & driver \\
\hline & & & & Mercedes & HGV/Constr & ruction & & & & & & & & Driver \\
\hline 170 & $113 / 2008$ & Allahra & Collision w/ & Toyota & suv & Single & Friday & $01 / 25 / 08$ & $10: 00 \mathrm{PM}$ & Night & Lahra rd & Kuwait city & lamghara & Driver \\
\hline 171 & $34 / 2008$ & Alsulaibiya & Run-over & Ford & suv & Single & Thursday & $01 / 10 / 08$ & $8: 00 \mathrm{PM}$ & Night & Alsulaibiya & 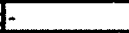 & 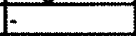 & Pedestrian \\
\hline 172 & $\operatorname{Lan}-08$ & Allahra & $\begin{array}{l}\text { Collision } \\
\text { w/Other } \\
\text { Vehicle(s) }\end{array}$ & Nissan & suv & Two & Tuesday & $01 / 01 / 08$ & $8: 30 \mathrm{PM}$ & Night & Alsalmi & aljahra & Alagraf & Driver \\
\hline 173 & $81 / 2008$ & Allahra & Rollover & Mitsubishi & suv & Single & Sunday & $01 / 20 / 08$ & $1: 00 \mathrm{PM}$ & Afternoon & Ali Alsalme & base & desert area & Driver \\
\hline 174 & $87 / 2008$ & & $\begin{array}{l}\text { Collision } \\
\text { w/Other } \\
\text { Vehicle(s) }\end{array}$ & tayota & Salon & Itwo & Friday & $01 / 25 / 08$ & Unknown & Unknown & Alsalmi & Aljahra & Idesert area & Driver \\
\hline 175 & $201 / 2008$ & alsulaibiya & Collision w/ & Mitsubishi & Salon & Single & Wednesday & $03 / 05 / 08$ & $7: 30 \mathrm{AM}$ & Morning & bt firdoos at & storage & prison & Driver \\
\hline 176 & $336 / 2008$ & Allahra & Rollover & Nissan & Pick-up True & Single & Wednesday & $03 / 05 / 08$ & Unknown & Unknown & & + & + & Driver \\
\hline 177 & $508 / 2008$ & Allahra & Rollover & Mirsubishi & 5uv & Single & Sunday & $04 / 20 / 08$ & $1: 30 \mathrm{PM}$ & Afternoon & Alabdily & jehra & desert area & driver \\
\hline & & & & Mitsubishi & $5 U \mathrm{~V}$ & & & & & & & & & Passenger \\
\hline & & & & Mitsubishi & suv & & & & & & & & & Passenger \\
\hline & & & & Mitsubishi & SUV & & & & & & & & & Passenger \\
\hline 178 & $490 / 2008$ & Atsubiya & $\begin{array}{l}\text { Eollision } \\
\text { w/Other } \\
\text { Vehicleis) } \\
\end{array}$ & Nissan & $\begin{array}{l}\text { Pick-up } \\
\text { Truck }\end{array}$ & Two & Thursday & $04 / 17 / 08$ & 10:30 AM & Morning & alsubiya & $\begin{array}{l}\text { bubyan } \\
\text { bridge }\end{array}$ & desert & Driver \\
\hline 179 & $294 / 1008$ & Alsulaibiya & $\begin{array}{l}\text { Collision } \\
\text { w/Other } \\
\text { Vehicie(s) }\end{array}$ & Chevrolet & $\begin{array}{l}\text { Pick-up } \\
\text { Truck }\end{array}$ & Itwo & Wednesday & $104 / 02 / 08$ & 2:30 PM & Afternoon & $\begin{array}{l}\text { Ala3laf } \\
\text { alsulaibiya } \\
\text { alzira3eya }\end{array}$ & kabd & $\begin{array}{l}\text { shaikh } \\
\text { hamad } \\
\text { farm }\end{array}$ & driver \\
\hline & & & & Chevrolet & \multicolumn{2}{|c|}{ Pick-up Truck } & & & & & & & & Passenger \\
\hline & & & & Cheurolet & \multicolumn{2}{|c|}{ Pick-up Truck } & & & & & & & & Passenger \\
\hline
\end{tabular}




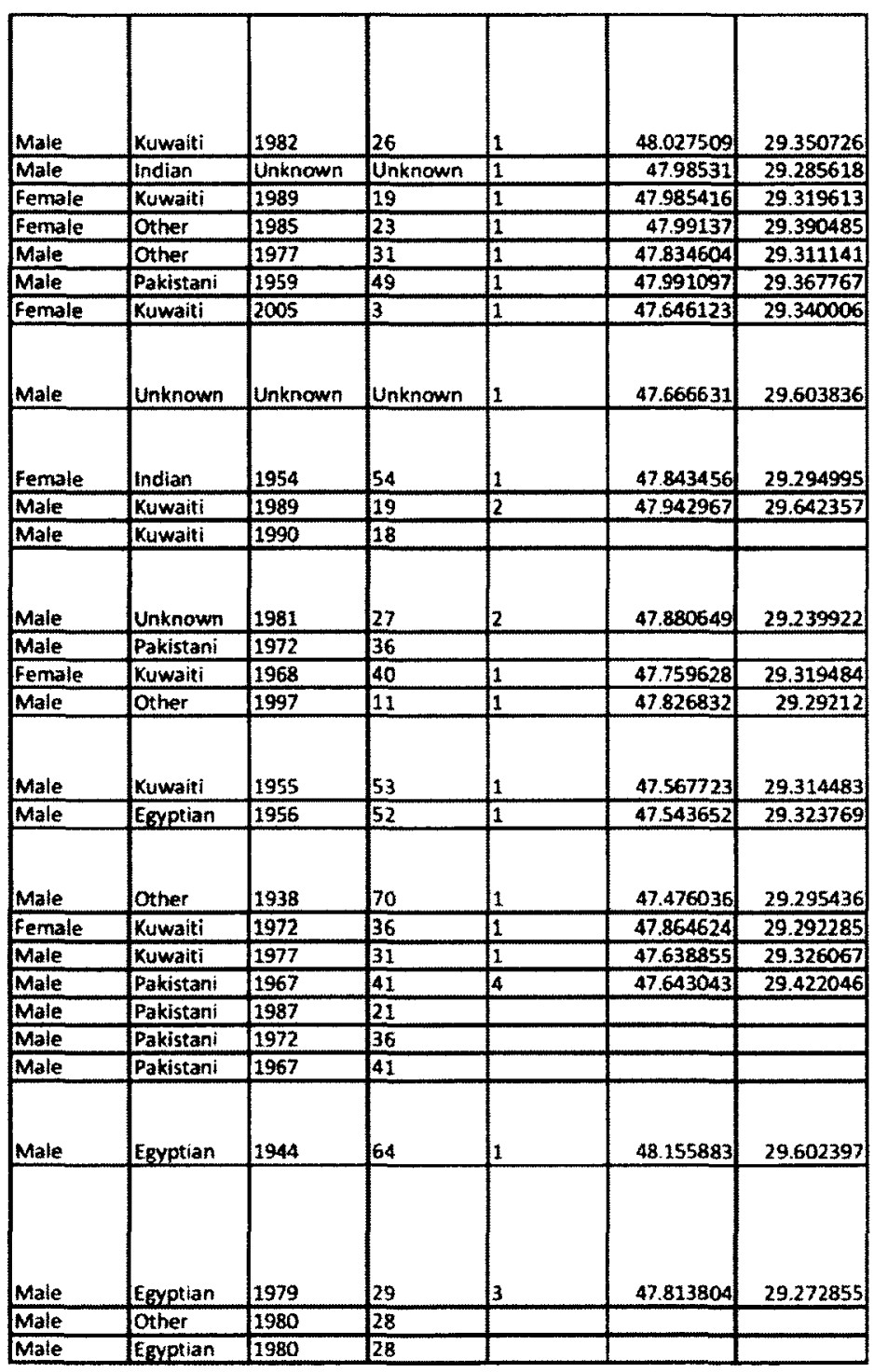




\begin{tabular}{|c|c|c|c|c|c|c|c|c|c|c|c|c|c|c|}
\hline 180 & $323 / 2008$ & Taima & $\begin{array}{l}\text { Collision } \\
\text { w/Other } \\
\text { vehicle(s) }\end{array}$ & Nissan & Salon & Itwo & Saturday & $08 / 12 / 08$ & $5: 00 \mathrm{AM}$ & Lown & Alsalmi & Aljahra & $\begin{array}{l}\text { Wahat } \\
\text { AlGhanim }\end{array}$ & Driver \\
\hline \multirow[t]{4}{*}{181} & $363 / 2008$ & Alsulaibiya & Rollover & Nissan & Bus & Single & Sunday & $04 / 27 / 08$ & $8: 00 \mathrm{PM}$ & Night & Gthrr & huwait city & & Driver \\
\hline & & & & Nissan & Bus & & & & & & & & & Passenger \\
\hline & & & & Nissan & Bus & & & & & & & & & Passenger \\
\hline & & & & Nissan & Bus & & & & & & & & & Passenger \\
\hline 182 & $551 / 2008$ & Aluahra & $\begin{array}{l}\text { Collision } \\
\text { w/Other } \\
\text { Vehicle(s) }\end{array}$ & Mercedes & $\begin{array}{l}\text { HGV/Const } \\
\text { ruction } \\
\text { Vehicle }\end{array}$ & Two & Sunday & $104 / 27 / 08$ & $10: 00$ AM & Morning & Alsubiya & Alsubiya & \begin{tabular}{|l} 
7aras \\
alwatany \\
coop
\end{tabular} & Driver \\
\hline \multirow[t]{2}{*}{183} & $643 / 2008$ & Aljahra & Rollover & Toyata & SUV & Single & Friday & $05 / 16 / 08$ & $12: 15 \mathrm{AM}$ & Night & Alabdily & Alabdily & kilo 2 & driver \\
\hline & & & & Toyota & suv & & & & & & & & & Passenger \\
\hline 184 & $678 / 2008$ & Allahra & Rollover & Nissan & Pick-up Tru & Single & Friday & $105 / 27 / 08$ & $12: 30 \mathrm{AM}$ & Night & alsubiya & Galahra & desert area & Driver \\
\hline 385 & $706 / 2008$ & Alsahra & Rollover & Crysler & Salon & Single & Saturday & $05 / 31 / 08$ & $8: 00 \mathrm{PM}$ & Night & Almitlas' & Aljahra & kilo 2 & Driver \\
\hline 186 & $741 / 2008$ & Aljahra & Rollover & Toyota & suv & Single & Unknown & Unknown & Unknown & Unknown & Alsubiya & & Taliahra & Driver \\
\hline 187 & $837 / 2008$ & Allahra & Rollover & Mitsubishi & suv & Single & Monday & $06 / 30 / 08$ & $8: 15 \mathrm{AM}$ & Morning & al3awazem & & desert & Driver \\
\hline \multirow[t]{3}{*}{188} & $577 / 2008$ & & Rollover & Mitsubishi & SUV & Tingle & Wednesday & $06 / 25 / 08$ & $10: 30 \mathrm{AM}$ & Morning & Alsalmi & alsalmi & desert & driver \\
\hline & & & & Mitsubishi & suv & & & & & & & & & Passenger \\
\hline & & & & Mitsubishi & suv & & & & & & & & & Passenger \\
\hline \multirow[t]{2}{*}{189} & $580 / 2008$ & & Rollover & Ford & Salon & Single & Thursday & $06 / 26 / 08$ & $6: 40 \mathrm{PM}$ & Twallight & Alsalmi & alsaimi & desent & driver \\
\hline & & & & Ford & Salon & & & & & & & & & Passenger \\
\hline 190 & $848 / 2008$ & Aljahra & Rollover & Suziki & Pick-up Tru & fsingle & Wednesday & $07 / 02 / 08$ & $5.00 \mathrm{PM}$ & Twilight & um gasser & um gasr & aljahra & Driver \\
\hline 191 & $1095 / 2008$ & Alfarwaniya & Run-over & Ford & Salon & Single & Saturday & $06 / 28 / 08$ & $12: 30 \mathrm{PM}$ & Afternaon & Airport Roa & Airport & E & Driver \\
\hline \multirow{2}{*}{192} & $334 / 2008$ & Hileeb Alshiy & Rollover & Lexus & suv & Single & Monday & $02 / 18 / 08$ & $3: 00 \mathrm{PM}$ & Afternoon & 7 ther & Aljahra & gas station & driver \\
\hline & & & & Lexus & suv & & & & & & & & & Passenger \\
\hline 193 & $167 / 2008$ & Alardhiya & $\begin{array}{l}\text { Collision } \\
\text { w/Other } \\
\text { vehicle(s) }\end{array}$ & Inissan & suv & Three & Thursday & $04 / 17 / 08$ & $3: 30 \mathrm{PM}$ & Afternoon & 5ethrr & Alsalmiya & Alardhiya & driver \\
\hline 194 & $806 / 2008$ & Jlleeb AlShiy & Rallover & Nissan & Pick-up Tru & Ssingle & Sunday & $04 / 20 / 08$ & $12: 30 \mathrm{PM}$ & Afternoon & $7 \mathrm{thrr}$ & eljahra & Traffic signa & Driver \\
\hline 195 & $39 / 2009$ & Alumariya & $\begin{array}{l}\text { Collision } \\
\text { w/Other } \\
\text { Vehicle(s) }\end{array}$ & Motorcycle & Motorcycle & Two & Saturday & $03 / 29 / 08$ & Unknown & Unknown & $\begin{array}{l}\text { be umariya } \\
\text { and } \\
\text { farwaniya }\end{array}$ & lairabya & Alumariya & Driver \\
\hline 196 & $18 / 2008$ & Alrai & $\begin{array}{l}\text { Collision } \\
\text { w/Other } \\
\text { vehicle(s) }\end{array}$ & Nissan & $\begin{array}{l}\text { Pick-up } \\
\text { Truck }\end{array}$ & Itwo & Saturday & $01 / 12 / 08$ & Unknown & Unknown & $\begin{array}{l}\text { int ghazally } \\
\text { w/ } 7 \text { th rr }\end{array}$ & & 1. & Passenger \\
\hline 197 & Jul-08 & Alumariya & $\begin{array}{l}\text { Collision } \\
\text { w/Other } \\
\text { Vehicle(s) } \\
\end{array}$ & Ford & Salon & Three & Thursday & $01 / 17 / 08$ & Unknown & Unknown & $\begin{array}{l}\text { Airport rd } \\
\text { be umariya } \\
\text { \& khaitan }\end{array}$ & & & driver \\
\hline & & & & Ford & Salon & & & & & & & & & Passenger \\
\hline 198 & $57 / 2008$ & Alrai & Run-over & Chevrolet & salon & Single & Thursday & $01 / 24 / 08$ & Unknown & Unknown & Airport rd & & E & driver \\
\hline 199 & Nov-08 & flileeb Alshiy & Rollover & Toyota & Salon & Single & Wednesday & $01 / 28 / 08$ & Unknown & Unknown & inside airpo & $F$ & $T$ & Driver \\
\hline 200 & $52 / 2008$ & Alrai & Rollover & Toyota & suv & Single & Unknown & Unknown & Unknown & Unknown & Sthrer & Aljahra & i & Driver \\
\hline 201 & Mar-08 & $\begin{array}{l}\text { iileeb } \\
\text { Alshiyookh }\end{array}$ & $\begin{array}{l}\text { Collision } \\
\text { w/Other } \\
\text { Vehicle(s) }\end{array}$ & Chevrolet & Salon & Three & IMonday & $101 / 02 / 08$ & 7:30 PM & INight & $\begin{array}{l}\text { int bridge } \\
\text { sabhan } \\
\text { w/almagwa }\end{array}$ & & $1-$ & Driver \\
\hline
\end{tabular}




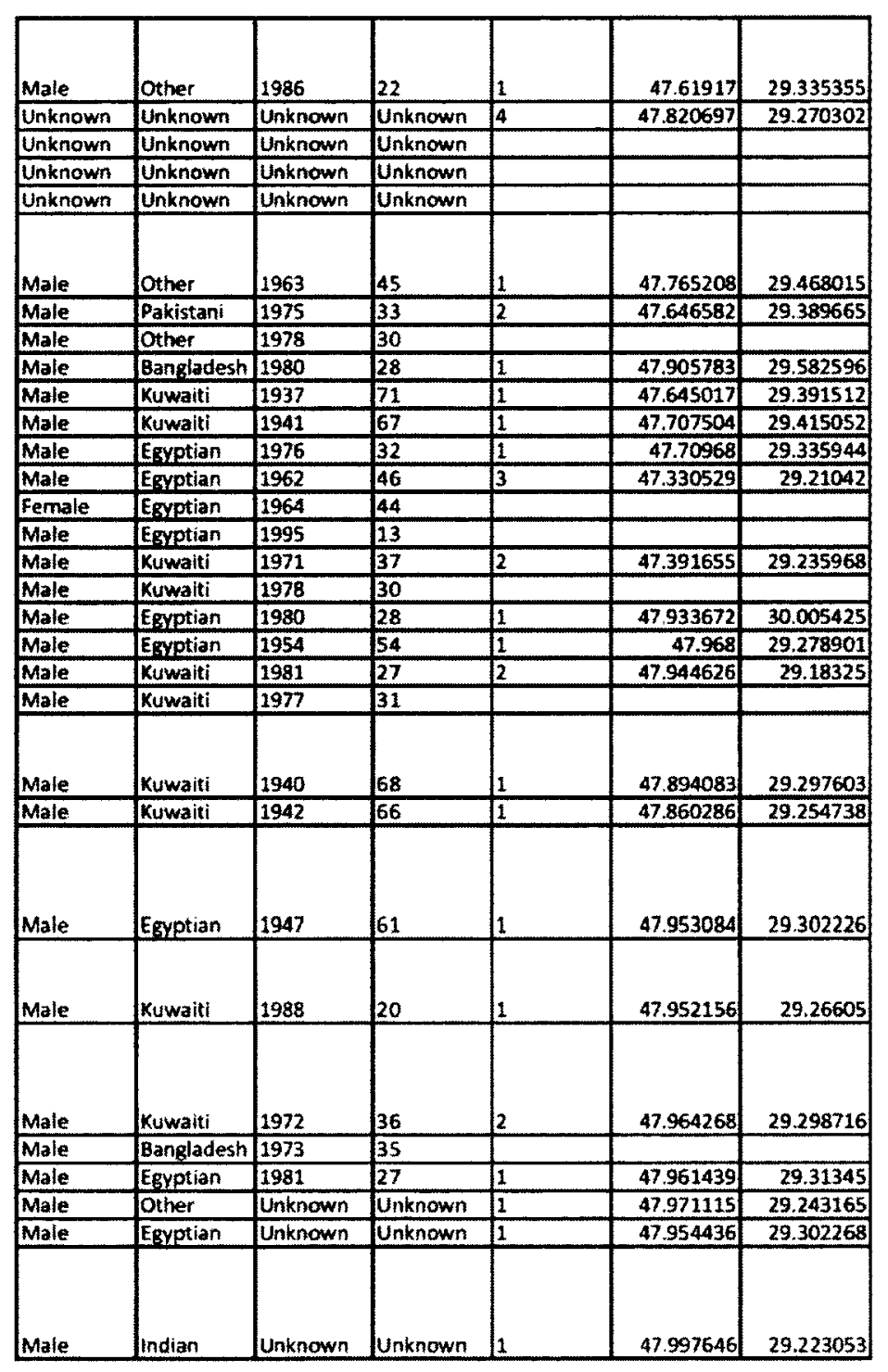




\begin{tabular}{|c|c|c|c|c|c|c|c|c|c|c|c|c|c|c|}
\hline 202 & $486 / 2008$ & Alfirdoos & $\begin{array}{l}\text { Collision } \\
\text { w/Other } \\
\text { Vehicle(s) }\end{array}$ & KIA & Salon & four & Friday & $12 / 12 / 08$ & Unknown & Unknown & Sther & aliahra & Alfirdoos & Idriver \\
\hline 203 & $250 / 2008$ & AlFarwaniye & Collision w/ & Toyola & HGV/Constr & Single & Friday & $12 / 28 / 08$ & Unknown & Unknown & 7 th RR & Aljahra & tons & Driver \\
\hline 204 & $300 / 2008$ & Im. Aboulla & $\begin{array}{l}\text { Collision } \\
\text { w/other } \\
\text { vehicle(s) }\end{array}$ & Mercedes & $\begin{array}{l}\text { HGV/Const } \\
\text { ruction } \\
\text { Vehicle }\end{array}$ & Two & Saturday & $05 / 03 / 08$ & $10: 00$ AM & Morning & Alwafra & $\begin{array}{l}\text { mina } \\
\text { abdulla }\end{array}$ & & Driver \\
\hline 205 & $53 / 2008$ & Alwafra & Rollover & Nissan & Pick-up Tru & Single & Wednesday & $104 / 16 / 08$ & $8: 00 \mathrm{PM}$ & Night & Wafra farms & & t & Driver \\
\hline 206 & $50 / 2008$ & Alwafra & Collision w & Toyota & salon & Single & Monday & $04 / 28 / 08$ & $7: 30 \mathrm{PM}$ & Night & Goos st & Alqurain & Alrigga & Oriver \\
\hline 207 & $20 / 2008$ & Alzoor & $\begin{array}{l}\text { Collision } \\
\text { w/Other } \\
\text { Vehicle(s) }\end{array}$ & Mitsubishi & suv & Iwo & Eriday & $04 / 25 / 08$ & $2: 00 \mathrm{PM}$ & Afternoon & king fahad & $\begin{array}{l}\text { Alnuwaisee } \\
b\end{array}$ & desert & Driver \\
\hline 208 & $466 / 2008$ & Alahmadi & Collision w/ & Fiat & Salon & Single & Sunday & $03 / 09 / 08$ & $10: 30 \mathrm{PM}$ & Night & kabd & kuwait city & & driver \\
\hline 209 & $98 / 2008$ & Alrigga & Run-over & Constructio & HGV/Constr & Single & Saturday & $03 / 15 / 08$ & $9: 15 \mathrm{AM}$ & Morning & work zone & & & Pedestrian \\
\hline 210 & $29 / 2008$ & Im. Abdulla & Run-over & Constructio & HGV/Constr & Single & Thursday & $02 / 14 / 08$ & $9: 00 \mathrm{AM}$ & Morning & inside comp & o & & Pedestrian \\
\hline 211 & $215 / 2008$ & Alahmadi & Run-aver & Chevrolet & Pick-up Tru & fingle & Sunday & $02 / 03 / 08$ & $9: 00 \mathrm{PM}$ & Night & inside ahma & & & Pedestrian \\
\hline 212 & $72 / 2008$ & Alrigga & Collision w/ & Daihatsu & Salon & Single & Thursday & $02 / 07 / 08$ & $11: 20 \mathrm{PM}$ & Night & Algoos st & Mubarak all & Alugaila & Pedestrian \\
\hline 213 & $206 / 2008$ & Alahmadi & Roilover & Ford & suv & Single & Wednesday & $02 / 06 / 08$ & $10: 50 \mathrm{PM}$ & Night & Kabd & Kuwait City & & Driver \\
\hline 214 & $199 / 2008$ & Alahrnadi & Rollover & Nissan & Pick-up Trur & Single & Saturday & $02 / 02 / 08$ & $11: 50 \mathrm{PM}$ & Night & kabd & kuwait city & diesert area & Driver \\
\hline 215 & $33 / 2008$ & Alwafia & Rollover & Mercedes & Salon & Single & Tuesday & $02 / 26 / 08$ & $11: 50 \mathrm{PM}$ & Night & alwafra kilo & alzoor & & driver \\
\hline 216 & 29/2008 & Alwafra & $\begin{array}{l}\text { Collision } \\
\text { w/Other } \\
\text { Vehicie(s) }\end{array}$ & GMC & suv & Itwa & Wednesday & $2 / 20 / 2008$ & 9:30 PM & Morning & $6^{\sim} \sim(\mathrm{NM})$ & Jalwafra & & Driver \\
\hline 217 & $125 / 2008$ & Alahmadi & $\begin{array}{l}\text { Collision } \\
\text { w/Other } \\
\text { Vehicle(s) }\end{array}$ & Nissan & $\begin{array}{l}\text { Pick-up } \\
\text { Truck }\end{array}$ & Two & Saturday & $01 / 19 / 08$ & 11:30 PM & Night & king fahad & south & Alsabahiya & driver \\
\hline 218 & Mar-08 & Alwafra & Rollover & Ford & suv & Single & Sunday & $101 / 05 / 08$ & $10: 00 \mathrm{PM}$ & Night & old wafra & west & desert area & Driver \\
\hline 219 & Feb-08 & alwa & Rollover & Mitsubishi & HGV/Constr & Single & Sunday & $01 / 06 / 08$ & $11: 30 \mathrm{AM}$ & Morning & wafra farms & & & Driver \\
\hline 220 & Jan-08 & Alzoor & \begin{tabular}{|l} 
Collision \\
w/Other \\
Vehicle(s)
\end{tabular} & Lexus & Saion & Two & Tuesday & $01 / 01 / 08$ & 9:20 PM & Night & desert lot & & {$[-$} & Driver \\
\hline 221 & $21 / 2008$ & Alahmadi & $\begin{array}{l}\text { Collision } \\
\text { w/Other } \\
\text { Vehicle(s) }\end{array}$ & Toyota & Salon & Two & Saturday & $01 / 05 / 08$ & 9:20 PM & Night & 7 th ir & aldhahar & desert area & Driver \\
\hline 222 & $95 / 2008$ & Alahmadi & Collision w/ & Chevrolet & SUV & Single & Monday & $01 / 21 / 08$ & $10: 30 \mathrm{PM}$ & Night & king fahad & kuwait & hadiya & Driver \\
\hline 223 & $18 / 2008$ & hadiya & Collision w/ & Mitsubishi & SUV & Single & Monday & $01 / 21 / 08$ & $6: 00 \mathrm{AM}$ & Morning & king foha & south & & Driver \\
\hline 224 & Dec-08 & m. Abdulla & Rollover & nissan & Pick-up Tru & Single & Friday & $101 / 04 / 08$ & $10: 30 \mathrm{PM}$ & Night & king abdula & kuwait city & dhubaziya s & Driver \\
\hline 225 & $148 / 2008$ & Alahmadi & Collision w/ & GMC & Salon & Single & Monday & $01 / 21 / 08$ & $11: 00 \mathrm{PM}$ & Night & king fahad & south & adan hospit & Driver \\
\hline 226 & Nov-08 & $\begin{array}{l}\text { ali subah } \\
\text { aisalem }\end{array}$ & $\begin{array}{l}\text { Collision } \\
\text { w/Other } \\
\text { Vehicle(s) }\end{array}$ & Ford & Salon & two & Thursday & $01 / 24 / 08$ & $11: 00 \mathrm{PM}$ & Night & $\begin{array}{l}\text { internal } \\
\text { area }\end{array}$ & & . & Driver \\
\hline 227 & $28 / 2008$ & latzoor & $\begin{array}{l}\text { Collision } \\
\text { w/Other } \\
\text { Vehicle(s) }\end{array}$ & Ford & Salon & two & Wednesday & $101 / 30 / 08$ & $19: 00 \mathrm{PM}$ & Night & king fahad & Inorth & & Driver \\
\hline 228 & $205 / 2008$ & Alahmadi & $\begin{array}{l}\text { Callision } \\
\text { w/Orher } \\
\text { Vehicle(5) }\end{array}$ & Jeep & suv & JThree & Thursday & $101 / 03 / 08$ & 6:20 AM & Morning & kabd & $\begin{array}{l}\text { sabah } \\
\text { alnasser }\end{array}$ & kabd & Joriver \\
\hline 229 & $837 / 2007$ & & Collision w/ & Chevrolet & Salon & Single & Thursday & $12 / 20 / 07$ & $1: 00 \mathrm{AM}$ & Night & king fahad & kuwait city & before ahm & Driver \\
\hline
\end{tabular}




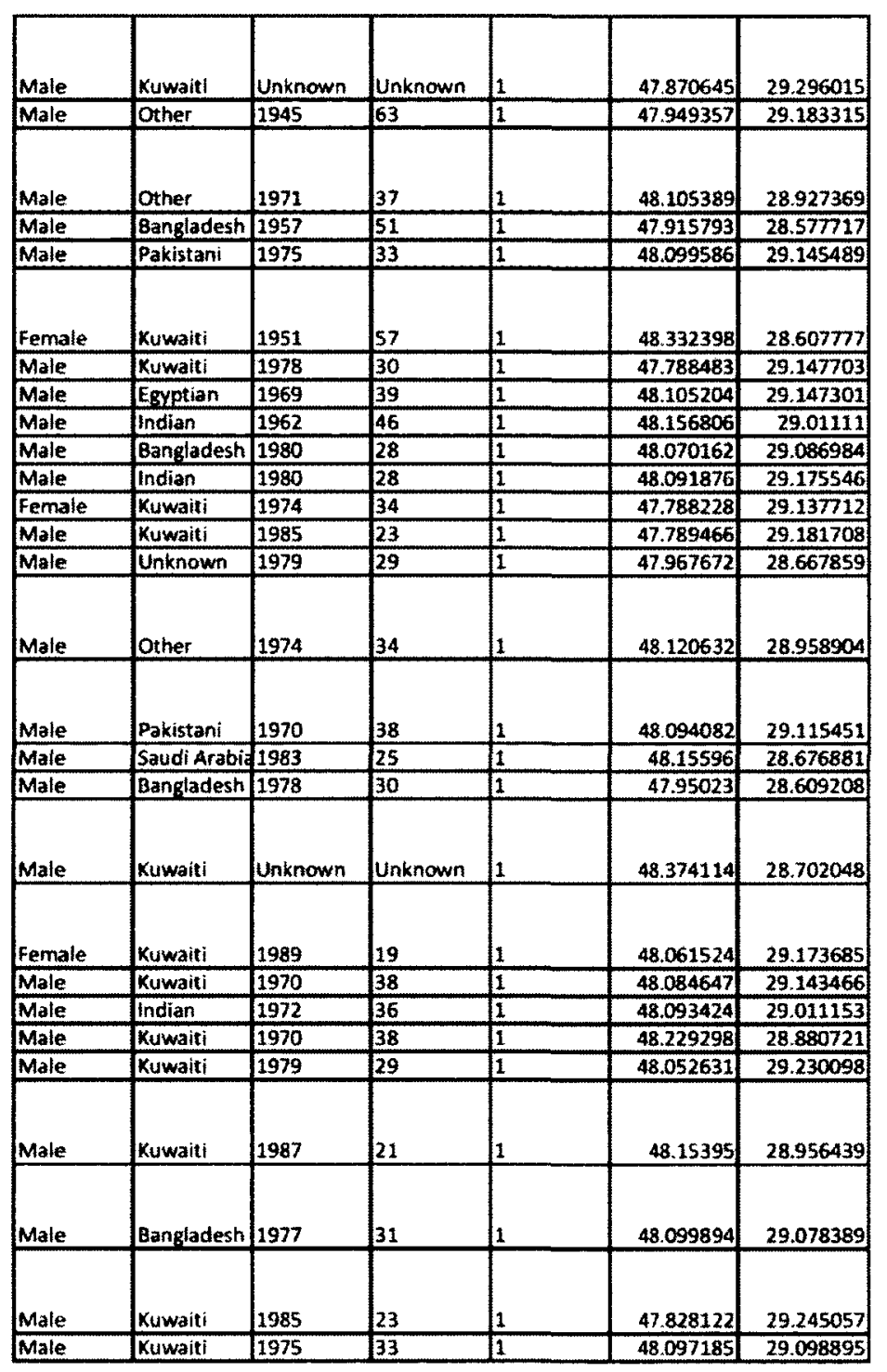




\begin{tabular}{|c|c|c|c|c|c|c|c|c|c|c|c|c|c|c|}
\hline 230 & $842 / 2007$ & Im. Abdulla & $\begin{array}{l}\text { Collision } \\
\text { w/Other } \\
\text { Vehicle(s) }\end{array}$ & BMW & Salon & Two & Wednesday & $12 / 26 / 07$ & 11:20 PM & Night & king fahad & Kuwait & bnaider & driver \\
\hline 231 & $822 / 2007$ & Im. Abdulla & $\begin{array}{l}\text { Collision } \\
\text { w/Other } \\
\text { Vehicle(s) }\end{array}$ & Mitsubishi & suv & Iwo & Thursday & $12 / 20 / 07$ & $9: 00 \mathrm{AM}$ & Morning & new wafra & west & desert area & driver \\
\hline 232 & $2336 / 2007$ & Alahmadi & $\begin{array}{l}\text { Collision } \\
\text { w/Other } \\
\text { Vehicle(s) }\end{array}$ & Toyota & Salon & Two & Sunday & $12 / 23 / 07$ & 11:00 PM & Night & Kabd & kuwait city & desert & Driver \\
\hline 233 & $916 / 2007$ & alfintas & Run-over & GMC & suv & Single & Saturday & $12 / 29 / 07$ & $10: 00 \mathrm{PM}$ & Night & Alsahili road & north & fintas & Pedestrian \\
\hline 234 & $485 / 2008$ & Alsulaibiya & $\begin{array}{l}\text { Collision } \\
\text { w/other } \\
\text { Vehicle(s) }\end{array}$ & Inissan & Salon & Two & Sunday & $06 / 01 / 08$ & $11: 00 \mathrm{AM}$ & Morning & $\begin{array}{l}\text { Kabd pulic } \\
\text { road }\end{array}$ & kabd & block 4 & Passenger \\
\hline 235 & $319 / 2008$ & Alsulaibiya & $\begin{array}{l}\text { Collision } \\
\text { w/Other } \\
\text { Vehicle(s) }\end{array}$ & Chevrolet & $\begin{array}{l}\text { Pick-up } \\
\text { Truck }\end{array}$ & Two & Friday & $04 / 11 / 08$ & 6:30 PM & Twilight & $\begin{array}{l}\text { Kabd pulic } \\
\text { road }\end{array}$ & Kabd & kabd & driver \\
\hline & & & & Chevrolet & Pick-up Truek & & & & & & & & & Passenger \\
\hline 236 & $86 / 2008$ & Alsulaibiya & $\begin{array}{l}\text { Collision } \\
\text { w/Other } \\
\text { Vehicle(s) }\end{array}$ & Mazda & $\begin{array}{l}\text { Pick-up } \\
\text { Truck }\end{array}$ & Two & Monday & $01 / 28 / 08$ & $2: 00 \mathrm{PM}$ & Afternoon & Kabd & kabd & $\begin{array}{l}\text { juwakheer } \\
\text { kabd } 2\end{array}$ & Driver \\
\hline 237 & $850 / 2008$ & Alsulaibiya & $\begin{array}{l}\text { Collision } \\
\text { w/Other } \\
\text { Vehicle(s) }\end{array}$ & Nissan & Salon & two & Friday & $10 / 17 / 08$ & 8:10 PM & Night & kabd & leabd & desert & driver \\
\hline 238 & $1227 / 2008$ & taima & Rollover & Mitsubishi & suv & Single & Tuesday & $12 / 23 / 08$ & $3.00 \mathrm{PM}$ & Afternoon & 6 thr & almissela & 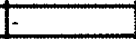 & Passenger \\
\hline 239 & $1433 / 2008$ & Aladan & Rollover & Toyota & Salon & Single & Saturday & $12 / 20 / 08$ & $6: 20 \mathrm{AM}$ & Morning & Aking Abdul & kuwait & 7 aras alwat & Passenger \\
\hline 240 & $1378 / 2008$ & Aljahra & Rollover & Toyota & Pick-up Trud & Single & Wednesday & $10 / 15 / 08$ & 6:00 PM & Twilight & Alsubiya ma & aljahra & 6okm away & doriver \\
\hline 241 & $1165 / 2008$ & Traima & Rollover & Chevrolet & suv & Single & Friday & $12 / 05 / 08$ & Unknown & Unknown & Alsalmi & taisalmi & gabl almark & Passenger \\
\hline 242 & $1569 / 2008$ & aljahra & Run-over & Mitsubishi & Saion & Single & Sunday & $11 / 23 / 08$ & 4:45PM & Afternoon & & Alwa7a & F & Pedestrian \\
\hline 243 & $1016 / 2008$ & Alsulaibiya & Rollaver & nissan & suv & Single & Tuesday & $12 / 02 / 08$ & $6: 00 \mathrm{PM}$ & Twilight & waglat a $\mid D_{0}$ & $6 \mathrm{th} r \mathrm{r}$ & desen & Passenger \\
\hline 244 & $3350 / 2008$ & Shuwaikh & $\begin{array}{l}\text { Collision } \\
\text { w/Other } \\
\text { Vehicle(s) }\end{array}$ & $\begin{array}{l}\text { Range } \\
\text { Rover }\end{array}$ & suv & Two & Thursday & $21 / 20 / 08$ & $8: 30$ AM & Morning & $\begin{array}{l}\text { inside } \\
\text { brnw } \\
\text { garage }\end{array}$ & F & 1. & Driver \\
\hline 245 & $2900 / 2008$ & Bayan & Collision w/ & Motorcycie & Motorcycle & Single & Thursday & $11 / 23 / 08$ & $4: 30 \mathrm{AM}$ & Night & Zahra' inter & roundabout & t. & Driver \\
\hline 246 & $2028 / 2008$ & Alahmadi & $\begin{array}{l}\text { Collision } \\
\text { w/Other } \\
\text { Vehicle(s) }\end{array}$ & nissan & $\begin{array}{l}\text { Hov/Const } \\
\text { ruction } \\
\text { Vehicle }\end{array}$ & three & Tuesday & $11 / 18 / 08$ & $5: 00 \mathrm{AM}$ & Dawn & 7 thrr & Dhahar & near hotel & Driver \\
\hline 247 & $2005 / 2008$ & Alsurra & $\begin{array}{l}\text { Collision } \\
\text { w/Other } \\
\text { Vehicle(s) }\end{array}$ & Mercedes & Salon & three & Truesday & $11 / 04 / 08$ & $10: 00$ AM & Morning & airpirt rd & $\begin{array}{l}\text { mina } \\
\text { shwaikh }\end{array}$ & yarmook & driver \\
\hline 248 & $1366 / 2008$ & AlRouda & Collision w/ & Porsche & Sports Vehid & Single & Tuesday & $09 / 09 / 08$ & $6: 00 \mathrm{PM}$ & Twilight & $4 \mathrm{th}$ rr & salmiya & qurtoba & driver \\
\hline 249 & $1899 / 2008$ & Alsurra & Rollover & Tayota & Salon & Single & Monday & $10 / 20 / 08$ & $6: 25 \mathrm{AM}$ & Morning & 5 thrr & Aljahra & alsurra & Driver \\
\hline 250 & & & Collision w/ & Honda & Saion & Single & Truesday & $08 / 19 / 08$ & $1: 00 \mathrm{AM}$ & Night & Jamal Abdul & kuwait city & flour mills & Driver \\
\hline 251 & $1494 / 2008$ & Allahra & Run-over & Mercedes & HGV/Constr & Single & Saturday & $11 / 08 / 08$ & $3: 15 \mathrm{PM}$ & Afternoon & Subiya dese & kilo 3 & E & Pedestrian \\
\hline 252 & $1052 / 2008$ & Taima & Run-over & Mitsubishi & SUV & Single & Monday & $11 / 03 / 08$ & $8.00 \mathrm{PM}$ & Night & Jahra rd & & soog al7arfy & Pedestrian \\
\hline 253 & $861 / 2008$ & Alsulaibiya & $\begin{array}{l}\text { Collision } \\
\text { w/Other } \\
\text { Vehiclets) }\end{array}$ & Daihatsu & \begin{tabular}{|l|} 
HGV/Const \\
ruction \\
Vehicle
\end{tabular} & three & Tuesday & $10 / 21 / 08$ & 6:00 PM & Twilight & 6th $r$ r & lalmissela & $\begin{array}{l}\text { shaikh } \\
\text { hamad } \\
\text { farm }\end{array}$ & driver \\
\hline 254 & $852 / 2008$ & Alsulaibiya & Rollover & Land Cruise & SUV & Single & Saturday & $10 / 18 / 08$ & $3: 00 \mathrm{PM}$ & Afternoon & 6ther & almissela & & driver \\
\hline
\end{tabular}




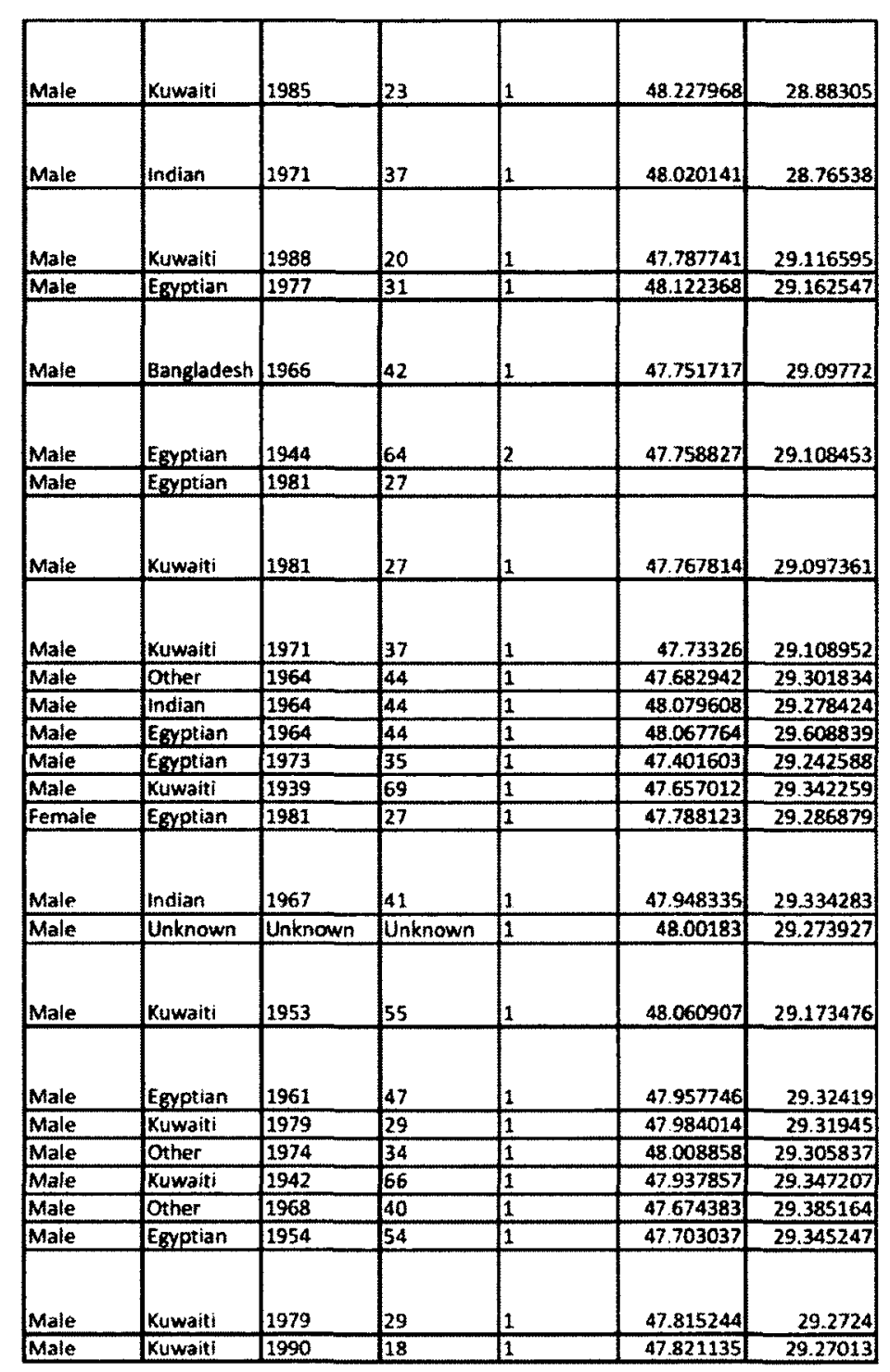




\begin{tabular}{|c|c|c|c|c|c|c|c|c|c|c|c|c|c|c|}
\hline 255 & $2388 / 2008$ & Bayan & \begin{tabular}{|l|} 
Collision \\
w/Other \\
vehicle(s) \\
\end{tabular} & Mitsubishi & suv & Two & Sunday & $07 / 06 / 08$ & 5:30 PM & Twilight & Geth & Aljahra & mishref & driver \\
\hline 256 & $1993 / 2008$ & jileeb Aishi & Run-over & Mercedes & salon & Single & Truesday & $09 / 30 / 08$ & $9: 30 \mathrm{AM}$ & Morning & finternal & m7amad bif & & Driver \\
\hline 257 & 1290/2008 & $\begin{array}{l}\text { Sabah } \\
\text { Alsalem } \\
\text { Asale }\end{array}$ & $\begin{array}{l}\text { Collision } \\
\text { w/Other } \\
\text { vehicle(s) }\end{array}$ & Chevrolet & suv & Iwo & Saturday & $09 / 20 / 08$ & Unknown & Unknown & \begin{tabular}{|l} 
internal \\
Satha \\
Alsalem \\
\end{tabular} & & block 9 & driver \\
\hline 258 & $731 / 2008$ & Alsulaibiya & $\begin{array}{l}\text { Collision } \\
\text { w/Other } \\
\text { vehicle(s) } \\
\end{array}$ & Mitsubishi & suv & Two & Sunday & $108 / 31 / 08$ & 1:30 PM & Afternoon & 6thir & Almissela & \begin{tabular}{|l|} 
Almakhaze \\
n \\
ilimoomiy \\
a
\end{tabular} & driver \\
\hline 259 & $873 / 2008$ & Taima & Rollover & GMC & suv & Single & Sunday & $09 / 21 / 08$ & $2: 00 \mathrm{AM}$ & Night & Alsalmi & Ajjahra & & Passenger \\
\hline 260 & $2271 / 2008$ & Eayan & $\begin{array}{l}\text { Collision } \\
\text { w/other } \\
\text { Vehicle(s) }\end{array}$ & & Junknown & Twa & Monday & $\mid 09 / 22 / 08$ & 10:00 PM & | & $\begin{array}{l}\text { Fahaheel } \\
\text { expmy }\end{array}$ & fahaheel & mishref & Deriver \\
\hline 261 & $755 / 2008$ & Alsulabibiya & $\begin{array}{l}\text { Collision } \\
\text { w/other } \\
\text { Vehicle(s) }\end{array}$ & Porsche & $\begin{array}{l}\text { Sports } \\
\text { vehicle }\end{array}$ & two & Thursday & $09 / 11 / 08$ & 4:00 AM & Night & 6 th rr & ALmissela & $\begin{array}{l}\text { before } 7 \text { th } \\
\text { ir bridge } \\
\end{array}$ & driver \\
\hline 262 & $770 / 2008$ & alsulaibiya & Collision w/ & Mitsubishi & HGV/Const & Single & Tuesday & $009 / 16 / 08$ & $4: 00 \mathrm{AM}$ & Night & 6 th & aljahra & shooting chu & Triver \\
\hline 263 & $1219 / 2008$ & Allahra & \begin{tabular}{|l} 
Collision \\
w/Other \\
Vehicle(s)
\end{tabular} & Mitsubishi & Salon & IThree & Wednesday & $100 / 10 / 08$ & 8:00 PM & Night & Alliyaa7 & Jalliyaar & $\begin{array}{l}\text { rosd split } \\
\text { from abdill }\end{array}$ & dariver \\
\hline 264 & $11162 / 2008$ & Allahra & \begin{tabular}{|l|} 
Rollover \\
\end{tabular} & Mitsubishi & sur & Single & Thursday & $08 / 28 / 08$ & 9:30 PM & Night & Alsubuiya & alsubiya & gas station & Passenger \\
\hline 265 & $811 / 1008$ & Taima & Rollower & Toyota & Salon & Single & Thursday & $109 / 04 / 08$ & 20:00 AM & orning & alsalmi & almanfath & & Driver \\
\hline 266 & $11206 / 2008$ & Allahra & Rollower & & Pick-up Tru & ISingle & Monday & $02 / 08 / 08$ & 9:00 PM & Night & Ainitga & \begin{tabular}{|l} 
Airitga \\
\end{tabular} & split from at & QDriver \\
\hline 267 & $765 / 2008$ & Mubarak A & Follover & Honda & Salon & Single & Sunday & $109 / 07 / 08$ & 3:30 PM & Afternoon & qurain bet bl & Tcoop & & Priver \\
\hline & & & & Honda & Salon & & & & & & & & & Passenger \\
\hline 268 & $1072 / 2008$ & Allahra & Rollover & 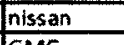 & Pick-up Tru & os single & unday & $08 / 11 / 08$ & 5:00 PM & Twilight & & & mazare 3 ala & Passenger \\
\hline 269 & $751 / 2008$ & Alsulabibiya & Rollover & GMC & suv & Single & Sunday & $02 / 07 / 08$ & $7.00 \mathrm{PM}$ & Night & Gethrr & ajjahra & shooting Clu & Passenger \\
\hline 270 & $798 / 2008$ & Taima & Rollover & Mitsubishi & & Single & Sunday & $108 / 31 / 08$ & $1: 45 \mathrm{AM}$ & Night & Alsalmi & aljahra & stables & Driver \\
\hline 271 & $661 / 2008$ & Taima & $\begin{array}{l}\text { Collision } \\
\text { w/Other } \\
\text { Vehicle(s) }\end{array}$ & KIA & $\begin{array}{l}\text { HGV/Const } \\
\text { ruction } \\
\text { Vehicle } \\
\end{array}$ & Itwo & Sunday & $07 / 20 / 08$ & 10:30 AM & Morning & 6th rr & Aljahra & bridge & drriver \\
\hline 272 & $1130 / 2008$ & lajiahra & \begin{tabular}{|l} 
Collision \\
w/Other \\
Vehicle(s)
\end{tabular} & Cheurolet & suv & Two & Saturday & $08 / 23 / 08$ & $12: 30 \mathrm{AM}$ & Night & alabdli & ahra & burger king & driver \\
\hline 273 & $722 / 2008$ & alsulaibiya & Collision w/ & Toyota & suv & Single & Thursday & $108 / 28 / 08$ & $11: 00 \mathrm{AM}$ & Morning & bet 2 cemetr & dalsulaibiya & 2 cemeterie & doriver \\
\hline 274 & $1041 / 2008$ & & $\begin{array}{l}\text { Collision } \\
\text { w/Other } \\
\text { Vehicle(s) }\end{array}$ & Toy & Salon & Two & Tuesday & $107 / 22 / 08$ & $8: 30 \mathrm{AM}$ & ng & $\begin{array}{l}\text { king } \\
\text { abdulaziz }\end{array}$ & fathaheel & $\begin{array}{l}\text { labah } \\
\text { alsalem } \\
\text { bridge }\end{array}$ & Driver \\
\hline 275 & $1077 / 2008$ & Allahra & Rollower & Toyota & sov & Single & Wednesday & $08 / 13 / 08$ & $8: 00 \mathrm{AM}$ & Morning & plabcilit & aljahra & kilo 29 & driver \\
\hline \begin{tabular}{l|l}
276 \\
\end{tabular} & $1075 / 2008$ & Allahra & Rollover & $\begin{array}{l}\text { Toyota } \\
\text { ford }\end{array}$ & $\frac{\text { suv }}{\text { salon }}$ & Tingle & Tuesday & $08 / 12 / 08$ & $5: 40 \mathrm{PM}$ & TFwilight & Talabdili & Afjiahra & kilo & $\begin{array}{l}\text { Passenger } \\
\text { Parsenter }\end{array}$ \\
\hline 277 & 666/2008 & alsulaibiya & $\begin{array}{l}\text { Callision } \\
\text { w/Other } \\
\text { Vehicle(s) }\end{array}$ & Lexus & Salon & Jiwo & Sunday & $108 / 10 / 08$ & 5: $30 \mathrm{PM}$ & Tiwilight & Eth or & almissela & $\begin{array}{l}\text { shooting } \\
\text { club }\end{array}$ & doriver \\
\hline
\end{tabular}




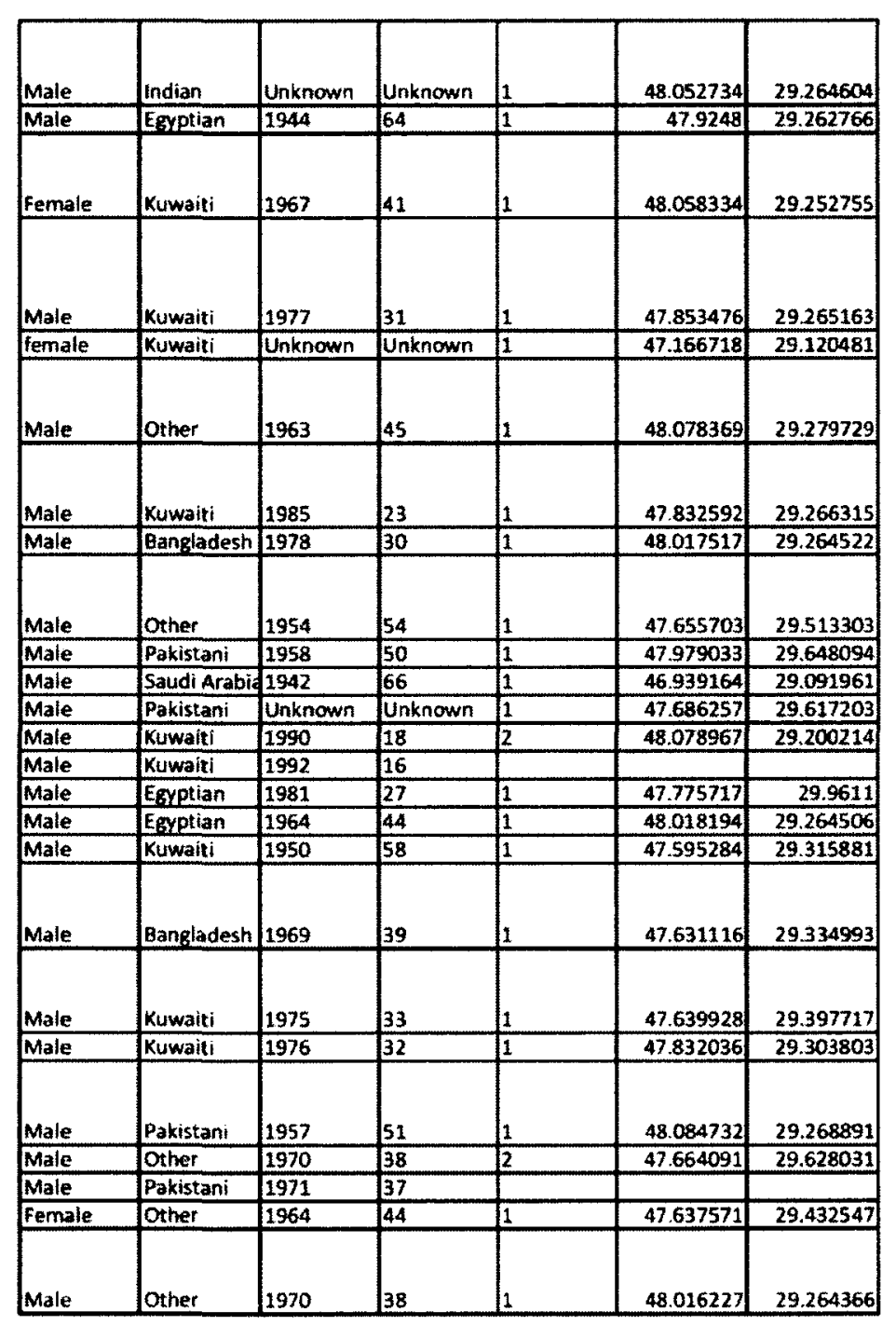




\begin{tabular}{|c|c|c|c|c|c|c|c|c|c|c|c|c|c|c|}
\hline 278 & $622 / 2008$ & alsulaibiya & $\begin{array}{l}\text { Collision } \\
\text { w/Other } \\
\text { Vehicle(s) }\end{array}$ & Chevrolet & suv & Two & Monday & $07 / 28 / 08$ & 5:30 PM & Imilight & liahra od & kuwait city & $\begin{array}{l}\text { soog } \\
\text { alharaj }\end{array}$ & Passenger \\
\hline 279 & $758 / 2008$ & taima & Rollover & nissan & Pick-up Trud & Single & Monday & 108/18/08 & $9: 00 \mathrm{AM}$ & Morning & alsalmi & alsamli & - & Passenger \\
\hline 280 & $695 / 2008$ & $\begin{array}{l}\text { Mubarak } \\
\text { Alkabeer }\end{array}$ & $\begin{array}{l}\text { Collision } \\
\text { w/Other } \\
\text { Vehicle(s) }\end{array}$ & Toyota & $\begin{array}{l}\text { Pick-up } \\
\text { Truck }\end{array}$ & two & Sunday & 08/17/08 & 8:25 AM & Morning & $\begin{array}{l}\text { sintas } \\
\text { ridge } \\
\text { intersectio } \\
n\end{array}$ & fintas & 7 thr & driver \\
\hline 281 & $1129 / 2008$ & \begin{tabular}{|l} 
Sabah \\
Aisalem
\end{tabular} & $\begin{array}{l}\text { Collision } \\
\text { w/Other } \\
\text { vehicle(s) }\end{array}$ & nissan & Salon & Two & Wednesday & $08 / 13 / 08$ & $9: 30$ AM & Morning & $\begin{array}{l}\text { sabhan } \\
\text { int.2 }\end{array}$ & sabhan & & Driver \\
\hline 282 & $769 / 2008$ & \begin{tabular}{|l} 
Mubarak \\
Alkabeer
\end{tabular} & $\begin{array}{l}\text { Collision } \\
\text { w/other } \\
\text { vehicle(s) }\end{array}$ & Mercedes & $\begin{array}{l}\text { HGV/Const } \\
\text { ruction } \\
\text { Vehicle }\end{array}$ & two & Sunday & $09 / 07 / 08$ & $5.00 P M$ & Trwilight & king fahad & kuwait city & $\begin{array}{l}\text { mubarak } \\
\text { alkabeer }\end{array}$ & driver \\
\hline 283 & $1012 / 2008$ & Aladan & Run-over & nissan & Salon & Single & Sunday & $09 / 14 / 08$ & 1:30 PM & Afternoon & king abdula & kuwait city & Imissela & Pedestrian \\
\hline 284 & $481 / 2010$ & Aisulaibiya & $\begin{array}{l}\text { Collision } \\
\text { w/other } \\
\text { Vehicle(s) }\end{array}$ & lother & Salon & Three & Monday & $06 / 28 / 10$ & $5.00 \mathrm{PM}$ & Trwilight & 6th ir & ljahra & $\begin{array}{l}\text { sikrab } \\
\text { bridge }\end{array}$ & Driver \\
\hline 285 & unknown & unknown & Run-over & Ford & SuV & Single & Wednesday & $06 / 02 / 10$ & Unknown & Unknown & blajat & & & Pedestrian \\
\hline 286 & $1914 / 2010$ & Aisalmiya & Run-over & Ford & Sports vehis & Single & Sunday & $06 / 13 / 10$ & $5: 30 \mathrm{PM}$ & Twilight & Alsalmiya B & internal rd & & Pedestrian \\
\hline 287 & $2220 / 2010$ & unknown & $\begin{array}{l}\text { Collision } \\
\text { w/Other } \\
\text { Vehicle(s) }\end{array}$ & Motorcycle & Motorcycle & Two & Wednesday & $07 / 07 / 10$ & $4: 45$ AM & Afternoon & $\begin{array}{l}\text { hamad } \\
\text { almubarak }\end{array}$ & & $\begin{array}{l}\text { NBK (to } \\
\text { right) }\end{array}$ & Driver \\
\hline 288 & $561 / 2010$ & taima & Rollover & nissan & HGV/Constr & Single & Monday & $06 / 21 / 10$ & $1: 30 \mathrm{PM}$ & Afternoon & & alsalmi & desent & Passenger \\
\hline & & & & nissan & HGV/Constr: & uction $v$ & & & & & & & & Passenger \\
\hline 289 & $662 / 10$ & taima & Rollover & Hummer & SUY & Single & 5 Sunday & $07 / 17 / 10$ & Unknown & Unknown & alsaimi & aljahra & & Passenger \\
\hline 290 & $607 / 2010$ & taima & Rallover & nissan & SUV & Single & Sunday & $07 / 01 / 10$ & Unknown & Afternoon & alsalmi & & $E$ & Driver \\
\hline 291 & $521 / 2010$ & alsulaibiya & $\begin{array}{l}\text { Collision } \\
\text { w/Other } \\
\text { Vehicle(s) }\end{array}$ & nissan & $\begin{array}{l}\text { HGV/Const } \\
\text { ruction } \\
\text { Vehicle } \\
\end{array}$ & Two & Monday & $07 / 19 / 10$ & 11:30 AM & Morning & Ath r r & kuwait city & garage cars & Driver \\
\hline 292 & $614 / 2010$ & taima & Run-over & Ford & Sports Vehic & SSingle & Sunday & $07 / 04 / 10$ & 12:15 AM & Night & br taima an & kuwait city & taima & Pedestrian \\
\hline 293 & $498 / 2010$ & alsulaibiya & Run-over & Motorcycle & Motorcycle & Single & Sunday & $07 / 04 / 10$ & $1: 30 \mathrm{PM}$ & Afternoan & kabd & 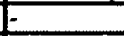 & kabd coop & Driver \\
\hline 294 & $518 / 2010$ & aisulaibiya & Run-over & Toyota & Salon & Single & Thursday & $07 / 08 / 10$ & $10: 30 \mathrm{PM}$ & Afternoon & 6 th $r$ r & jahra & shooting clu & Pedestrian \\
\hline 295 & Unknown & taima & Collision wl & Chevrolet & Salon & Single & Monday & $07 / 19 / 10$ & $5: 00 \mathrm{AM}$ & Dawn & Alsalmi & Kuwait city & Kilo 87 & Driver \\
\hline 296 & $504 / 2010$ & Aisulabiya & Rollover & Chevrolet & SUV & Single & Monday & $07 / 05 / 10$ & $7: 30 \mathrm{PM}$ & Night & 6ther & Aljahra & gas station & Passenger \\
\hline 297 & $530 / 2010$ & Alsulaibiya & Run-over & Toyota & Salon & Single & Monday & $07 / 12 / 10$ & 8:00 PM & Night & behind & towards sat & $500 \mathrm{~g}$ almaj & Pedestrian \\
\hline 298 & $531 / 2010$ & Alsulaibiyz & $\begin{array}{l}\text { Collision } \\
\text { w/Other } \\
\text { vehicle(s) }\end{array}$ & Hundai & Salon & Three & Tuesday & $107 / 13 / 10$ & 11::00 PM & Night & Sther & Almissela & firdoos & lpassenger \\
\hline 299 & $184 / 2010$ & taima & $\begin{array}{l}\text { Collision } \\
\text { w/Other } \\
\text { Vehicle(s) }\end{array}$ & GMC & \begin{tabular}{|l} 
Pick-up \\
Truck
\end{tabular} & Two & Truesday & $102 / 01 / 10$ & $9: 00 \mathrm{AM}$ & Morning & alsalmi & kuwait & $\mid \begin{array}{l}\text { arter } \\
\text { markan } \\
\text { alsalmi } 10 \\
\text { kilo }\end{array}$ & Driver \\
\hline
\end{tabular}




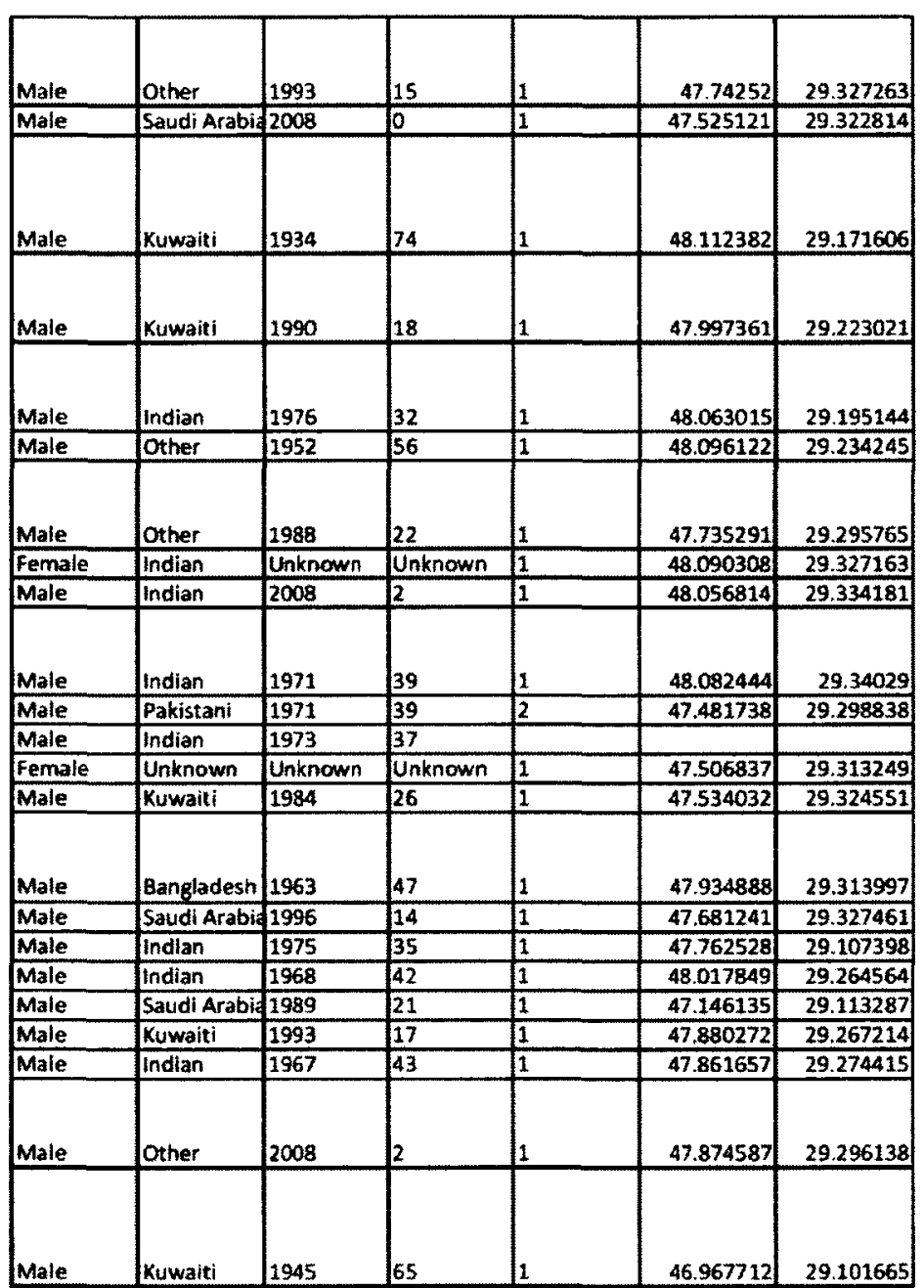




\section{Appendix B}

\section{Automated Traffic Counts}


AL SHAMLAN INTERNATIONAL

Location: $\quad$ Ist Ring Road - WEEK 1

Counter \#1

\begin{tabular}{|c|c|c|c|c|c|c|}
\hline & \multicolumn{2}{|l|}{ Date: } & \multicolumn{3}{|c|}{ wens day,December 01,2010} & \multirow[b]{2}{*}{$\begin{array}{c}\text { Coming From } \\
\text { Istiqal St. }\end{array}$} \\
\hline & Time & Chamnet & $\begin{array}{c}\text { Coming From } \\
\text { Sheraton } \\
\end{array}$ & Time & Chanturet & \\
\hline AmPeak & & 11:00 & 2002 & & $11: 00$ & 1390 \\
\hline PMPeak & & $16: 00$ & 1519 & & $16: 00$ & 621 \\
\hline
\end{tabular}

\begin{tabular}{|l|r|r|r|}
\hline 24 Hr. Volume & 28262 & & 16888 \\
\hline
\end{tabular}

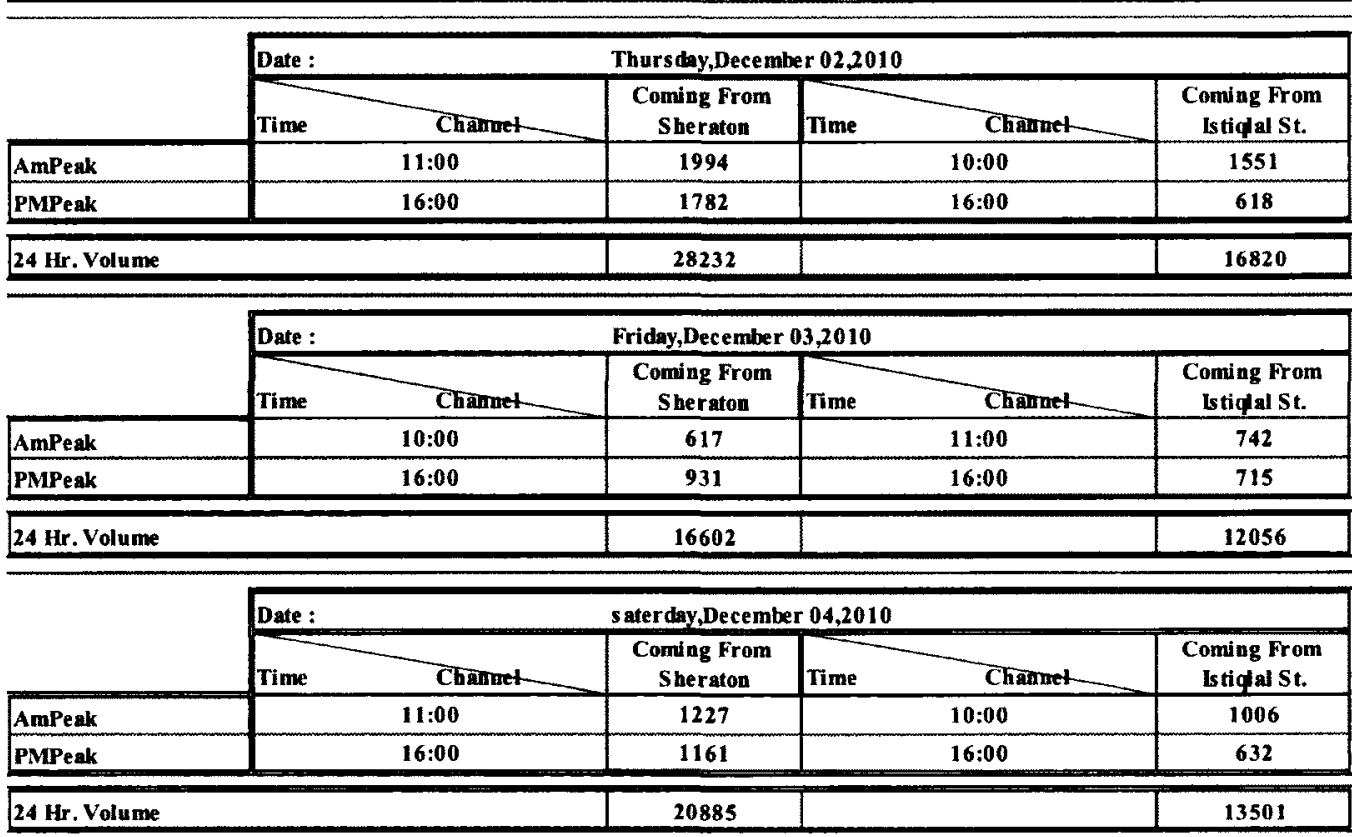

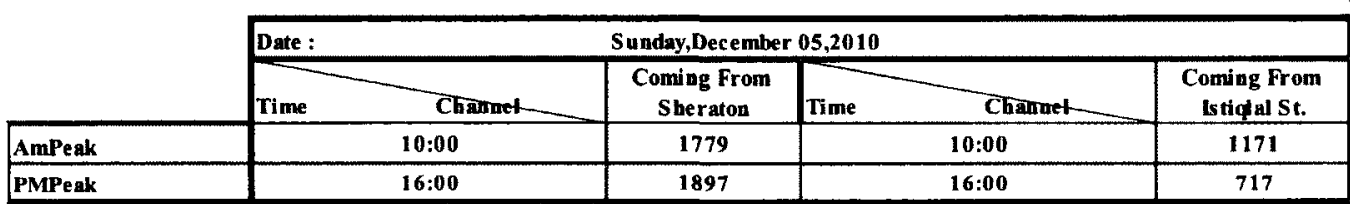

\begin{tabular}{|c|c|c|c|c|c|c|}
\hline \multirow[t]{3}{*}{$24 \mathrm{Hr}$. Volume } & & & 28410 & & & 16868 \\
\hline & \multicolumn{6}{|c|}{ Monday,December 06,2010 } \\
\hline & Time & Charnet & $\begin{array}{l}\text { Coming From } \\
\text { Sheraton }\end{array}$ & Time & Chamaet & $\begin{array}{c}\text { Coming From } \\
\text { Istiqlal St. }\end{array}$ \\
\hline AmPeak & & 11:00 & 1993 & & 10:00 & 1525 \\
\hline PMPeak & & 16:00 & 1806 & & 16:00 & 669 \\
\hline \multirow[t]{3}{*}{$24 \mathrm{Hr}$. Volume } & & & 28148 & & & 17024 \\
\hline & \multicolumn{6}{|c|}{ Tues day, December 07,2010 } \\
\hline & Time & Charmet & $\begin{array}{c}\text { Coming From } \\
\text { Sheraton }\end{array}$ & Time & Chanuet. & $\begin{array}{c}\text { Coming From } \\
\text { Istiqlal St. }\end{array}$ \\
\hline AmPeak & & 10:00 & 1718 & & 11:00 & 1337 \\
\hline PMPeak & & 16:00 & 1471 & & 16:00 & 692 \\
\hline $24 \mathrm{Hr}$. Volume & & & 28032 & & & 16920 \\
\hline
\end{tabular}


Location: $\quad$ 1st Ring Road - WEEK 2

Counter \#1

\begin{tabular}{|c|c|c|c|c|c|}
\hline & \multicolumn{5}{|c|}{ Wensday,December 08,2010} \\
\hline & Time & Channel & \begin{tabular}{|c|} 
Coming From \\
Sheraton
\end{tabular} & Time & $\begin{array}{c}\text { Coming From } \\
\text { Istiglal St. }\end{array}$ \\
\hline AmPeak & & $10: 00$ & 1872 & 10:00 & 1599 \\
\hline PMPeak & & $16: 00$ & 1510 & 17:00 & 832 \\
\hline
\end{tabular}

\begin{tabular}{|l|l|l|l|}
\hline $24 \mathrm{Hr}$. Volume & 28342 & & 16975 \\
\hline
\end{tabular}

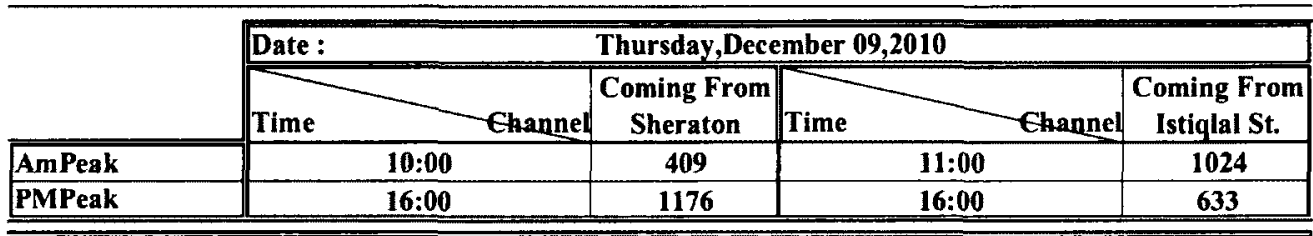

\begin{tabular}{|l|c|c|c|}
\hline $24 \mathrm{Hr}$. Volume & 21311 & & 13787 \\
\hline
\end{tabular}

\begin{tabular}{|c|c|c|c|c|}
\hline & Date : & \multicolumn{3}{|c|}{ Friday,December 10,2010} \\
\hline & Ghannel & \begin{tabular}{|c|}
$\begin{array}{c}\text { Coming From } \\
\text { Sheraton }\end{array}$ \\
\end{tabular} & Ghannel & \begin{tabular}{|c|}
$\begin{array}{c}\text { Coming From } \\
\text { Istiqlal St. }\end{array}$ \\
\end{tabular} \\
\hline AmPeak & $10: 00$ & 858 & $10: 00$ & 619 \\
\hline PMPeak & $16: 00$ & 971 & $17: 00$ & 901 \\
\hline \multirow[t]{3}{*}{$24 \mathrm{Hr}$. Volume } & & 16290 & & 11894 \\
\hline & Date: & saterday,Decem & nber 11,2010 & \\
\hline & Ghannel & \begin{tabular}{|c|}
$\begin{array}{c}\text { Coming From } \\
\text { Sheraton }\end{array}$ \\
\end{tabular} & Channel & $\begin{array}{c}\text { Coming From } \\
\text { Istiqlal St. }\end{array}$ \\
\hline AmPeak & $11: 00$ & 834 & 11:00 & 717 \\
\hline PMPeak & $16: 00$ & 1218 & $17: 00$ & 981 \\
\hline \multirow[t]{3}{*}{24 Hr. Volume } & & 14338 & & 10666 \\
\hline & Date: & Sunday,Deceml & ber 12,2010 & \\
\hline & Channel & \begin{tabular}{|c|}
$\begin{array}{c}\text { Coming From } \\
\text { Sheraton }\end{array}$ \\
\end{tabular} & Time & $\begin{array}{c}\text { Coming From } \\
\text { Istiqlal St. }\end{array}$ \\
\hline AmPeak & $11: 00$ & 981 & 10:00 & 789 \\
\hline PMPeak & $16: 00$ & 1263 & 16:00 & 1014 \\
\hline \multirow[t]{3}{*}{24 Hr. Volume } & & 16546 & & 12279 \\
\hline & Date: & Monday,Decem & nber 13,2010 & \\
\hline & Channel & \begin{tabular}{|c|} 
Coming From \\
Sheraton \\
\end{tabular} & Time & \begin{tabular}{|c|}
$\begin{array}{c}\text { Coming From } \\
\text { Istiqlal St. }\end{array}$ \\
\end{tabular} \\
\hline AmPeak & $11: 00$ & 1247 & 10:00 & 947 \\
\hline PMPeak & 13:00 & 1542 & 13:00 & 703 \\
\hline \multirow[t]{3}{*}{24 Hr. Volume } & & 17692 & & 12565 \\
\hline & Date: & Tuesday,Decem & nber 14,2010 & \\
\hline & Channel & \begin{tabular}{|c|}
$\begin{array}{c}\text { Coming From } \\
\text { Sheraton }\end{array}$ \\
\end{tabular} & Time & \begin{tabular}{|c|}
$\begin{array}{c}\text { Coming From } \\
\text { Istiglal St. }\end{array}$ \\
\end{tabular} \\
\hline AmPeak & $10: 00$ & 1843 & 10:00 & 1409 \\
\hline PMPeak & $16: 00$ & 2584 & 16:00 & 1165 \\
\hline 24 Hr. Volume & & 27438 & & 16784 \\
\hline
\end{tabular}


Location: Jahra Rd.Nr.Sheraton RdAbt WEEK 1 Counter \#2

\begin{tabular}{|c|c|c|c|c|c|c|}
\hline & \multicolumn{2}{|l|}{ Date: } & \multicolumn{4}{|c|}{ wensday,December 01,2010} \\
\hline & Time & Chatmel & $\begin{array}{c}\text { Coming From } \\
\text { Jahra }\end{array}$ & Time & Charael & $\begin{array}{c}\text { Coming From } \\
\text { Sheraton } \\
\text { RdAbt }\end{array}$ \\
\hline AmPeak & & $11: 00$ & 2578 & $11: 00$ & & 1986 \\
\hline PMPeak & & $16: 00$ & 2341 & 16:00 & & 2023 \\
\hline 24 Hr. Volume & & & 35678 & & & 36231 \\
\hline
\end{tabular}

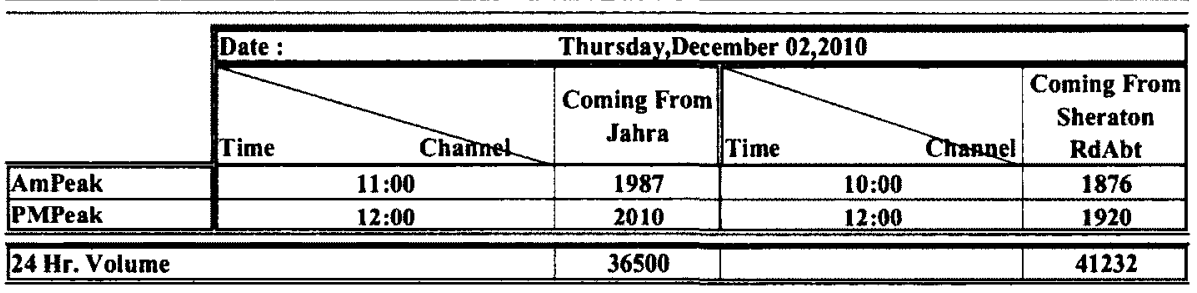

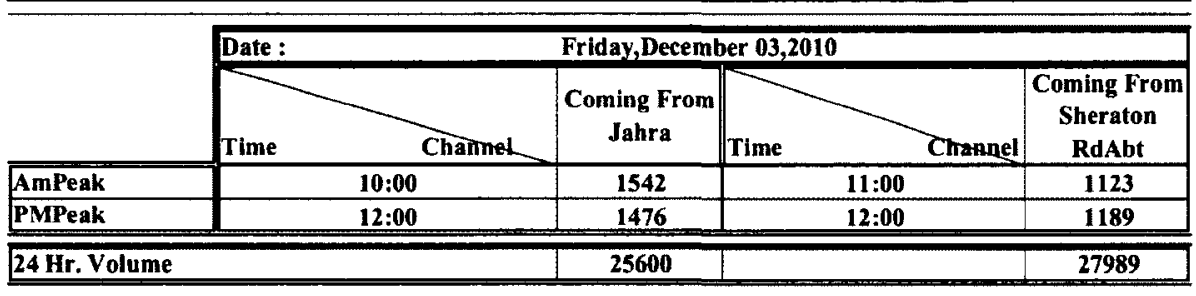

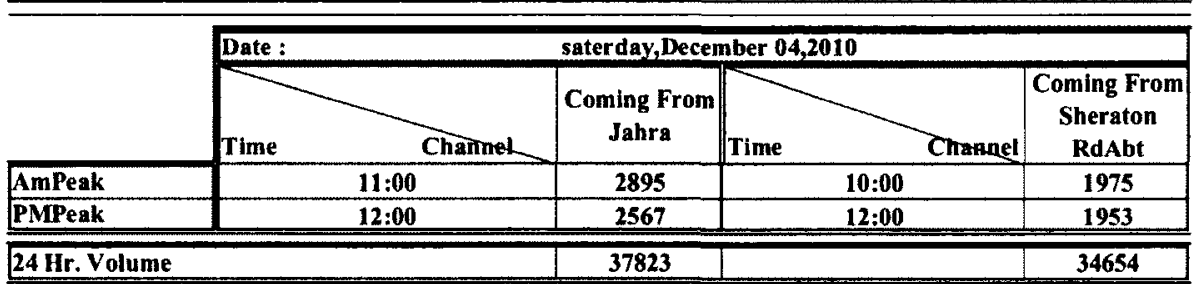

\begin{tabular}{|c|c|c|c|c|c|c|}
\hline & \multicolumn{2}{|l|}{ Date : } & \multicolumn{4}{|c|}{ Sunday,December 05,2010} \\
\hline & Time & Chammet & $\begin{array}{c}\text { Coming From } \\
\text { Jahra }\end{array}$ & Time & Crannel & $\begin{array}{c}\text { Coming From } \\
\text { Sheraton } \\
\text { RdAbt } \\
\end{array}$ \\
\hline AmPeak & & $10: 00$ & 2876 & $10: 00$ & & 2213 \\
\hline PMPeak & & $16: 00$ & 2458 & 16:00 & & 2034 \\
\hline
\end{tabular}

\begin{tabular}{|l|l|l|l|}
\hline $24 \mathrm{Hr}$. Volume & 38790 & & 36547 \\
\hline
\end{tabular}

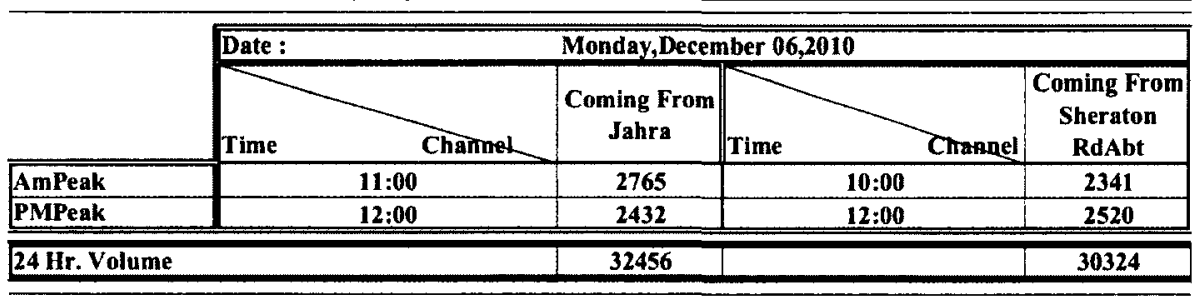

\begin{tabular}{|c|c|c|c|c|c|}
\hline & \multicolumn{2}{|l|}{ Date: } & \multicolumn{2}{|c|}{ Tuesday,December 07,2010 } & \multirow[b]{2}{*}{$\begin{array}{c}\text { Coming From } \\
\begin{array}{c}\text { Sheraton } \\
\text { RdAbt }\end{array} \\
\end{array}$} \\
\hline & Time & Chantmel & $\underset{\mathrm{J} a h r a}{C}$ & Crangel & \\
\hline AmPeak & & 10:00 & 2897 & 11:00 & 2220 \\
\hline PMPeak & & 16:00 & 2451 & 16:00 & 2048 \\
\hline \multicolumn{3}{|c|}{24 Hr. Volume } & 37862 & & 34220 \\
\hline
\end{tabular}


Location: Jahra Rd.Nr.Sheraton RdA WEEK 2

Counter \#2

\begin{tabular}{|c|c|c|c|c|c|c|}
\hline & \multicolumn{2}{|l|}{ Date : } & \multicolumn{3}{|c|}{ Wensday,December 08,2010} & \multirow[b]{2}{*}{$\begin{array}{c}\text { Coming From } \\
\text { Sheraton } \\
\text { RdAbt }\end{array}$} \\
\hline & Time & Changel & $\begin{array}{c}\text { Coming From } \\
\text { Jahra }\end{array}$ & Time & Channel & \\
\hline AmPeak & $10: 00$ & & 2564 & $10: 00$ & & 2227 \\
\hline PMPeak & 12:00 & & 2498 & $12: 00$ & & 2376 \\
\hline $24 \mathrm{Hr} . \mathrm{Vo}_{0}$ & & & 40143 & & & $\mathbf{3 8 7 5 3}$ \\
\hline
\end{tabular}

\begin{tabular}{|c|c|c|c|c|c|}
\hline & \multirow{2}{*}{ Date : } & \multirow[b]{2}{*}{ Channel } & \multicolumn{3}{|c|}{ Thursday, December 09,2010} \\
\hline & & & $\begin{array}{c}\text { Coming From } \\
\text { Jahra }\end{array}$ & Crannel & $\begin{array}{c}\text { Coming From } \\
\text { Sheraton } \\
\text { RdAbt }\end{array}$ \\
\hline AmPeak & $10: 00$ & & 2231 & $11: 00$ & 2010 \\
\hline PMPeak & $12: 00$ & & 2342 & $16: 00$ & 1564 \\
\hline
\end{tabular}

24 Hr. Volume

31452

29654

\begin{tabular}{|c|c|c|c|c|c|c|}
\hline & \multirow{2}{*}{\multicolumn{2}{|c|}{ Dime }} & \multicolumn{4}{|c|}{ Friday,December 10,2010} \\
\hline & & & $\underset{\text { Jahra }}{\text { Coming From }}$ & Time & Crannel & $\begin{array}{c}\text { Coming From } \\
\text { Sheraton } \\
\text { RdAbt }\end{array}$ \\
\hline AmPeak & 10:00 & & 1128 & $10: 00$ & & 1048 \\
\hline PMPeak & $12: 00$ & & 993 & $12: 00$ & & 871 \\
\hline
\end{tabular}

\begin{tabular}{|c|c|c|c|c|c|}
\hline & \multicolumn{2}{|l|}{ Date : } & \multicolumn{2}{|c|}{ saterday,December 11,2010} & \multirow[b]{2}{*}{$\begin{array}{c}\text { Coming From } \\
\text { Sheraton } \\
\text { RdAbt }\end{array}$} \\
\hline & Time & Channel & $\underset{\text { Jahra }}{\text { Coming From }}$ & Channel & \\
\hline AmPeak & $11: 00$ & & 2024 & $11: 00$ & 1976 \\
\hline PMPeak & $12: 00$ & & 2323 & $12: 00$ & 2010 \\
\hline \multirow[t]{3}{*}{$24 \mathrm{Hr}$. Volume } & & & 32876 & & 31765 \\
\hline & Date: & & Sunday,Decem & ber 12,2010 & \\
\hline & Time & Channel & $\underset{\text { Jahra }}{\text { Coming From }}$ & Channel & $\begin{array}{c}\text { Coming From } \\
\text { Sheraton } \\
\text { RdAbt }\end{array}$ \\
\hline AmPeak & 11:00 & & 2024 & $10: 00$ & 2098 \\
\hline PMPeak & $12: 00$ & & 2341 & 12:00 & 2174 \\
\hline
\end{tabular}

\begin{tabular}{|l|r|r|r|}
\hline 24 Hr. Volume & 36782 & & 32674 \\
\hline
\end{tabular}

\begin{tabular}{|c|c|c|c|c|c|}
\hline & \multicolumn{2}{|l|}{ Date: } & \multicolumn{3}{|c|}{ Monday,December 13,2010 } \\
\hline & Time & Clrannel & $\underset{\text { Jahra }}{\text { Coming From }}$ & Clrangel & \begin{tabular}{|c|}
$\begin{array}{c}\text { Coming From } \\
\text { Sheraton } \\
\text { RdAbt }\end{array}$ \\
\end{tabular} \\
\hline AmPeak & 11:00 & & 2186 & $10: 00$ & 1834 \\
\hline PMPeak & 13:00 & & 1802 & 13:00 & 2223 \\
\hline
\end{tabular}

\begin{tabular}{|l|l|l|l|}
\hline 24 Hr. Volume & 37853 & & 31641 \\
\hline
\end{tabular}

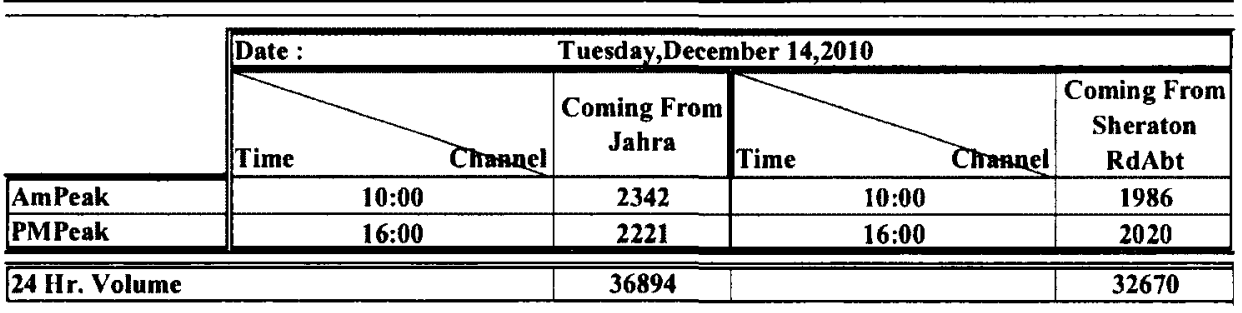


Location: Istiqlal St.bet 3rd\&4th R.R WEEK 1 Counter \#3

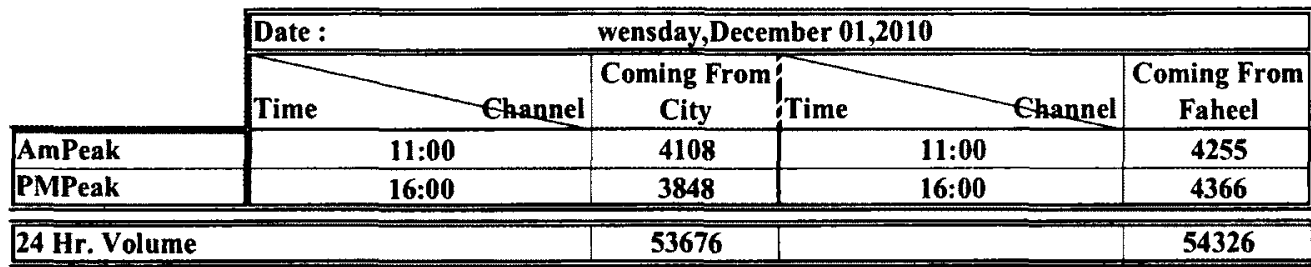

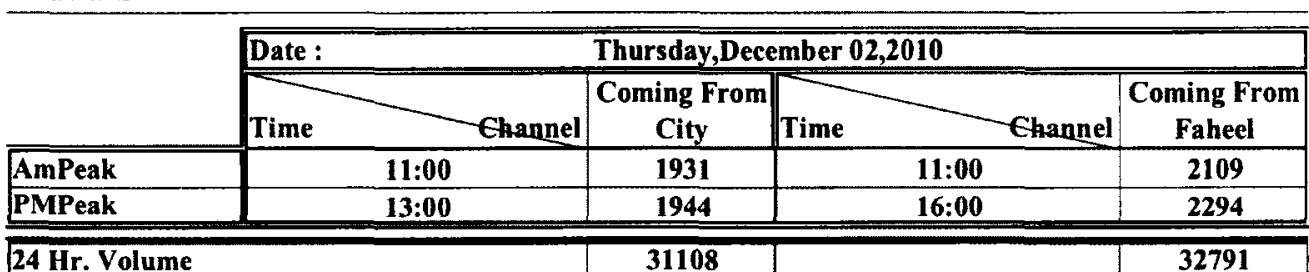

\begin{tabular}{|c|c|c|c|c|c|}
\hline & \multicolumn{2}{|l|}{ Date: } & \multicolumn{3}{|c|}{ Friday,December 03,2010} \\
\hline & & Channel & $\begin{array}{c}\text { Coming From } \\
\text { City }\end{array}$ & Channel & $\begin{array}{c}\text { Coming From } \\
\text { Faheel }\end{array}$ \\
\hline AmPeak & & $11: 00$ & 1875 & $10: 00$ & 2054 \\
\hline PMPeak & & 13:00 & 2184 & 16:00 & 2586 \\
\hline 24 Hr. Volume & & & 31295 & & 32302 \\
\hline
\end{tabular}

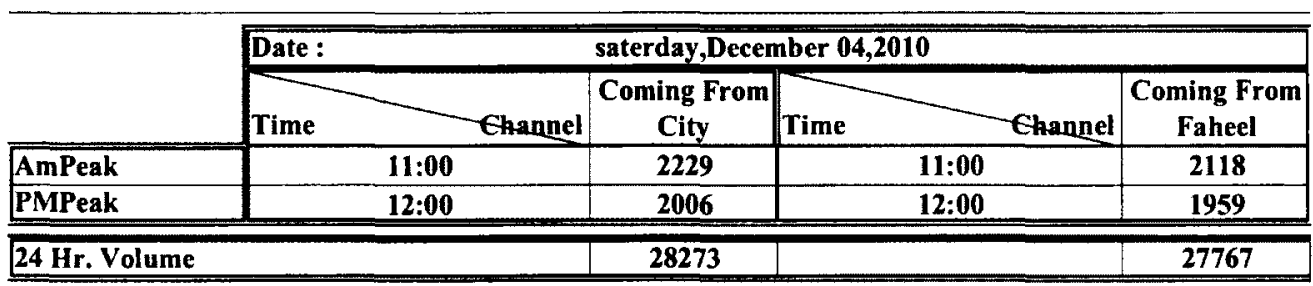

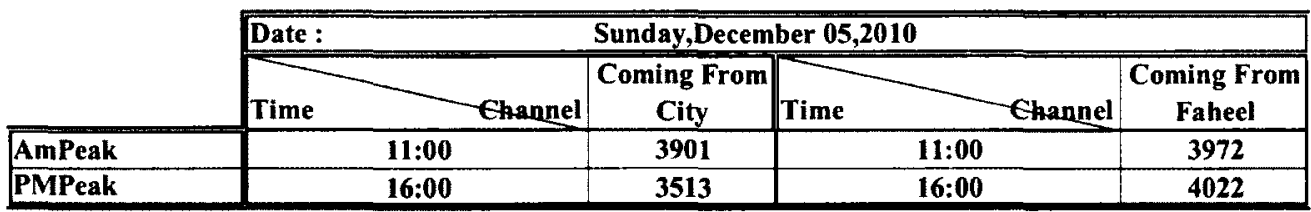

\begin{tabular}{|l|c|c|c|}
\hline 24 Hr. Volume & 50906 & & 51557 \\
\hline
\end{tabular}

\begin{tabular}{|c|c|c|c|c|}
\hline & Date: & \multicolumn{3}{|c|}{ Monday,December 06,2010 } \\
\hline & Time & \begin{tabular}{|c|} 
Coming From \\
City
\end{tabular} & Time & $\begin{array}{c}\begin{array}{c}\text { Coming From } \\
\text { Faheel }\end{array} \\
\end{array}$ \\
\hline AmPeak & $11: 00$ & 4603 & 11:00 & 4515 \\
\hline PMPeak & $12: 00$ & 4244 & 12:00 & 4601 \\
\hline 24 Hr. Volume & & 61180 & & 61040 \\
\hline
\end{tabular}

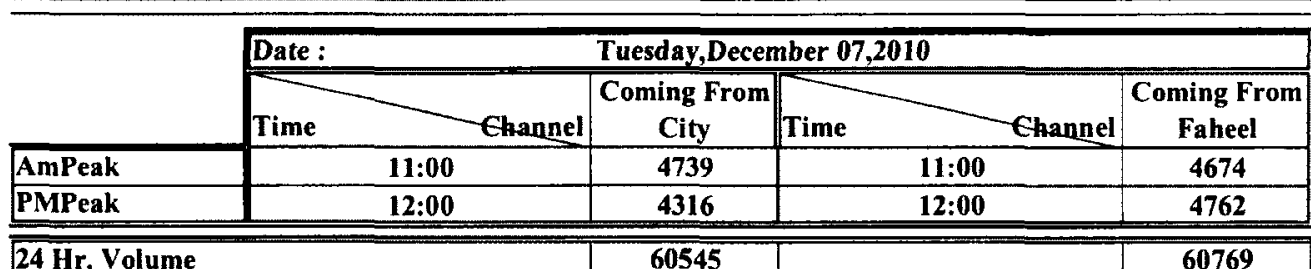


Location: Istiqlal St.bet 3rd\&4th R.R WEEK 2

\section{Counter \#3}

\begin{tabular}{|c|c|c|c|c|c|c|}
\hline & \multicolumn{2}{|l|}{ Date: } & \multicolumn{4}{|c|}{ Wensday,December 08,2010} \\
\hline & Time & Channel & $\begin{array}{c}\text { Coming From } \\
\text { City }\end{array}$ & |Time & Channel & $\begin{array}{c}\text { Coming From } \\
\text { Faheel }\end{array}$ \\
\hline AmPeak & & 11:00 & 5064 & $11: 00$ & & 4860 \\
\hline PMPeak & & $12: 00$ & 4527 & $12: 00$ & & 4842 \\
\hline 24 Hr. Volume & & & 62321 & & & 62818 \\
\hline
\end{tabular}

\begin{tabular}{|c|c|c|c|c|c|}
\hline & \multicolumn{2}{|l|}{ Date : } & \multicolumn{3}{|c|}{ Thursday,December 09,2010 } \\
\hline & Time & Channel & \begin{tabular}{|} 
Coming From \\
City
\end{tabular} & Time & $\begin{array}{c}\text { Coming From } \\
\text { Faheel }\end{array}$ \\
\hline AmPeak & & 11:00 & 3914 & $10: 00$ & 4124 \\
\hline PMPeak & & $12: 00$ & 4254 & 12:00 & 4707 \\
\hline 24 Hr. Volume & & & 53265 & & 56538 \\
\hline
\end{tabular}

\begin{tabular}{|c|c|c|c|c|c|}
\hline & \multicolumn{2}{|l|}{ Date: } & \multicolumn{3}{|c|}{ Friday, December 10,2010} \\
\hline & Time & Channel & $\begin{array}{c}\text { Coming From } \\
\text { City }\end{array}$ & Time & $\begin{array}{c}\text { Coming From } \\
\text { Faheel }\end{array}$ \\
\hline AmPeak & & $11: 00$ & 1896 & 11:00 & 2100 \\
\hline PMPeak & & $16: 00$ & 2657 & 16:00 & $\mathbf{3 2 3 7}$ \\
\hline $24 \mathrm{Hr}$. Volume & & & 35012 & & 37164 \\
\hline
\end{tabular}

\begin{tabular}{|c|c|c|c|c|c|}
\hline & \multicolumn{2}{|l|}{ Date : } & \multicolumn{3}{|c|}{ saterday,December 11,2010} \\
\hline & Time & Channel & $\begin{array}{c}\begin{array}{c}\text { Coming From } \\
\text { City }\end{array} \\
\end{array}$ & $\overline{\text { Time }}$ & $\begin{array}{c}\text { Coming From } \\
\text { Faheel }\end{array}$ \\
\hline AmPeak & & 11:00 & 4729 & 11:00 & 4826 \\
\hline PMPeak & & $12: 00$ & 4405 & $16: 00$ & 4900 \\
\hline 24 Hr. Volume & & & 63709 & & 64864 \\
\hline
\end{tabular}

\begin{tabular}{|c|c|c|c|c|c|}
\hline & \multicolumn{2}{|l|}{ Date: } & \multicolumn{3}{|c|}{ Sunday,December 12,2010} \\
\hline & & Channel & $\begin{array}{c}\text { Coming From } \\
\text { City }\end{array}$ & Channel & $\begin{array}{c}\text { Coming From } \\
\text { Faheel }\end{array}$ \\
\hline AmPeak & & $10: 00$ & 4578 & $10: 00$ & 4567 \\
\hline PMPeak & & $12: 00$ & 4298 & 16:00 & 4730 \\
\hline 24 Hr. Volume & & & 62993 & & 63305 \\
\hline
\end{tabular}

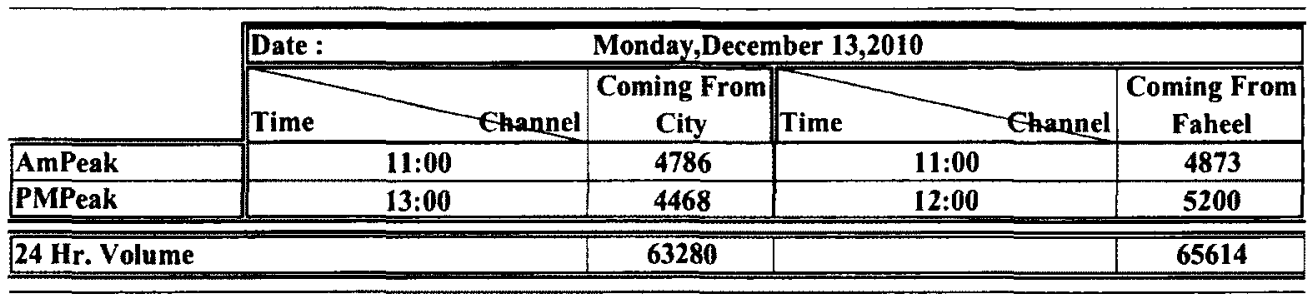

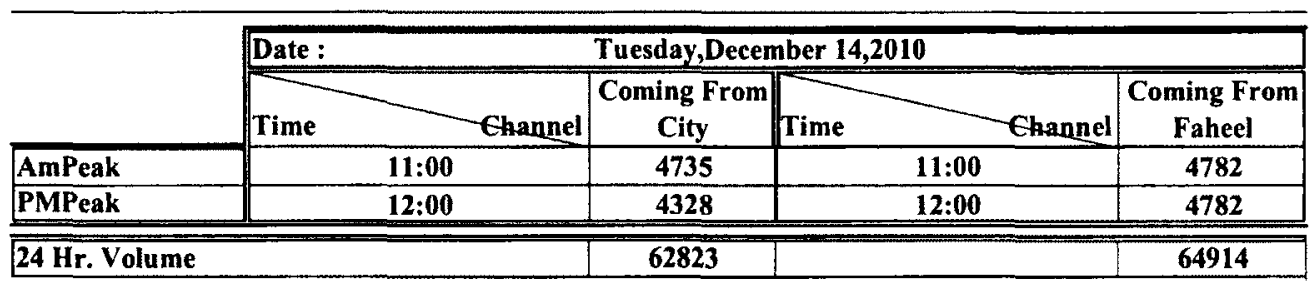


AL SHAMLAN INTERNATIONAL

Location: Cairo St. WEEK 1

Counter \#4

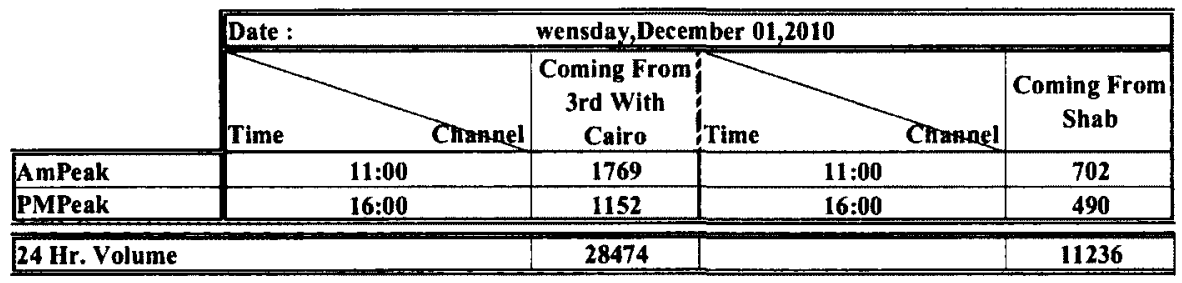

\begin{tabular}{|c|c|c|c|c|c|}
\hline & \multicolumn{2}{|l|}{ Date : } & \multicolumn{3}{|c|}{ Thursday,December 02,2010 } \\
\hline & Time & Channel & $\begin{array}{c}\text { Coming From } \\
\text { 3rd With } \\
\text { Cairo }\end{array}$ & Channel & $\begin{array}{c}\text { Coming From } \\
\text { Shab }\end{array}$ \\
\hline AmPeak & & & 1738 & $10: 00$ & 958 \\
\hline PMPeak & & & 1452 & $16: 00$ & 601 \\
\hline
\end{tabular}

\begin{tabular}{|l|l|l|l|}
\hline 24 Hr. Volume & 28445 & 11448 \\
\hline
\end{tabular}

\begin{tabular}{|c|c|c|c|c|c|}
\hline & \multicolumn{2}{|l|}{ Date : } & \multicolumn{3}{|c|}{ Friday,December 03,2010} \\
\hline & Time & Channel & $\begin{array}{c}\text { Coming From } \\
\text { 3rd With } \\
\text { Cairo }\end{array}$ & Comannel & $\begin{array}{c}\text { Coming From } \\
\text { Shab }\end{array}$ \\
\hline AmPeak & $10: 00$ & & 489 & 11:00 & 384 \\
\hline PMPeak & 16:00 & & 1515 & 16:00 & 641 \\
\hline 24 Hr. Volume & & & 19909 & & 8514 \\
\hline
\end{tabular}

\begin{tabular}{|c|c|c|c|c|c|}
\hline & \multicolumn{2}{|l|}{ Date: } & \multicolumn{3}{|c|}{ saterday, December 04,2010 } \\
\hline & Time & Chanael & \begin{tabular}{|c|} 
Coming From \\
3rd With \\
Cairo
\end{tabular} & Chrannel & $\begin{array}{c}\text { Coming From } \\
\text { Shab }\end{array}$ \\
\hline AmPeak & 11:00 & & 1313 & 10:00 & 571 \\
\hline PMPeak & $16: 00$ & & 1474 & $16: 00$ & 595 \\
\hline 24 Hr. Volume & & & 25743 & & 10418 \\
\hline
\end{tabular}

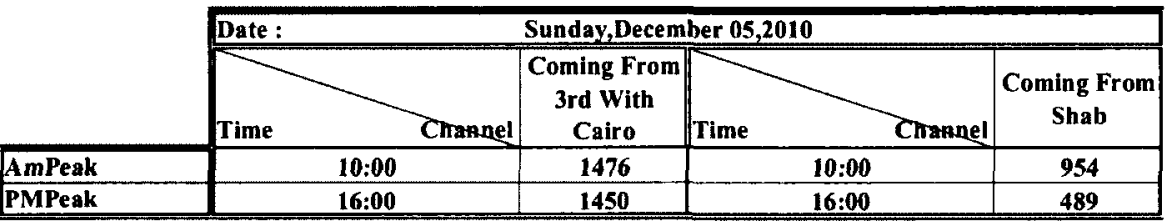

\begin{tabular}{|c|c|c|c|c|}
\hline \multicolumn{2}{|l|}{$24 \mathrm{Hr}$. Volume } & 29207 & & 11947 \\
\hline & \multicolumn{4}{|c|}{ Monday,December 06,2010 } \\
\hline & Channel & $\begin{array}{c}\text { Coming From } \\
\text { 3rd With } \\
\text { Cairo }\end{array}$ & Changel & $\begin{array}{c}\text { Coming From } \\
\text { Shab }\end{array}$ \\
\hline AmPeak & $11: 00$ & 1852 & $10: 00$ & 1048 \\
\hline PMPeak & $16: 00$ & 1529 & 16:00 & 583 \\
\hline \multirow[t]{3}{*}{$24 \mathrm{Hr}$. Volume } & & 29896 & & 11700 \\
\hline & \multicolumn{4}{|c|}{ Tuesday,December 07,2010 } \\
\hline & Chandel & $\begin{array}{c}\text { Coming From } \\
\text { 3rd With } \\
\text { Cairo }\end{array}$ & Channel & $\begin{array}{c}\text { Coming From } \\
\text { Shab }\end{array}$ \\
\hline AmPeak & $10: 00$ & 1503 & $11: 00$ & 838 \\
\hline PMPeak & $16: 00$ & 1593 & $16: 00$ & 545 \\
\hline $24 \mathrm{Hr}$. Volume & & 30320 & & 12068 \\
\hline
\end{tabular}


Location: $\quad$ Cairo St. WEEK 2 Counter \#4

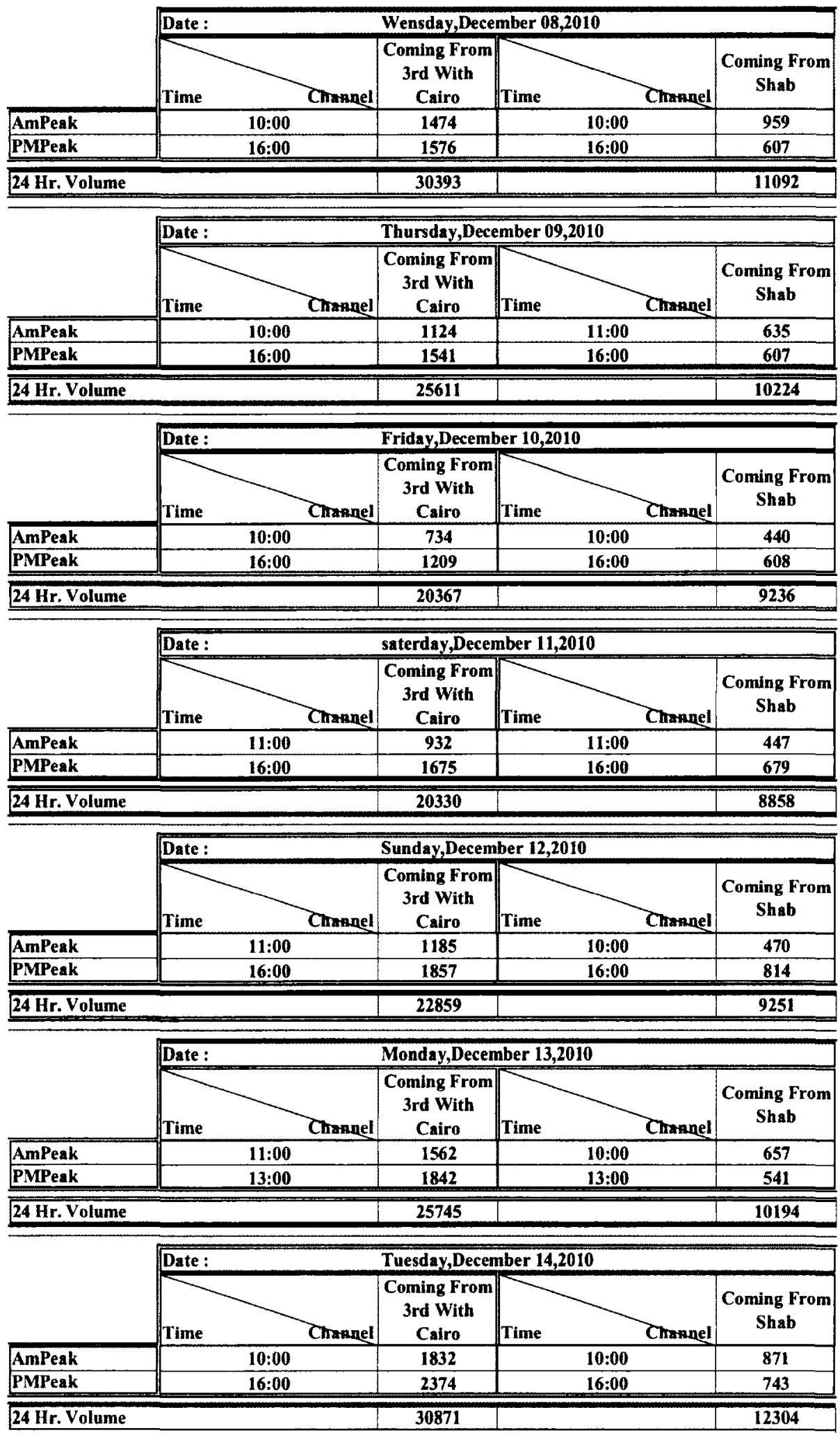


Location: $\quad$ King Fahd Expressway(bet.3rd\&4th R.R) WEEK 1 Counter \#5

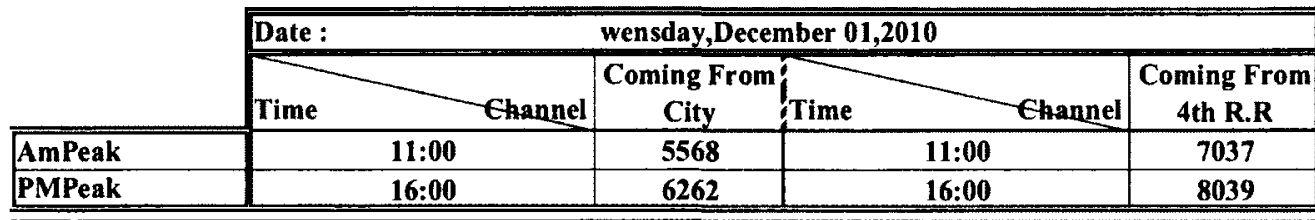

\begin{tabular}{|l|l|l|l|}
\hline 24 Hr. Volume & 72345 & & 69874 \\
\hline
\end{tabular}

\begin{tabular}{|c|c|c|c|c|}
\hline & Date: & \multicolumn{3}{|c|}{ Thursday,December 02,2010 } \\
\hline & Time & \begin{tabular}{|c|} 
Coming From \\
City \\
\end{tabular} & Time & $\begin{array}{c}\text { Coming From } \\
\text { 4th R.R } \\
\end{array}$ \\
\hline AmPeak & 11:00 & 4976 & $10: 00$ & 5321 \\
\hline PMPeak & $12: 00$ & 5678 & $12: 00$ & 5268 \\
\hline 24 Hr. Volume & & 74537 & & 67890 \\
\hline
\end{tabular}

\begin{tabular}{|c|c|c|c|c|}
\hline & Date: & \multicolumn{3}{|c|}{ Friday,December 03,2010 } \\
\hline & Channel & \begin{tabular}{|c|}
$\begin{array}{c}\text { Coming From } \\
\text { City }\end{array}$ \\
\end{tabular} & Time & \begin{tabular}{|c|} 
Coming From \\
4th R.R \\
\end{tabular} \\
\hline AmPeak & $10: 00$ & 3789 & 11:00 & 3568 \\
\hline PMPeak & $12: 00$ & 4012 & $12: 00$ & 3896 \\
\hline $24 \mathrm{Hr}$. Volume & & 43568 & & 42124 \\
\hline
\end{tabular}

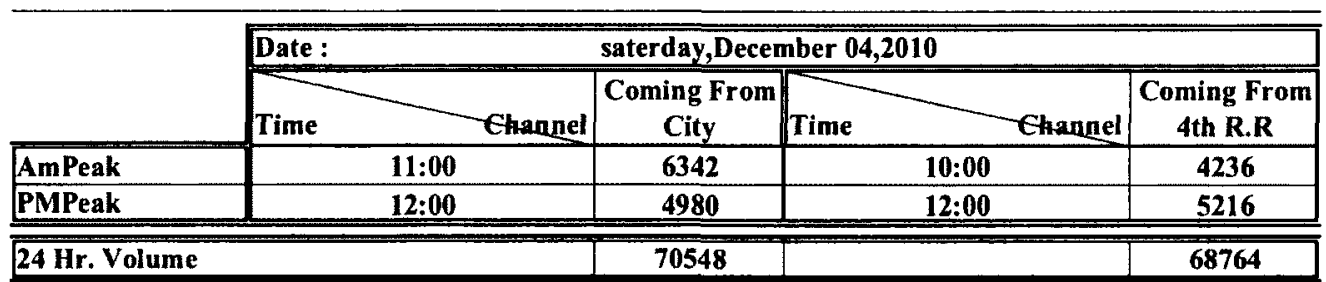

\begin{tabular}{|c|c|c|c|c|c|}
\hline & \multicolumn{2}{|l|}{ Date: } & \multicolumn{3}{|c|}{ Sunday,December 05,2010 } \\
\hline & Time & Channel & \begin{tabular}{|c|} 
Coming From \\
City
\end{tabular} & Channel & $\begin{array}{c}\text { Coming From } \\
\text { 4th R.R }\end{array}$ \\
\hline AmPeak & & $10: 00$ & 6430 & 10:00 & 6236 \\
\hline PMPeak & & 16:00 & 5896 & $16: 00$ & 7011 \\
\hline 24 Hr. Volume & & & 73456 & & $\overline{68754}$ \\
\hline
\end{tabular}

\begin{tabular}{|c|c|c|c|c|c|}
\hline & \multicolumn{2}{|l|}{ Date : } & \multicolumn{3}{|c|}{ Monday,December 06,2010} \\
\hline & Time & Channel & \begin{tabular}{|c|} 
Coming From \\
City
\end{tabular} & Channel & $\begin{array}{c}\text { Coming From } \\
\text { 4th R.R }\end{array}$ \\
\hline AmPeak & & 11:00 & 4786 & $10: 00$ & 4897 \\
\hline PMPeak & & 12:00 & 5634 & $12: 00$ & 6543 \\
\hline 24 Hr. Volume & & & 71675 & & $\overline{669542}$ \\
\hline
\end{tabular}

\begin{tabular}{|c|c|c|c|c|c|}
\hline & \multicolumn{2}{|l|}{ Date: } & \multicolumn{3}{|c|}{ Tuesday, December 07,2010 } \\
\hline & Time & Channel & $\begin{array}{c}\text { Coming From } \\
\text { City }\end{array}$ & Time & $\begin{array}{c}\text { Coming From } \\
\text { 4th R.R }\end{array}$ \\
\hline AmPeak & & & 4368 & $11: 00$ & 4512 \\
\hline PMPeak & & & 5764 & $16: 00$ & 5434 \\
\hline 24 Hr. Volume & & & 65986 & & 67845 \\
\hline
\end{tabular}


Location: $\quad$ King Fahd Expressway(bet.3rd\&4th R.R) WEEK 2 Counter \#5

\begin{tabular}{|c|c|c|c|c|c|}
\hline & \multicolumn{2}{|l|}{ Date: } & \multicolumn{3}{|c|}{ Wensday,December 08,2010} \\
\hline & Time & Channel & \begin{tabular}{|c|} 
Coming From \\
City
\end{tabular} & Channel & $\begin{array}{c}\text { Coming From } \\
\text { 4th R.R }\end{array}$ \\
\hline AmPeak & & & 4568 & $10: 00$ & 4876 \\
\hline PMPeak & & & 4236 & $12: 00$ & 5743 \\
\hline
\end{tabular}

\begin{tabular}{|l|c|c|c|c|}
\hline 24 Hr. Volume & 65879 & & 62345 \\
\hline
\end{tabular}

\begin{tabular}{|c|c|c|c|c|}
\hline & Date: & \multicolumn{3}{|c|}{ Thursday,December 09,2010 } \\
\hline & Time Channel & \begin{tabular}{|c|} 
Coming From \\
City
\end{tabular} & Time & $\begin{array}{c}\text { Coming From } \\
\text { 4th R.R } \\
\end{array}$ \\
\hline AmPeak & $10: 00$ & 5436 & 11:00 & 4987 \\
\hline PMPeak & $12: 00$ & 4678 & $16: 00$ & 5012 \\
\hline \multirow[t]{3}{*}{$24 \mathrm{Hr}$. Volume } & & 69870 & & 65431 \\
\hline & Date: & Friday,Decemb & ber 10,2010 & \\
\hline & Time & \begin{tabular}{|c|} 
Coming From \\
City
\end{tabular} & Time & \begin{tabular}{|c|} 
Coming From \\
4th R.R
\end{tabular} \\
\hline AmPeak & $10: 00$ & 3215 & $10: 00$ & 2876 \\
\hline PMPeak & 12:00 & 2897 & $12: 00$ & 3032 \\
\hline \multirow[t]{3}{*}{24 Hr. Volume } & & 44568 & & 42789 \\
\hline & Date: & saterday,Decem & nber 11,2010 & \\
\hline & Channel & $\begin{array}{c}\text { Coming From } \\
\text { City }\end{array}$ & Time & $\begin{array}{c}\text { Coming From } \\
\text { 4th R.R }\end{array}$ \\
\hline AmPeak & $11: 00$ & 4890 & 11:00 & 5342 \\
\hline PMPeak & 12:00 & 5013 & 12:00 & 6784 \\
\hline \multirow[t]{3}{*}{$24 \mathrm{Hr}$. Volume } & & 66780 & & 70234 \\
\hline & Date: & Sunday,Decemt & ber 12,2010 & \\
\hline & Channel & \begin{tabular}{|c|}
$\begin{array}{c}\text { Coming From } \\
\text { City }\end{array}$ \\
\end{tabular} & Time & \begin{tabular}{|c|}
$\begin{array}{c}\text { Coming From } \\
\text { 4th R.R }\end{array}$ \\
\end{tabular} \\
\hline AmPeak & $11: 00$ & 4876 & $10: 00$ & 5498 \\
\hline PMPeak & $12: 00$ & 5234 & 12:00 & 6354 \\
\hline \multicolumn{2}{|l|}{24 Hr. Volume } & 74532 & & 69873 \\
\hline
\end{tabular}

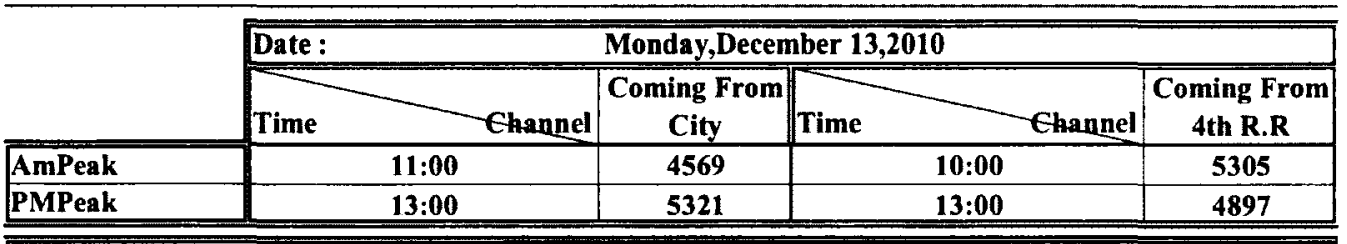

\begin{tabular}{|c|c|c|c|c|}
\hline \multirow[t]{3}{*}{24 Hr. Volume } & & 6989 & & 6874 \\
\hline & Date : & \multicolumn{3}{|c|}{ Tuesday,December 14,2010} \\
\hline & Channel & $\begin{array}{c}\text { Coming From } \\
\text { City }\end{array}$ & $\overline{\text { Time }}$ & $\begin{array}{c}\text { Coming From } \\
\text { 4th R.R }\end{array}$ \\
\hline AmPeak & $10: 00$ & 4210 & $10: 00$ & 5430 \\
\hline PMPeak & $16: 00$ & 4564 & $16: 00$ & 4986 \\
\hline 24 Hr. Volume & & 73450 & & 64789 \\
\hline
\end{tabular}




\section{Location: $\quad$ 4th Ring(Bet.Aidiliya\&Qurtuba) WEEK 1 Counter \#6}

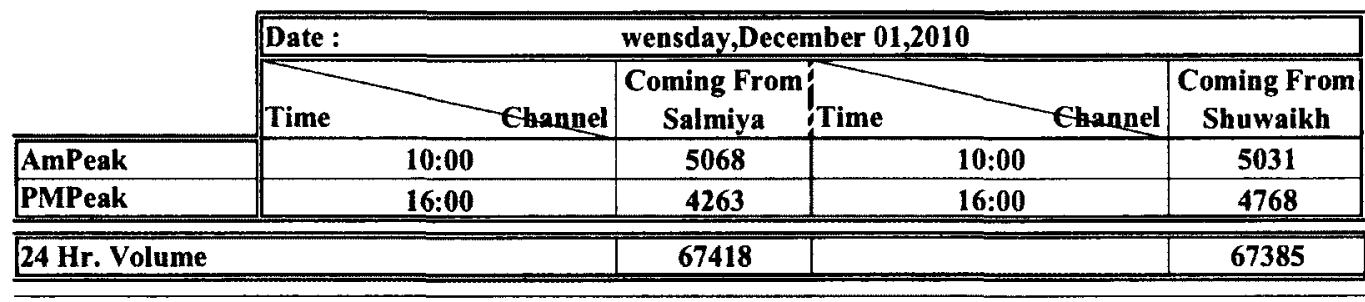

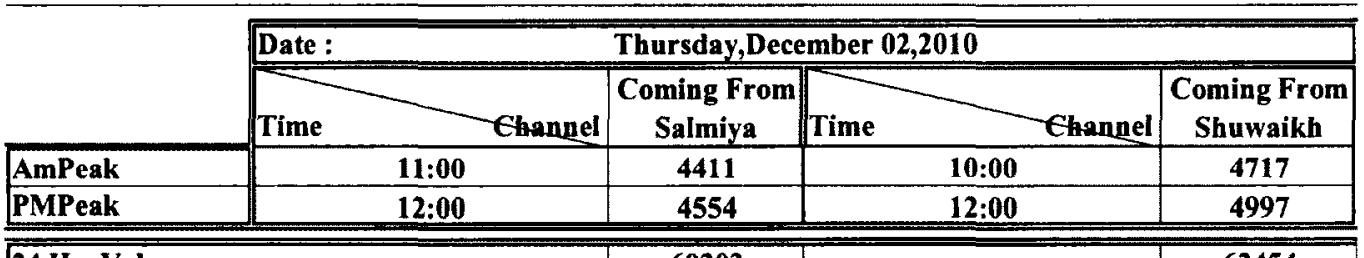

60203

62454

\begin{tabular}{|c|c|c|c|c|}
\hline & Date: & \multicolumn{3}{|c|}{ Friday,December 03,2010} \\
\hline & Time & $\begin{array}{c}\text { Coming From } \\
\text { Salmiya }\end{array}$ & Channel & $\begin{array}{c}\text { Coming From } \\
\text { Shuwaikh }\end{array}$ \\
\hline AmPeak & $10: 00$ & 1915 & 11:00 & 2182 \\
\hline PMPeak & $17: 00$ & 3158 & $16: 00$ & 3772 \\
\hline \multirow[t]{3}{*}{24 Hr. Volume } & & $\mathbf{3 8 3 3 7}$ & & 40445 \\
\hline & Date: & saterday,Decem & nber 04,2010 & \\
\hline & Channel & \begin{tabular}{c|} 
Coming From \\
Salmiya
\end{tabular} & Channel & $\begin{array}{c}\text { Coming From } \\
\text { Shuwaikh }\end{array}$ \\
\hline AmPeak & $10: 00$ & 4744 & $10: 00$ & 4853 \\
\hline PMPeak & $12: 00$ & 4494 & $12: 00$ & 5023 \\
\hline 24 Hr. Volume & & 66928 & & 67944 \\
\hline
\end{tabular}

\begin{tabular}{|c|c|c|c|c|}
\hline & Date: & \multicolumn{2}{|c|}{ Sunday,December 05,2010} & \multirow[b]{2}{*}{$\begin{array}{c}\text { Coming From } \\
\text { Shuwaikh } \\
\end{array}$} \\
\hline & Time Channel & \begin{tabular}{|c||}
$\begin{array}{c}\text { Coming From } \\
\text { Salmiya }\end{array}$ \\
\end{tabular} & Channel & \\
\hline AmPeak & $10: 00$ & 4916 & 11:00 & 4806 \\
\hline PMPeak & $12: 00$ & 4691 & $16: 00$ & 4949 \\
\hline
\end{tabular}

\begin{tabular}{|l|l|l|l|}
\hline 24 Hr. Volume & 66619 & & 66829 \\
\hline
\end{tabular}

\begin{tabular}{|c|c|c|c|c|c|}
\hline & \multicolumn{2}{|l|}{ Date: } & \multicolumn{3}{|c|}{ Monday,December 06,2010 } \\
\hline & Time & Cbannel & $\begin{array}{c}\text { Coming From } \\
\text { Salmiya }\end{array}$ & Channel & $\begin{array}{c}\text { Coming From } \\
\text { Shuwaikh }\end{array}$ \\
\hline AmPeak & & $10: 00$ & 5005 & $10: 00$ & 4458 \\
\hline PMPeak & & 12:00 & 4551 & $12: 00$ & 4835 \\
\hline \multirow[t]{3}{*}{24 Hr. Volume } & & & 62925 & & 62814 \\
\hline & Date : & & \multicolumn{3}{|c|}{ Tuesday,December 07,2010 } \\
\hline & Time & Channel & $\begin{array}{c}\text { Coming From } \\
\text { Salmiya }\end{array}$ & Channel & $\begin{array}{c}\text { Coming From } \\
\text { Shuwaikh }\end{array}$ \\
\hline AmPeak & & 11:00 & 4735 & 11:00 & 4782 \\
\hline PMPeak & & 12:00 & 4328 & $12: 00$ & 4782 \\
\hline 24 Hr. Volume & & & 62823 & & 64914 \\
\hline
\end{tabular}


Location: $\quad$ 4th Ring(Bet.Aidiliya\&Qurtuba) WEEK 2 Counter \#6

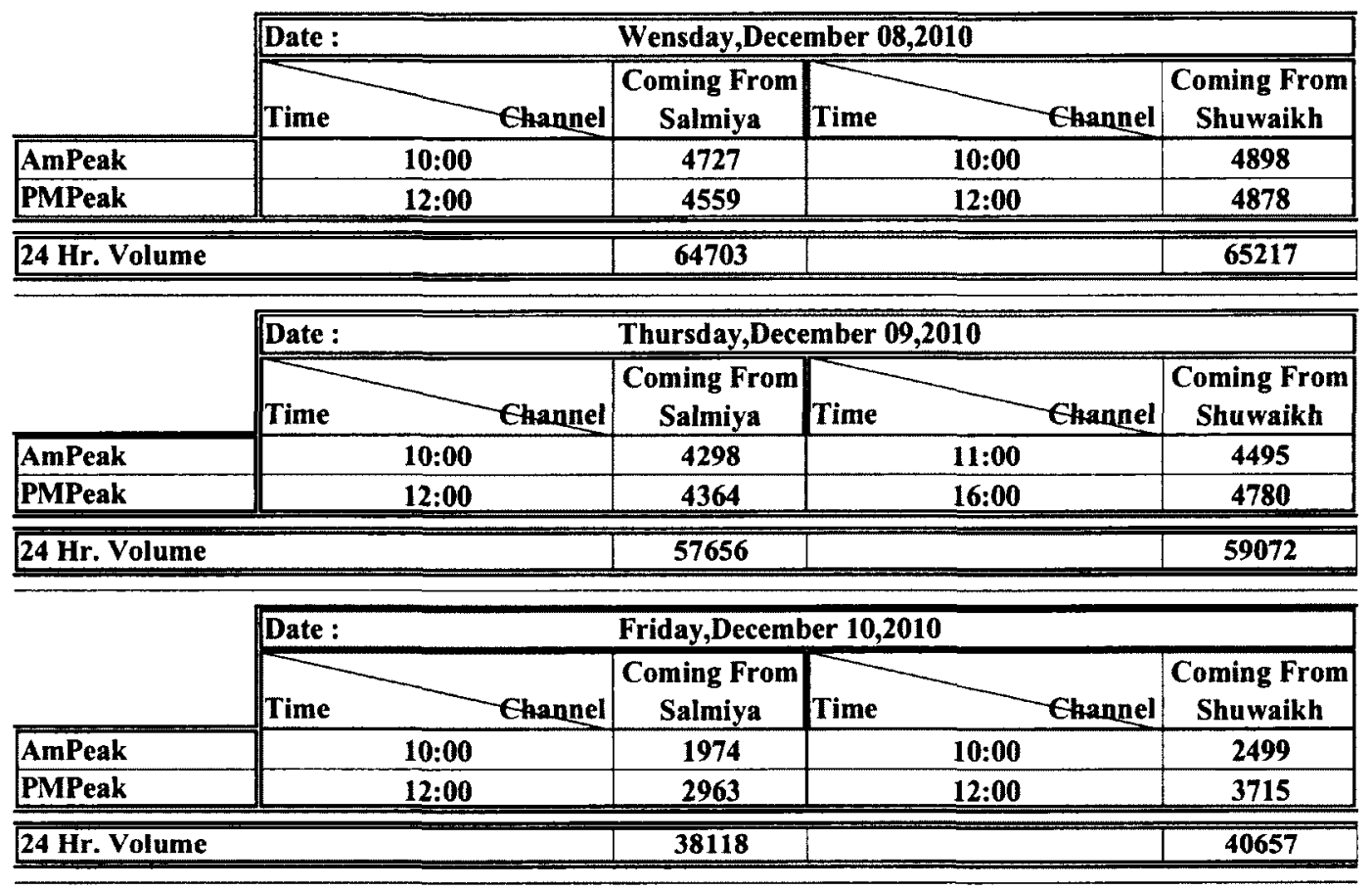

\begin{tabular}{|c|c|c|c|c|}
\hline & Date : & \multicolumn{3}{|c|}{ saterday,December 11,2010} \\
\hline & Channel & $\begin{array}{c}\text { Coming From } \\
\text { Salmiya }\end{array}$ & Channel & $\begin{array}{l}\text { Coming From } \\
\text { Shuwaikh }\end{array}$ \\
\hline AmPeak & $11: 00$ & 4651 & $11: 00$ & 4874 \\
\hline PMPeak & 12:00 & 4584 & 12:00 & 5041 \\
\hline 24 Hr. Volume & & 65394 & & 65885 \\
\hline
\end{tabular}

\begin{tabular}{|c|c|c|c|c|c|}
\hline & \multicolumn{2}{|l|}{ Date: } & \multicolumn{3}{|c|}{ Sunday,December 12,2010} \\
\hline & Time & Channel & $\begin{array}{c}\text { Coming From } \\
\text { Salmiya }\end{array}$ & Time & $\begin{array}{l}\text { Coming From } \\
\text { Shuwaikh }\end{array}$ \\
\hline AmPeak & & 11:00 & 4790 & 11:00 & 4969 \\
\hline PMPeak & & $12: 00$ & 4600 & $16: 00$ & 4980 \\
\hline 24 Hr. Volume & & & 64176 & & 64054 \\
\hline
\end{tabular}

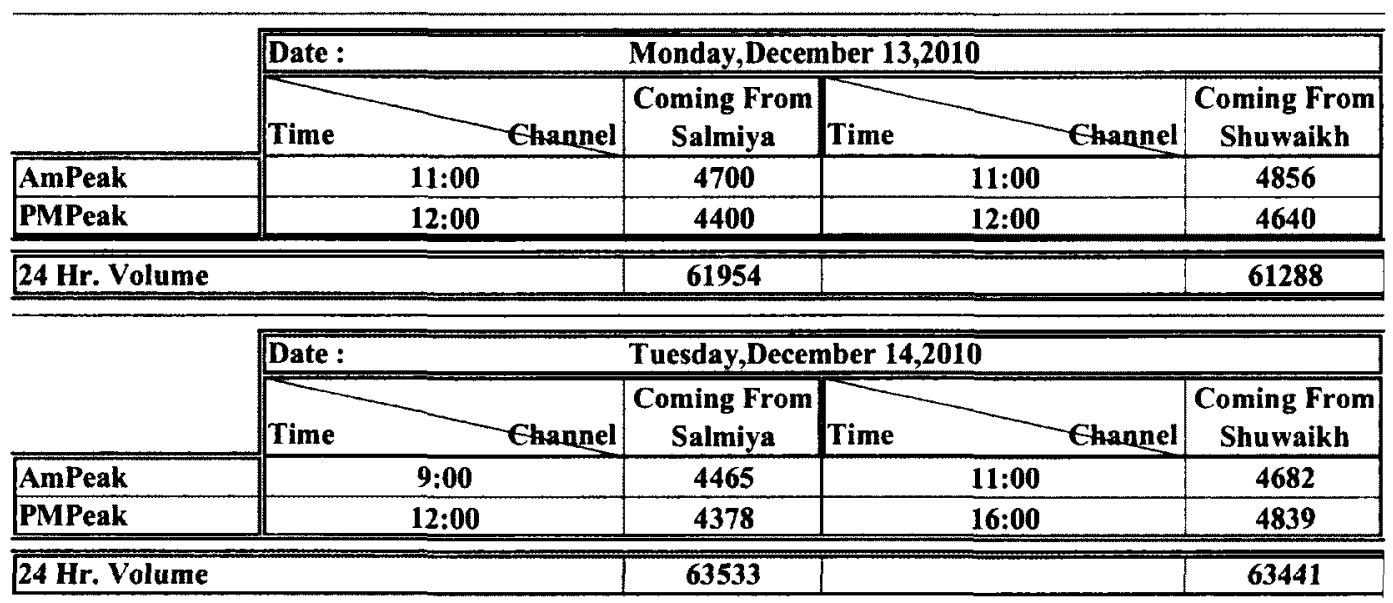


Location: $\quad$ Riyadh St. WEEK 1

\section{Counter \#7}

\begin{tabular}{|c|c|c|c|c|}
\hline & \multicolumn{4}{|c|}{ Date : $\quad$ wensday,December 01,2010 } \\
\hline & Time & $\begin{array}{c}\text { Coming From } \\
\text { City }\end{array}$ & Channel & Going To City \\
\hline AmPeak & 11:00 & 3690 & $11: 00$ & 3879 \\
\hline PMPeak & 16:00 & 2026 & 16:00 & 2124 \\
\hline \multirow[t]{3}{*}{$24 \mathrm{Hr}$. Volume } & & 51058 & & 54651 \\
\hline & Date: & Thursday,DeceI & mber 02,2010 & \\
\hline & Time & \begin{tabular}{|c|} 
Coming From \\
City
\end{tabular} & Channel & Going To City \\
\hline AmPeak & 11:00 & 2235 & 10:00 & 2694 \\
\hline PMPeak & 16:00 & 2226 & $16: 00$ & 2162 \\
\hline \multirow[t]{3}{*}{24 Hr. Volume } & & 41899 & & 63518 \\
\hline & Date: & Friday,Decemb & er 03,2010 & \\
\hline & Time & $\begin{array}{c}\text { Coming From } \\
\text { City }\end{array}$ & Channel & Going To City \\
\hline AmPeak & $10: 00$ & 3449 & $11: 00$ & 4468 \\
\hline PMPeak & $16: 00$ & 3331 & 16:00 & 4321 \\
\hline \multirow[t]{3}{*}{24 Hr. Volume } & & 62832 & & 66911 \\
\hline & Date: & saterday,Decem & nber 04,2010 & \\
\hline & Channel & \begin{tabular}{|c|} 
Coming From \\
City
\end{tabular} & Time & Going To City \\
\hline AmPeak & 11:00 & 2561 & $10: 00$ & 2652 \\
\hline PMPeak & $16: 00$ & 3303 & 16:00 & 4265 \\
\hline \multicolumn{2}{|l|}{24 Hr. Volume } & 47372 & & 51342 \\
\hline
\end{tabular}

\begin{tabular}{|c|c|c|c|c|}
\hline & Date: & \multicolumn{3}{|c|}{ Sunday, December 05,2010} \\
\hline & $\begin{array}{ll}\text { Time } & \text { Channel } \\
\end{array}$ & \begin{tabular}{|c|}
$\begin{array}{c}\text { Coming From } \\
\text { City }\end{array}$ \\
\end{tabular} & Channel & Going To City \\
\hline AmPeak & $10: 00$ & 2355 & $10: 00$ & 2928 \\
\hline PMPeak & $16: 00$ & 3203 & $16: 00$ & 4332 \\
\hline
\end{tabular}

\begin{tabular}{|c|c|c|c|c|}
\hline \multicolumn{2}{|l|}{24 Hr. Volume } & 50252 & & 52648 \\
\hline & \multicolumn{4}{|c|}{ Monday, December 06,2010 } \\
\hline & Time Channel & \begin{tabular}{|c|} 
Coming From \\
City
\end{tabular} & Channel & Going To City \\
\hline AmPeak & $11: 00$ & 3410 & $10: 00$ & 3577 \\
\hline PMPeak & $16: 00$ & 3684 & 16:00 & 4890 \\
\hline \multirow[t]{3}{*}{$24 \mathrm{Hr}$. Volume } & & $\mathbf{5 4 3 0 2}$ & & 56307 \\
\hline & Date : & \multicolumn{3}{|c|}{ Tuesday,December 07,2010 } \\
\hline & Time & \begin{tabular}{|c|} 
Coming From \\
City \\
\end{tabular} & Channel & Going To City \\
\hline AmPeak & $10: 00$ & 5078 & 11:00 & 4903 \\
\hline PMPeak & 16:00 & 4938 & $16: 00$ & 4023 \\
\hline $24 \mathrm{Hr}$. Volume & & 73332 & & 74496 \\
\hline
\end{tabular}


Location: $\quad$ Riyadh St. WEEK 2

Counter \#7

\begin{tabular}{|c|c|c|c|c|c|}
\hline & \multicolumn{5}{|c|}{ Wensday,December 08,2010 } \\
\hline & Time & Channel & \begin{tabular}{|c|} 
Coming From \\
City
\end{tabular} & Channel & Going To City \\
\hline$\overline{\text { AmPeak }}$ & & $10: 00$ & 5358 & $10: 00$ & 6479 \\
\hline PMPeak & & $12: 00$ & 6551 & 12:00 & 4575 \\
\hline 24 Hr. Volume & & & 75059 & & 77085 \\
\hline
\end{tabular}

\begin{tabular}{|c|c|c|c|c|}
\hline & Date: & \multicolumn{3}{|c|}{ Thursday,December 09,2010 } \\
\hline & Time Chanuel & \begin{tabular}{|c|} 
Coming From \\
City
\end{tabular} & Channel & Going To City \\
\hline AmPeak & $10: 00$ & 5506 & 11:00 & 5738 \\
\hline PMPeak & $12: 00$ & 6818 & 16:00 & 5081 \\
\hline 24 Hr. Volume & & 75379 & & 77636 \\
\hline
\end{tabular}

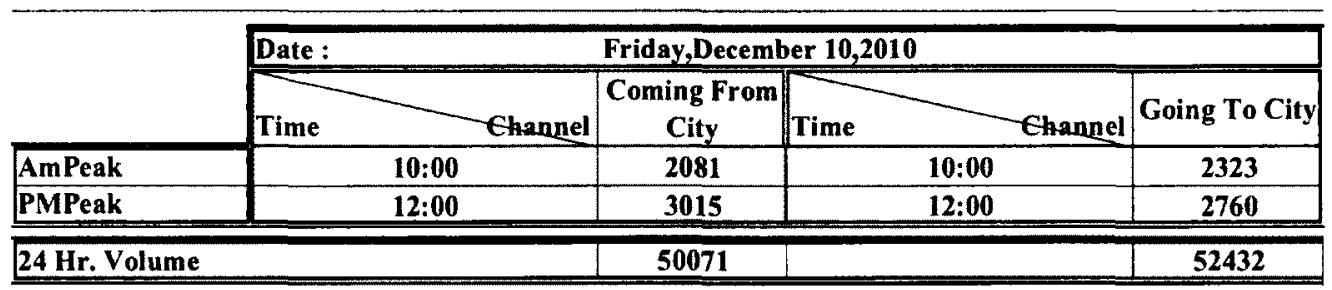

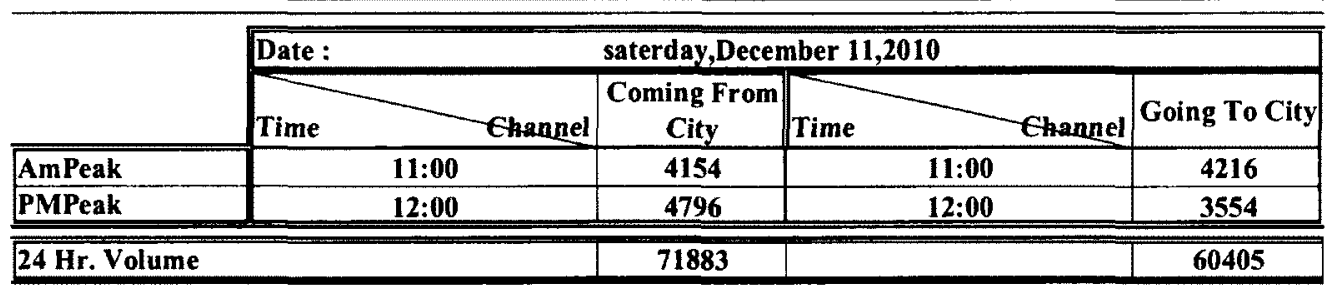

\begin{tabular}{|c|c|c|c|c|}
\hline & Date: & \multicolumn{3}{|c|}{ Sunday,December 12,2010} \\
\hline & Time Ghannel & \begin{tabular}{|c|} 
Coming From \\
City
\end{tabular} & Channel & Going To City \\
\hline AmPeak & $11: 00$ & 6782 & $10: 00$ & 6878 \\
\hline PMPeak & 12:00 & 7879 & $12: 00$ & 4719 \\
\hline 24 Hr. Volume & & 82279 & & 81651 \\
\hline
\end{tabular}

\begin{tabular}{|c|c|c|c|c|c|}
\hline & \multicolumn{2}{|l|}{ Date : } & \multicolumn{3}{|c|}{ Monday,December 13,2010} \\
\hline & Time & Ehannel & \begin{tabular}{|c|} 
Coming From \\
City
\end{tabular} & Channel & Going To City \\
\hline AmPeak & & 11:00 & 7014 & $10: 00$ & 6879 \\
\hline PMPeak & & $13: 00$ & 7765 & 13:00 & 4736 \\
\hline $24 \mathrm{Hr}$. Volume & & & 81284 & & 81747 \\
\hline
\end{tabular}

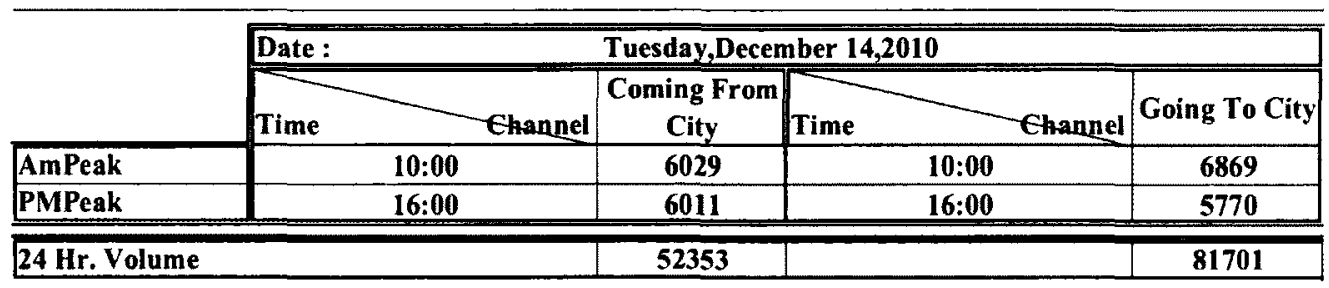


Location: $\quad$ Airport Road(Bet.3rd\&4th RR) WEEK 1 Counter $\# 8$

\begin{tabular}{|c|c|c|c|c|}
\hline & Date: & \multicolumn{3}{|c|}{ wensday,December 01,2010 } \\
\hline & Time Channel & $\begin{array}{c}\text { Coming From } \\
\text { City Center }\end{array}$ & Ehannel & $\begin{array}{c}\text { Coming From } \\
\text { 4th Airport }\end{array}$ \\
\hline AmPeak & 11:00 & 4312 & 11:00 & 4021 \\
\hline PMPeak & 19:00 & 4538 & 16:00 & 3897 \\
\hline \multirow[t]{3}{*}{24 Hr. Volume } & & 66782 & & 66213 \\
\hline & Date : & Thursday,Dece & mber 02,2010 & \\
\hline & Channel & \begin{tabular}{|c|} 
Coming From \\
City Center
\end{tabular} & Channel & $\begin{array}{c}\text { Coming From } \\
\text { 4th Airport }\end{array}$ \\
\hline AmPeak & 11:00 & 4179 & $10: 00$ & 3987 \\
\hline PMPeak & 12:00 & 4671 & 12:00 & 4582 \\
\hline \multirow[t]{3}{*}{24 Hr. Volume } & & 68564 & & 62647 \\
\hline & Date : & Friday,Decemb & er 03,2010 & \\
\hline & Channel & \begin{tabular}{c|} 
Coming From \\
City Center
\end{tabular} & Channel & $\begin{array}{c}\text { Coming From } \\
\text { 4th Airport } \\
\end{array}$ \\
\hline AmPeak & $10: 00$ & 2976 & 11:00 & 3124 \\
\hline PMPeak & $12: 00$ & 2856 & 12:00 & 2589 \\
\hline \multirow[t]{3}{*}{$24 \mathrm{Hr}$. Volume } & & 36453 & & 30994 \\
\hline & Date : & saterday,Decen & nber 04,2010 & \\
\hline & Ehannel & \begin{tabular}{|c|} 
Coming From \\
City Center \\
\end{tabular} & Channel & \begin{tabular}{|c|} 
Coming From \\
4th Airport \\
\end{tabular} \\
\hline AmPeak & 11:00 & 4210 & $10: 00$ & 4739 \\
\hline PMPeak & $12: 00$ & 3986 & $12: 00$ & 4185 \\
\hline 24 Hr. Volume & & 63821 & & 57862 \\
\hline
\end{tabular}

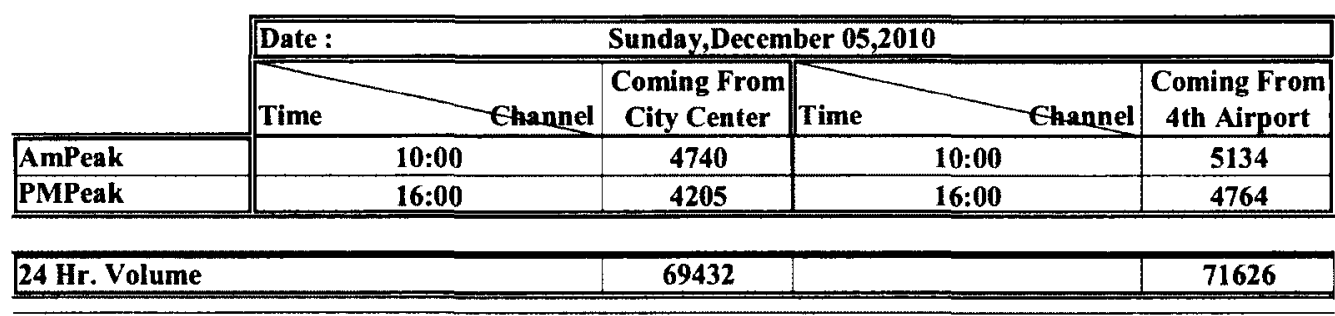

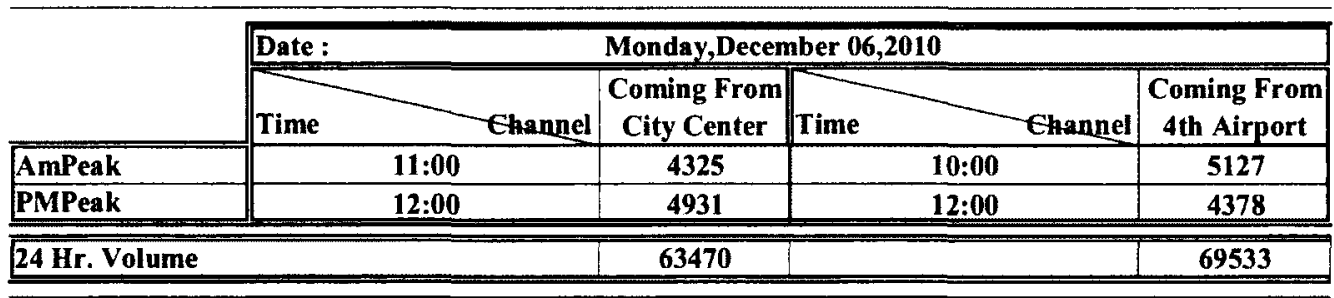

\begin{tabular}{|c|c|c|c|c|}
\hline & Date: & \multicolumn{3}{|c|}{ Tuesday,December 07,2010 } \\
\hline & Channel & $\begin{array}{l}\text { Coming From } \\
\text { City Center }\end{array}$ & Time & $\begin{array}{c}\text { Coming From } \\
\text { 4th Airport }\end{array}$ \\
\hline AmPeak & $10: 00$ & 4238 & $11: 00$ & 5013 \\
\hline PMPeak & $16: 00$ & 4862 & 16:00 & 4239 \\
\hline
\end{tabular}

\begin{tabular}{|l|c|c|c|c|}
\hline 24 Hr. Volume & 67432 & & 64782 \\
\hline
\end{tabular}


Location: $\quad$ Airport Road(Bet.3rd\&4th RR) WEEK 2 Counter \#8

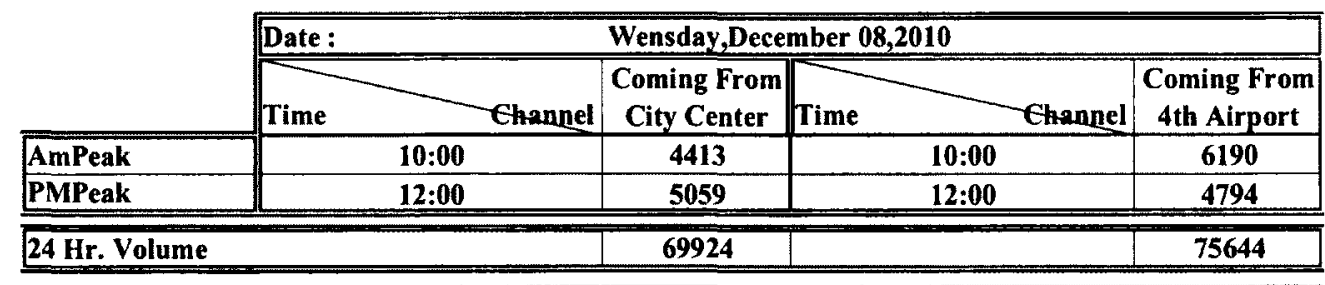

\begin{tabular}{|c|c|c|c|c|}
\hline & Date : & \multicolumn{3}{|c|}{ Thursday,December 09,2010 } \\
\hline & Channel & \begin{tabular}{|c|} 
Coming From \\
City Center
\end{tabular} & Time & $\begin{array}{c}\text { Coming From } \\
\text { 4th Airport }\end{array}$ \\
\hline AmPeak & 10:00 & 4749 & 11:00 & 5960 \\
\hline PMPeak & $12: 00$ & 4720 & $16: 00$ & 4742 \\
\hline
\end{tabular}

\begin{tabular}{|l|c|c|c|c|}
\hline \hline 24 Hr. Volume & 68534 & & 74769 \\
\hline
\end{tabular}

\begin{tabular}{|c|c|c|c|c|c|}
\hline & \multicolumn{2}{|l|}{ Date: } & \multicolumn{3}{|c|}{ Friday,December 10,2010} \\
\hline & Time & Channel & $\begin{array}{c}\text { Coming From } \\
\text { City Center }\end{array}$ & Channel & $\begin{array}{c}\text { Coming From } \\
\text { 4th Airport }\end{array}$ \\
\hline AmPeak & & $10: 00$ & 2459 & 10:00 & 2657 \\
\hline PMPeak & & $12: 00$ & 2361 & $12: 00$ & 3248 \\
\hline
\end{tabular}

\begin{tabular}{|l|l|l|l|}
\hline 24 Hr. Volume & 34671 & 31732 \\
\hline
\end{tabular}

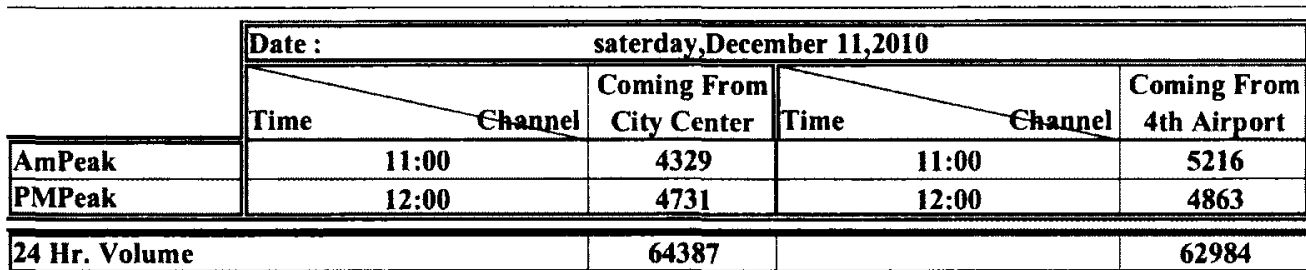

\begin{tabular}{|c|c|c|c|c|}
\hline & Date: & \multicolumn{3}{|c|}{ Sunday,December 12,2010} \\
\hline & Time & \begin{tabular}{|c|} 
Coming From \\
City Center
\end{tabular} & Channel & $\begin{array}{c}\text { Coming From } \\
\text { 4th Airport }\end{array}$ \\
\hline AmPeak & 11:00 & 5230 & $10: 00$ & 4321 \\
\hline PMPeak & $12: 00$ & 4368 & $12: 00$ & 4028 \\
\hline \multirow[t]{3}{*}{24 Hr. Volume } & & 68620 & & 71184 \\
\hline & \multicolumn{4}{|c|}{ Monday,December 13,2010} \\
\hline & Channel & $\begin{array}{c}\text { Coming From } \\
\text { City Center }\end{array}$ & Channel & $\begin{array}{l}\text { Coming From } \\
\text { 4th Airport }\end{array}$ \\
\hline AmPeak & $11: 00$ & 5295 & $10: 00$ & 4681 \\
\hline PMPeak & $13: 00$ & 4034 & 13:00 & 3983 \\
\hline \multirow[t]{3}{*}{24 Hr. Volume } & & 62307 & & 64364 \\
\hline & \multicolumn{4}{|c|}{ Tuesday, December 14,2010} \\
\hline & Channel & \begin{tabular}{|c|} 
Coming From \\
City Center \\
\end{tabular} & Channel & $\begin{array}{c}\text { Coming From } \\
\text { 4th Airport }\end{array}$ \\
\hline AmPeak & $10: 00$ & 4231 & $10: 00$ & 4530 \\
\hline PMPeak & 16:00 & 4447 & 16:00 & 4381 \\
\hline 24 Hr. Volume & & 66532 & & 62890 \\
\hline
\end{tabular}


Location: Ghazali Expressway WEEK 1 Counter \#9

\begin{tabular}{|c|c|c|c|c|c|}
\hline & \multicolumn{2}{|l|}{ Date: } & \multicolumn{3}{|c|}{ wensday, December 01,2010} \\
\hline & Time & Chrangel & $\begin{array}{c}\text { Coming From } \\
\text { mina } \\
\text { Shuwaikh }\end{array}$ & Crranel & $\begin{array}{c}\text { Coming From } \\
\text { 4th With } \\
\text { Ghazali }\end{array}$ \\
\hline AmPeak & $11: 00$ & & 4521 & $11: 00$ & 3100 \\
\hline PMPeak & 16:00 & & 1454 & 16:00 & 1870 \\
\hline \multirow[t]{3}{*}{$24 \mathrm{Hr}$. Volume } & & & 40276 & & 28819 \\
\hline & Date: & & Thursday,Dece & mber 02,2010 & \\
\hline & Time & Channel & \begin{tabular}{|c|} 
Coming From \\
mina \\
Shuwaikh
\end{tabular} & Channel & $\begin{array}{c}\text { Coming From } \\
\text { 4th With } \\
\text { Ghazali }\end{array}$ \\
\hline AmPeak & 11:00 & & 4393 & $10: 00$ & 2780 \\
\hline PMPeak & $16: 00$ & & 2979 & $16: 00$ & 1884 \\
\hline \multirow[t]{3}{*}{$24 \mathrm{Hr}$. Volume } & & & 39430 & & 30367 \\
\hline & Date: & & Friday,Decemb & er 03,2010 & \\
\hline & |Time & Chrangel & $\begin{array}{c}\text { Coming From } \\
\text { mina } \\
\text { Shuwaikh }\end{array}$ & Crannel & $\begin{array}{c}\text { Coming From } \\
\text { 4th With } \\
\text { Ghazall }\end{array}$ \\
\hline AmPeak & $10: 00$ & & 1191 & $11: 00$ & 787 \\
\hline PMPeak & $16: 00$ & & 1735 & 16:00 & 1003 \\
\hline \multirow[t]{3}{*}{24 Hr. Volume } & & & 16858 & & 13891 \\
\hline & Date: & & saterday,Decem & nber 04,2010 & \\
\hline & Time & Chranel & \begin{tabular}{|c|} 
Coming From \\
mina \\
Shuwaikh
\end{tabular} & Charnel & \begin{tabular}{|c|} 
Coming From \\
4th With \\
Ghazali
\end{tabular} \\
\hline AmPeak & 11:00 & & 4278 & $10: 00$ & 2874 \\
\hline PMPeak & 16:00 & & 2992 & 16:00 & 1954 \\
\hline \multicolumn{3}{|l|}{24 Hr. Volume } & 39706 & & 30237 \\
\hline
\end{tabular}

\begin{tabular}{|c|c|c|c|c|c|}
\hline & \multicolumn{2}{|l|}{ Date: } & \multicolumn{3}{|c|}{ Sunday,December 05,2010} \\
\hline & Time & Crrannel & $\begin{array}{c}\text { Coming From } \\
\text { mina } \\
\text { Shuwaikh }\end{array}$ & Crangel & $\begin{array}{c}\text { Coming From } \\
\text { 4th With } \\
\text { Ghazali }\end{array}$ \\
\hline AmPeak & $10: 00$ & & 4108 & $10: 00$ & 3048 \\
\hline PMPeak & $16: 00$ & & 2577 & $16: 00$ & 1848 \\
\hline
\end{tabular}

\begin{tabular}{|c|c|c|c|c|c|}
\hline 24 Hr. Volume & & & 38409 & & 29315 \\
\hline & Date: & & \multicolumn{3}{|c|}{ Monday,December 06,2010 } \\
\hline & Time & Chrannel & \begin{tabular}{|c||}
$\begin{array}{c}\text { Coming From } \\
\text { mina } \\
\text { Shuwaikh }\end{array}$ \\
\end{tabular} & Channel & $\begin{array}{c}\text { Coming From } \\
\text { 4th With } \\
\text { Ghazali } \\
\end{array}$ \\
\hline AmPeak & $11: 00$ & & 844 & $10: 00$ & 482 \\
\hline PMPeak & 16:00 & & 1491 & 16:00 & 827 \\
\hline \multirow[t]{3}{*}{24 Hr. Volume } & & & 14734 & & 12214 \\
\hline & \multicolumn{5}{|c|}{ Tuesday,December 07,2010 } \\
\hline & Time & Crannel & $\begin{array}{c}\text { Coming From } \\
\text { mina } \\
\text { Shuwaikh }\end{array}$ & Channel & $\begin{array}{c}\text { Coming From } \\
\text { 4th With } \\
\text { Ghazali }\end{array}$ \\
\hline AmPeak & 10:00 & & 1291 & 11:00 & 1255 \\
\hline PMPeak & $16: 00$ & & 1857 & $16: 00$ & 1438 \\
\hline $24 \mathrm{Hr}$. Volum & & & 17723 & & 14029 \\
\hline
\end{tabular}


Location: Ghazali Expressway WEEK 2 Counter \#9

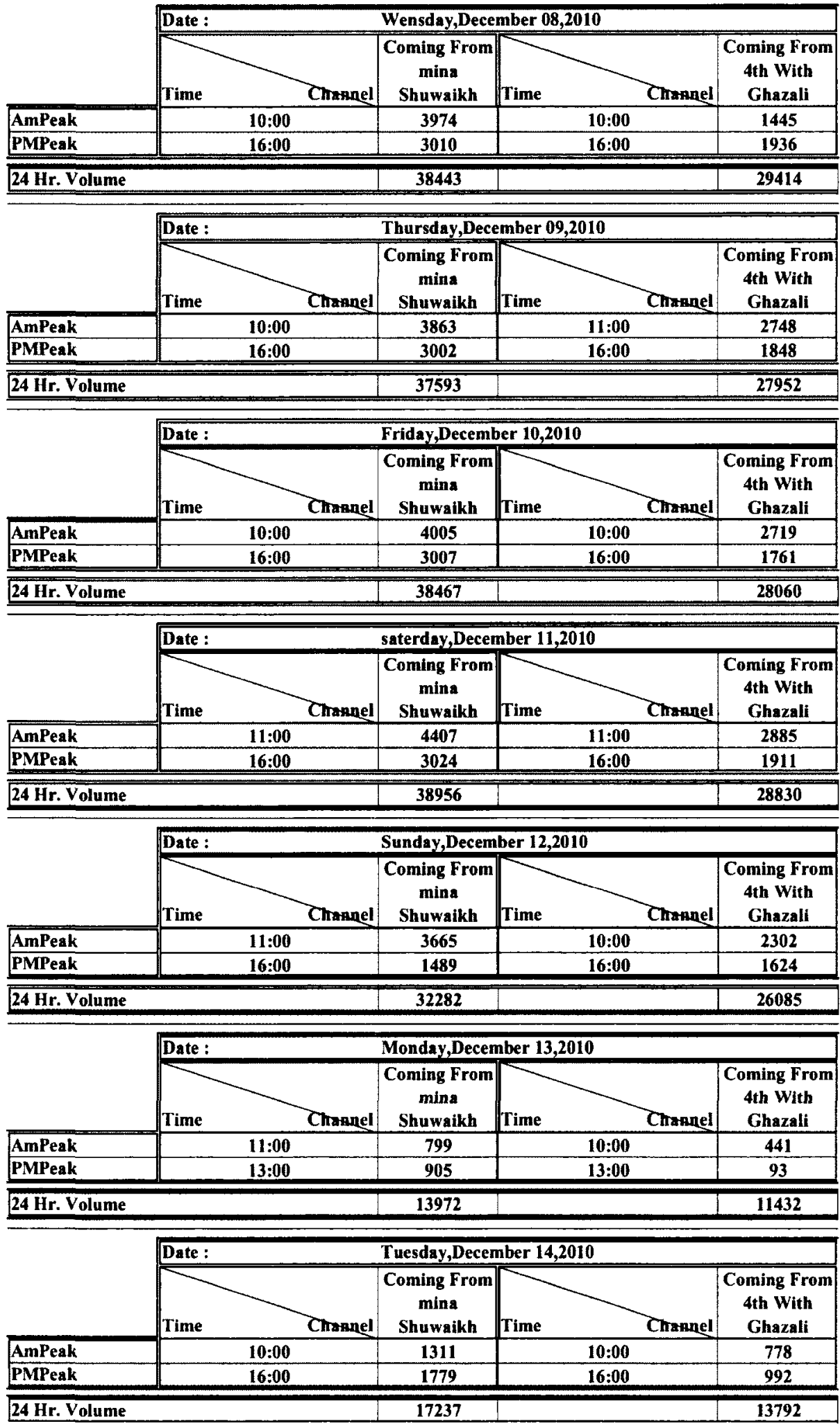


Location: Jamal Abdul Nasser St WEEK 1

\section{Counter \#10}

\begin{tabular}{|c|c|c|c|c|}
\hline & \multicolumn{4}{|c|}{\begin{tabular}{|l} 
Date : $\quad$ wensday,December 01,2010 \\
\end{tabular}} \\
\hline & Channel & $\begin{array}{c}\text { Coming From } \\
\text { jahra }\end{array}$ & Channel & $\begin{array}{c}\text { Coming From } \\
\text { City }\end{array}$ \\
\hline AmPeak & $11: 00$ & 4040 & 11:00 & 2743 \\
\hline PMPeak & 16:00 & 2065 & 16:00 & 1686 \\
\hline \multirow[t]{3}{*}{24 Hr. Volume } & & 36431 & & 27840 \\
\hline & Date : & Thursday,Dece & ember 02,2010 & \\
\hline & Channel & $\begin{array}{c}\text { Coming From } \\
\text { jahra }\end{array}$ & Channel & $\begin{array}{c}\text { Coming From } \\
\text { City }\end{array}$ \\
\hline AmPeak & 11:00 & 4264 & $10: 00$ & 3008 \\
\hline PMPeak & 16:00 & 3079 & 16:00 & 1683 \\
\hline \multirow[t]{3}{*}{24 Hr. Volume } & & 36848 & & 29502 \\
\hline & Date : & Friday,Decemt & ber 03,2010 & \\
\hline & Channel & \begin{tabular}{|c|} 
Coming From \\
jahra
\end{tabular} & Time & \begin{tabular}{|c|c|} 
Coming From \\
City
\end{tabular} \\
\hline AmPeak & $10: 00$ & 3957 & 11:00 & 3209 \\
\hline PMPeak & $16: 00$ & 2974 & $16: 00$ & 1885 \\
\hline \multicolumn{5}{|l|}{24 Hr. Volume } \\
\hline & Date: & \multicolumn{3}{|c|}{ saterday,December 04,2010 } \\
\hline & Channel & $\begin{array}{c}\text { Coming From } \\
\text { jahra }\end{array}$ & Time & $\begin{array}{c}\text { Coming From } \\
\text { City }\end{array}$ \\
\hline AmPeak & 11:00 & 4283 & $10: 00$ & 3053 \\
\hline PMPeak & 16:00 & 3138 & 16:00 & 2126 \\
\hline 24 Hr. Volume & & 37780 & & 29153 \\
\hline
\end{tabular}

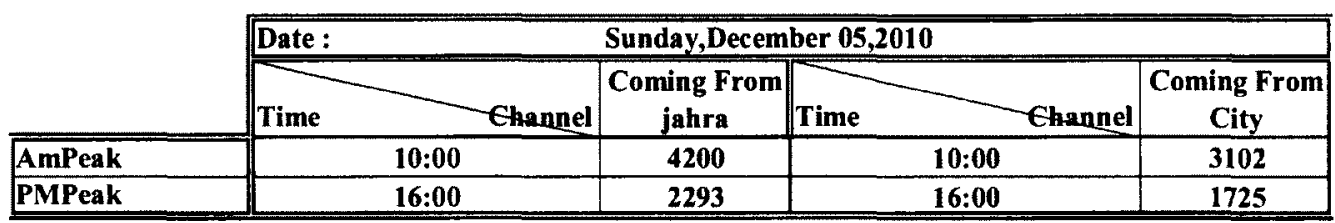

\begin{tabular}{|l|l|l|l|}
\hline 24 Hr. Volume & 38127 & & 30441 \\
\hline
\end{tabular}

\begin{tabular}{|c|c|c|c|c|c|}
\hline & \multicolumn{2}{|l|}{ Date: } & \multicolumn{3}{|c|}{ Monday,December 06,2010 } \\
\hline & Time & Channel & $\begin{array}{c}\text { Coming From } \\
\text { jahra }\end{array}$ & Time & $\begin{array}{c}\text { Coming From } \\
\text { City }\end{array}$ \\
\hline AmPeak & & $11: 00$ & 809 & $10: 00$ & 481 \\
\hline PMPeak & & $16: 00$ & 1458 & 16:00 & 918 \\
\hline 24 Hr. Volume & & & 14759 & & 12378 \\
\hline
\end{tabular}

\begin{tabular}{|c|c|c|c|c|c|}
\hline & \multicolumn{2}{|l|}{ Date: } & \multicolumn{3}{|c|}{ Tuesday,December 07,2010 } \\
\hline & Time & Channel & $\begin{array}{c}\text { Coming From } \\
\text { jahra }\end{array}$ & Ehannel & $\begin{array}{c}\text { Coming From } \\
\text { City }\end{array}$ \\
\hline AmPeak & & $11: 00$ & 1821 & $11: 00$ & 1052 \\
\hline PMPeak & & $16: 00$ & 1770 & $16: 00$ & 963 \\
\hline $24 \mathrm{Hr}$. Volume & & & 18810 & & $\overline{14745}$ \\
\hline
\end{tabular}


Location: $\quad$ Jamal Abdul Nasser St WEEK 2 Counter \#10

\begin{tabular}{|c|c|c|c|c|}
\hline & $\overline{\text { Date: }}$ & \multicolumn{3}{|c|}{ Wensday,December 08,2010 } \\
\hline & Time Channel & $\begin{array}{c}\text { Coming From } \\
\text { jahra }\end{array}$ & Channel & $\begin{array}{c}\text { Coming From } \\
\text { City }\end{array}$ \\
\hline$\overline{\text { AmPeak }}$ & $10: 00$ & 4167 & $10: 00$ & 3127 \\
\hline PMPeak & 16:00 & 2721 & 16:00 & 1684 \\
\hline \multirow[t]{3}{*}{24 Hr. Volume } & & 39224 & & 29789 \\
\hline & Date: & Thursday,Dece & mber 09,2010 & \\
\hline & Channel & $\begin{array}{c}\text { Coming From } \\
\text { jahra }\end{array}$ & Time & \begin{tabular}{|c|} 
Coming From \\
City
\end{tabular} \\
\hline AmPeak & $10: 00$ & 3238 & 11:00 & 1817 \\
\hline PMPeak & $16: 00$ & 2979 & $16: 00$ & 1793 \\
\hline \multirow[t]{3}{*}{$24 \mathrm{Hr}$. Volume } & & 37064 & & 26869 \\
\hline & Date: & Friday,Decemb & oer 10,2010 & \\
\hline & Channel & $\begin{array}{c}\text { Coming From } \\
\text { jahra }\end{array}$ & Ehannel & $\begin{array}{c}\text { Coming From } \\
\text { City }\end{array}$ \\
\hline AmPeak & $10: 00$ & 4172 & $10: 00$ & 3076 \\
\hline PMPeak & $16: 00$ & 2780 & 16:00 & 1692 \\
\hline \multirow[t]{3}{*}{$24 \mathrm{Hr}$. Volume } & & 39874 & & 29869 \\
\hline & Date: & saterday,Decen & nber 11,2010 & \\
\hline & Channel & $\begin{array}{c}\text { Coming From } \\
\text { jahra }\end{array}$ & Channel & \begin{tabular}{|c|} 
Coming From \\
City
\end{tabular} \\
\hline AmPeak & 11:00 & 4532 & 11:00 & 2981 \\
\hline PMPeak & $16: 00$ & 2985 & 16:00 & 1805 \\
\hline \multirow[t]{3}{*}{24 Hr. Volume } & & 39505 & & 29755 \\
\hline & Date: & Sunday,Decem & ber 12,2010 & \\
\hline & Channel & $\begin{array}{c}\text { Coming From } \\
\text { jahra }\end{array}$ & Time & $\begin{array}{c}\text { Coming From } \\
\text { City }\end{array}$ \\
\hline AmPeak & $11: 00$ & 4358 & $10: 00$ & 2824 \\
\hline PMPeak & 16:00 & 1955 & 16:00 & 1559 \\
\hline \multirow[t]{3}{*}{24 Hr. Volume } & & 38041 & & 28842 \\
\hline & Date: & Monday,Decem & nber 13,2010 & \\
\hline & Time & $\begin{array}{c}\begin{array}{c}\text { Coming From } \\
\text { jahra }\end{array} \\
\end{array}$ & Time & \begin{tabular}{|c|} 
Coming From \\
City
\end{tabular} \\
\hline AmPeak & 11:00 & 815 & $10: 00$ & 468 \\
\hline PMPeak & $13: 00$ & 969 & 13:00 & 755 \\
\hline \multirow[t]{3}{*}{$24 \mathrm{Hr}$. Volume } & & 15030 & & 12659 \\
\hline & Date : & Tuesday,Decem & nber 14,2010 & \\
\hline & Channel & $\begin{array}{c}\text { Coming From } \\
\text { jahra }\end{array}$ & Time & $\begin{array}{c}\text { Coming From } \\
\text { City }\end{array}$ \\
\hline AmPeak & $10: 00$ & 1375 & $10: 00$ & 754 \\
\hline PMPeak & $16: 00$ & 1928 & $16: 00$ & 1128 \\
\hline 24 Hr. Volume & & 17782 & & 14317 \\
\hline
\end{tabular}


Location: $\quad$ 4Th R.R(opp.Safat Alghanim,Rai) WEEK 1 Counter \#11

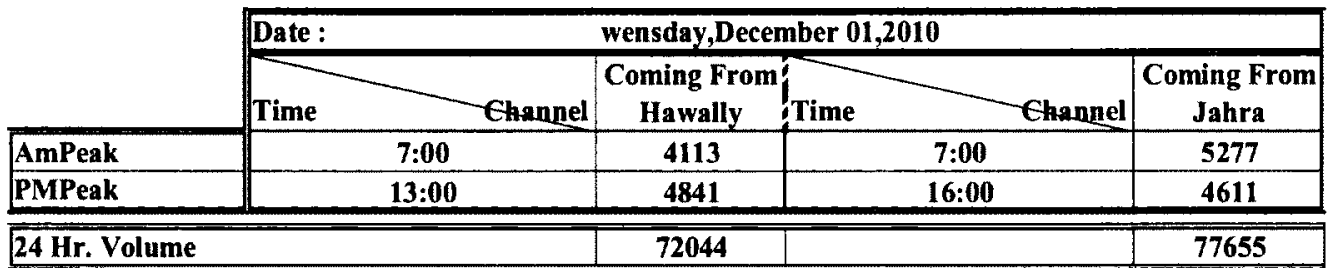

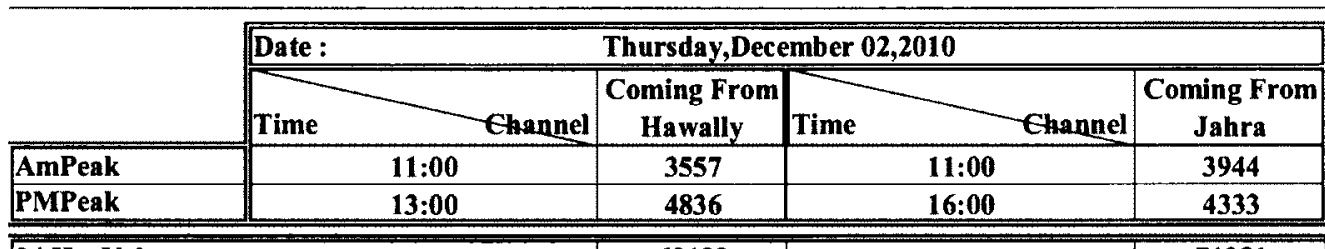

\begin{tabular}{|l|l|l|l|}
\hline 24 Hr. Volume & 63123 & & 71381 \\
\hline
\end{tabular}

\begin{tabular}{|c|c|c|c|c|c|}
\hline & \multicolumn{2}{|l|}{ Date: } & \multicolumn{3}{|c|}{ Friday,December 03,2010 } \\
\hline & Time & Channel & $\begin{array}{c}\text { Coming From } \\
\text { Hawally }\end{array}$ & $\overline{\text { Time }}$ & $\begin{array}{c}\text { Coming From } \\
\text { Jahra }\end{array}$ \\
\hline AmPeak & & $11: 00$ & 1944 & $0: 00$ & 2303 \\
\hline PMPeak & & 19:00 & 3518 & $16: 00$ & 3581 \\
\hline $24 \mathrm{Hr}$. Volume & & & 43525 & & 52132 \\
\hline
\end{tabular}

\begin{tabular}{|c|c|c|c|c|c|}
\hline & \multicolumn{2}{|l|}{ Date : } & \multicolumn{3}{|c|}{ saterday,December 04,2010} \\
\hline & Time & Channel & $\begin{array}{c}\text { Coming From } \\
\text { Hawally }\end{array}$ & Time & \begin{tabular}{|c|} 
Coming From \\
Jahra
\end{tabular} \\
\hline AmPeak & & 11:00 & 4207 & 7:00 & 4953 \\
\hline PMPeak & & 13:00 & 5262 & 13:00 & 4706 \\
\hline $24 \mathrm{Hr}$. Volume & & & 70427 & & 75880 \\
\hline
\end{tabular}

\begin{tabular}{|c|c|c|c|c|}
\hline & Date: & \multicolumn{3}{|c|}{ Sunday,December 05,2010 } \\
\hline & Time Channel & $\begin{array}{c}\text { Coming From } \\
\text { Hawally }\end{array}$ & Channel & $\begin{array}{c}\text { Coming From } \\
\text { Jahra }\end{array}$ \\
\hline AmPeak & $7: 00$ & 4215 & $7: 00$ & 5393 \\
\hline PMPeak & $13: 00$ & 5051 & $13: 00$ & 4563 \\
\hline \multirow[t]{3}{*}{$24 \mathrm{Hr}$. Volume } & & 69091 & & 75941 \\
\hline & \multicolumn{4}{|c|}{ Monday,December 06,2010 } \\
\hline & Channel & $\begin{array}{c}\text { Coming From } \\
\text { Hawally }\end{array}$ & Time & $\begin{array}{c}\text { Coming From } \\
\text { Jahra }\end{array}$ \\
\hline AmPeak & 11:00 & 3749 & $10: 00$ & 4426 \\
\hline PMPeak & $13: 00$ & 4889 & $13: 00$ & 4352 \\
\hline 24 Hr. Volume & & 66085 & & 71713 \\
\hline
\end{tabular}

\begin{tabular}{|c|c|c|c|c|c|}
\hline & \multicolumn{2}{|l|}{ Date : } & \multicolumn{3}{|c|}{ Tuesday,December 07,2010 } \\
\hline & Time & Channel & $\begin{array}{c}\text { Coming From } \\
\text { Hawally }\end{array}$ & Time & $\begin{array}{c}\text { Coming From } \\
\text { Jahra }\end{array}$ \\
\hline AmPeak & & 11:00 & 3966 & $7: 00$ & 5413 \\
\hline PMPeak & & 13:00 & 4972 & $13: 00$ & 4509 \\
\hline $24 \mathrm{Hr}$. Volume & & & 68204 & & 75360 \\
\hline
\end{tabular}


Location: $\quad$ 4Th R.R(opp.Safat Alghanim,Rai) WEEK 2

\section{Counter \#11}

\begin{tabular}{|c|c|c|c|c|c|}
\hline & \multicolumn{2}{|l|}{ Date: } & \multicolumn{3}{|c|}{ Wensday, December 08,2010} \\
\hline & Time & Channel & $\begin{array}{c}\text { Coming From } \\
\text { Hawally }\end{array}$ & Ghannel & $\begin{array}{c}\text { Coming From } \\
\text { Jahra }\end{array}$ \\
\hline AmPeak & & 11:00 & 4015 & $10: 00$ & 4455 \\
\hline PMPeak & & 13:00 & 4857 & 16:00 & 4737 \\
\hline $24 \mathrm{Hr}$. Volume & & & 70796 & & 74697 \\
\hline
\end{tabular}

\begin{tabular}{|c|c|c|c|c|c|}
\hline & \multicolumn{2}{|l|}{ Date: } & \multicolumn{3}{|c|}{ Thursday,December 09,2010 } \\
\hline & Time & Channel & $\begin{array}{c}\text { Coming From } \\
\text { Hawally }\end{array}$ & Channel & $\begin{array}{c}\text { Coming From } \\
\text { Jahra }\end{array}$ \\
\hline AmPeak & & $11: 00$ & 3469 & 11:00 & 3859 \\
\hline PMPeak & & $13: 00$ & 4939 & $13: 00$ & 4327 \\
\hline 24 Hr. Volume & & & $\overline{62204}$ & & $6 \mathbf{6 9 7 3 8}$ \\
\hline
\end{tabular}

\begin{tabular}{|c|c|c|c|c|c|}
\hline & \multicolumn{2}{|l|}{ Date : } & \multicolumn{2}{|c|}{ Friday,December 10,2010} & \multirow[b]{2}{*}{$\begin{array}{c}\text { Coming From } \\
\text { Jahra }\end{array}$} \\
\hline & Time & Channel & \begin{tabular}{|c|}
$\begin{array}{c}\text { Coming From } \\
\text { Hawally }\end{array}$ \\
\end{tabular} & Channel & \\
\hline AmPeak & & 11:00 & 1962 & 11:00 & 2265 \\
\hline PMPeak & & 18:00 & 3525 & 16:00 & 3575 \\
\hline $24 \mathrm{Hr}$. Volume & & & 45720 & & 52774 \\
\hline
\end{tabular}

\begin{tabular}{|c|c|c|c|c|c|}
\hline & \multicolumn{2}{|l|}{ Date : } & \multicolumn{3}{|c|}{ saterday,December 11,2010} \\
\hline & & Channel & $\begin{array}{c}\text { Coming From } \\
\text { Hawally }\end{array}$ & Channel & $\begin{array}{c}\text { Coming From } \\
\text { Jahra }\end{array}$ \\
\hline AmPeak & & & 4171 & $7: 00$ & 5398 \\
\hline PMPeak & & & 5144 & $16: 00$ & 4491 \\
\hline
\end{tabular}

\begin{tabular}{|c|c|c|c|c|}
\hline & Date: & \multicolumn{3}{|c|}{ Sunday,December 12,2010} \\
\hline & Time & $\begin{array}{c}\text { Coming From } \\
\text { Hawally }\end{array}$ & Channel & $\begin{array}{c}\text { Coming From } \\
\text { Jahra }\end{array}$ \\
\hline AmPeak & 11:00 & 4113 & $7: 00$ & 5485 \\
\hline PMPeak & 13:00 & 5045 & 16:00 & 4414 \\
\hline \multirow[t]{3}{*}{24 Hr. Volume } & & 67536 & & 75282 \\
\hline & Date: & Monday,Decem & nber 13,2010 & \\
\hline & Time & \begin{tabular}{|c|}
$\begin{array}{c}\text { Coming From } \\
\text { Hawally }\end{array}$ \\
\end{tabular} & Channel & $\begin{array}{c}\text { Coming From } \\
\text { Jahra }\end{array}$ \\
\hline AmPeak & 11:00 & 4046 & $7: 00$ & 5436 \\
\hline PMPeak & $13: 00$ & 4697 & $13: 00$ & 4297 \\
\hline \multirow[t]{3}{*}{24 Hr. Volume } & & 67039 & & 72396 \\
\hline & Date : & Tuesday,Decem & nber 14,2010 & \\
\hline & Channel & \begin{tabular}{|c|}
$\begin{array}{c}\text { Coming From } \\
\text { Hawally }\end{array}$ \\
\end{tabular} & Time & $\begin{array}{c}\begin{array}{c}\text { Coming From } \\
\text { Jahra }\end{array} \\
\end{array}$ \\
\hline AmPeak & 11:00 & 4126 & $7: 00$ & 5186 \\
\hline PMPeak & $13: 00$ & 4644 & 16:00 & 4447 \\
\hline $24 \mathrm{Hr}$. Volume & & 68401 & & 73149 \\
\hline
\end{tabular}


Location: Arabian Gulf St. WEEK 1

Counter \#12

\begin{tabular}{|c|c|c|c|c|}
\hline & Date: & \multicolumn{3}{|c|}{ wensday,December 01,2010 } \\
\hline & Time $\quad$ Ghannel & $\begin{array}{c}\text { Coming From } \\
\text { Salmiya }\end{array}$ & Channel & $\begin{array}{c}\text { Coming From } \\
\text { Marinamal }\end{array}$ \\
\hline$\overline{\text { AmPeak }}$ & $11: 00$ & 2347 & $11: 00$ & 2843 \\
\hline PMPeak & 19:00 & 2678 & $16: 00$ & 2349 \\
\hline $24 \mathrm{Hr}$. Volume & & 32567 & & 28976 \\
\hline
\end{tabular}

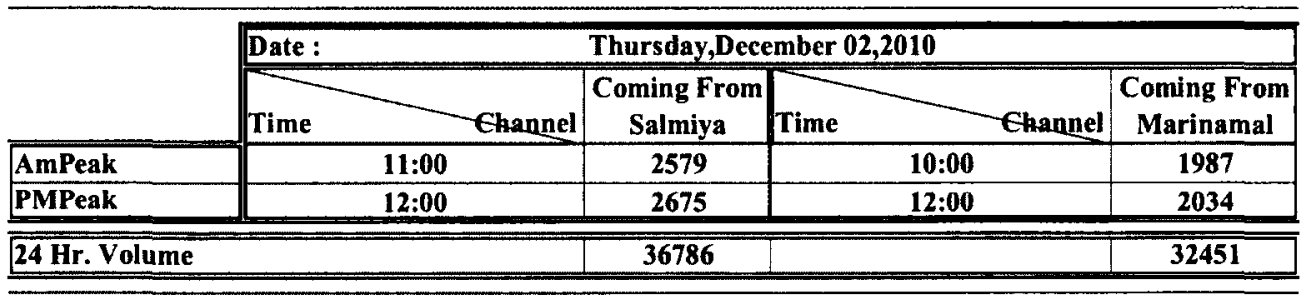

\begin{tabular}{|c|c|c|c|c|}
\hline & Date: & \multicolumn{3}{|c|}{ Friday,December 03,2010 } \\
\hline & Time & $\begin{array}{c}\text { Coming From } \\
\text { Salmiya }\end{array}$ & Time & $\begin{array}{c}\text { Coming From } \\
\text { Marinamal }\end{array}$ \\
\hline AmPeak & $10: 00$ & 2341 & 11:00 & 1985 \\
\hline PMPeak & 12:00 & 2110 & 12:00 & 2010 \\
\hline 24 Hr. Volume & & 22453 & & 23568 \\
\hline
\end{tabular}

\begin{tabular}{|c|c|c|c|c|c|}
\hline & \multicolumn{2}{|l|}{ Date: } & \multicolumn{3}{|c|}{ saterday,December 04,2010 } \\
\hline & Time & Channel & $\begin{array}{c}\text { Coming From } \\
\text { Salmiya }\end{array}$ & Time & $\begin{array}{c}\text { Coming From } \\
\text { Marinamal }\end{array}$ \\
\hline AmPeak & & 11:00 & 2015 & $10: 00$ & 1987 \\
\hline PMPeak & & $12: 00$ & 1896 & 12:00 & 2011 \\
\hline $24 \mathrm{Hr}$. Volume & & & 30567 & & 32457 \\
\hline
\end{tabular}

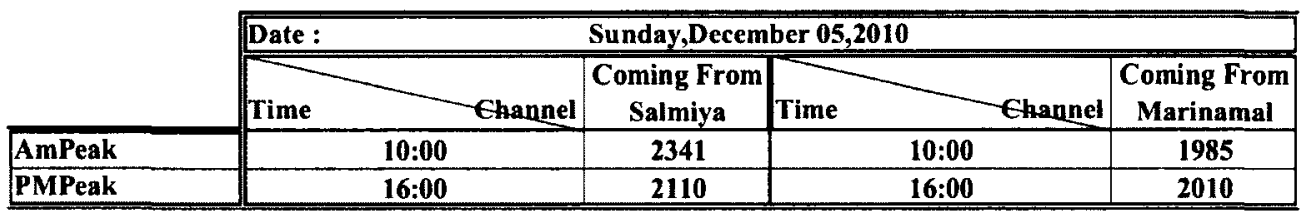

\begin{tabular}{|c|c|c|c|c|}
\hline 24 Hr. Volume & & 32466 & & 29873 \\
\hline & \multicolumn{4}{|c|}{ Monday,December 06,2010} \\
\hline & Channel & $\begin{array}{c}\text { Coming From } \\
\text { Salmiya }\end{array}$ & Time & $\begin{array}{c}\begin{array}{c}\text { Coming From } \\
\text { Marinamal }\end{array} \\
\end{array}$ \\
\hline AmPeak & $11: 00$ & 2436 & 10:00 & 1875 \\
\hline PMPeak & 12:00 & 2231 & $12: 00$ & 1968 \\
\hline \multirow[t]{3}{*}{24 Hr. Volume } & & 30345 & & 29876 \\
\hline & \multicolumn{4}{|c|}{$\begin{array}{ll}\text { Date : } & \text { Tuesday,December 07,2010 }\end{array}$} \\
\hline & Ghannel & $\begin{array}{c}\text { Coming From } \\
\text { Salmiya }\end{array}$ & Time & $\begin{array}{c}\text { Coming From } \\
\text { Marinamal }\end{array}$ \\
\hline AmPeak & $10: 00$ & 2431 & 11:00 & 1987 \\
\hline PMPeak & 16:00 & 2091 & $16: 00$ & 2020 \\
\hline 24 Hr. Volume & & 29789 & & 26751 \\
\hline
\end{tabular}


Location: Arabian Gulf St. WEEK 2

Counter \#12

\begin{tabular}{|c|c|c|c|c|}
\hline & Date: & \multicolumn{3}{|c|}{ Wensday,December 08,2010} \\
\hline & Channel & $\begin{array}{c}\text { Coming From } \\
\text { Salmiya }\end{array}$ & Channel & $\begin{array}{c}\begin{array}{c}\text { Coming From } \\
\text { Marinamal }\end{array} \\
\end{array}$ \\
\hline$\overline{\text { AmPeak }}$ & $10: 00$ & 2349 & $10: 00$ & 2034 \\
\hline PMPeak & $12: 00$ & 2675 & 12:00 & 1765 \\
\hline \multirow[t]{3}{*}{24 Hr. Volume } & & 33456 & & 30178 \\
\hline & Date: & Thursday,Dece & ember 09,2010 & \\
\hline & Channel & $\begin{array}{c}\text { Coming From } \\
\text { Salmiya }\end{array}$ & Channel & $\begin{array}{c}\text { Coming From } \\
\text { Marinamal }\end{array}$ \\
\hline AmPeak & 10:00 & 2457 & 11:00 & 1789 \\
\hline PMPeak & 12:00 & 1867 & 16:00 & 2021 \\
\hline \multirow[t]{3}{*}{24 Hr. Volume } & & 31045 & & 29876 \\
\hline & Date : & Friday,Decemb & ber 10,2010 & \\
\hline & Channel & \begin{tabular}{|c|}
$\begin{array}{c}\text { Coming From } \\
\text { Salmiya }\end{array}$ \\
\end{tabular} & Channel & $\begin{array}{c}\text { Coming From } \\
\text { Marinamal } \\
\end{array}$ \\
\hline AmPeak & $10: 00$ & 1478 & 10:00 & 1237 \\
\hline PMPeak & 12:00 & 1986 & 12:00 & 1543 \\
\hline \multirow[t]{3}{*}{24 Hr. Volume } & & 24587 & & 22781 \\
\hline & Date : & saterday,Decen & nber 11,2010 & \\
\hline & Channel & \begin{tabular}{|c|} 
Coming From \\
Salmiya
\end{tabular} & Time & $\begin{array}{c}\text { Coming From } \\
\text { Marinamal } \\
\end{array}$ \\
\hline AmPeak & $11: 00$ & 2034 & 11:00 & 1986 \\
\hline PMPeak & 12:00 & 2270 & 12:00 & 1867 \\
\hline \multirow[t]{3}{*}{24 Hr. Volume } & & 28976 & & 30231 \\
\hline & Date: & Sunday, Decem & ber 12,2010 & \\
\hline & Time & \begin{tabular}{|c|}
$\begin{array}{c}\text { Coming From } \\
\text { Salmiya }\end{array}$ \\
\end{tabular} & Channel & \begin{tabular}{|c|}
$\begin{array}{c}\text { Coming From } \\
\text { Marinamal }\end{array}$ \\
\end{tabular} \\
\hline AmPeak & 11:00 & 2221 & $10: 00$ & 1967 \\
\hline PMPeak & 12:00 & 2045 & 12:00 & 1873 \\
\hline \multirow[t]{3}{*}{$24 \mathrm{Hr}$. Volume } & & 30121 & & 29120 \\
\hline & Date: & Monday,Decem & nber 13,2010 & \\
\hline & Channel & \begin{tabular}{|c|} 
Coming From \\
Salmiya
\end{tabular} & Time & \begin{tabular}{|c|}
$\begin{array}{c}\text { Coming From } \\
\text { Marinamal }\end{array}$ \\
\end{tabular} \\
\hline AmPeak & 11:00 & 1786 & $10: 00$ & 2017 \\
\hline PMPeak & 13:00 & 1890 & 13:00 & 1765 \\
\hline \multirow[t]{3}{*}{24 Hr. Volume } & & 26785 & & 29851 \\
\hline & Date : & Tuesday,Decem & nber 14,2010 & \\
\hline & Channel & \begin{tabular}{|c|}
$\begin{array}{c}\text { Coming From } \\
\text { Salmiya }\end{array}$ \\
\end{tabular} & Time & \begin{tabular}{|c|}
$\begin{array}{c}\text { Coming From } \\
\text { Marinamal }\end{array}$ \\
\end{tabular} \\
\hline AmPeak & $10: 00$ & 1954 & $10: 00$ & 2220 \\
\hline PMPeak & 16:00 & 2013 & 16:00 & 2347 \\
\hline 24 Hr. Volume & & 27891 & & 30459 \\
\hline
\end{tabular}


Location: $\quad$ 5Th Ring Road WEEK 1 Counter \#13

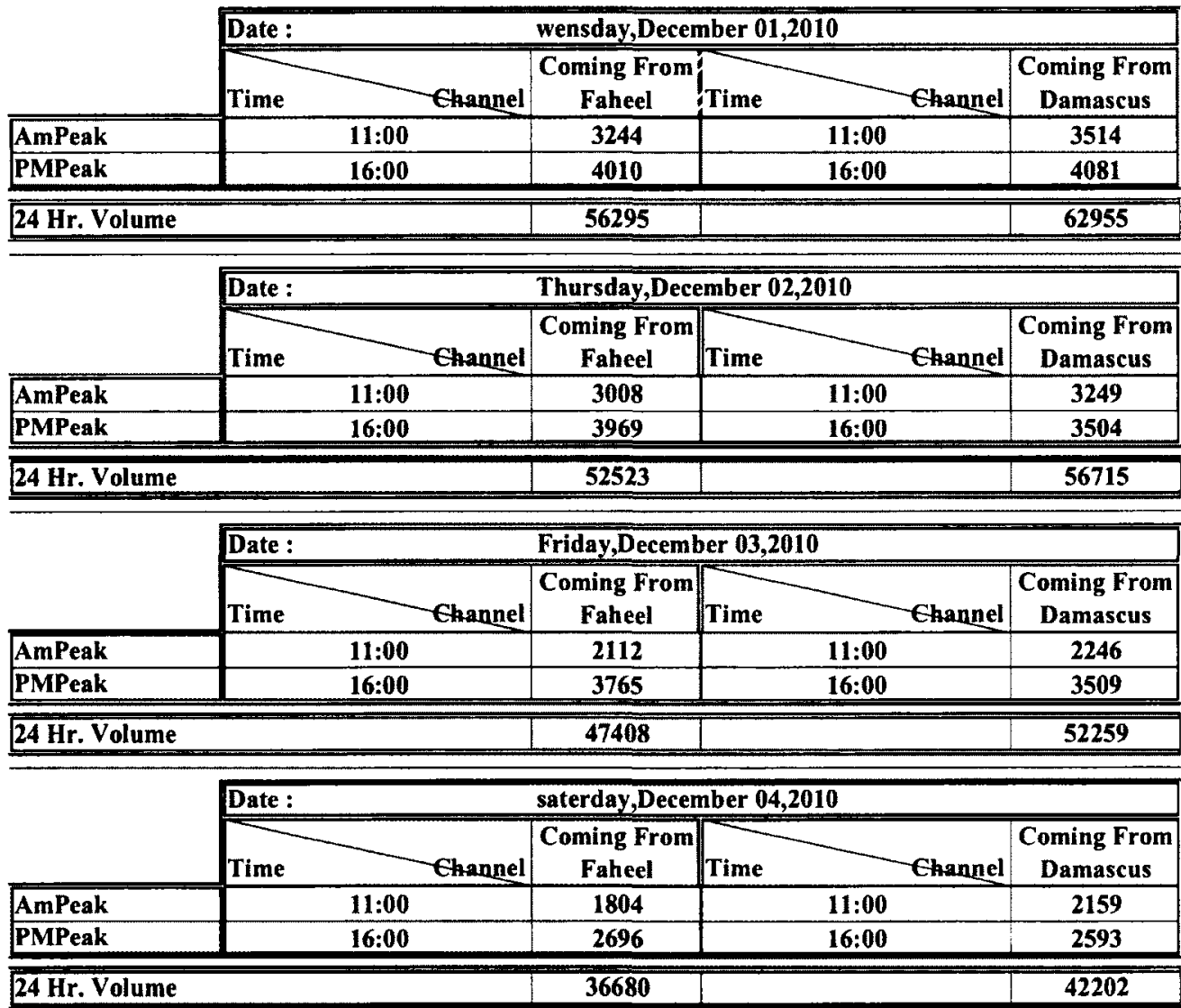

\begin{tabular}{|c|c|c|c|c|}
\hline & Date : & \multicolumn{3}{|c|}{ Sunday,December 05,2010 } \\
\hline & Time & $\begin{array}{c}\text { Coming From } \\
\text { Faheel }\end{array}$ & Time & $\begin{array}{c}\text { Coming From } \\
\text { Damascus }\end{array}$ \\
\hline AmPeak & 11:00 & 2621 & $7: 00$ & 2959 \\
\hline PMPeak & 16:00 & 4287 & $16: 00$ & 4199 \\
\hline \multirow[t]{3}{*}{24 Hr. Volume } & & 54745 & & $\overline{60547}$ \\
\hline & Date : & \multicolumn{3}{|c|}{ Monday,December 06,2010 } \\
\hline & Channel & $\begin{array}{c}\text { Coming From } \\
\text { Faheel }\end{array}$ & Time & $\begin{array}{c}\text { Coming From } \\
\text { Damascus }\end{array}$ \\
\hline AmPeak & $11: 00$ & 3173 & $7: 00$ & 4691 \\
\hline PMPeak & 13:00 & 4345 & $16: 00$ & 4087 \\
\hline 24 Hr. Volume & & 60704 & & 67906 \\
\hline
\end{tabular}

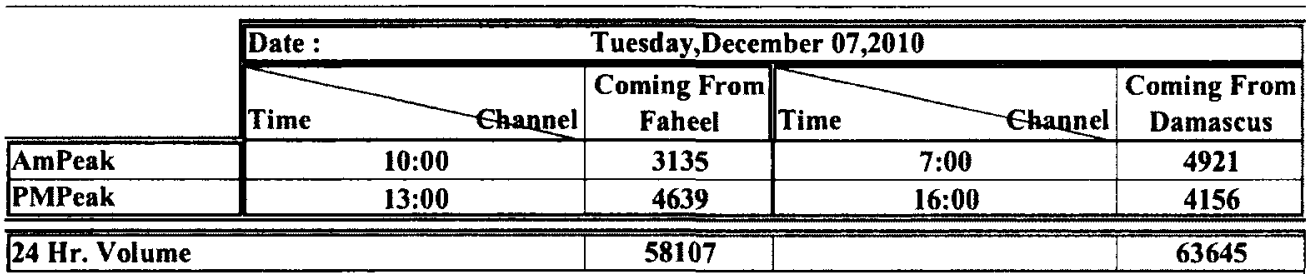


Location: $\quad 5 T h$ Ring Road WEEK 2

Counter \#13

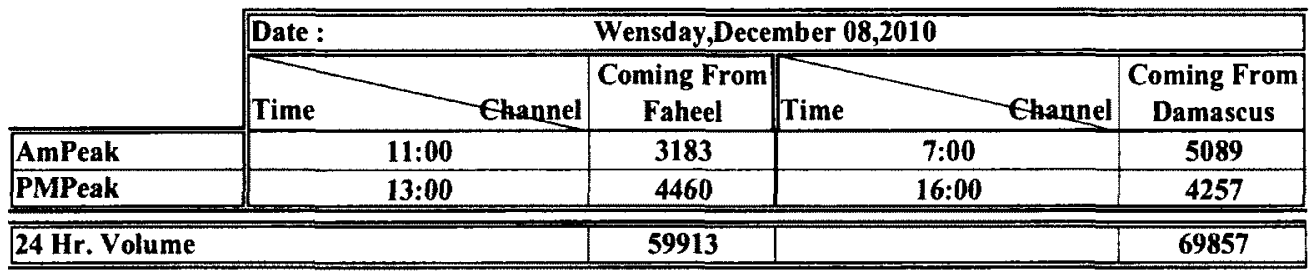

\begin{tabular}{|c|c|c|c|c|c|}
\hline & \multicolumn{2}{|l|}{ Date : } & \multicolumn{3}{|c|}{ Thursday, December 09,2010} \\
\hline & Time & Channel & $\begin{array}{c}\text { Coming From } \\
\text { Faheel }\end{array}$ & Time & $\begin{array}{c}\text { Coming From } \\
\text { Damascus }\end{array}$ \\
\hline AmPeak & & 11:00 & 2752 & $7: 00$ & 3411 \\
\hline PMPeak & & 13:00 & 4321 & 16:00 & 3682 \\
\hline 24 Hr. Volume & & & 55177 & & 63606 \\
\hline
\end{tabular}

\begin{tabular}{|c|c|c|c|c|c|}
\hline & \multicolumn{2}{|l|}{ Date: } & \multicolumn{3}{|c|}{ Friday,December 10,2010} \\
\hline & Time & Channel & $\begin{array}{c}\text { Coming From } \\
\text { Faheel }\end{array}$ & Time & $\begin{array}{c}\text { Coming From } \\
\text { Damascus }\end{array}$ \\
\hline AmPeak & & $11: 00$ & 1830 & $0: 00$ & 2075 \\
\hline PMPeak & & $16: 00$ & 3918 & $16: 00$ & 3464 \\
\hline 24 Hr. Volume & & & 43443 & & 49947 \\
\hline
\end{tabular}

\begin{tabular}{|c|c|c|c|c|c|}
\hline & \multicolumn{2}{|l|}{ Date: } & \multicolumn{3}{|c|}{ saterday,December 11,2010} \\
\hline & Time & Channel & $\begin{array}{c}\text { Coming From } \\
\text { Faheel }\end{array}$ & Channel & $\begin{array}{c}\begin{array}{c}\text { Coming From } \\
\text { Damascus }\end{array} \\
\end{array}$ \\
\hline AmPeak & & 11:00 & 3392 & $7: 00$ & 5777 \\
\hline PMPeak & & $13: 00$ & 4804 & 16:00 & 4284 \\
\hline 24 Hr. Volume & & & 60462 & & 72592 \\
\hline
\end{tabular}

\begin{tabular}{|c|c|c|c|c|c|}
\hline & \multicolumn{2}{|l|}{ Date: } & \multicolumn{3}{|c|}{ Sunday,December 12,2010} \\
\hline & Time & Channel & \begin{tabular}{|c|} 
Coming From \\
Faheel
\end{tabular} & Time & $\begin{array}{c}\text { Coming From } \\
\text { Damascus }\end{array}$ \\
\hline AmPeak & & $11: 00$ & 3130 & $7: 00$ & 5773 \\
\hline PMPeak & & $13: 00$ & 4398 & 16:00 & 3998 \\
\hline 24 Hr. Volume & & & 57449 & & (68164 \\
\hline
\end{tabular}

\begin{tabular}{|c|c|c|c|c|c|}
\hline & \multicolumn{2}{|l|}{ Date: } & \multicolumn{3}{|c|}{ Monday,December 13,2010} \\
\hline & Time & Channel & \begin{tabular}{|c|}
$\begin{array}{c}\text { Coming From } \\
\text { Faheel }\end{array}$ \\
\end{tabular} & Time & $\begin{array}{c}\text { Coming From } \\
\text { Damascus } \\
\end{array}$ \\
\hline AmPeak & & $11: 00$ & 3147 & $7: 00$ & 5996 \\
\hline PMPeak & & 13:00 & 5388 & 16:00 & 4760 \\
\hline 24 Hr. Volume & & & 64968 & & 75344 \\
\hline
\end{tabular}

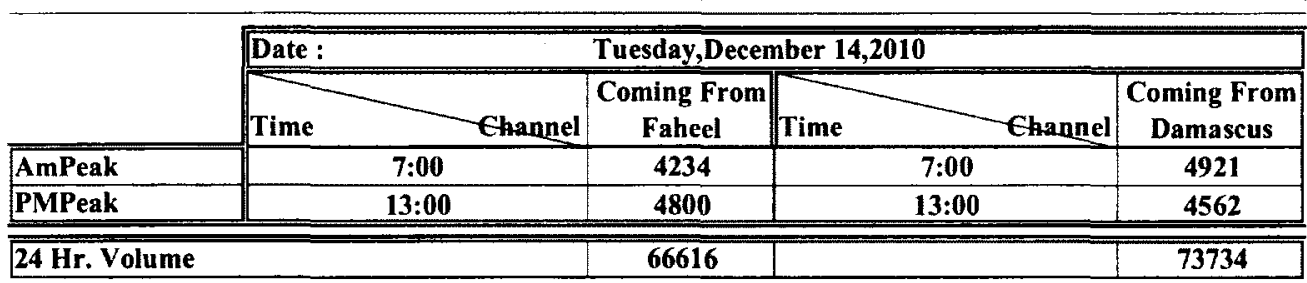


Location: $\quad$ 5th R.R-Gazali Expressway.(on Bridge) WEEK 1 Counter \#14

\begin{tabular}{|c|c|c|c|c|}
\hline & Date : & \multicolumn{3}{|c|}{ wensday,December 01,2010} \\
\hline & Channel & $\begin{array}{c}\text { Coming From } \\
\text { 4Th R.R }\end{array}$ & Channel & $\begin{array}{c}\text { Coming From } \\
\text { Shuwaikh }\end{array}$ \\
\hline AmPeak & 11:00 & 4267 & $10: 00$ & 4165 \\
\hline PMPeak & 16:00 & 4850 & 16:00 & 4307 \\
\hline \multirow[t]{3}{*}{24 Hr. Volume } & & 63900 & & 64019 \\
\hline & Date: & Thursday,Dece & mber 02,2010 & \\
\hline & Channel & \begin{tabular}{|c|} 
Coming From \\
4Th R.R \\
\end{tabular} & Time & \begin{tabular}{|c|}
$\begin{array}{c}\text { Coming From } \\
\text { Shuwaikh }\end{array}$ \\
\end{tabular} \\
\hline AmPeak & 11:00 & 3645 & 11:00 & 3411 \\
\hline PMPeak & 12:00 & 3524 & 12:00 & 3245 \\
\hline \multirow[t]{3}{*}{$24 \mathrm{Hr}$. Volume } & & 51656 & & 49173 \\
\hline & Date: & Friday,Decemb & 03,2010 & \\
\hline & Channel & \begin{tabular}{|c|} 
Coming From \\
4Th R.R \\
\end{tabular} & Time & $\begin{array}{c}\text { Coming From } \\
\text { Shuwaikh }\end{array}$ \\
\hline AmPeak & 11:00 & 3022 & 10:00 & 2594 \\
\hline PMPeak & 16:00 & 3537 & 13:00 & 3117 \\
\hline 24 Hr. Volume & & 46961 & & 44527 \\
\hline
\end{tabular}

\begin{tabular}{|c|c|c|c|c|c|}
\hline & \multicolumn{2}{|l|}{ Date : } & \multicolumn{3}{|c|}{ saterday,December 04,2010} \\
\hline & Time & Channel & $\begin{array}{c}\text { Coming From } \\
\text { 4Th R.R }\end{array}$ & Channel & $\begin{array}{c}\text { Coming From } \\
\text { Shuwaikh }\end{array}$ \\
\hline AmPeak & & 10:00 & 7286 & $10: 00$ & 7516 \\
\hline PMPeak & & 13:00 & 20947 & 13:00 & 22362 \\
\hline $24 \mathrm{Hr}$. Volume & & & 66826 & & 75023 \\
\hline
\end{tabular}

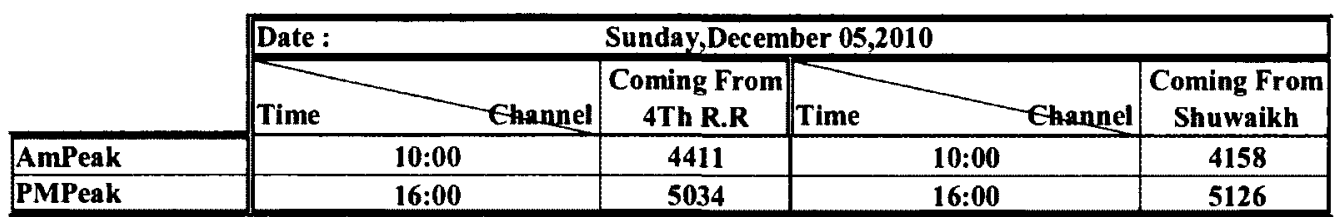

\begin{tabular}{|c|c|c|c|c|}
\hline \multicolumn{2}{|l|}{24 Hr. Volume } & 61747 & & 67960 \\
\hline & \multicolumn{4}{|c|}{ Monday,December 06,2010 } \\
\hline & Channel & $\begin{array}{c}\text { Coming From } \\
\text { 4Th R.R }\end{array}$ & Channel & $\begin{array}{c}\text { Coming From } \\
\text { Shuwaikh }\end{array}$ \\
\hline AmPeak & 11:00 & 4639 & 10:00 & 4305 \\
\hline PMPeak & $12: 00$ & 4901 & $12: 00$ & 5339 \\
\hline \multirow[t]{3}{*}{24 Hr. Volume } & & 63345 & & 70169 \\
\hline & Date: & \multicolumn{3}{|c|}{ Tuesday, December 07,2010} \\
\hline & Time & $\begin{array}{c}\text { Coming From } \\
\text { 4Th R.R } \\
\end{array}$ & Time & $\begin{array}{c}\text { Coming From } \\
\text { Shuwaikh }\end{array}$ \\
\hline AmPeak & 10:00 & 4103 & 11:00 & 4462 \\
\hline PMPeak & 16:00 & 5384 & 16:00 & 5373 \\
\hline 24 Hr. Volume & & 65501 & & 71224 \\
\hline
\end{tabular}


Location: $\quad$ 5th R.R-Gazali Expressway.(on Bridge) WEEK 2 Counter \#14

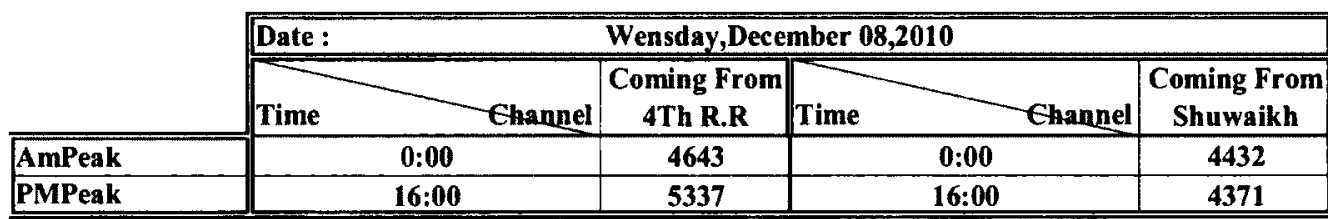

\begin{tabular}{|l|c|c|c|}
\hline \hline 24 Hr. Volume & 62481 & 66839 \\
\hline
\end{tabular}

\begin{tabular}{|c|c|c|c|c|}
\hline & Date : & \multicolumn{3}{|c|}{ Thursday, December 09,2010} \\
\hline & Time Channel & $\begin{array}{c}\text { Coming From } \\
\text { 4Th R.R }\end{array}$ & Channel & $\begin{array}{c}\text { Coming From } \\
\text { Shuwaikh }\end{array}$ \\
\hline AmPeak & $0: 00$ & 4231 & $0: 00$ & 3777 \\
\hline PMPeak & 16:00 & 3308 & 16:00 & 3378 \\
\hline \multirow[t]{3}{*}{24 Hr. Volume } & & $\overline{50443}$ & & 49503 \\
\hline & \multicolumn{4}{|c|}{ Friday,December 10,2010 } \\
\hline & Channel & $\begin{array}{c}\text { Coming From } \\
\text { 4Th R.R }\end{array}$ & Channel & $\begin{array}{c}\begin{array}{c}\text { Coming From } \\
\text { Shuwaikh }\end{array} \\
\end{array}$ \\
\hline AmPeak & $0: 00$ & 3924 & $0: 00$ & 3162 \\
\hline PMPeak & $16: 00$ & 5533 & $16: 00$ & 5837 \\
\hline 24 Hr. Volume & & 64313 & & 68299 \\
\hline
\end{tabular}

\begin{tabular}{|c|c|c|c|c|}
\hline & Date: & \multicolumn{3}{|c|}{ saterday, December 11,2010} \\
\hline & Time & $\begin{array}{c}\text { Coming From } \\
\text { 4Th R.R }\end{array}$ & Time & $\begin{array}{c}\text { Coming From } \\
\text { Shuwaikh }\end{array}$ \\
\hline AmPeak & $0: 00$ & 4871 & $0: 00$ & 4601 \\
\hline PMPeak & 20:00 & 5333 & 15:00 & 5670 \\
\hline 24 Hr. Volume & & 68276 & & 73761 \\
\hline
\end{tabular}

\begin{tabular}{|c|c|c|c|c|}
\hline & Date: & \multicolumn{3}{|c|}{ Sunday,December 12,2010} \\
\hline & Channel & $\begin{array}{c}\text { Coming From } \\
\text { 4Th R.R }\end{array}$ & Channel & $\begin{array}{c}\text { Coming From } \\
\text { Shuwaikh }\end{array}$ \\
\hline AmPeak & $0: 00$ & 4936 & $0: 00$ & 4551 \\
\hline PMPeak & $16: 00$ & 5447 & $15: 00$ & 5818 \\
\hline 24 Hr. Volume & & $\overline{67875}$ & & 72419 \\
\hline
\end{tabular}

\begin{tabular}{|c|c|c|c|c|}
\hline & Date: & \multicolumn{3}{|c|}{ Monday,December 13,2010 } \\
\hline & Time & $\begin{array}{c}\text { Coming From } \\
\text { 4Th R.R }\end{array}$ & Time & \begin{tabular}{|c|} 
Coming From \\
Shuwaikh
\end{tabular} \\
\hline AmPeak & 0:00 & 4837 & 0:00 & 4615 \\
\hline PMPeak & 16:00 & 7037 & $16: 00$ & 5726 \\
\hline 24 Hr. Volume & & 82710 & & 81745 \\
\hline
\end{tabular}

\begin{tabular}{|c|c|c|c|c|c|}
\hline & \multicolumn{2}{|l|}{ Date: } & \multicolumn{3}{|c|}{ Tuesday,December 14,2010} \\
\hline & Time & Channel & \begin{tabular}{|c|} 
Coming From \\
4Th R.R \\
\end{tabular} & Time & $\begin{array}{c}\text { Coming From } \\
\text { Shuwaikh }\end{array}$ \\
\hline AmPeak & & $11: 00$ & 4752 & $7: 00$ & 5989 \\
\hline PMPeak & & 16:00 & 4691 & 16:00 & 4662 \\
\hline$\overline{24 \text { Hr. Volume }}$ & & & 67804 & & 74465 \\
\hline
\end{tabular}


Location:

Faheel Expressway WEEK 1

Counter \#15

\begin{tabular}{|c|c|c|c|c|}
\hline & Date: & \multicolumn{3}{|c|}{ wensday, December 01,2010} \\
\hline & Time & $\begin{array}{c}\text { Coming From } \\
\text { Faheel }\end{array}$ & Time & $\begin{array}{c}\text { Coming From } \\
\text { 6th R.R }\end{array}$ \\
\hline AmPeak & 11:00 & 5231 & 11:00 & 4387 \\
\hline PMPeak & $16: 00$ & 4846 & $16: 00$ & 4765 \\
\hline \multirow[t]{3}{*}{24 Hr. Volume } & & 71328 & & 64674 \\
\hline & Date: & Thursday,Dece & ember 02,2010 & \\
\hline & Time & $\begin{array}{c}\text { Coming From } \\
\text { Faheel }\end{array}$ & Time & $\begin{array}{c}\text { Coming From } \\
\text { 6th R.R }\end{array}$ \\
\hline AmPeak & 11:00 & 4768 & 10:00 & 4281 \\
\hline PMPeak & $12: 00$ & 4863 & $12: 00$ & 5328 \\
\hline \multirow[t]{3}{*}{24 Hr. Volume } & & 68311 & & 70368 \\
\hline & Date: & Friday,Decemb & ber 03,2010 & \\
\hline & Channel & $\begin{array}{c}\text { Coming From } \\
\text { Faheel }\end{array}$ & Time & $\begin{array}{c}\text { Coming From } \\
\text { 6th R.R }\end{array}$ \\
\hline AmPeak & $10: 00$ & 3240 & $11: 00$ & 2986 \\
\hline PMPeak & $12: 00$ & 2853 & 12:00 & 3012 \\
\hline \multirow[t]{3}{*}{24 Hr. Volume } & & 35824 & & 37420 \\
\hline & Date: & saterday,Decen & nber 04,2010 & \\
\hline & Channel & $\begin{array}{c}\text { Coming From } \\
\text { Faheel }\end{array}$ & $\overline{T i m e}$ & $\begin{array}{c}\text { Coming From } \\
\text { 6th R.R }\end{array}$ \\
\hline AmPeak & $11: 00$ & 5420 & $10: 00$ & 4587 \\
\hline PMPeak & $12: 00$ & 5011 & $12: 00$ & 4231 \\
\hline 24 Hr. Volume & & 64380 & & 67345 \\
\hline
\end{tabular}

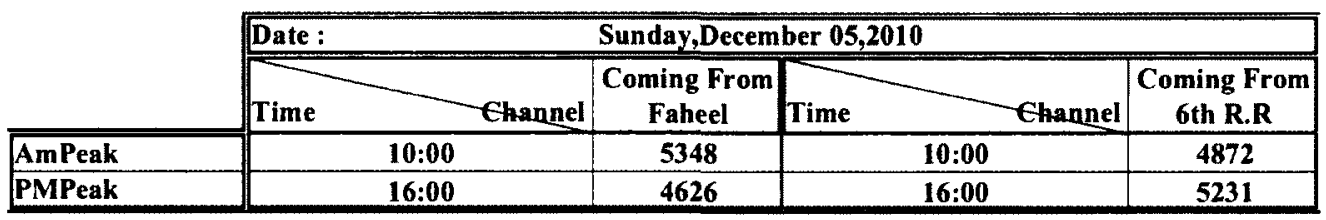

\begin{tabular}{|c|c|c|c|c|}
\hline \multicolumn{2}{|l|}{$24 \mathrm{Hr}$. Volume } & 69840 & & 70134 \\
\hline & Date: & \multicolumn{3}{|c|}{ Monday,December 06,2010 } \\
\hline & Time & $\begin{array}{c}\text { Coming From } \\
\text { Faheel }\end{array}$ & Time & $\begin{array}{c}\text { Coming From } \\
\text { 6th R.R }\end{array}$ \\
\hline AmPeak & 11:00 & 4320 & 10:00 & 4205 \\
\hline PMPeak & 12:00 & 3986 & $12: 00$ & 4011 \\
\hline \multirow[t]{3}{*}{24 Hr. Volume } & & 64536 & & 64320 \\
\hline & Date: & \multicolumn{3}{|c|}{ Tuesday,December 07,2010} \\
\hline & Channel & \begin{tabular}{|c|}
$\begin{array}{c}\text { Coming From } \\
\text { Faheel }\end{array}$ \\
\end{tabular} & Channel & \begin{tabular}{|c|} 
Coming From \\
6th R.R \\
\end{tabular} \\
\hline AmPeak & $10: 00$ & 3786 & $11: 00$ & 3986 \\
\hline PMPeak & 16:00 & 3765 & 16:00 & 4023 \\
\hline 24 Hr.Volume & & $\overline{56843}$ & & 58917 \\
\hline
\end{tabular}


Location: $\quad$ Faheel Expressway WEEK 2 Counter \#15

\begin{tabular}{|c|c|c|c|c|c|c|}
\hline & \multicolumn{2}{|l|}{ Date: } & \multicolumn{4}{|c|}{ Wensday,December 08,2010 } \\
\hline & Time & Channel & \begin{tabular}{|c|}
$\begin{array}{c}\text { Coming From } \\
\text { Faheel }\end{array}$ \\
\end{tabular} & Time & Channel & \begin{tabular}{|c|} 
Coming From \\
6th R.R \\
\end{tabular} \\
\hline AmPeak & & $10: 00$ & 4387 & & & 4023 \\
\hline PMPeak & & $12: 00$ & 4129 & & & 3984 \\
\hline 24 Hr. Volume & & & 59873 & & & 49856 \\
\hline
\end{tabular}

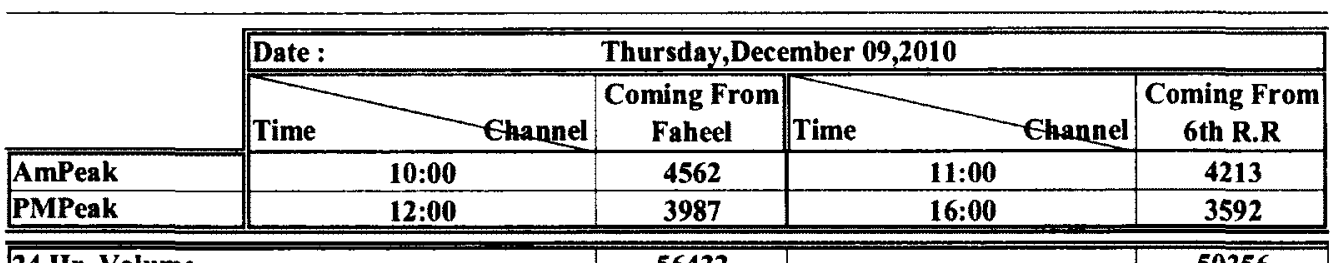

\begin{tabular}{|l|c|c|c|}
\hline 24 Hr. Volume & 56432 & & 50356 \\
\hline
\end{tabular}

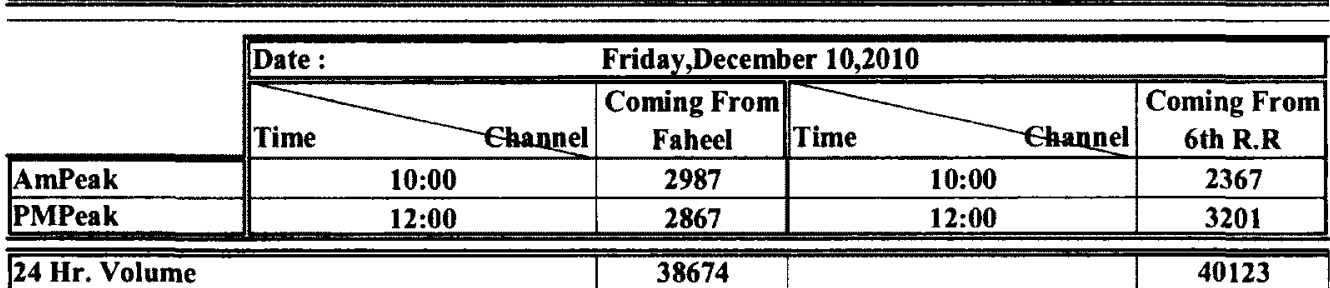

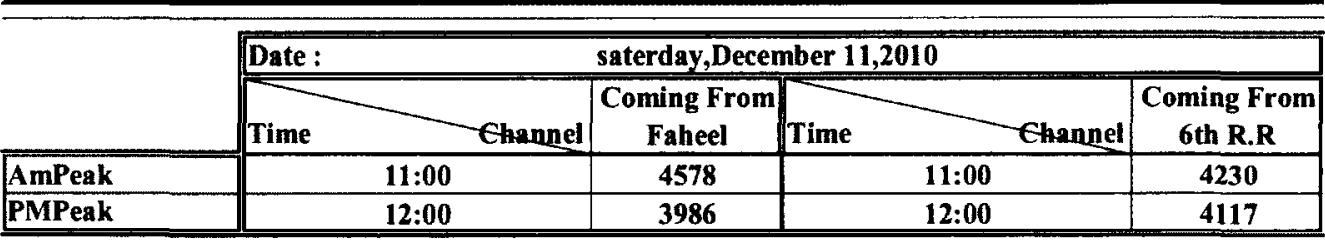

\begin{tabular}{|l|c|c|c|}
\hline $24 \mathrm{Hr}$. Volume & 62348 & & 56760 \\
\hline
\end{tabular}

\begin{tabular}{|c|c|c|c|c|}
\hline & Date : & \multicolumn{3}{|c|}{ Sunday,December 12,2010} \\
\hline & Time Channel & \begin{tabular}{|c|}
$\begin{array}{c}\text { Coming From } \\
\text { Faheel }\end{array}$ \\
\end{tabular} & Channel & $\begin{array}{c}\text { Coming From } \\
\text { 6th R.R }\end{array}$ \\
\hline AmPeak & 11:00 & 3876 & 10:00 & 4043 \\
\hline PMPeak & 12:00 & 3798 & 12:00 & 3983 \\
\hline \multirow[t]{3}{*}{24 Hr. Volume } & & 60347 & & 59870 \\
\hline & \multicolumn{4}{|c|}{ Monday,December 13,2010 } \\
\hline & Channel & \begin{tabular}{|c|}
$\begin{array}{c}\text { Coming From } \\
\text { Faheel }\end{array}$ \\
\end{tabular} & Channel & $\begin{array}{c}\text { Coming From } \\
\text { 6th R.R } \\
\end{array}$ \\
\hline AmPeak & 11:00 & 4210 & $10: 00$ & 4423 \\
\hline PMPeak & $13: 00$ & 3786 & 13:00 & 4340 \\
\hline 24 Hr. Volume & & 54789 & & 57321 \\
\hline
\end{tabular}

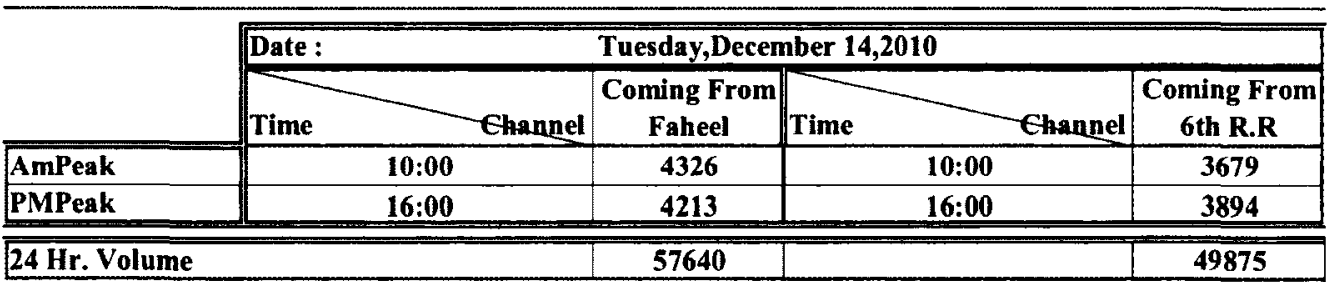


Location: Faheel Expressway WEEK 1

Counter \#16

\begin{tabular}{|c|c|c|c|c|}
\hline & Date: & \multicolumn{3}{|c|}{ wens day, December 01,2010} \\
\hline & Time Channel & $\begin{array}{c}\text { Coming From } \\
\text { Airport }\end{array}$ & Time & $\begin{array}{c}\text { Coming From } \\
\text { JaberAli }\end{array}$ \\
\hline AmPeak & $11: 00$ & 4690 & $7: 00$ & 5938 \\
\hline PMPeak & 13:00 & 5177 & $16: 00$ & 4992 \\
\hline \multirow[t]{3}{*}{$24 \mathrm{Hr}$. Volume } & & 72465 & & 77098 \\
\hline & Date : & Thursday,Dece & mber 02,2010 & \\
\hline & Time & $\begin{array}{c}\text { Coming From } \\
\text { Airport }\end{array}$ & Time & $\begin{array}{c}\text { Coming From } \\
\text { JaberAli }\end{array}$ \\
\hline AmPeak & $11: 00$ & 4279 & $10: 00$ & 5125 \\
\hline PMPeak & 13:00 & 5494 & 12:00 & 4488 \\
\hline \multirow[t]{3}{*}{24 Hr. Volume } & & 65699 & & 70951 \\
\hline & Date : & Friday,Decemb & per 03,2010 & \\
\hline & Channel & \begin{tabular}{|c|}
$\begin{array}{c}\text { Coming From } \\
\text { Airport }\end{array}$ \\
\end{tabular} & Time & $\begin{array}{c}\text { Coming From } \\
\text { JaberAli }\end{array}$ \\
\hline AmPeak & $11: 00$ & 2483 & $10: 00$ & 2481 \\
\hline PMPeak & $17: 00$ & 3884 & $16: 00$ & 3759 \\
\hline \multirow[t]{3}{*}{$24 \mathrm{Hr}$. Volume } & & 46528 & & 48108 \\
\hline & Date : & saterday,Decen & nber 04,2010 & \\
\hline & Time & $\begin{array}{c}\text { Coming From } \\
\text { Airport }\end{array}$ & Time & \begin{tabular}{|c|}
$\begin{array}{c}\text { Coming From } \\
\text { JaberAli }\end{array}$ \\
\end{tabular} \\
\hline AmPeak & 10:00 & 4492 & $7: 00$ & 5913 \\
\hline PMPeak & $13: 00$ & 5121 & 16:00 & 5206 \\
\hline $24 \mathrm{Hr}$. Volume & & 71321 & & 77137 \\
\hline
\end{tabular}

\begin{tabular}{|c|c|c|c|c|}
\hline & Date : & \multicolumn{3}{|c|}{ Sunday,December 05,2010} \\
\hline & Time & $\begin{array}{c}\text { Coming From } \\
\text { Airport }\end{array}$ & Time & \begin{tabular}{|c|}
$\begin{array}{c}\text { Coming From } \\
\text { JaberAli }\end{array}$ \\
\end{tabular} \\
\hline AmPeak & 11:00 & 4641 & $8: 00$ & 5620 \\
\hline PMPeak & $13: 00$ & 4994 & $16: 00$ & 4916 \\
\hline \multirow[t]{3}{*}{24 Hr. Volume } & & 71104 & & 75725 \\
\hline & Date: & Monday,Decem & aber 06,2010 & \\
\hline & Channel & $\begin{array}{c}\text { Coming From } \\
\text { Airport }\end{array}$ & Channel & \begin{tabular}{|c|}
$\begin{array}{c}\text { Coming From } \\
\text { JaberAli }\end{array}$ \\
\end{tabular} \\
\hline AmPeak & 11:00 & 4269 & $10: 00$ & 5218 \\
\hline PMPeak & $13: 00$ & 5044 & 16:00 & 4753 \\
\hline \multirow[t]{3}{*}{$24 \mathrm{Hr}$. Volume } & & 67475 & & 70821 \\
\hline & Date: & Tuesday,Decem & nber 07,2010 & \\
\hline & Time & \begin{tabular}{|c|} 
Coming From \\
Airport
\end{tabular} & Time & $\begin{array}{c}\text { Coming From } \\
\text { JaberAli } \\
\end{array}$ \\
\hline AmPeak & 11:00 & 4752 & $7: 00$ & 5989 \\
\hline PMPeak & $17: 00$ & 4691 & $16: 00$ & 4662 \\
\hline 24 Hr. Volume & & 67804 & & 74465 \\
\hline
\end{tabular}


Location: $\quad$ Faheel Expressway WEEK 2

Counter \#16

\begin{tabular}{|c|c|c|c|c|c|}
\hline & \multicolumn{2}{|l|}{ Date: } & \multicolumn{3}{|c|}{ Wensday,December 08,2010 } \\
\hline & Time & Channel & $\begin{array}{c}\text { Coming From } \\
\text { Airport }\end{array}$ & Channel & $\begin{array}{c}\text { Coming From } \\
\text { JaberAli }\end{array}$ \\
\hline AmPeak & & $11: 00$ & 4584 & $8: 00$ & 5998 \\
\hline PMPeak & & $13: 00$ & 5123 & 16:00 & 4668 \\
\hline 24 Hr. Volume & & & 70610 & & 76870 \\
\hline
\end{tabular}

\begin{tabular}{|c|c|c|c|c|}
\hline & Date: & \multicolumn{3}{|c|}{ Thursday,December 09,2010} \\
\hline & Time Channel & $\begin{array}{c}\text { Coming From } \\
\text { Airport }\end{array}$ & Channel & $\begin{array}{c}\text { Coming From } \\
\text { JaberAli }\end{array}$ \\
\hline AmPeak & 11:00 & 4144 & $10: 00$ & 4889 \\
\hline PMPeak & $13: 00$ & 5104 & $12: 00$ & 4051 \\
\hline
\end{tabular}

24 Hr. Volume

63541

68118

\begin{tabular}{|c|c|c|c|c|}
\hline & \multicolumn{4}{|c|}{ Friday,December 10,2010} \\
\hline & Channel & \begin{tabular}{|c|} 
Coming From \\
Airport
\end{tabular} & Channel & \begin{tabular}{|c|} 
Coming From \\
Jaber Ali
\end{tabular} \\
\hline AmPeak & $11: 00$ & 2756 & 10:00 & 2636 \\
\hline PMPeak & 17:00 & 3814 & 13:00 & 3345 \\
\hline
\end{tabular}

\begin{tabular}{|l|c|l|l|}
\hline $24 \mathrm{Hr}$. Volume & $\mathbf{4 7 3 4 8}$ & & 48271 \\
\hline
\end{tabular}

\begin{tabular}{|c|c|c|c|c|c|}
\hline & \multicolumn{2}{|l|}{ Date : } & \multicolumn{3}{|c|}{ saterday,December 11,2010} \\
\hline & Time & Channel & $\begin{array}{c}\text { Coming From } \\
\text { Airport }\end{array}$ & Channel & $\begin{array}{c}\text { Coming From } \\
\text { JaberAli }\end{array}$ \\
\hline AmPeak & & $11: 00$ & 4764 & $7: 00$ & 6002 \\
\hline PMPeak & & $13: 00$ & 5247 & $16: 00$ & 4871 \\
\hline 24 Hr. Volume & & & 70940 & & 75639 \\
\hline
\end{tabular}

\begin{tabular}{|c|c|c|c|c|c|}
\hline & \multicolumn{2}{|l|}{ Date: } & \multicolumn{3}{|c|}{ Sunday,December 12,2010} \\
\hline & Time & Channel & \begin{tabular}{|c|} 
Coming From \\
Airport
\end{tabular} & Channel & \begin{tabular}{|c|} 
Coming From \\
Jaber Ali
\end{tabular} \\
\hline AmPeak & & & 4778 & $7: 00$ & 6089 \\
\hline PMPeak & & & 5040 & 16:00 & 4864 \\
\hline
\end{tabular}

\begin{tabular}{|l|c|c|c|}
\hline 24 Hr. Volume & 67341 & & 75105 \\
\hline
\end{tabular}

\begin{tabular}{|c|c|c|c|c|c|}
\hline & \multicolumn{5}{|c|}{ Monday,December 13,2010} \\
\hline & Time & Channel & \begin{tabular}{|c|} 
Coming From \\
Airport
\end{tabular} & Channel & $\begin{array}{c}\text { Coming From } \\
\text { Jaber Ali }\end{array}$ \\
\hline AmPeak & & 11:00 & 4788 & $7: 00$ & 5844 \\
\hline PMPeak & & 13:00 & 4427 & 16:00 & 4222 \\
\hline $24 \mathrm{Hr}$. Volume & & & 61146 & & 73386 \\
\hline
\end{tabular}

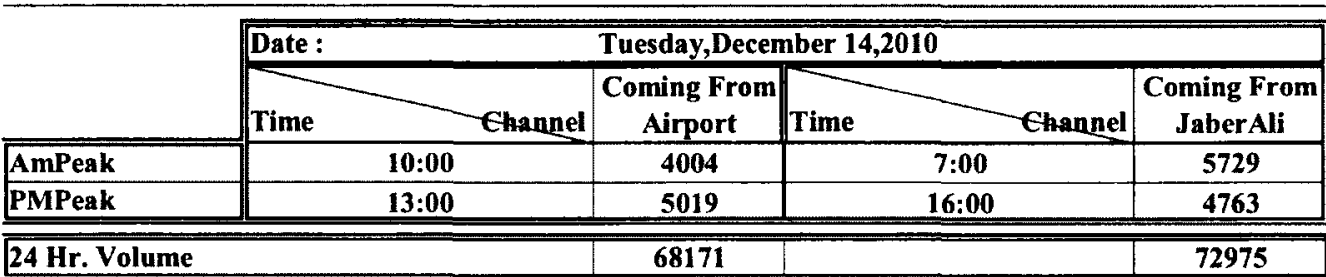


Appendix C

SAS Input \& Output - 500m Radius Influence Area 
$500 \mathrm{M}$ RADIUS INFLUENCE AREA (SAS INPUT)

\begin{tabular}{|c|c|c|c|c|c|c|c|c|c|c|}
\hline $\begin{array}{c}\text { Case } \\
\#\end{array}$ & SRN & HighFlow & AADT & LnAADT & Length & LnLength & Expo & LnExpo & Accidents & Cam \\
\hline 1 & 1 & 1 & 117103 & 11.67 & 3.03 & 1.11 & 354773 & 12.78 & 0 & 1 \\
\hline 2 & 1 & 1 & 97850 & 11.49 & 3.02 & 1.11 & 295707 & 12.60 & 0 & 0 \\
\hline 3 & 0 & 0 & 52250 & 10.86 & 3.02 & 1.11 & 157882 & 11.97 & 0 & 0 \\
\hline 4 & 0 & 0 & 43700 & 10.69 & 3.02 & 1.11 & 132022 & 11.79 & 0 & 0 \\
\hline 5 & 1 & 1 & 117325 & 11.67 & 3.00 & 1.10 & 352183 & 12.77 & 0 & 0 \\
\hline 6 & 0 & 0 & 39995 & 10.60 & 2.99 & 1.10 & 119705 & 11.69 & 0 & 0 \\
\hline 7 & 0 & 0 & 24700 & 10.11 & 2.99 & 1.09 & 73769 & 11.21 & 0 & 0 \\
\hline 8 & 0 & 0 & 37050 & 10.52 & 2.98 & 1.09 & 110538 & 11.61 & 0 & 0 \\
\hline 9 & 0 & 0 & 38048 & 10.55 & 2.98 & 1.09 & 113361 & 11.64 & 0 & 0 \\
\hline 10 & 0 & 0 & 54042 & 10.90 & 2.98 & 1.09 & 160828 & 11.99 & 0 & 1 \\
\hline 11 & 1 & 1 & 110516 & 11.61 & 2.98 & 1.09 & 328896 & 12.70 & 0 & 1 \\
\hline 12 & 1 & 1 & 109250 & 11.60 & 2.96 & 1.08 & 323145 & 12.69 & 3 & 0 \\
\hline 13 & 1 & 1 & 105450 & 11.57 & 2.96 & 1.08 & 311639 & 12.65 & 0 & 0 \\
\hline 14 & 0 & 0 & 32300 & 10.38 & 2.94 & 1.08 & 94954 & 11.46 & 0 & 0 \\
\hline 15 & 0 & 0 & 36100 & 10.49 & 2.93 & 1.07 & 105771 & 11.57 & 0 & 0 \\
\hline 16 & 0 & 0 & 66500 & 11.10 & 2.90 & 1.06 & 192804 & 12.17 & 1 & 0 \\
\hline 17 & 1 & 1 & 118750 & 11.68 & 2.87 & 1.06 & 341339 & 12.74 & 1 & 0 \\
\hline 18 & 0 & 0 & 38950 & 10.57 & 2.86 & 1.05 & 111589 & 11.62 & 0 & 0 \\
\hline 19 & 0 & 0 & 52250 & 10.86 & 2.86 & 1.05 & 149546 & 11.92 & 0 & 0 \\
\hline 20 & 0 & 0 & 35910 & 10.49 & 2.86 & 1.05 & 102639 & 11.54 & 0 & 0 \\
\hline 21 & 0 & 0 & 23750 & 10.08 & 2.84 & 1.04 & 67367 & 11.12 & 0 & 0 \\
\hline 22 & 0 & 0 & 35625 & 10.48 & 2.83 & 1.04 & 100660 & 11.52 & 0 & 0 \\
\hline 23 & 0 & 0 & 32300 & 10.38 & 2.82 & 1.04 & 90937 & 11.42 & 0 & 0 \\
\hline 24 & 1 & 1 & 113050 & 11.64 & 2.81 & 1.03 & 318056 & 12.67 & 0 & 0 \\
\hline 25 & 0 & 0 & 37763 & 10.54 & 2.80 & 1.03 & 105770 & 11.57 & 0 & 0 \\
\hline 26 & 0 & 0 & 50350 & 10.83 & 2.80 & 1.03 & 140849 & 11.86 & 2 & 0 \\
\hline 27 & 0 & 0 & 33250 & 10.41 & 2.79 & 1.03 & 92712 & 11.44 & 0 & 0 \\
\hline 28 & 0 & 0 & 51538 & 10.85 & 2.79 & 1.02 & 143626 & 11.87 & 0 & 0 \\
\hline 29 & 1 & 1 & 114000 & 11.64 & 2.77 & 1.02 & 316008 & 12.66 & 1 & 0 \\
\hline 30 & 1 & 1 & 116850 & 11.67 & 2.77 & 1.02 & 323368 & 12.69 & 1 & 0 \\
\hline 31 & 0 & 0 & 55100 & 10.92 & 2.76 & 1.02 & 152255 & 11.93 & 0 & 0 \\
\hline 32 & 1 & 1 & 117997 & 11.68 & 2.76 & 1.01 & 325581 & 12.69 & 1 & 1 \\
\hline 33 & 0 & 0 & 32775 & 10.40 & 2.73 & 1.01 & 89594 & 11.40 & 0 & 0 \\
\hline 34 & 0 & 0 & 53675 & 10.89 & 2.72 & 1.00 & 145768 & 11.89 & 1 & 0 \\
\hline 35 & 0 & 0 & 76000 & 11.24 & 2.70 & 0.99 & 205281 & 12.23 & 0 & $\underline{0}$ \\
\hline 36 & 0 & 0 & 53200 & 10.88 & 2.70 & 0.99 & 143393 & 11.87 & 0 & 0 \\
\hline 37 & 0 & 0 & 52250 & 10.86 & 2.69 & 0.99 & 140749 & 11.85 & 0 & 0 \\
\hline 38 & 0 & 0 & 47500 & 10.77 & 2.69 & 0.99 & 127880 & 11.76 & 0 & 0 \\
\hline 39 & 1 & 1 & 116850 & 11.67 & 2.69 & 0.99 & 314045 & 12.66 & 0 & 0 \\
\hline 40 & 0 & 0 & 26600 & 10.19 & 2.68 & 0.99 & 71410 & 11.18 & 0 & 0 \\
\hline 41 & 0 & 0 & 35150 & 10.47 & 2.67 & 0.98 & 94002 & 11.45 & 0 & 0 \\
\hline 42 & 0 & 0 & 38000 & 10.55 & 2.66 & 0.98 & 101257 & 11.53 & 0 & 0 \\
\hline 43 & 0 & 0 & 51300 & 10.85 & 2.65 & 0.97 & 135715 & 11.82 & 0 & 0 \\
\hline 44 & 0 & 0 & 21850 & 9.99 & 2.64 & 0.97 & 57783 & 10.96 & 0 & 0 \\
\hline 45 & 0 & 1 & 123500 & 11.72 & 2.61 & 0.96 & 322534 & 12.68 & 0 & 0 \\
\hline 46 & 0 & 0 & 38000 & 10.55 & 2.61 & 0.96 & 99137 & 11.50 & 0 & 0 \\
\hline
\end{tabular}




\begin{tabular}{|c|c|c|c|c|c|c|c|c|c|c|}
\hline 47 & 1 & 1 & 117610 & 11.68 & 2.61 & 0.96 & 306684 & 12.63 & 0 & 0 \\
\hline 48 & 0 & 0 & 45600 & 10.73 & 2.60 & 0.96 & 118739 & 11.68 & 1 & 0 \\
\hline 49 & 1 & 1 & 114950 & 11.65 & 2.60 & 0.96 & 299267 & 12.61 & 0 & 0 \\
\hline 50 & 0 & 0 & 36100 & 10.49 & 2.60 & 0.96 & 93983 & 11.45 & 1 & 0 \\
\hline 51 & 1 & 1 & 115900 & 11.66 & 2.60 & 0.96 & 301670 & 12.62 & 1 & 0 \\
\hline 52 & 1 & 1 & 110977 & 11.62 & 2.60 & 0.96 & 288592 & 12.57 & 0 & 1 \\
\hline 53 & 0 & 0 & 19000 & 9.85 & 2.60 & 0.95 & 49358 & 10.81 & 0 & 0 \\
\hline 54 & 0 & 0 & 38000 & 10.55 & 2.60 & 0.95 & 98685 & 11.50 & 0 & 0 \\
\hline 55 & 0 & 0 & 38000 & 10.55 & 2.59 & 0.95 & 98439 & 11.50 & 0 & 0 \\
\hline 56 & 0 & 1 & 108932 & 11.60 & 2.59 & 0.95 & 282112 & 12.55 & 0 & 1 \\
\hline 57 & 1 & 1 & 101650 & 11.53 & 2.59 & 0.95 & 263164 & 12.48 & 0 & 0 \\
\hline 58 & 0 & 0 & 23750 & 10.08 & 2.59 & 0.95 & 61460 & 11.03 & 0 & 0 \\
\hline 59 & 1 & 1 & 119406 & 11.69 & 2.59 & 0.95 & 308937 & 12.64 & 2 & 1 \\
\hline 60 & 0 & 0 & 43493 & 10.68 & 2.58 & 0.95 & 112332 & 11.63 & 0 & 1 \\
\hline 61 & 1 & 1 & 111150 & 11.62 & 2.57 & 0.94 & 285857 & 12.56 & 1 & 0 \\
\hline 62 & 0 & 0 & 33250 & 10.41 & 2.56 & 0.94 & 85243 & 11.35 & 0 & 0 \\
\hline 63 & 0 & 0 & 55955 & 10.93 & 2.56 & 0.94 & 143288 & 11.87 & 0 & 0 \\
\hline 64 & 0 & 0 & 34200 & 10.44 & 2.56 & 0.94 & 87566 & 11.38 & 0 & 0 \\
\hline 65 & 1 & 1 & 108300 & 11.59 & 2.56 & 0.94 & 277072 & 12.53 & 0 & 0 \\
\hline 66 & 1 & 1 & 101650 & 11.53 & 2.56 & 0.94 & 260020 & 12.47 & 1 & 0 \\
\hline 67 & 0 & 0 & 36100 & 10.49 & 2.56 & 0.94 & 92323 & 11.43 & 0 & 0 \\
\hline 68 & 0 & 0 & 56050 & 10.93 & 2.56 & 0.94 & 143326 & 11.87 & 0 & 0 \\
\hline 69 & 1 & 1 & 112100 & 11.63 & 2.55 & 0.94 & 286034 & 12.56 & 0 & 0 \\
\hline 70 & 0 & 1 & 105450 & 11.57 & 2.55 & 0.94 & 268977 & 12.50 & 0 & 0 \\
\hline 71 & 0 & 0 & 33250 & 10.41 & 2.55 & 0.94 & 84790 & 11.35 & 0 & 0 \\
\hline 72 & 1 & 1 & 104025 & 11.55 & 2.55 & 0.94 & 265263 & 12.49 & 0 & 0 \\
\hline 73 & 0 & 0 & 46522 & 10.75 & 2.55 & 0.94 & 118535 & 11.68 & 0 & 1 \\
\hline 74 & 0 & 0 & 49875 & 10.82 & 2.54 & 0.93 & 126802 & 11.75 & 1 & 0 \\
\hline 75 & 0 & 1 & 117946 & 11.68 & 2.54 & 0.93 & 299176 & 12.61 & 0 & 0 \\
\hline 76 & 0 & 0 & 41325 & 10.63 & 2.54 & 0.93 & 104779 & 11.56 & 0 & 0 \\
\hline 77 & 1 & 1 & 116850 & 11.67 & 2.53 & 0.93 & 295577 & 12.60 & 1 & 0 \\
\hline 78 & 0 & 0 & 42750 & 10.66 & 2.52 & 0.93 & 107870 & 11.59 & 2 & 0 \\
\hline 79 & 0 & 0 & 55575 & 10.93 & 2.52 & 0.92 & 139823 & 11.85 & 1 & 0 \\
\hline 80 & 0 & 0 & 30638 & 10.33 & 2.52 & 0.92 & 77075 & 11.25 & 0 & 0 \\
\hline 81 & 1 & 1 & 103550 & 11.55 & 2.51 & 0.92 & 259789 & 12.47 & 0 & 0 \\
\hline 82 & 1 & 1 & 104500 & 11.56 & 2.51 & 0.92 & 262075 & 12.48 & 1 & 0 \\
\hline 83 & 1 & 1 & 114475 & 11.65 & 2.51 & 0.92 & 286965 & 12.57 & 0 & 0 \\
\hline 84 & 0 & 0 & 33250 & 10.41 & 2.51 & 0.92 & 83333 & 11.33 & 0 & 0 \\
\hline 85 & 1 & 1 & 104975 & 11.56 & 2.51 & 0.92 & 263049 & 12.48 & 4 & 0 \\
\hline 86 & 1 & 0 & 53223 & 10.88 & 2.50 & 0.92 & 133190 & 11.80 & 0 & 1 \\
\hline 87 & 0 & 0 & 37050 & 10.52 & 2.50 & 0.92 & 92701 & 11.44 & 0 & 0 \\
\hline 88 & 0 & 0 & 19000 & 9.85 & 2.50 & 0.92 & 47528 & 10.77 & 0 & 0 \\
\hline 89 & 0 & 0 & 40850 & 10.62 & 2.50 & 0.92 & 102180 & 11.53 & 0 & 0 \\
\hline 90 & 0 & 0 & 32775 & 10.40 & 2.50 & 0.92 & 81977 & 11.31 & 0 & 0 \\
\hline 91 & 0 & 0 & 54863 & 10.91 & 2.50 & 0.92 & 137117 & 11.83 & 0 & 0 \\
\hline 92 & 0 & 0 & 31635 & 10.36 & 2.50 & 0.92 & 79056 & 11.28 & 0 & 0 \\
\hline 93 & 0 & 0 & 3628 & 8.20 & 2.50 & 0.92 & 9059 & 9.11 & 1 & 1 \\
\hline 94 & 0 & 0 & 21850 & 9.99 & 2.49 & 0.91 & 54514 & 10.91 & 1 & 0 \\
\hline
\end{tabular}




\begin{tabular}{|c|c|c|c|c|c|c|c|c|c|c|}
\hline 95 & 0 & 0 & 62339 & 11.04 & 2.49 & 0.91 & 155431 & 11.95 & 0 & 1 \\
\hline 96 & 0 & 0 & 34960 & 10.46 & 2.49 & 0.91 & 87109 & 11.37 & 0 & 0 \\
\hline 97 & 0 & 0 & 36100 & 10.49 & 2.49 & 0.91 & 89913 & 11.41 & 0 & 0 \\
\hline 98 & 0 & 0 & 36575 & 10.51 & 2.49 & 0.91 & 91073 & 11.42 & 0 & 0 \\
\hline 99 & 0 & 0 & 35150 & 10.47 & 2.49 & 0.91 & 87388 & 11.38 & 0 & 0 \\
\hline 100 & 0 & 0 & 53200 & 10.88 & 2.48 & 0.91 & 132191 & 11.79 & 0 & 0 \\
\hline 101 & 0 & 0 & 30400 & 10.32 & 2.48 & 0.91 & 75481 & 11.23 & 0 & 0 \\
\hline 102 & 0 & 0 & 32775 & 10.40 & 2.48 & 0.91 & 81272 & 11.31 & 0 & 0 \\
\hline 103 & 0 & 0 & 28500 & 10.26 & 2.48 & 0.91 & 70649 & 11.17 & 0 & 0 \\
\hline 104 & 0 & 0 & 31350 & 10.35 & 2.48 & 0.91 & 77692 & 11.26 & 0 & 0 \\
\hline 105 & 0 & 0 & 47500 & 10.77 & 2.47 & 0.91 & 117424 & 11.67 & 0 & 0 \\
\hline 106 & 0 & 1 & 95628 & 11.47 & 2.47 & 0.90 & 236205 & 12.37 & 0 & 1 \\
\hline 107 & 1 & 1 & 113525 & 11.64 & 2.47 & 0.90 & 280346 & 12.54 & 1 & 0 \\
\hline 108 & 0 & 0 & 35625 & 10.48 & 2.47 & 0.90 & 87896 & 11.38 & 0 & 0 \\
\hline 109 & 0 & 0 & 35625 & 10.48 & 2.46 & 0.90 & 87809 & 11.38 & 0 & 0 \\
\hline 110 & 0 & 0 & 33725 & 10.43 & 2.46 & 0.90 & 83109 & 11.33 & 0 & 0 \\
\hline 111 & 0 & 0 & 34105 & 10.44 & 2.46 & 0.90 & 83945 & 11.34 & 0 & 0 \\
\hline 112 & 0 & 0 & 39900 & 10.59 & 2.46 & 0.90 & 98193 & 11.49 & 0 & 0 \\
\hline 113 & 0 & 0 & 36100 & 10.49 & 2.46 & 0.90 & 88828 & 11.39 & 0 & 0 \\
\hline 114 & 1 & 1 & 115900 & 11.66 & 2.46 & 0.90 & 285161 & 12.56 & 0 & 0 \\
\hline 115 & 0 & 0 & 35768 & 10.48 & 2.46 & 0.90 & 87949 & 11.38 & 0 & 0 \\
\hline 116 & 0 & 0 & 30875 & 10.34 & 2.46 & 0.90 & 75897 & 11.24 & 0 & 0 \\
\hline 117 & 0 & 0 & 33250 & 10.41 & 2.46 & 0.90 & 81675 & 11.31 & 0 & 0 \\
\hline 118 & 0 & 0 & 33250 & 10.41 & 2.45 & 0.89 & 81352 & 11.31 & 0 & 0 \\
\hline 119 & 0 & 0 & 39900 & 10.59 & 2.44 & 0.89 & 97519 & 11.49 & 0 & 0 \\
\hline 120 & 0 & 1 & 125400 & 11.74 & 2.44 & 0.89 & 306413 & 12.63 & 0 & 0 \\
\hline 121 & 0 & 1 & 121600 & 11.71 & 2.44 & 0.89 & 296683 & 12.60 & 0 & 0 \\
\hline 122 & 0 & 0 & 33250 & 10.41 & 2.44 & 0.89 & 81051 & 11.30 & 1 & 0 \\
\hline 123 & 0 & 0 & 22800 & 10.03 & 2.44 & 0.89 & 55552 & 10.93 & 0 & 0 \\
\hline 124 & 0 & 0 & 85500 & 11.36 & 2.44 & 0.89 & 208311 & 12.25 & 1 & 0 \\
\hline 125 & 0 & 0 & 38000 & 10.55 & 2.44 & 0.89 & 92576 & 11.44 & 0 & 0 \\
\hline 126 & 1 & 1 & 115727 & 11.66 & 2.43 & 0.89 & 281216 & 12.55 & 0 & 1 \\
\hline 127 & 0 & 1 & 109250 & 11.60 & 2.43 & 0.89 & 265175 & 12.49 & 0 & 0 \\
\hline 128 & 0 & 1 & 99750 & 11.51 & 2.43 & 0.89 & 242064 & 12.40 & 0 & 0 \\
\hline 129 & 0 & 1 & 114895 & 11.65 & 2.43 & 0.89 & 278741 & 12.54 & 1 & 0 \\
\hline 130 & 0 & 0 & 35150 & 10.47 & 2.43 & 0.89 & 85241 & 11.35 & 0 & 0 \\
\hline 131 & 0 & 0 & 32300 & 10.38 & 2.42 & 0.89 & 78305 & 11.27 & 0 & 0 \\
\hline 132 & 0 & 0 & 29688 & 10.30 & 2.42 & 0.89 & 71937 & 11.18 & 0 & 0 \\
\hline 133 & 0 & 0 & 39900 & 10.59 & 2.42 & 0.88 & 96520 & 11.48 & 0 & 0 \\
\hline 134 & 0 & 1 & 125400 & 11.74 & 2.42 & 0.88 & 303081 & 12.62 & 1 & 0 \\
\hline 135 & 0 & 0 & 37763 & 10.54 & 2.41 & 0.88 & 91099 & 11.42 & 0 & 0 \\
\hline 136 & 1 & 0 & 53536 & 10.89 & 2.41 & 0.88 & 129049 & 11.77 & 0 & 1 \\
\hline 137 & 0 & 0 & 37525 & 10.53 & 2.41 & 0.88 & 90433 & 11.41 & 1 & 0 \\
\hline 138 & 0 & 0 & 36813 & 10.51 & 2.41 & 0.88 & 88609 & 11.39 & 1 & 0 \\
\hline 139 & 0 & 0 & 57497 & 10.96 & 2.41 & 0.88 & 138379 & 11.84 & 1 & 1 \\
\hline 140 & 0 & 0 & 35711 & 10.48 & 2.41 & 0.88 & 85938 & 11.36 & 0 & 0 \\
\hline 141 & 0 & 0 & 52250 & 10.86 & 2.41 & 0.88 & 125714 & 11.74 & 1 & 0 \\
\hline 142 & 0 & 0 & 50350 & 10.83 & 2.41 & 0.88 & 121126 & 11.70 & 0 & 0 \\
\hline
\end{tabular}




\begin{tabular}{|c|c|c|c|c|c|c|c|c|c|c|}
\hline 143 & 0 & 0 & 50350 & 10.83 & 2.40 & 0.88 & 120950 & 11.70 & 1 & 0 \\
\hline 144 & 0 & 0 & 42750 & 10.66 & 2.40 & 0.88 & 102656 & 11.54 & 0 & 0 \\
\hline 145 & 1 & 1 & 113525 & 11.64 & 2.40 & 0.88 & 272598 & 12.52 & 0 & 0 \\
\hline 146 & 0 & 0 & 53200 & 10.88 & 2.40 & 0.88 & 127633 & 11.76 & 0 & 0 \\
\hline 147 & 0 & 0 & 36575 & 10.51 & 2.40 & 0.88 & 87740 & 11.38 & 0 & 0 \\
\hline 148 & 0 & 0 & 37050 & 10.52 & 2.40 & 0.87 & 88747 & 11.39 & 0 & 0 \\
\hline 149 & 1 & 1 & 114950 & 11.65 & 2.39 & 0.87 & 275144 & 12.53 & 0 & 0 \\
\hline 150 & 1 & 1 & 104025 & 11.55 & 2.39 & 0.87 & 248848 & 12.42 & 0 & 0 \\
\hline 151 & 0 & 0 & 35625 & 10.48 & 2.39 & 0.87 & 85157 & 11.35 & 0 & 0 \\
\hline 152 & 0 & 0 & 48450 & 10.79 & 2.39 & 0.87 & 115708 & 11.66 & 0 & 0 \\
\hline 153 & 0 & 0 & 59706 & 11.00 & 2.39 & 0.87 & 142482 & 11.87 & 0 & 1 \\
\hline 154 & 0 & 0 & 34200 & 10.44 & 2.38 & 0.87 & 81558 & 11.31 & 0 & 0 \\
\hline 155 & 0 & 0 & 36575 & 10.51 & 2.38 & 0.87 & 87100 & 11.37 & 0 & 0 \\
\hline 156 & 0 & 0 & 38000 & 10.55 & 2.38 & 0.87 & 90448 & 11.41 & 0 & 0 \\
\hline 157 & 0 & 0 & 30400 & 10.32 & 2.37 & 0.86 & 72143 & 11.19 & 0 & 0 \\
\hline 158 & 0 & 0 & 50150 & 10.82 & 2.37 & 0.86 & 118836 & 11.69 & 0 & 0 \\
\hline 159 & 1 & 1 & 109250 & 11.60 & 2.37 & 0.86 & 258431 & 12.46 & 1 & 0 \\
\hline 160 & 0 & 0 & 32300 & 10.38 & 2.36 & 0.86 & 76367 & 11.24 & 0 & 0 \\
\hline 161 & 0 & 0 & 49115 & 10.80 & 2.36 & 0.86 & 116117 & 11.66 & 3 & 0 \\
\hline 162 & 0 & 0 & 57475 & 10.96 & 2.36 & 0.86 & 135863 & 11.82 & 1 & 0 \\
\hline 163 & 0 & 0 & 47500 & 10.77 & 2.36 & 0.86 & 112281 & 11.63 & 0 & 0 \\
\hline 164 & 0 & 0 & 47500 & 10.77 & 2.36 & 0.86 & 112255 & 11.63 & 0 & 0 \\
\hline 165 & 0 & 0 & 52250 & 10.86 & 2.36 & 0.86 & 123326 & 11.72 & 0 & 0 \\
\hline 166 & 1 & 1 & 101261 & 11.53 & 2.36 & 0.86 & 238956 & 12.38 & 0 & 1 \\
\hline 167 & 0 & 0 & 38950 & 10.57 & 2.36 & 0.86 & 91835 & 11.43 & 0 & 0 \\
\hline 168 & 0 & 0 & 31350 & 10.35 & 2.36 & 0.86 & 73913 & 11.21 & 0 & 0 \\
\hline 169 & 0 & 0 & 29450 & 10.29 & 2.36 & 0.86 & 69394 & 11.15 & 0 & 0 \\
\hline 170 & 1 & & 95000 & 11.46 & 2.36 & 0.86 & 223783 & 12.32 & 0 & 0 \\
\hline 171 & 1 & 1 & 102600 & 11.54 & 2.36 & 0.86 & 241660 & 12.40 & 2 & 0 \\
\hline 172 & 1 & 1 & 104500 & 11.56 & 2.35 & 0.86 & 246030 & 12.41 & 0 & 0 \\
\hline 173 & 1 & 1 & 113763 & 11.64 & 2.35 & 0.86 & 267749 & 12.50 & 2 & 0 \\
\hline 174 & 0 & 0 & 56525 & 10.94 & 2.35 & 0.85 & 132739 & 11.80 & 1 & 0 \\
\hline 175 & 1 & 1 & 117325 & 11.67 & 2.35 & 0.85 & 275464 & 12.53 & 1 & 0 \\
\hline 176 & 0 & 0 & 35059 & 10.46 & 2.34 & 0.85 & 82120 & 11.32 & 1 & 0 \\
\hline 177 & 0 & 0 & 31350 & 10.35 & 2.34 & 0.85 & 73424 & 11.20 & 0 & 0 \\
\hline 178 & 0 & 0 & 47500 & 10.77 & 2.34 & 0.85 & 111241 & 11.62 & 0 & 0 \\
\hline 179 & 1 & 1 & 115589 & 11.66 & 2.34 & 0.85 & 270334 & 12.51 & 0 & 1 \\
\hline 180 & 1 & 1 & 120650 & 11.70 & 2.34 & 0.85 & 282060 & 12.55 & 0 & 0 \\
\hline 181 & 1 & 1 & 102600 & 11.54 & 2.34 & 0.85 & 239602 & 12.39 & 0 & 0 \\
\hline 182 & 1 & 1 & 104500 & 11.56 & 2.33 & 0.85 & 243774 & 12.40 & 0 & 0 \\
\hline 183 & 0 & 0 & 33250 & 10.41 & 2.33 & 0.85 & 77559 & 11.26 & 0 & 0 \\
\hline 184 & 0 & 0 & 30400 & 10.32 & 2.33 & 0.85 & 70906 & 11.17 & 0 & 0 \\
\hline 185 & 1 & 1 & 116090 & 11.66 & 2.33 & 0.85 & 270587 & 12.51 & 0 & 0 \\
\hline 186 & 0 & 0 & 48450 & 10.79 & 2.33 & 0.85 & 112913 & 11.63 & 0 & 0 \\
\hline 187 & 0 & 0 & 39045 & 10.57 & 2.32 & 0.84 & 90758 & 11.42 & 0 & 0 \\
\hline 188 & 0 & 0 & 38000 & 10.55 & 2.32 & 0.84 & 88162 & 11.39 & 0 & 0 \\
\hline 189 & 1 & 0 & 36100 & 10.49 & 2.32 & 0.84 & 83612 & 11.33 & 0 & 0 \\
\hline 190 & 1 & 1 & 113763 & 11.64 & 2.31 & 0.84 & 263267 & 12.48 & 1 & 0 \\
\hline
\end{tabular}




\begin{tabular}{|c|c|c|c|c|c|c|c|c|c|c|}
\hline 191 & 0 & 0 & 36100 & 10.49 & 2.31 & 0.84 & 83540 & 11.33 & 0 & 0 \\
\hline 192 & 0 & 0 & 51775 & 10.85 & 2.31 & 0.84 & 119785 & 11.69 & 0 & 0 \\
\hline 193 & 0 & 0 & 57000 & 10.95 & 2.31 & 0.84 & 131759 & 11.79 & 0 & 0 \\
\hline 194 & 0 & 0 & 51775 & 10.85 & 2.31 & 0.84 & 119553 & 11.69 & 0 & 0 \\
\hline 195 & 1 & 0 & 39900 & 10.59 & 2.31 & 0.84 & 92076 & 11.43 & 0 & 0 \\
\hline 196 & 1 & 1 & 100700 & 11.52 & 2.31 & 0.84 & 232303 & 12.36 & 0 & 0 \\
\hline 197 & 0 & 0 & 45600 & 10.73 & 2.31 & 0.84 & 105142 & 11.56 & 1 & 0 \\
\hline 198 & 0 & 0 & 36813 & 10.51 & 2.30 & 0.83 & 84834 & 11.35 & 0 & 0 \\
\hline 199 & 0 & 0 & 52250 & 10.86 & 2.30 & 0.83 & 120365 & 11.70 & 0 & 0 \\
\hline 200 & 0 & 0 & 36100 & 10.49 & 2.30 & 0.83 & 83156 & 11.33 & 1 & 0 \\
\hline 201 & 0 & 0 & 42750 & 10.66 & 2.30 & 0.83 & 98461 & 11.50 & 0 & 0 \\
\hline 202 & 0 & 0 & 33250 & 10.41 & 2.30 & 0.83 & 76439 & 11.24 & 0 & 0 \\
\hline 203 & 0 & 0 & 36100 & 10.49 & 2.29 & 0.83 & 82754 & 11.32 & 0 & 0 \\
\hline 204 & 1 & 1 & 99275 & 11.51 & 2.29 & 0.83 & 227343 & 12.33 & 0 & 0 \\
\hline 205 & 0 & 0 & 36575 & 10.51 & 2.29 & 0.83 & 83725 & 11.34 & 0 & 0 \\
\hline 206 & 1 & 1 & 104500 & 11.56 & 2.29 & 0.83 & 239165 & 12.38 & 2 & 0 \\
\hline 207 & 0 & 0 & 51300 & 10.85 & 2.28 & 0.83 & 117202 & 11.67 & 0 & 0 \\
\hline 208 & 0 & 0 & 47025 & 10.76 & 2.28 & 0.83 & 107429 & 11.58 & 0 & 0 \\
\hline 209 & 0 & 0 & 52250 & 10.86 & 2.28 & 0.83 & 119366 & 11.69 & 0 & 0 \\
\hline 210 & 0 & 0 & 54625 & 10.91 & 2.28 & 0.83 & 124693 & 11.73 & 1 & 0 \\
\hline 211 & 0 & 0 & 33250 & 10.41 & 2.28 & 0.82 & 75711 & 11.23 & 0 & 0 \\
\hline 212 & 0 & 0 & 57000 & 10.95 & 2.27 & 0.82 & 129326 & 11.77 & 0 & 0 \\
\hline 213 & 0 & 1 & 128683 & 11.77 & 2.27 & 0.82 & 291937 & 12.58 & 1 & 0 \\
\hline 214 & 0 & 0 & 33725 & 10.43 & 2.27 & 0.82 & 76498 & 11.25 & 0 & 0 \\
\hline 215 & 0 & 0 & 34960 & 10.46 & 2.27 & 0.82 & 79296 & 11.28 & 0 & 0 \\
\hline 216 & 1 & 1 & 109013 & 11.60 & 2.27 & 0.82 & 247187 & 12.42 & 0 & 0 \\
\hline 217 & 0 & 1 & 122005 & 11.71 & 2.27 & 0.82 & 276589 & 12.53 & 1 & 1 \\
\hline 218 & 0 & 0 & 51775 & 10.85 & 2.27 & 0.82 & 117338 & 11.67 & 0 & 0 \\
\hline 219 & 0 & 0 & 31350 & 10.35 & 2.27 & 0.82 & 71020 & 11.17 & 0 & 0 \\
\hline 220 & 0 & 0 & 38000 & 10.55 & 2.27 & 0.82 & 86083 & 11.36 & 1 & 0 \\
\hline 221 & 1 & 1 & 118750 & 11.68 & 2.26 & 0.82 & 268877 & 12.50 & 0 & 0 \\
\hline 222 & 1 & 1 & 114000 & 11.64 & 2.26 & 0.82 & 258064 & 12.46 & 1 & 0 \\
\hline 223 & 0 & 0 & 52250 & 10.86 & 2.26 & 0.82 & 118252 & 11.68 & 0 & 0 \\
\hline 224 & 0 & 0 & 46550 & 10.75 & 2.26 & 0.82 & 105308 & 11.56 & 0 & 0 \\
\hline 225 & 1 & 0 & 57414 & 10.96 & 2.26 & 0.82 & 129874 & 11.77 & 1 & 1 \\
\hline 226 & 0 & 0 & 28025 & 10.24 & 2.26 & 0.82 & 63388 & 11.06 & 0 & 0 \\
\hline 227 & 0 & 0 & 55543 & 10.92 & 2.26 & 0.82 & 125556 & 11.74 & 0 & 0 \\
\hline 228 & 0 & 0 & 38000 & 10.55 & 2.26 & 0.81 & 85804 & 11.36 & 0 & 0 \\
\hline 229 & 1 & 1 & 117800 & 11.68 & 2.26 & 0.81 & 265986 & 12.49 & 0 & 0 \\
\hline 230 & 0 & 0 & 37050 & 10.52 & 2.26 & 0.81 & 83652 & 11.33 & 0 & 0 \\
\hline 231 & 0 & 0 & 36100 & 10.49 & 2.26 & 0.81 & 81481 & 11.31 & 0 & 0 \\
\hline 232 & 0 & 0 & 46522 & 10.75 & 2.26 & 0.81 & 104971 & 11.56 & 0 & 1 \\
\hline 233 & 1 & 1 & 117942 & 11.68 & 2.26 & 0.81 & 266026 & 12.49 & 0 & 1 \\
\hline 234 & 0 & 0 & 34200 & 10.44 & 2.25 & 0.81 & 77033 & 11.25 & 1 & 0 \\
\hline 235 & 1 & 1 & 106400 & 11.57 & 2.25 & 0.81 & 239078 & 12.38 & 0 & 0 \\
\hline 236 & 1 & 1 & 113050 & 11.64 & 2.25 & 0.81 & 253904 & 12.44 & 0 & 0 \\
\hline 237 & 0 & 0 & 37050 & 10.52 & 2.24 & 0.81 & 83058 & 11.33 & 0 & 0 \\
\hline 238 & 1 & 1 & 113918 & 11.64 & 2.24 & 0.81 & 255302 & 12.45 & 0 & 1 \\
\hline
\end{tabular}




\begin{tabular}{|c|c|c|c|c|c|c|c|c|c|c|}
\hline 239 & 0 & 0 & 37050 & 10.52 & 2.24 & 0.81 & 82949 & 11.33 & 0 & 0 \\
\hline 240 & 0 & 0 & 31160 & 10.35 & 2.24 & 0.81 & 69726 & 11.15 & 0 & 0 \\
\hline 241 & 0 & 0 & 38000 & 10.55 & 2.24 & 0.80 & 84962 & 11.35 & 0 & 0 \\
\hline 242 & 0 & 0 & 23750 & 10.08 & 2.23 & 0.80 & 52969 & 10.88 & 0 & 0 \\
\hline 243 & 0 & 0 & 38000 & 10.55 & 2.23 & 0.80 & 84729 & 11.35 & 0 & 0 \\
\hline 244 & 0 & 0 & 36813 & 10.51 & 2.23 & 0.80 & 81959 & 11.31 & 0 & 0 \\
\hline 245 & 0 & 0 & 34913 & 10.46 & 2.22 & 0.80 & 77650 & 11.26 & 0 & 0 \\
\hline 246 & 0 & 0 & 37050 & 10.52 & 2.22 & 0.80 & 82390 & 11.32 & 0 & 0 \\
\hline 247 & 0 & 0 & 53030 & 10.88 & 2.22 & 0.80 & 117896 & 11.68 & 1 & 1 \\
\hline 248 & 1 & 1 & 122271 & 11.71 & 2.22 & 0.80 & 271629 & 12.51 & 0 & 0 \\
\hline 249 & 0 & 0 & 38000 & 10.55 & 2.22 & 0.80 & 84392 & 11.34 & 0 & 0 \\
\hline 250 & 1 & 1 & 114950 & 11.65 & 2.22 & 0.80 & 255254 & 12.45 & 0 & 0 \\
\hline 251 & 0 & 0 & 33250 & 10.41 & 2.22 & 0.80 & 73829 & 11.21 & 0 & 0 \\
\hline 252 & 0 & 0 & 31825 & 10.37 & 2.22 & 0.80 & 70589 & 11.16 & 0 & 0 \\
\hline 253 & 1 & 1 & 113050 & 11.64 & 2.22 & 0.80 & 250439 & 12.43 & 1 & 0 \\
\hline 254 & 0 & 0 & 55100 & 10.92 & 2.22 & 0.80 & 122060 & 11.71 & 1 & 0 \\
\hline 255 & 1 & 1 & 114000 & 11.64 & 2.22 & 0.80 & 252528 & 12.44 & 0 & 0 \\
\hline 256 & 1 & 1 & 104025 & 11.55 & 2.21 & 0.79 & 230119 & 12.35 & 0 & 0 \\
\hline 257 & 1 & 0 & 76000 & 11.24 & 2.21 & 0.79 & 168104 & 12.03 & 0 & 0 \\
\hline 258 & 0 & 0 & 52250 & 10.86 & 2.21 & 0.79 & 115487 & 11.66 & 0 & 0 \\
\hline 259 & 1 & 1 & 98563 & 11.50 & 2.21 & 0.79 & 217807 & 12.29 & 0 & 0 \\
\hline 260 & 0 & 0 & 38000 & 10.55 & 2.21 & 0.79 & 83969 & 11.34 & 0 & 0 \\
\hline 261 & 0 & 0 & 26600 & 10.19 & 2.21 & 0.79 & 58750 & 10.98 & 0 & 0 \\
\hline 262 & 1 & 1 & 104522 & 11.56 & 2.21 & 0.79 & 230617 & 12.35 & 3 & 1 \\
\hline 263 & 0 & 0 & 38475 & 10.56 & 2.21 & 0.79 & 84877 & 11.35 & 0 & 0 \\
\hline 264 & 1 & 1 & 109250 & 11.60 & 2.20 & 0.79 & 240650 & 12.39 & 0 & 0 \\
\hline 265 & 0 & 0 & 37050 & 10.52 & 2.20 & 0.79 & 81566 & 11.31 & 0 & 0 \\
\hline 266 & 1 & 1 & 98325 & 11.50 & 2.20 & 0.79 & 216447 & 12.29 & 0 & 0 \\
\hline 267 & 0 & 0 & 54042 & 10.90 & 2.20 & 0.79 & 118938 & 11.69 & 0 & 1 \\
\hline 268 & 0 & 0 & 54150 & 10.90 & 2.20 & 0.79 & 119009 & 11.69 & 1 & 0 \\
\hline 269 & 1 & 1 & 104310 & 11.56 & 2.20 & 0.79 & 229120 & 12.34 & 0 & 0 \\
\hline 270 & 0 & 1 & 128683 & 11.77 & 2.20 & 0.79 & 282625 & 12.55 & 0 & 0 \\
\hline 271 & 1 & 1 & 103075 & 11.54 & 2.20 & 0.79 & 226380 & 12.33 & 0 & 0 \\
\hline 272 & 1 & 1 & 107350 & 11.58 & 2.19 & 0.79 & 235439 & 12.37 & 2 & 0 \\
\hline 273 & 1 & 1 & 114475 & 11.65 & 2.19 & 0.78 & 250881 & 12.43 & 1 & 0 \\
\hline 274 & 0 & 0 & 33250 & 10.41 & 2.19 & 0.78 & 72800 & 11.20 & 0 & 0 \\
\hline 275 & 1 & 1 & 100700 & 11.52 & 2.19 & 0.78 & 220469 & 12.30 & 1 & 0 \\
\hline 276 & 0 & 0 & 52250 & 10.86 & 2.19 & 0.78 & 114225 & 11.65 & 0 & 0 \\
\hline 277 & 1 & 1 & 117800 & 11.68 & 2.19 & 0.78 & 257492 & 12.46 & 0 & 0 \\
\hline 278 & 1 & 1 & 109583 & 11.60 & 2.18 & 0.78 & 239424 & 12.39 & 0 & 0 \\
\hline 279 & 1 & 1 & 106400 & 11.57 & 2.18 & 0.78 & 231927 & 12.35 & 0 & 0 \\
\hline 280 & 0 & 0 & 38950 & 10.57 & 2.18 & 0.78 & 84846 & 11.35 & 0 & 0 \\
\hline 281 & 0 & 1 & 104500 & 11.56 & 2.18 & 0.78 & 227309 & 12.33 & 0 & 0 \\
\hline 282 & 0 & 1 & 105450 & 11.57 & 2.18 & 0.78 & 229375 & 12.34 & 0 & 0 \\
\hline 283 & 0 & 0 & 55100 & 10.92 & 2.17 & 0.78 & 119821 & 11.69 & 0 & 0 \\
\hline 284 & 1 & 0 & 32300 & 10.38 & 2.17 & 0.78 & 70207 & 11.16 & 4 & 0 \\
\hline 285 & 0 & 0 & 61750 & 11.03 & 2.17 & 0.78 & 134150 & 11.81 & 0 & 0 \\
\hline 286 & 0 & 0 & 38000 & 10.55 & 2.17 & 0.77 & 82448 & 11.32 & 0 & 0 \\
\hline
\end{tabular}




\begin{tabular}{|c|c|c|c|c|c|c|c|c|c|c|}
\hline 287 & 0 & 0 & 30400 & 10.32 & 2.17 & 0.77 & 65918 & 11.10 & 0 & 0 \\
\hline 288 & 0 & 0 & 38000 & 10.55 & 2.17 & 0.77 & 82355 & 11.32 & 0 & 0 \\
\hline 289 & 0 & 0 & 57000 & 10.95 & 2.17 & 0.77 & 123497 & 11.72 & 0 & 0 \\
\hline 290 & 0 & 0 & 54492 & 10.91 & 2.16 & 0.77 & 117931 & 11.68 & 0 & 1 \\
\hline 291 & 0 & 0 & 54863 & 10.91 & 2.16 & 0.77 & 118455 & 11.68 & 0 & 0 \\
\hline 292 & 1 & 1 & 117325 & 11.67 & 2.16 & 0.77 & 253191 & 12.44 & 1 & 0 \\
\hline 293 & 0 & 0 & 49400 & 10.81 & 2.16 & 0.77 & 106574 & 11.58 & 0 & 0 \\
\hline 294 & 0 & 0 & 35625 & 10.48 & 2.15 & 0.77 & 76727 & 11.25 & 0 & 0 \\
\hline 295 & 0 & 1 & 118750 & 11.68 & 2.15 & 0.77 & 255435 & 12.45 & 0 & 0 \\
\hline 296 & 1 & 1 & 114475 & 11.65 & 2.15 & 0.77 & 246218 & 12.41 & 1 & 0 \\
\hline 297 & 1 & 1 & 107086 & 11.58 & 2.15 & 0.76 & 229788 & 12.34 & 0 & 1 \\
\hline 298 & 0 & 0 & 42750 & 10.66 & 2.14 & 0.76 & 91632 & 11.43 & 0 & 0 \\
\hline 299 & 0 & 0 & 32300 & 10.38 & 2.14 & 0.76 & 69176 & 11.14 & 0 & 0 \\
\hline 300 & 0 & 0 & 31825 & 10.37 & 2.14 & 0.76 & 67970 & 11.13 & 0 & 0 \\
\hline 301 & 0 & 0 & 40850 & 10.62 & 2.13 & 0.76 & 87186 & 11.38 & 0 & 0 \\
\hline 302 & 1 & 1 & 104025 & 11.55 & 2.13 & 0.76 & 221975 & 12.31 & 0 & 0 \\
\hline 303 & 0 & 0 & 34675 & 10.45 & 2.13 & 0.76 & 73980 & 11.21 & 0 & 0 \\
\hline 304 & 0 & 0 & 28500 & 10.26 & 2.13 & 0.76 & 60805 & 11.02 & 0 & 0 \\
\hline 305 & 0 & 0 & 37050 & 10.52 & 2.13 & 0.76 & 79023 & 11.28 & 0 & 0 \\
\hline 306 & 1 & 1 & 118750 & 11.68 & 2.13 & 0.76 & 253256 & 12.44 & 0 & 0 \\
\hline 307 & 0 & 0 & 54863 & 10.91 & 2.13 & 0.76 & 116922 & 11.67 & 0 & 0 \\
\hline 308 & 1 & 1 & 101175 & 11.52 & 2.13 & 0.76 & 215496 & 12.28 & 1 & 0 \\
\hline 309 & 1 & 1 & 102600 & 11.54 & 2.13 & 0.76 & 218515 & 12.29 & 0 & 0 \\
\hline 310 & 0 & 0 & 39425 & 10.58 & 2.13 & 0.76 & 83952 & 11.34 & 0 & 0 \\
\hline 311 & 1 & 1 & 101798 & 11.53 & 2.13 & 0.76 & 216647 & 12.29 & 0 & 1 \\
\hline 312 & 1 & 1 & 114713 & 11.65 & 2.13 & 0.75 & 244063 & 12.41 & 0 & 0 \\
\hline 313 & 0 & 0 & 33250 & 10.41 & 2.13 & 0.75 & 70688 & 11.17 & 0 & 0 \\
\hline 314 & 1 & 1 & 102165 & 11.53 & 2.12 & 0.75 & 217097 & 12.29 & 1 & 1 \\
\hline 315 & 0 & 0 & 39900 & 10.59 & 2.12 & 0.75 & 84766 & 11.35 & 0 & 0 \\
\hline 316 & 1 & 1 & 116850 & 11.67 & 2.12 & 0.75 & 248060 & 12.42 & 0 & 0 \\
\hline 317 & 0 & 0 & 24225 & 10.10 & 2.12 & 0.75 & 51388 & 10.85 & 0 & 0 \\
\hline 318 & 1 & 0 & 38000 & 10.55 & 2.12 & 0.75 & 80518 & 11.30 & 0 & 0 \\
\hline 319 & 0 & 0 & 54042 & 10.90 & 2.12 & 0.75 & 114499 & 11.65 & 2 & 1 \\
\hline 320 & 0 & 1 & 114895 & 11.65 & 2.12 & 0.75 & 243371 & 12.40 & 0 & 0 \\
\hline 321 & 0 & 0 & 37050 & 10.52 & 2.12 & 0.75 & 78466 & 11.27 & 0 & 0 \\
\hline 322 & 0 & 0 & 34200 & 10.44 & 2.12 & 0.75 & 72422 & 11.19 & 0 & 0 \\
\hline 323 & 0 & 0 & 52725 & 10.87 & 2.12 & 0.75 & 111641 & 11.62 & 0 & 0 \\
\hline 324 & 0 & 0 & 50825 & 10.84 & 2.12 & 0.75 & 107526 & 11.59 & 0 & 0 \\
\hline 325 & 1 & 1 & 101413 & 11.53 & 2.12 & 0.75 & 214511 & 12.28 & 0 & 0 \\
\hline 326 & 1 & 1 & 105450 & 11.57 & 2.11 & 0.75 & 222829 & 12.31 & 1 & 0 \\
\hline 327 & 0 & 0 & 33725 & 10.43 & 2.11 & 0.75 & 71194 & 11.17 & 0 & 0 \\
\hline 328 & 0 & 0 & 55100 & 10.92 & 2.11 & 0.75 & 116116 & 11.66 & 1 & 0 \\
\hline 329 & 1 & 1 & 98810 & 11.50 & 2.11 & 0.75 & 208185 & 12.25 & 1 & 0 \\
\hline 330 & 1 & 1 & 103550 & 11.55 & 2.11 & 0.75 & 218158 & 12.29 & 4 & 0 \\
\hline 331 & 0 & 0 & 40375 & 10.61 & 2.11 & 0.75 & 85048 & 11.35 & 0 & 0 \\
\hline 332 & 0 & 0 & 34675 & 10.45 & 2.10 & 0.74 & 72964 & 11.20 & 0 & 0 \\
\hline 333 & 0 & 0 & 36100 & 10.49 & 2.10 & 0.74 & 75938 & 11.24 & 0 & 0 \\
\hline 334 & 0 & 0 & 36100 & 10.49 & 2.10 & 0.74 & 75930 & 11.24 & 0 & 0 \\
\hline
\end{tabular}




\begin{tabular}{|c|c|c|c|c|c|c|c|c|c|c|}
\hline 335 & 0 & 0 & 23750 & 10.08 & 2.10 & 0.74 & 49948 & 10.82 & 0 & 0 \\
\hline 336 & 1 & 1 & 112813 & 11.63 & 2.10 & 0.74 & 237218 & 12.38 & 0 & 0 \\
\hline 337 & 0 & 1 & 104500 & 11.56 & 2.10 & 0.74 & 219254 & 12.30 & 4 & 0 \\
\hline 338 & 0 & 1 & 118750 & 11.68 & 2.10 & 0.74 & 249068 & 12.43 & 1 & 0 \\
\hline 339 & 0 & 0 & 35625 & 10.48 & 2.10 & 0.74 & 74684 & 11.22 & 0 & 0 \\
\hline 340 & 0 & 0 & 58546 & 10.98 & 2.10 & 0.74 & 122654 & 11.72 & 1 & 1 \\
\hline 341 & 1 & 1 & 116125 & 11.66 & 2.09 & 0.74 & 243233 & 12.40 & 0 & 0 \\
\hline 342 & 0 & 0 & 58425 & 10.98 & 2.09 & 0.74 & 122355 & 11.71 & 0 & 0 \\
\hline 343 & 1 & 1 & 102125 & 11.53 & 2.09 & 0.74 & 213813 & 12.27 & 0 & 0 \\
\hline 344 & 0 & 0 & 38475 & 10.56 & 2.09 & 0.74 & 80363 & 11.29 & 1 & 0 \\
\hline 345 & 0 & 0 & 35625 & 10.48 & 2.09 & 0.74 & 74360 & 11.22 & 0 & 0 \\
\hline 346 & 1 & 1 & 119225 & 11.69 & 2.08 & 0.73 & 248271 & 12.42 & 3 & 0 \\
\hline 347 & 1 & 1 & 116375 & 11.66 & 2.08 & 0.73 & 241712 & 12.40 & 0 & 0 \\
\hline 348 & 1 & 0 & 42275 & 10.65 & 2.07 & 0.73 & 87714 & 11.38 & 0 & 0 \\
\hline 349 & 0 & 0 & 51300 & 10.85 & 2.07 & 0.73 & 106417 & 11.58 & 0 & 0 \\
\hline 350 & 1 & 1 & 104694 & 11.56 & 2.07 & 0.73 & 216955 & 12.29 & 0 & 1 \\
\hline 351 & 0 & 0 & 32775 & 10.40 & 2.07 & 0.73 & 67911 & 11.13 & 0 & 0 \\
\hline 352 & 0 & 0 & 31350 & 10.35 & 2.07 & 0.73 & 64956 & 11.08 & 0 & 0 \\
\hline 353 & 1 & 1 & 114713 & 11.65 & 2.07 & 0.73 & 237531 & 12.38 & 1 & 0 \\
\hline 354 & 0 & 0 & 53200 & 10.88 & 2.07 & 0.73 & 110142 & 11.61 & 0 & 0 \\
\hline 355 & 1 & 1 & 100357 & 11.52 & 2.07 & 0.73 & 207732 & 12.24 & 1 & 1 \\
\hline 356 & 0 & 0 & 32680 & 10.39 & 2.07 & 0.73 & 67630 & 11.12 & 0 & 0 \\
\hline 357 & 0 & 0 & 32775 & 10.40 & 2.07 & 0.73 & 67815 & 11.12 & 0 & 0 \\
\hline 358 & 0 & 0 & 47500 & 10.77 & 2.07 & 0.73 & 98246 & 11.50 & 0 & 0 \\
\hline 359 & 0 & 0 & 32775 & 10.40 & 2.07 & 0.73 & 67709 & 11.12 & 1 & 0 \\
\hline 360 & 0 & 0 & 52922 & 10.88 & 2.06 & 0.72 & 109226 & 11.60 & 0 & 0 \\
\hline 361 & 0 & 0 & 28500 & 10.26 & 2.06 & 0.72 & 58796 & 10.98 & 0 & 0 \\
\hline 362 & 0 & 0 & 36575 & 10.51 & 2.06 & 0.72 & 75449 & 11.23 & 0 & 0 \\
\hline 363 & 0 & 0 & 50350 & 10.83 & 2.06 & 0.72 & 103793 & 11.55 & 0 & 0 \\
\hline 364 & 0 & 0 & 60325 & 11.01 & 2.06 & 0.72 & 124319 & 11.73 & 0 & 0 \\
\hline 365 & 0 & 0 & 47500 & 10.77 & 2.06 & 0.72 & 97881 & 11.49 & 0 & 0 \\
\hline 366 & 1 & 1 & 114000 & 11.64 & 2.06 & 0.72 & 234663 & 12.37 & 1 & 0 \\
\hline 367 & 0 & 0 & 39425 & 10.58 & 2.06 & 0.72 & 81141 & 11.30 & 0 & 0 \\
\hline 368 & 0 & 0 & 31350 & 10.35 & 2.06 & 0.72 & 64501 & 11.07 & 0 & 0 \\
\hline 369 & 0 & 0 & 26600 & 10.19 & 2.06 & 0.72 & 54673 & 10.91 & 1 & 0 \\
\hline 370 & 0 & 0 & 53200 & 10.88 & 2.06 & 0.72 & 109332 & 11.60 & 0 & 0 \\
\hline 371 & 0 & 0 & 38000 & 10.55 & 2.05 & 0.72 & 78087 & 11.27 & 1 & 0 \\
\hline 372 & 0 & 1 & 118750 & 11.68 & 2.05 & 0.72 & 243920 & 12.40 & 1 & 0 \\
\hline 373 & 0 & 0 & 54150 & 10.90 & 2.05 & 0.72 & 111165 & 11.62 & 0 & 0 \\
\hline 374 & 1 & 1 & 104500 & 11.56 & 2.05 & 0.72 & 214516 & 12.28 & 0 & 0 \\
\hline 375 & 0 & 0 & 23275 & 10.06 & 2.05 & 0.72 & 47776 & 10.77 & 0 & 0 \\
\hline 376 & 0 & 0 & 76000 & 11.24 & 2.05 & 0.72 & 155972 & 11.96 & 0 & 0 \\
\hline 377 & 1 & 1 & 117103 & 11.67 & 2.05 & 0.72 & 240208 & 12.39 & 0 & 1 \\
\hline 378 & 0 & 0 & 28975 & 10.27 & 2.05 & 0.72 & 59401 & 10.99 & 0 & 0 \\
\hline 379 & 0 & 0 & 38950 & 10.57 & 2.05 & 0.72 & 79836 & 11.29 & 0 & 0 \\
\hline 380 & 0 & 0 & 29450 & 10.29 & 2.05 & 0.72 & 60263 & 11.01 & 0 & 0 \\
\hline 381 & 0 & 0 & 23275 & 10.06 & 2.04 & 0.71 & 47563 & 10.77 & 0 & 0 \\
\hline 382 & 0 & 0 & 52250 & 10.86 & 2.04 & 0.71 & 106760 & 11.58 & 0 & 0 \\
\hline
\end{tabular}




\begin{tabular}{|c|c|c|c|c|c|c|c|c|c|c|}
\hline 383 & 0 & 0 & 57950 & 10.97 & 2.04 & 0.71 & 118380 & 11.68 & 1 & 0 \\
\hline 384 & 1 & 1 & 117800 & 11.68 & 2.04 & 0.71 & 240447 & 12.39 & 0 & 0 \\
\hline 385 & 0 & 0 & 38475 & 10.56 & 2.04 & 0.71 & 78518 & 11.27 & 0 & 0 \\
\hline 386 & 0 & 0 & 56050 & 10.93 & 2.04 & 0.71 & 114384 & 11.65 & 0 & 0 \\
\hline 387 & 0 & 0 & 49400 & 10.81 & 2.04 & 0.71 & 100754 & 11.52 & 1 & 0 \\
\hline 388 & 1 & 1 & 114000 & 11.64 & 2.04 & 0.71 & 232506 & 12.36 & 0 & 0 \\
\hline 389 & 0 & 0 & 40109 & 10.60 & 2.04 & 0.71 & 81706 & 11.31 & 0 & 0 \\
\hline 390 & 0 & 0 & 35625 & 10.48 & 2.04 & 0.71 & 72563 & 11.19 & 0 & 0 \\
\hline 391 & 1 & 1 & 113015 & 11.64 & 2.04 & 0.71 & 230056 & 12.35 & 1 & 1 \\
\hline 392 & 0 & 0 & 52250 & 10.86 & 2.03 & 0.71 & 106319 & 11.57 & 0 & 0 \\
\hline 393 & 1 & 1 & 119225 & 11.69 & 2.03 & 0.71 & 242591 & 12.40 & 0 & 0 \\
\hline 394 & 1 & 1 & 123022 & 11.72 & 2.03 & 0.71 & 250286 & 12.43 & 0 & 0 \\
\hline 395 & 0 & 0 & 33250 & 10.41 & 2.03 & 0.71 & 67614 & 11.12 & 0 & 0 \\
\hline 396 & 0 & 0 & 27550 & 10.22 & 2.03 & 0.71 & 56012 & 10.93 & 0 & 0 \\
\hline 397 & 0 & 0 & 53200 & 10.88 & 2.03 & 0.71 & 108107 & 11.59 & 0 & 0 \\
\hline 398 & 1 & 1 & 116850 & 11.67 & 2.03 & 0.71 & 237368 & 12.38 & 1 & 0 \\
\hline 399 & 0 & 1 & 106400 & 11.57 & 2.03 & 0.71 & 216137 & 12.28 & 0 & 0 \\
\hline 400 & 1 & 1 & 117800 & 11.68 & 2.03 & 0.71 & 239066 & 12.38 & 0 & 0 \\
\hline 401 & 0 & 0 & 36100 & 10.49 & 2.03 & 0.71 & 73255 & 11.20 & 1 & 0 \\
\hline 402 & 0 & 0 & 53010 & 10.88 & 2.03 & 0.71 & 107563 & 11.59 & 0 & 0 \\
\hline 403 & 1 & 1 & 98895 & 11.50 & 2.03 & 0.71 & 200582 & 12.21 & 0 & 0 \\
\hline 404 & 1 & 1 & 113050 & 11.64 & 2.03 & 0.71 & 229233 & 12.34 & 1 & 0 \\
\hline 405 & 1 & 1 & 99750 & 11.51 & 2.03 & 0.71 & 202220 & 12.22 & 0 & 0 \\
\hline 406 & 1 & 1 & 116185 & 11.66 & 2.03 & 0.71 & 235492 & 12.37 & 0 & 0 \\
\hline 407 & 0 & 0 & 29916 & 10.31 & 2.03 & 0.71 & 60609 & 11.01 & 2 & 0 \\
\hline 408 & 0 & 0 & 50793 & 10.84 & 2.03 & 0.71 & 102874 & 11.54 & 0 & 0 \\
\hline 409 & 0 & 0 & 35663 & 10.48 & 2.02 & 0.71 & 72193 & 11.19 & 0 & 0 \\
\hline 410 & 0 & 0 & 32063 & 10.38 & 2.02 & 0.70 & 64888 & 11.08 & 0 & 0 \\
\hline 411 & 0 & 0 & 46313 & 10.74 & 2.02 & 0.70 & 93715 & 11.45 & 0 & 0 \\
\hline 412 & 1 & 1 & 104500 & 11.56 & 2.02 & 0.70 & 211125 & 12.26 & 0 & 0 \\
\hline 413 & 0 & 0 & 33250 & 10.41 & 2.02 & 0.70 & 67081 & 11.11 & 0 & 0 \\
\hline 414 & 0 & 0 & 28025 & 10.24 & 2.02 & 0.70 & 56527 & 10.94 & 0 & 0 \\
\hline 415 & 0 & 0 & 33250 & 10.41 & 2.01 & 0.70 & 66950 & 11.11 & 0 & 0 \\
\hline 416 & 0 & 0 & 33725 & 10.43 & 2.01 & 0.70 & 67848 & 11.13 & 2 & 0 \\
\hline 417 & 0 & 0 & 43700 & 10.69 & 2.01 & 0.70 & 87872 & 11.38 & 0 & 0 \\
\hline 418 & 0 & 0 & 38000 & 10.55 & 2.01 & 0.70 & 76288 & 11.24 & 0 & 0 \\
\hline 419 & 1 & 1 & 109250 & 11.60 & 2.01 & 0.70 & 219299 & 12.30 & 1 & 0 \\
\hline 420 & 0 & 0 & 42750 & 10.66 & 2.01 & 0.70 & 85810 & 11.36 & 1 & 0 \\
\hline 421 & 0 & 0 & 45600 & 10.73 & 2.01 & 0.70 & 91501 & 11.42 & 0 & 0 \\
\hline 422 & 0 & 0 & 47500 & 10.77 & 2.01 & 0.70 & 95301 & 11.46 & 0 & 0 \\
\hline 423 & 0 & 0 & 38000 & 10.55 & 2.01 & 0.70 & 76231 & 11.24 & 0 & 0 \\
\hline 424 & 0 & 0 & 31350 & 10.35 & 2.01 & 0.70 & 62884 & 11.05 & 0 & 0 \\
\hline 425 & 0 & 1 & 112100 & 11.63 & 2.01 & 0.70 & 224775 & 12.32 & 0 & 0 \\
\hline 426 & 0 & 0 & 50588 & 10.83 & 2.01 & 0.70 & 101430 & 11.53 & 0 & 0 \\
\hline 427 & 1 & 1 & 114000 & 11.64 & 2.00 & 0.70 & 228551 & 12.34 & 0 & 0 \\
\hline 428 & 1 & 1 & 113516 & 11.64 & 2.00 & 0.69 & 227327 & 12.33 & 0 & 1 \\
\hline 429 & 0 & 0 & 23275 & 10.06 & 2.00 & 0.69 & 46606 & 10.75 & 0 & 0 \\
\hline 430 & 0 & 1 & 112575 & 11.63 & 2.00 & 0.69 & 225243 & 12.32 & 0 & 0 \\
\hline
\end{tabular}




\begin{tabular}{|c|c|c|c|c|c|c|c|c|c|c|}
\hline 431 & 1 & 1 & 103550 & 11.55 & 2.00 & 0.69 & 207116 & 12.24 & 0 & 0 \\
\hline 432 & 0 & 0 & 38701 & 10.56 & 2.00 & 0.69 & 77353 & 11.26 & 0 & 1 \\
\hline 433 & 1 & 1 & 118275 & 11.68 & 2.00 & 0.69 & 236356 & 12.37 & 1 & 0 \\
\hline 434 & 1 & 1 & 115259 & 11.65 & 2.00 & 0.69 & 230311 & 12.35 & 4 & 1 \\
\hline 435 & 0 & 0 & 50175 & 10.82 & 2.00 & 0.69 & 100257 & 11.52 & 2 & 1 \\
\hline 436 & 1 & 1 & 110165 & 11.61 & 2.00 & 0.69 & 220099 & 12.30 & 0 & 1 \\
\hline 437 & 1 & 1 & 108356 & 11.59 & 2.00 & 0.69 & 216479 & 12.29 & 1 & 1 \\
\hline 438 & 0 & 1 & 104500 & 11.56 & 2.00 & 0.69 & 208754 & 12.25 & 0 & 0 \\
\hline 439 & 1 & 1 & 102125 & 11.53 & 2.00 & 0.69 & 204007 & 12.23 & 0 & 0 \\
\hline 440 & 0 & 0 & 38000 & 10.55 & 2.00 & 0.69 & 75893 & 11.24 & 0 & 0 \\
\hline 441 & 1 & 1 & 114713 & 11.65 & 2.00 & 0.69 & 229068 & 12.34 & 2 & 0 \\
\hline 442 & 1 & 1 & 99275 & 11.51 & 2.00 & 0.69 & 198221 & 12.20 & 0 & 0 \\
\hline 443 & 1 & 1 & 117325 & 11.67 & 2.00 & 0.69 & 234240 & 12.36 & 0 & 0 \\
\hline 444 & 0 & 1 & 105450 & 11.57 & 2.00 & 0.69 & 210472 & 12.26 & 0 & 0 \\
\hline 445 & 0 & 0 & 27550 & 10.22 & 2.00 & 0.69 & 54972 & 10.91 & 0 & 0 \\
\hline 446 & 0 & 0 & 54625 & 10.91 & 2.00 & 0.69 & 108986 & 11.60 & 1 & 0 \\
\hline 447 & 0 & 0 & 22563 & 10.02 & 1.99 & 0.69 & 45002 & 10.71 & 1 & 0 \\
\hline 448 & 1 & 1 & 103550 & 11.55 & 1.99 & 0.69 & 206496 & 12.24 & 0 & 0 \\
\hline 449 & 1 & 1 & 118275 & 11.68 & 1.99 & 0.69 & 235704 & 12.37 & 0 & 0 \\
\hline 450 & 1 & 1 & 116375 & 11.66 & 1.99 & 0.69 & 231891 & 12.35 & 0 & 0 \\
\hline 451 & 1 & 1 & 115900 & 11.66 & 1.99 & 0.69 & 230884 & 12.35 & 0 & 0 \\
\hline 452 & 0 & 0 & 36100 & 10.49 & 1.99 & 0.69 & 71912 & 11.18 & 0 & 0 \\
\hline 453 & 1 & 1 & 112233 & 11.63 & 1.99 & 0.69 & 223517 & 12.32 & 0 & 0 \\
\hline 454 & 1 & 1 & 100700 & 11.52 & 1.99 & 0.69 & 200510 & 12.21 & 0 & 0 \\
\hline 455 & 0 & 1 & 104975 & 11.56 & 1.99 & 0.69 & 208904 & 12.25 & 0 & 0 \\
\hline 456 & 1 & 1 & 116613 & 11.67 & 1.99 & 0.69 & 231784 & 12.35 & 0 & 0 \\
\hline 457 & 0 & 0 & 26600 & 10.19 & 1.99 & 0.69 & 52837 & 10.87 & 0 & 0 \\
\hline 458 & 0 & 0 & 25175 & 10.13 & 1.99 & 0.69 & 49978 & 10.82 & 0 & 0 \\
\hline 459 & 0 & 0 & 23275 & 10.06 & 1.98 & 0.69 & 46193 & 10.74 & 0 & 0 \\
\hline 460 & 1 & 1 & 104500 & 11.56 & 1.98 & 0.68 & 207211 & 12.24 & 0 & 0 \\
\hline 461 & 0 & 0 & 42750 & 10.66 & 1.98 & 0.68 & 84672 & 11.35 & 0 & 0 \\
\hline 462 & 0 & 0 & 33250 & 10.41 & 1.98 & 0.68 & 65813 & 11.09 & 0 & 0 \\
\hline 463 & 0 & 0 & 32300 & 10.38 & 1.98 & 0.68 & 63922 & 11.07 & 0 & 0 \\
\hline 464 & 0 & 0 & 33250 & 10.41 & 1.98 & 0.68 & 65783 & 11.09 & 0 & 0 \\
\hline 465 & 0 & 0 & 57000 & 10.95 & 1.98 & 0.68 & 112728 & 11.63 & 0 & 0 \\
\hline 466 & 1 & 1 & 102600 & 11.54 & 1.98 & 0.68 & 202869 & 12.22 & 0 & 0 \\
\hline 467 & 0 & 0 & 40138 & 10.60 & 1.98 & 0.68 & 79321 & 11.28 & 0 & 0 \\
\hline 468 & 0 & 0 & 33820 & 10.43 & 1.98 & 0.68 & 66809 & 11.11 & 1 & 0 \\
\hline 469 & 0 & 0 & 31730 & 10.37 & 1.97 & 0.68 & 62644 & 11.05 & 0 & 0 \\
\hline 470 & 1 & 1 & 117800 & 11.68 & 1.97 & 0.68 & 232570 & 12.36 & 2 & 0 \\
\hline 471 & 1 & 1 & 103550 & 11.55 & 1.97 & 0.68 & 204350 & 12.23 & 1 & 0 \\
\hline 472 & 1 & 1 & 114950 & 11.65 & 1.97 & 0.68 & 226710 & 12.33 & 1 & 0 \\
\hline 473 & 0 & 0 & 38000 & 10.55 & 1.97 & 0.68 & 74912 & 11.22 & 0 & 0 \\
\hline 474 & 0 & 1 & 105925 & 11.57 & 1.97 & 0.68 & 208767 & 12.25 & 0 & 0 \\
\hline 475 & 1 & 1 & 98325 & 11.50 & 1.97 & 0.68 & 193746 & 12.17 & 0 & 0 \\
\hline 476 & 0 & 0 & 30400 & 10.32 & 1.97 & 0.68 & 59890 & 11.00 & 0 & 0 \\
\hline 477 & 1 & 1 & 103313 & 11.55 & 1.97 & 0.68 & 203424 & 12.22 & 0 & 0 \\
\hline 478 & 0 & 0 & 37050 & 10.52 & 1.97 & 0.68 & 72940 & 11.20 & 0 & 0 \\
\hline
\end{tabular}




\begin{tabular}{|c|c|c|c|c|c|c|c|c|c|c|}
\hline 479 & 0 & 0 & 27313 & 10.22 & 1.97 & 0.68 & 53760 & 10.89 & 1 & 0 \\
\hline 480 & 1 & 1 & 116585 & 11.67 & 1.97 & 0.68 & 229444 & 12.34 & 0 & 1 \\
\hline 481 & 1 & 1 & 121600 & 11.71 & 1.96 & 0.67 & 238688 & 12.38 & 2 & 0 \\
\hline 482 & 0 & 1 & 104975 & 11.56 & 1.96 & 0.67 & 206019 & 12.24 & 0 & 0 \\
\hline 483 & 0 & 0 & 36100 & 10.49 & 1.96 & 0.67 & 70809 & 11.17 & 1 & 0 \\
\hline 484 & 0 & 0 & 30400 & 10.32 & 1.96 & 0.67 & 59556 & 10.99 & 0 & 0 \\
\hline 485 & 0 & 0 & 33250 & 10.41 & 1.96 & 0.67 & 65109 & 11.08 & 0 & 0 \\
\hline 486 & 1 & 1 & 117800 & 11.68 & 1.96 & 0.67 & 230486 & 12.35 & 0 & 0 \\
\hline 487 & 1 & 1 & 104025 & 11.55 & 1.96 & 0.67 & 203397 & 12.22 & 1 & 0 \\
\hline 488 & 0 & 0 & 38000 & 10.55 & 1.96 & 0.67 & 74295 & 11.22 & 0 & 0 \\
\hline 489 & 0 & 0 & 38000 & 10.55 & 1.95 & 0.67 & 74282 & 11.22 & 1 & 0 \\
\hline 490 & 1 & 1 & 104500 & 11.56 & 1.95 & 0.67 & 204234 & 12.23 & 0 & 0 \\
\hline 491 & 0 & 0 & 40850 & 10.62 & 1.95 & 0.67 & 79818 & 11.29 & 0 & 0 \\
\hline 492 & 0 & 0 & 57000 & 10.95 & 1.95 & 0.67 & 111235 & 11.62 & 0 & 0 \\
\hline 493 & 1 & 1 & 112233 & 11.63 & 1.95 & 0.67 & 218916 & 12.30 & 1 & 0 \\
\hline 494 & 0 & 0 & 23750 & 10.08 & 1.95 & 0.67 & 46234 & 10.74 & 0 & 0 \\
\hline 495 & 0 & 0 & 49163 & 10.80 & 1.95 & 0.67 & 95696 & 11.47 & 1 & 0 \\
\hline 496 & 1 & 1 & 102600 & 11.54 & 1.94 & 0.66 & 199047 & 12.20 & 0 & 0 \\
\hline 497 & 1 & & 95000 & 11.46 & 1.94 & 0.66 & 184291 & 12.12 & 0 & 0 \\
\hline 498 & 0 & 0 & 30400 & 10.32 & 1.94 & 0.66 & 58946 & 10.98 & 0 & 0 \\
\hline 499 & 1 & 1 & 111150 & 11.62 & 1.94 & 0.66 & 215484 & 12.28 & 1 & 0 \\
\hline 500 & 0 & 0 & 35150 & 10.47 & 1.94 & 0.66 & 68106 & 11.13 & 1 & 0 \\
\hline 501 & 1 & 1 & 104500 & 11.56 & 1.93 & 0.66 & 201931 & 12.22 & 0 & 0 \\
\hline 502 & 0 & 1 & 114000 & 11.64 & 1.93 & 0.66 & 220049 & 12.30 & 0 & 0 \\
\hline 503 & 0 & 0 & 71250 & 11.17 & 1.92 & 0.65 & 136767 & 11.83 & 0 & 0 \\
\hline 504 & 1 & 1 & 104975 & 11.56 & 1.92 & 0.65 & 201469 & 12.21 & 0 & 0 \\
\hline 505 & 0 & 0 & 28025 & 10.24 & 1.92 & 0.65 & 53720 & 10.89 & 0 & 0 \\
\hline 506 & 0 & 0 & 53965 & 10.90 & 1.92 & 0.65 & 103369 & 11.55 & 0 & 1 \\
\hline 507 & 1 & 1 & 104975 & 11.56 & 1.91 & 0.65 & 201012 & 12.21 & 0 & 0 \\
\hline 508 & 1 & 1 & 103550 & 11.55 & 1.91 & 0.65 & 198263 & 12.20 & 0 & 0 \\
\hline 509 & 1 & 0 & 38000 & 10.55 & 1.91 & 0.65 & 72654 & 11.19 & 0 & 0 \\
\hline 510 & 0 & 0 & 36575 & 10.51 & 1.91 & 0.65 & 69912 & 11.15 & 0 & 0 \\
\hline 511 & 0 & 0 & 35625 & 10.48 & 1.91 & 0.65 & 67992 & 11.13 & 0 & 0 \\
\hline 512 & 0 & 0 & 52250 & 10.86 & 1.91 & 0.65 & 99649 & 11.51 & 0 & 0 \\
\hline 513 & 0 & 0 & 52250 & 10.86 & 1.91 & 0.65 & 99649 & 11.51 & 0 & 0 \\
\hline 514 & 0 & 0 & 34675 & 10.45 & 1.91 & 0.64 & 66089 & 11.10 & 0 & 0 \\
\hline 515 & 1 & 1 & 112110 & 11.63 & 1.90 & 0.64 & 213210 & 12.27 & 0 & 1 \\
\hline 516 & 1 & 1 & 104500 & 11.56 & 1.90 & 0.64 & 198383 & 12.20 & 3 & 0 \\
\hline 517 & 0 & 0 & 28975 & 10.27 & 1.90 & 0.64 & 54910 & 10.91 & 0 & 0 \\
\hline 518 & 0 & 1 & 122271 & 11.71 & 1.89 & 0.64 & 231434 & 12.35 & 0 & 0 \\
\hline 519 & 0 & 1 & 106163 & 11.57 & 1.89 & 0.64 & 200908 & 12.21 & 1 & 0 \\
\hline 520 & 1 & 1 & 102125 & 11.53 & 1.89 & 0.64 & 193264 & 12.17 & 0 & 0 \\
\hline 521 & 1 & 0 & 38000 & 10.55 & 1.89 & 0.64 & 71861 & 11.18 & 0 & 0 \\
\hline 522 & 1 & 1 & 117325 & 11.67 & 1.89 & 0.64 & 221763 & 12.31 & 4 & 0 \\
\hline 523 & 0 & 0 & 47975 & 10.78 & 1.89 & 0.64 & 90624 & 11.41 & 0 & 0 \\
\hline 524 & 0 & 0 & 55100 & 10.92 & 1.88 & 0.63 & 103703 & 11.55 & 1 & 0 \\
\hline 525 & 1 & 1 & 109630 & 11.60 & 1.88 & 0.63 & 206122 & 12.24 & 1 & 0 \\
\hline 526 & 1 & 1 & 104025 & 11.55 & 1.88 & 0.63 & 195495 & 12.18 & 0 & 0 \\
\hline
\end{tabular}




\begin{tabular}{|c|c|c|c|c|c|c|c|c|c|c|}
\hline 527 & 0 & 0 & 29925 & 10.31 & 1.87 & 0.63 & 56104 & 10.93 & 0 & 0 \\
\hline 528 & 0 & 0 & 35150 & 10.47 & 1.87 & 0.63 & 65837 & 11.09 & 0 & 0 \\
\hline 529 & 0 & 1 & 116850 & 11.67 & 1.87 & 0.63 & 218820 & 12.30 & 0 & 0 \\
\hline 530 & 1 & 1 & 104500 & 11.56 & 1.87 & 0.63 & 195546 & 12.18 & 0 & 0 \\
\hline 531 & 0 & 1 & 113050 & 11.64 & 1.87 & 0.63 & 211529 & 12.26 & 0 & 0 \\
\hline 532 & 0 & 0 & 28500 & 10.26 & 1.87 & 0.62 & 53228 & 10.88 & 0 & 0 \\
\hline 533 & 1 & 1 & 111206 & 11.62 & 1.86 & 0.62 & 207203 & 12.24 & 0 & 1 \\
\hline 534 & 1 & 0 & 94038 & 11.45 & 1.86 & 0.62 & 175201 & 12.07 & 0 & 1 \\
\hline 535 & 0 & 0 & 38000 & 10.55 & 1.86 & 0.62 & 70694 & 11.17 & 1 & 0 \\
\hline 536 & 1 & 1 & 118275 & 11.68 & 1.86 & 0.62 & 219963 & 12.30 & 0 & 0 \\
\hline 537 & 0 & 0 & 63413 & 11.06 & 1.86 & 0.62 & 117851 & 11.68 & 0 & 0 \\
\hline 538 & 1 & 1 & 114475 & 11.65 & 1.86 & 0.62 & 212633 & 12.27 & 0 & 0 \\
\hline 539 & 0 & 0 & 38475 & 10.56 & 1.86 & 0.62 & 71449 & 11.18 & 0 & 0 \\
\hline 540 & 0 & 0 & 32300 & 10.38 & 1.86 & 0.62 & 59962 & 11.00 & 0 & 0 \\
\hline 541 & 0 & 0 & 23750 & 10.08 & 1.85 & 0.62 & 43980 & 10.69 & 1 & 0 \\
\hline 542 & 0 & 0 & 52250 & 10.86 & 1.85 & 0.62 & 96716 & 11.48 & 1 & 0 \\
\hline 543 & 0 & 0 & 32918 & 10.40 & 1.85 & 0.62 & 60895 & 11.02 & 0 & 0 \\
\hline 544 & 0 & 0 & 31825 & 10.37 & 1.85 & 0.61 & 58858 & 10.98 & 1 & 0 \\
\hline 545 & 1 & 1 & 104500 & 11.56 & 1.85 & 0.61 & 193101 & 12.17 & 0 & 0 \\
\hline 546 & 0 & 0 & 33250 & 10.41 & 1.84 & 0.61 & 61303 & 11.02 & 0 & 0 \\
\hline 547 & 0 & 0 & 52725 & 10.87 & 1.84 & 0.61 & 97125 & 11.48 & 1 & 0 \\
\hline 548 & 0 & 0 & 52963 & 10.88 & 1.84 & 0.61 & 97359 & 11.49 & 0 & 0 \\
\hline 549 & 0 & 0 & 38000 & 10.55 & 1.84 & 0.61 & 69848 & 11.15 & 0 & 0 \\
\hline 550 & 0 & 0 & 33963 & 10.43 & 1.84 & 0.61 & 62333 & 11.04 & 0 & 0 \\
\hline 551 & 0 & 0 & 36575 & 10.51 & 1.83 & 0.61 & 67052 & 11.11 & 0 & 0 \\
\hline 552 & 0 & 0 & 63465 & 11.06 & 1.83 & 0.61 & 116286 & 11.66 & 0 & 0 \\
\hline 553 & 0 & 0 & 37050 & 10.52 & 1.83 & 0.60 & 67745 & 11.12 & 0 & 0 \\
\hline 554 & 1 & 1 & 104975 & 11.56 & 1.83 & 0.60 & 191801 & 12.16 & 1 & 0 \\
\hline 555 & 0 & 0 & 33250 & 10.41 & 1.83 & 0.60 & 60711 & 11.01 & 0 & 0 \\
\hline 556 & 1 & 1 & 115425 & 11.66 & 1.82 & 0.60 & 210578 & 12.26 & 0 & 0 \\
\hline 557 & 0 & 0 & 59850 & 11.00 & 1.82 & 0.60 & 109188 & 11.60 & 0 & 0 \\
\hline 558 & 0 & 0 & 38000 & 10.55 & 1.82 & 0.60 & 69322 & 11.15 & 0 & 0 \\
\hline 559 & 1 & 1 & 118750 & 11.68 & 1.82 & 0.60 & 216552 & 12.29 & 1 & 0 \\
\hline 560 & 0 & 0 & 50350 & 10.83 & 1.82 & 0.60 & 91674 & 11.43 & 0 & 0 \\
\hline 561 & 0 & 0 & 32300 & 10.38 & 1.82 & 0.60 & 58788 & 10.98 & 0 & 0 \\
\hline 562 & 0 & 0 & 38000 & 10.55 & 1.82 & 0.60 & 69151 & 11.14 & 0 & 0 \\
\hline 563 & 0 & 0 & 27075 & 10.21 & 1.82 & 0.60 & 49200 & 10.80 & 0 & 0 \\
\hline 564 & 0 & 0 & 34675 & 10.45 & 1.82 & 0.60 & 62951 & 11.05 & 0 & 0 \\
\hline 565 & 0 & 0 & 52250 & 10.86 & 1.82 & 0.60 & 94835 & 11.46 & 0 & 0 \\
\hline 566 & 0 & 0 & 38000 & 10.55 & 1.81 & 0.60 & 68939 & 11.14 & 0 & 0 \\
\hline 567 & 0 & 0 & 56050 & 10.93 & 1.81 & 0.60 & 101620 & 11.53 & 0 & 0 \\
\hline 568 & 1 & 1 & 113415 & 11.64 & 1.81 & 0.59 & 205373 & 12.23 & 0 & 1 \\
\hline 569 & 0 & 0 & 36100 & 10.49 & 1.81 & 0.59 & 65366 & 11.09 & 2 & 0 \\
\hline 570 & 0 & 0 & 55100 & 10.92 & 1.81 & 0.59 & 99753 & 11.51 & 0 & 0 \\
\hline 571 & 1 & 1 & 114950 & 11.65 & 1.81 & 0.59 & 207946 & 12.25 & 0 & 0 \\
\hline 572 & 0 & 0 & 80750 & 11.30 & 1.81 & 0.59 & 145909 & 11.89 & 0 & 0 \\
\hline 573 & 0 & 0 & 22278 & 10.01 & 1.81 & 0.59 & 40222 & 10.60 & 0 & 0 \\
\hline 574 & 0 & 0 & 38000 & 10.55 & 1.80 & 0.59 & 68522 & 11.13 & 0 & 0 \\
\hline
\end{tabular}




\begin{tabular}{|c|c|c|c|c|c|c|c|c|c|c|}
\hline 575 & 1 & 1 & 106400 & 11.57 & 1.80 & 0.59 & 191061 & 12.16 & 0 & 0 \\
\hline 576 & 0 & 0 & 36100 & 10.49 & 1.79 & 0.58 & 64732 & 11.08 & 0 & 0 \\
\hline 577 & 1 & 1 & 114950 & 11.65 & 1.79 & 0.58 & 206002 & 12.24 & 0 & 0 \\
\hline 578 & 0 & 0 & 27550 & 10.22 & 1.79 & 0.58 & 49346 & 10.81 & 0 & 0 \\
\hline 579 & 0 & 0 & 52250 & 10.86 & 1.79 & 0.58 & 93521 & 11.45 & 0 & 0 \\
\hline 580 & 1 & 1 & 114713 & 11.65 & 1.79 & 0.58 & 205191 & 12.23 & 0 & 0 \\
\hline 581 & 0 & 0 & 33060 & 10.41 & 1.79 & 0.58 & 59029 & 10.99 & 0 & 0 \\
\hline 582 & 0 & 0 & 46550 & 10.75 & 1.78 & 0.58 & 83035 & 11.33 & 0 & 0 \\
\hline 583 & 1 & 0 & 53200 & 10.88 & 1.78 & 0.58 & 94884 & 11.46 & 0 & 0 \\
\hline 584 & 0 & 1 & 102600 & 11.54 & 1.78 & 0.58 & 182970 & 12.12 & 0 & 0 \\
\hline 585 & 1 & 1 & 111150 & 11.62 & 1.78 & 0.58 & 197877 & 12.20 & 2 & 0 \\
\hline 586 & 0 & 0 & 36100 & 10.49 & 1.78 & 0.58 & 64258 & 11.07 & 0 & 0 \\
\hline 587 & 1 & 0 & 35150 & 10.47 & 1.78 & 0.58 & 62563 & 11.04 & 0 & 0 \\
\hline 588 & 0 & 0 & 37050 & 10.52 & 1.78 & 0.58 & 65919 & 11.10 & 0 & 0 \\
\hline 589 & 0 & 0 & 52241 & 10.86 & 1.78 & 0.58 & 92908 & 11.44 & 0 & 1 \\
\hline 590 & 0 & 0 & 57000 & 10.95 & 1.78 & 0.57 & 101269 & 11.53 & 0 & 0 \\
\hline 591 & 0 & 0 & 51300 & 10.85 & 1.77 & 0.57 & 90929 & 11.42 & 1 & 0 \\
\hline 592 & 1 & 1 & 110302 & 11.61 & 1.77 & 0.57 & 195426 & 12.18 & 1 & 1 \\
\hline 593 & 1 & 1 & 114950 & 11.65 & 1.77 & 0.57 & 203320 & 12.22 & 0 & 0 \\
\hline 594 & 0 & 0 & 35625 & 10.48 & 1.77 & 0.57 & 62906 & 11.05 & 0 & 0 \\
\hline 595 & 0 & 0 & 35150 & 10.47 & 1.76 & 0.57 & 61911 & 11.03 & 0 & 0 \\
\hline 596 & 0 & 0 & 22800 & 10.03 & 1.75 & 0.56 & 39831 & 10.59 & 0 & 0 \\
\hline 597 & 0 & 0 & 32300 & 10.38 & 1.75 & 0.56 & 56393 & 10.94 & 0 & 0 \\
\hline 598 & 0 & 0 & 47500 & 10.77 & 1.74 & 0.55 & 82721 & 11.32 & 0 & 0 \\
\hline 599 & 1 & 1 & 117800 & 11.68 & 1.73 & 0.55 & 204142 & 12.23 & 0 & 0 \\
\hline 600 & 0 & 0 & 29450 & 10.29 & 1.73 & 0.55 & 50933 & 10.84 & 0 & 0 \\
\hline 601 & 0 & 0 & 38000 & 10.55 & 1.63 & 0.49 & 61801 & 11.03 & 0 & 0 \\
\hline 602 & 0 & 0 & 38000 & 10.55 & 1.61 & 0.48 & 61119 & 11.02 & 0 & 0 \\
\hline 603 & 0 & 0 & 28025 & 10.24 & 1.58 & 0.46 & 44323 & 10.70 & 0 & 0 \\
\hline 604 & 0 & 0 & 47025 & 10.76 & 1.56 & 0.44 & 73315 & 11.20 & 0 & 0 \\
\hline 605 & 1 & 1 & 116850 & 11.67 & 1.48 & 0.39 & 173191 & 12.06 & 0 & 0 \\
\hline 606 & 0 & 0 & 50793 & 10.84 & 1.44 & 0.36 & 72997 & 11.20 & 0 & 0 \\
\hline 607 & 0 & 0 & 39188 & 10.58 & 1.42 & 0.35 & 55501 & 10.92 & 0 & 0 \\
\hline 608 & 0 & 0 & 38000 & 10.55 & 1.40 & 0.34 & 53276 & 10.88 & 0 & 0 \\
\hline 609 & 0 & 0 & 38000 & 10.55 & 1.39 & 0.33 & 52752 & 10.87 & 0 & 0 \\
\hline 610 & 0 & 0 & 54150 & 10.90 & 1.30 & 0.26 & 70449 & 11.16 & 0 & 0 \\
\hline 611 & 1 & 1 & 114000 & 11.64 & 1.30 & 0.26 & 147806 & 11.90 & 0 & 0 \\
\hline 612 & 0 & 0 & 57000 & 10.95 & 1.20 & 0.19 & 68656 & 11.14 & 0 & 0 \\
\hline 613 & 0 & 0 & 36100 & 10.49 & 1.18 & 0.17 & 42605 & 10.66 & 0 & 0 \\
\hline 614 & 0 & 0 & 35625 & 10.48 & 1.17 & 0.15 & 41532 & 10.63 & 0 & 0 \\
\hline 615 & 0 & 0 & 51300 & 10.85 & 1.09 & 0.08 & 55829 & 10.93 & 0 & 0 \\
\hline 616 & 0 & 0 & 22610 & 10.03 & 1.07 & 0.07 & 24216 & 10.09 & 0 & 0 \\
\hline 617 & 0 & 0 & 56145 & 10.94 & 1.00 & 0.00 & 56096 & 10.93 & 0 & 0 \\
\hline 618 & 0 & 0 & 55860 & 10.93 & 1.00 & 0.00 & 55800 & 10.93 & 0 & 0 \\
\hline 619 & 0 & 0 & 55575 & 10.93 & 1.00 & 0.00 & 55468 & 10.92 & 0 & 0 \\
\hline 620 & 0 & 0 & 55100 & 10.92 & 1.00 & 0.00 & 54992 & 10.91 & 0 & 0 \\
\hline 621 & 0 & 0 & 33250 & 10.41 & 1.00 & 0.00 & 33182 & 10.41 & 2 & 0 \\
\hline 622 & 0 & 0 & 55813 & 10.93 & 0.99 & -0.01 & 55470 & 10.92 & 0 & 0 \\
\hline
\end{tabular}




\begin{tabular}{|l|l|l|l|l|l|l|l|l|l|l|}
623 & 0 & 0 & 56050 & 10.93 & 0.99 & -0.01 & 55642 & 10.93 & 0 & 0 \\
\hline 624 & 0 & 0 & 56050 & 10.93 & 0.99 & -0.01 & 55553 & 10.93 & 0 & 0 \\
\hline 625 & 0 & 0 & 56098 & 10.93 & 0.99 & -0.01 & 55560 & 10.93 & 0 & 0 \\
\hline 626 & 0 & 0 & 36813 & 10.51 & 0.99 & -0.01 & 36449 & 10.50 & 0 & 0 \\
\hline 627 & 0 & 0 & 50825 & 10.84 & 0.96 & -0.04 & 48797 & 10.80 & 0 & 0 \\
\hline 628 & 0 & 0 & 30400 & 10.32 & 0.93 & -0.07 & 28216 & 10.25 & 0 & 0 \\
\hline
\end{tabular}


SAS Output

The SAS System

The GEMMOD Procedure

\begin{tabular}{|lr|}
\hline \multicolumn{2}{|c|}{ Model Information } \\
\hline Data Set & WOrK TESTDATA \\
Distribution & Negative Binomial \\
Link Function & Log \\
Dependent Variable & Accidents Acoidents \\
\hline
\end{tabular}

Number of Observations Read 628

Number of Observations Used 628

Criteria For Assessing Goodness of Fit

\begin{tabular}{|c|c|c|c|}
\hline Criterion & DF & Vahue & ValuelDF \\
\hline Deviance & 625 & 300.0044 & 0.6241 \\
\hline Scaled Deviance & 025 & 300.0844 & 0.6241 \\
\hline Pearson Chi-Square & 625 & 684.1354 & 1.0626 \\
\hline Scaled Pearson $\times 2$ & 025 & 684.1354 & 1.0020 \\
\hline Log Likelihood & & -3610200 & \\
\hline Full Log Likelihood & & -401.4306 & \\
\hline AIC (smaller is better) & & 810.8612 & \\
\hline AICC (smaller is better) & & 810.9254 & \\
\hline BIC (smaller is betten) & & 828.6314 & \\
\hline
\end{tabular}

Algovitum converged.

\begin{tabular}{|c|c|c|c|c|c|c|c|}
\hline \multirow{3}{*}{$\frac{\text { Parameter }}{\text { Intercept }}$} & \multicolumn{6}{|c|}{ Analysis Of Maximum Likelihood Parameter Estimates } & \multirow[b]{2}{*}{$\operatorname{Pr}>$ Chisq } \\
\hline & DF & Estimate & $\begin{array}{r}\text { Standard } \\
\text { Error }\end{array}$ & $\begin{array}{r}\text { Wald 95\% } \\
\text { Lim }\end{array}$ & $\begin{array}{l}\text { nfidence } \\
8\end{array}$ & $\begin{array}{l}\text { Wald Chi- } \\
\text { Square }\end{array}$ & \\
\hline & 1 & -2.7310700 & 0.6300164 & -3.9058800 & -1.4802612 & 18.79 & $<, 0001$ \\
\hline AADT & 1 & .000013703 & 0.0000025 & 0.0000087 & 0.0000187 & 29.31 & $<.0001$ \\
\hline Length & 1 & .203120795 & 0.2745529 & -0.3340031 & 0.7412347 & 0.55 & 0.4504 \\
\hline Dispersion & 1 & 1.22218808 & 0.3623873 & 0.6835194 & 2.1853712 & & \\
\hline
\end{tabular}

Wolk: The negative binomial dispersion parameter was estimated by maximum likelhood. 


\section{SAS Output}

\section{The SAS System}

The GEMMOD Procedure

\begin{tabular}{|lr|}
\hline \multicolumn{2}{|c|}{ Model Information } \\
\hline Data Set & WORK TESTDATA \\
Distribution & Negative Binomial \\
Link Function & Log \\
Dependent Variable & Acoidents Accidents \\
\hline
\end{tabular}

Number of Observations Read 628

Number of Observations Used taz

Criteria For Assessing Goodness of Fit

\begin{tabular}{|c|c|c|c|}
\hline Criterion & DF & Vahue & Value/DF \\
\hline Deviance & 620 & 380.0486 & 0.6215 \\
\hline Scaled Deviance & 626 & 380.0486 & 0.6215 \\
\hline Pearson Chi-Square & 620 & 6020012 & 1.0575 \\
\hline Scaled Pearson X2 & 626 & 602.0012 & 1.0575 \\
\hline Log Likelihood & & -361.7385 & \\
\hline Full Log Likelihood & & -401.5482 & \\
\hline AlC (smaller is better) & & 800.0083 & \\
\hline AICC (smaller is better) & & 800.1368 & \\
\hline BIC (smaller is better) & & 8024259 & \\
\hline
\end{tabular}

Agoritem converged.

\begin{tabular}{|l|cccccc|}
\hline \multicolumn{5}{|c|}{ Analysis Of Maximum Likelihood Parameter Estimates } \\
Parameter & DF & Estimate & $\begin{array}{c}\text { Standard } \\
\text { Error }\end{array}$ & Wakd 95\% Confidence & Limits & Wald Chi- \\
Square Pr > ChiSq
\end{tabular}

Nole: The negative binomial dispersion parameter was estimated by maximum tikel hood. 


\section{SAS Output}

The SAS System

The GENMOD Procedure

\begin{tabular}{|lr|}
\hline \multicolumn{2}{|c|}{ Model Information } \\
\hline Data Set & WORK.TESTDATA \\
Distribution & Negative Binomial \\
Link Function & Log \\
Dependent Variable & Aocidents Accidents \\
\hline
\end{tabular}

Number of Observations Read 628

Number of Observations Used 628

\begin{tabular}{|lrrr|}
\hline \multicolumn{4}{|c|}{ Criteria For Assessing Goodness Of Fit } \\
Criterion & DF & Value & ValueidF \\
\hline Deviance & 620 & 301.8251 & 0.0259 \\
Scaled Deviance & 026 & 301.8251 & 0.0250 \\
Pearson Chi-Square & 020 & 689.8104 & 1.1005 \\
Scaled Pearson X2 & 620 & 688.8104 & 1.1005 \\
Log Likelihood & -363.2541 & \\
Full Log Likelihood & -403.0047 & \\
AlC (smaller is better) & 812.1294 \\
AlCC (smalker is better) & 812.1870 \\
BIC (smaller is better) & 825.4570 \\
\hline
\end{tabular}

Agorittm converged.

\begin{tabular}{|c|c|c|c|c|c|c|c|}
\hline \multirow{2}{*}{ Parameter } & \multicolumn{6}{|c|}{ Analys is of Maximum Likelihood Parameter Estimates } & \multirow[b]{2}{*}{ Pr $>$ Chisq } \\
\hline & DF & Estimate & $\begin{array}{r}\text { Standard } \\
\text { Error }\end{array}$ & $\begin{array}{l}\text { Wald } 95 \% \\
\text { Lim }\end{array}$ & $\begin{array}{l}\text { nfidence } \\
8\end{array}$ & $\begin{array}{l}\text { Wald Chi- } \\
\text { Square }\end{array}$ & \\
\hline Intercept & 1 & -10.803091 & 1.8000515 & -14.600284 & -7.1768894 & 33.01 & $<.0001$ \\
\hline LnAADT & 1 & .868314497 & 0.1702649 & 0.5346014 & 1.2020276 & 20.01 & $<.0001$ \\
\hline Dispersion & 1 & 1.24188730 & 0.3064163 & 0.0005310 & 22142722 & & \\
\hline
\end{tabular}

Note: The negative binomial dispersion parameter was esimated by maximum thelihood. 
SAS Output

The SAS System

The GEMMOD Procedure

\begin{tabular}{|lr|}
\hline \multicolumn{2}{|c|}{ Model Information } \\
\hline Data Set & WOFK.TESTDATA \\
Distribution & Negative Binomial \\
Link function & Log \\
Dependent Variable & Accidents Accidents \\
\hline
\end{tabular}

Number of Observations Read 628

Number of Observations Used 628

Criteria For Assessing Goodness of Fit

Criterion DF Value Value/DF

$\begin{array}{llll}\text { Deviance } & 625 & 3922317 & 0.0278\end{array}$

Scaled Deviance $\quad 025 \quad 3022317 \quad 0.6276$

Pearson Chi-Square $\quad 025 \quad 04.6661 \quad 1.1115$

Scated Pearson $\times 2 \quad 025 \quad 004.6661 \quad 1.1115$

Log Likelihood $\quad \mathbf{3 6 2 . 7 9 2 8}$

Full Log Likelihood $\quad 402.6032$

AIC (emaller is better) $\quad 8132006$

AICC (smaller is better) $\quad 813.2707$

BIC (smalter is better) $\quad 830.9766$

Algorithm corverged.

\begin{tabular}{|c|c|c|c|c|c|c|c|}
\hline \multirow{2}{*}{ Parameter } & \multicolumn{6}{|c|}{ Analysis Of Maxinum Likelihood Parameter Estimates } & \multirow[b]{2}{*}{ Pr $>$ Chisq } \\
\hline & DF & Estimate & $\begin{array}{r}\text { Standard } \\
\text { Error }\end{array}$ & Wald $95 \%$ & Infidence & $\begin{array}{l}\text { Wald Chi- } \\
\text { Square }\end{array}$ & \\
\hline Intercept & 1 & -11.213090 & 1.8270180 & -14.000887 & -7.4371117 & 33.86 & 5.0001 \\
\hline LnAADT & 1 & .860801147 & 0.1700299 & 0.5276387 & 1.1941436 & 25.64 & $<.0001$ \\
\hline LnLength & $\mathbf{1}$ & .520201211 & 0.5583310 & -0.5050158 & 1.0235082 & 0.00 & 0.3431 \\
\hline Dispersion & 1 & 1.22473388 & 0.3633727 & 0.6843819 & 2. 1917837 & & \\
\hline
\end{tabular}

Note: The negative binomial dispersion parameter was es timated by maximum likelhood. 
SAS Output

The SAS System

The GENMOD Procedure

\begin{tabular}{|lr|}
\hline \multicolumn{2}{|c|}{ Model Information } \\
\hline Data Set & WORK TESTDATA \\
Distribution & Negative Binomial \\
Link Function & Log \\
Dependent Variable & Acoidents Aocidents \\
\hline
\end{tabular}

Number of Observations Read 228

Number of Observations Used 028

Criteria For Assessing Goodness of Fit

\begin{tabular}{|c|c|c|c|}
\hline Criterion & DF & Value & ValuefDF \\
\hline Deviance & 628 & 302.1677 & 0.6285 \\
\hline Scaled Deviance & 626 & 302167 & 0.6205 \\
\hline Pearson Chi-Square & 626 & 000.0432 & 1.1110 \\
\hline Scaled Pearson $\times 2$ & 626 & 600.0432 & 1.1118 \\
\hline Log Likelihood & & -362.9402 & \\
\hline Full Log Likelihood & & -402.7508 & \\
\hline AIC (smaller is better) & & 811.5100 & \\
\hline AICC (smaller is better) & & 811.5580 & \\
\hline BIC (smaller is better) & & 824.8472 & \\
\hline
\end{tabular}

Algoritum converged

\begin{tabular}{|c|c|c|c|c|c|c|c|}
\hline \multirow{2}{*}{ Parameter } & \multicolumn{6}{|c|}{ Analysis Of Maximum Likelihood Parameter Estimates } & \multirow[b]{2}{*}{ Pr $>$ Chisq } \\
\hline & DF & Estimate & $\begin{array}{r}\text { Standard } \\
\text { Error }\end{array}$ & $\begin{array}{r}\text { Wald 95\% } \\
\text { Lm }\end{array}$ & $\begin{array}{l}\text { mfidence } \\
8\end{array}$ & $\begin{array}{l}\text { Wald Chj- } \\
\text { Square }\end{array}$ & \\
\hline Intercept & 1 & -11.110076 & 1.0238790 & -14.887711 & -7.3462406 & 33.39 & $<.0001$ \\
\hline LnExpo & 1 & .831308431 & 0.1616315 & 0.5145105 & 1.1481003 & 20.45 & $<.0001$ \\
\hline Dispersion & 1 & 1.220600074 & 0.3845267 & 0.0877202 & 2.1084134 & & \\
\hline
\end{tabular}

Moke: The negative binomial dispersion parameter was estimated by maximum likelihood. 


\section{SAS Output}

The SAS System

The GEMMOD Procedure

\begin{tabular}{|lr|}
\hline \multicolumn{2}{|c|}{ Model Information } \\
\hline Data Set & WORK TESTDATA \\
Distribution & Negative Binomid \\
Link Function & Log \\
Dependent Variable & Acoidents Accidents \\
\hline
\end{tabular}

Number of Observations Read 628

Number of Observations Used 628

\begin{tabular}{|c|c|c|c|}
\hline \multicolumn{4}{|c|}{ Criteria For Assessing Goodness Of Fit } \\
\hline Criterion & DF & Value & VaherDF \\
\hline Deviance & 625 & 380.2260 & 0.6228 \\
\hline Scaled Deviance & 625 & 380.2260 & 0.6228 \\
\hline Pearson Chi-Square & 625 & 658.8677 & 1.0542 \\
\hline Scaled Pearson $\times 2$ & 625 & 058.807 & 1.0542 \\
\hline Log Likelihood & & -300.8685 & \\
\hline Full Log Likelihood & & -400.0701 & \\
\hline AIC (smaller is better) & & 600.3583 & \\
\hline AICC (smaller is better) & & 800.4225 & \\
\hline BIC (smaller is better) & & 827.1284 & \\
\hline
\end{tabular}

Algorithm converged.

\begin{tabular}{|c|c|c|c|c|c|c|c|}
\hline \multirow{3}{*}{\begin{tabular}{|l} 
Parameter \\
Intercept
\end{tabular}} & \multicolumn{6}{|c|}{ Analysis Of Maximum Likelihood Parameter Estimates } & \multirow[b]{2}{*}{ Pr $>$ Chisq } \\
\hline & DF & Estimate & $\begin{array}{r}\text { Standard } \\
\text { Error }\end{array}$ & $\begin{array}{r}\text { Wald } 95 \% \\
\text { Lim }\end{array}$ & is & $\begin{array}{l}\text { Wald Chi- } \\
\text { Square }\end{array}$ & \\
\hline & 1 & -2.2080448 & 0.2154364 & -2.7208925 & -1.8783971 & 113.84 & $<.0001$ \\
\hline AADT & $\mathbf{1}$ & .000013201 & 0.0000028 & 0.0000082 & 0.0000182 & 20.52 & $<, 0001$ \\
\hline Cam & 1 & .403787023 & 0.2778551 & -0.1407890 & 0.0483830 & 2.11 & 0.1462 \\
\hline Dispersion & 1 & 1.21300394 & 0.3602811 & 0.6785027 & 2.1717857 & & \\
\hline
\end{tabular}

Wote: The negative binomial dispersion parameter was extimated by maximum likelihood. 
SAS Output

The SAS System

The GEMMOD Procedure

\begin{tabular}{|lr|}
\hline \multicolumn{2}{|c|}{ Nodel Intormation } \\
\hline Data Set & Work. TESTDATA \\
Distribution & Negative Binomia \\
Link Function & Log \\
Dependent Variable & Accidents Accidents \\
\hline
\end{tabular}

Number of Observations Read 628

Number of Observations Used 626

Missing Vahues

2

\begin{tabular}{|c|c|c|c|}
\hline \multicolumn{4}{|c|}{ Criteria For Assessing Goodness of Fit } \\
\hline Criterion & DF & Vahe & Valuelof \\
\hline Deviance & 622 & 388.8400 & 0.6251 \\
\hline Scaled Deviance & 622 & 388.8400 & 0.0251 \\
\hline Pearson Chi-Square & 022 & 686.0343 & 1.0547 \\
\hline Scaled Pearson $\times 2$ & 622 & 650.0343 & 1.0547 \\
\hline Log Likelihood & & -3002787 & \\
\hline Full Log Likelihood & & -400.0993 & \\
\hline AIC (smaller is better) & & 810.1780 & \\
\hline AICC (smaller is better) & & B10 2754 & \\
\hline BIC (smaller is better) & & 832.3754 & \\
\hline
\end{tabular}

Algoritum converged.

\begin{tabular}{|c|c|c|c|c|c|c|c|}
\hline \multirow{3}{*}{$\frac{\text { Parameter }}{\text { Intercept }}$} & \multicolumn{6}{|c|}{ Analys of Maximum Likelihood Parameter Estimates } & \multirow[b]{2}{*}{ Pr $>$ Chisq } \\
\hline & DF & Estimate & $\begin{array}{l}\text { Standard } \\
\text { Error }\end{array}$ & Wald $95 \%$ & nfidence & $\begin{array}{l}\text { Wald Chi- } \\
\text { Square }\end{array}$ & \\
\hline & 1 & -2.2761040 & 0.4168074 & 3.0032080 & -1.4500001 & 20.81 & $<.0001$ \\
\hline AADT & 1 & .000012002 & 0.0000004 & -0.0000050 & 0.0000310 & 1.84 & 0.1750 \\
\hline Cam & 1 & .300840015 & 0.2788933 & -0.1460808 & 0.0462608 & 2.05 & 0.1510 \\
\hline HighFlow & 1 & .042192336 & 0.0628067 & -1.2568849 & 1.3412995 & 0.00 & 0.9402 \\
\hline Dispersion & 1 & 1.20375305 & 0.3583312 & 0.6716085 & 2.1573568 & & \\
\hline
\end{tabular}




\section{SAS Output}

\section{The SAS System}

The GEMMOD Procedure

\begin{tabular}{|lr|}
\hline \multicolumn{2}{|c|}{ Model Information } \\
\hline Data Set & WOFiK. TESTDATA \\
Distribution & Negative Binomial \\
Link Function & $\log$ \\
Dependent Variable & Acoidents Accidents \\
\hline
\end{tabular}

Number of Observations Read 628

Number of Observations Used 129

Criteria For Assessing Goodness of Fit

\begin{tabular}{|c|c|c|c|}
\hline Criterion & DF & Value & Value/DF \\
\hline Deviance & 624 & 389.3217 & 0.0239 \\
\hline Scaled Deviance & 624 & 390.3217 & 0.6230 \\
\hline Pearson Chi-Square & 624 & 030.4000 & 1.0200 \\
\hline Scaled Pearson X2 & 624 & 636.4600 & 1.0200 \\
\hline Log Likelihood & & -360.827 & \\
\hline Full Log Likelihood & & -300.6377 & \\
\hline AIC (smaller is better) & & 8000.2755 & \\
\hline AlCC (smalker is better) & & 800.3719 & \\
\hline BIC (smaller is better) & & 831.4882 & \\
\hline
\end{tabular}

Agorithm converged

\begin{tabular}{|c|c|c|c|c|c|c|c|}
\hline \multirow{3}{*}{$\frac{\text { Parameter }}{\text { Intercept }}$} & \multicolumn{6}{|c|}{ Analysis Of Maximum Likelihood Parameter Estimates } & \multirow[b]{2}{*}{ Pr $>$ Chisq } \\
\hline & DF & Estimate & $\begin{array}{l}\text { Standard } \\
\text { Error }\end{array}$ & $\begin{array}{r}\text { Wald } 95 \% c \\
\mathrm{Lim}\end{array}$ & nfidence & $\begin{array}{l}\text { Wald Chi- } \\
\text { Square }\end{array}$ & \\
\hline & 1 & -2.1340145 & 0.2423411 & -20008942 & -1.0509347 & 77.61 & $<.0001$ \\
\hline AADT & 1 & .000008815 & 0.0000041 & 0.0000000 & 0.0000187 & 4.41 & 0.0357 \\
\hline Cam & 1 & .376063293 & 0.2781434 & -0.1694877 & 0.0218143 & 1.83 & 0.1757 \\
\hline SRN & 1 & .420070830 & 0.2930202 & -0.1533382 & 0.0052700 & 2.00 & 0.1508 \\
\hline Dispersion & 1 & 1.18615104 & 0.3555751 & 0.0581330 & 21345500 & & \\
\hline
\end{tabular}




\section{SAS Output}

The SAS System

The GEvinOD Procedure

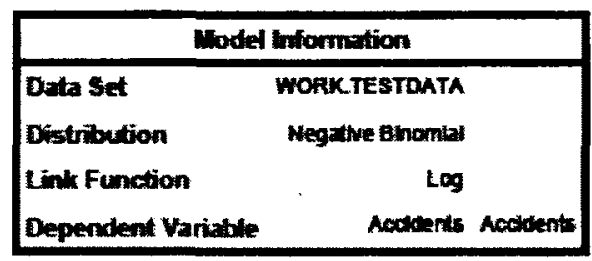

\begin{tabular}{|l|} 
Mumber of Observations Read 628 \\
Mumber of Observations Used 625 \\
Missing Vilues
\end{tabular}

Criteria For Assessing Goodness Of FA

Criterion DF Valle Vahuefof

$\begin{array}{llll}\text { Deviance } & 621 & 388.7237 & 0.6260\end{array}$

Scaled Deviance $\quad 621 \quad 398.7237 \quad 0.6260$

Pearson Chi-square $\quad 621 \quad 637.4601 \quad 1.0265$

Scaled Pearson X2 $621 \quad 637.4601 \quad 1.0265$

Log Lihelihood -359.0094

Fun Log Liket thood -398.8200

AIC (smaller is better) $\quad 809.6400$

AKCC (smaller is better) $\quad 009775$

BAC (snneller is better) $\quad 836.2361$

Agowan converged.

\begin{tabular}{|c|c|c|c|c|c|c|c|}
\hline \multicolumn{8}{|c|}{ Analysis of Maximum Libelihood Paraneter Estimates } \\
\hline Parameter & DF & Estande & Stamdard Erior & Wald 95\% Con & idenee Linits & Wald Chi-square & $\operatorname{Pr}>$ Chisq \\
\hline Intercept & 1 & -23129461 & 0.4177954 & 3.1318119 & -1.4940002 & 30.65 & $<0001$ \\
\hline AADT & 1 & .000013004 & 0.0000004 & 0.0000053 & 0.0900314 & 196 & 0.1620 \\
\hline $\operatorname{com}$ & 1 & 340336498 & 0.2801437 & 0.2906951 & 0.0974581 & 1.55 & 0.2136 \\
\hline Hohriow & 1 & -.38979633 & 0.7159094 & -1.7931088 & 1.0135161 & 0.30 & 0.5862 \\
\hline SPW & & .502483980 & 0.3175550 & 0.1199144 & 1.1248924 & 250 & 0.1136 \\
\hline Dispersion & 1 & 1.17303224 & 0.3528665 & a.6505:17 & 2.11525649 & & \\
\hline
\end{tabular}

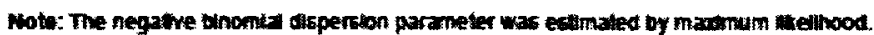




\section{SAS Output}

\section{The SAS System}

The GEMMOD Procedure

\begin{tabular}{|lr|}
\hline \multicolumn{2}{|c|}{ Model Information } \\
\hline Data Set & WORK.TESTDATA \\
Distribution & Negative Binomiza \\
Link Function & Log \\
Dependent Variable & Accidents Accidents \\
\hline
\end{tabular}

Number of Observations Read 628 Number of Observations Used 620 Missing Vahes 2

\begin{tabular}{|c|c|c|c|}
\hline \multicolumn{4}{|c|}{ Criteria For Assessing Goodness of Fit } \\
\hline Criterion & DF & Vahue & Value/of \\
\hline Deviance & 623 & 380.4375 & 0.6251 \\
\hline Scaled Deviance & 023 & 399.4375 & 0.0251 \\
\hline Pearson Chi-Square & 623 & 058.1270 & 1.0564 \\
\hline Scaled Pearson $\times 2$ & 623 & 058.1270 & 1.0584 \\
\hline Log Likelihood & & -3612780 & \\
\hline Full Log Likelihood & & -401.0886 & \\
\hline AlC (smaller is better) & & 810.1772 & \\
\hline AICC (smaller is better) & & 8102416 & \\
\hline BIC (smaller is better) & & 827.8340 & \\
\hline
\end{tabular}

Algorithm comerged

\begin{tabular}{|l|rrrrrrr|}
\hline \multicolumn{7}{|c}{ Analysis Of Maximum Likelihood Parameter Estimates } \\
Parameter & DF & Estimate & $\begin{array}{r}\text { Standard } \\
\text { Error }\end{array}$ & Wald 95\% Confidence & Wald Chi- \\
Intercept & 1 & -2.3191087 & 0.4170218 & -3.1377232 & -1.5000701 & 30.84 & $<.0001$ \\
AADT & 1 & .000014413 & 0.0000003 & -0.0000039 & 0.0000327 & 2.39 & 0.1220 \\
HighFlow & 1 & -.04340090 & 0.6031540 & -1.3431678 & 1.2563482 & 0.00 & 0.9478 \\
Dispersion & 1 & 1.22171005 & 0.3619080 & 0.6835238 & 2.1836504 & & \\
\hline
\end{tabular}




\section{SAS Output}

\section{The SAS System}

The GEMMOD Procedure

\begin{tabular}{|lr|}
\hline \multicolumn{2}{|c|}{ Model Information } \\
\hline Data Set & Work.TESTDATA \\
Diatribution & Negative Binomia \\
Link Function & Log \\
Dependent Variable & Accidents Accidents \\
\hline
\end{tabular}

Number of Observations Read

Number of Observations Used 628

\begin{tabular}{|c|c|c|c|}
\hline \multicolumn{4}{|c|}{ Criteria For Assessing Goodness of Fit } \\
\hline Criterion & DF & Value & ValuelDF \\
\hline Devience & 625 & 300.1180 & 0.0242 \\
\hline Scaled Deviance & 625 & 300.1180 & 0.6242 \\
\hline Pearson Chi-Square & 625 & 637.3390 & 1.0197 \\
\hline Scaled Pearson $\times 2$ & 625 & 037.3380 & 1.0197 \\
\hline Log Likelihood & & -300.7206 & \\
\hline Full Log Likelihood & & -400.5311 & \\
\hline AIC (smaller is better) & & 800.0022 & \\
\hline AICC (amalker is better) & & 809.1204 & \\
\hline BIC (smaller is betten) & & 820.8324 & \\
\hline
\end{tabular}

Agorithm converged:

\begin{tabular}{|c|c|c|c|c|c|c|c|}
\hline \multirow{2}{*}{ Parameter } & \multicolumn{6}{|c|}{ Analysis of Maxinum Likelihood Parameter Estimates } & \multirow[b]{2}{*}{ Pr $>$ Chisq } \\
\hline & DF & Estimate & $\begin{array}{l}\text { Standard } \\
\text { Error }\end{array}$ & $\begin{array}{l}\text { Waid } 95 \% \\
\mathrm{Lim}\end{array}$ & nfidence & $\begin{array}{l}\text { Wald Chi- } \\
\text { Square }\end{array}$ & \\
\hline Intercept & 1 & -2.1224594 & 0.2418240 & -2.5904258 & -1.6484091 & 77.03 & $<.0001$ \\
\hline AADT & 1 & .000008838 & 0.0000041 & 0.0000008 & 0.0000160 & 4.60 & 0.0303 \\
\hline SRK & 1 & .44640787 & 0.2025015 & -0.1269708 & 1.0100088 & 2.33 & 0.1270 \\
\hline Dispergion & 1 & 1.19873873 & 0.3585022 & 0.0070491 & 2.1542189 & & \\
\hline
\end{tabular}

Mote: The negative binomial dispersion parameter was estinated by maximum likethood. 
SAS Output

The SAS System

The GENMOD Procedure

\begin{tabular}{|lr|}
\hline \multicolumn{2}{|c|}{ Model Information } \\
\hline Data Set & WORK.TESTDATA \\
Distribution & Negative Binomial \\
Link Function & Log \\
Dependent Variable & Accidents Accidents \\
\hline
\end{tabular}

Number of Observations Read 628

Number of Observations Used 628

\begin{tabular}{|c|c|c|c|}
\hline \multicolumn{4}{|c|}{ Criteria For Assessing Goodness of Fit } \\
\hline Criterion & DF & Value & Value/DF \\
\hline Deviance & 625 & 380.8060 & 0.6239 \\
\hline Scaled Deviance & 625 & 380.9050 & 0.6239 \\
\hline Pearson Chi-Square & 625 & 840.0379 & 1.0250 \\
\hline Scaled Pearson $\times 2$ & 625 & 640.8370 & 1.0250 \\
\hline Log Likelihood & & -3002597 & \\
\hline Full Log Likelihood & & 400.0703 & \\
\hline AIC (smaller is better) & & 800.1400 & \\
\hline AICC (smaller is better) & & 808.2048 & \\
\hline BIC (smaller is better) & & B25.9108 & \\
\hline
\end{tabular}

Algorithm converged

\begin{tabular}{|c|c|c|c|c|c|c|c|}
\hline \multirow{3}{*}{$\frac{\text { Parameter }}{\text { Intercept }}$} & \multicolumn{6}{|c|}{ Analysis Of Maximum Likelihood Parameter Estimates } & \multirow[b]{2}{*}{ Pr $>$ ChiSq } \\
\hline & DF & Estimate & $\begin{array}{r}\text { Standard } \\
\text { Error }\end{array}$ & \multicolumn{2}{|c|}{$\begin{array}{c}\text { Wald 95\% Confidence } \\
\text { Limits }\end{array}$} & $\begin{array}{l}\text { Wald Chi- } \\
\text { Square }\end{array}$ & \\
\hline & 1 & -2.0080744 & 0.2181253 & -2.5261820 & -1.6711506 & 92.57 & $<.0001$ \\
\hline Expo & 1 & .000003880 & 0.0000016 & 0.0000007 & 0.0000071 & 5.63 & 0.0176 \\
\hline SRN & 1 & .405000004 & 0.2710855 & -0.0056272 & D.9970085 & 2.85 & 0.0858 \\
\hline Dispersion & 1 & 1.18806007 & 0.3564823 & 0.6006201 & 2.1398328 & & \\
\hline
\end{tabular}

Wote: The negative binorrid dispersion parameter was estimated by maximum stekhood 
SAS Output

The SAS System

The GEMMOD Procedure

\begin{tabular}{|lr|}
\hline \multicolumn{2}{|c|}{ Model Information } \\
\hline Data Set & WORK TESTDATA \\
Distribution & Negative Binomial \\
Link Function & Log \\
Dependent Variable & Acoidents Acsidents \\
\hline
\end{tabular}

Number of Observations Read 028

Number of Observations Used 628

Criteria For Assessing Goodness Of Fit

\begin{tabular}{|c|c|c|c|}
\hline Criterion & DF & Value & ValuedDF \\
\hline Devisance & 625 & 388.0173 & 0.6208 \\
\hline Scaled Deviance & 625 & 398.0173 & 0.0208 \\
\hline Pearson Chi-Square & 625 & 0502360 & 1.0548 \\
\hline Scaled Pearson $\times 2$ & 025 & 050.2300 & 1.0548 \\
\hline Log Likelifhood & & -300.7748 & \\
\hline Full Log Likelihood & & -400.5852 & \\
\hline AIC (smaller is better) & & 800.1704 & \\
\hline AICC (smaller is better) & & 8002346 & \\
\hline BIC (smaller is better) & & 820.9406 & \\
\hline
\end{tabular}

Algorithm converged.

\begin{tabular}{|c|c|c|c|c|c|c|c|}
\hline \multirow{3}{*}{$\begin{array}{l}\text { Parameter } \\
\text { Intercept }\end{array}$} & \multicolumn{6}{|c|}{ Anslysis of Maximum Likelihood Parameter Estimates } & \multirow[b]{2}{*}{ Pr $>$ Chisq } \\
\hline & DF & Estimate & $\begin{array}{r}\text { Standard } \\
\text { Error }\end{array}$ & $\begin{array}{r}\text { Wald 95\% } \\
\text { Lim }\end{array}$ & mfidence & $\begin{array}{l}\text { Wald Chi- } \\
\text { Square }\end{array}$ & \\
\hline & 1 & -2.2408485 & 0.2042002 & -2.6412409 & -1.8404471 & 120.32 & $<.0001$ \\
\hline Expo & 1 & .000005722 & 0.0000011 & 0.0000036 & 0.0000070 & 26.74 & $<.0001$ \\
\hline Cam & 1 & .3002965402 & 0.2783570 & -0.1545754 & 0.9404862 & 1.08 & 0.1585 \\
\hline Dispersion & 1 & 1.22702984 & 0.360734 & 0.6906243 & 2.1832209 & & \\
\hline
\end{tabular}

Wote: The negative binomid dispersion parameter was estimated by maximum wikethood. 
SAS Output

The SAS System

The GEMMOD Procedure

\begin{tabular}{|lr|}
\hline \multicolumn{2}{|c|}{ Model Intormation } \\
\hline Data Set & WORK TESTDATA \\
Distribution & Negative Bincrial \\
Link Function & Log \\
Dependent Variable & Accidents Accidents \\
\hline
\end{tabular}

Number of Observations Read 028 Number of Observations Used 20 Missing Vafues

Criteria For Assessing Goodness of Fit

\begin{tabular}{|c|c|c|c|}
\hline Criterion & DF & Value & Value/DF \\
\hline Deviance & 622 & 398.1650 & 0.0241 \\
\hline Scaled Deviance & 622 & 388.1850 & 0.0241 \\
\hline Pearson Chi-square & 622 & 652.6880 & 1.0403 \\
\hline Scaled Pearson $\times 2$ & 622 & 062.0860 & 1.0483 \\
\hline Log Likelihood & & -360.0009 & \\
\hline Full Log Likelihood & & -309.8009 & \\
\hline AIC (smaller is better) & & 800.0197 & \\
\hline AlCC (smaller is better) & & 800.7186 & \\
\hline BIC (smaller is better) & & 8318105 & \\
\hline
\end{tabular}

Algoritum converged.

\begin{tabular}{|c|c|c|c|c|c|c|c|}
\hline \multirow{2}{*}{ Parameter } & \multicolumn{6}{|c|}{ Analysis Of Maximum Likelihood Parameter Estimates } & \multirow[b]{2}{*}{ Pr $>$ ChiSq } \\
\hline & DF & Estimate & $\begin{array}{r}\text { Standard } \\
\text { Error }\end{array}$ & Wald $95 \%$ & isfidence & $\begin{array}{l}\text { Wald Chi- } \\
\text { Square }\end{array}$ & \\
\hline & 1 & -2.1202476 & 0.2774408 & -2.6840213 & -1.5764740 & 58.40 & $<.0001$ \\
\hline Expo & 1 & .000004184 & 0.0000027 & 0.0000011 & 0.0000005 & 2.40 & 0.1213 \\
\hline Cam & 1 & .397188081 & 0.2702160 & -0.1500071 & 0.0444432 & 2.02 & 0.1549 \\
\hline HighFlow & 1 & .281500871 & 0.4440744 & -0.5800488 & 1.1530505 & 0.40 & 0.5267 \\
\hline Dispersion & 1 & 1.20524800 & 0.3677090 & 0.6730070 & 2.1502023 & & \\
\hline
\end{tabular}


SAS Output

The SAS System

The GEMMOD Procedure

\begin{tabular}{|lr|}
\hline \multicolumn{2}{|c|}{ Model Information } \\
\hline Data Set & WORK. TESTDATA \\
Distribution & Negative Binomial \\
Link Function & Log \\
Dependent Variable & Acoidents Accidents \\
\hline
\end{tabular}

Number of Observations Read 628

Number of Observations Used 628

\begin{tabular}{|c|c|c|c|}
\hline \multicolumn{4}{|c|}{ Criteria For Assessing Goodness of Fït } \\
\hline Criterion & DF & Value & ValuerDF \\
\hline Deviance & 624 & 388.0089 & 0.6233 \\
\hline Scaled Deviance & 624 & 388.8968 & 0.0233 \\
\hline Pearson Chi-Square & 624 & 638.0327 & 1.0225 \\
\hline Scaled Pearson $\times 2$ & 624 & 038.0327 & 1.0225 \\
\hline Log Likelihood & & -350.4323 & \\
\hline Full Log Likelihood & & -300.2428 & \\
\hline AIC (smaller is better) & & 808.4858 & \\
\hline AICC (smalier is better) & & 808.5822 & \\
\hline BIC (smaller is better) & & 830.6085 & \\
\hline
\end{tabular}

Algorithm corverged.

\begin{tabular}{|c|c|c|c|c|c|c|c|}
\hline \multirow{2}{*}{ Parameter } & \multicolumn{6}{|c|}{ Analysis Of Maximum Likelihood Parameter Estimates } & \multirow[b]{2}{*}{ Pr $>$ Chisq } \\
\hline & DF & Estimate & $\begin{array}{l}\text { Standard } \\
\text { Error }\end{array}$ & Wald $95 \%$ & onfidence & $\begin{array}{l}\text { Wald Chi- } \\
\text { Square }\end{array}$ & \\
\hline Intercept & 1 & -2.1081050 & 0.2180421 & -2.5367256 & -1.6700044 & 02.87 & $<.0001$ \\
\hline Expo & 1 & .000003744 & 0.0000010 & 0.0000005 & 0.0000070 & 5.21 & 0.0224 \\
\hline Cam & 1 & .382740330 & 0.2785860 & -0.1832978 & 0.6087785 & 1.70 & 0.1920 \\
\hline SRN & 1 & .444414843 & 0.2715208 & 0.0877558 & 0.8786854 & 2.88 & 0.1017 \\
\hline Dispersion & 1 & 1.18137926 & 0.3541200 & 0.6565078 & 2.1258802 & & \\
\hline
\end{tabular}


SAS Output

\section{The SAS System}

The Geveno Procedure

\begin{tabular}{|c|c|}
\hline \multicolumn{2}{|c|}{ Wodel Information } \\
\hline Daba set & MORK.TESTDATA \\
\hline Distribution & Negtwe Bnema: \\
\hline Link Function & Leg \\
\hline Beperafiend Varitile & Aostients Aockaents \\
\hline
\end{tabular}

Nhwiter of Otscervations Recad 628 thember of Observations Used 626 Iissing Values 2

Criteria for Assessing Goodness of F: Criturion DF Value Valuedof

Dewionce $\quad 6213823475 \quad 0.6254$
Seled Deviance $\quad 621 \quad 3863475 \quad 0.6254$ Peursonchiequare $621636.4732 \quad 1.0249$ Seviled Pewson X2 $6216364732 \quad 10249$ Log Livelihood $-358.7262$ Ful Lon Livelionod -3as36s

NC (smaller is betier) 809.0735

ACC (smiller is better) $\quad 603.2093$

BIC (sangerer is bether) 835.7097

Agorming corwerged

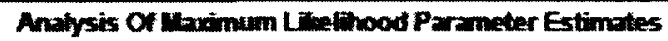

Parmeter DF Estwate Standiurd Erow Mild 95\% Confidenoe Limits Wald Chi-Square Pr $>$ Chisq

\begin{tabular}{|c|c|c|c|c|c|c|}
\hline Intercept & $1-2.1496594$ & 0.2776653 & -2.6843105 & -1.6050004 & 59.84 & .0901 \\
\hline Expo & 1 o00704285 & 0.0000027 & 0.0000010 & 0.0000096 & 2.53 & $0.1+20$ \\
\hline Cam & 1.346441626 & 0.2799502 & 0.2018506 & 0.0955338 & 1.53 & 0.2154 \\
\hline Highflow & $1-.14100024$ & 0.5187363 & -1.1577947 & $0.8756+42$ & 0.07 & 0.7856 \\
\hline SRA & 1.504502058 & 0.3181477 & A.1t90559 & 1.1280000 & 2.51 & 0.1128 \\
\hline Osppersion & 11.17063656 & 0.3519755 & 0.6493634 & 2.1103427 & & \\
\hline
\end{tabular}

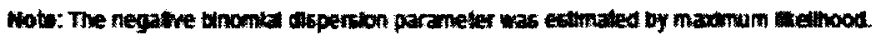




\section{SAS Output}

\section{The SAS System}

The GENMOD Procedure

\begin{tabular}{|lr|}
\hline \multicolumn{2}{|c|}{ Model Intormation } \\
\hline Data Set & WOFK.TESTDATA \\
Distribution & Negtive Binomial \\
Link Function & Log \\
Dependent Variable & Accidents Accidents \\
\hline
\end{tabular}

Number of Observations Read 628

Number of Observations Used 428

Misoing Values

2

Criteria For Assessing Goodness Of Fit

\begin{tabular}{|c|c|c|c|}
\hline Crĭterion & DF & Value & ValuelDF \\
\hline Deviance & 623 & 390.1050 & 0.0240 \\
\hline Scaled Deviance & 623 & 380.1050 & 0.6240 \\
\hline Pesrson Chi-Square & e23 & 650.0470 & 1.0530 \\
\hline Scaled Pearson $\times 2$ & 623 & 656.0470 & 1.0530 \\
\hline Log Likelihood & & -360.8844 & \\
\hline Full Log Likelihood & & -400.7050 & \\
\hline AIC (smaller is better) & & 800.5900 & \\
\hline AICC (smaller is better) & & 800.6544 & \\
\hline BIC (smaller is better) & & 827.3474 & \\
\hline
\end{tabular}

Agorittm converged

\begin{tabular}{|c|c|c|c|c|c|c|c|}
\hline \multirow{2}{*}{ Parameter } & \multicolumn{6}{|c|}{ Analysis of Maximum Likelihood Parameter Estimates } & \multirow[b]{2}{*}{ Pr $>$ Chisq } \\
\hline & DF & Estimate & $\begin{array}{r}\text { Standard } \\
\text { Error }\end{array}$ & $\begin{array}{r}\text { Wald } 95 \% \mathrm{C} \\
\text { Lim }\end{array}$ & nfidence & $\begin{array}{l}\text { Wald Chi- } \\
\text { Square }\end{array}$ & \\
\hline Intercept & 1 & -2.1315896 & 0.2772214 & -2.6740320 & -1.5882445 & 59.12 & $<.0001$ \\
\hline Expo & 1 & .000004032 & 0.0000027 & -0.0000006 & 0.0000000 & 2.08 & 0.0845 \\
\hline HighFlow & 1 & .246222588 & 0.4440003 & -0.6257860 & 1.1182111 & 0.31 & 0.5800 \\
\hline Dispersion & 1 & 1.21843930 & 0.3810146 & 0.6817092 & 2.1777532 & & \\
\hline
\end{tabular}


SAS Output

The SAS System

The GENMOD Procedure

\begin{tabular}{|lr|}
\hline \multicolumn{2}{|c|}{ Model Information } \\
\hline Data Set & WOFKTESTDATA \\
Distribution & Negative Binomial \\
Link Function & Log \\
Dependent Variable & Accidents Accidents \\
\hline
\end{tabular}

Number of Observations Read 628

Number of Observations Used 628

\begin{tabular}{|c|c|c|c|}
\hline \multicolumn{4}{|c|}{ Criteria For Assessing Goodness of Fit } \\
\hline Criterion & DF & Value & ValuefDF \\
\hline Deviance & 625 & 300.0059 & 0.0254 \\
\hline Scaled Deviance & 025 & 300.0050 & 0.6254 \\
\hline Pearson Chi-Square & 625 & 883.4170 & 1.0035 \\
\hline Scaled Pearson $\times 2$ & 625 & 083.4170 & 1.00035 \\
\hline Log Likelihood & & -361.8541 & \\
\hline Full Log Likelihood & & -401.7647 & \\
\hline AIC (smaller is better) & & 811.5286 & \\
\hline AICC (smaller is better) & & 011.5037 & \\
\hline BIC (smaller is better) & & 8202000 & \\
\hline
\end{tabular}

Agorithm corverged.

\begin{tabular}{|c|c|c|c|c|c|c|c|}
\hline \multirow{3}{*}{ Parameter } & \multicolumn{6}{|c|}{ Analysis of Maximum Likelihood Parameter Estimates } & \multirow[b]{2}{*}{ Pr $>$ Chisq } \\
\hline & DF & Estimate & $\begin{array}{r}\text { Standard } \\
\text { Error }\end{array}$ & $\begin{array}{l}\text { Wald } 95 \% \\
\operatorname{Lim}\end{array}$ & nfidence & $\begin{array}{l}\text { Waid Chi- } \\
\text { Square }\end{array}$ & \\
\hline & 1 & -10.687011 & 1.0452001 & -14.500009 & -6.8752123 & 30. 19 & $<.0001$ \\
\hline LnExpo & 1 & .701320019 & 0.1038140 & 0.4700002 & 1.1125830 & 23.31 & $<.0001$ \\
\hline Cam & 1 & .308203792 & 0.2788415 & -0.1483950 & 0.0447232 & 2.04 & 0.1533 \\
\hline Dispersion & 1 & 1.22021875 & 0.3821396 & 0.6820495 & 2.1830288 & & \\
\hline
\end{tabular}

Nolv: The negative binomial dispersion parameter was es bimated by maximum likelhood 


\section{SAS Output}

The SAS System

The GEMMOD Procedure

\begin{tabular}{|c|c|c|c|}
\hline \multicolumn{4}{|c|}{ Model Information } \\
\hline \\
\hline \multirow{3}{*}{$\begin{array}{l}\text { Dala Set } \\
\text { Distribution } \\
\text { Link Function } \\
\text { Dependent Variable }\end{array}$} & \multicolumn{3}{|c|}{ Negative Binomial } \\
\hline & \multicolumn{3}{|c|}{$\log$} \\
\hline & \multicolumn{3}{|c|}{ Accidents Accidents } \\
\hline \multirow{3}{*}{\multicolumn{4}{|c|}{$\begin{array}{l}\text { Number of Observations Read } 628 \\
\text { Number of Observations Used } 626 \\
\text { Missing Vahues }\end{array}$}} \\
\hline & & & \\
\hline & & & \\
\hline \multicolumn{4}{|c|}{ Criteria For Assessing Goodness Of Fit } \\
\hline Criterion & DF & Value & Value/DF \\
\hline Deviance & 022 & 390.1652 & 0.0257 \\
\hline Scaled Deviance & 622 & 369.1652 & 0.0257 \\
\hline Pearson Chi-Square & 622 & 652.0390 & 1.0497 \\
\hline Scaled Pearson X2 & 622 & 852.9390 & 1.0497 \\
\hline Log Likelihood & & -300.4053 & \\
\hline Full Log Likelihood & & -400.3050 & \\
\hline AIC (smaller is better) & & 810.6118 & \\
\hline AICC (smaller is better) & & 810.7086 & \\
\hline BIC (smaller is better) & & 8328085 & \\
\hline
\end{tabular}

Algoritm comerged.

\begin{tabular}{|c|c|c|c|c|c|c|c|}
\hline \multirow{3}{*}{$\begin{array}{l}\text { Parameter } \\
\text { Intercept }\end{array}$} & \multicolumn{6}{|c|}{ Analysis of Maximum Likelihood Parameter Estimates } & \multirow[b]{2}{*}{ Pr $>$ Chisq } \\
\hline & \multirow{2}{*}{$\frac{D F}{1}$} & \multirow{2}{*}{$\begin{array}{l}\text { Estimate } \\
-2284229\end{array}$} & \multirow{2}{*}{$\begin{array}{r}\text { Standard } \\
\text { Error }\end{array}$} & \multicolumn{2}{|c|}{$\begin{array}{l}\text { Wald } 95 \% \text { Confidence } \\
\text { Limits }\end{array}$} & \multirow{2}{*}{$\begin{array}{r}\text { Wald Chi- } \\
\text { Square } \\
2.58\end{array}$} & \\
\hline & & & & -13.825177 & 1.3883311 & & 0.1081 \\
\hline LnExpo & 1 & .304905877 & 0.3408050 & -02730873 & 1.0630791 & 1.34 & 0.2465 \\
\hline Can & 1 & .414140343 & 0.2792100 & -0.1331011 & 0.9613818 & 2.20 & 0.1380 \\
\hline HighFlow & 1 & .508820531 & 0.3880020 & -02518270 & 1.2694687 & 1.72 & 0.1898 \\
\hline Dispersion & 1 & 1.20514424 & 0.3688750 & 0.6723001 & 2.1000042 & & \\
\hline
\end{tabular}


SAS Output

The SAS System

The GEMMOD Procedure

\begin{tabular}{|lr|}
\hline \multicolumn{2}{|c|}{ Wodel Information } \\
\hline Data Set & WORK. TESTDATA \\
Distribution & Negative Binomial \\
Link Function & Log \\
Dependent Variable & Accidents Accidents \\
\hline
\end{tabular}

Number of Observations Read 028

Number of Observations Used 628

\begin{tabular}{|c|c|c|c|}
\hline \multicolumn{4}{|c|}{ Criteria For Assessing Goodness of Fit } \\
\hline Criterion & DF & Value & Valuedof \\
\hline Deviance & 624 & 389.7707 & 0.6246 \\
\hline Scaled Deviance & 624 & 399.7797 & 0.0246 \\
\hline Pearson Chi-Square & 624 & 640.3850 & 1.0203 \\
\hline Scaled Pearson $X_{2}$ & 624 & 40.3858 & 1.0203 \\
\hline Log Likelihood & & -300.0163 & \\
\hline Full Log Likelihood & & -300.8260 & \\
\hline AlC (smaller is better) & & 809.6530 & \\
\hline AICC (smalker is better) & & 800.7503 & \\
\hline BIC (smaller is betten) & & 831.8668 & \\
\hline
\end{tabular}

Agoritum comerged.

\begin{tabular}{|c|c|c|c|c|c|c|c|}
\hline \multirow{2}{*}{ Parameter } & \multicolumn{6}{|c|}{ Analysis Of Maximum Likelihood Parameter Estimates } & \multirow[b]{2}{*}{ Pr $>$ Chisq } \\
\hline & DF & Estimate & $\begin{array}{r}\text { Standard } \\
\text { Error }\end{array}$ & $\begin{array}{l}\text { Wald 95\% } \\
\text { Lin }\end{array}$ & $\begin{array}{l}\text { nfidence } \\
8\end{array}$ & $\begin{array}{l}\text { Wald Chi- } \\
\text { Square }\end{array}$ & \\
\hline Intercept & 1 & -6.9671087 & 2.6824532 & -12.224020 & -1.7005971 & 9.75 & 0.0004 \\
\hline LnExpo & 1 & .458601130 & 0.2332634 & 0.0015032 & 0.8158781 & 3.87 & 0.0483 \\
\hline Cam & 1 & .380971598 & 0.2789288 & -0.1705225 & 0.8134867 & 1.73 & 0.1881 \\
\hline SRN & 1 & .520400054 & 0.2064250 & 0.0001772 & 1.0406241 & 3.84 & 0.0400 \\
\hline Dispersion & 1 & 1.18514220 & 0.3556903 & 0.6581183 & 2.1342001 & & \\
\hline
\end{tabular}




\section{SAS Output}

The SAS System

The Geilloo Procedire

\begin{tabular}{|c|c|}
\hline \multicolumn{2}{|c|}{ Natel tafommotion } \\
\hline Data set & MORK JESTDATA \\
\hline Distribution & Negithe Bhombl \\
\hline Lak Funation & $\log$ \\
\hline Deperdent Wariolite & Aocideris Aocidents \\
\hline
\end{tabular}

Rumber of Otservations Read 620 Number of Observations Used 626

Miscing Vilues

Criterit For Assesxing Goodness of FA

Criterion DF Vane Valtuent

Deväariase

$621 \quad 389.3613 \quad 0.6270$

Sealed Deviance

$621389.3613 \quad 0.5270$

Pearsonchi-square $6216361119 \quad 1.0243$

ScaledPearwomX2 $6216361119 \quad 1.0243$

Log Linethood

$-3592067$

Fill Log Libutinod $\quad$-399.0974

ALC (smmer is better) 810.194

ACC (smoller is better) 810.3304

BNC (smoller is better) $\quad 836.8300$

Agariun contrerged.

\begin{tabular}{|c|c|c|c|c|c|c|c|}
\hline \multirow[b]{2}{*}{ Parrmater } & \multicolumn{6}{|c|}{ Antysis Of Monimam Livalinood Paraneter Estimates } & \multirow[b]{2}{*}{$\mathrm{Pr} \times \mathrm{ChiSq}$} \\
\hline & DF & Estimnte & Standird Eror & Wrid 95x Con & Aderno Limits & Wald Ch-square & \\
\hline Whercept & 1 & -6.2593607 & 3.6094770 & $-13 \cdot 602595$ & 1.3638741 & 2.59 & 0.1075 \\
\hline LnExpo & 1 & 395981514 & 0.3120418 & -0.2744091 & 1.0663711 & 1.34 & 0.2470 \\
\hline $\cos$ & 1 & 365940609 & 0.2600359 & -0.1629213 & 0.9140033 & 1.71 & 0.1913 \\
\hline Hohflow & 1 & .111173271 & $0.46538 \% 1$ & -0.0029306 & 1.0052772 & 0.06 & 0.8116 \\
\hline san & 1 & 491196019 & 0.3179535 & -0.1319613 & 1.1143733 & 239 & 0.1224 \\
\hline Disparsion & 1 & 1.17190863 & 0.3532557 & 0.6491684 & 2.1156730 & & \\
\hline
\end{tabular}

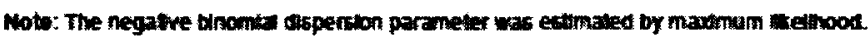


SAS Output

The SAS System

The GENMOD Procedure

\begin{tabular}{|lr|}
\hline \multicolumn{2}{|c|}{ Model Information } \\
\hline Data Set & WORK.TESTDATA \\
Distribution & Negative Binonial \\
Link Function & Log \\
Dependent Variable & Acoidents Accidents \\
\hline
\end{tabular}

Number of Observations Read 628 Number of Observations Used 620 Missing Vahes 2

\begin{tabular}{|c|c|c|c|}
\hline \multicolumn{4}{|c|}{ Criteria For Assessing Goodness of Fit } \\
\hline Criterion & $\mathbf{D F}$ & Value & ValueloF \\
\hline Deviance & 623 & 300.3466 & 0.0266 \\
\hline Scaled Deviance & 623 & 390.3406 & 0.0260 \\
\hline Pearson Chi-Square & a23 & 060.5870 & 1.0587 \\
\hline Scaled Pearson $\times 2$ & 623 & 058.5870 & 1.0587 \\
\hline Log Likelinood & & -361.5663 & \\
\hline Full Log Likelihood & & -401.3760 & \\
\hline AIC (smaller is better) & & 810.7537 & \\
\hline AICC (smaller is better) & & 810.8182 & \\
\hline BIC (smaller is better) & & 828.5111 & \\
\hline
\end{tabular}

Agoritim comerged

\begin{tabular}{|l|rrrrrrr|}
\hline \multicolumn{7}{|c|}{ Analysis Of Maximum Likelihood Parameter Estimates } \\
Parameter & DF & Estimate & $\begin{array}{r}\text { Standard } \\
\text { Error }\end{array}$ & Wald 95\% Confidence & Wimits & Wald Chi- \\
Square Pr > ChiSq
\end{tabular}




\section{SAS Output}

The SAS System

The GEMMOD Procedure

\begin{tabular}{|lr|}
\hline \multicolumn{2}{|c|}{ Model Information } \\
\hline Data Set & Work.TESTDATA \\
Distribution & Negative Binomia \\
Link Function & Log \\
Dependent Variable & Accidents Accidents \\
\hline
\end{tabular}

Number of Observations Read 628

Number of Observations Used

Criteria For Assessing Goodness Of Fit

\begin{tabular}{|c|c|c|c|}
\hline Criterion & DF & Value & ValuelDF \\
\hline Deviance & 625 & 300.9404 & 0.0256 \\
\hline Scaled Deviance & 025 & 300.9494 & 0.6255 \\
\hline Pearson Chi-Square & 625 & 645.6051 & 1.0331 \\
\hline Scaled Pearson $\times 2$ & 025 & 845.6951 & 1.0331 \\
\hline Log Likelihood & & -300.8023 & \\
\hline Full Log Likelihood & & -400.0730 & \\
\hline AIC (smaller is better) & & 809.3459 & \\
\hline AICC (smaller is better) & & 800.4101 & \\
\hline BIC (smaller is better) & & 827.1161 & \\
\hline
\end{tabular}

Agorittm converged

\begin{tabular}{|c|c|c|c|c|c|c|c|}
\hline \multirow{2}{*}{ Parameter } & \multicolumn{6}{|c|}{ Analysis of Maximum Likelihood Parameter Estimates } & \multirow[b]{2}{*}{ Pr $>$ ChiSq } \\
\hline & DF & Estimate & $\begin{array}{l}\text { Standard } \\
\text { Error }\end{array}$ & $\begin{array}{r}\text { Wald } 95 \% \\
\text { Lin }\end{array}$ & nfidence & $\begin{array}{l}\text { Wald Chi- } \\
\text { Square }\end{array}$ & \\
\hline Intercept & 1 & -7.2045612 & 2.6891178 & -12.475135 & -1.8339872 & 7.18 & 0.0074 \\
\hline LnExpo & 1 & .481491262 & 0.2337098 & 0.0234285 & 0.0305540 & 4.24 & 0.0394 \\
\hline SRN & 1 & .5402350060 & 0.2650551 & 0.0195607 & 1.0000095 & 4.14 & 0.0420 \\
\hline Dispersion & 1 & 1.10180043 & 0.3576454 & 0.6818879 & 2.1400513 & & \\
\hline
\end{tabular}

Wote: The negative binomial dispersion parameter was estimated by maximum thelhood. 


\section{Appendix D}

\section{SAS Input \& Output - 1000m Radius Influence Area}




\begin{tabular}{|c|c|c|c|c|c|c|c|c|c|c|}
\hline $\begin{array}{c}\text { Case } \\
\#\end{array}$ & SRN & Highflow & AADT & LnAADT & Length & LnLength & Expo & LnExpo & Accidents & Cam \\
\hline 1 & 0 & 0 & 29754 & 10.30 & 1.30 & 0.26 & 38606 & 10.56 & 2 & 0 \\
\hline 2 & 1 & 1 & 113516 & 11.64 & 5.64 & 1.73 & 640150 & 13.37 & 0 & 1 \\
\hline 3 & 0 & 0 & 21769 & 9.99 & 3.60 & 1.28 & 78472 & 11.27 & 0 & 0 \\
\hline 4 & 0 & 0 & 18609 & 9.83 & 5.50 & 1.71 & 102436 & 11.54 & 1 & 0 \\
\hline 5 & 1 & 0 & 64545 & 11.08 & 5.42 & 1.69 & 349932 & 12.77 & 2 & 0 \\
\hline 6 & 0 & 0 & 72056 & 11.19 & 5.33 & 1.67 & 383981 & 12.86 & 0 & 0 \\
\hline 7 & 0 & 0 & 49538 & 10.81 & 5.33 & 1.67 & 263984 & 12.48 & 0 & 0 \\
\hline 8 & 0 & 0 & 20157 & 9.91 & 3.30 & 1.19 & 66585 & 11.11 & 0 & 0 \\
\hline 9 & 0 & 0 & 34615 & 10.45 & 5.28 & 1.66 & 182882 & 12.12 & 0 & 0 \\
\hline 10 & 1 & 1 & 100357 & 11.52 & 5.21 & 1.65 & 523005 & 13.17 & 0 & 0 \\
\hline 11 & 0 & 0 & 56744 & 10.95 & 5.17 & 1.64 & 293244 & 12.59 & 1 & 0 \\
\hline 12 & 0 & 0 & 37589 & 10.53 & 3.14 & 1.14 & 117941 & 11.68 & 0 & 0 \\
\hline 13 & 0 & 0 & 63049 & 11.05 & 5.12 & 1.63 & 322496 & 12.68 & 0 & 0 \\
\hline 14 & 0 & 0 & 54042 & 10.90 & 5.11 & 1.63 & 276274 & 12.53 & 0 & 1 \\
\hline 15 & 1 & 1 & 112711 & 11.63 & 5.08 & 1.63 & 572763 & 13.26 & 0 & 0 \\
\hline 16 & 1 & 1 & 103521 & 11.55 & 5.02 & 1.61 & 519270 & 13.16 & 2 & 0 \\
\hline 17 & 1 & 1 & 115259 & 11.65 & 4.99 & 1.61 & 575333 & 13.26 & 2 & 0 \\
\hline 18 & 1 & 1 & 101623 & 11.53 & 4.99 & 1.61 & 506941 & 13.14 & 0 & 0 \\
\hline 19 & 1 & 1 & 115727 & 11.66 & 4.97 & 1.60 & 575165 & 13.26 & 1 & 0 \\
\hline 20 & 1 & 1 & 113014 & 11.64 & 4.94 & 1.60 & 557741 & 13.23 & 1 & 0 \\
\hline 21 & 1 & 0 & 94038 & 11.45 & 4.89 & 1.59 & 459437 & 13.04 & 0 & 1 \\
\hline 22 & 0 & 0 & 31635 & 10.36 & 4.88 & 1.58 & 154321 & 11.95 & 1 & 0 \\
\hline 23 & 1 & 1 & 96817 & 11.48 & 4.85 & 1.58 & 469733 & 13.06 & 4 & 0 \\
\hline 24 & 1 & 1 & 114337 & 11.65 & 4.83 & 1.57 & 552239 & 13.22 & 0 & 0 \\
\hline 25 & 1 & 1 & 101261 & 11.53 & 4.71 & 1.55 & 476708 & 13.07 & 1 & 1 \\
\hline 26 & 1 & 1 & 117103 & 11.67 & 4.71 & 1.55 & 551011 & 13.22 & 2 & 1 \\
\hline 27 & 0 & 0 & 41869 & 10.64 & 4.68 & 1.54 & 195928 & 12.19 & 0 & 0 \\
\hline 28 & 0 & 0 & 26796 & 10.20 & 4.66 & 1.54 & 124983 & 11.74 & 0 & 0 \\
\hline 29 & 1 & 1 & 110516 & 11.61 & 4.64 & 1.53 & 512705 & 13.15 & 0 & 0 \\
\hline 30 & 0 & 0 & 27913 & 10.24 & 4.62 & 1.53 & 128864 & 11.77 & 0 & 0 \\
\hline 31 & 0 & 0 & 59706 & 11.00 & 4.59 & 1.52 & 273889 & 12.52 & 0 & 1 \\
\hline 32 & 0 & 0 & 36928 & 10.52 & 4.56 & 1.52 & 168452 & 12.03 & 1 & 0 \\
\hline 33 & 1 & 0 & 82986 & 11.33 & 4.56 & 1.52 & 378454 & 12.84 & 1 & 0 \\
\hline 34 & 0 & 0 & 26052 & 10.17 & 4.56 & 1.52 & 118676 & 11.68 & 1 & 0 \\
\hline 35 & 1 & 0 & 82986 & 11.33 & 4.55 & 1.52 & 377878 & 12.84 & 1 & 0 \\
\hline 36 & 1 & 1 & 106038 & 11.57 & 4.54 & 1.51 & 481766 & 13.09 & 2 & 0 \\
\hline 37 & 0 & 0 & 49299 & 10.81 & 4.52 & 1.51 & 223013 & 12.31 & 0 & 0 \\
\hline 38 & 1 & 1 & 116181 & 11.66 & 4.52 & 1.51 & 524742 & 13.17 & 2 & 0 \\
\hline 39 & 0 & 0 & 33250 & 10.41 & 4.49 & 1.50 & 149454 & 11.91 & 1 & 0 \\
\hline 40 & 0 & 1 & 108932 & 11.60 & 4.39 & 1.48 & 478507 & 13.08 & 4 & 0 \\
\hline 41 & 1 & 1 & 117942 & 11.68 & 4.39 & 1.48 & 517934 & 13.16 & 0 & 1 \\
\hline 42 & 1 & 0 & 36883 & 10.52 & 4.38 & 1.48 & 161724 & 11.99 & 0 & 0 \\
\hline 43 & 0 & 0 & 3628 & 8.20 & 4.38 & 1.48 & 15882 & 9.67 & 2 & 1 \\
\hline 44 & 1 & 1 & 101984 & 11.53 & 4.38 & 1.48 & 446297 & 13.01 & 0 & 0 \\
\hline 45 & 1 & 1 & 108804 & 11.60 & 4.35 & 1.47 & 473031 & 13.07 & 1 & 0 \\
\hline 46 & 1 & 0 & 53536 & 10.89 & 4.34 & 1.47 & 232572 & 12.36 & 3 & 1 \\
\hline
\end{tabular}




\begin{tabular}{|c|c|c|c|c|c|c|c|c|c|c|}
\hline 47 & 0 & 0 & 31635 & 10.36 & 4.33 & 1.46 & 136882 & 11.83 & 0 & 0 \\
\hline 48 & 1 & 1 & 103702 & 11.55 & 4.32 & 1.46 & 447978 & 13.01 & 0 & 0 \\
\hline 49 & 1 & 1 & 103069 & 11.54 & 4.31 & 1.46 & 444020 & 13.00 & 2 & 0 \\
\hline 50 & 0 & 0 & 37829 & 10.54 & 4.30 & 1.46 & 162734 & 12.00 & 2 & 0 \\
\hline 51 & 1 & 1 & 111206 & 11.62 & 4.30 & 1.46 & 477992 & 13.08 & 0 & 0 \\
\hline 52 & 0 & 0 & 54042 & 10.90 & 4.28 & 1.45 & 231178 & 12.35 & 4 & 0 \\
\hline 53 & 1 & 1 & 119406 & 11.69 & 4.27 & 1.45 & 510385 & 13.14 & 2 & 1 \\
\hline 54 & 1 & 1 & 119405 & 11.69 & 4.26 & 1.45 & 509147 & 13.14 & 2 & 0 \\
\hline 55 & 0 & 0 & 30704 & 10.33 & 4.26 & 1.45 & 130755 & 11.78 & 3 & 0 \\
\hline 56 & 0 & 1 & 95628 & 11.47 & 4.26 & 1.45 & 407211 & 12.92 & 0 & 1 \\
\hline 57 & 0 & 0 & 36748 & 10.51 & 4.25 & 1.45 & 156327 & 11.96 & 0 & 0 \\
\hline 58 & 1 & 1 & 110516 & 11.61 & 4.25 & 1.45 & 469880 & 13.06 & 0 & 1 \\
\hline 59 & 1 & 1 & 103973 & 11.55 & 4.24 & 1.45 & 441168 & 13.00 & 0 & 0 \\
\hline 60 & 0 & 0 & 67552 & 11.12 & 4.24 & 1.45 & 286606 & 12.57 & 1 & 0 \\
\hline 61 & 0 & 0 & 19539 & 9.88 & 4.24 & 1.44 & 82801 & 11.32 & 0 & 0 \\
\hline 62 & 0 & 0 & 41869 & 10.64 & 4.23 & 1.44 & 177112 & 12.08 & 1 & 0 \\
\hline 63 & 1 & 1 & 109726 & 11.61 & 4.22 & 1.44 & 462905 & 13.05 & 1 & 0 \\
\hline 64 & 1 & 0 & 60396 & 11.01 & 4.20 & 1.44 & 253812 & 12.44 & 0 & 0 \\
\hline 65 & 0 & 0 & 52241 & 10.86 & 4.19 & 1.43 & 218904 & 12.30 & 0 & 1 \\
\hline 66 & 0 & 0 & 60399 & 11.01 & 4.17 & 1.43 & 251797 & 12.44 & 0 & 0 \\
\hline 67 & 1 & 1 & 107086 & 11.58 & 4.17 & 1.43 & 446336 & 13.01 & 3 & 1 \\
\hline 68 & 0 & 0 & 20469 & 9.93 & 4.17 & 1.43 & 85288 & 11.35 & 3 & 0 \\
\hline 69 & 0 & 0 & 53141 & 10.88 & 4.17 & 1.43 & 221392 & 12.31 & 2 & 0 \\
\hline 70 & 1 & 1 & 101713 & 11.53 & 4.04 & 1.40 & 411425 & 12.93 & 1 & 0 \\
\hline 71 & 1 & 0 & 57414 & 10.96 & 4.04 & 1.40 & 232054 & 12.35 & 1 & 1 \\
\hline 72 & 1 & 1 & 117997 & 11.68 & 4.04 & 1.40 & 476527 & 13.07 & 4 & 1 \\
\hline 73 & 1 & 1 & 108494 & 11.59 & 4.00 & 1.39 & 433635 & 12.98 & 0 & 0 \\
\hline 74 & 1 & 1 & 114337 & 11.65 & 3.98 & 1.38 & 455522 & 13.03 & 0 & 0 \\
\hline 75 & 1 & 1 & 108933 & 11.60 & 3.98 & 1.38 & 433692 & 12.98 & 1 & 0 \\
\hline 76 & 0 & 0 & 31542 & 10.36 & 3.98 & 1.38 & 125487 & 11.74 & 2 & 0 \\
\hline 77 & 1 & 1 & 104522 & 11.56 & 3.97 & 1.38 & 415139 & 12.94 & 2 & 0 \\
\hline 78 & 1 & 1 & 100628 & 11.52 & 3.96 & 1.38 & 398920 & 12.90 & 2 & 0 \\
\hline 79 & 1 & 0 & 59474 & 10.99 & 3.96 & 1.38 & 235255 & 12.37 & 0 & 0 \\
\hline 80 & 0 & 0 & 54492 & 10.91 & 3.94 & 1.37 & 214819 & 12.28 & 1 & 0 \\
\hline 81 & 0 & 0 & 32565 & 10.39 & 3.93 & 1.37 & 127992 & 11.76 & 1 & 0 \\
\hline 82 & 0 & 0 & 71155 & 11.17 & 3.90 & 1.36 & 277260 & 12.53 & 1 & 0 \\
\hline 83 & 1 & 1 & 113918 & 11.64 & 3.88 & 1.36 & 442074 & 13.00 & 1 & 1 \\
\hline 84 & 1 & 0 & 71921 & 11.18 & 3.87 & 1.35 & 278125 & 12.54 & 0 & 0 \\
\hline 85 & 1 & 0 & 59935 & 11.00 & 3.86 & 1.35 & 231549 & 12.35 & 2 & 0 \\
\hline 86 & 1 & 1 & 108042 & 11.59 & 3.86 & 1.35 & 417278 & 12.94 & 3 & 0 \\
\hline 87 & 1 & 1 & 110302 & 11.61 & 3.86 & 1.35 & 425537 & 12.96 & 2 & 1 \\
\hline 88 & 0 & 0 & 62339 & 11.04 & 3.86 & 1.35 & 240347 & 12.39 & 0 & 1 \\
\hline 89 & 1 & 1 & 108042 & 11.59 & 3.81 & 1.34 & 411472 & 12.93 & 0 & 0 \\
\hline 90 & 1 & 0 & 78376 & 11.27 & 3.80 & 1.34 & 298060 & 12.61 & 1 & 0 \\
\hline 91 & 0 & 0 & 71155 & 11.17 & 3.78 & 1.33 & 269155 & 12.50 & 2 & 0 \\
\hline 92 & 0 & 0 & 38000 & 10.55 & 3.78 & 1.33 & 143598 & 11.87 & 2 & 0 \\
\hline 93 & 0 & 0 & 46522 & 10.75 & 3.76 & 1.32 & 174937 & 12.07 & 0 & 1 \\
\hline 94 & 1 & 1 & 102436 & 11.54 & 3.75 & 1.32 & 384461 & 12.86 & 0 & 0 \\
\hline
\end{tabular}




\begin{tabular}{|c|c|c|c|c|c|c|c|c|c|c|}
\hline 95 & 1 & 1 & 110187 & 11.61 & 3.74 & 1.32 & 411587 & 12.93 & 1 & 0 \\
\hline 96 & 0 & 0 & 54492 & 10.91 & 3.73 & 1.32 & 203371 & 12.22 & 0 & 1 \\
\hline 97 & 1 & 1 & 112110 & 11.63 & 3.73 & 1.32 & 418374 & 12.94 & 1 & 1 \\
\hline 98 & 0 & 0 & 40313 & 10.60 & 3.71 & 1.31 & 149735 & 11.92 & 0 & 0 \\
\hline 99 & 0 & 0 & 54042 & 10.90 & 3.71 & 1.31 & 200342 & 12.21 & 1 & 1 \\
\hline 100 & 1 & 1 & 113415 & 11.64 & 3.64 & 1.29 & 412585 & 12.93 & 1 & 1 \\
\hline 101 & 0 & 0 & 50175 & 10.82 & 3.62 & 1.29 & 181775 & 12.11 & 2 & 1 \\
\hline 102 & 0 & 0 & 32379 & 10.39 & 3.62 & 1.29 & 117072 & 11.67 & 1 & 0 \\
\hline 103 & 1 & 1 & 115589 & 11.66 & 3.61 & 1.28 & 417554 & 12.94 & 4 & 1 \\
\hline 104 & 0 & 1 & 108932 & 11.60 & 3.61 & 1.28 & 393027 & 12.88 & 0 & 1 \\
\hline 105 & 0 & 0 & 43493 & 10.68 & 3.59 & 1.28 & 156174 & 11.96 & 0 & 1 \\
\hline 106 & 0 & 0 & 49538 & 10.81 & 3.57 & 1.27 & 177082 & 12.08 & 1 & 0 \\
\hline 107 & 0 & 0 & 71155 & 11.17 & 3.55 & 1.27 & 252434 & 12.44 & 1 & 0 \\
\hline 108 & 0 & 0 & 37217 & 10.52 & 3.55 & 1.27 & 132034 & 11.79 & 1 & 0 \\
\hline 109 & 1 & 1 & 113876 & 11.64 & 3.52 & 1.26 & 400834 & 12.90 & 3 & 0 \\
\hline 110 & 0 & 0 & 53030 & 10.88 & 3.51 & 1.26 & 186296 & 12.14 & 1 & 1 \\
\hline 111 & 1 & 1 & 110977 & 11.62 & 3.48 & 1.25 & 386333 & 12.86 & 0 & 1 \\
\hline 112 & 0 & 0 & 46522 & 10.75 & 3.47 & 1.24 & 161250 & 11.99 & 0 & 1 \\
\hline 113 & 1 & 1 & 116585 & 11.67 & 3.44 & 1.24 & 401395 & 12.90 & 4 & 1 \\
\hline 114 & 1 & 1 & 100357 & 11.52 & 3.44 & 1.24 & 345411 & 12.75 & 2 & 1 \\
\hline 115 & 1 & 1 & 111206 & 11.62 & 3.43 & 1.23 & 381634 & 12.85 & 0 & 1 \\
\hline 116 & 0 & 0 & 50175 & 10.82 & 3.40 & 1.22 & 170357 & 12.05 & 1 & 0 \\
\hline 117 & 0 & 0 & 35356 & 10.47 & 3.36 & 1.21 & 118876 & 11.69 & 0 & 0 \\
\hline 118 & 1 & 1 & 115727 & 11.66 & 3.36 & 1.21 & 389052 & 12.87 & 1 & 1 \\
\hline 119 & 0 & 0 & 71155 & 11.17 & 3.36 & 1.21 & 238728 & 12.38 & 1 & 0 \\
\hline 120 & 1 & 1 & 113015 & 11.64 & 3.32 & 1.20 & 375449 & 12.84 & 1 & 1 \\
\hline 121 & 0 & 0 & 54042 & 10.90 & 3.31 & 1.20 & 178823 & 12.09 & 2 & 1 \\
\hline 122 & 0 & 0 & 36028 & 10.49 & 3.27 & 1.19 & 117962 & 11.68 & 1 & 0 \\
\hline 123 & 0 & 0 & 57497 & 10.96 & 3.25 & 1.18 & 186622 & 12.14 & 1 & 1 \\
\hline 124 & 1 & 1 & 100809 & 11.52 & 3.23 & 1.17 & 325970 & 12.69 & 0 & 0 \\
\hline 125 & 1 & 1 & 109398 & 11.60 & 3.22 & 1.17 & 352630 & 12.77 & 1 & 0 \\
\hline 126 & 1 & 1 & 102527 & 11.54 & 3.22 & 1.17 & 329939 & 12.71 & 2 & 0 \\
\hline 127 & 0 & 0 & 33030 & 10.41 & 3.18 & 1.16 & 105153 & 11.56 & 1 & 0 \\
\hline 128 & 1 & 1 & 117946 & 11.68 & 3.14 & 1.14 & 370432 & 12.82 & 1 & 0 \\
\hline 129 & 0 & 0 & 31444 & 10.36 & 3.07 & 1.12 & 96555 & 11.48 & 1 & 0 \\
\hline 130 & 0 & 0 & 58546 & 10.98 & 3.05 & 1.12 & 178815 & 12.09 & 1 & 1 \\
\hline 131 & 0 & 0 & 31635 & 10.36 & 3.02 & 1.10 & 95491 & 11.47 & 0 & 0 \\
\hline 132 & 1 & 0 & 53223 & 10.88 & 3.00 & 1.10 & 159512 & 11.98 & 0 & 1 \\
\hline 133 & 1 & 0 & 59750 & 11.00 & 2.99 & 1.10 & 178879 & 12.09 & 1 & 0 \\
\hline 134 & 0 & 1 & 122005 & 11.71 & 2.96 & 1.08 & 361057 & 12.80 & 1 & 1 \\
\hline 135 & 0 & 0 & 32251 & 10.38 & 2.96 & 1.08 & 95324 & 11.47 & 0 & 0 \\
\hline 136 & 0 & 0 & 58545 & 10.98 & 2.95 & 1.08 & 172637 & 12.06 & 1 & 0 \\
\hline 137 & 1 & 0 & 64545 & 11.08 & 2.95 & 1.08 & 190261 & 12.16 & 1 & 0 \\
\hline 138 & 1 & 1 & 119516 & 11.69 & 2.92 & 1.07 & 349189 & 12.76 & 0 & 0 \\
\hline 139 & 1 & 0 & 68233 & 11.13 & 2.88 & 1.06 & 196386 & 12.19 & 1 & 0 \\
\hline 140 & 1 & 0 & 59474 & 10.99 & 2.84 & 1.04 & 168943 & 12.04 & 0 & 0 \\
\hline 141 & 0 & 0 & 38701 & 10.56 & 2.79 & 1.03 & 107892 & 11.59 & 2 & 1 \\
\hline 142 & 1 & 1 & 101261 & 11.53 & 2.66 & 0.98 & 269645 & 12.50 & 0 & 0 \\
\hline
\end{tabular}




\begin{tabular}{|c|c|c|c|c|c|c|c|c|c|c|}
\hline 143 & 0 & 0 & 57194 & 10.95 & 2.66 & 0.98 & 151890 & 11.93 & 1 & 0 \\
\hline 144 & 1 & 0 & 93129 & 11.44 & 2.58 & 0.95 & 240351 & 12.39 & 1 & 0 \\
\hline 145 & 0 & 0 & 37682 & 10.54 & 2.51 & 0.92 & 94727 & 11.46 & 1 & 0 \\
\hline 146 & 0 & 0 & 72056 & 11.19 & 2.50 & 0.92 & 180110 & 12.10 & 0 & 0 \\
\hline 147 & 1 & 1 & 117083 & 11.67 & 2.49 & 0.91 & 291110 & 12.58 & 2 & 0 \\
\hline 148 & 1 & 1 & 108494 & 11.59 & 2.46 & 0.90 & 267247 & 12.50 & 0 & 0 \\
\hline 149 & 1 & 1 & 110648 & 11.61 & 2.46 & 0.90 & 272427 & 12.52 & 2 & 0 \\
\hline 150 & 0 & 0 & 32565 & 10.39 & 2.32 & 0.84 & 75555 & 11.23 & 0 & 0 \\
\hline 151 & 0 & 0 & 76000 & 11.24 & 2.32 & 0.84 & 176126 & 12.08 & 1 & 0 \\
\hline 152 & 1 & 1 & 102165 & 11.53 & 2.30 & 0.83 & 234963 & 12.37 & 4 & 0 \\
\hline 153 & 1 & 1 & 107590 & 11.59 & 2.30 & 0.83 & 247016 & 12.42 & 1 & 0 \\
\hline 154 & 1 & 1 & 104694 & 11.56 & 2.23 & 0.80 & 233502 & 12.36 & 0 & 1 \\
\hline 155 & 1 & 1 & 119980 & 11.70 & 2.21 & 0.79 & 265070 & 12.49 & 1 & 0 \\
\hline 156 & 1 & 0 & 82986 & 11.33 & 2.19 & 0.78 & 181487 & 12.11 & 1 & 0 \\
\hline 157 & 0 & 0 & 37217 & 10.52 & 2.11 & 0.75 & 78423 & 11.27 & 0 & 0 \\
\hline 158 & 1 & 1 & 108494 & 11.59 & 2.02 & 0.70 & 219248 & 12.30 & 5 & 0 \\
\hline 159 & 0 & 0 & 53030 & 10.88 & 2.02 & 0.70 & 106963 & 11.58 & 2 & 0 \\
\hline 160 & 1 & 1 & 112493 & 11.63 & 1.94 & 0.66 & 218518 & 12.29 & 0 & 0 \\
\hline 161 & 0 & 0 & 58545 & 10.98 & 1.93 & 0.66 & 112932 & 11.63 & 0 & 0 \\
\hline 162 & 1 & 1 & 110165 & 11.61 & 1.93 & 0.66 & 212324 & 12.27 & 2 & 1 \\
\hline 163 & 1 & 1 & 107409 & 11.58 & 1.91 & 0.65 & 204869 & 12.23 & 0 & 0 \\
\hline 164 & 1 & 1 & 104522 & 11.56 & 1.89 & 0.64 & 197916 & 12.20 & 0 & 0 \\
\hline 165 & 1 & 1 & 107882 & 11.59 & 1.88 & 0.63 & 202637 & 12.22 & 1 & 0 \\
\hline 166 & 1 & 0 & 60857 & 11.02 & 1.87 & 0.63 & 113981 & 11.64 & 4 & 0 \\
\hline 167 & 1 & 1 & 102165 & 11.53 & 1.79 & 0.58 & 182958 & 12.12 & 1 & 1 \\
\hline 168 & 1 & 0 & 60672 & 11.01 & 1.79 & 0.58 & 108466 & 11.59 & 0 & 0 \\
\hline 169 & 0 & 0 & 23382 & 10.06 & 1.73 & 0.55 & 40442 & 10.61 & 0 & 0 \\
\hline 170 & 1 & 1 & 104522 & 11.56 & 1.72 & 0.54 & 179483 & 12.10 & 4 & 1 \\
\hline 171 & 1 & 1 & 101798 & 11.53 & 1.72 & 0.54 & 174711 & 12.07 & 0 & 1 \\
\hline 172 & 0 & 0 & 41869 & 10.64 & 1.69 & 0.52 & 70692 & 11.17 & 3 & 0 \\
\hline 173 & 1 & 1 & 108356 & 11.59 & 1.68 & 0.52 & 182572 & 12.11 & 1 & 1 \\
\hline 174 & 0 & 0 & 32251 & 10.38 & 1.68 & 0.52 & 54056 & 10.90 & 2 & 0 \\
\hline 175 & 0 & 0 & 23261 & 10.05 & 1.67 & 0.51 & 38768 & 10.57 & 0 & 0 \\
\hline 176 & 1 & 1 & 117103 & 11.67 & 1.61 & 0.47 & 188226 & 12.15 & 0 & 1 \\
\hline 177 & 1 & 0 & 59935 & 11.00 & 1.50 & 0.41 & 89984 & 11.41 & 1 & 0 \\
\hline 178 & 1 & 1 & 100809 & 11.52 & 1.47 & 0.38 & 148061 & 11.91 & 0 & 0 \\
\hline 179 & 1 & 1 & 109579 & 11.60 & 1.45 & 0.37 & 159202 & 11.98 & 1 & 0 \\
\hline 180 & 0 & 0 & 24188 & 10.09 & 1.43 & 0.36 & 34669 & 10.45 & 0 & 0 \\
\hline 181 & 1 & 1 & 115259 & 11.65 & 1.41 & 0.34 & 162001 & 12.00 & 6 & 1 \\
\hline 182 & 0 & 0 & 32565 & 10.39 & 1.35 & 0.30 & 43845 & 10.69 & 1 & 0 \\
\hline 183 & 1 & 1 & 97850 & 11.49 & 1.33 & 0.28 & 129770 & 11.77 & 0 & 0 \\
\hline 184 & 1 & 1 & 99584 & 11.51 & 1.33 & 0.28 & 131954 & 11.79 & 0 & 0 \\
\hline 185 & 0 & 0 & 24188 & 10.09 & 1.27 & 0.24 & 30705 & 10.33 & 0 & 0 \\
\hline 186 & 1 & 1 & 103431 & 11.55 & 1.03 & 0.03 & 107024 & 11.58 & 1 & 0 \\
\hline 187 & 0 & 0 & 53965 & 10.90 & 0.33 & -1.11 & 17740 & 9.78 & 1 & 1 \\
\hline
\end{tabular}




\section{SAS Output}

The SAS System

The GEMWOD Procedure

\begin{tabular}{|lr|}
\hline \multicolumn{2}{|c|}{ Model Information } \\
\hline Data Set & WORK.TESTDATA \\
Distribution & Negative Binomial \\
Link Function & Log \\
Dependent Variable & Accidents Accidents \\
\hline
\end{tabular}

Number of Observations Read 194

Number of Observations Used 187

Missing Vahues

7

\begin{tabular}{|c|c|c|c|}
\hline \multicolumn{4}{|c|}{ Criteria For Assessing Goodness Of Fit } \\
\hline Criterion & DF & Value & Valuelof \\
\hline Deviance & 185 & 202.1401 & 1.0926 \\
\hline Scaled Deviance & 185 & 202.1401 & 1.0926 \\
\hline Pearson Chi-Square & 186 & 183.1668 & 0.9001 \\
\hline Scaled Pearson X2 & 185 & 183.1808 & 0.9801 \\
\hline Log Likelihood & & -180.4473 & \\
\hline Full Log Likelihood & & -253.7533 & \\
\hline AIC (smaller is better) & & 513.5005 & \\
\hline AICC (smaller is better) & & 513.6377 & \\
\hline BIC (smaller is better) & & 523.1909 & \\
\hline
\end{tabular}

Algonithen comverged.

\begin{tabular}{|c|c|c|c|c|c|c|c|}
\hline \multirow{2}{*}{ Parameter } & \multicolumn{6}{|c|}{ Analysis Of Maximum Likelihood Parameter Estimates } & \multirow[b]{2}{*}{ Pr $>$ Chisq } \\
\hline & DF & Estimete & $\begin{array}{r}\text { Standard } \\
\text { Error }\end{array}$ & $\begin{array}{r}\text { Wald } 95 \% \mathrm{C} \\
\text { Lim }\end{array}$ & nfidence & $\begin{array}{l}\text { Wald Chi- } \\
\text { Square }\end{array}$ & \\
\hline Intercept & 1 & -42627053 & 0.2185710 & -0.8546619 & 0.0021208 & 3.80 & 0.0511 \\
\hline AADT & 1 & .000005080 & 0.0000025 & 0.00000003 & 0.0000100 & 5.10 & 0.0239 \\
\hline Dispersion & 1 & .281023894 & 0.1406467 & 0.1053002 & 0.7493007 & & \\
\hline
\end{tabular}

Mote: The negative binoriat dispersion parameter was estimated by maximum tikelhood. 
SAS Output

The SAS System

The GEMMOD Procedure

\begin{tabular}{|lr|}
\hline \multicolumn{2}{|c|}{ Model Information } \\
\hline Data Set & WORK.TESTDATA \\
Distribution & Negative Binomial \\
Link Function & Log \\
Dependent Variable & Accidents Accidents \\
\hline
\end{tabular}

Number of Observations Read 194

Number of Observations Used 187

Missing Values

7

\begin{tabular}{|lrrr|}
\hline \multicolumn{4}{|c|}{ Criteria For Assessing Goodness Of Fit } \\
Criterion & DF & Value & ValuelDF \\
\hline Deviance & 184 & 202.2304 & 1.0091 \\
Scaled Deviance & 184 & 202.2394 & 1.0081 \\
Pearson Chi-Square & 194 & 181.7480 & 0.9878 \\
Scaled Pearson X2 & 184 & 181.7480 & 0.9878 \\
Log Likelihood & & -180.1554 & \\
Full Log Likelihood & -253.4613 & \\
AlC (smaller is better) & 514.0220 & \\
AICC (smaller is better) & 515.1424 \\
BIC (smaller is better) & 527.8471 \\
\hline
\end{tabular}

Algoritum comerget.

\begin{tabular}{|c|c|c|c|c|c|c|c|}
\hline \multirow{3}{*}{$\begin{array}{l}\text { Parameter } \\
\text { Intercept }\end{array}$} & \multicolumn{6}{|c|}{ Analysis of Maximum Likelihood Parameter Estimates } & \multirow[b]{2}{*}{ Pr $>$ Chisq } \\
\hline & \multirow{2}{*}{$\frac{D F}{1}$} & \multirow{2}{*}{$\begin{array}{l}\text { Estimate } \\
-23120160\end{array}$} & \multirow{2}{*}{$\begin{array}{r}\text { Standard } \\
\text { Error }\end{array}$} & \multicolumn{2}{|c|}{$\begin{array}{c}\text { Wakd 95\% Confidence } \\
\text { Limits }\end{array}$} & \multirow{2}{*}{$\begin{array}{r}\text { Wald Chi- } \\
\text { Square }\end{array}$} & \\
\hline & & & & -0.8958052 & 0.4230219 & & 0.4894 \\
\hline AADT & $\mathbf{1}$ & .000005060 & 0.0000025 & 0.0000007 & 0.0000100 & 5.07 & 0.0244 \\
\hline Length & 1 & -.05607127 & 0.0728992 & 0.1980471 & 0.0871045 & 0.59 & 0.4432 \\
\hline Dispersion & 1 & .275761353 & 0.1396370 & 0.1020000 & 0.7450284 & & \\
\hline
\end{tabular}


SAS Output

The SAS System

The GENMOD Procedure

\begin{tabular}{|lr|}
\hline \multicolumn{2}{|c|}{ Model Information } \\
\hline Data Set & WORK TESTDATA \\
Distribution & Negative Binomial \\
Link Function & Log \\
Dependent Variable & Aocidents Acsidents \\
\hline
\end{tabular}

Number of Observations Read 194 Number of Observations Used 187 Missing Vahes 7

\begin{tabular}{|lrrr|}
\hline \multicolumn{4}{|c|}{ Criteria For Assessing Goodness Of Fit } \\
Criterion & DF & Value & ValuelDF \\
\hline Deviance & 185 & 201.8867 & 1.0013 \\
Scaled Deviance & 185 & 201.8867 & 1.0013 \\
Pearson Chi-Square & 185 & 180.0872 & 1.0221 \\
Scaled Pearson X2 & 185 & 189.0872 & 1.0221 \\
Log Likelihood & -1823441 & \\
Full Log Likelihood & -255.0501 & \\
AlC (8maller is better) & 517.3901 \\
AlCC (smaller is better) & 517.4313 \\
BIC (smaller is better) & 520.9035 \\
\hline
\end{tabular}

Algoritum corverged.

\begin{tabular}{|c|c|c|c|c|c|c|c|}
\hline \multirow{2}{*}{ Parameter } & \multicolumn{6}{|c|}{ Analysis of Maximum Likelihood Parameter Estimates } & \multirow[b]{2}{*}{ Pr $>$ Chisq } \\
\hline & DF & Estinate & $\begin{array}{r}\text { Standard } \\
\text { Error }\end{array}$ & $\begin{array}{r}\text { Wald } 95 \% \\
\text { Lim }\end{array}$ & nfidence & $\begin{array}{l}\text { Wald Chi- } \\
\text { Square }\end{array}$ & \\
\hline Intercept & 1 & -.15158946 & 0.4735356 & -0.4917120 & 0.1886351 & 0.78 & 0.3824 \\
\hline Expo & $\mathbf{1}$ & .000000840 & 0.0000000 & -0.0000005 & 0.0000017 & 1.32 & 0.2504 \\
\hline Dispersion & 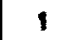 & .312777005 & 0.1454032 & 0.1250855 & 0.7783670 & & \\
\hline
\end{tabular}

Wole: The negative binomial dispersion parameter was estumated by maximum Ikellood. 
SAS Output

The SAS System

The GENMOD Procedure

\begin{tabular}{|lr|}
\hline \multicolumn{2}{|c|}{ Model Information } \\
\hline Data Set & WOPK.TESTDATA \\
Distribution & Negative Binomial \\
Link Function & Log \\
Dependent Variable & Accidents Accidents \\
\hline
\end{tabular}

Number of Observations Read 194 Number of Observations Used 187 Missing Values

\begin{tabular}{|lrrr|}
\hline \multicolumn{4}{|c|}{ Criteria For Assessing Goodness Of Fit } \\
Criterion & DF & Value & Value/DF \\
\hline Deviance & 185 & 202.4183 & 1.0042 \\
Scaled Deviance & 185 & 202.4108 & 1.0042 \\
Pearson Chi-Square & 185 & 185.6283 & 1.0034 \\
Scaled Pearson X2 & 185 & 185.6283 & 1.0034 \\
Log Likelihood & -181.3127 & \\
Full Log Likelihood & -254.6186 & \\
AIC (8maller is better) & 515.2373 & \\
AlCC (smaller is betten) & 515.3694 \\
BIC (smaller is better) & 524.0300 \\
\hline
\end{tabular}

Agorittm comverged.

\begin{tabular}{|c|c|c|c|c|c|c|c|}
\hline \multirow{2}{*}{ Parameter } & \multicolumn{6}{|c|}{ Analysis of Maximum Likelihood Parameter Estimates } & \multirow[b]{2}{*}{ Pr $>$ Chisq } \\
\hline & DF & Estimate & $\begin{array}{r}\text { Standard } \\
\text { Error }\end{array}$ & 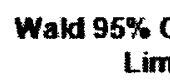 & nfidence & $\begin{array}{r}\text { Wald Chi- } \\
\text { Square }\end{array}$ & \\
\hline Intercept & 1 & 3.1188933 & $1.743008 \mathrm{BB}$ & -6.5300000 & 0.2001440 & 3.20 & 0.0737 \\
\hline LnAADT & 1 & .281689990 & 0.1559354 & 0.0239377 & 0.5873177 & 3.26 & 0.0700 \\
\hline Dispersion & 1 & .292205300 & 0.1426100 & 0.1123319 & 0.7005722 & & \\
\hline
\end{tabular}

Wote: The negative binomial dispersion parameter was estimated by maximum thethood. 
SAS Output

The SAS System

The GEMMOD Procedure

\begin{tabular}{|lr|}
\hline \multicolumn{2}{|c|}{ Model Information } \\
\hline Data Set & WOFK TESTDATA \\
Distribution & Negdive Binomial \\
Link Function & Log \\
Dependent Variable & Accidents Accidents \\
\hline
\end{tabular}

Number of Observations Read 194 Number of Observations Used 187 Missing Vakues

Criteria For Assessing Goodness Of Fit

\begin{tabular}{|c|c|c|c|}
\hline Criterion & DF & Value & Value/DF \\
\hline Deviance & 184 & 202.5330 & 1.1007 \\
\hline Scaled Deviance & 184 & 202.5330 & 1.1007 \\
\hline Pearson Chi-Square & 194 & 184.3400 & 1.0019 \\
\hline Scaled Pearson $\times 2$ & 184 & 184.3400 & 1.0010 \\
\hline Log Likelihood & & -181.1152 & \\
\hline Full Log Likelihood & & -254.4212 & \\
\hline AIC (smaller is better) & & 516.8424 & \\
\hline AICC (smaller is better) & & 5170021 & \\
\hline BIC (smaller is better) & & 520.7068 & \\
\hline
\end{tabular}

Algorithm comerged.

\begin{tabular}{|c|c|c|c|c|c|c|c|}
\hline \multirow{2}{*}{ Parameter } & \multicolumn{6}{|c|}{ Analys is Of Maximum Likelihood Parameter Estimates } & \multirow[b]{2}{*}{ Pr $>$ Chisq } \\
\hline & DF & Estimate & $\begin{array}{r}\text { Standard } \\
\text { Error }\end{array}$ & $\begin{array}{r}\text { Waid } 95 \% \mathrm{C} \\
\mathrm{Lim}\end{array}$ & nfidence & $\begin{array}{l}\text { Wald Chi- } \\
\text { Square }\end{array}$ & \\
\hline Intercept & 1 & -2.6865876 & 1.7600045 & -8.4178070 & 0.4847218 & 284 & 0.0020 \\
\hline LnAADT & 1 & 281001104 & 0.1560150 & -0.0240838 & 0.5988760 & 3.25 & 0.0710 \\
\hline LnLength & 1 & -12473028 & 0.1800029 & -0.5107728 & 0.2013000 & 0.40 & 0.5265 \\
\hline Dispersion & 1 & .288327211 & 0.1420001 & 0.1097728 & 0.7573147 & & \\
\hline
\end{tabular}


SAS Output

The SAS System

The GENMOD Procedure

\begin{tabular}{|lr|}
\hline \multicolumn{2}{|c|}{ Model Information } \\
\hline Data Set & WORK TESTDATA \\
Distribution & Negative Binomial \\
Link Function & Log \\
Dependent Variable & Accidents Accidents \\
\hline
\end{tabular}

Number of Observations Read 194 Number of Observations Used 187 Missing Vahues

7

\begin{tabular}{|c|c|c|c|}
\hline \multicolumn{4}{|c|}{ Criteria For Assessing Goodness Of Fit } \\
\hline Criterion & $\mathbf{D F}$ & Value & Value/oF \\
\hline Deviance & 185 & 201.8478 & 1.0916 \\
\hline Scaled Deviance & 185 & 201.9478 & 1.0010 \\
\hline Pearson Chi-Square & 195 & 188.4008 & 1.0180 \\
\hline Scaled Pearson $\times 2$ & 185 & 188.4906 & 1.0180 \\
\hline Log Likelihood & & -182.4090 & \\
\hline Full Log Likelihood & & -255.7156 & \\
\hline AIC (smaller is better) & & 517.4311 & \\
\hline AICC (smaller is better) & & 517.5823 & \\
\hline BIC (smaller is better) & & 527.1244 & \\
\hline
\end{tabular}

Algoritim comerged

\begin{tabular}{|c|c|c|c|c|c|c|c|}
\hline \multirow{2}{*}{ Parameter } & \multicolumn{6}{|c|}{ Analysis of Maximum Likelihood Parameter Estimates } & \multirow[b]{2}{*}{$\mathrm{Pr}>\mathrm{ChiSq}$} \\
\hline & DF & Estimate & $\begin{array}{l}\text { Standard } \\
\text { Error }\end{array}$ & $\begin{array}{r}\text { Wald 95\% } \\
\text { Lim }\end{array}$ & nfidence & $\begin{array}{l}\text { Wald Chi- } \\
\text { Square }\end{array}$ & \\
\hline Intercept & 1 & -1.6160243 & 1.5229810 & 4.0010121 & 13880036 & 1.13 & 0.2880 \\
\hline LnExpo & 1 & .132956072 & 0.1233307 & -0.1087688 & 0.3746789 & 1.16 & 0.2810 \\
\hline Dispersion & 1 & .313333018 & 0. 1456359 & 0.1260000 & 0.7789860 & & \\
\hline
\end{tabular}

Note: The negative binomial dispersion parameter wiss estimated by maximum fikelhood. 


\section{SAS Output}

The SAS System

The GEMMOD Procedure

\begin{tabular}{|lr|}
\hline \multicolumn{2}{|c|}{ Model Infomstion } \\
\hline Data Set & WORK TESTDATA \\
Distribution & Negative Binamial \\
Link Function & Log \\
Dependent Variable & Accidents Accidents \\
\hline
\end{tabular}

Number of Observations Read 194 Number of Observations Used 187 Missing Values 7

\begin{tabular}{|c|c|c|c|}
\hline \multicolumn{4}{|c|}{ Criteria For Assessing Goodness Of Fit } \\
\hline Criterion & DF & Value & Value/DF \\
\hline Deviance & 184 & 2022910 & 1.0094 \\
\hline Scaled Deviance & 184 & 202.2016 & 1.0004 \\
\hline Pearson Chi-Square & 184 & 182.5012 & 0.9923 \\
\hline Scaled Pearson X2 & 184 & 182.5012 & 0.0923 \\
\hline Log Likelihood & & -180.1546 & \\
\hline Full Log Likelihood & & -253.4604 & \\
\hline AIC (smaller is better) & & 514.9208 & \\
\hline AICC (smaller is better) & & 515.1400 & \\
\hline BIC (smaller is better) & & 527.8453 & \\
\hline
\end{tabular}

Algoritim comverged.

\begin{tabular}{|c|c|c|c|c|c|c|c|}
\hline \multirow{2}{*}{ Par ameter } & \multicolumn{6}{|c|}{ Analysis of Maximum Likelihood Parameter Estimates } & \multirow[b]{2}{*}{ Pr $>$ Chisq } \\
\hline & DF & Estimate & $\begin{array}{r}\text { Standard } \\
\text { Error }\end{array}$ & $\begin{array}{r}\text { Wald } 95 \%( \\
\text { Lim }\end{array}$ & infidence & $\begin{array}{l}\text { Wald Chi- } \\
\text { Square }\end{array}$ & \\
\hline Intercept & 1 & -.43385618 & 0.2183136 & -0.8617430 & -0.0050004 & 3.05 & 0.0469 \\
\hline AADT & 1 & .000005255 & 0.0000020 & 0.0000002 & 0.0000103 & 4.17 & 0.0412 \\
\hline $\operatorname{Cam}$ & 1 & .140384824 & 0.1823851 & -0.2170835 & 0.4978531 & 0.50 & 0.4415 \\
\hline Dispersion & 1 & .275346235 & 0.1398600 & 0.1017389 & 0.7451869 & & \\
\hline
\end{tabular}




\section{SAS Output}

The SAS System

The GEMMOD Procedure

\begin{tabular}{|lr|}
\hline \multicolumn{2}{|c|}{ Model Information } \\
\hline Data Set & WORK.TESTDATA \\
Diatriburtion & Negative Binornia \\
Link Function & Log \\
Dependent Variable & Accidents Accidents \\
\hline
\end{tabular}

Number of Observations Read ig Number of Observations Used 187 Missing Vahues 7

\begin{tabular}{|lrrr|}
\hline \multicolumn{4}{|c|}{ Criteria For Assessing Goodness Of Fit } \\
Criterion & DF & Value & ValuelDF \\
\hline Deviance & 183 & 202.2878 & 1.1054 \\
Scaled Deviance & 183 & 202.2878 & 1.1054 \\
Pearson Chi-Square & 183 & 181.0703 & 0.0028 \\
Scaled Pearson X2 & 183 & 181.6703 & 0.0928 \\
Log Likelihood & & -180.1113 & \\
Full Log Likelihood & -253.4173 & \\
AIC (smaller is better) & 516.8346 & \\
AlCC (smaller is better) & 517.1681 & \\
BIC (smaller is better) & 532.0901 \\
\hline
\end{tabular}

Algorithm comerged.

\begin{tabular}{|c|c|c|c|c|c|c|c|}
\hline \multirow{3}{*}{$\begin{array}{l}\text { Parameter } \\
\text { Intercept }\end{array}$} & \multicolumn{6}{|c|}{ Analysis of Maximam Likelihood Parameter Estimates } & \multirow[b]{2}{*}{ Pr $>$ Chisq } \\
\hline & DF & Estimate & $\begin{array}{r}\text { Standard } \\
\text { Error }\end{array}$ & $\begin{array}{r}\text { Wald 95\% } \\
\text { Lim }\end{array}$ & nfidence & $\begin{array}{l}\text { Wakd Chi- } \\
\text { Square }\end{array}$ & \\
\hline & 1 & -.36120481 & 0.3280756 & -1.0259851 & 0.2835755 & 1.21 & 0.2722 \\
\hline AADT & 1 & .000003570 & 0.0000063 & 0.0000089 & 0.0000150 & 0.32 & 0.5703 \\
\hline Cam & 1 & .141800005 & 0.1824039 & 02156418 & 0.4000034 & 0.61 & 0.4365 \\
\hline HighFlow & 1 & .120405388 & 0.4100096 & -0.6847607 & 0.0255715 & 0.09 & 0.7094 \\
\hline Dispersion & 1 & .274713367 & 0.1397572 & 0.1013641 & 0.7446022 & & \\
\hline
\end{tabular}


SAS Output

The SAS System

The Gexmoo Procedure

\begin{tabular}{|c|c|}
\hline \multicolumn{2}{|c|}{ Model unformution } \\
\hline Data set & MORK TESTDATA \\
\hline Distribution & Wegative Bnemal \\
\hline Link Function & $\log$ \\
\hline Dependent Variatie & Aortients Aootidents \\
\hline
\end{tabular}

Number of Observations Read 194

Number of Observations Used 187

Missing Values

7

Criteria For Assessing Goodness Of Fit

\begin{tabular}{|c|c|c|c|}
\hline Criterion & DF & Valie & Valkerof \\
\hline Deniance & 182 & 2023166 & 1.1116 \\
\hline Scaled Deviance & 182 & 2023166 & 1.1116 \\
\hline Pearson Chi-Square & 182 & 181.5724 & 0.997 \\
\hline Scaled Pearson $x 2$ & 122 & 181.5724 & 0.9977 \\
\hline $\log$ Linelithood & & -180.0011 & \\
\hline Full Log Liturinood & & -253.3971 & \\
\hline ACC (smaller is better) & & 518.774 & \\
\hline ANCC (smaler is better) & & 519.2406 & \\
\hline BIC (swaller is better) & & S53. 1600 & \\
\hline
\end{tabular}

Avarmin coowerged.

\begin{tabular}{|c|c|c|c|c|c|c|c|}
\hline \multicolumn{8}{|c|}{ Anolysis of Whatimum Livelihood Parrmeter Estimntes } \\
\hline Parameter & DF & Estonte & Standard Error & Wald 95\% Con & fidence Limits & Wald Chi-square & $\mathrm{Pr}>\mathrm{ChiSq}$ \\
\hline Intercept & 1 & -.33942679 & $0.34033 a 58$ & -1.0065726 & 0.3277190 & 0.99 & 0.3107 \\
\hline AADT & & .000002780 & 0.00000071 & -8.0000111 & 0.0000166 & 0.16 & 0.6937 \\
\hline Cam & & .147466244 & 0.1637514 & -0.2126779 & 0.5075144 & 0.64 & 0.4222 \\
\hline Hogfiow & & .117168483 & 0.4101540 & -0.6857181 & 0.9210559 & 0.08 & 0.7751 \\
\hline SRN & & .06094005 & 0.2003079 & -0.4604494 & $0.6 t 83374$ & 0.06 & $0.805 T$ \\
\hline Dispersion & 1 & .274020570 & 0.1396819 & 0.1009041 & 0.7441882 & & \\
\hline
\end{tabular}

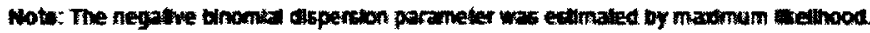


SAS Output

The SAS System

The GEMMOD Procedure

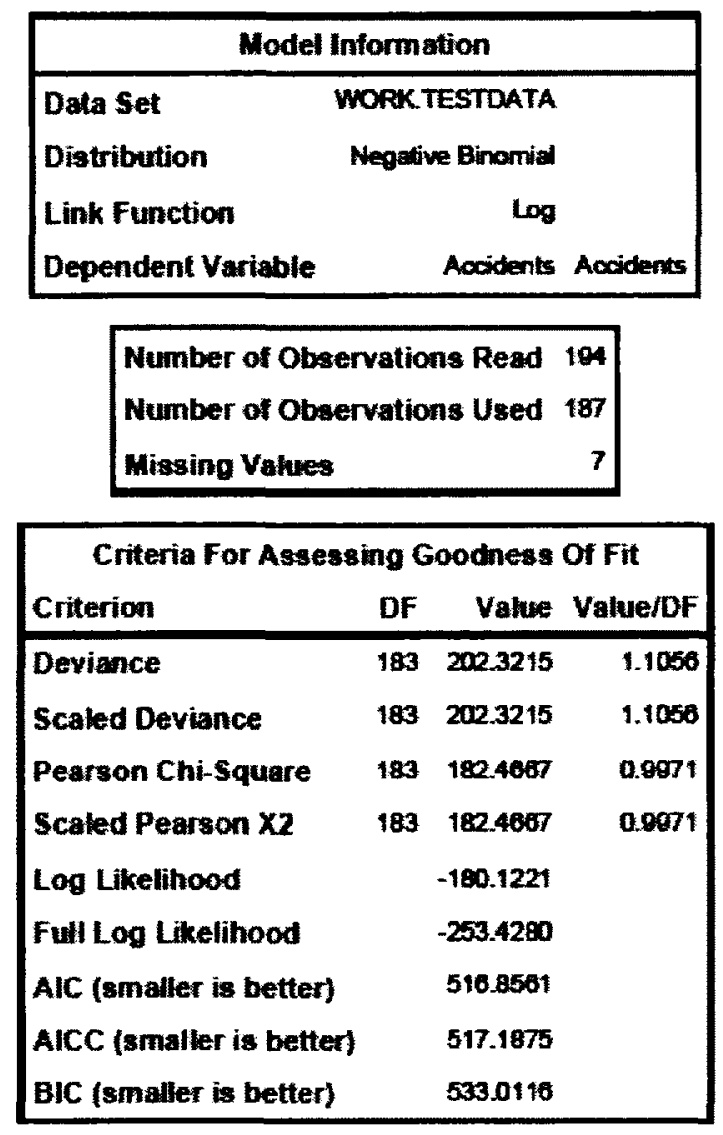

Agoritum converged

\begin{tabular}{|c|c|c|c|c|c|c|c|}
\hline \multirow{3}{*}{$\begin{array}{l}\text { Parameter } \\
\text { Intercept }\end{array}$} & \multicolumn{6}{|c|}{ Analysis of Maximum Likelihood Parameter Estimates } & \multirow[b]{2}{*}{ Pr $>$ Chisq } \\
\hline & \multirow{2}{*}{$\frac{D F}{1}$} & \multirow{2}{*}{$\frac{\text { Estimate }}{-.40940088}$} & \multirow{2}{*}{$\begin{array}{r}\text { Standard } \\
\text { ErTor }\end{array}$} & \multicolumn{2}{|c|}{$\begin{array}{l}\text { Wald 96\% Confidence } \\
\text { Limits }\end{array}$} & \multirow{2}{*}{$\begin{array}{r}\text { Wald Chi- } \\
\text { Square } \\
2.05\end{array}$} & \\
\hline & & & & 0.8762700 & 0.0574743 & & 0.0857 \\
\hline AADT & 1 & .000004305 & 0.0000042 & -0.0000039 & 0.0000127 & 1.07 & 0.3003 \\
\hline Cam & $\mathbf{t}$ & .148109308 & 0.1836919 & -0.2139202 & 0.5007388 & 0.83 & 0.4264 \\
\hline SRN & 1 & .070005010 & 0.2788843 & 0.4755768 & 0.6175489 & 0.06 & 0.7891 \\
\hline Dispersion & $\mathbf{1}$ & .274018302 & 0.1307803 & 0.1012837 & D.7447485 & & \\
\hline
\end{tabular}




\section{SAS Output}

The SAS System

The GEMMOD Procedure

\begin{tabular}{|lr|}
\hline \multicolumn{2}{|c|}{ Model Information } \\
\hline Data Set & Work TESTDATA \\
Distribution & Negative Binomial \\
Link Function & Log \\
Dependent Variable & Accidents Acridents \\
\hline
\end{tabular}

Number of Observations Read 194 Number of Observations Used 187 Miasing Vahes

\begin{tabular}{|lrrr|}
\hline \multicolumn{4}{|c|}{ Criteria For Assessing Goodness Of Fit } \\
Criterion & DF & Vahe & Value/DF \\
\hline Deviance & 184 & 202.1060 & 1.0094 \\
Scaled Deviance & 194 & 202.1060 & 1.0084 \\
Pearson Chi-Square & 184 & 182.2781 & 0.0900 \\
Scaled Pearson X2 & 184 & 182.2781 & 0.0900 \\
Log Likelihood & & -180.4105 & \\
Full Log Likelihood & -253.7166 & \\
AlC (smaller is better) & 515.4330 & \\
AICC (smalker is better) & 515.6528 & \\
BIC (smaller is better) & 529.3574 & \\
\hline
\end{tabular}

Agorithm comerged:

\begin{tabular}{|c|c|c|c|c|c|c|c|}
\hline \multirow{3}{*}{$\frac{\text { Parameter }}{\text { Intercept }}$} & \multicolumn{6}{|c|}{ Analysis of Maximum Likefihood Parameter Estimates } & \multirow[b]{2}{*}{ Pr $>$ Chisq } \\
\hline & \multirow{2}{*}{$\frac{\mathrm{DF}}{1}$} & \multirow{2}{*}{$\begin{array}{l}\text { Estimate } \\
-35914206\end{array}$} & \multirow{2}{*}{$\begin{array}{r}\text { Standard } \\
\text { Error }\end{array}$} & \multicolumn{2}{|c|}{$\begin{array}{c}\text { Wald } 95 \% \text { Confidence } \\
\text { Limits }\end{array}$} & \multirow{2}{*}{$\begin{array}{r}\text { Wald Chi- } \\
\text { Square } \\
1.10\end{array}$} & \\
\hline & & & & -1.0046734 & 0.28639993 & & 0.2755 \\
\hline AADT & 1 & .000004136 & 0.0000002 & -0.0000081 & 0.0000184 & 0.44 & 0.5079 \\
\hline HighFlow & 1 & .111046372 & 0.4102208 & -0.6029894 & 0.9150821 & 0.07 & 0.7866 \\
\hline Dispersion & 1 & .280719785 & 0.1405404 & 0.1052264 & 0.7469954 & & \\
\hline
\end{tabular}


SAS Output

The SAS System

The GEMMOD Procedure

\begin{tabular}{|lr|}
\hline \multicolumn{2}{|c|}{ Model Information } \\
\hline Data Set & WORK. TESTDATA \\
Distribution & Negative Binomial \\
Link Function & Lod \\
Dependent Variable & Acoidents Accidents \\
\hline
\end{tabular}

Number of Observations Read 194 Number of Observations Used 187

Missing Values

7

\begin{tabular}{|lrrr|}
\hline \multicolumn{4}{|c|}{ Criteria For Assessing Goodness Of Fit } \\
Criterion & DF & Value & ValuefDF \\
\hline Deviance & 184 & 202.1181 & 1.0095 \\
Scaled Deviance & 194 & 202.1181 & 1.0985 \\
Pearson Chi-Square & 184 & 182.9809 & 0.0945 \\
Scaled Pearson X2 & 184 & 182.9809 & 0.0045 \\
Log Likelihood & -180.4346 & \\
Full Log Likelihood & -253.7406 & \\
AIC (smaller is better) & 515.4811 & \\
AlCC (smaller is betten) & 515.7000 \\
BIC (smaller is better) & 528.4055 & \\
\hline
\end{tabular}

Agorithm converged:

\begin{tabular}{|c|c|c|c|c|c|c|c|}
\hline \multirow{2}{*}{ Pafameter } & \multicolumn{6}{|c|}{ Analysis of Maximum Likelihood Parameter Estimates } & \multirow[b]{2}{*}{ Pr $>$ Chisq } \\
\hline & DF & Estimate & $\begin{array}{r}\text { Standard } \\
\text { Error }\end{array}$ & $\begin{array}{r}\text { Wald } 95 \% \\
\text { Lim }\end{array}$ & ntidence & $\begin{array}{l}\text { Wald Chi- } \\
\text { Square }\end{array}$ & \\
\hline Intercept & 1 & -41074640 & 0.2301095 & 0.8793904 & 0.0578976 & 2.05 & 0.0858 \\
\hline AADT & 1 & .000005150 & 0.0000042 & -0.0000030 & 0.0000133 & 1.54 & 0.2139 \\
\hline SRN & 1 & .044311512 & 0.2779133 & .0 .5003885 & 0.5890115 & 0.03 & 0.8733 \\
\hline Dispersion & 1 & .280908045 & 0.1405059 & 0.1053924 & 0.7491905 & & \\
\hline
\end{tabular}




\section{Appendix E}

SAS Input \& Output - 2000m Radius Influence Area 


\begin{tabular}{|c|c|c|c|c|c|c|c|c|c|c|}
\hline $\begin{array}{c}\text { Case } \\
\#\end{array}$ & SRN & HighFlow & AADT & LnAADT & Length & Lnlength & Expo & LnExpo & Accidents & Cam \\
\hline 1 & 1 & 0 & 53536 & 10.89 & 8.93 & 2.19 & 478263 & 13.08 & 1 & 1 \\
\hline 2 & 1 & 1 & 115900 & 11.66 & 8.79 & 2.17 & 1018787 & 13.83 & 4 & 0 \\
\hline 3 & 0 & 0 & 54042 & 10.90 & 8.66 & 2.16 & 468142 & 13.06 & 4 & 1 \\
\hline 4 & 0 & 0 & 53965 & 10.90 & 9.31 & 2.23 & 502276 & 13.13 & 2 & 1 \\
\hline 5 & 1 & 1 & 104500 & 11.56 & 8.45 & 2.13 & 883456 & 13.69 & 3 & 0 \\
\hline 6 & 1 & 1 & 113516 & 11.64 & 8.45 & 2.13 & 959045 & 13.77 & 1 & 1 \\
\hline 7 & 1 & 0 & 57414 & 10.96 & 8.44 & 2.13 & 484678 & 13.09 & 2 & 1 \\
\hline 8 & 0 & 0 & 35663 & 10.48 & 8.43 & 2.13 & 300748 & 12.61 & 0 & 0 \\
\hline 9 & 0 & 0 & 54042 & 10.90 & 8.40 & 2.13 & 453952 & 13.03 & 2 & 1 \\
\hline 10 & 1 & 1 & 116585 & 11.67 & 8.37 & 2.12 & 975962 & 13.79 & 8 & 1 \\
\hline 11 & 0 & 0 & 54042 & 10.90 & 8.36 & 2.12 & 451751 & 13.02 & 0 & 1 \\
\hline 12 & 1 & 1 & 110516 & 11.61 & 8.30 & 2.12 & 917652 & 13.73 & 1 & 1 \\
\hline 13 & 1 & 1 & 112100 & 11.63 & 8.30 & 2.12 & 930718 & 13.74 & 1 & 0 \\
\hline 14 & 1 & 0 & 85500 & 11.36 & 8.23 & 2.11 & 703545 & 13.46 & 0 & 0 \\
\hline 15 & 1 & 1 & 115900 & 11.66 & 8.20 & 2.10 & 949959 & 13.76 & 5 & 0 \\
\hline 16 & 0 & 0 & 43493 & 10.68 & 8.16 & 2.10 & 354949 & 12.78 & 3 & 1 \\
\hline 17 & 1 & 1 & 98810 & 11.50 & 8.11 & 2.09 & 801692 & 13.59 & 0 & 0 \\
\hline 18 & 0 & 0 & 43225 & 10.67 & 8.10 & 2.09 & 350278 & 12.77 & 1 & 0 \\
\hline 19 & 1 & 1 & 101175 & 11.52 & 8.10 & 2.09 & 819704 & 13.62 & 5 & 0 \\
\hline 20 & 1 & 1 & 96900 & 11.48 & 8.10 & 2.09 & 784895 & 13.57 & 1 & 0 \\
\hline 21 & 1 & 1 & 117103 & 11.67 & 7.96 & 2.07 & 932330 & 13.75 & 4 & 1 \\
\hline 22 & 1 & 0 & 80750 & 11.30 & 7.94 & 2.07 & 640958 & 13.37 & 1 & 0 \\
\hline 23 & 0 & 0 & 50175 & 10.82 & 7.93 & 2.07 & 398007 & 12.89 & 3 & 1 \\
\hline 24 & 0 & 0 & 57497 & 10.96 & 7.91 & 2.07 & 454789 & 13.03 & 3 & 1 \\
\hline 25 & 1 & 1 & 117103 & 11.67 & 7.88 & 2.06 & 922826 & 13.74 & 3 & 1 \\
\hline 26 & 1 & 1 & 109250 & 11.60 & 7.86 & 2.06 & 858559 & 13.66 & 0 & 0 \\
\hline 27 & 1 & 0 & 76000 & 11.24 & 7.84 & 2.06 & 596133 & 13.30 & 0 & 0 \\
\hline 28 & 0 & 0 & 52250 & 10.86 & 7.81 & 2.06 & 407996 & 12.92 & 2 & 0 \\
\hline 29 & 1 & 0 & 53223 & 10.88 & 7.81 & 2.05 & 415441 & 12.94 & 0 & 1 \\
\hline 30 & 1 & 1 & 115259 & 11.65 & 7.79 & 2.05 & 898162 & 13.71 & 7 & 1 \\
\hline 31 & 1 & 1 & 101798 & 11.53 & 7.76 & 2.05 & 790462 & 13.58 & 2 & 1 \\
\hline 32 & 1 & 1 & 114000 & 11.64 & 7.76 & 2.05 & 884937 & 13.69 & 2 & 0 \\
\hline 33 & 1 & 1 & 108356 & 11.59 & 7.74 & 2.05 & 839100 & 13.64 & 3 & 1 \\
\hline 34 & 0 & 0 & 53030 & 10.88 & 7.66 & 2.04 & 406304 & 12.91 & 4 & 1 \\
\hline 35 & 1 & 1 & 119035 & 11.69 & 7.61 & 2.03 & 906445 & 13.72 & 2 & 0 \\
\hline 36 & 1 & 0 & 85500 & 11.36 & 7.58 & 2.03 & 648193 & 13.38 & 1 & 0 \\
\hline 37 & 1 & 1 & 115589 & 11.66 & 7.56 & 2.02 & 874048 & 13.68 & 4 & 1 \\
\hline 38 & 0 & 0 & 52241 & 10.86 & 7.55 & 2.02 & 394570 & 12.89 & 0 & 1 \\
\hline 39 & 0 & 0 & 58546 & 10.98 & 7.51 & 2.02 & 439847 & 12.99 & 5 & 1 \\
\hline 40 & 1 & & 95000 & 11.46 & 7.48 & 2.01 & 710665 & 13.47 & 1 & 0 \\
\hline 41 & 0 & 0 & 38701 & 10.56 & 7.47 & 2.01 & 288931 & 12.57 & 4 & 1 \\
\hline 42 & 1 & 0 & 94038 & 11.45 & 7.22 & 1.98 & 678555 & 13.43 & 4 & 1 \\
\hline 43 & 1 & 0 & 79800 & 11.29 & 7.21 & 1.98 & 575370 & 13.26 & 3 & 0 \\
\hline 44 & 1 & 0 & 82650 & 11.32 & 7.21 & 1.98 & 595919 & 13.30 & 2 & 0 \\
\hline 45 & 1 & 1 & 112100 & 11.63 & 7.20 & 1.97 & 807271 & 13.60 & 2 & 0 \\
\hline 46 & 0 & 0 & 36100 & 10.49 & 7.18 & 1.97 & 259087 & 12.46 & 4 & 0 \\
\hline
\end{tabular}




\begin{tabular}{|c|c|c|c|c|c|c|c|c|c|c|}
\hline 47 & 0 & 0 & 46522 & 10.75 & 7.14 & 1.97 & 332201 & 12.71 & 1 & 1 \\
\hline 48 & 1 & 1 & 110977 & 11.62 & 7.12 & 1.96 & 790556 & 13.58 & 1 & 1 \\
\hline 49 & 0 & 0 & 52250 & 10.86 & 7.12 & 1.96 & 371935 & 12.83 & 2 & 0 \\
\hline 50 & 0 & 0 & 57000 & 10.95 & 7.11 & 1.96 & 405293 & 12.91 & 5 & 0 \\
\hline 51 & 0 & 0 & 47975 & 10.78 & 7.11 & 1.96 & 341056 & 12.74 & 0 & 0 \\
\hline 52 & 1 & 1 & 110302 & 11.61 & 7.09 & 1.96 & 781525 & 13.57 & 2 & 1 \\
\hline 53 & 1 & 1 & 113415 & 11.64 & 7.08 & 1.96 & 803512 & 13.60 & 0 & 1 \\
\hline 54 & 1 & 0 & 33250 & 10.41 & 7.08 & 1.96 & 235527 & 12.37 & 0 & 0 \\
\hline 55 & 0 & 0 & 47500 & 10.77 & 7.08 & 1.96 & 336462 & 12.73 & 0 & 0 \\
\hline 56 & 1 & 1 & 112110 & 11.63 & 7.07 & 1.96 & 792489 & 13.58 & 3 & 1 \\
\hline 57 & 0 & 0 & 62339 & 11.04 & 7.05 & 1.95 & 439698 & 12.99 & 2 & 1 \\
\hline 58 & 0 & 1 & 108932 & 11.60 & 7.05 & 1.95 & 768231 & 13.55 & 2 & 1 \\
\hline 59 & 0 & 1 & 95628 & 11.47 & 7.02 & 1.95 & 670942 & 13.42 & 1 & 1 \\
\hline 60 & 1 & 1 & 104500 & 11.56 & 7.00 & 1.95 & 731279 & 13.50 & 2 & 0 \\
\hline 61 & 0 & 0 & 46522 & 10.75 & 6.98 & 1.94 & 324644 & 12.69 & 1 & 1 \\
\hline 62 & 1 & 1 & 101261 & 11.53 & 6.97 & 1.94 & 705701 & 13.47 & 4 & 1 \\
\hline 63 & 1 & 1 & 99750 & 11.51 & 6.96 & 1.94 & 694220 & 13.45 & 1 & 0 \\
\hline 64 & 0 & 0 & 54492 & 10.91 & 6.95 & 1.94 & 378919 & 12.85 & 1 & 1 \\
\hline 65 & 0 & 0 & 59706 & 11.00 & 6.95 & 1.94 & 414833 & 12.94 & 1 & 1 \\
\hline 66 & 1 & 0 & 63465 & 11.06 & 6.92 & 1.93 & 439200 & 12.99 & 1 & 0 \\
\hline 67 & 1 & 1 & 113015 & 11.64 & 6.80 & 1.92 & 768067 & 13.55 & 3 & 1 \\
\hline 68 & 0 & & 95000 & 11.46 & 6.76 & 1.91 & 641976 & 13.37 & 4 & 0 \\
\hline 69 & 1 & 1 & 119406 & 11.69 & 6.67 & 1.90 & 796750 & 13.59 & 2 & 1 \\
\hline 70 & 1 & 1 & 104694 & 11.56 & 6.59 & 1.89 & 690286 & 13.44 & 0 & 1 \\
\hline 71 & 1 & 1 & 102165 & 11.53 & 6.59 & 1.89 & 673373 & 13.42 & 5 & 1 \\
\hline 72 & 0 & 0 & 42750 & 10.66 & 6.57 & 1.88 & 281021 & 12.55 & 0 & 0 \\
\hline 73 & 1 & 1 & 106875 & 11.58 & 6.56 & 1.88 & 700998 & 13.46 & 1 & 0 \\
\hline 74 & 1 & 1 & 107086 & 11.58 & 6.56 & 1.88 & 702167 & 13.46 & 4 & 1 \\
\hline 75 & 1 & 1 & 104522 & 11.56 & 6.55 & 1.88 & 684947 & 13.44 & 5 & 1 \\
\hline 76 & 1 & 1 & 110165 & 11.61 & 6.46 & 1.87 & 711803 & 13.48 & 1 & 1 \\
\hline 77 & 1 & 1 & 117942 & 11.68 & 6.45 & 1.86 & 760377 & 13.54 & 1 & 1 \\
\hline 78 & 1 & 1 & 104975 & 11.56 & 6.44 & 1.86 & 675541 & 13.42 & 3 & 0 \\
\hline 79 & 1 & 1 & 111206 & 11.62 & 6.43 & 1.86 & 715479 & 13.48 & 1 & 1 \\
\hline 80 & 1 & 0 & 90250 & 11.41 & 6.11 & 1.81 & 551049 & 13.22 & 0 & 0 \\
\hline 81 & 0 & 1 & 122005 & 11.71 & 6.05 & 1.80 & 738275 & 13.51 & 2 & 1 \\
\hline 82 & 1 & 1 & 113918 & 11.64 & 6.04 & 1.80 & 687826 & 13.44 & 2 & 1 \\
\hline 83 & 1 & 1 & 117997 & 11.68 & 6.01 & 1.79 & 708605 & 13.47 & 7 & 1 \\
\hline 84 & 0 & 0 & 3628.1 & 8.20 & 5.92 & 1.78 & 21461 & 9.97 & 4 & 1 \\
\hline 85 & 1 & 1 & 115727 & 11.66 & 5.81 & 1.76 & 672729 & 13.42 & 5 & 1 \\
\hline 86 & 0 & 0 & 19000 & 9.85 & 5.75 & 1.75 & 109252 & 11.60 & 0 & 0 \\
\hline 87 & 1 & 1 & 100357 & 11.52 & 5.57 & 1.72 & 558756 & 13.23 & 3 & 1 \\
\hline 88 & 0 & 0 & 52922 & 10.88 & 5.43 & 1.69 & 287571 & 12.57 & 0 & 0 \\
\hline 89 & 0 & 0 & 9500 & 9.16 & 4.35 & 1.47 & 41286 & 10.63 & 1 & 0 \\
\hline 90 & 1 & 0 & 80750 & 11.30 & 4.29 & 1.46 & 346553 & 12.76 & 3 & 0 \\
\hline 91 & 1 & 0 & 28500 & 10.26 & 4.09 & 1.41 & 116672 & 11.67 & 0 & 0 \\
\hline 92 & 0 & 0 & 27883 & 10.24 & 4.01 & 1.39 & 111775 & 11.62 & 0 & 0 \\
\hline 93 & 1 & 1 & 107350 & 11.58 & 4.00 & 1.39 & 429127 & 12.97 & 0 & 0 \\
\hline 94 & 0 & 0 & 27550 & 10.22 & 3.89 & 1.36 & 107299 & 11.58 & 4 & 0 \\
\hline
\end{tabular}




\begin{tabular}{|r|r|r|r|r|r|r|r|r|r|r|}
95 & 0 & 0 & 28025 & 10.24 & 3.12 & 1.14 & 87401 & 11.38 & 0 & 0 \\
\hline 96 & 0 & 0 & 54150 & 10.90 & 2.69 & 0.99 & 145806 & 11.89 & 1 & 0 \\
\hline
\end{tabular}




\section{SAS Output}

The SAS System

The GEMMOD Procedure

\begin{tabular}{|lr|}
\hline \multicolumn{2}{|c|}{ Model Information } \\
\hline Data Set & WORK.TESTDATA \\
Distribution & Negative Binomial \\
Link Function & log \\
Dependent Variable & Acoidents Accidents \\
\hline
\end{tabular}

Number of Observations Read 130

Number of Observations Used 86

Missing Vahes

34

\begin{tabular}{|c|c|c|c|}
\hline \multicolumn{4}{|c|}{ Criteria For Assessing Goodness Of Fit } \\
\hline Criterion & DF & Value & Vahe/DF \\
\hline Deviance & 94 & 1128002 & 1.2001 \\
\hline Scaled Deviance & 94 & 112.0002 & 1.2001 \\
\hline Pearson Chi-Square & 94 & 852010 & 1.0129 \\
\hline Scaled Pearson $\times 2$ & 04 & 052019 & 1.0128 \\
\hline Log Likelihood & & -41.8671 & \\
\hline Full Log Likelihood & & -177.6337 & \\
\hline AIC (smaller is better) & & 361.2675 & \\
\hline AlCC (smaller is better) & & 361.5283 & \\
\hline BIC (smaller is better) & & 308.9605 & \\
\hline
\end{tabular}

Agaritum comverged.

\begin{tabular}{|c|c|c|c|c|c|c|c|}
\hline \multirow{2}{*}{ Parameter } & \multicolumn{6}{|c|}{ Analysis of Maximum Likelihood Parameter Estimates } & \multirow[b]{2}{*}{ Pr $>$ Chisq } \\
\hline & DF & Estimate & $\begin{array}{r}\text { Standard } \\
\text { Error }\end{array}$ & $\begin{array}{r}\text { Wald } 95 \% \mathrm{C} \\
\operatorname{Lim}\end{array}$ & nfidence & $\begin{array}{l}\text { Wald Chi- } \\
\text { Square }\end{array}$ & \\
\hline & 1 & .006801659 & 0.2500308 & -0.4120894 & 0.0032827 & 0.14 & 0.7121 \\
\hline AADT & 1 & .000007653 & 0.0000028 & 0.0000021 & 0.0000132 & 7.29 & 0.0000 \\
\hline Dispersion & 1 & .250421300 & 0.1181643 & 0.0085423 & 0.0383850 & & \\
\hline
\end{tabular}

Mole: The negative binomial dispersion parameter was estimated by maximum likethood. 
SAS Output

The SAS System

The GENMOD Procedure

\begin{tabular}{|lr|}
\hline \multicolumn{2}{|c|}{ Nodel Information } \\
\hline Data Set & WOFK.TESTDATA \\
Distribution & Negative Binamial \\
Link Function & Log \\
Dependent Variable & Accidents Accidents \\
\hline
\end{tabular}

Number of Observations Read 130

Number of Observations Used

Missing Values

Criteria For Aasessing Goodness of Fit

Criterion of Value Vahuerof

$\begin{array}{llll}\text { Deviance } \$ 3 & 1127030 & 1.2128\end{array}$

$\begin{array}{llll}\text { Scaled Deviance } & 83 & 1127838 & 12128\end{array}$

Pearson Chi-Square $\quad 93 \quad 005903 \quad 1.0300$

$\begin{array}{llll}\text { Scaled Pearson } X 2 & 83 & 06.5803 \quad 1.0380\end{array}$

Log Likelihood $\quad-\$ 1.3003$

Full Log Likelihood $\quad-177.1270$

AlC (smaller is better) $\mathbf{3 0 2 2 5 4 0}$

AICC (smaller is better) $\quad 362.0935$

BIC (smaller is better) $\quad 3725114$

Agorithm converged.

\begin{tabular}{|c|c|c|c|c|c|c|c|}
\hline \multirow{2}{*}{ Parameter } & \multicolumn{6}{|c|}{ Analysis Of Maximum Likelihood Parameter Estimates } & \multirow[b]{2}{*}{ Pr $>$ Chisq } \\
\hline & DF & Estimate & $\begin{array}{r}\text { Standard } \\
\text { Error }\end{array}$ & $\begin{array}{r}\text { Wakt } 95 \% \mathrm{C} \\
\operatorname{Lim}\end{array}$ & nfidence & $\begin{array}{l}\text { Wald Chi- } \\
\text { Square }\end{array}$ & \\
\hline Intercept & 1 & -.41737283 & 0.5788354 & -1.5518760 & 0.7171167 & 0.52 & 0.4700 \\
\hline AADT & 1 & .000007212 & 0.0000029 & 0.0000010 & 0.0000128 & 6.32 & 0.0110 \\
\hline Length & 1 & .077225211 & 0.0771581 & -0.0740019 & 02294523 & 1.00 & 0.3160 \\
\hline Dispersion & 1 & .242025343 & 0.1176401 & 0.0933515 & 0.6274800 & & \\
\hline
\end{tabular}




\section{SAS Output}

The SAS System

The GENMOD Procedure

\begin{tabular}{|lr|}
\hline \multicolumn{2}{|c|}{ Model Information } \\
\hline Data Set & WORK.TESTDATA \\
Distribution & Negative Binomial \\
Link Function & Log \\
Dependent Variable & Acoidents Aocidents \\
\hline
\end{tabular}

\begin{tabular}{|lr|}
\hline Number of Observations Read & 130 \\
Number af Observations Used & 66 \\
Missing Values & 34 \\
\hline
\end{tabular}

Criteria For Assessing Goodness Of Fit

\begin{tabular}{|c|c|c|c|}
\hline Criterion & DF & Value & Vaherof \\
\hline Deviance & 94 & 1128404 & 1.2004 \\
\hline Scaled Deviance & 94 & 1128404 & 1.2004 \\
\hline Pearson Chi-Square & 94 & 05.0064 & 1.0180 \\
\hline Scaled Pearson $\times 2$ & 94 & 05.6004 & 1.0189 \\
\hline Log Likelihood & & -41.4342 & \\
\hline Full Log Likelihood & & -177.2000 & \\
\hline AlC (smaller is better) & & 360.4018 & \\
\hline AICC (smaller is better) & & 360.6027 & \\
\hline BIC (smaller is better) & & 308.0948 & \\
\hline
\end{tabular}

Agorithm comerged.

\begin{tabular}{|c|c|c|c|c|c|c|c|}
\hline \multirow{2}{*}{ Parameter } & \multicolumn{6}{|c|}{ Analysis of Maximum Likelihood Parameter Estimates } & \multirow[b]{2}{*}{ Pr $>$ Chisq } \\
\hline & DF & Estimate & $\begin{array}{r}\text { Standard } \\
\text { Error }\end{array}$ & $\begin{array}{r}\text { Wald } 95 \% 0 \\
\text { Lim }\end{array}$ & nfidence & $\begin{array}{l}\text { Wald Chi- } \\
\text { Square }\end{array}$ & \\
\hline Intercept & 1 & .111733352 & 0.2400824 & .0 .3500050 & 0.5834023 & 0.22 & 0.8425 \\
\hline Expo & 1 & .000001037 & 0.0000004 & 0.0000003 & 0.0000017 & 8.22 & 0.0041 \\
\hline Dispersion & 1 & .242871122 & 0.1178090 & 0.0938104 & 0.6287420 & & \\
\hline
\end{tabular}

Mole: The negative binomial dispersion parameter was estinated by maximum thelihood. 


\section{SAS Output}

The SAS System

The GEMNOD Procedure

\begin{tabular}{|lr|}
\hline \multicolumn{2}{|c|}{ Model Information } \\
\hline Data Set & WORK.TESTDATA \\
Distribution & Negative Binomial \\
Link Function & Log \\
Dependent Variable & Acoidents Aocidents \\
\hline
\end{tabular}

Number of Observations Read 130 Number of Observations Used 90

Missing Values

\begin{tabular}{|c|c|c|c|}
\hline \multicolumn{4}{|c|}{ Criteria For Assessing Goodness of Fit } \\
\hline Criterion & DF & Valtue & Vahuelof \\
\hline Deviance & 94 & 1128930 & 1.2010 \\
\hline Scaled Deviance & 94 & 112.8938 & 1.2010 \\
\hline Pearson Chi-Square & 94 & 85.5081 & 1.0170 \\
\hline Scaled Pearson $\times 2$ & 94 & 05.5881 & 1.0170 \\
\hline Log Likelihood & & -43.7350 & \\
\hline Full Log Likelihood & & -170.5017 & \\
\hline AIC (smaller is better) & & 305.0034 & \\
\hline AlCC (smaller is better) & & 365.2643 & \\
\hline BiC (smaller is better) & & 3720004 & \\
\hline
\end{tabular}

Algaritum comverged

\begin{tabular}{|c|c|c|c|c|c|c|c|}
\hline \multirow{2}{*}{ Parameter } & \multicolumn{6}{|c|}{ Analysis of Maximum Likelihood Parameter Estimates } & \multirow[b]{2}{*}{ Pr $>$ Chisq } \\
\hline & DF & Estimate & $\begin{array}{r}\text { Standard } \\
\text { Error }\end{array}$ & $\begin{array}{r}\text { Wald } 95 \% \mathrm{C} \\
\operatorname{Lim}\end{array}$ & nfidence & $\begin{array}{l}\text { Wald Chi- } \\
\text { Square }\end{array}$ & \\
\hline Intercept & 1 & -2.0109656 & 1.8010738 & -6.2580232 & 10300520 & 1.97 & 0.1800 \\
\hline LnAADT & 1 & .208730043 & 0.1652770 & 0.0252060 & 0.0226679 & 3.27 & 0.0707 \\
\hline Dispersion & 1 & .282046042 & 0.1252175 & 0.1181458 & 0.6733182 & & \\
\hline
\end{tabular}

Hote: The negative binomial dispersion paraneter was estinated by maximum likethood. 


\section{SAS Output}

The SAS System

The GENMOD Procedure

\begin{tabular}{|lr|}
\hline \multicolumn{2}{|c|}{ Model Information } \\
\hline Data Set & WORK.TESTDATA \\
Diatribution & Negative Binomial \\
Link Function & Lod \\
Dependent Variable & Acoidents Accidents \\
\hline
\end{tabular}

Number of Observations Read 130 Number of Observations Used Missing Vahues

\begin{tabular}{|c|c|c|c|}
\hline \multicolumn{4}{|c|}{ Criteria For Assessing Goodness Of Fit } \\
\hline Criterion & DF & Value & ValuedDF \\
\hline Deviance & 103 & 1126301 & 12111 \\
\hline Scaled Deviance & 93 & 112.6301 & 1.2111 \\
\hline Pearson Chi-Square & 9 & 90.0644 & 1.0390 \\
\hline Scaled Pearson $\times 2$ & e3 & 90.0044 & 1.0330 \\
\hline Log Likelihood & & -431070 & \\
\hline Full Log Liketihood & & -178.8737 & \\
\hline AIC (smaller is better) & & 305.7474 & \\
\hline ACC (smaller is better) & & 306.1870 & \\
\hline BlC (smaller is better) & & 370.0048 & \\
\hline
\end{tabular}

Agorithm comerged

\begin{tabular}{|c|c|c|c|c|c|c|c|}
\hline \multirow{2}{*}{ Parameter } & \multicolumn{6}{|c|}{ Analysis of Maximum Likelihood Parameter Estimates } & \multirow[b]{2}{*}{ Pr $>$ Chisq } \\
\hline & DF & Estimate & $\begin{array}{l}\text { Standard } \\
\text { Error }\end{array}$ & $\begin{array}{r}\text { Wald } 95 \% \mathrm{C} \\
\text { Lim }\end{array}$ & nfidence & $\begin{array}{l}\text { Wald Chi- } \\
\text { Square }\end{array}$ & \\
\hline Intercept & 1 & -3.0004540 & 1.9174525 & -0.8575919 & 0.6580838 & 201 & 0.1060 \\
\hline LnAADT & 1 & .250048214 & 0.1707873 & -0.0046887 & 0.5847851 & 2.14 & 0.1432 \\
\hline LnLength & 1 & .531702288 & 0.4900576 & -0.4103003 & 1.4738338 & 1.22 & 0.2886 \\
\hline Dispersion & 1 & .2733089744 & 0.1233732 & 0.1129278 & 0.0020502 & & \\
\hline
\end{tabular}


SAS Output

The SAS System

The GEMMOD Procedure

\begin{tabular}{|lr|}
\hline \multicolumn{2}{|c|}{ Model Information } \\
\hline Data Set & WOrK.TESTDATA \\
Distribution & Negative Binomial \\
Link Function & Log \\
Dependent Varibble & Accidents Accidents \\
\hline
\end{tabular}

Number of Observations Read 130 Number of Observations Used 66

Missing Values

34

\begin{tabular}{|lrrr|}
\hline \multicolumn{4}{|c|}{ Criteria For Assessing Goodness Of Fit } \\
Criterion & DF & Value & Vahe/DF \\
\hline Deviance & 94 & 112.0882 & 1.2020 \\
Scaled Deviance & 94 & 112.0882 & 1.2020 \\
Pearson Chi-Square & 94 & 90.0204 & 1.0312 \\
Scaled Pearson X2 & 94 & 96.0294 & 1.0312 \\
Log Likelihood & & -43.2401 & \\
Full Log Likelihood & -170.0068 & \\
AlC (smaller is better) & 304.0130 \\
AlCC (smaller is better) & 304.2744 \\
BlC (smaller is better) & 371.7060 \\
\hline
\end{tabular}

Agoritim comerged.

\begin{tabular}{|c|c|c|c|c|c|c|c|}
\hline \multirow{3}{*}{ Parameter } & \multicolumn{6}{|c|}{ Analysis Of Maximum Likelihood Parameter Estimates } & \multirow[b]{2}{*}{ Pr $>$ Chisq } \\
\hline & DF & Eatimate & $\begin{array}{l}\text { Standard } \\
\text { Error }\end{array}$ & $\begin{array}{r}\text { Wald } 95 \% \\
\text { Lim }\end{array}$ & nfidence & $\begin{array}{l}\text { Wald Chi- } \\
\text { Square }\end{array}$ & \\
\hline & 1 & 3.1733508 & 1.9181979 & -6.9329494 & 0.5662481 & 274 & 0.0961 \\
\hline LnExpo & 1 & .207200810 & 0.1451525 & 0.0127782 & 0.5817634 & 4.10 & 0.0400 \\
\hline Dispersion & 1 & .272504865 & 0.1235110 & 0.1120014 & 0.6624944 & & \\
\hline
\end{tabular}

Note: The negative binomial dispersion parameter was esimated by maximum likefhood. 


\section{SAS Output}

The SAS System

The GEMMOD Procedure

\begin{tabular}{|lr|}
\hline \multicolumn{2}{|c|}{ Model Information } \\
\hline Data Set & WOFK.TESTDATA \\
Distribution & Negative Binomial \\
Link Function & Log \\
Dependent Variable & Accidients Accidents \\
\hline
\end{tabular}

Number of Observations Read 130 Number of Observations Used 96

Missing Vahues $\quad 34$

\begin{tabular}{|lrrr|}
\hline \multicolumn{4}{|c|}{ Criteria For Assessing Goodness Of Fit } \\
Criterion & DF & Value & ValuelDF \\
\hline Deviance & 93 & 112.8060 & 1.2130 \\
Scaled Deviance & 93 & 1120000 & 1.2130 \\
Pearson Chi-Square & 93 & 96.0504 & 1.0000 \\
Scaled Pearson X2 & 93 & 08.6504 & 1.0000 \\
Log Likelihood & & -38.2000 & \\
Full Log Likelihood & -173.0757 & \\
AlC (smaller is better) & 356.0514 & \\
AlCC (smalter is better) & 356.3010 \\
BIC (smaller is better) & 366.2008 \\
\hline
\end{tabular}

Algorithm comverged.

\begin{tabular}{|c|c|c|c|c|c|c|c|}
\hline \multirow{2}{*}{ Parameter } & \multicolumn{6}{|c|}{ Analysis Of Maximum Likelihood Parameter Estimates } & \multirow[b]{2}{*}{$\mathrm{Pr}>$ Chisq } \\
\hline & DF & Estimate & $\begin{array}{r}\text { Standard } \\
\text { Error }\end{array}$ & $\begin{array}{r}\text { Wald } 95 \% \mathrm{C} \\
\mathrm{Lim}\end{array}$ & nfidence & $\begin{array}{l}\text { Wald Ch:- } \\
\text { Square }\end{array}$ & \\
\hline Intercept & 1 & $-0,8260492$ & 0.2600234 & .0 .5040059 & 0.4297058 & 0.10 & 0.7510 \\
\hline AADT & 1 & .000000350 & 0.0000028 & 0.0000000 & 0.0000118 & 5.24 & 0.0221 \\
\hline Cam & 1 & .482261908 & 0.1767761 & 0.1357871 & 0.8287368 & 7.44 & 0.0064 \\
\hline Dispersion & 1 & .101287959 & 0.1078604 & 0.0632821 & 0.5782218 & & \\
\hline
\end{tabular}




\section{SAS Output}

The SAS System

The GEMMOD Procedure

\begin{tabular}{|lr|}
\hline \multicolumn{2}{|c|}{ Model Information } \\
\hline Data Set & MorKKTESTDATA \\
Distribution & Negative Binomial \\
Link Function & Log \\
Dependent Variable & Acoidents Accidents \\
\hline
\end{tabular}

Number of Observations Read 130 Number of Observations Used an Miasing Values 36

\begin{tabular}{|c|c|c|c|}
\hline \multicolumn{4}{|c|}{ Criteria For Assessing Goodness Of Fit } \\
\hline Criterion & DF & Yalue & VahuelDF \\
\hline Deviance & 8 & 110.5170 & 12280 \\
\hline Scaled Deviance & $\mathbf{8 0}$ & 110.5176 & 12280 \\
\hline Pearson Chi-Square & $\infty 0$ & 007461 & 1.0750 \\
\hline Scaled Pearson X2 & $\boldsymbol{\infty}$ & 90.7401 & 1.0750 \\
\hline Log Likelihood & & -37.4119 & \\
\hline Full Log Likelihood & & -170.0006 & \\
\hline AIC (smaller is better) & & 350.0011 & \\
\hline ACC (smaller is better) & & 350.6830 & \\
\hline BIC (smaller is better) & & 3027170 & \\
\hline
\end{tabular}

Algoritimn comerged.

\begin{tabular}{|c|c|c|c|c|c|c|c|}
\hline \multirow{3}{*}{$\begin{array}{l}\text { Parameter } \\
\text { Intercept }\end{array}$} & \multicolumn{6}{|c|}{ Analysis Of Maximum Likelihood Parameter Estimates } & \multirow[b]{2}{*}{ Pr $>$ Chisq } \\
\hline & \multirow{2}{*}{$\frac{\text { DF }}{1}$} & \multirow{2}{*}{$\frac{\text { Estimate }}{-04039930}$} & \multirow{2}{*}{$\begin{array}{r}\text { Standard } \\
\text { Error }\end{array}$} & \multicolumn{2}{|c|}{$\begin{array}{l}\text { Wald } 95 \% \text { Confidence } \\
\text { Limits }\end{array}$} & \multirow{2}{*}{$\begin{array}{r}\text { Wald Chi- } \\
\text { Square } \\
0.01\end{array}$} & \\
\hline & & & & -0.7703786 & 0.0805810 & & 0.9136 \\
\hline AADT & 1 & .0000050027 & 0.0000003 & -0.0000073 & 0.0000173 & 0.84 & 0.4229 \\
\hline Cam & 1 & .508854046 & 0.1817256 & 0.1506785 & 0.8630290 & 7.78 & 0.0053 \\
\hline HighFlow & 1 & .082273325 & 0.3681075 & 0.0040031 & 0.8586287 & 0.94 & 0.8355 \\
\hline Dispersion & 1 & .194191005 & 0.1000175 & 0.0640362 & 0.5889882 & & \\
\hline
\end{tabular}




\section{SAS Output}

The SAS System

The GERIOD Procedure

\begin{tabular}{|c|c|}
\hline \multicolumn{2}{|c|}{ Model hriommation } \\
\hline Deta Set & WORK.TESTOATA \\
\hline Distribution & Wegatwe Bnorital \\
\hline Link Funation & $\log$ \\
\hline Dependent Varintle & Aecterts Acodoents \\
\hline
\end{tabular}

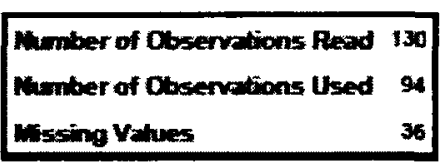

Criteria For Acsessing Goodness of Fit Criterian

Devionse $\quad 09109.0580 \quad 12344$

Scoled Devionce

Peursan Chisqune

So-led Person xo

Log LAdillood

Full Log Lilcellwood

ACC (swmer is bettier)

AxCC (samiler is better)

Buc fromither is betier)
$80109.0580 \quad 1.2344$

b $95.5962 \quad 1.0741$

$89 \quad 95.5952 \quad 1.0741$

$-37.2001$

$-169.7907$

351.5815

3525170

366.412

Arsomim corerefged

Arolycis Of liatimum Livelinoed Parameter Estimates

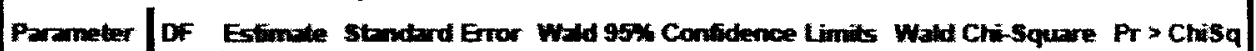

\begin{tabular}{|c|c|c|c|c|c|c|}
\hline Intercept & $1-09013667$ & 0.3055021 & -0.8560373 & 0.6897599 & 0.06 & 0.7997 \\
\hline AADT & 1.000007433 & 0.0000074 & -0.0000070 & 0.0000219 & 1.02 & 0.3131 \\
\hline $\cos$ & 1475312751 & 0.183616 & 0.1061308 & 0.8444947 & 6.37 & 0.0116 \\
\hline HehFlow & $1.075 t 55340$ & 0.4003264 & -0.7094695 & 0.6597812 & 0.04 & 0.8511 \\
\hline Sax & $1-.16996597$ & 02950111 & -0.7681180 & A. 3983041 & 0.41 & 0.5198 \\
\hline Dispersion & 1.195101696 & 0.1098922 & 0.0553056 & 0.5981403 & & \\
\hline
\end{tabular}

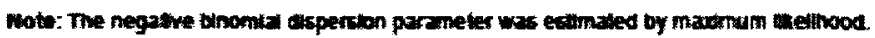


SAS Output

The SAS System

The GEMMOD Procedure

\begin{tabular}{|lr|}
\hline \multicolumn{2}{|c|}{ Model Information } \\
\hline Data Set & WORK.TESTDATA \\
Distriburtion & Negative Binomial \\
Link Function & Log \\
Dependent Variable & Acoidenk Accidents \\
\hline
\end{tabular}

Number of Observations Resd 130 Number of Observations Used 96

Missing Values

\begin{tabular}{|c|c|c|c|}
\hline \multicolumn{4}{|c|}{ Criteria For Assessing Goodness of Fit } \\
\hline Criterion & DF & Value & VahuedoF \\
\hline Deviance & 82 & 111.0516 & 12136 \\
\hline Scaled Deviance & $\mathbf{0 2}$ & 111.0518 & 1.2130 \\
\hline Pearson Chi-Square & $\infty 2$ & Q6.6218 & 1.0524 \\
\hline Scaled Pearson $\times 2$ & 92 & 96.8218 & 1.0524 \\
\hline Log Likelhood & & -37.6406 & \\
\hline Fult Log Cikelihood & & -173.4133 & \\
\hline AIC (smaller is better) & & 356.8260 & \\
\hline AICC (smaller is befter) & & 357.4933 & \\
\hline BIC (smaller is better) & & 309.6483 & \\
\hline
\end{tabular}

Agorittum comverged

\begin{tabular}{|l|rrrrrrr|}
\hline \multicolumn{7}{|c|}{ Analysis Of Maximum Likelihood Parameter Estimates } \\
Parameter & DF & Estimate & $\begin{array}{c}\text { Standard } \\
\text { Error }\end{array}$ & Wald 95\% Confidence & Wimits & Wald Chi- \\
Square Pr > ChiSq
\end{tabular}


SAS Output

The SAS System

The GEMMOD Procedure

\begin{tabular}{|lr|}
\hline \multicolumn{2}{|c|}{ Model Information } \\
\hline Daka Set & WORK.TESTDATA \\
Distribution & Negative Binomial \\
Link Function & Log \\
Dependent Variable & Accidents Accidents \\
\hline
\end{tabular}

Number of Observations Read 130 Number of Observations Used Missing Vahues

Criteria For Assessing Goodness Of Fit

\begin{tabular}{|c|c|c|c|}
\hline Criterion & DF & Value & VahuefDF \\
\hline Deviance & e1 & 110.4508 & 1.2138 \\
\hline Scaled Deviance & 91 & 110.4508 & 12138 \\
\hline Pearson Chi-Square & g1 & 92.4580 & 1.0160 \\
\hline Scaled Pearson $\times 2$ & 91 & 92.4580 & 1.0160 \\
\hline Log Likellhood & & -41.2343 & \\
\hline Full Log Likelihood & & -173.8220 & \\
\hline AIC (smaller is better) & & 355.6450 & \\
\hline AICC (smalter is better) & & 356.0053 & \\
\hline BKC (smaller is better) & & 305.8101 & \\
\hline
\end{tabular}

Algoritim comerged

\begin{tabular}{|c|c|c|c|c|c|c|c|}
\hline \multirow{2}{*}{ Parameter } & \multicolumn{6}{|c|}{ Analysis of Maximum Likelihood Parameter Estimates } & \multirow[b]{2}{*}{ Pr $>$ Chisq } \\
\hline & DF & Estimate & $\begin{array}{r}\text { Standard } \\
\text { Error }\end{array}$ & $\begin{array}{r}\text { Wald } 95 \% \mathrm{c} \\
\text { Lim }\end{array}$ & nfidence & $\begin{array}{l}\text { Wald Ch:- } \\
\text { Square }\end{array}$ & \\
\hline Intercept & 1 & .106809121 & 0.3679497 & 0.5245020 & 0.8177742 & 0.29 & 0.5831 \\
\hline AADT & 1 & .000005427 & 0.0000004 & -0.0000071 & 0.0000170 & 0.72 & D.3947 \\
\hline HighFlow & 1 & .156224831 & 0.4034675 & -0.6355570 & 0.0460067 & 0.15 & 0.7004 \\
\hline Dispersion & 1 & .258686801 & 0.1222022 & 0.1024030 & 0.6532332 & & \\
\hline
\end{tabular}


SAS Output

The SAS System

The GENMOD Procedure

\begin{tabular}{|lr|}
\hline \multicolumn{2}{|c|}{ Model Information } \\
\hline Data Set & WORK.TESTDATA \\
Distribution & Negative Binornia \\
Link Function & Log \\
Dependent Variable & Accidents Accidents \\
\hline
\end{tabular}

Number of Observations Read 130 Number of Observations Used Missing Vahues

Criteria For Assessing Goodness Of Fit

Criterion DF Value Valuefof

$\begin{array}{llll}\text { Deviance } & 111.8006 & 1.2028\end{array}$

Scaled Deviance $\quad 93 \quad 111.8005 \quad 1.2028$

$\begin{array}{llll}\text { Pearson Chi-Square } & 93 & 05.2020 & 1.0243\end{array}$

$\begin{array}{llll}\text { Scaled Pearson } \times 2 & 93 \quad 95.2628 & 1.0243\end{array}$

Log Likelihood $\quad \mathbf{4 0 . 5 8 5 2}$

Full Log Likelihood $\quad-176.3510$

AIC (smaller is better) $\quad 3607038$

AlCC (smaller is better) $\quad 361.1434$

BKC (smaller is better) 3709612

Algaritum converged.

\begin{tabular}{|c|c|c|c|c|c|c|c|}
\hline \multirow{2}{*}{ Parameter } & \multicolumn{6}{|c|}{ Analysis of Maximum Likelihood Parameter Estimates } & \multirow[b]{2}{*}{ Pr $>$ Chisq } \\
\hline & DF & Estimate & $\begin{array}{r}\text { Standard } \\
\text { Error }\end{array}$ & $\begin{array}{r}\text { Wald } 95 \% \mathrm{C} \\
\text { Lim }\end{array}$ & nfidence & $\begin{array}{l}\text { Wald Chi- } \\
\text { Square }\end{array}$ & \\
\hline Intercept & 1 & -.004013882 & 0.2704979 & -0.6127008 & 0.4828419 & 0.05 & 0.8162 \\
\hline AADT & 1 & .000012930 & 0.0000044 & 0.0000043 & 0.00000215 & 8.60 & 0.0033 \\
\hline SRN & 1 & -.44080004 & 0.2802157 & -1.0040022 & 0.1052829 & 252 & 0.112 \\
\hline Dispersion & 1 & .236866016 & 0.1154829 & 0.0911118 & 0.6158905 & & \\
\hline
\end{tabular}


SAS Output

The SAS System

The GEMMOD Procedure

\begin{tabular}{|lr|}
\hline \multicolumn{2}{|c|}{ Model Information } \\
\hline Data Set & WOPK.TESTDATA \\
Distribution & Negative Binomial \\
Link Function & Log \\
Dependent Variable & Acoidents Accidents \\
\hline
\end{tabular}

Number of Observations Read 130 Number of Observations Used Missing Values:

\begin{tabular}{|lrrr|}
\hline \multicolumn{4}{|c|}{ Criteria For Assessing Goodness Of Fit } \\
Criterion & DF & Value & VahuelDF \\
\hline Deviance & 03 & 120800 & 1.2148 \\
Scaled Deviance & 93 & 1120800 & 1.2148 \\
Pearson Chi-Square & 03 & 90.5317 & 1.0702 \\
Scaled Pearson X2 & 93 & 90.5317 & 1.0702 \\
Log Likelihood & & -37.6722 & \\
Full Log Likelihood & -173.4399 & \\
AlC (smaller is better) & 354.8778 & \\
AlCC (smaller is better) & 355.3174 \\
Bic (smaller is better) & 305.1352 \\
\hline
\end{tabular}

Algorithm converged

\begin{tabular}{|c|c|c|c|c|c|c|c|}
\hline \multirow{3}{*}{$\begin{array}{l}\text { Parameter } \\
\text { Intercent }\end{array}$} & \multicolumn{6}{|c|}{ Analysis of Maximum Likelihood Parameter Estimates } & \multirow[b]{2}{*}{$\mathrm{Pr}>$ Chisq } \\
\hline & DF & Estimate & $\begin{array}{l}\text { Standard } \\
\text { Error }\end{array}$ & $\begin{array}{r}\text { Wald } 95 \% 0 \\
\operatorname{Lim}\end{array}$ & nfidence & $\begin{array}{l}\text { Wald Chi- } \\
\text { Square }\end{array}$ & \\
\hline & 1 & -.00571823 & 0.2495700 & 0.5848810 & 0.3934425 & 0.15 & 0.7013 \\
\hline Expo & 1 & .000000001 & 0.0000004 & 0.0000002 & 0.0000016 & 6.39 & 0.0115 \\
\hline Cam & 1 & .494117838 & 0.1740189 & 0.1412830 & 0.8260527 & 7.88 & $0.005 \mathrm{~A}$ \\
\hline Dispersion & 1 & .181743239 & 0.1003522 & 0.0577238 & 0.5722200 & & \\
\hline
\end{tabular}




\section{SAS Output}

The SAS System

The GEMMOD Procedure

\begin{tabular}{|lr|}
\hline \multicolumn{2}{|c|}{ Model Information } \\
\hline Data Set & Work TESTDATA \\
Distribution & Negative Binornial \\
Link Function & Log \\
Dependent Variable & Accidents Accidents \\
\hline
\end{tabular}

Number of Observations Read 130

Number of Observations Used

Misging Vahes

34

\begin{tabular}{|lrrr|}
\hline \multicolumn{4}{|c|}{ Criteria For Assessing Goodness Of Fit } \\
Criterion & DF & Value & VahuelOF \\
\hline Deviance & 00 & 110.7244 & 1.2303 \\
Scaled Deviance & 90 & 110.7244 & 1.2303 \\
Pearson Chi-Square & 80 & 97.9149 & 1.0979 \\
Scaled Pearson X2 & $\infty 0$ & 97.9149 & 1.0879 \\
Log Likelihood & & -36.8159 & \\
Full Log Likelihood & -169.4045 & \\
AIC (smaller is better) & 348.8000 \\
AlCC (smalter is better) & 349.4908 \\
BIC (smaller is better) & 361.5254 \\
\hline
\end{tabular}

Agoritim converped

\begin{tabular}{|c|c|c|c|c|c|c|c|}
\hline \multirow{2}{*}{ Parameter } & \multicolumn{6}{|c|}{ Analysis of Maximum Likelihood Parameter Estimates } & \multirow[b]{2}{*}{ Pr $>$ Chisq } \\
\hline & DF & Estimate & $\begin{array}{r}\text { Standard } \\
\text { Error }\end{array}$ & $\begin{array}{r}\text { Wald } 95 \% \mathrm{C} \\
\text { Lim }\end{array}$ & nfidence & $\begin{array}{l}\text { Wald Chi- } \\
\text { Square }\end{array}$ & \\
\hline Intercept & 1 & -.10789003 & 0.2804905 & -0.0048991 & 0.4791172 & 0.13 & 0.7187 \\
\hline Expo & 1 & .000000601 & 0.0000000 & -0.0000004 & 0.0000021 & 1.84 & 0.1753 \\
\hline Cam & 1 & .500279530 & 0.1801863 & 0.1501209 & 0.8624382 & 7.00 & 0.0047 \\
\hline HighFlow & 1 & .020160088 & 0.3097159 & -0.5840028 & 0.6252411 & 0.00 & 0.8479 \\
\hline Dispersion & 1 & .183171104 & 0.1080317 & 0.0570542 & 0.5819470 & & \\
\hline
\end{tabular}


SAS Output

The SAS System

The GEMMOD Procedure

\begin{tabular}{|lr|}
\hline \multicolumn{2}{|c|}{ Model Infomation } \\
\hline Data Set & WORK.TESTDATA \\
Distribution & Negative Binomiat \\
Link Function & Log \\
Dependent Variable & Accidents Accidents \\
\hline
\end{tabular}

Number of Observations Read 130

Number of Observations Uzed 96

Missing Vahes

34

\begin{tabular}{|c|c|c|c|}
\hline \multicolumn{4}{|c|}{ Criteria For Assessing Goodness Of Fit } \\
\hline Criterion & DF & Value & ValuefoF \\
\hline Deviance & $\infty 2$ & 112.1985 & 1.2185 \\
\hline Scaled Deviance & 92 & 1121886 & 12186 \\
\hline Pearson Chi-Square & $\infty 2$ & 98.6007 & 1.0728 \\
\hline Scaled Pearson $\times 2$ & $\mathbf{\infty}$ & 08.6907 & 1.0728 \\
\hline Log Likelhood & & -37.0786 & \\
\hline Full Log Likelihood & & -1728463 & \\
\hline AlC (smaller is better) & & 355.0025 & \\
\hline AKC (smaller is better) & & 356.3502 & \\
\hline BKC (smaller is better) & & 308.5142 & \\
\hline
\end{tabular}

Algarithm comerged

\begin{tabular}{|c|c|c|c|c|c|c|c|}
\hline \multirow{2}{*}{ Parameter } & \multicolumn{6}{|c|}{ Analysis of Maximum Likelihood Parameter Estimates } & \multirow[b]{2}{*}{ Pr $>$ Chisq } \\
\hline & DF & Estimate & $\begin{array}{l}\text { Standard } \\
\text { Error }\end{array}$ & $\begin{array}{r}\text { Wald } 95 \% c \\
\operatorname{Lim}\end{array}$ & nfidence & $\begin{array}{l}\text { Wald Chi- } \\
\text { Square }\end{array}$ & \\
\hline & 1 & -14922439 & 0.2566705 & -0.6503411 & 0.3518923 & 0.34 & 0.5505 \\
\hline Expo & 1 & .000001312 & 0.0000005 & 0.0000003 & 0.0000023 & 6.31 & 0.0120 \\
\hline Cam & 1 & .451237717 & 0.1770328 & 0.1042601 & 0.7882153 & 6.50 & 0.0108 \\
\hline SRN & 1 & -.27805049 & 0.2572004 & 0.7831715 & 0.2252700 & 1.18 & 0.2782 \\
\hline Dispersion & 1 & .178087014 & 0.1050316 & 0.0504029 & 0.5654912 & & \\
\hline
\end{tabular}




\section{SAS Output}

The SAS System

The GEMIOD Procedire

\begin{tabular}{|c|c|c|}
\hline \multicolumn{3}{|c|}{ Hodel Irformmtion } \\
\hline Data set & WORK.TESTDATA & \\
\hline Distribution & Negitre Bnomta! & \\
\hline Link Function & $\log$ & \\
\hline Dependert Variatle & Mockitents & Acolients \\
\hline
\end{tabular}

Munber of Observations Read 130

Mumber of Observations Used

Missing Values

Criteria For Assessing Goodness of FA

Criterion DF Veluz Viluefor

Deviance

$89110.1404 \quad 12375$

Soxed Devinne

$89110.1404 \quad 1.2375$

Pearson Chisquare

$89 \quad 96.9463 \quad 1.0993$

Sevied Person X2

69 $96.9493 \quad 1.0893$

Log Likelfiood

$-36.5240$

Fun Log Lilutiond

$-1691135$

AC (smiller is better) $\quad 3502269$

ACC (swaller is better) 351.1924

BAC (Enaller is betted) $\quad 365.4967$

Agorwh converged:

\begin{tabular}{|c|c|c|c|c|c|c|c|}
\hline \multicolumn{8}{|c|}{ Aralysis Of Mlaximum Live Chood Parameter Estimattes } \\
\hline Parameter & DF & Estimale & Standiurd Error & Wald s5es Cona & fidence Limits & Mald Ch-Square & Pr Chisq \\
\hline intercept & 1 & -.11442240 & 0.3005550 & -0.7034994 & 0.4746545 & 0.14 & 0.7034 \\
\hline Expo & 1 & oocobvert & 0.00000077 & -0.0000003 & 0,0000024 & 2.37 & 0.1239 \\
\hline $\cos$ & 1 & $.76552+49$ & 0.1650019 & 0.1140551 & 0.8392492 & 6.64 & 0.0100 \\
\hline KohFlow & 1 & 074820250 & 0.3201346 & -0.5525689 & 0.7023365 & 0.05 & 0.8151 \\
\hline san & 1 & $-2 p 998988$ & 0.2753657 & -0.7437376 & 0.3307500 & 0.58 & 0.4479 \\
\hline Bispersion & 1 & .163405531 & 0.1075621 & 0.0579s51 & 0.5790227 & & \\
\hline
\end{tabular}

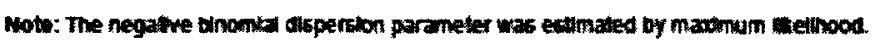


SAS Output

The SAS System

The GEMMOD Procedure

\begin{tabular}{|lr|}
\hline \multicolumn{2}{|c|}{ Nodel Information } \\
\hline Data Set & WORK.TESTDATA \\
Distribution & Neqative Binomial \\
Link Function & Log \\
Dependent Variable & Accidents Accidents \\
\hline
\end{tabular}

Number of Observations Read 130 Number of Observations Used Mirsing Values

\begin{tabular}{|lrrr|}
\hline \multicolumn{4}{|c|}{ Criteria For Assessing Goodness Of Fit } \\
Criterion & DF & Value & Valuefof \\
\hline Deviance & 01 & 110.6128 & 1.2155 \\
Scaled Deviance & 91 & 110.6128 & 1.2155 \\
Pearson Chi-5quare & 01 & 93.3043 & 1.0283 \\
Scaled Pearson X2 & 91 & 93.3043 & 1.0283 \\
Log Likelihood & & -40.7400 & \\
Full Log Likelihood & -173.3205 & \\
AlC (smaller is better) & 354.0501 \\
AlCC (smaller is better) & 355.1085 \\
BlC (smaller is better) & 364.8323 \\
\hline
\end{tabular}

Agarithm corwerged.

\begin{tabular}{|c|c|c|c|c|c|c|c|}
\hline \multirow{2}{*}{ Parameter } & \multicolumn{6}{|c|}{ Analysis of Maximum Likelihood Parameter Estimates } & \multirow[b]{2}{*}{ Pr $>$ Chisq } \\
\hline & DF & Estimate & $\begin{array}{l}\text { Standard } \\
\text { Error }\end{array}$ & $\begin{array}{r}\text { Wald } 95 \% 0 \\
\text { Lim }\end{array}$ & nfidence & $\begin{array}{l}\text { Wald Chi- } \\
\text { Square }\end{array}$ & \\
\hline Intercept & 1 & .160473833 & 0.2848400 & 0.3978024 & 0.7187600 & 0.32 & 0.5732 \\
\hline Expo & 1 & .000000948 & 0.0000000 & 0.0000004 & 0.0000021 & 1.72 & 0. 1890 \\
\hline HighFlow & 1 & .115890525 & 0.3187285 & 0.5089099 & 0.7406830 & 0.13 & 0.7162 \\
\hline Dispersion & 1 & .248000024 & 0.1206386 & 0.0061045 & 0.6435361 & & \\
\hline
\end{tabular}




\section{SAS Output}

\section{The SAS System}

The GEMMOD Procedure

\begin{tabular}{|lr|}
\hline \multicolumn{2}{|c|}{ Model Information } \\
\hline Data Set & WORK.TESTDATA \\
Distribution & Negative Binoria \\
Link Function & Log \\
Dependent Variable & Accidents Accidents \\
\hline
\end{tabular}

\begin{tabular}{|lr|}
\hline Number of Observations Read & 130 \\
Number of Observations Used & 98 \\
Missing Values & 34
\end{tabular}

\begin{tabular}{|c|c|c|c|}
\hline \multicolumn{4}{|c|}{ Criteria For Assessing Goodness Of Fit } \\
\hline Criterion & DF & Value & Vahefof \\
\hline Deviance & B & 1125007 & 1.2007 \\
\hline Scaled Deviance & 93 & 1125007 & 1.2007 \\
\hline Pearson Chi-Square & 93 & 97.3312 & 1.0460 \\
\hline Scaled Pearson $\times 2$ & $\infty 3$ & 97.3312 & 1.0460 \\
\hline Log Likelihood & & -40.2041 & \\
\hline Full Log Likelihood & & -176.0008 & \\
\hline AIC (smaller is better) & & 360.1216 & \\
\hline AICC (amaller is better) & & 360.5612 & \\
\hline BlC (smaller is better) & & 370.3700 & \\
\hline
\end{tabular}

Agorithm comerged

\begin{tabular}{|c|c|c|c|c|c|c|c|}
\hline \multirow{2}{*}{ Parameter } & \multicolumn{6}{|c|}{ Analysis of Maximum Likelihood Parameter Estimates } & \multirow[b]{2}{*}{ Pr $>$ Chisq } \\
\hline & DF & Estimate & $\begin{array}{r}\text { Standard } \\
\text { Error }\end{array}$ & $\begin{array}{r}\text { Wald } 95 \%(0 \\
\operatorname{Lim}\end{array}$ & nfidence & $\begin{array}{l}\text { Wald Chi- } \\
\text { Square }\end{array}$ & \\
\hline & $\mathbf{1}$ & .019405541 & 0.2403044 & 0.4672021 & 0.5061331 & 0.01 & 0.0375 \\
\hline Expo & 1 & .000001602 & 0.0000005 & 0.0000000 & 0.0000028 & 9.40 & 0.0022 \\
\hline SRK & 1 & -.38577680 & 0.2023004 & -0.9008937 & 0.1183401 & 2.28 & 0.1313 \\
\hline Dispersion & 1 & .220822808 & 0.1145070 & 0.0043281 & 0.6101001 & & \\
\hline
\end{tabular}


SAS Output

The SAS System

The GEMMOD Procedure

\begin{tabular}{|lr|}
\hline \multicolumn{2}{|c|}{ Model Information } \\
\hline Data Set & WORK.TESTOATA \\
Distribution & Negative Binomial \\
Link Function & Log \\
Dependent Variable & Accidents Accidents \\
\hline
\end{tabular}

Number of Observations Read 130

Number of Observations Used 96

Missing Vahues

34

\begin{tabular}{|c|c|c|c|}
\hline \multicolumn{4}{|c|}{ Criteria For Assessing Goodness of Fit } \\
\hline Criterion & DF & Value & Vakeref \\
\hline Deviance & 93 & 1127850 & 12127 \\
\hline Scaled Deviance & 83 & 1127850 & 1.2127 \\
\hline Pearson Chi-Square & 83 & 98.4093 & 1.0582 \\
\hline Scaled Pearaon $\times 2$ & 93 & 98.4093 & 1.0582 \\
\hline Log Likelibood & & -39.3032 & \\
\hline Full Log Likelihood & & -175.1500 & \\
\hline AlC (smaller is better) & & 358.3108 & \\
\hline ACC (smaller is better) & & 358.7593 & \\
\hline BIC (smaller is better) & & 368.5772 & \\
\hline
\end{tabular}

Agorithm comerged

\begin{tabular}{|c|c|c|c|c|c|c|c|}
\hline \multirow{2}{*}{ Parameter } & \multicolumn{6}{|c|}{ Analysis of Maximum Likelihood Parameter Estimates } & \multirow[b]{2}{*}{$\operatorname{Pr}>$ Chisq } \\
\hline & DF & Estimate & $\begin{array}{r}\text { Standard } \\
\text { Error }\end{array}$ & $\begin{array}{r}\text { Wald } 95 \% \mathrm{C} \\
\mathrm{Lim}\end{array}$ & nfidence & $\begin{array}{l}\text { Wald Chi- } \\
\text { Square }\end{array}$ & \\
\hline Intercept & 1 & 2.6318680 & 1.8604569 & -62782875 & 1.0145587 & 200 & 0.1572 \\
\hline LnExpo & 1 & .233484250 & 0.1418000 & -0.0440545 & 0.5115830 & 2.71 & 0.0000 \\
\hline Cam & 1 & .500183186 & 0.1788058 & 0.1408127 & 0.9507537 & 7.82 & 0.0052 \\
\hline Dispersion & 1 & .210004238 & 0.1116178 & 0.0740998 & 0.5951742 & & \\
\hline
\end{tabular}


SAS Output

The SAS System

The GENMOD Procedure

\begin{tabular}{|lc|}
\hline \multicolumn{2}{|c|}{ Model Information } \\
\hline Data Set & WORKTESTDATA \\
Distribution & Negative Binomial \\
Link Function & Log \\
Dependent Variable & Accidents Accidents \\
\hline
\end{tabular}

Number of Observations Read 130 Number of Observations Used

Missing Values

\begin{tabular}{|lrrr|}
\hline \multicolumn{4}{|c|}{ Criteria For Assessing Goodness Of Fit } \\
Criterion & DF & Value & Vahe/DF \\
\hline Deviance & 60 & 110.4056 & 1.2267 \\
Scaled Deviance & 60 & 110.4056 & 1.2267 \\
Pearson Chi-Square & 10 & 95.7768 & 1.0042 \\
Scaled Pearson X2 & $\infty$ & 95.7768 & 1.0042 \\
Log Likelihood & & -37.6700 & \\
Full Log Likelihood & -170.2586 & \\
AlC (smaller is better) & 350.5172 & \\
AlCC (smaller is better) & 351.1060 \\
BKC (smaller is better) & 363.2336 \\
\hline
\end{tabular}

Algorithm corwerged.

\begin{tabular}{|l|rrrrrrr|}
\hline \multicolumn{7}{|c|}{ Analysis Of Maximum Likelihood Parameter Estimates } \\
Parameter & DF & Estimate & $\begin{array}{r}\text { Standard } \\
\text { Error }\end{array}$ & Wakd 95\% Confidence & Wimits & Wald Chi- \\
Square Pr > ChiSq
\end{tabular}




\section{SAS Output}

The SAS System

The GEMMOD Procedure

\begin{tabular}{|lr|}
\hline \multicolumn{2}{|c|}{ Model Information } \\
\hline Data Set & WORK.TESTDATA \\
Diatribution & Negative Binomial \\
Link Function & Log \\
Dependent Variable & Acoidents Acoidents \\
\hline
\end{tabular}

Number of Observations Read 130 Number of Observations Used 86 Missing Valwes

\begin{tabular}{|lrrr|}
\hline \multicolumn{4}{|c|}{ Criteria For Assessing Goodness Of Fit } \\
Criterion & DF & Value & ValuelDF \\
\hline Deviance & 02 & 112.7831 & 1.2200 \\
Scaled Deviance & 2 & 112.7931 & 1.2200 \\
Pearson Chi-Square & 02 & 98.4013 & 1.0006 \\
Scaled Pearson X2 & 02 & 09.4013 & 1.0000 \\
Log Likelihood & & -30.3020 & \\
Full Log Likelihood & -175.1505 & \\
AIC (smalier is better) & 360.3101 & \\
AlCC (smalter is better) & 360.0858 \\
BiC (smalier is better) & 373.1400 \\
\hline
\end{tabular}

Algoritim comerged.

\begin{tabular}{|c|c|c|c|c|c|c|c|}
\hline \multirow{2}{*}{ Parameter } & \multicolumn{6}{|c|}{ Analysis of Meximum Likelihood Parameter Estimates } & \multirow[b]{2}{*}{ Pr $>$ Chisq } \\
\hline & DF & Estimate & $\begin{array}{r}\text { Standard } \\
\text { Error }\end{array}$ & $\begin{array}{r}\text { Wald } 95 \% \mathrm{C} \\
\text { Lim }\end{array}$ & nfidence & $\begin{array}{l}\text { Wald Chi- } \\
\text { Square }\end{array}$ & \\
\hline & 1 & 2.5008400 & 2.2811917 & -7.0678006 & 18742068 & 1.30 & 0.2550 \\
\hline LnExpo & 1 & .230481603 & 0.1810585 & -0.1243884 & 0.5853501 & 1.62 & 0.2030 \\
\hline Cam & 1 & .500000587 & 0.1800457 & 0.1402025 & 0.8556567 & 7.60 & 0.0056 \\
\hline SRN & 1 & .000041111 & 0.2281761 & -0.4411758 & 0.4532560 & 0.00 & 0.9789 \\
\hline Dispersion & 1 & .200034167 & 0.1118385 & 0.0740342 & 0.59 .52972 & & \\
\hline
\end{tabular}


SAS Output

The SAS System

The GENWOD Procedure

\begin{tabular}{|c|c|}
\hline \multicolumn{2}{|c|}{ Wodel thformation } \\
\hline Data Set & MORK.TESTDATA \\
\hline Distribution & Negratwe Bhosnat \\
\hline Link Function & $\log$ \\
\hline Dependent Variable & Acolderts Acoldents \\
\hline
\end{tabular}

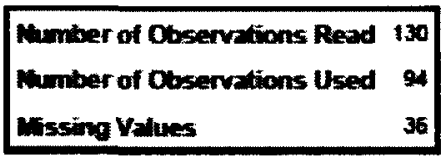

Criteria For Assessing Gooduess Of FA Criterion aF Volse Valuemf

Devileme: 89 110.189t 12361

Seviled Devizune

89 t10.1891 1.2381

Pewson Chi-Square

Seoled Pearson $X$

$69 \quad 95.3396 \quad 1.0712$

Log Lfelliood

$69 \quad 95.3398 \quad 1.0712$

Full Log Lilbelimood

$-37.6279$

AC (smolier is better)

$-1702165$

AxC (swaller is better)

352.4330

ax (smoller is better)

353.3905

367.6928

Aparmin converged

\begin{tabular}{|c|c|c|c|c|c|c|c|}
\hline \multicolumn{8}{|c|}{ Analysis Of Iloximum Limefhood Parameter Estinates } \\
\hline Parameter & $\mathbf{D F}$ & Esturnete & Standiand Error & Wald 95\% Con & Widerwe linnts & Wald Chï-square & Pr $>$ Chisq \\
\hline Intercept & 1 & -77367569 & 23972000 & -5.4723199 & 3.9245675 & 0.10 & 0.7468 \\
\hline LnExpo & $\mathbf{1}$ & .081126308 & 0.1912327 & -0.29365820 & 0.4552354 & 0.18 & 0.6714 \\
\hline $\operatorname{Cans}$ & 1 & .493615452 & 0.1881690 & 0.1247730 & 0.6524571 & 6.88 & 0.0007 \\
\hline MghFlow & 1 & .352509620 & 0.2704377 & -0.1775396 & 0.6425578 & 1.70 & 0.1924 \\
\hline SRN & 1 & -.07600671 & 0.2694492 & -0.60691155 & 0.4591020 & 0.08 & 0.7722 \\
\hline Dispersion & 1 & .200267534 & 0.1107501 & 0.0677213 & 0.5922370 & & \\
\hline
\end{tabular}

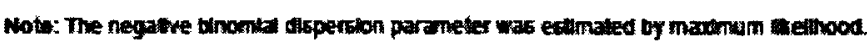


SAS Output

The SAS System

The GEMMOD Procedure

\begin{tabular}{|lr|}
\hline \multicolumn{2}{|c|}{ Model Information } \\
\hline Data Set & WORKTESTDATA \\
Distribution & Negative Binomial \\
Link Function & Log \\
Dependent Variable & Accidents Accidents \\
\hline
\end{tabular}

Number of Observations Read 130 Number of Observations Used

Missing Vahues

\begin{tabular}{|c|c|c|c|}
\hline \multicolumn{4}{|c|}{ Criteria For Assessing Goodness of Fit } \\
\hline Criterion & DF & Value & Vahuedof \\
\hline Deviance & 91 & 110.3358 & 1.2125 \\
\hline Scaled Deviance & 91 & 110.3356 & 1.2125 \\
\hline Pearson Chi-square & 91 & 91.8839 & 1.0097 \\
\hline Scaled Pearson $\times 2$ & 91 & 01.8938 & 1.0007 \\
\hline Log Likelinood & & -41.4528 & \\
\hline Fult Log Likelihood & & -174.0414 & \\
\hline AIC (smaller is better) & & 350.0828 & \\
\hline AlCC (smaller is better) & & 350.5322 & \\
\hline BIC (smaller is better) & & 360.2560 & \\
\hline
\end{tabular}

Algoritum corverged.

\begin{tabular}{|c|c|c|c|c|c|c|c|}
\hline \multirow{2}{*}{ Parameter } & \multicolumn{6}{|c|}{ Analysis of Maximum Likelihood Parameter Estimates } & \multirow[b]{2}{*}{$\operatorname{Pr}>\mathrm{ChiSq}$} \\
\hline & DF & Estimate & $\begin{array}{r}\text { Standard } \\
\text { Error }\end{array}$ & $\begin{array}{r}\text { Wakd } 95 \%( \\
\operatorname{Lim}\end{array}$ & nfidence & $\begin{array}{l}\text { Wald Chi- } \\
\text { Square }\end{array}$ & \\
\hline Intercept & 1 & -76718231 & 2.3708945 & -5.4140501 & 3.8798855 & 0.10 & 0.7463 \\
\hline LnExpo & 1 & .008782581 & 0.1804015 & .02687340 & 0.4642991 & 0.28 & 0.5063 \\
\hline HighFlow & 1 & .378827115 & 0.2438916 & -0.1011917 & 0.8548458 & 2.30 & 0.1223 \\
\hline Dispersion & 1 & .263505800 & 0.1226009 & 0.1059130 & 0.6578499 & & \\
\hline
\end{tabular}




\section{SAS Output}

The SAS System

The GENMOD Procedure

\begin{tabular}{|lc|}
\hline \multicolumn{2}{|c|}{ Model Informstion } \\
\hline Data Set & WORk. TESTDATA \\
Distribution & Negative Binornia \\
Link Function & Log \\
Dependent Variable & Accidents Accidents \\
\hline
\end{tabular}

Number of Observations Read 130 Number of Observations Used 96 Missing Values 34

\begin{tabular}{|lccr|}
\hline \multicolumn{4}{|c|}{ Criteria For Assessing Goodness Of Fit } \\
Criterion & DF & Value & VahuelDF \\
\hline Deviance & 93 & 113.1724 & 1.2160 \\
Scaled Deviance & 93 & 113.1724 & 1.2160 \\
Pearson Chi-Square & 03 & 98.4823 & 1.0589 \\
Scaled Pearson X2 & 93 & 98.4823 & 1.0580 \\
Log Likelihood & & -43.1656 & \\
Full Log Likelimood & -178.0323 & \\
AlC (smaller is better) & 365.8640 \\
AlCC (smaller is better) & 366.3042 \\
BlC (smaller is better) & 376.1220 \\
\hline
\end{tabular}

Algoritim comerged

\begin{tabular}{|c|c|c|c|c|c|c|c|}
\hline \multirow{3}{*}{$\begin{array}{l}\text { Parameter } \\
\text { Intercept }\end{array}$} & \multicolumn{6}{|c|}{ Analysis of Maximum Likelihood Parameter Estimates } & \multirow[b]{2}{*}{ Pr $>$ Chisq } \\
\hline & \multirow{2}{*}{$\frac{\text { DF }}{1}$} & \multirow{2}{*}{$\begin{array}{l}\text { Estimate } \\
3.7026802\end{array}$} & \multirow{2}{*}{$\begin{array}{r}\text { Standard } \\
\text { Error }\end{array}$} & \multicolumn{2}{|c|}{$\begin{array}{l}\text { Wald 95\% Confidence } \\
\text { Limits }\end{array}$} & \multirow{2}{*}{$\begin{array}{r}\text { Wald Chi- } \\
\text { Square }\end{array}$} & \\
\hline & & & & -8.3615017 & 0.0502313 & & 0.1193 \\
\hline $\operatorname{LnExpo}$ & 1 & .341850818 & 0.1808393 & -0.0243674 & 0.7080291 & 3.35 & 0.0073 \\
\hline SRN & 1 & -.00111831 & 0.2357921 & -0.5532023 & 0.3710257 & 0.15 & 0.6092 \\
\hline Dispersion & 1 & .200000019 & 0.1232715 & 0.1100317 & 0.6605749 & & \\
\hline
\end{tabular}

